


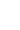




\section{ANALES DE LA UNIVERSIDAD DE ALICANTE.}

HISTORIA MODERNA 


\section{ANALES DE LA UNIVERSIDAD DE ALICANTE. HISTORIA MODERNA}

N. ${ }^{\circ} 2$

CONSEJO DE REDACCION:

Director: Antonio MESTRE SANCHIS

Secretario: Enrique GIMENEZ LOPEZ

Consejo de Redacción:

Armando ALBEROLA ROMA

Mario MARTINEZ GOMIS

Primitivo PLA ALBEROLA

David BERNABE GIL

Juan RICO GIMENEZ

Eduardo RANCH SALES

SECRETARIADO DE PUBLICACIONES UNIVERSIDAD DE ALICANTE

Depósito Legal: A-81 - 1982 


\section{anales}

de la universidad

de alicante.

historia moderna 



\section{N D I C E}

\section{1.-ARTICULOS}

Pág.

Dámaso DE LARIO

Monarquías y Parlamentos en la España Moderna ...........

Fernando ANDRES ROBRES

Los derechos de monopolio en la Valencia del Antiguo Régimen:

El ejemplo de Alfara y Burjasot durante el siglo XVII . . . . . . . . .

Rafael BENITEZ SANCHEZ-BLANCO

Rentabilidad de una pequeña explotación agraria en Vall de Uxo, 1721-1739

José Miguel LOPEZ GARCIA

Economía monástica y sociedad rural en Valladolid durante el Antiguo Régimen: La Real Cartuja de Ntra. Sra. de Aniago . . . . . .

Mario MARTINEZ GOMIS

La larga espera de la muerte en una ciudad valenciana del siglo XVII. (Orihuela ante la peste de 1676-1678)

Armando ALBEROLA ROMA

Enrique GIMENEZ LOPEZ

Las temporalidades de la Compañía de Jesús en Alicante (Siglos

XVII-XVIII)

François LOPEZ

Una utopía española en busca de autor: Sinapia. Historia de una equivocación. Inicios para un acierto

Rafael OLAECHEA ALBISTUR

Una viajera rusa del XVIII en los pirineos franceses . . . . . . . . .

Emilio BALAGUER PERIGÜELL

Continuidad y ruptura en la renovación científica valenciana ....

Cayetano MAS GALVAÑ

Jansenismo y Regalismo en el Seminario de San Fulgencio de Murcia

Guillermo CARNERO

Juan Nicolás Bőhl de Faber y la polémica dieciochesca sobre

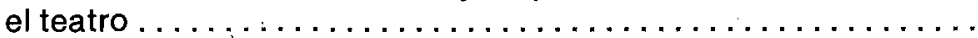


Pág.

\section{2.-NOTAS}

Joaquín SAEZ VIDAL

Inventario de la biblioteca de D. Nicolás Pro, ilustrado alicantino del siglo XVIII . . . . . . . . . . . . . . . . . . . . . .

José SANCHIS COSTA

Manifiesto de los moriscos que quedaron en Gandia en el año 1611

\section{3.-BIBLIOGRAFIA}

Emilio LA PARRA LOPEZ

GIMENEZ LOPEZ, E., Alicante en el siglo XVIII. Economía de una ciudad portuaria en el antiguo régimen . . . . . . . . . . . . .

Armando ALBEROLA ROMA

BERNABE GIL, DAVID, Tierra y sociedad en el Bajo Segura (1700-1750)

R. M. N.

BERCHEX, Joaquín y CORELL, Vicente, Catálogo de diseños de arquitectura de la Real Academia de Bellas Artes de San Carlos de Valencia, 1768-1846.......................... 


\title{
MONARQUIAS Y PARLAMENTOS EN LA ESPAÑA MODERNA
}

\author{
Acotaciones al “Dominium Regale o \\ Dominium Politicum et Regales de \\ H. G. Koenigsberger.
}

Por Dámaso DE LARIO

Ministerio de Asuntos Exteriores

Introducción

A finales de 1.977, aparecía en el Boletín de la Real Academia de la Historia la versión castellana del artículo de H. G. Koenigsberger: Dominium Regale o Dominium Politicum et Regale(1). Se trataba de la lección inaugural de la Cátedra de Historia del King's College de Londres, pronunciada por su titular en febrero de 1.975. En ella su autor planteaba el problema del surgimiento de la diferente distribución de poderes políticos entre reyes y parlamentos en la Europa Moderna, enfocando la cuestión como una "búsqueda de las razones de los cambios de las estructuras politicas de los Estados europeos entre los siglos XV y XVIIIm(2). Para ello, Koenigsberger arranca de la distinción que Sir John Fortescue hiciera en su obra The Governance of England, publicada en los años 1.470, entre dominium regale-el de los países gobernados por una monarquia absoluta-y dominium politicum et regale-el de los países gobernados por una monarquía constitucional-dominium que, siendo la regla y no la excepción-según Konigsberger-producirá una serie de nítidas distinciones que permitirán clasificar a los distintos paises en tres grupos, según fuera la monarquía o el parlamento el polo dominante de la estructura de poder. 
A partir de ahí, y utilizando de manera crítica las aportaciones de Otto Hintze y, sobre todo, de Norbert Elias(3), el profesor de Londres trata de aportar nuevos elementos y de clarificar, sistematizar y contrastar con la historia los planteamientos existentes y sus propias sugerencias, a fin de acortar el camino a recorrer hasta lograr una teoría general satisfactoria, capaz de resolver el problema planteado, y al que más arriba se hacia referencia.

El objeto del presente artículo no es, sin embargo, el de hacer una ulterior aproximación a esa deseada teoría general, sino el de reexaminar algunas de las cuestiones del sugestivo artículo de $\mathrm{H}$. G. Koenigsberger y, fundamentalmente, el de centrar-dentro de nuestras modestas posibilidades-el caso español en la sistemática planteada por el profesor inglés y contemplar el funcionamiento del dominium regale y el dominium politicum et regale en las Cortes de algunos de los Reinos españoles de la Edad Moderna(4), con el fin de aportar nuevos elementos, capaces de ayudar a una futura solución del problema.

\section{Diversidad de los Parlamentos en la España Moderna.}

Creo necesario, en primer lugar, replantear la cuestión del dominium politicum et ragale en las monarquias europeas, dado que en las tres clasificaciones o grupos que de ella derivan, vienen encajados los distintos países existentes en la Europa Moderna(5). Si por dominium regale Fortescue entendía "un régimen en que el rey cargaba impuestos a los plebeyos a su libre arbitrio, eximiendo a los nobles del pago de los mismos»(6) y por dominium politicum et regale-cuya manifestación por excelencia era Inglaterra(7) - un régimen en el que el rey "no podía cargar impuestos a sus súbditos sin el consentimiento del parlamento $\mathrm{y}$, por tanto, no podía exigirles contribuciones excesivas»(8), Castilla era un claro ejemplo de dominium regale, la excepción de la regla tal vez'9).

"El pacto bajomedieval entre reyes y parlamentos", que hubo en toda Europa(10), no existió en Castilla, tal y como ha demostrado el profesor Pérez-Prendes. El fundamento jurídico de las Cortes castellanas en la Edad Media, fundamento que se prolongará a lo largo de la Modernidad, era exclusivamente el «deber del Consejow(11). De tal suerte, el Parlamento castellano era "un órgano político-administrativo, dirigido y controlado por el monarca, dentro de la supeditación de éste a las normas vigentes, las cuales ni emanaban ni eran controladas por las Cortes, cuya única misión era dar consejo, servir, y en las minorias vigilar el exacto cumplimiento de lo previsto para el caso por la legislación rea|»(12). En la práctica, como más adelante veremos, los monarcas se encargarán de que esa teoria se cumpla, arbitrando las reformas y mecanismos necesarios a fin de evitar 
cualquier posibilidad de que las Cortes tuvieran, o de facto ejercieran, alguna parcela de poder. Se trataba pues-en nuestra opinión-de un dominium regale.

Ese mismo dominium es, creemos, el de los "paises o provincias de paises... en que las monarquias se impusieron a sus parlamentos $y$, o los abolieron, o simplemente no los volvieron a convocarm(13); el posible equilibrio político reyes-parlamentos quebrará definitivamente en beneficio de los primeros, siendo entonces su dominio completo y desapareciendo, en consecuencia, cualquier forma de dominium politicum et regale. Por ello, tal vez resultaría más preciso clasificar de dominium regale a ese grupo de países, junto con Castilla, donde los reyes sí convocan al Parlamento, si bien subsista, no obstante, este dominium.

Ahora bien, Castilla sólo, y no España(14), vendría clasificada de dominium regale; una de las características principales de la España Moderna es la diversidad de sus Parlamentos, claro reflejo de las distintas concepciones políticas que ilustraban las Coronas de Castilla y Aragón, y que se mantienen tras el matrimonio de los Reyes Católicos.

Así, mientras e!' sentido integracionista castellano dará a sus Cortes el carácter descrito, las distintas entidades políticas de la Corona de Aragón-los Reinos de Aragón y Valencia y el Principado de Cataluña-verán reflejadas en sus Cortes la concepción federalista aragonesa en la que, siguiendo la doctrina del derecho público catalanoaragonés, las relaciones entre los monarcas castellanos y los distintos reinos de la Corona de Aragón eran producto de un contrato público. Por éste, los reyes juraban al comienzo de su reinado el respeto a las leyes de cada Reino y, en contrapartida, éste le juraba obediencia como su legítimo monarca. De esta forma, las relaciones rey-Reinos quedaban insertas en un plano de igualdad, el dominium politicum et regale era, teóricamente, perfecto(15).

Esa misma concepción informará también los Parlamentos de los territorios extrapeninsulares de la Corona de Aragón: Cerdeña, Nápoles y Sicilia. Fernando el Católico incrementaría el papel de los dos primeros, mientras el tercero asumiría las funciones y estructura de las Cortes catalano-aragonesa ya desde $1.398^{(16)}$.

Ahora bien, al margen de las teorías informadoras de las Cortes de Castilla y Aragón, el problema de la distribución del poder será el que ilustre-una vez más-la dinámica de esos Parlamentos, problema que llevará, en las sucesivas reuniones de los mismos, a intentar romper el equilibrio existente al polo más débil del binomio rey-Parlamento, ora para usurpar un poder que no se detenta, ora para aumentar el que ya se posee. En cualquier caso, los cambios de distribución de poder que se produzcan, tendrán lugar siempre de manera no consensual, ya implique ésta violen- 
cia física o violencia moral. Tal y como afirma el profesor Koenigsberger, "nadie cede lo que considera vital para la defensa de su status... mientras tenga alguna posibilidad de defenderlo con éxito, 0 , por lo menos, mientras asi lo crean(17).

\section{Cortes de Castilla.}

Hemos visto ya el fundamento jurídico de las Cortes castellanas. Los miembros integrantes de las mismas acudían "para cumplir el imperioso deber de asistencia y consejon, no para "ejercer el derecho de estar presente y participar de las grandes decisiones politicas en nombre de un sector de la población del reinos(18). No era pues un Parlamento representativo, en el sentido moderno del término. El hecho que no existiera principio alguno, capaz de invalidar los actos del rey, cuando el criterio adoptado por éste fuera discordante con el de sus.Cortes, y que el monarca pudiera convocarlas a su libre albedrio(19), resulta muy significativo a este respecto.

Desde esta perspectiva, no puede afirmarse que las Cortes de Castilia perdieran el control del gravamen de impuestos, desde mediados del siglo $\mathrm{XV}$, o que con los Reyes Católicos éstas se vieran desprovistas de la capacidad de legislar en beneficio del Consejo Real(20). Las rentas réales-los impuestos - nunca fueron, en ninguno de sus aspectos, jurisdicción de las Cortes(21). En lo relativo a la potestad legislativa, según ha sido demostrado, el monarca nunca tuvo la obligación de compartirla con aquéllas: «la misión de las Cortes no era otra que la de prestar difusión y conocimiento por parte de los súbditos, a las leyes promulgadas por el rey en ellas, no con ellas, (22).

Ahora bien, es evidente que la presencia en las Cortes de procuradores de las ciudades, nobles y alto clero representaba, de facto, un peligro potencial para el poder real. En consecuencia, los Reyes Católicos redujeron a dieciocho el número de ciudades habilitadas para enviar procuradores a Cortes, y a partir de 1.538 , con Carlos I, nobles y alto clero desaparecerán de las mismas. El funcionamiento del "mecanismo real" (Königsmechanismus)-a que el profesor Elias se refiere(23) -en Castilla empezaba asi a dar sus frutos.

La no obligatoriedad de los monarcas de convocar Cortes de modo regular, dotaba al poder real de un formidable instrumento para mantener su status. El objetivo fundamental de la convocatoria del Parlamento era la obtención de un servicio, que ayudara al Reino a atender sus necesidades económicas(24); sin embargo, era lógico que en el curso de esas reuniones se suscitaran problemas y pretensiones no del agrado de la Corona. Con el incremento de ingresos independientes de las concesiones de Cortes, los Reyes Católicos podrían prescindir de éstas durante un largo período, y si 
bien a finales del cuatrocientos la guerra de Granada y las campañas italianas les obligó nuevamente a recurrir a sus Cortes, el hecho de la convocatoria de nobles y alto clero no fuera obligatoria, y que la asistencia de las ciudades hubiera sido reducida a dieciocho-lo que arrojaba una corporación de sóio treinta y seis burgueses(25) — haría sumamente fácil a los reyes la petición de consejo y, sobre todo, de servicio a su Parlamento.

En las Cortes de Valladolid de 1.518, preludio de las decisivas reuniones de 1.520, se asiste al primer intento serio, si bien tímido, de quiebra del dominium regale en Castilla. En ellas se afirma que cel rey está al servicio de la nación (nuestro mercenario es); no puede hacer lo que le plazca. Tiene unos ciertos deberes que cumplirw(26). Ahora bien, aunque era cierto que el rey no estaba por encima de la ley(27), ni esas leyes tenian que emanar de las Cortes, como antes ha sido expuesto, ni éstas, en cuanto instituciones no-representativas, estaban legitimadas para ir más allá del "deber de consejo", cuestionando la acción del monarca al que, precisamente la ley, permite obrar en desacuerdo con el criterio de su Parlamento.

Pero de lo que se trataba era de alterar la legalidad existente, y los términos en que las Cortes de 1.518 definirian las relaciones rey-nación, serian suficientes para que los comuneros promovieran serios incidentes en León, al término de aquellas reuniones(28), y lanzaran una importante campaña de agitación, previa a las reuniones de las Cortes de Santiago-La Coruña de 1.520. En éstas, la vieja aspiración de que, antes de conceder el servicio pedido se examinarán las peticiones hechas por los procuradores como "conditio sine qua non", se quiso llevar hasta sus últimas consecuencias(29), sin embargo la desunión de los procuradores de las distintas ciudades favorecería el mantenimiento del "status quo" en la relación reyCortes. Fuera de ésta, y fracasado el intento de cambio pacífico de distribución de poder, los comuneros intentarán la vía de la violencia, procurando una rebelión que, según ha señalado J. H. Elliott, se presentó, desde el punto de vista constitucional, como un movimiento de defensa frente a la erosión que muchos de los municipios castellanos habían experimentado en sus poderes tradicionales y prerrogativas por la acción del gobierno real(30). No en balde, "en los proyectos elaborados por los comuneros las Cortes constituian la institución más importante del reino", en que sus atribuciones limitaban notablemente el poder real(31). Se trató, claramente, de un intento frustrado de convertir un dominium regale en un dominium politicum et regale, de neta preponderancia parlamentaria.

Si las Cortes de 1.520 constituyeron el último intento del pueblo llano de obtener una parcela de poder, que le permitiera participar de iure en las decisiones políticas del Reino, las Cortes de Toledo de 1.538 serian consideradas por Sánchez Montes como uel último momento de una tensión efectiva entre el monarca y los órdenes privilegiados»(32). En -el curso de esas reuniones Carlos I trataria de introduicr un sistema más equitativo de 
recaudación, que implicaba el gravamen de ricos y pobres-la sisa-, en lugar de solicitar el tradicional servicio, que afectaba solamente a las capas llanas. El estamento aristocrático se negaría, sin embargo, a aceptar el impuesto, que implicaba la renuncia a sus privilegios de exención tributaria(33).

Muy posiblemente, Carlos I reaccionaría del mismo modo que lo hizo, cuando le fue negado el servicio en las Cortes de Valladolid de 1.527:

«nunca les dijo palabra desabrida ni aún les mostró mal gesto, - antes les dio gracias por el socorro que le ofrecian y les envió mandar que se fuesen a sus casas y que estuviesen aparejados para cuando fuesen Ilamados»(34).

Pero, tras aquellas sesiones de 1.538 , nobles y alto clero no volverían a ser convocados. La Corona buscaría nuevas fuentes de ingreso, y con ello reduciria la influencia de las Cortes en el único terreno que les hubiera permitido hacer quebrar el dominium regale: el de las finanzas. Como ha escrito Elliott, el estamento aristocrático habia destruido, con su proceder, "la última esperanza de constitucionalismo en Castilla(35).

Felipe II convocaria Cortes prácticamente de manera protocolaria, para realizar el juramento del principe, y a partir de 1.665 las Cortes castellanas no volverán a convocarse hasta la reunión de Madrid de 1.701, la cual se realiza sin las formalidades exigidas(36).

Así pues, los monarcas españoles habian logrado mantener en Castilla la adecuación de la teoria que informaba sus Cortes a la realidad de las mismas, favoreciendo y reforzando una legalidad que justificaba y propiciaba su poder absoluto, el mantenimiento de un dominium regale.

La situación seria distinta, sin, embargo, en los otros reinos de la península.

3. Cortes de la Corona de Aragón.

A diferencia de Castilla, la Corona de Aragón se había constituído-como señalará Joan Reglà- "mediante la armonia entre imperio y libertad, basada en el desarrollo de una concepción federalista, de unión personal, dinástica, de los diversos reinos integrantes»(37). Esa concepción sería la que informara la unión de las dos Coronas, con el matrimonio de los Reyes Católicos, lo que implicaria una paradoja «entre la hegemonía de iure ejercida por las instituciones catalano-aragonesas, y la hegemonía de facto en manos de Castillaw(38). Ello iba a provocar, pese a los esfuerzos de las Cortes, los futuros desequilibrios de la Corolla aragonesa. 
Así, mientras el análisis diacrónico de las Cortes de Castilla muestra, en la tensión rey-Parlamento, los intentos de éste por transformar el dominium regale en un dominium politicum et regale, y el triunfo del primero en el mantenimiento y posterior reforzamiento de la estructura de poder existente al iniciarse la época moderna, el exámen de las Cortes aragonesas nos revelará el proceso inverso: el esfuerzo progresivo de la monarquia por transformar el dominium politicum et regale en un dominium regale, lo que terminará lográndose en cierta medida en Aragón y, particularmente, en Valencia, alterándose así, de manera definitiva, el equilibrio existente en la Corona de Aragón en el momento de producirse su unión con Castilla.

\subsection{Cortes del Reino de Aragón.}

En Aragón, al igual que en Cataluña y Valencia, el consentimiento de las Cortes-instituciones tipicamente representativas-era fundamental para la aprobación de las leyes, cuya elaboración era una de las principales tareas del Parlamento. Este se componia de cuatro brazos-eclesiástico, militar, ricos-hombres y caballeros-todos los cuales debian de aprobar las decisiones que las Cortes presentaran, por unanimidad; de ahí que algunos tratadistas llegaran a afirmar que "la promulgación de cualquier ley en Aragón era poco menos que un milagros(39). He aquí uno de los principales escollos con que los monarcas se encontraban en este Parlamento, obstáculo que operaba también a la hora de conceder el servicio. Por lo que respecta a este último problema, en las Cortes de Monzón de 1.552 Felipe II obviaría las largas negociaciones de los «tractadores", enviando a su secretario, Gonzalo Pérez, a negociar directamente con el arzobispo de Zaragoza y diversas villas y ciudades la contribución de las Cortes fuera de éstas(40). Un importante precedente había quedado así establecido.

Las Cortes de Monzón de 1.563 y 1.583 servirian para eliminar progresivamente una importante función del Parlamento aragonés: Ios juicios de apelación, en cuanto tribunal supremo de justicia, ante el que podian presentarse quejas por violaciones de las leyes del Reino, realizadas por el rey o sus ministros ${ }^{(41)}$. Y si bien las Cortes de Monzón de 1.585 aumentaron los ya enormes poderes de los nobles aragoneses, al decidir "que todo vasallo que tomase las armas contra su señor era reo de muertex(42), las Cortes de Tarazona de 1.592 representarían una neta victoria realista, al modificar dos importantes factores del Parlamento aragonés: la regla de la unanimidad en los votos de los cuatro estamentos, sustituída por la de la mayoria(43), y la reforma de la institución del Justicia, quintaesencia de las libertades aragonesas, quien, a partir de entonces, podría ser destituido por el rey. Asimismo, el monarca obtenía el derecho a nombrar virreyes no aragoneses(44). 
La revuelta de Aragón de 1.591-92 habia dado al rey la excusa que necesitaba para debilitar profundamente el Parlamento de Aragón y terminar de romper el equilibrio de poder existente hasta entonces. Las Cortes no desaparecen, pero siguen funcionando gracias a su docilidad. Cuando en 1.626 Felipe IV convoque Cortes generales a la Corona de Aragón, para poner en pie la Unión de Armas ideada por Olivares, mientras la reunión de las Cortes catalanas terminará provocando el estallido revolucionario de 1.640 y las de Valencia se resistirán-si bien infructuosamente-a conceder el servicio pedido, las Cortes de Aragón votarán sin grandes dificultades un subsidio que duplicaba al otorgado finalmente por Valencia.

Tras las reuniones de 1.626, las Cortes aragonesas no volvieron a ser reunidas hasta 1.701, En 1.709 serán convocadas en Madrid con ocasión del reconocimiento del Príncipe de Asturias. Estas reuniones, al igual que las de $1.712,1.724,1.760$ y 1.789(45), tendrán, sin embargo, muy poco en común con las Cortes aragonesas de los siglos XV y XVI. Como A. R. Myers señala, resulta característica su protesta en 1.760: "Oh señor, el reyno está dispuesto, no sólo a prestar juramento de fidelidad y rendir el homenaje que corresponde, sino a realizar cualquier cosa que Su Majestad propongan(46).

Aragón no se había convertido en un dominium regale, pero los monarcas habian conseguido transformar un dominium politicum et regale en que el Parlamento conservaba importantes poderes, en otro en el que el Parlamento logra sobrevivir, si bien con unos poderes rigurosamente delimitados y cada vez mayormente reducidos. Una vez más, al igual que en Castilla, se había producido el triunfo de la monarquía.

\subsection{Cortes catalanas.}

Con todo, parece ser en el Principado de Cataluña donde cel desarrollo de la institución parlamentaria alcanzó un concepto constitucional efectivo y planteo eficazmente las relaciones operantes entre la autoridad y los sujetos, entre el monarca y sus vasallosw(47). El caso ha sido comparado-creemos que con acierto-por Vicens al del Parlamento inglés(48). Desłe que en las Cortes de 1.480-81: Fernando ei Católico aceptara e! sistema político tradicional del Principado, perfeccionándolo con la Observança, en que se reconocian las limitaciones al poder real, e ideando un procedimiento legal para la intervención de la Generalidad, caso de que el rey o sus funcionarios incurrieran en contrafuero(49), el dominium politicum et regale no haria sino perfeccionarse. A pesar de los intentos del poder real, sólo con los Borbones se rompería el equilibrio de poder existente en el Principado.

Las sucesivas reuniones de Cortes catalanas con Carlos I y Felipe II 
no hacen sino confirmar ese equilibrio rey-Parlamento, fruto del pactismo catalán y del constitucionalismo monárquico en la Corona de Aragón. El derecho a legislar, junto con el rey, había sido logrado por el Parlamento catalán ya en 1.283(50). Y, dentro de la más pura tradición del dominium politicum et regale, los tres brazos de este Parlamento-eclesiástico, militar y real-intervenian al igual que en Aragón, en el control de las sumas ofrecidas al rey. La necesidad, por otra parte, de que los greuges (agravios) planteados por las Cortes al rey, debieran ser resueltos antes de la concesión del servicio, dotaba al Parlamento de un poderoso instrumento para asegurarse el respeto y la pervivencia de sus fueros y privilegios.

Las Cortes de Barcelona de 1.599-únicas que convoca Felipe III-marcarán, como ha escrito Reglà, uel momento de máximo idilio entre la realeza y el Principado, cuando la crisis empezaba a dibujarsex(51). Sin embargo, con la reunión de Cortes Generales en 1.626, aparecerán los primeros intentos del poder real de quebrar el dominium existente. Cataluña se opondrá a participar en la Unión de Armas y, en consecuencia, a otorgar el servicio pedido; cuando en 1.632 el rey y su valido vuelva a Barcelona para reanudar las Cortes interrumpidas, el resultado será idéntico. La presión real tendria como consecuencia el estallido revolucionarioseparatista de 1.640, capitaneado por la Diputacio, símbolo tradicional de las libertades catalanas. Desde el punto de vista jurídico, el pleito secesionista giraría en torno al pactismo.

Tanto en Aragón como en Cataluña las revueltas estallan con los símbolos tradicionales de sus libertades como pretexto (el Justicia y la Diputación). Símbolos que la monarquía absoluta trata de desmantelar, para forzar al dominium regale a las entidades políticas que representaban. Ya hemos visto cual fue el resultado de esa acción en Aragón. En Cataluña, no sólo el propósito del poder real fracasa, sino que el pactismo catalán, a partir de 1.652, recupera su esencia y sale reforzado de la prueba. Durante el reinado de Carlos II nadie se atrevió a discutirlo(52). Mientras tanto, por toda Europa, incluida Inglaterra, "el iusconstitucionalismo desaparecia devorado por el absolutismo monárquicos(53).

Así, en la lucha por el poder, el Parlamento catalán había logrado mantener con éxito el dominium politicum et regale. Sería el único caso del Estado español, con la excepción de Portugal, donde al igual que en la Corona de Aragón, el rey era constitucional, y que, tras la revolución de 1.640 lograría su independencia definitiva de la monarquia española.

Felipe $V$ reuniría en 1.701 las Cortes catalanas, que desde 1.632 no se habian vuelto a convocar. Sin embargo, aunque éstas fueran unas de las reuniones que mejores resultados proporcionaron a los catalanes(54), la invasión francesa en Cataluña en los años de la revolución, habia sometido a desgaste el pactismo, perdiendo éste consistencia y decayendo, de 
hecho, en el espíritu catalán. En la gưerra de 1.705-1.714 el Principado lucharía por otros intereses(55).

Tras la promulgación de los Derechos de Nueva Planta en 1.716, destruidas ya las instituciones catalanas tradicionales, las Cortes serán reunidas en Madrid en 1.724, 1.760 y 1.780(56). Su signo, empero, había cambiado.

\subsection{Cortes valencianas.}

Las Cortes valencianas, creadas también según el éspíritu pactista de la Corona de Aragón, compartían asimismo con el monarca las tareas legislativas del Reino. A pesar de que el Parlamento debía ser convocado cada tres años, a lo largo del período moderno los reyes sólo lo reunirían, sin embargo, cuando las necesidades financieras les obligaran a ello, con el fin de obtener los subsidios que precisaban. No obstante, el dominium politicum et regale funcionaría en Valencia sin desequilibrios importantes hasta finales del reinado de Felipe II.

El interés del Reino por mantener ese dominium se observa en la preocupación por conservar el control y equilibrio de la Generalidad, desde las Cortes de Tarazona-Valencia-Orihuela de 1.484-88(57). Este organismo había surgido en Valencia a fines del Trescientos con Pedro el Ceremonioso, convirtiéndose, con las reformas adoptadas en las Cortes de $1.537 \mathrm{y}$ 1.547 , en unna entidad que asumía virtualmente la representación del Reino cuando las Cortes no funcionaban e intervenia en todos los asuntos de carácter general, sociales y económicos»(58). De ahí su importancia para el Reino.

La institución de la Generalidad volvería a recibir una atención preferente en las Cortes de 1.563, primeras de Felipe II(59) y últimas en que el poder real respeta, dentro de las tensiones habituales, el equilibrio de poder existente en Valencia. En las Cortes de 1.585 los estamentos valencianos pretenderian fundamentalmente defenderse de los representantes del rey en el Reino, o, lo que es lo mismo, del propio monarca; los primeros capítulos de estas Cortes serán de abierta contestación a la política virreinal(60).

A lo largo del Quinientos, dos de las características principales del Parlamento valenciano: el reconocimiento de los agravios y el cáiàcter pactado de la legislación entre el rey y representantes $\approx$ Heino-a cambio, lógicamente, del servicio-va perdiendo eficacia( ${ }^{\left(6^{a}\right)}$. Con las Cortes de 1.604 se iniciará el plano inclinado hacia el aominium regale: la legislación foral, al igual que otras formas de participación en el poder, se verán, de facto, ampliamente desatendidas y las preocupaciones del Parlamento 
que recaben la atención del monarca serán prácticamente las económicas(62).

Las Cortes de Monzón de 1.626 suponen la ruptura definitiva del dominium politicum et regale existente en Valencia, que pasa a convertirse en un dominium análogo al antes señalado en Aragón, tras sus Cortes de 1.626, y que sigue deteriorándose a lo largo de la centuria.

Sin embargo, a diferencia de Aragón y Cataluña, donde la quiebra-o los intentos de quiebra-de su dominium se iniciaron con el ataque a los simbolos de sus libertades-Justicia y Generalidad-por parte del poder real, en Valencia éste atentaría directamente contra las Cortes, o más concretamente, contra su autoridad.

Violando las leyes y costumbre establecidas, Felipe IV comenzaría, con ocasión del Parlamento de 1.626, haciendo su petición antes de prestar el obligado juramento de los fueros(63). Utilizando la violencia moral(64), el monarca y su valido lograrian que, progresivamente, fuera cayendo la oposición de las Cortes a conceder un servicio, que suponía la imposición del programa austracista y la pérdida de su equilibrio políticoinstitucional. Las contrapartidas obtenidas por el Reino serian de escasa entidad: las leyes elaboradas en estas Cortes venían a dar una idea de la debilidad institucional y económico-social que padecía Valencia.

Ahora bien, los intentos de ruptura del equilibrio de poder monarquiaParlamento habian producido una revuelta frustrada en Aragón y otra, lograda, en Cataluña. En Valencia no se pasaría del conato de revuelta(65).

Las Cortes de 1.645 reflejarán ya el cambio de dominium producido en el Reino. El monarca obtuvo en ellas un cuantioso servicio, aprobando tarde y sólo parcialmente las decretadas de los Fueros(66).

A partir de esta última convocatoria, las Cortes valencianas no volverán a reunirse ya. Los representantes del poder real en Valencia lograrian que, en lo sucesivo, los estamentos concedieran los servicios "voluntarios" y "extraordinarios" que la monarquía precisaba, sin necesidad de convocar las Cortes $(67)$. Cuando en el siglo XVIII, con la publicación de los Decretos de Nueva Planta, Felipe $V$ abola los fueros y privilegios del Reino, éstos-a diferencia de lo sucedido en Cataluña y Aragón-no volverán a ser recuperados. Lo que podriamos calificar de dominium quasi-regale, se había implantado así en Valencia.

\section{Conclusiones.}

A la vista de los caracteres y evolución del equilibrio de poder entre monarquías y Parlamentos en España a lo largo de la época moderna, tal vez resulte oportuno intentar extraer algunas conclusiones dentro de la óptica apuntada al comenzar este estudio. 
1. Dominium politicum et regale, si bien fue la regla en España en las distintas entidades políticas de la Corona de Aragón, no lo fue en Castilla, donde, tanto de iure como de facto, existió un dominium regale.

2. A lo largo de la época moderna persistió de manera constante una tendencia a quebrar el equilibrio de poder existente por parte de las fuerzas sociopolíticas en presencia, ya fuera en la dirección del dominium politicum et regale, como acontece en Castilla, o en lo del dominium regale, como sucede en la Corona de Aragón.

3. Esos intentos de quiebra se producirán siempre de manera no consensual, mediante actos de violencia física o de violencia moral, dirigidos contra elementos o instituciones esenciales al mantenimiento del equilibrio de poder actuante.

4. Las necesidades financieras de la monarquia española fueron una de las razones principales para afianzar el dominium regale en Castilla y forzar la ruptura del dominium politicum et regale en la Corona de Aragón.

5. La quiebra y deterioro posterior del pactismo catalano-aragonés, con la desaparición y, en el mejor de los casos, el menoscabo de las leyes e instituciones representativas que aquél comportaba, constituiria un factor decisivo en la implantación del centralismo borbónico.

No se ha pretendido, a lo largo de este trabajo, cuestionar las tesis y modelos que Helmut G. Koenigsberger presenta en su lección inaugural de 1.975. He intentado simplemente recoger sus sugerencias con el fin de intentar explicar los procesos operados en los cambios de distribución de poder entre reyes y Parlamentos en la España Moderna, a la luz de sus planteamientos. Sin embargo, todavía ando demasiado lejos para recoger en bloque el reto que el profesor de Londres plantea, y presentar siquiera una aproximación a esa apasionante teoría general que nuestro autor sugiere. 
(1) Vid. tomo CLXXIV, Cuaderno III, Septiembre-Diciembre 1.977, pp. 460-93. El artículo Ileva el subtítulo: "Monarquías y Parlamentos en la Europa Moderna”.

(2) Cfr. "Dominium Regale or Dominium Politicum et Regale» en Boletín de la Real Academia de la Historia, cit., p. 466.

(3) Ver notas 10 y 12 del art. cit. de H. G. KOENIGSBERGER.

(4) Me referiré concretamente a las Cortes de Castilla, Cataluña, Valencia y, someramente, a las de Aragón.

(5) Vid. KOENIGSBERGER, H. G.: op. cit., pp. 465-66. Se mencionan tan sólo dos excepciones de dificil clasificación: la Dieta del Sacro Imperio Germánico y el caso sueco.

(6) Ibidem, p. 461.

(7) Evidentemente en opinión de Sir John Fortescue. Más adelante veremos que no es asi.

(8) KOENIGSBERGER, H. G.: op. cit., p. 462.

(9) No menciono el caso de Rusia, porque éste queda totalmente fuera de la consideración de Koenigsberger, quizás a causa de la estructura primitiva, comparada con los demás Parlamentos europeos, de las Zemski Sobor. Sin embargo, A. R. MYERS lo incluirá en su Jibro Parlaments and Estates in Europe to 1.789. London, Thames and Hudson, 1.975, aparecido con. posterioridad a la lección inaugural del profesor del King's College.

(10) Así lo afirma Koenigsberger en su artículo, cit., p. 464.

(11) Ver argumentación «in extenso" en PEREZ-PRENDES, J. M.: Cortes de Castilla. BarceIona, Ariel, 1.974, p.p. 16-41.

(12) Ibidem, pp. 155-56.

(13) Cfr. KOENIGSBERGER, H. G.: op. cit., p. 465. Los tres grupos de paises de dominium politicum et regale propuestos son: (1) el de paises en que los Parlamentos, o bien habian abolido totalmente la monarquía o se había establecido una clara preponderancia de aquéllos en un pacto que había sido reconvertido; (2) el de paises en que el predominio de los parlamentos en el pacto con la monarquia no era tan inequívoco como en el grupo anterior, adoleciendo su posición siempre de cierta precariedad, si bien sus poderes siguieran siendo importantes; (3) el de los paises o provincias de paises en que las monarquias se impusieron a sus Parlamentos y los abolen o no los convocan, y el de aquéllos cuyos Parlamentos sobrevivieron pero con unos poderes rigurosamente delimitados y con frecuencia progresivamente reducidos por las monarquias. Passim.

(14) Al margen de la discrepancia apuntada en la clasificación del dominium de un determinado grupo de países, no parece correcta la firmación de que en España y Portugal, Nápoles, Piamonte y Cerdeña "los Parlamentos desaparecieron completamente»; cfr. KOENIGSBERGER, H. G.: op. cit., p. 465. En primer lugar, es imprescindible hacer distinciones dentro de España, dadas las distintas características de las Coronas de Castilla y Aragón. En segundo lugar, Nápoles y Cerdeña formaron parte durante largo tiempo de la Corona aragonesa, y por ende de "España", por lo que su mención necesariamente debe ir acompañada de acotaciones diacrónicas. Por último, en la España peninsular, tanto en Castilla como en Aragón, las Cortes llegaron a estar sin convocarse durante largo tiempo, pero, excepto en el caso de Valencia, que más adelante se analizará, no desaparecieron; en el siglo XVIII comenzaron a ser reunidas en Madrid, pero ello no significo su completa desaparición, hasta el siglo XIX en que, tras la invasión napoleónica, el sistema institucional español, ya alterado con la llegada de los Borbones, cambiarla de signo. Vid., para las Cortes de Castilla, Aragón y Cataluña en el XVIII, BENEYTO, J.: "Les Cortès d'Espagne du XVle au XIXe siècle", en Recueils de la Société Jean Bodin pour I'Histoire Comparative des Institucions, Vol 24 (1.966), pp. 472-74.

(15) Para el pactismo y el concepto clásico de éste, ver VICENS VIVES, J.: Notícia de CataIunya. Barcelona, Destino, 4. ${ }^{a}$ edic., 1.969, pp. 10-14. 
(16) Cfr. MYERS, A. R.: Parliaments and Estates..., pp. 93 y 94. Como señala H. G. KOENIGSBERGER, «lt is clear that the history of the Parliaments of Sicily and Naples can be understood only in terms of the history of the composite Aragones-Spanis monarchy of which there kingdoms had become a part". En cuanto a Cerdeña, "the very institution of Parliament was imported from Sapin"; cfr. "The Italian Parliaments from their origins to the end of the leth centuri". en The Journal of Italian History, Vol. I, Number I, Spring 1.870, p. 35.

(17) Cfr. Dominium regale..., p. 466. El subrayado es nuestro.

(18) Cfr. PEREZ-PRENDES, J. M.: op. cit., p. 74.

(19) Vid. PEREZ-PRENDES, J. M.: op. cit., p. 62 y 63-68.

(20) Vid. MYERS, A. R.: op. cit., pp. 29-30 y 97, y BENEYTO, J.: op. cit., p. 462.

(21) Vid. PEREZ-PRENDES, J. M.: op. cit., pp. 98-99 y 114-15.

(22) Cfr. PEREZ-PRENDES, J. M.: op. cit., pp. 140-46 y 147. También, ELLIOTT, J. H.: La España Imperial. 1.469-1.716. Barcelona, Ed. Vicens Vives, 1.965, p. 30.

(23) Vid. KOENIGSBERGER, H. G.: Dominium regale.., p. 472.

(24) A diferencia del impuesto, el sevicio era una prestación económica aprobada en Cortes, cuya base juridica para su exacción era el acuerdo libérrimo de los que habrán de pagar; cfr. PEREZ:PRENDES, J. M.: op. cit., p. 96.

(25) Vid. ELLIOTT, J. H.: op. cit., pp. 94-95. La asistencia de nobleza y clero era, por otra parte, irrelevante desde el punto de vista de la concesión del servicio, pues ambos estaban exentos del pago, al igual que los procuradores de las ciudades; tras éstos se encontraba, sin embargo, el pueblo llano, que era quien debia soportar las cargas económicas aprobadas por aquéllos.

(26) Cfr. PEREZ, J.: La revolución de las Comunidades de Castilla (1.520-1.521). Madrid, Siglo XXI, 1.977 , p. 119 .

(27) Ibidem, p. 120.

(28) Passim.

(29) Vid. PEREZ, J.: op. cit., pp. 153-54.

(30) Op. cit., p. 159.

(31) Cfr. PEREZ, J.: op. cit., p. 539. Según este autor, cel papel preeminente reservado a las Cortes en la vida politica del reino, constituye la gran originalidad del programa de los comuneros en el plano politicon. Ibidem, p. 541.

(32) Cfr. BENEYTO, J.: op. cit., p. 463.

(33) ELLIOTT, J. H.: op. cit., p. 218.

(34) Cfr. PEREZ-PRENDES, J. M.: op. cit., p. 97.

(35) Op. cit., p. 218.

(36) Ver BENEYTO, J.: op. cit., p. 472.

(37) Cfr. Introducció a la Història de la Corona de Aragó. Palma de Mallorca, Ed. Moll, 1.973, p. 93.

(38) REGLA, J.: op. cit., p. 94

(39) MYERS, A. R.: op. cit., p. 32.

(40) Cfr. BENEYTO, J.: op. cit., p. 469.

(41) Ibidem. También MYERS, A. R.: op. cit., p. 33.

(42) ELLIOTT, J. H.: op. cit., pp. 301-02.

(43) No obstante, siguió manteniéndose la unanimidad para la aprobación de nuevas imposiciones y para algunos casos de torturas, galeras, confiscación y enriquecimiento ilicito. Vid. ELLIOTT, J. H.: op. cit., p. 306 y BENEYTO, J.: op. cit., pp. 469-70.

(44) ELLIOTT, J. H.: op. cit., p. 307.

(45) Cfr. BENEYTO, J.: op. cit. p. 473.

(46) Op. cit., p. 100. 
(47) Cfr. VICENS VIVES, J.: Noticia de Catalunya, cit., p. 112.

(48) Ibidem.

(49) ELLIOTT, J. H.: op. cit., p. 82.

(50) Ibidem, pp. 23-24.

(51) Cfr. Historia de Cataluña. Madrid, Alianza, 1.974, p. 105. En aquella ocasión las Cortes ofrecieron un espléndido servicio, mientras el rey hacia una verdadera "hornada nobiliaria" y devolvía a la ciudad de Barcelona las insaculaciones de alcaldes y jueces. Passim.

(52) Ver VICENS VIVES, J.: op. cit., p. 119. La ciudad de Barcelona, sin embargo, sí resultarla afectada por ese intento del poder real de quebrar el pactismo catalán. En 1.652-53 "la Corona aprovechó, con cautela, la oportunidad de robustecer su autoridad en Cataluña, introduciendo pocas, pero decisivas novedades en el status constitucional que Barcelona, como cabeza del principado, habia tenido hasta entices en la Monarquia hispánican ha señalado Fernando SANCHEZ MARCOS en su interesante articulo "El nuevo status de Barcelona tras su reincorporación a la Monarquía Hispánica en 1.652" en Homenaje al Dr. D. Juan Reglà Campistol, Vol. I, Valencia, Facultad de Filosofia y Letras, 1.975, p. 608.

(53) Ibidem, p.118.

(54) ELLIOT, J. H.: op. cit., p. 408.

(55) VICENS VIVES, J.: op. cit., p. 119.

(56) Vid. BENEYTO, J.: op. cit., p. 473.

(57) Vid. estudio preliminar de E. BELENGUER CEBRIA a las Cortes del Reinado de Fernando el Católico. Valencia, Depto. de H. ${ }^{a}$ Moderna de la Universidad (DHMU), 1.972, pp. XXIV. XXVI.

(58) Cfr. REGLA, J.: "Les estructures politiques: els esdeveniments" en Historia del Pais Valencià. Vol. III, Barcelona, Ed. 62, p. 121. También el estudio preliminar de R. GARCIA CARCEL a las Cortes del Reinado de Carlos I. Valencia, DHMU, 1.972, p. XI.

(59) Vid. Estudio introductorio de E. SALVADOR ESTEBAN a las Cortes Valencianas del Reinado de Fellpe II. Valencia, DHMU, 1.973, p. XXII.

(60) Ibidem, pp. XXXIII y XXXV.

(61) Vid. introducción de Eugenio CISCAR PALLARES a las Cortes Valencianas de Felipe III. Valencia. DHMU, 1.973 pp. 8 y 9.

(62) Ibidem, p. 17.

(63) Vid. introducción de D. de LARIO RAMIREZ a Cortes del Reinado de Felipe IV. I. Cortes valencianas de 1.626. Valencia, DHMU, pp. X-XI.

(64) El último reducto opositor fue el estamento militar, al que Felipe IV llegó a declararles enemigos suyos y de su Corona, si no votaban el servicio. Olivares le amenazó con quitarles la nobleza hasta la cuarta generación. Cfr. LARIO RAMIREZ, D. de: op. cit., pp. XII-XIII.

(65) Vid. LARIO, D. de: «Un conato de revuelta social en Valencia durante el reinado de Felipe IV” en Homenaje al Dr. D. Juan Reglà Campistol. Vol. I, cit., pp. 571-78.

(66) Cfr. GUIA MARIN, L.: «Los estamentos valencianos y el Duque de Montalto: los inicios de la reacción foral", en Estudis, 4, 1.975, pp. 130-31.

(67) Ibidem, p. 145. 



\title{
LOS DERECHOS DE MONOPOLIO EN LA VALENCIA DEL ANTIGUO REGIMEN: EL EJEMPLO DE ALFARA Y BURJASOT DURANTE EL SIGLO XVII
}

\author{
Por Fernando ANDRES ROBRES \\ Universidad de Valencia
}

Como es sabido, los derechos de monopolio constituyen uno de los más sólidos pilares en que se basa el régimen señorial, tanto en el sentido de importante fuente generadora de rentas como en el de su actuación como freno a la capacidad de desarrollo de las fuerzas productivas, contribuyendo así notablemente al estancamiento y estabilidad que caracterizan la organización feudal de la producción. Se trata además de un fenómeno muy amplio geográfica y cronológicamente, y los señoríos del País Valenciano en la etapa final del Antiguo Régimen no fueron excepción a esta regla general, como ha puesto de manifiesto E. Ciscar al estudiar las cartas de población surgidas a raíz del episodio de la expulsión de los moriscos en 1.609(1).

No obstante carecemos de estudios monográficos que se refieran a las características concretas que, en nuestra zona, reviste su administración y pongan de manifiesto el papel que desempeñan dentro del conjunto de relaciones económicas que, para la explotación de los señoríos, se establecen entre cualquier señor y sus vasallos.

Dentro de estas coordenadas se inscribe la presente aportación, centrada en los antiguos señorios de Alfara y Burjasot(2), dependientes del Colegio de Corpus Christi y sobre los que se guarda una completísima información en el Archivo del Colegio del Patriarca-concretamente en las secciones de Varios y Sindicado-que nos permite acometer tres análisis diferentes: 
-el sistema de explotación de los monopolios

- la evolución de las rentas que devengan a lo largo del siglo XVII.

- la importancia de los derechos en relación a las otras fuentes productoras de rentas.

Pero antes de adentrarnos en estos temas es conveniente realizar un par de aclaraciones previas. La primera se refiere a un problema conceptual; nuestra documentación alude a los derechos monopolísticos como "regalías", término que es inequívocamente sinónimo de derecho de la Corona. No obstante, su uso, común en todos los estudios sobre Régimen señorial valenciano durante los siglos XVII-XVIII está justificado, ya que:

"se llaman regalías haciendo alusión a la primigenia propiedad real de estos monopolios en los comienzos de la reconquista para luego, bien sea por donación o por usurpación nobiliaria, pasar a formar parte de los bienes propios del señor feudal»(3).

Así, utilizaremos indistintamente los términos regalías y monopolios, aunque sin duda, este último resulta más correcto.

El segundo punto es más delicado: entre las diversas regalías controladas por el Colegio se incluye el tercio-diezmo de Burjasot(4), que poco tiene que ver con los monopolios pese a ser el derecho que con más base puede considerarse antigua regalía. Recordemos que el tercio-diezmo es una porción determinada del diezmo eclesiástico que la corona consiguió percibir después de grandes esfuerzos, pero que en el Pais Valenciano pasa a ser cobrado muy pronto por el señor feudal(5). Sus diferencias con el resto de derechos son pués muy claras y aumentan si tenemos en cuenta que es el único que, por definición, debe hacerse efectivo en especie. Sin embargo, su inclusión en nuestras fuentes al mismo nivel que los monopolios y, sobre todo, su importancia testimonial-sobre la que insistiremos más adelante-, nos han llevado a incluirlo, aunque intentaremos en todo momento ser conscientes de esta pequeña irregularidad, separándolo claramente del análisis del resto de derechos.

1.-Regalías o monopolios: características y método de explotación.

En palabras de Ciscar, los derechos de monopolio pueden definirse como:

"conjunto de atribuciones que se arroga el señor tendentes a obligar a los vasallos a utilizar una serie de bienes del señorio en beneficio propios(6).

Y los más comunes son prácticamente los mismos que hemos encontrado para los señorios de Alfara y Burjasot, es decir, molino, horno, 
carnicería, huerto y tienda en ambos lugares, almacera de aceite y ladrillar o "rojalar" en Alfara y mesón-que aparece incorporado a la tienda-en Burjasot.

El origen de todos ellos es anterior a la época en que el Colegio se hizo cargo de la administración de los señoríos(7), excepto en los casos del horno y el molino de Alfara. El primero, inexistente hasta entonces, fue construido a principios del siglo XVII, y el molino, perteneciente a un particular, fue adquirido por las mismas fechas, en sendas operaciones que supusieron a la Institución un desembolso de 1.000 y 6.963 libras respectivamente(8) y que nos hablan del interés del Colegio por controlar la vida económica en sus dominios.

Pero pasemos al estudio concreto de su régimen de funcionamiento. Normalmente son explotados mediante contratos de arrendamiento a corto plazo cuya duración oscila entre 4-6-8 años, con puntas de dos años por defecto(9) y de diez por exceso, coincidiendo estos últimos, casi siempre, con la crítica etapa que sufre el País mediado el siglo. En estos "largos" arrendamientos suele constar en los contratos que de los 10 años, 5 están considerados como "de firme", y los otros como "de respit» = prórroga(10). Las únicas excepciones a estas normas habituales son tres:

- los huertos de la señoría que, aproximadamente desde la década de los 70 y hasta el final del siglo pasan a arrendarse "por tiempo a beneplácito del colegion(11).

- los pilones de carniceria que son también arrendados por tiempo indefinido-a excepción de los primeros años en Burjasot-y que presentan otra originalidad: en vez de ser arrendados a particulares, el contrato es acordado entre la Institución y el lugar, cuyos responsables ponen al frente del negocio a un encargado(12).

-el ladrillar de Alfara, que en 1.689 es vendido a debitorio como muchas otras propiedades del Colegio y que nos plantea un serio problema. ¿Como es posible que se venda-aunque particularmente pensamos que la venta a debitorio tiene bastante de ficticio(13) _ precisamente un monopolio que si por algo se define es por su exclusividad?. Sólo cabe una explicación teórica ya que nada se señala en los documentos y es que la fabricación de ladrillos por cualquier causa ha dejado de ser monopolistica(14). De todos modos el hecho resulta bastante extraño ya que, como es lógico, el Colegio vela por el cumplimiento de las reglas que aseguran el carácter exclusivo de estos derechos(15).

El cobro del importe de estos arrendamientos, que se estipula por anualidades, es abonado en una o varias pagas, dependiendo del tipo de bien de que se trate. Los monopolios más importantes desde el punto de vista de las rentas-molinos y hornos-suelen comprender cuatro plazos anuales, aunque hemos encontrado en el molino de Alfara contratos que 
establecen hasta un abono mensual(16). Los monopolios modestos-todo el resto-suelen hacerse efectivos en una o dos pagas anuales.

Por último, las fechas en que deben realizarse estas pagas dependen, lógicamente, de la época estacional en que haya comenzado el arrendamiento. Como es normal los contratos no comienzan un $1 .^{\circ}$ de Enero para concluir en 31 de Diciembre. Este relativo detalle, que carece de importancia para aquellos monopolios que poco o nada tienen que ver con el año agricola-carnicerias, tienda, ladrillar-es importante para el resto. Los molinos, hornos, huertos y almacera suelen arrendarse con el año agricola y las dos principales pagas que se realizan en Navidad y San Juan de Junio, intercalándose el resto, cuando las haya, en fechas equidistantes a estas dos. El Cuadro n. ${ }^{\circ} 1$ nos sintetiza lo que acabamos de comentar.

\section{CUADRO N. ${ }^{\circ} 1$}

\section{CARACTERISTICAS DE LOS ARRENDAMIENTOS DE DERECHOS MONOPOLISTICOS}

\begin{tabular}{|c|c|c|c|c|c|}
\hline MONOPOLIO & LUCAR & $\begin{array}{c}\text { Duración } \\
\text { Arrdmto. } \\
\text { AÑ̃OS }\end{array}$ & $\begin{array}{c}\text { Carácter } \\
\text { Estacional } \\
\text { arredmtos. }\end{array}$ & $\begin{array}{l}\text { PAGAS } \\
\text { ANUALES }\end{array}$ & Fechas de las pagas anuales \\
\hline Molino & ALF. & $4-8$ & Jun. Julio & $4-12$ & $\begin{array}{l}1^{\circ} \text { Nov., Nav., Carnestoltes, } \\
\text { S. Joan. }\end{array}$ \\
\hline Molino & BUR. & $4-6$ & $n$ & 4 & $"$ \\
\hline Horno & AlF. & $2-6$ & $n$ & $2-4$ & Nav. - S. Joan. \\
\hline Horno & BUR & $4-6$ & $n$ & 4 & $\begin{array}{l}\text { 1. Nov., Nav., Carnestoltes, } \\
\text { S. Joan. }\end{array}$ \\
\hline Carnicería & ALF. & - & - & 1 & Nav. \\
\hline Carnicería & BUR. & - & - & 1 & Nav. \\
\hline Tienda & ALF. & $4-10$ & - & 1 & - \\
\hline Tienda & BUR. & $4-8$ & - & 2 & - \\
\hline Huerto & ALF. & $6-x$ & S. Joan-S. Joan & $1-2$ & S. Joan-Nav. \\
\hline Huerto & BUR. & $6-X$ & $"$ & 1 & S. Joan \\
\hline Almacera & ALF. & $4-10$ & $"$ & $1-3$ & Nav., Carnestoltes, S. Joan. \\
\hline Rajolar & ALF. & $4-8$ & - & 1 & - \\
\hline
\end{tabular}

En cuanto al derecho del tercio-diezmo de Burjasot, la Institución arrendaba su cobro a un particular(77), que recolectaba los pagos en especie, los comercializaba y se comprometía a pagar al Colegio un importe en metálico estipulado al realizarse el contrato. Los contratos tienen carácter 
cuatrienal con dos únicas excepciones(18) y comienzan normalmente en Carnestoltes hasta que en los años finales del siglo se hacen coincidir con el año común. Por último sabemos que era abonado en dos pagas anuales que se hacian efectivas en Julio y Carnestoltes cuando se finalizaba en esa fecha, y en San Juan y Navidad en el caso de los arrendamientos de final de siglo.

2.-La evolución de las rentas derivadas del arrendamiento de monopolios durante el siglo XVII.

Gran parte de la información que nos ha servido para comentar estos aspectos del funcionamiento formal de los monopolios procede de los libros de sindicado que, por sus características-reflejan anualmente los ingresos de la Institución en concepto de diferentes rentas-y su amplitud cronológica-para nuestro período existe un volumen anual desde 1.613 hasta 1.700- nos ha permitido realizar otro tipo de estudio: se trata del análisis de la evolución de las rentas que el Colegio percibía en concepto del arrendamiento de estos derechos y que puede entenderse como una nueva aportación de datos de carácter monográfico acerca de la coyuntura económica valenciana durante el polémico período que supone el siglo XVII.

Disponemos para ello de series completas para la mayor parte del siglo que han sido rabajadas, o lo que es lo mismo, deflactadas con los precios del trigo y representadas(19). Las series pueden encontrarse en el apéndice numérico y los resultados, creemos, son lo suficientemente significativos como para comentarlos individualmente y colectivamente.

Los molinos (Gráfico $n .^{\circ}$ 1) son, con bastante diferencia, los monopolios que producen rentas más elevadas(20). Sus valores en libras-de 210 a 341 en Alfara y de 126 a 226 en Burjasot-, siempre anualmente, hacen que se situen cerca del $50 \%$ de la renta total que se detrae de este tipo de derechos. La lectura de las gráficas es un tanto sorprendente: mientras que la curva de Alfara tiene un trazado muy claro, con un hundimiento progresivo que alcanza su cénit en la crisis de 1.648 , y un claro enderamiento posterior que se afianza a partir de los años 80 , la correspondiente a Burjasot, Ilena de altibajos - aunque estos no sean excesivamente violentos-, presenta su máxima inflexiónen 1.681, después de haber atravesado serios problemas en la crisis central del siglo(21). En definitiva, muestra una tendencia decreciente, y la leve recuperación de la década 85-95 no tiene continuación al final del periodo. 

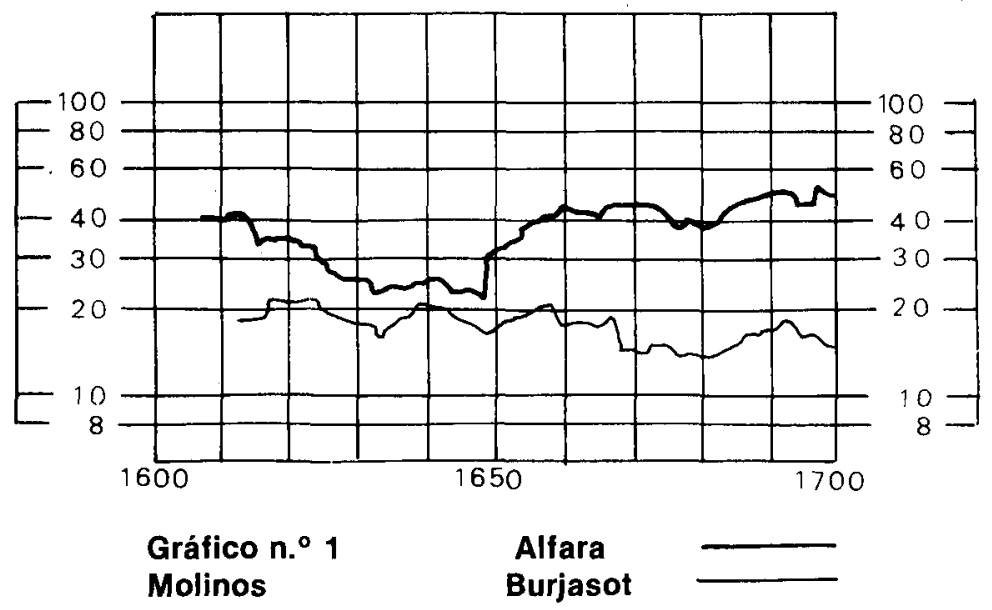

Los hornos (Gráfico n. ${ }^{\circ}$ ), en segundo lugar en cuanto al montante absoluto de las rentas que suponen, forman una gráfica relativamente coherente, pero en base, precisamente, de presentar fuertes convulsiones. Al igual que los molinos, la tendencia a la baja en la primera mitad de siglo es más rápidamente invetida en Alfara, pero al concluir el siglo cambia el panorama: al tiempo que en Burjasot se advierte una fuerte recuperación, la curva de Alfara sufre una vertiginosa caida que no logramos explicarnos lógicamente. De todas formas puede ser significativo el que ambos trazos finalicen el siglo prácticamente a los mismos niveles que lo comenzaron. Otro problema estriba, por último, en las diferencias entre molinos y hornos, que presentan evoluciones distintas cuando, teóricamente, al ser dos eslabones de un mismo proceso-la elaboración del pan-debieran presentar mayores analogías.
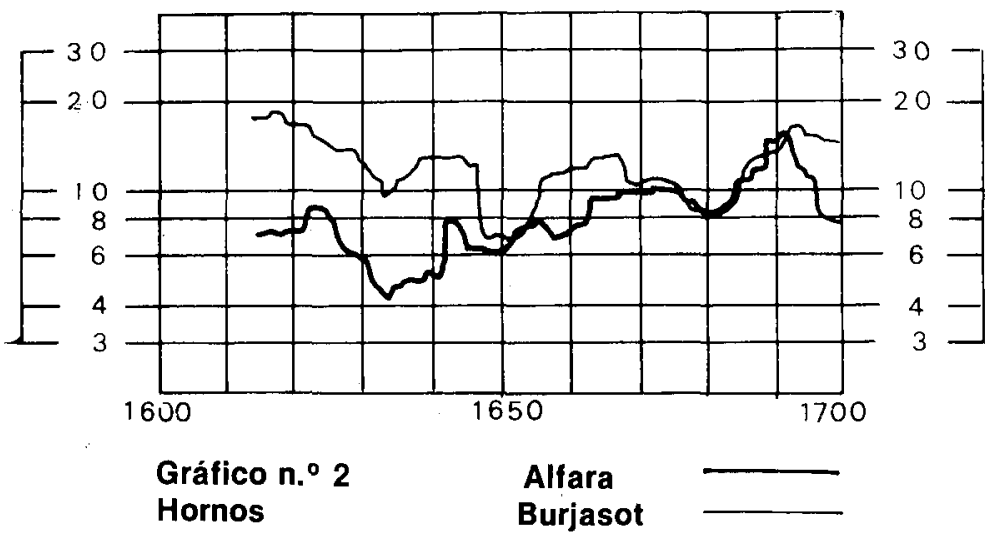
El arrendamiento de las carnicerias (Gráfico n. ${ }^{\circ} 3$ ) es el de precios más estables a lo largo del siglo. Tanto es así que sus curvas son, prácticamente, un calco a la inversa de los precios del trigo, únicamente alterada por ese brusco "zigzag" que presenta el trazado de Burjasot entre 1.636 y 1.642, para el que no hemos encontrado explicación en la documentación.

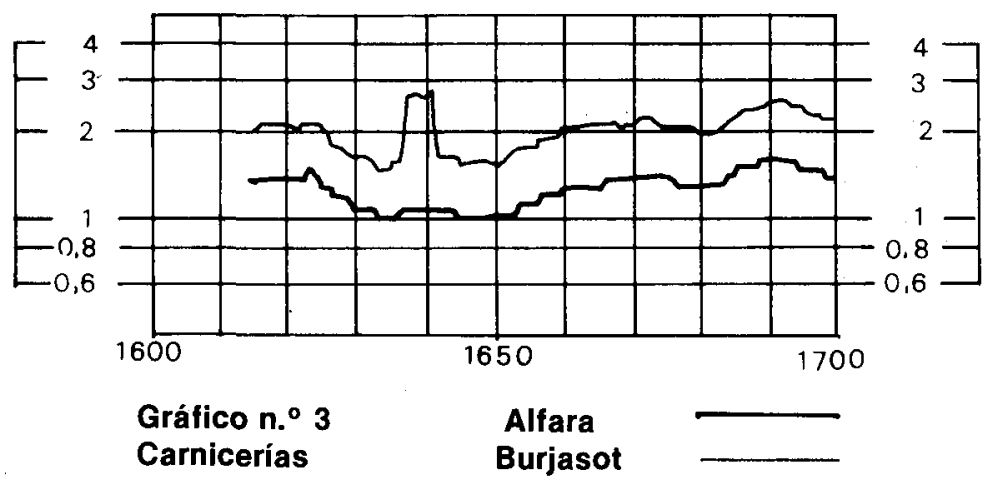

La representación de los arrendamientos de las tiendas de Alfara y Burjasot (Gráfico n. ${ }^{\circ}$ ) no admite un comentario conjunto. Mientras que

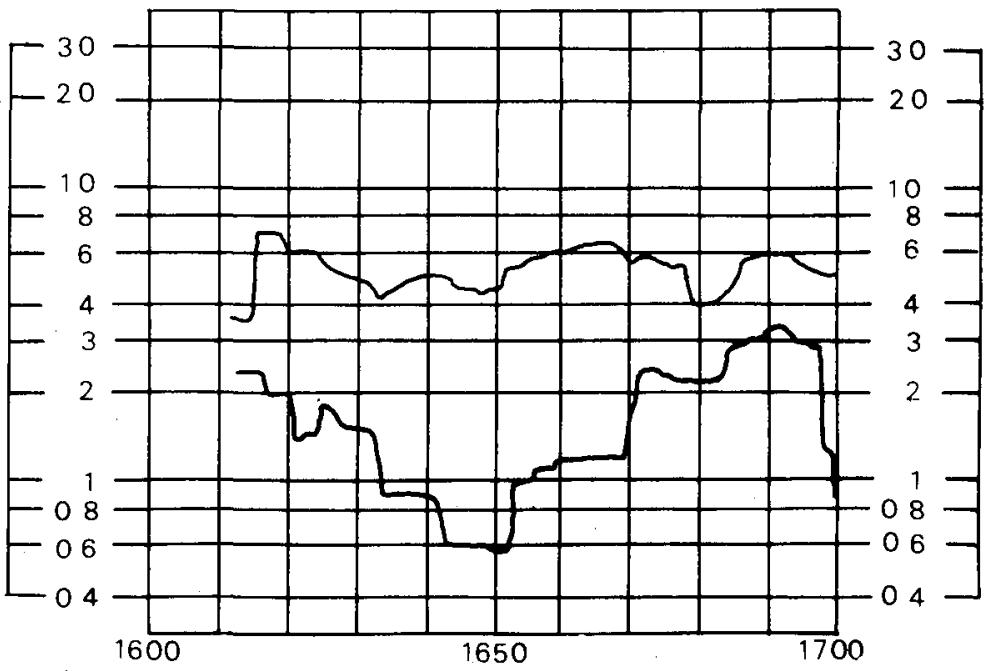

Gráfico n. ${ }^{\circ} 4$

Alfara

Tiendas

Burjasot 
esta última se mantiene siempre en unos niveles coherentes-la súbita escalada del principio se justifica en base a que el monopolio pasa de ser tienda exclusivamente a incluir también el mesón(22) - la curva de Alfara es del todo desconcertante. Podemos hablar de un impresionante descenso hasta 1.648-52, una subida si cabe más importante desde entonces hasta los años $90 \mathrm{y}$, y esto es lo verdaderamente inverosimil, un vertiginoso picado en el quinquenio final del siglo. Su valor arrendado-si la documentación no nos ha escondido algún detalle que lo justifique-pasa de estar tasado en 19 libras 6 sueldos en 1.697 a sólo 6 libras y 10 sueldos en 1.700 , es decir, se deprecia en un $300 \%$ aproximadamente.

En cambio, los huertos de la señoria (Gráfica n. ${ }^{\circ}$ ) muestran idèntica evolución: una notable depreciación hasta el crítico periodo central del siglo y, a partir de este punto, una lenta recuperación pero que no va a llegar a alcanzar en ningún momento los niveles del primer cuarto del período. Se trata, además de una subida del producto deflactado, basada en el descenso de los precios del cereal, ya que el importe de los arrendamientos en libras no varia desde 1.635 en Alfara y 1.650 en Burjasot hasta 1.700 .

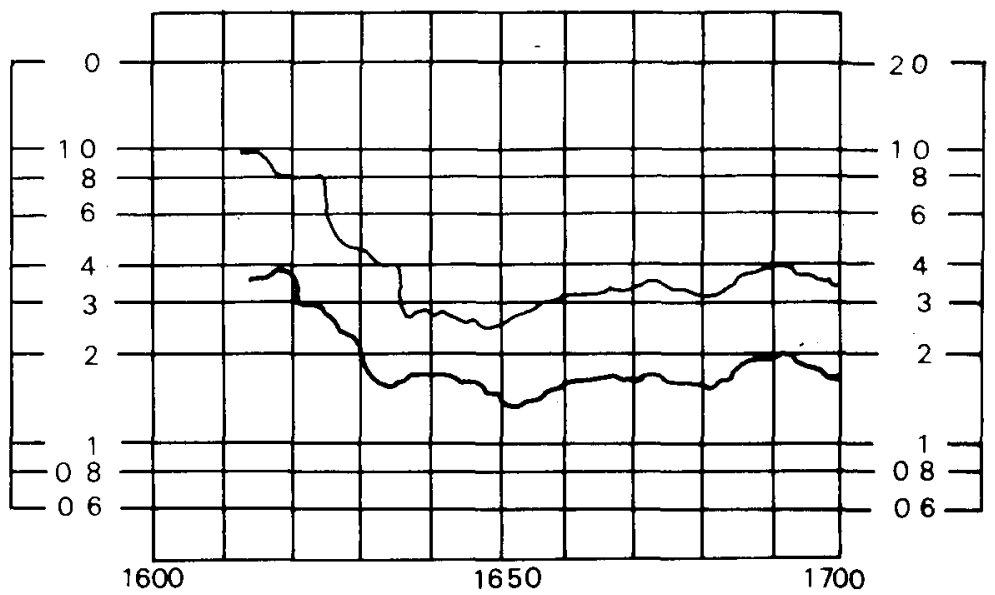

Gráfico $n .^{\circ} 5$ Huertos 
La almazara de aceite de Alfara (Gráfico $n .^{\circ}$ 6) es un claro exponente, aunque exagerado en su escala, de la coyuntura secular: nitido descenso hasta los años centrales del siglo, periodos críticos en torno a los años $1.648,1.660$ y 1.680 y, entre ellos, evidentes síntomas de relativas mejorías.

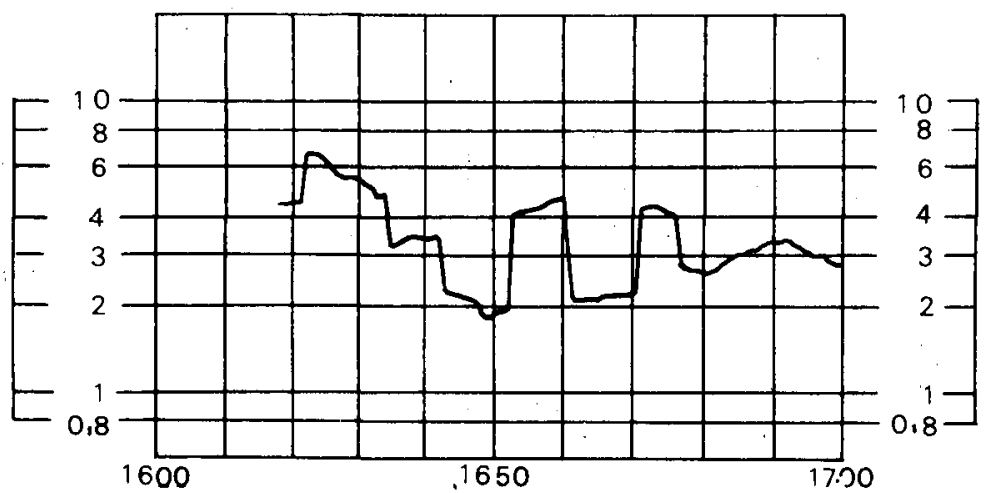

Gráfico $n .^{\circ} 6$

Almácera. Alfara

Por último, el ladrillar de Alfara (Gráfico $n^{\circ}{ }^{7}$ ) presenta unas fuertes convulsiones que, afortunadamente, parecen tener sus lógicas explicaciones. Por un lado, la discontinuidad en el trazo no se debe a lagunas en la serie, sino a la inexistencia de contratos de arrendamiento entre 1.636 y 1.645. En 1.637 aún no está abandonado: "lo tiene Pedro Verdet porque no esté vacío. Da una poca obra de cuando en cuando»(23), pero más adelante "está encomendado por no haver quien lo arriendew(24). Y, por otra parte, la fuerte bajada dẹl final del siglo es debida a su paso a propiedad «vendida a debitorio», en una maniobra que ya hemos comentado antes.

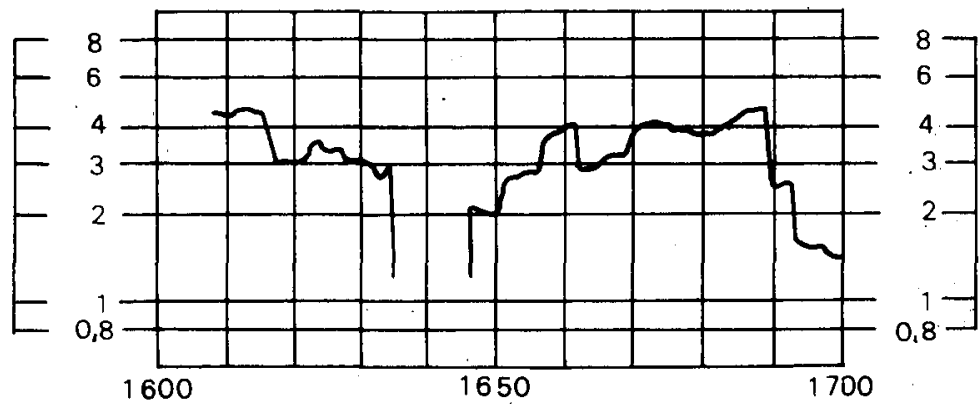

Gráfico n. ${ }^{\circ} 7$

Ladrillar. Alfara 
El derecho del tercio diezmo merece una mayor atención, ya que su importancia testimonial supera ampliamante la de cualquiera de los monopolios que acabamos de comentar. En efecto, el hecho de ser una renta detraída en especie-aunque se arriende su explotación-y que afecta prácticamente a la totalidad de los productos(25) y de las tierras cultivadas - independientemente de que las propiedades estén o no sujetas a enfiteusis-nos permite, al menos en teoria conocer la evolución de la producción agricola del periodo al que se refiera. Para el estudio de la serie, que ha sido trabajada como las de arrendamientos de monopolios (Gráfico $n .^{\circ} 8$ ) hemos podido contar con una valiosa ayuda: las series del "delme de pa i vi" elaboradas, para Masagrell y la huerta en su conjunto por J. M. Palop (Gráfico $n .{ }^{\circ} 9$ ) y J. Casey (Gráfico n. ${ }^{\circ}$ 10)(26) respectivamente que nos permitirán, por esta vez, comparar los resultados. Desde luego se trata de series de diferente composición pero que, en definitiva, al reflejar todas ellas la evolución de las cosechas, se prestan a un análisis conjunto.

La lectura de la gráfica de Burjasot podría ser ésta: tendencia a la baja con dos importantes inflexiones en 1.633 y $1.648-50$ para, inmediatamente a continuación emprender una ascensión que, si no es excesivamente espectacular, si se muestra lo suficiente clara como para no verse apenas afectada por la crisis de los años 60 y 80 . Por último, la recuperación que parece afianzarse tras estos tres últimos periodos depresivos y que ha sido objeto de tantos comentarios 27 ) aparece con bastante nitidez. Ahora bien, todo ello teniendo en cuenta que nos movemos en unos niveles moderados en cuanto a la amplitud de las oscilaciones, debido, como señala Palop, al cultivo siempre intensivo que caracteriza a las zonas de huerta, donde no pueden aparecer variaciones en función de nuevas roturaciones o de la introducción de nuevos cultivos(28). Aún así, el gráfico de Burjasot muestra una tendencia en general más definida que el de Masamagrell y en cuanto a la comparación con el gráfico de Casey, casi no es necesaria: salvando la diferencia de escalas podemos apreciar perfectamente la similitud-que raya el calco-entre ambos trazados.

Para finalizar este apartado analizaremos las series resultantes de la suma de los valores de cada uno de los derechos en las tendencias coyuntural y secular, pero antes quisiéramos advertir un par de cosas. En primer lugar, la curva de Burjasot incluye en sus valores los relativos al terciodiezmo por una sencilla razon y pese a las diferencias antes apuntadas: si los trazados resultantes deben ser un reflejo de la coyuntura económica del seiscientos valenciano nos ha parecido lógico incluir el más significativo de todos los derechos, sobre todo después de haber comprobado la coherencia de su comportamiento. $Y$, por otra parte, la enorme diferencia existente en cuanto al montante de la renta que supone cada uno de los derechos, hace que los gráficos totales sean prácticamente la suma de los molinos, hornos, tercio diezmo de Burjasot y poco más, aunque particular- 


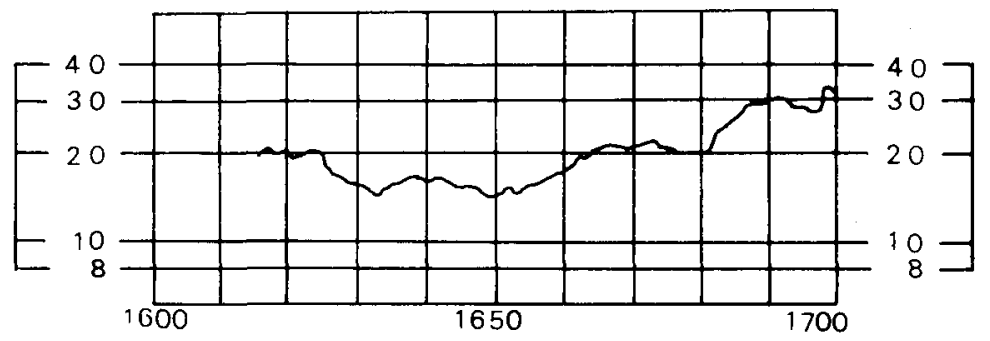

Gráfico n. $^{\circ} 8$

Tercio Diezmo. Burjasot

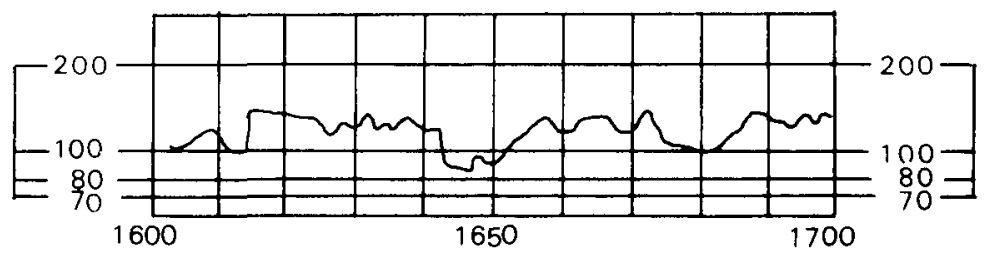

Gráfico n. ${ }^{\circ} 9$

Masamagrell (J. M. Palop)

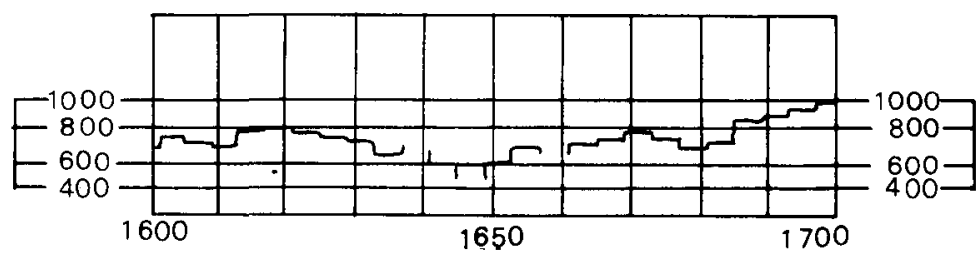

Gráfico n. ${ }^{\circ}$ 10. Delme de pa i vi Huerta de Valencia (J. Casey) 
mente consideremos este aspecto como positivo, al ser estos los trazados que nos resultan más fiables.

Con todo, la lectura de las curvas resultantes (Gráficos $n .{ }^{\circ} 11,12$ y 13 ) en el movimiento coyuntural nos hace ser francamente optimistas al coincidir a grandes rasgos con las procedentes de la evolución de los productos diezmales. Aparece nítidamente el profundo descenso que caracteriza la primera mitad del siglo, pero que no resulta exagerado si pensamos que tras la curva depresiva centrada en 1.648 , la recuperación es tan rápida que Ilega en Alfara a superar en pocos años los niveles de 1.618, presagiando una segunda mitad de siglo mucho menos difícil. Tras el acusado cambio de tendencia, la estabilidad es la nota dominante entre 1.655 y 1.680 y sólo se verá rota por pequeñas depresiones en torno a 1.660 y esa última fecha. A partir de entonces el crecimiento es importante, pero no continuo como cabria esperar, siendo ésta la única fase en que nuestros datos difieren de los de otros trabajos: si en las series estudiadas por $\mathrm{Pa}$ lop el ascenso no se ve frenado hasta la Guerra de Sucesión, las nuestras acusan perfectamente la subida de los precios del trigo que contempla el último quinquenio del siglo XVII.

En cuanto a la tendencia secular nos llaman profundamente la atención las difencias entre ambos señorios. Mientras que, como dijimos, la curva de Alfara supera ampliamante en su ascensión desde mediado el siglo los niveles de los años 20 , la de Burjasot observa un prolongado estancamiento, cuando menos hasta los últimos años de la centuria y, aún así, sin alcanzar nunca la altura de los primeros datos de que disponemos. Impresión que se afianza cuando nos fijamos no ya en la tendencia, sino en los valores absolutos. Si tenemos en cuenta que Burjasot es demográfica y territorialmente más importante que Alfara y que, además, contrarresta teóricamente la ausencia de derechos como la almazara y el ladrillar con otro de mucha más envergadura como es el tercio-diezmo, parece muy significativo el que sus niveles sólo estén por encima de los de Alfara hasta los años 50 , que se equiparen desde entonces hasta 1.680 y que estén por debajo en la última fase del siglo. ¿Hemos de pensar en una proporcionalmente mayor retabilidad de este tipo de derechos en Alfara? Puede ser. Sólo resta añadir que el gráfico conjunto de ambas series, que lógicamente las suaviza, es poco significativo.

\section{3. - La renta señorial: el papel de los derechos de monopolio.}

A través de las series estudiadas conocemos exactamente el importe que anualmente iba a parar a las arcas del Colegio como fruto de la explotación de los derechos monopolísticos. Las cifras brutas bien poco podrian indicarnos, pero sí creemos interesante averiguar, aunque sea de forma aproximada, lo que estos ingresos suponen en relación a las rentas 


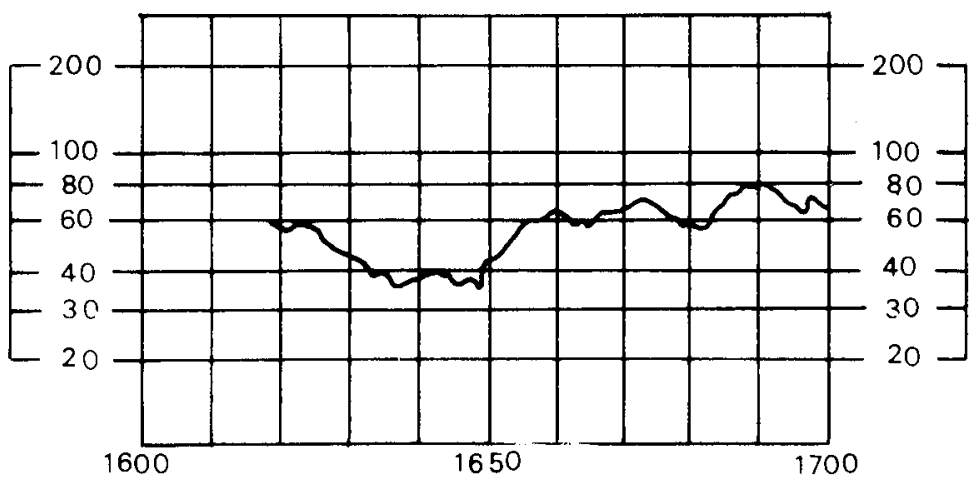

Gráfico n. ${ }^{\circ} 11$

Totales Alfara

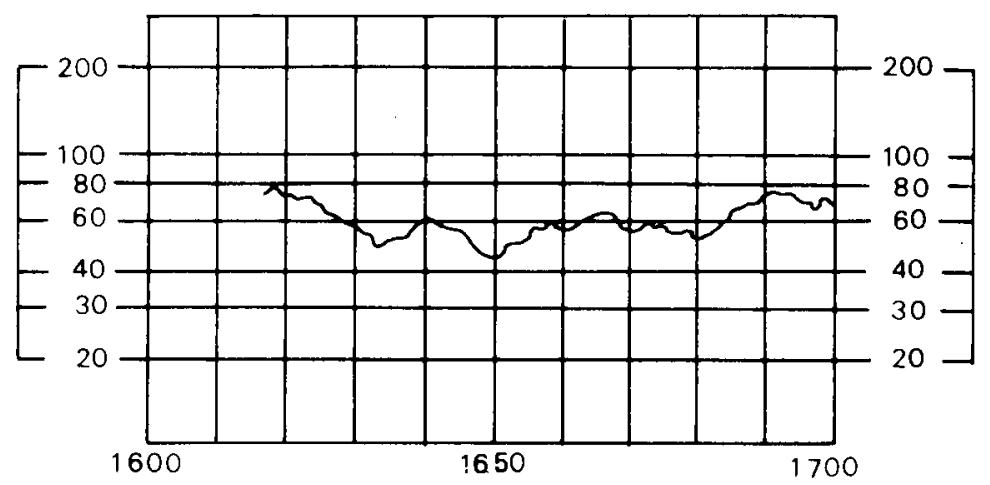

Gráfico n. ${ }^{\circ} 12$

Totales Burjasot

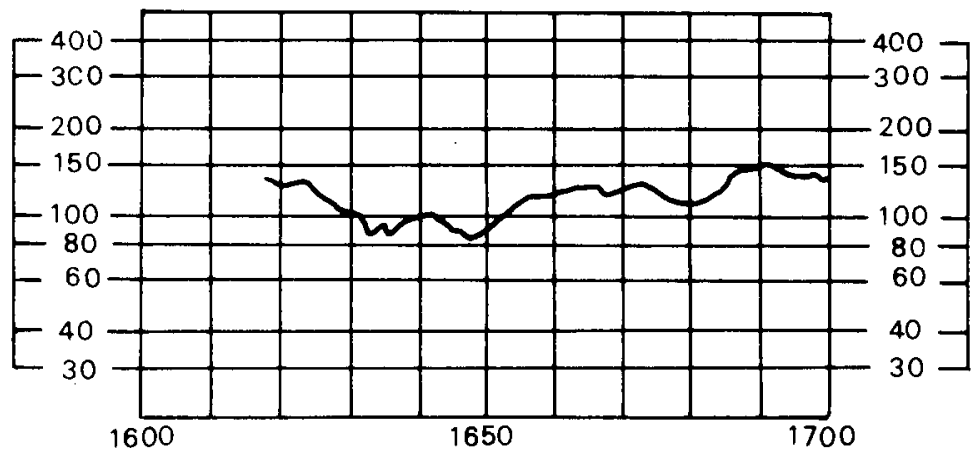

Gráfico n. ${ }^{\circ} 13$

Totales Alfara-Burjasot 
totales que la Institución obtiene de la administración de los señorios de Alfara y Burjasot.

Ello ha sido posible, no nos cansamos de insistir, gracias a la excelente base documental existente sobre dichos lugares, que nos ha permitido conocer la mayoria de las fuentes productoras de rentas y su evolución en el sentido cuantitativo a lo largo del XVI|(29). Pero vayamos por partes.

Al margen de los derechos monopolísticos o regalias-entre los que volveremos a incluir el tercio-diezmo de Burjasot y que consideramos suficientemente explicados-el Colegio obtenía rentas de otras dos principales fuentes: los censales y la tierra(30).

Sobre los censales poco hay que decir; de sobra es conocido el papel que este sistema de préstamo jugó en la sociedad valenciana a partir del siglo XV, y del que la Institución es fiel reflejo actuando siempre como acreedor(31). En el caso concreto de los señoríos y dejando a un lado algunos cargados a paticulares y poco importantes económicamente, encontramos tres censales cargados a la "Universidad de Cristianos"(32) de Alfara que datąn de la época de las donaciones y que resultan significativos en cuanto a su importe: dos de ellos tienen propiedad de 2.750 libras y pensión de 68 libras 15 sueldos y el tercero, 1.800 y pensión de 105 libras(33). También sabemos de algunos cargados sobre Burjasot, pero como quiera que están fechados en $1.700 \mathrm{y}$, por tanto, se comenzaron a abonar en 1.701, quedan fuera de nuestro ámbito cronológico(34).

El caso de las rentas procedentes de la tierra es más complejo. Generalmente, durante el Antiguo Régimen, la explotación agraria en el Pais Valenciano se lleva a cabo mediante contratos de enfiteusis, como sucede en los señorios de Alfara y Burjasot a principios de siglo. Sin embargo, y pese a que este sistema se seguirá utilizando a lo largo de todo el XVII en parte de las propiedades, va a dejar de ser el método exclusivo para convertirse, además, en el menos rentable económicamente. La base de estos cambios se encuentra en una serie de transformaciones llevadas a cabo por el Colegio y consistentes en la adquisición de respetables extensiones de tierras en sus propios dominios - tierras a veces francas, a veces incluso sometidas a censo-para después emprender su explotación mediante contratos de arrendamiento o ventas a debitorio bien diferenciados del tradicional método de propiedad compartida y que convierte a Alfara y Burjasot en dos señoríos atípicos en este sentido. Como consecuencia nos ha parecido conveniente distinguir claramente entre ambos tipos de ingresos-censos enfitéuticos y otros métodos de explotación agraria-, que junto a censales y monopolios forman la columna vertebral de la renta señorial en nuestros lugares.

Teóricamente sólo una de ellas, los censales, es fija, ya que los censos enfitéuticos(35) debieron sufrir variaciones en sentido decreciente a 
medida que el Colegio iba adquiriendo propiedades y sustituyendo los censos por los nuevos métodos; no obstante, al haber encontrado únicamente un cabreve fidedigno, fechado en 1.640, asignaremos sus valores a todo el siglo sin que ello, creemos, pueda desfigurar exageradamente los resultados debido a la escasa entidad que, como veremos, caracteriza esta fuente de rentas.

Para pasar al análisis del Cuadro $n .^{\circ} 2$, donde se condensa toda la información de que diponemos sólo es necesario añadir que se ha construido con periodicidad decenal y que en él se expresa, nominal y porcentualmente, el importe de todas las rentas(36).

La primera observación claramente marcada es la del espectacular aumento de las rentas totales que casi llegan a duplicarse a lo largo del siglo y que se produce de forma bastante gradual. La causa del incremento estriba, casi exclusivamente, a las rentas derivadas de arrendamientos y debitorios que pasan, en su conjunto, de un 20 a un $54 \%$ y cuyo depegue se manifiesta mucho más fuertemente en Burjasot, donde las 100 libras y el $12,8 \%$ de 1.620 se convierten, en 1.700 , en 1.005 libras y un $59,6 \%$. Las cifras no dejan lugar a dudas sobre la rentabilidad obtenida por el Colegio del conjunto de transformaciones al que aludiamos.

Por otra parte y en este marco, es lógico que se dé una tendencia a la baja en los valores porcentuales de aquellas fuentes de ingresos que permanecen estables a lo largo de la centuria. Los censales de Alfara, que suponen a comienzos de siglo un $20,3 \%$ de las rentas del señorío y un $12,3 \%$ de las totales, quedan al final del período a unos niveles del 12,1 y el $6,5 \%$ respectivamente, es decir, se reducen aproximadamente a la mitad. $Y$ algo parecido sucede con los censos enfitéuticos, cuyo descenso porcentual sería aún mayor si dispusiéramos de datos relativos al que debió experimentar en términos brutos.

Pero analicemos los datos que más nos interesan en el contexto del presente trabajo: los ingresos derivados de los derechos de monopolio y antiguas regalías resultan, sin duda, más importantes de lo que esperábamos. Sus niveles brutos oscilan entre las 829 y las 968 libras anuales, cifras nada despreciables para la época, y mucho más significativos resultan los valores respecto al conjunto de ingresos, que hay que analizar con cuidado.

Normalmente su aportación se sitúa en torno al $30 \%$, llegando tan sólo ocasionalmente a valores inferiores al $25 \%$. Esta estabilidad resulta ya significativa si tenemos en cuenta el espectacular incremento experimentado por otras fuentes mientras que las regalias permanecen inalterables en cuanto a sus posibilidades de explotación. Pero su gran importancia se confirma al analizar los datos correspondientes a 1.620 y 1.630 , cuando todavia no se han materializado las consecuencias de las atipicas trans- 
ESTRUCTURA DE LA RENTA SEÑORIAL

\begin{tabular}{|c|c|c|c|c|c|c|c|c|c|c|c|}
\hline \multirow[t]{2}{*}{ AÑo } & \multirow[t]{2}{*}{ LUGAR } & \multicolumn{2}{|c|}{ CENSALES } & \multicolumn{2}{|c|}{ CENS. ENF } & \multicolumn{2}{|c|}{$\begin{array}{l}\text { OTROS METODOS } \\
\text { DE EXPLOTACION }\end{array}$} & \multicolumn{2}{|c|}{ RECALIAS } & \multicolumn{2}{|c|}{ TOTAL } \\
\hline & & lib. & $\%$ & lib. & $\%$ & lib. & $\%$ & lib. & $\%$ & & $\%$ \\
\hline 1.620 & ALF. & 242 & 20,3 & 274 & 23 & 290 & 24,3 & 385 & 32,3 & 1191 & 100 \\
\hline 1.620 & BUR. & & & 182 & 23,4 & 100 & 12,8 & 497 & 63,8 & 779 & 100 \\
\hline 1.620 & тот. & 242 & 12,3 & 456 & 23,1 & 390 & 19,8 & 882 & 44,8 & 1970 & 100 \\
\hline
\end{tabular}

$\begin{array}{llllllllllll}1.630 & \text { AlF. } & 242 & 19,5 & 274 & 22,0 & 331 & 26,6 & 395 & 31,8 & 1242 & 100\end{array}$ $\begin{array}{llllllllll}1.630 & \text { BUR. } & 184 & 23,5 & 109 & 13,9 & 491 & 62,6 & 784 & 100\end{array}$ $\begin{array}{lllllllllll}1.630 & \text { TOT. } 242 & 11,9 & 458 & 22,6 & 440 & 21,7 & 886 & 43,7 & 2026 & 100\end{array}$

$\begin{array}{llllllllllll}1.640 & \text { ALF. } 242 & 21,0 & 274 & 23,8 & 318 & 27,6 & 318 & 27,6 & 1152 & 100\end{array}$ $\begin{array}{llllllllll}1.640 & \text { BUR. } & 182 & 11,6 & 870 & 55,6 & 512 & 32,7 & 1564 & 100\end{array}$ $\begin{array}{lllllllllll}1.640 & \text { TOT. } 242 & 8,9 & 456 & 16,8 & 1188 & 43,7 & 830 & 30,5 & 2716 & 100\end{array}$

$\begin{array}{llllllllllll}1.650 & \text { ALF. } & 242 & 18,4 & 274 & 20,9 & 376 & 28,8 & 419 & 32,0 & 1311 & 100\end{array}$ $\begin{array}{llllllllll}1.650 & \text { BUR. } & 182 & 12,2 & 864 & 58,0 & 443 & 29,7 & 1489 & 100\end{array}$ $\begin{array}{llllllllllll}1.650 & \text { TOT. } 242 & 8,6 & 456 & 16,3 & 1240 & 44,3 & 862 & 30,8 & 2800 & 100\end{array}$

$\begin{array}{llllllllllll}1.660 & \text { ALF. } & 242 & 13,4 & 274 & 15,1 & 819 & 45,3 & 473 & 26,2 & 1808 & 100\end{array}$ $\begin{array}{llllllllll}1.660 & \text { BUR. } & 182 & 13,8 & 856 & 58,2 & 433 & 29,4 & 1471 & 100\end{array}$ $\begin{array}{llllllllllll}1.660 & \text { TOT. } 242 & 7,3 & 456 & 13,9 & 1675 & 51,1 & 906 & 27,6 & 3279 & 100\end{array}$

$\begin{array}{llllllllllll}1.670 & \text { ALF. } & 242 & 13,6 & 274 & 15,4 & 795 & 44,8 & 462 & 26,0 & 1173 & 100\end{array}$ $\begin{array}{llllllllll}1.670 & \text { BUR. } & 182 & 10,3 & 1182 & 67,1 & 395 & 22,4 & 1762 & 100\end{array}$ $\begin{array}{llllllllllll}1.640 & \text { TOT. } 242 & 6,8 & 456 & 12,9 & 1974 & 55,8 & 857 & 24,2 & 3535 & 100\end{array}$

$\begin{array}{llllllllllll}1.680 & \text { ALF. } & 242 & 13,8 & 274 & 15,6 & 803 & 45,8 & 434 & 24,7 & 1753 & 100\end{array}$ $\begin{array}{llllllllll}1.680 & \text { BUR. } & 182 & 10,4 & 1164 & 66,8 & 395 & 22,7 & 1741 & 100\end{array}$ $\begin{array}{llllllllllll}1.680 & \text { TOT. } 242 & 6,9 & 456 & 13,0 & 1967 & 56,3 & 829 & 23,7 & 3494 & 100\end{array}$

$\begin{array}{llllllllllll}1.690 & \text { ALF. } & 242 & 13,3 & 274 & 15,1 & 834 & 46,1 & 460 & 25,4 & 1810 & 100\end{array}$ $\begin{array}{llllllllll}1.690 & \text { BUR. } & 182 & 10,8 & 1071 & 63,4 & 435 & 25,8 & 1688 & 100\end{array}$ $\begin{array}{lllllllllll}1.690 & \text { TOT. } 242 & 6,9 & 456 & 13,0 & 1905 & 54,4 & 895 & 25,6 & 3498 & 100\end{array}$

$\begin{array}{llllllllllll}1.700 & \text { ALF. } & 242 & 12,1 & 274 & 13,7 & 1009 & 50,6 & 469 & 23,5 & 1994 & 100\end{array}$ $\begin{array}{llllllllll}1.700 & \text { BUR. } & 182 & 10,8 & 1005 & 59,6 & 499 & 29,6 & 1686 & 100\end{array}$ $\begin{array}{lllllllllll}1.700 & \text { TOT. } 242 & 6,5 & 456 & 12,4 & 2014 & 54,7 & 968 & 26,3 & 3680 & 100\end{array}$ 
formaciones sufridas por los señoríos: si entendemos que en Alfara el porcentaje-32,4\%-se ve reducido por la existencia de los censales y por unos censos enfitéuticos más elevados(37), el 63,8 \% de Burjasot no deja lugar a dudas. Y puede no resultar exagerado el pensar que esa pudo ser la importancia normal en los señorios del País Valenciano a comienzos del siglo XVII, antes de que el surgimiento del señorio de nuevo tipo derivado de las repoblaciones que siguieron a la expulsión de los moriscos permitiese a los señores incrementar sensiblemente las rentas derivadas de la explotación agraria al poner al día los antiguos y desfasados censos.

Por último vuelve a confirmarse la impresión de la mayor incidencia relativa al señor sobre Alfara, cuyas rentas sólo son superadas por las de Burjasot en 1.640 y 1.650 cuando, recordemos, es el menor de los lugares.

\section{NOTAS:}

(1) E. CISCAR PALLARES, Tierra y señorio en el Pais Valenciano. 1570-1620. Valencia, 1.977.

(2). Alfara y Burjasot son dos pequeños lugares enclavados en la huerta norte de Valencia, con diminutos términos municipales y poblaciones en el siglo XVII de entre 50 y 100 vecinos -cristianos viejos desde antiguo-dedicados casi exclusivamente a las tareas agrícolas.

(3) Ibid. p. 228.

(4) Aunque parece dificil suponer que siguiera yendo a parar a las arcas reales, nada en absoluto sabemos sobre el mismo derecho en el señorío de Alfara.

(5) Ver al respecto, I. MORANT DEUSA, Economia y sociedad en un señorio del Pais Valenciano: el ducado de Gandia (siglos XVII-XVIII). Gandla, 1.978, p. 23. A. MESTRE, "La recolección de diezmos en la diócesis de Valencia según la encuesta capitular de 1.758", art. en Primer Congreso de Historia del Pais Valenciano. Vol. III, Valencia, 1.973. pp. 631-642.

(6) E. CISCAR, op. cit., p. 228.

(7) El Colegio de Corpus Christi accede a la administración de los señoríos de Alfara y Burjasot merced a las donaciones de Juan de Ribera que, a su vez, Jos habia adquirido a sus an. tiguos propietarios a finales del siglo XVI. Las donaciones se efectuan, concretamente, el 14-9-1.601 en el caso de Alfara y el 10-6-1.604 para Burjasot. Archivo del Colegio del Patriarca, Valencia (A.C.P.V.), VARIOS, Libro de Titulos n. ${ }^{\circ}$, fols. 44 y 73.

(8) Ibid. fols. $46 \mathrm{v}, 47,47 \mathrm{v}$.

(9) Se trata de uno de los arrendamientos del horno de Alfara. A.C.P.V., SINDICADO, 1.613 fol. 73.

(10)Encontramos arrendamientos de 10 años en la tienda y la almazara de Alfara. A.C.P.V., SINDICADO, 1.641, fols. 109 y 110.

(11) A.C.P.V., SINDICADO, 1.673 , fols. 3 y 81.

(12) Ibíd., 1.661, fol. 135 y 1.665, fol. 93. Esta posibilidad de arrendamiento al lugar es también apuntada por E. CISCAR, op. cit. p. 129.

(13) Efectivamente pensamos que la venta a debitorio, tal y como la aplicaba el Colegio, puede ser considerada como un simple método de explotación alternativo al arrendamiento. Puede consultarse F. ANDRES ROBRES, "La detracción de la renta agraria en los señorios del Colegio de Corpus Christi durante el siglo XVII", art. en ESTUDIS VIII, Valencia, 1.982. 
(14) Basamos esta afirmación a vista de un libro "cabreve de Alfara en el que aparecen hasta un total de 12 parcelas que, ubicadas en el secano, han sido empleadas para la construcción de ladrillares. A.C.P.V., CENSOS, Cabreve de Alfara y Burjasot de 1.701-1.704, fols. 33, 47, $49,51,79,111,113,117,119,135,137,151$.

(15) Sobre este particular podemos poner un claro ejemplo: la Institución compra en 1.663 el Ilamado "Molino del Raig", situado en el término municipal de Burjasot (A.C.P.V., VARIOS, Libro de Títulos n. ${ }^{\circ} 1$, fol. 252) y, rápidamente lo cede en arrendamiento aunque dejando muy claro en el contrato que éste se hacía "con pacto de no poder entrar a buscar molienda a Burchaçot" (A.C.P.V. SINDICADO, 1.673, fol. 130.

(16) A.C.P.V., SINDICADO, 1.625 fol. $63,1.629$ fol. 68 y 1.633 fol. 71 .

(17) Los arrendamientos se inician en 1.615-1.616. Con anterioridad se indica que el derecho está uen administración". A.C.P.V., SINDICADO, 1.613 fol. 119.

(18) Estas excepciones son dos contratos de ocho años suscritos por un indivíduo que debió gozar de la confianza del Colegio: el bayle Bautista Andrés. Los periodos son 1.632-1.640 y 1.652-1.660. A.C.P.V. SINDICADO, 1.633 fol. 97 y 1.653 fol. 164 .

(19) Para la extracción de los datos hemos utilizado los volúmenes de Sindicado correspondientes a $1.613,1.617,1.621,1.625,1.629,1.633,1.637,1.641,1.645,1.649,1.653,1.657,1.661$, $1.665,1.669,1.673,1.677,1.681,1.685,1.689,1.693,1.697$ y 1.700 (A.C.P.V., SINDICADO). Los precios del trigo utilizados para deflactar proceden del trabajo de J. M. PALOP RAMOS, "El producto diezmal valenciano durante los siglos XVII-XVIII. Aproximación a su estudion, y están suavizados con una media movil de nueve términos (4.1.4), perfectamente aplicable a la duración de nuestros arrendamientos.

(20) Hay que tener en cuenta, no obstante, que ambos molinos suelen arrendarse junto a un lote de tierras, por lo que de los ingresos totales cabría deducir algunas libras para averiguar exactamente la importancia económica del monopolio. A modo de aproximación diremos que junto al de Alfara se arriendan tres cahizadas de huerta y çon el de Burjasot, una cahizada. Y que podríamos dar la cifra de 15 libras por cahizada como precio de un arrendamiento normal, por to que de los precios brutos deberiamos detraer 45 y 15 libras respectivamente para acercarnos más a la realidad.

(21) El Colegio tiene dificultades para encontrar arrendatario para el molino de Burjasot. A.C.P.V., SINDICADO, 1.645 fol. 49 .

(22) El cambio debe corresponder, aproximadamente, a una fecha cercana a 1.615 . A.C.P.V., SINDICADO, 1.621 fol. 92.

(23) Ibid., 1.637 fol. 85.

(24) Ibid., 1.641 fol. 92.

(26) Precisamente en el acta de compra del lugar de Burjasot se especifican los productos que se hallan sometidos a este derecho, y que son «trigo, vino, azeyte, canyamo, cebolla, ojas, garbanços, cañamones, cevada, daça, alfalfa, fruta i cualquier otro panerı, es decir, la práctica totalidad de los cultivos típicos de la huerta del Antiguo Régimen. A.C.P.V., VARIOS, Libros de Títulos $\mathrm{n} .{ }^{\circ} 1 \mathrm{fol} .76 \mathrm{v}$. En cuanto al grado de partición que suponía el diezmo mayor en Burjasot puede consultarse A-MESTRE, art. cit. La mayoria de los productos se diezman en proporciones de $1 / 9$.

(26) Ver J. M. PALOP, art. cit. y J. CASEY, "Structure et d'eveloppement de l'agriculture de Valence à l'époque moderne. 1.500-1.700". Casey trabaja con datos procedented de diezmos de Alboraya, Alfafar, Burjasot, Carpesa, Chirivella, Foyos, Masamagrell, Moncada, Museros, Patraix, Paterna y Torrente.

(27) Ver al respecto, por ejemplo, J. REGLA, Aproximacío a la história del País Valencià. Valencia, 1.973, pp. 146:148.

(28) J. M. PALOP, art. cit. p. 5n.

(29) Sobre todas estas fuentes, que ahora expondremos muy brevemente puede consultarse un análisis más profundo en F. ANDRES ROBRES, Aproximación al estudio del funciona- 
miento económico del señori valenciano: Alfara y Burjasot durante el siglo XVII. Tesis de licenciatura inédita, Valencia 1.980. En el apéndice numérico pueden encontrarse las series en que basamos la confección del Cuadro $\mathrm{n}^{\circ} 2$.

(30) Damos por supuesto que existirían más fuentes de rentas, como podrian ser las derivadas de la administración de la justicia, el cobro de luismos, etc., pero no poseemos información sobre ellas. Además, pensamos, su importancia no sería comparable a la de las fuentes que aqui estudiamos.

(31) En efecto, pese a que no entra en nuestro objeto de estudio hemos podido comprobar que el Colegio tenía cargados censales sobre, al menos, una treintena de villas reales del País-entre ellas las más importantes-, sobre algunas capitales de fuera del Reino-caso de Sevilla, lógico por la vinculación del Patriarca a esa ciudad-y sobre un gran número de particulares, pertenecientes en su mayoria a las más altas esferas sociales de Valencia.

(32) Se trata de un sistema de préstamo habitual en el País y responde generalmente a la necesidad de una villa en un momento determinado de realizar cualquier tipo de obras, abastecerse 0 acometer procesos litigiosos por ejemplo. Ver E. CISCAR, op. cit. p. 118.

(33) A.C.P.V., VARIOS, Libro de Títulos n. ${ }^{\circ} 1$, fols. $46,46 \mathrm{v}$.

(34) lbíd. fols. $280,423,425,426$.

(35) Los censos enfitéuticos incluyen, además de las rentas de la tierra, aquellas derivadas de las casas y algunos otros bienes inmuebles.

(36) Es decir, los datos se han trabajado en uno de cada 10 años. Debe quedar claro que las cifras del cuadro reflejan ingresos anuales, no decenales. Por otra parte, proceden de los libros de la serie sindicado que indicábamos en la nota 18.

(37) Esta superior cuantia de los censos en Alfara se explica por una serie de nuevos establecimientos fechados en 1.602 y realizados ya por el Colegio, con unas condiciones mucho más duras para los pobladores. Tanto que de sólo 12 lotes compuestos de una casa y una cahizada de tierra huerta se obtienen rentas por valor de 150 libras anuales. A.C.P.V., VARIOS, Libro de Títulos n. ${ }^{\circ}$, fols. 47,47 v, 48 . 


\section{APENDICE NUMERICO}

SERIES DE ARRENDAMIENTOS DE REGALIAS Y MONOPOLIOS DEFACTADAS CON LOS PRECIOS DEL TRIGO EN VALENCIA

\begin{tabular}{|c|c|c|c|c|c|c|c|c|c|}
\hline \multicolumn{2}{|r|}{ Precio Trigo } & \multicolumn{2}{|c|}{ MOLINO ALF. } & \multicolumn{2}{|c|}{ HORNO ALF. } & \multicolumn{2}{|c|}{ ALMACERA ALF. } & \multicolumn{2}{|c|}{ TIENDA ALF. } \\
\hline AÑO & $\begin{array}{l}\text { MM 4.1.4. } \\
\text { libras/cahiz }\end{array}$ & $\begin{array}{l}\text { Precio } \\
\text { libras }\end{array}$ & $\begin{array}{l}\text { Prodt. } \\
\text { Defl. }\end{array}$ & $\begin{array}{l}\text { Precio } \\
\text { libras }\end{array}$ & $\begin{array}{l}\text { Prodt. } \\
\text { Defl. }\end{array}$ & $\begin{array}{l}\text { Precio } \\
\text { libras }\end{array}$ & $\begin{array}{l}\text { Prodt. } \\
\text { Defl. }\end{array}$ & $\begin{array}{l}\text { Precio } \\
\text { libras }\end{array}$ & $\begin{array}{r}\text { Prodt. } \\
\text { Defi. }\end{array}$ \\
\hline
\end{tabular}

\begin{tabular}{|c|c|c|c|c|c|c|c|c|c|}
\hline 1605 & 7,11 & & & & & & & & \\
\hline 1606 & 6,99 & & & & & & & & \\
\hline 1607 & 7,05 & 285 & 40,4 & & & & & & \\
\hline 1608 & 6,89 & 285 & 41,3 & & & & & & \\
\hline 1609 & 6,96 & 285 & 40,9 & & & & & & \\
\hline 1610 & 7,00 & 285 & 40,7 & & & & & & \\
\hline 1611 & 7,01 & 285 & 40,6 & & & & & & \\
\hline 1612 & 6,75 & 285 & 42,2 & & & & & & \\
\hline 1613 & 6,82 & 285 & 41,7 & & & & & 16 & 2,3 \\
\hline 1614 & 6,85 & 285 & 41,6 & 50 & 7,2 & & & 16 & 2,3 \\
\hline 1615 & 6,88 & 285 & 41,4 & 50 & 7,2 & & & 16 & 2,3 \\
\hline 1616 & 6,79 & 235 & 34,6 & 50 & 7,3 & & & 16 & 2,3 \\
\hline 1617 & 6,70 & 235 & 35,0 & 50 & 7,4 & & & 14 & 2,0 \\
\hline 1618 & 6,76 & 235 & 34,7 & 50 & 7,3 & 30 & 4,4 & 14 & 2,0 \\
\hline 1619 & 6,80 & 235 & 34,5 & 50 & 7,3 & 30 & 4,4 & 14 & 2,0 \\
\hline 1620 & 6,80 & 235 & 34,5 & 50 & 7,3 & 30 & 4,4 & 14 & 2,0 \\
\hline 1621 & 6,84 & 235 & 34,3 & 50 & 7,3 & 30 & 4,3 & 10 & 1,4 \\
\hline 1622 & 6,87 & 220 & 32,4 & 60,5 & 8,9 & 44,2 & 6,5 & 10 & 1,4 \\
\hline 1623 & 6,66 & 220 & 33,0 & 60,5 & 9,0 & 44,2 & 6,6 & 10 & 1,5 \\
\hline 1624 & 6,77 & 220 & 32,4 & 60,5 & 8,9 & 44,2 & 6,5 & 10 & 1,4 \\
\hline 1625 & 7,18 & 220 & 30,6 & 60,5 & 8,4 & 44,2 & 6,1 & 13 & 1,8 \\
\hline 1626 & 7,58 & 220 & 29,0 & 54 & 7,1 & 44,2 & 5,8 & 13 & 1,7 \\
\hline 1627 & 8,02 & 220 & 27,4 & 54 & 6,7 & 44,2 & 5,5 & 13 & 1,6 \\
\hline 1628 & 8,15 & 220 & 26,9 & 54 & 6,6 & 44,2 & 5,4 & 13 & 1,5 \\
\hline 1629 & 8,35 & 220 & 26,3 & 54 & 6,4 & 46 & 5,5 & 13 & 1,5 \\
\hline 1630 & 8,46 & 226 & 26,7 & 54 & 6,3 & 46 & 5,4 & 13 & 1,5 \\
\hline 1631 & 8,57 & 226 & 26,3 & 45 & 5,2 & 46 & 5,3 & 13 & 1,5 \\
\hline 1632 & 9,01 & 226 & 25,0 & 45 & 4,9 & 46 & 5,1 & 13 & 1,4 \\
\hline 1633 & 9,89 & 226 & 22,8 & 45 & 4,5 & 46 & 4,6 & 8,5 & 0,8 \\
\hline 1634 & 9,38 & 226 & 24,0 & 45 & 4,7 & 46 & 4,9 & 8,5 & \\
\hline
\end{tabular}




\begin{tabular}{|c|c|c|c|c|c|c|c|c|c|}
\hline \multirow[b]{2}{*}{ AÑO } & \multirow[b]{2}{*}{$\begin{array}{r}\text { Precio } \\
\text { Trigo }\end{array}$} & \multicolumn{2}{|c|}{ MOLINO ALF. } & \multicolumn{2}{|c|}{ HORNO ALF. } & \multicolumn{2}{|c|}{ ALMACERA ALF. } & \multicolumn{2}{|c|}{ TIENDA ALF. } \\
\hline & & $\begin{array}{l}\text { Precio } \\
\text { libras }\end{array}$ & $\begin{array}{l}\text { Prodt. } \\
\text { Defl. }\end{array}$ & $\begin{array}{l}\text { Precio } \\
\text { libras }\end{array}$ & $\begin{array}{l}\text { Prodt. } \\
\text { Defl. }\end{array}$ & $\begin{array}{l}\text { Precio } \\
\text { libras }\end{array}$ & $\begin{array}{l}\text { Prodt. } \\
\text { Defl. }\end{array}$ & $\begin{array}{l}\text { Precio } \\
\text { libras }\end{array}$ & $\begin{array}{l}\text { Prodt. } \\
\text { Defl. }\end{array}$ \\
\hline 1635 & 9,19 & 226 & 24,5 & 45 & 4,8 & 30 & 3,2 & 8,5 & 0,9 \\
\hline 1636 & 8,99 & 210 & 23,3 & 45 & 5,0 & 30 & 3,3 & 8,5 & 0,9 \\
\hline 1637 & 8,67 & 210 & 24,2 & 45 & 5,1 & 30 & 3,4 & 8 & 0,9 \\
\hline 1638 & 8,57 & 210 & 24,5 & 45 & 5,2 & 30 & 3,5 & 8 & 0,9 \\
\hline 1639 & 8,43 & 210 & 24,9 & 45 & 5,3 & 30 & 3,5 & 8 & 0,9 \\
\hline 1640 & 8,65 & 210 & 24,5 & 45 & 5,2 & 30 & 3,4 & 8 & 0,9 \\
\hline 1641 & 8,58 & 220 & 25,6 & 70,5 & 8,2 & 30 & 3,4 & 8 & 0,9 \\
\hline 1642 & 8,51 & 220 & 25,8 & 70,5 & 8,2 & 30 & 3,5 & 6 & 0,7 \\
\hline 1643 & 8,74 & 220 & 25,1 & 70,5 & 8,0 & 20 & 2,2 & 6 & 0,6 \\
\hline 1644 & 8,96 & 220 & 24,5 & 70,5 & 7,3 & 20 & 2,2 & 6 & 0,6 \\
\hline 1645 & 9,13 & 220 & 24,0 & 60 & 6,5 & 20 & 2,1 & 6 & 0,6 \\
\hline 1646 & 9,15 & 220 & 24,0 & 60 & 6,5 & 20 & 2,1 & 6 & 0,6 \\
\hline 1647 & 9,36 & 220 & 23,5 & 60 & 6,4 & 20 & 2,1 & 6 & 0,6 \\
\hline 1648 & 9,71 & 220 & 22,6 & 60 & 6,1 & 18 & 1,8 & 6 & 0,6 \\
\hline 1649 & 9,60 & 290 & 30,2 & 60 & 6,2 & 18 & 1,8 & 6 & 0,6 \\
\hline 1650 & 9,45 & 290 & 30,6 & 60 & 6,3 & 18 & 1,9 & 6 & 0,6 \\
\hline 1651 & 9,21 & 290 & 31,4 & 65 & 7,0 & 18 & 1,9 & 6 & 0,6 \\
\hline 1652 & 8,82 & 290 & 32,8 & 65 & 7,3 & 18 & 2,0 & 6 & 0,6 \\
\hline 1653 & 8,59 & 290 & 33,7 & 65 & 7,5 & 36 & 4,1 & 9 & 1,0 \\
\hline 1654 & 8,44 & 320 & 37,9 & 65 & 7,7 & 36 & 4,2 & 9 & $1,0^{\circ}$ \\
\hline 1655 & 8,28 & 320 & 38,6 & 65 & $7,8^{\circ}$ & 36 & 4,3 & 9 & 1,0 \\
\hline 1656 & 8,12 & 320 & 39,4 & 65 & 8,0 & 36 & 4,4 & 9 & 1,1 \\
\hline 1657 & 7,96 & 320 & 40,2 & 56 & 7,0 & 36 & 4,5 & 9 & 1,1 \\
\hline 1658 & 7,82 & 320 & 40,9 & 56 & 7,1 & 36 & 4,6 & 9 & 1,1 \\
\hline 1659 & 7.63 & 320 & 41,9 & 56 & 7,3 & 36 & 4,7 & 9 & 1,1 \\
\hline 1660 & 7,50 & 320 & 42,6 & 56 & 7,4 & 36 & 4,8 & 9 & 1,2 \\
\hline 1661 & 7,35 & 320 & 43,5 & 56 & 7,6 & 16 & 2,1 & 9 & 1,2 \\
\hline 1662 & 7,38 & 300 & 40,6 & 70 & 9,4 & 16 & 2,1 & 9 & 1,2 \\
\hline 1663 & 7,34 & 300 & 40,8 & 70 & 9,5 & 16 & 2,1 & 9,5 & 1,2 \\
\hline 1664 & 7,38 & 300 & 40,6 & 70 & 9,4 & 16 & 2,1 & 9 & 1,2 \\
\hline 1665 & 7,29 & 300 & 41,1 & 70 & 9,6 & 16 & 2,1 & 9 & 1,2 \\
\hline 1666 & 7,14 & 309,5 & 43,3 & 70 & 9,8 & 16 & 2,2 & 9 & 1,2 \\
\hline 1667 & 7,01 & 309,5 & 44,1 & 70 & 9,9 & 16 & 2,2 & 9 & 1,2 \\
\hline
\end{tabular}




\begin{tabular}{|c|c|c|c|c|c|c|c|c|c|}
\hline \multirow[b]{2}{*}{ ANÑO } & \multirow[b]{2}{*}{$\begin{array}{r}\text { Precio } \\
\text { Trigo } \\
\end{array}$} & \multicolumn{2}{|c|}{ MOLINO ALF. } & \multicolumn{2}{|c|}{ HORNO ALF. } & \multicolumn{2}{|c|}{ ALMACERA ALF. } & \multicolumn{2}{|c|}{ TIENDA ALF. } \\
\hline & & $\begin{array}{l}\text { Precio } \\
\text { libras }\end{array}$ & $\begin{array}{r}\text { Prodt. } \\
\text { Defl. }\end{array}$ & $\begin{array}{l}\text { Precio } \\
\text { libras }\end{array}$ & $\begin{array}{l}\text { Prodt. } \\
\text { Defl. }\end{array}$ & $\begin{array}{l}\text { Precio } \\
\text { libras }\end{array}$ & $\begin{array}{l}\text { Prodt. } \\
\text { Defi. }\end{array}$ & $\begin{array}{l}\text { Precio } \\
\text { libras }\end{array}$ & $\begin{array}{l}\text { Prodt. } \\
\text { Defl. }\end{array}$ \\
\hline 1668 & 7,13 & 309,5 & 43,4 & 70 & 9,8 & 16 & 2,2 & 9 & 1,2 \\
\hline 1669 & 7,11 & 309,5 & 43,5 & 70 & 9,8 & 16 & 2,2 & 9 & 1,2 \\
\hline 1670 & 7,02 & 310 & 44,1 & 70 & 9,9 & 16 & 2,2 & 16,5 & 2,3 \\
\hline 1671 & 6,86 & 310 & 45,1 & 70 & 10,2 & 30 & 4,3 & 16,5 & 2,4 \\
\hline 1672 & 6,76 & 310 & 45,8 & 70 & 10,3 & 30 & 4,4 & 16,5 & 2,4 \\
\hline 1673 & 6,78 & 310 & 45,7 & 70 & 10,3 & 30 & 4,4 & 16,5 & 2,4 \\
\hline 1674 & 6,97 & 310 & 44,4 & 70 & 10,0 & 30 & 4,3 & 16,5 & 2,3 \\
\hline 1675 & 7,10 & 290 & 40,8 & 70 & 9,8 & 30 & 4,2 & 16,5 & 2,3 \\
\hline 1676 & 7,31 & 290 & 39,6 & 70 & 9,5 & 30 & 4,1 & 16,5 & 2,2 \\
\hline 1677 & 7,32 & 290 & 39,6 & 70 & 9,5 & 20 & 2,7 & 16,5 & 2,2 \\
\hline 1678 & 7,26 & 290 & 39,9 & 57,5 & 7,9 & 20 & 2,7 & 16,5 & 2,2 \\
\hline 1679 & 7,37 & 290 & 39,3 & 57,5 & 7,8 & 20 & 2,7 & 16,5 & 2,2 \\
\hline 1680 & 7,50 & 290 & 38,6 & 57,5 & 7,6 & 20 & 2,6 & 16,5 & 2,2 \\
\hline 1681 & 7,53 & 290 & 38,5 & 57,5 & 7,6 & 20 & 2,6 & 16,5 & 2,2 \\
\hline 1682 & 7,38 & 290 & 39,2 & 57,5 & 7,7 & 20 & 2,7 & 16,5 & 2,2 \\
\hline 1683 & 7,12 & 290 & 40,7 & 57,5 & 8,0 & 20 & 2,8 & 16,5 & 2,3 \\
\hline 1684 & 6,86 & 290 & 42,2 & 74 & 10,7 & 20 & 2,9 & 19,3 & 2,8 \\
\hline 1685 & 6,49 & 290 & 44,6 & 74 & 11,0 & 20 & 3,0 & 19,3 & 2,9 \\
\hline 1686 & 6,31 & 290 & 45,9 & 74 & 11,7 & 20 & 3,1 & 19,3 & 3,0 \\
\hline 1687 & 6,27 & 290 & 46,2 & 74 & 11,8 & 20 & 3,1 & 19,3 & 3,0 \\
\hline 1688 & 6,17 & 290 & 47,0 & 94 & 15,2 & 20 & 3,2 & 19,3 & 3,1 \\
\hline 1689 & 6,04 & 290 & 48,0 & 94 & 15,5 & 20 & 3,3 & 19,3 & 3,1 \\
\hline 1690 & 6,02 & 290 & 48,1 & 94 & 15,6 & 20 & 3,3 & 19,3 & 3,2 \\
\hline 1691 & 5,95 & 290 & 48,7 & 94 & 15,7 & 20 & 3,3 & 19,3 & 3,2 \\
\hline 1692 & 5,95 & 290 & 48,7 & 75 & 12,6 & 20 & 3,3 & 19,3 & 3,2 \\
\hline 1693 & 6,09 & 290 & 47,6 & 75 & 12,3 & 20 & 3,2 & 19,3 & 3,1 \\
\hline 1694 & 6,33 & 290 & 45,8 & 75 & 11,8 & 20 & 3,1 & 19,3 & 3,0 \\
\hline 1695 & 6,35 & 290 & 45,6 & 75 & 11,8 & 20 & 3,1 & 19,3 & 3,0 \\
\hline 1696 & 6,48 & 290 & 44,7 & 57,5 & 8,8 & 20 & 3,0 & 19,3 & 2,9 \\
\hline 1697 & 6,64 & 341 & 51,3 & 57,5 & 8,6 & 20 & 3,0 & 19,3 & 2,9 \\
\hline 1698 & 6,84 & 341 & 49,8 & 57,5 & 8,4 & 20 & 2,9 & 9 & 1,3 \\
\hline 1699 & 6,92 & 341 & 49,2 & 57,5 & 8,3 & 20 & 2,8 & 9 & 1,3 \\
\hline 1700 & 6,95 & 341 & & 57,5 & & 70 & & 9 & \\
\hline
\end{tabular}




\begin{tabular}{|c|c|c|c|c|c|c|c|c|c|}
\hline \multirow[b]{2}{*}{ AÑO } & \multirow[b]{2}{*}{$\begin{array}{r}\text { Precio } \\
\text { Trigo }\end{array}$} & \multicolumn{2}{|c|}{ CARNRIA. ALF. } & \multicolumn{2}{|c|}{ RAJOLAR ALF. } & \multicolumn{2}{|c|}{ HTO. SRIA. ALF. } & \multicolumn{2}{|c|}{ TOTALES ALF. } \\
\hline & & $\begin{array}{l}\text { Precio } \\
\text { libras }\end{array}$ & $\begin{array}{l}\text { Prodt. } \\
\text { Defl. }\end{array}$ & $\begin{array}{l}\text { Precio } \\
\text { libras }\end{array}$ & $\begin{array}{l}\text { Prodt. } \\
\text { Defl. }\end{array}$ & $\begin{array}{l}\text { Precio } \\
\text { - libras }\end{array}$ & $\begin{array}{l}\text { Prodt. } \\
\text { Defi. }\end{array}$ & $\begin{array}{l}\text { Precio } \\
\text { libras }\end{array}$ & $\begin{array}{r}\text { Prodt } \\
\text { Defl. }\end{array}$ \\
\hline
\end{tabular}

$1605 \quad 7,11$

$1606 \quad 6,99$

$1607 \quad 7,05$

$1608 \quad 6,89$

$1609 \quad 6,96$

32

4,6

$1610 \quad 7,00$

32

4,5

$1611 \quad 7,01$

32

4,5

$1612 \quad 6,75$

32

4,5

$1613 \quad 6,82 \quad 10$

$1,4 \quad 32$

4,7

$1614 \quad 6,85 \quad 10$

$1,4 \quad 32$

4,6

$\begin{array}{lll}1615 & 6,88 & 10\end{array}$

$1,4 \quad 32$

4,6

3,6

$\begin{array}{lll}1616 & 6,79 & 10\end{array}$

$1,4 \quad 21$

$4,6 \quad 25$

3,6

$1617 \quad 6,70 \quad 10$

$1,4 \quad 21$

$3,0 \quad 25$

3,6

$1618 \quad 6,76 \quad 10$

$1,4 \cdot 21$

$3,1 \quad 25$

3,7

$1619 \quad 6,80 \quad 10$

$1,4 \quad 21$

$3,1 \quad 25$

3,6

385

56,9

$3,0 \quad 25$

$3,6 \quad 385$

56,6

$\begin{array}{lll}1620 & 6,80 & 10\end{array}$

$1,4 \quad 21$

$3,0 \quad 25$

$3,6 \quad 385 \quad 56,6$

$1,4 \quad 21$

$3,0 \quad 20$

$2,9 \quad 376 \quad 54,9$

$1622 \quad 6,77 \quad 10$

$1,4 \quad 24$

$3,5 \quad 20$

$2,9 \quad 388,7 \quad 57,4$

$1623 \quad 6,66 \quad 10$

$1,5 \quad 24$

$3,6 \quad 20$

$3,0 \quad 388,7 \quad 58,3$

$1624 \quad 6,77 \quad 10$

$1,4 \quad 24$

$3,5 \quad 20$

$2,9 \quad 388,7 \quad 57,4$

$1625 \quad 7,18 \quad 10$

$1,3 \quad 24$

$3,3 \quad 20$

$2,7 \quad 391,7 \quad 54,5$

$1626 \quad 7,58 \quad 10$

$1,3 \quad 26$

$3,4 \quad 20$

$2,6 \quad 387,2 \quad 51,0$

$1627 \quad 8,02 \quad 10$

$1,2 \quad 26$

$3,2 、 20$

$2,4 \quad 387,2 \quad 48,2$

$1628 \quad 8,14 \quad 10$

$1,2 \quad 26$

$3,1 \quad 20$

$2,4 \quad 387,2 \quad 47,5$

$1629 \quad 8,35 \quad 10$

$1,1 \quad 26$

$3,1 \quad 20$

$2,3 \quad 389 \quad 46,5$

$\begin{array}{lll}1630 & 8,46 \quad 10\end{array}$

$1,1 \quad 26$

$3,0 \quad 20$

$2,3 \quad 395 \quad 46,6$

$\begin{array}{lll}1631 & 8,57 \quad 10\end{array}$

$1,1 \quad 26$

$3,0 \quad 15$

$1,7 \quad 381 \quad 44,4$

$1632 \quad 9,01 \quad 10$

$1,1 \quad 26$

$2,8 \quad 15$

$1,6 \quad 381 \quad 42,2$

$\begin{array}{lll}1633 & 9,89 & 10\end{array}$

$1,0 \quad 26$

$2,6 \quad 15$

$1,5 \quad 376,5 \quad 38,0$

$1634 \quad 9,38 \quad 10$

$1,0 \quad 26$

$2,7 \quad 15$

$1,5 \quad 376,5 \quad 40,1$ 


\begin{tabular}{|c|c|c|c|c|c|c|c|c|c|}
\hline \multirow[b]{2}{*}{ AÑO } & \multirow[b]{2}{*}{$\begin{array}{r}\text { Precio } \\
\text { Trigo } \\
\end{array}$} & \multicolumn{2}{|c|}{ CARNRIA. ALF. } & \multicolumn{2}{|c|}{ RAJOLAR ALF. } & \multicolumn{2}{|c|}{ HTO. SRIA. ALF. } & \multicolumn{2}{|c|}{ TOTALES ALF. } \\
\hline & & $\begin{array}{l}\text { Precio } \\
\text { libras }\end{array}$ & $\begin{array}{l}\text { Prodt. } \\
\text { Defl. }\end{array}$ & $\begin{array}{l}\text { Precio } \\
\text { libras }\end{array}$ & $\begin{array}{l}\text { Prodt. } \\
\text { Defi. }\end{array}$ & $\begin{array}{l}\text { Precio } \\
\text { libras }\end{array}$ & $\begin{array}{l}\text { Prodt. } \\
\text { Defl. }\end{array}$ & $\begin{array}{l}\text { Precio } \\
\text { libras }\end{array}$ & $\begin{array}{r}\text { Prodt. } \\
\text { Defl. }\end{array}$ \\
\hline 1635 & 9,19 & 10 & 1,0 & 26 & 2,8 & 15 & 1,6 & 360,5 & 39,2 \\
\hline 1636 & 8,99 & 10 & 1,1 & & & 15 & 1,6 & 318,5 & 35,4 \\
\hline 1637 & 8,67 & 10 & 1,1 & & & 15 & 1,7 & 318 & 36,6 \\
\hline 1638 & 8,57 & 10 & 1,1 & & & 15 & 1,7 & 318 & 37,1 \\
\hline 1639 & 8,43 & 10 & 1,1 & & & 15 & 1,7 & 318 & 37,7 \\
\hline 1640 & 8,65 & 10 & 1,1 & & & 15 & 1,7 & 318 & 36,7 \\
\hline 1641 & 8,58 & 10 & 1,1 & & & 15 & 1,7 & 353,5 & 41,2 \\
\hline 1642 & 8,51 & 10 & 1,1 & & & 15 & 1,7 & 351,5 & 41,3 \\
\hline 1643 & 8,74 & 10 & 1,1 & & & 15 & 1,7 & 341,5 & 39,0 \\
\hline 1644 & 8,96 & 10 & 1,1 & & & 15 & 1,6 & 341,5 & 38,1 \\
\hline 1645 & 9,13 & 10 & 1,0 & & & 15 & 1,6 & 331 & 36,2 \\
\hline 1646 & 9,15 & 10 & 1,0 & 20 & 2,1 & 15 & 1,6 & 351 & 38,3 \\
\hline 1647 & 9,36 & 10 & 1,0 & 20 & 2,1 & 15 & 1,6 & 351 & 37,5 \\
\hline 1648 & 9,71 & 10 & 1,0 & 20 & 2,0 & 15 & 1,5 & 349 & 35,9 \\
\hline 1649 & 9,60 & 10 & 1,0 & 20 & 2,0 & 15 & 1,5 & 419 & 43,6 \\
\hline 1650 & 9,45 & 10 & 1,0 & 20 & 2,1 & 15 & 1,5 & 419 & 44,3 \\
\hline 1651 & 9,21 & 10 & 1,0 & 24 & 2,6 & 12 & 1,3 & 425 & 46,1 \\
\hline 1652 & 8,82 & 10 & 1,1 & 24 & 2,7 & 12 & 1,3 & 425 & 48,1 \\
\hline 1653 & 8,59 & 10 & 1,1 & 24 & 2,7 & 12 & 1,3 & 446 & 51,9 \\
\hline 1654 & 8,44 & 10 & 1,1 & 24 & 2,8 & 12 & 1,4 & 476 & 56,3 \\
\hline 1655 & 8,28 & 10 & 1,1 & 24 & 2,8 & 12 & 1,4 & 476 & 57,4 \\
\hline 1656 & 8,12 & 10 & 1,2 & 24 & 2,9 & 12 & 1,4 & 476 & 58,6 \\
\hline 1657 & 7,96 & 10 & 1,2 & 30 & 3,7 & 12 & 1,5 & 473 & 59,4 \\
\hline 1658 & 7,82 & 10 & 1,2 & 30 & 3,8 & 12 & 1,5 & 473 & 60,4 \\
\hline 1659 & 7,63 & 10 & 1,3 & 30 & 3,9 & 12 & 1,5 & 473 & 61,9 \\
\hline 1660 & 7,50 & 10 & 1,3 & 30 & 4,0 & 12 & 1,6 & 473 & 63,0 \\
\hline 1661 & 7,35 & 10 & 1,3 & 30 & 4,0 & 12 & 1,6 & 453 & 61,6 \\
\hline 1662 & 7,38 & 10 & 1,3 & 22 & 2,9 & 12 & 1,6 & 439 & 59,4 \\
\hline 1663 & 7,34 & 10 & 1,3 & 22 & 2,9 & 12 & 1,6 & 439 & 59,8 \\
\hline 1664 & 7,38 & 10 & 1,3 & 22 & 2,9 & 12 & 1,6 & 439 & 59,4 \\
\hline 1665 & 7,29 & 10 & 1,3 & 22 & 3,0 & 12 & 1,6 & 439 & 60,2 \\
\hline 1666 & 7,14 & 10 & 1,4 & 23 & 3,2 & 12 & 1,6 & 449,5 & 62,9 \\
\hline 1667 & 7,01 & 10 & 1,4 & 23 & 3,2 & 12 & 1,7 & 449,5 & 64,1 \\
\hline
\end{tabular}




\begin{tabular}{|c|c|c|c|c|c|c|c|c|c|}
\hline \multirow[b]{2}{*}{ AÑo } & \multirow[b]{2}{*}{$\begin{array}{r}\text { Precio } \\
\text { Trigo }\end{array}$} & \multicolumn{2}{|c|}{ CARNRIA. ALF. } & \multicolumn{2}{|c|}{ RAJOLAR ALF. } & \multicolumn{2}{|c|}{ HTO SRIA. ALF. } & \multicolumn{2}{|c|}{ TOTALES ALF. } \\
\hline & & $\begin{array}{l}\text { Precio } \\
\text { libras }\end{array}$ & $\begin{array}{l}\text { Prodt. } \\
\text { Defl. }\end{array}$ & $\begin{array}{l}\text { Precio } \\
\text { libras }\end{array}$ & $\begin{array}{l}\text { Prodt. } \\
\text { Defl. }\end{array}$ & $\begin{array}{l}\text { Precio } \\
\text { libras }\end{array}$ & $\begin{array}{l}\text { Prodt. } \\
\text { Defl. }\end{array}$ & $\begin{array}{l}\text { Precio } \\
\text { libras }\end{array}$ & $\begin{array}{r}\text { Prodt. } \\
\text { Defl. }\end{array}$ \\
\hline 1668 & 7,13 & 10 & 1,4 & 23 & 3,2 & 12 & 1,6 & 449,5 & 63,0 \\
\hline 1669 & 7,11 & 10 & 1,4 & 23 & 3,2 & 12 & 1,6 & 449,5 & 63,2 \\
\hline 1670 & 7,02 & 10 & 1,4 & 28 & 3,9 & 12 & 1,7 & 462,5 & 65,8 \\
\hline 1671 & 6,86 & 10 & 1,4 & 28 & 4,0 & 12 & 1,7 & 476,5 & 69,4 \\
\hline 1672 & 6,76 & 10 & 1,4 & 28 & 4,1 & 12 & 1,7 & 476,5 & 70,4 \\
\hline 1673 & 6,78 & 10 & 1,4 & 28 & 4,1 & 12 & 1,7 & 476,5 & 70,2 \\
\hline 1674 & 6,97 & 10 & 1,4 & 28 & 4,0 & 12 & 1,7 & 476,5 & 68,3 \\
\hline 1675 & 7,10 & 10 & 1,4 & 28 & 3,9 & 12 & 1,6 & 456,5 & 64,3 \\
\hline 1676 & 7,31 & 10 & 1,3 & 28 & 3,8 & 12 & 1,6 & 456,5 & 62,4 \\
\hline 1677 & 7,32 & 10 & 1,3 & 28 & 3,8 & 12 & 1,6 & 446,5 & 61,0 \\
\hline 1678 & 7,26 & 10 & 1,3 & 28 & 3,8 & 12 & 1,6 & 434 & 59,2 \\
\hline 1679 & 7,37 & 10 & 1,3 & 28 & 3,7 & 12 & 1,6 & 434 & 58,8 \\
\hline 1680 & 7,50 & 10 & 1,3 & 28 & 3,7 & 12 & 1,6 & 434 & 57,8 \\
\hline 1681 & 7,53 & 10 & 1,3 & 28,5 & 3,7 & 12 & 1,5 & 434,5 & 57,2 \\
\hline 1682 & 7,38 & 10 & 1,3 & 28,5 & 3,8 & 12 & 1,6 & 434,5 & 58,8 \\
\hline 1683 & 7,12 & 10 & 1,4 & 28,5 & 4,0 & 12 & 1,6 & 434,5 & 61,0 \\
\hline 1684 & 6,86 & 10 & 1,4 & 28,5 & 4,1 & 12 & 1,7 & 453,8 & 66,1 \\
\hline 1685 & 6,49 & 10 & 1,5 & 28,5 & 4,3 & 12 & 1,8 & 453,8 & 69,9 \\
\hline 1686 & 6,31 & 10 & 1,5 & 28,5 & 4,5 & 12 & 1,9 & 453,8 & 71,9 \\
\hline 1687 & 6,27 & 10 & 1,5 & 28,5 & 4,5 & 12 & 1,9 & 453,8 & 72,3 \\
\hline 1688 & 6,17 & 10 & 1,6 & 28,5 & 4,6 & 12 & 1,9 & 473,8 & 76,7 \\
\hline 1689 & 6,04 & 10 & 1,6 & 15 (DB) & 2,4 & 12 & 1,9 & 460,3 & 76,2 \\
\hline 1690 & 6,02 & 10 & 1,6 & 15 & 2,4 & 12 & 1,9 & 460,3 & 76,4 \\
\hline 1691 & 5,95 & 10 & 1,6 & 15 & 2,5 & 12 & 2,0 & 460,3 & 77,3 \\
\hline 1692 & 5,95 & 10 & 1,6 & 15 & 2,5 & 12 & 2,0 & 441,3 & 74,1 \\
\hline 1693 & 6,09 & 10 & 1,6 & 10 & 1,6 & 12 & 1,9 & 436,3 & 71,6 \\
\hline 1694 & 6,33 & 10 & 1,5 & 10 & 1,5 & 12 & 1,8 & 436,3 & 68,9 \\
\hline 1695 & 6,35 & 10 & 1,5 & 10 & 1,5 & 12 & 1,8 & 436,3 & 68,7 \\
\hline 1696 & 6,48 & 10 & 1,5 & 10 & 1,5 & 12 & 1,8 & 418,8 & 64,6 \\
\hline 1697 & 6,64 & 10 & 1,5 & 10 & 1,5 & 12 & 1,8 & 469,8 & 70,7 \\
\hline 1698 & 6,84 & 10 & 1,4 & 10 & 1,4 & 12 & 1,7 & 459,5 & 66,4 \\
\hline 1699 & 6,92 & 10 & 1,4 & 10 & 1,4 & 12 & 1,7 & 459,5 & 66,4 \\
\hline 1700 & 6,95 & 10 & 1,4 & 10 & 1,4 & 12 & 1,7 & 469,5 & 67,5 \\
\hline
\end{tabular}




\begin{tabular}{cccccccccr}
\hline & & \multicolumn{2}{c}{ TER. DIEZMO BUR. } & \multicolumn{2}{c}{ MOLINO BUR. } & \multicolumn{2}{c}{ HORNO BUR. } & \multicolumn{2}{c}{ TIENDA-MESN BUR. } \\
AÑo & Precio & Precio & Prodt. & Precio & Prodt. & Precio & Prodt. & Precio & Prodt. \\
& Trigo & libras & Defl. & libras & Defl. & libras & Defl. & libras & Defl. \\
\hline
\end{tabular}

$1610 \quad 7,00$

16117,01

$1612 \quad 6,75$

25

3,7

$1613 \quad 6,82$

$120,5 \quad 17,6$

25

3,6

$1614 \quad 6,85$ Admon

$120,5 \quad 17,5 \quad 120 \quad 17,4 \quad 25$

3,6

$1615 \quad 6,88$

$\begin{array}{lllll}120,5 & 17,5 & 120 & 17,4 & 25\end{array}$

3,6

1616

6.79

135

19,8

$120,5 \quad 17,7 \quad 120$

$17,6 \quad 50$

7,3

$\begin{array}{lllll}1617 & 1,70 & 135 & 20,1 & 140\end{array}$

$1618 \quad 6,76$

135

$19,9 \quad 140$

$20,8 \quad 120$

$17,9 \quad 50$

7,4

$1619 \quad 6,80$

135

198

$20,7 \quad 120$

$17,7 \quad 50$

7,3

$\begin{array}{lllllllll}1620 & 6,80 & 135 & 19,8 & 140 & 20,5 & 110,2 & 16,2 & 42\end{array}$

7,3

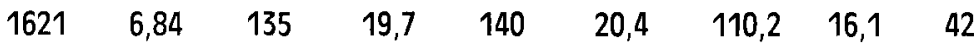

6,1

$1622 \quad 6,77 \quad 135 \quad 19,9 \quad 140$

$20,6 \quad 110,2 \quad 16,2 \quad 42$

6,1

$1623 \quad 6,66 \quad 135 \quad 20,2 \quad 140$

$21,0 \quad 100 \quad 15,0 \quad 42$

6,2

$1624 \quad 6,77$

135

19,9

140

$20,6 \quad 100$

$14,7 \quad 42$

6,3

$1625 \quad 7,18 \quad 135 \quad 18,8 \quad 14$

$19,4 \quad 100 \quad 13,9 \quad 42$

6,2

$\begin{array}{llll}7626 & 735 & 17,8\end{array}$

150

$19,7 \quad 100$

$13,1 \quad 42$

5,8

$1627 \quad 8,02 \quad 135$

$16,8 \quad 150$

$18,7 \quad 110$

$13,7 \quad 42$

5,5

$1628 \quad 8,15 \quad 135$

$16,5 \quad 15$

$18,4 \quad 110$

$13,4 \quad 42$

5,2

$1629 \quad 8,35 \quad 135$

$16,1 \quad 150$

$17,9 \quad 110$

13,1

42

5,1

$1630 \quad 8,46 \quad 135$

$15,9 \quad 150$

$17,7 \quad 110$

13,0

42

5,0

$1631 \quad 8,57 \quad 135$

$15,7 \quad 150$

17,5

$95 \quad 11,0$

42

4,9

$1632 \quad 9,01 \quad 135$

14,9

155

17,2

95

10,5

42

4,9

$1633 \quad 9,89 \quad 140$

14,1

155

15,6

95

9,6

42

4,6

$1634 \quad 9,38 \quad 140$

14,9

155

16,5

95

10,2

42

4,2

4,4 


\begin{tabular}{|c|c|c|c|c|c|c|c|c|c|}
\hline \multirow[b]{2}{*}{ AÑO } & \multirow[b]{2}{*}{$\begin{array}{r}\text { Precio } \\
\text { Trigo }\end{array}$} & \multicolumn{2}{|c|}{ TER. DIEZMO BUR. } & \multicolumn{2}{|c|}{ MOLINO BUR. } & \multicolumn{2}{|c|}{ HORNO BUR. } & \multicolumn{2}{|c|}{ TIENDA-MESN BUR. } \\
\hline & & $\begin{array}{l}\text { Precio } \\
\text { libras }\end{array}$ & $\begin{array}{l}\text { Prodt. } \\
\text { Defl. }\end{array}$ & $\begin{array}{l}\text { Precio } \\
\text { libras }\end{array}$ & $\begin{array}{l}\text { Prodt. } \\
\text { Defl. }\end{array}$ & $\begin{array}{l}\text { Precio } \\
\text { libras }\end{array}$ & $\begin{array}{l}\text { Prodt. } \\
\text { Defl. }\end{array}$ & $\begin{array}{l}\text { Precio } \\
\text { libras }\end{array}$ & $\begin{array}{l}\text { Prodt } \\
\text { Defi }\end{array}$ \\
\hline 1635 & 9,19 & 140 & 15,2 & 155 & 16,8 & 95 & 10,3 & 42 & 4,5 \\
\hline 1636 & 8,99 & 140 & 15,5 & 155 & 17,2 & 95 & 10,5 & 43 & 4,7 \\
\hline 1637 & 8,67 & 140 & 16,1 & 155 & 17,8 & 110 & 12,6 & 43 & 4,9 \\
\hline 1638 & 8,57 & 140 & 16,3 & 170,5 & 19,8 & 110 & 12,8 & 43 & 5,0 \\
\hline 1639 & 8,43 & 140 & 16,6 & 170,5 & 20,2 & 110 & 13,0 & 43 & 5,1 \\
\hline 1640 & 8,65 & 140 & 16,1 & 170,5 & 19,7 & 110 & 12,7 & 43 & 4,9 \\
\hline 1641 & 8,58 & 140,5 & 16,3 & 170,5 & 19,8 & 110 & 12,8 & 43 & 5,0 \\
\hline 1642 & 8,51 & 140,5 & 16,5 & 170,5 & 20,0 & 110 & 12,9 & 43 & 5,0 \\
\hline 1643 & 8,74 & 140,5 & 16,0 & 170,5 & 19,5 & 111 & 12,7 & 43 & 4,9 \\
\hline 1644 & 8,96 & 140,5 & 15,6 & 170,5 & 19,0 & 111 & 12,3 & 43 & 4,7 \\
\hline 1645 & 9,30 & 145,2 & 15,6 & 170,5 & 18,3 & 111 & 11,9 & 43 & 4,6 \\
\hline 1646 & 9,15 & 145,2 & 15,8 & 160,5 & 17,5 & 111 & 12,1 & 43 & 4,6 \\
\hline 1647 & 9,36 & 145,2 & 15,5 & 160,5 & 17,1 & 65 & 6,9 & 43 & 4,5 \\
\hline 1648 & 9,71 & 145,2 & 14,9 & 160,5 & 16,5 & 65 & 6,6 & 43 & 4,4 \\
\hline 1649 & 9,60 & 135 & 14,0 & 160,5 & 16,7 & 65 & 6,7 & 43 & 4,4 \\
\hline 1650 & 9,45 & 135 & 14,2 & 160,5 & 16,9 & 65 & 6,8 & 43 & 4,5 \\
\hline 1651 & 9,21 & 135 & 14,6 & 160,5 & 17,5 & 65 & 7,0 & 43 & 4,7 \\
\hline 1652 & 8,82 & 135 & 15,3 & 160,5 & 18,1 & 65 & 7,3 & 47 & 5,3 \\
\hline 1653 & 8,59 & 126,2 & 14,6 & 160,5 & 18,6 & 65 & 7,5 & 47 & 5,4 \\
\hline 1654 & 8,44 & 126,2 & 14,9 & 160,6 & 19,0 & 65 & 7,7 & 47 & 5,5 \\
\hline 1655 & 8,28 & 126,2 & 15,2 & 162,7 & 19,6 & 90,3 & 10,9 & 47 & 5,6 \\
\hline 1656 & 8,12 & 126,2 & 15,5 & 162,7 & 20,0 & 90,3 & 11,1 & 47 & 5,7 \\
\hline 1657 & 7,96 & 126,2 & 15,8 & 162,7 & 20,4 & 90,3 & 11,3 & 47 & 5,9 \\
\hline 1658 & 7,82 & 126,2 & 16,1 & 162,7 & 20,8 & 90,3 & 11,5 & 47 & 6,0 \\
\hline 1659 & 7,63 & 126,2 & 16,5 & 130 & 17,0 & 90 & 11,7 & 47 & 6,1 \\
\hline 1660 & 7,50 & 126,2 & 16,8 & 130 & 17,3 & 90 & 12,0 & 42 & 6,2 \\
\hline 1661 & 7,35 & 126,2 & 17,1 & 130 & 17,6 & 90 & 12,2 & 47 & 6,3 \\
\hline 1662 & 7,38 & 144,5 & 19,5 & 130 & 17,6 & 90 & 12,1 & 47 & 6,3 \\
\hline 1663 & 7,34 & 144,5 & 19,6 & 130 & 17,7 & 96 & 13,0 & 47 & 6,4 \\
\hline 1664 & 7,38 & 144,5 & 19,5 & 100 & 17,6 & 96 & 13,0 & 47 & 6,3 \\
\hline 1665 & 7,29 & 150 & 20,5 & 130 & 17,8 & 96 & 13,1 & 47 & 6,4 \\
\hline 1666 & 7,14 & 150 & 21,0 & 130 & 18,2 & 96 & 13,4 & 47 & 6,5 \\
\hline 1667 & 7,01 & 150 & 21,3 & 130 & 18,5 & 75 & 10,6 & 47 & 6,5 \\
\hline
\end{tabular}




\begin{tabular}{|c|c|c|c|c|c|c|c|c|c|}
\hline \multirow[b]{2}{*}{ AÑO } & \multirow[b]{2}{*}{$\begin{array}{r}\text { Precio } \\
\text { Trigo }\end{array}$} & \multicolumn{2}{|c|}{ TER. DIEZMO BUR. } & \multicolumn{2}{|c|}{ MOLINO BUR. } & \multicolumn{2}{|c|}{ HORNO BUR. } & \multicolumn{2}{|c|}{ TIENDA-MESN BUR. } \\
\hline & & $\begin{array}{l}\text { Precio } \\
\text { libras }\end{array}$ & $\begin{array}{l}\text { Prodt. } \\
\text { Defl. }\end{array}$ & $\begin{array}{l}\text { Precio } \\
\text { libras }\end{array}$ & $\begin{array}{l}\text { Prodt. } \\
\text { Defi. }\end{array}$ & $\begin{array}{l}\text { Precio } \\
\text { libras }\end{array}$ & $\begin{array}{l}\text { Prodt. } \\
\text { Defl. }\end{array}$ & $\begin{array}{l}\text { Precio } \\
\text { libras }\end{array}$ & $\begin{array}{r}\text { Prodt. } \\
\text { Defl. }\end{array}$ \\
\hline 1668 & 7,13 & 150 & 21,0 & 100 & 14,0 & 75 & 10,5 & 47 & 6,5 \\
\hline 1669 & 7,11 & 145 & 20,3 & 100 & 14,0 & 75 & 10,5 & 47 & 6,6 \\
\hline 1670 & 7,02 & 145 & 20,6 & 96 & 13,6 & 75 & 10,6 & 40 & 5,6 \\
\hline 1671 & 6,86 & 145 & 21,1 & 96 & 13,9 & 75 & 10,9 & 40 & 5,8 \\
\hline 1672 & 6,76 & 145 & 21,4 & 100 & 14,7 & 75 & 11,0 & 40 & 5,9 \\
\hline 1673 & 6,78 & 150 & 22,1 & 100 & 14,7 & 75 & 11,0 & 40 & 5,8 \\
\hline 1674 & 6,97 & 150 & 21,5 & 100 & 14,3 & 75 & 10,7 & 40 & 5,7 \\
\hline 1675 & 7,10 & 150 & 21,1 & 100 & 14,0 & 75 & 10,5 & 40 & 5,6 \\
\hline 1676 & 7,71 & 150 & 20,5 & 100 & 13,6 & 75 & 10,2 & 40 & 5,4 \\
\hline 1677 & 7,32 & 150 & 20,4 & 100 & 13,6 & 75 & 10,2 & 40 & 5,4 \\
\hline 1678 & 7,26 & 150 & 20,6 & 100 & 13,7 & 75 & 10,3 & 40 & 5,5 \\
\hline 1679 & 7,37 & 150 & 20,3 & 100 & 13,5 & 75 & 10,1 & 30,5 & 4,1 \\
\hline 1680 & 7,50 & 150 & 20,0 & 100 & 13,3 & 75 & 10,0 & 30,5 & 4,0 \\
\hline 1681 & 7,53 & 150 & 19,9 & 100 & 13,2 & 75 & 9,9 & 30,5 & 4,0 \\
\hline 1682 & 7,38 & 170,5 & 23,1 & 100 & 13,5 & 75 & 10,1 & 30,5 & 4,1 \\
\hline 1683 & 7,12 & 170,5 & 23,9 & 100 & 14,0 & 75 & 10,5 & 30,5 & 4,2 \\
\hline 1684 & 6,86 & 170,5 & 24,8 & 100 & 14,5 & 75 & 10,9 & 30,5 & 4,4 \\
\hline 1685 & 6,49 & 170,5 & 26,2 & 100 & 15,4 & 80 & 12,3 & 30,5 & 4,6 \\
\hline 1686 & 6,31 & 180 & 28,5 & 100 & 15,8 & 80 & 12,6 & 35,5 & 5,6 \\
\hline 1687 & 6,27 & 180 & 28,7 & 100 & 15,9 & 80 & 12,7 & 35,5 & 5,6 \\
\hline 1688 & 6,17 & 180 & 29,1 & 100 & 16,2 & 80 & 12,9 & 35,5 & 5,7 \\
\hline 1689 & 6,04 & 180,5 & 29,8 & 100 & 16,5 & 80 & 13,2 & 35,5 & 5,8 \\
\hline 1690 & 6,02 & 180,5 & 29,9 & 100 & 16,6 & 80 & 13,2 & 15,5 & 5,8 \\
\hline 1691 & 5,95 & 180,5 & 30,3 & 100 & 16,8 & 98 & 16,4 & 35,5 & 5,9 \\
\hline 1692 & 5,95 & 180,5 & 30,3 & 100 & 16,8 & 98 & 16,4 & 35,5 & 5,9 \\
\hline 1693 & 6,09 & 180,5 & 29,6 & 100 & 16,4 & 98 & 16,0 & 35,5 & 5,8 \\
\hline 1694 & 6,33 & 180,5 & 28,5 & 100 & 15,7 & 98 & 15,4 & 35,5 & 5,6 \\
\hline 1695 & 6,35 & 180,5 & 28,4 & 100 & 15,7 & 98 & 15,4 & 35,5 & 5,5 \\
\hline 1696 & 6,48 & 180,5 & 27,8 & 100 & 15,4 & 98 & 15,1 & 35,5 & 5,4 \\
\hline 1697 & 6,64 & 180,5 & 27,1 & 100 & 15,0 & 98 & 14,7 & 35,5 & 5,3 \\
\hline 1698 & 6,84 & 226,5 & 33,1 & 100 & 14,6 & 98 & 14,3 & 35,5 & 5,1 \\
\hline 1699 & 6,92 & 225,5 & 32,7 & 100 & 14,4 & 98 & 14,1 & 35,5 & 5,1 \\
\hline 1700 & 6,95 & 226,5 & 32,1 & 100 & 14,3 & 98 & 14,1 & 35,5 & 5,1 \\
\hline
\end{tabular}


CARN BUR.

Año Precio Procio Prod

Tringo libras Dof

HTO. BUR

TOTAL BUR

TOTAL ALF-BIRR

Precio Prial libras
Prequi Prisit libles baf

$1610 \quad 7,00$

$1611 \quad 7,01$

$1612 \quad 6,75$

$1613 \quad 6,82$

$15 \quad 2,1 \quad 65,2 \quad 9,5$

$1614 \quad 6,85$

$2,1 \quad 65,2 \quad 9,5$

$\begin{array}{lll}1615 & 6,88 & 15\end{array}$

$2,1 \quad 65,2 \quad 9,4$

$1616 \quad 6,79 \quad 15$

$2,2 \quad 65,2$

$9,6 \quad 505,7 \quad 74,4$

$1617 \quad 1,70 \quad 15$

2,2

65,2

$9,2 \quad 525,2 \quad 78,3$

$1618 \quad 6,76 \quad 15$

$2,2 \quad 55,2$

$8,1 \quad 515,2 \quad 76$,

$900,2 \quad 133,1$

$1619 \quad 6,80 \quad 15$

$2,2 \quad 55,2$

$8,1 \quad 505,5 \quad 74$,

$890,5 \quad 130,9$

$\begin{array}{lll}1620 & 6,80 & 15\end{array}$

2,2

55,2

$8,1 \quad 497,5 \quad 73,1$

$882,5 \quad 129,7$

$\begin{array}{lll}1621 & 6,84 & 15\end{array}$

$21-55,2$

80

$497,5 \quad 72,6$

$873,5 \quad 127,6$

$\begin{array}{lll}1622 & 6,77 & 15\end{array}$

$22 \quad 55,2$

8,1

$497,5 \quad 73,4$

$886,2 \quad 130,8$

$\begin{array}{lll}1523 & 6,66 & 15\end{array}$

$2,2 \quad 55,2$

8,2

487,2

$2,2 \quad 55,2$

8,1

487,2

75,1

$876 \quad 131,5$

$1624 \quad 6,77 \quad 15$

$2,0 \quad 40$

$5,5 \quad 472$

697

876

127,1

$1625 \quad 7,18 \quad 15$

$1,9 \quad 40$

$5,2 \quad 482$

65,5

$865,7 \quad 120,2$

$1626 \quad 7,58 \quad 15$

$1,8 \quad 40$

$4,9 \quad 492$

$65,5 \quad 869 ? \quad 114,6$

$1627 \quad 8,02 \quad 15$

$1,8 \quad 39$

$4,7 \quad 491$

61,3

$879, ? \quad 109,6$

$1628 \quad 8,15 \quad 15$

$1,7 \quad 39$

$4,6 \quad 491$

60,2

$878,2107,7$

$1629 \quad 8,35 \quad 15$

$1,7 \quad 39$

$\begin{array}{lllll}4.6 & 491 & 58,0 & 886 & 104,7\end{array}$

$\begin{array}{lll}1631 & 8,57 \quad 15\end{array}$

$1,7 \quad 39$

$4,5 \quad 476$

55,

$857 \quad 100,0$

$\begin{array}{lll}1632 & 9,01 & 15\end{array}$

$1,6 \quad 39$

$4, \overline{3} \quad 481$

53,3

$1,5 \quad 39$

$3,9 \quad 486$

49,1

$1,5 \quad 39$

$4,1 \quad 486$

518

862. 95,6

$1634 \quad 9,38 \quad 15$

$862.5 \quad 072$

$862,5 \quad 91,9$ 


\begin{tabular}{|c|c|c|c|c|c|c|c|c|c|}
\hline \multirow[b]{2}{*}{ AÑO } & \multirow[b]{2}{*}{$\begin{array}{r}\text { Precio } \\
\text { Trigo }\end{array}$} & \multicolumn{2}{|c|}{ CAR. BUR. } & \multicolumn{2}{|c|}{ HTO. BUR. } & \multicolumn{2}{|c|}{ TOTAL BUR. } & \multicolumn{2}{|c|}{ TOTAL ALF.- BUR. } \\
\hline & & $\begin{array}{l}\text { Precio } \\
\text { libras }\end{array}$ & $\begin{array}{l}\text { Prodt. } \\
\text { Defl. }\end{array}$ & $\begin{array}{l}\text { Precio } \\
\text { libras }\end{array}$ & $\begin{array}{l}\text { Prodt. } \\
\text { Defl. }\end{array}$ & $\begin{array}{l}\text { Precio } \\
\text { libras }\end{array}$ & $\begin{array}{l}\text { Prodt. } \\
\text { Defl. }\end{array}$ & $\begin{array}{l}\text { Precio } \\
\text { libras }\end{array}$ & $\begin{array}{l}\text { Prodt. } \\
\text { Defl. }\end{array}$ \\
\hline 1635 & 9,19 & 15 & 1,6 & 39 & 4,2 & 486 & 52,8 & 846,5 & 92,1 \\
\hline 1636 & 8,99 & 15 & 1,6 & 24 & 2,6 & 472 & 52,5 & 790,5 & 87,9 \\
\hline 1637 & 8,67 & 25 & 2,8 & 24 & 2,7 & 497 & 57,3 & 815 & 94,0 \\
\hline 1638 & 8,57 & 25 & 2,9 & 24 & 2,8 & 512,5 & 59,8 & 830,5 & 96,9 \\
\hline 1639 & 8,43 & 25 & 2,9 & 24 & 2,8 & 512,5 & 60,7 & 830,5 & 98,5 \\
\hline 1640 & 8,65 & 25 & 2,8 & 24 & 2,7 & 512,5 & 59,2 & 830,5 & 96,0 \\
\hline 1641 & 8,58 & 25 & 2,9 & 24 & 2,7 & 513 & 59,7 & 866,5 & 100,9 \\
\hline 1642 & 8,51 & 15 & 1,7 & 24 & 2,8 & 503 & 59,1 & 854,5 & 100,4 \\
\hline 1643 & 8,74 & 15 & 1,7 & 24 & 2,7 & 504 & 57,6 & 845,5 & 96,7 \\
\hline 1644 & 8,96 & 15,5 & 1,7 & 24 & 2,6 & 504,5 & 56,3 & 846 & 94,4 \\
\hline 1645 & 9,13 & 15,5 & 1,6 & 24 & 2,5 & 509,3 & 54,7 & 840,3 & 90,3 \\
\hline 1646 & 9,15 & 15,5 & 1,6 & 24 & 2,6 & 499,3 & 54,5 & 850,3 & 92,9 \\
\hline 1647 & 9,36 & 15,5 & 1,6 & 24 & 2,5 & 453,3 & 48,4 & 804,3 & 85,9 \\
\hline 1648 & 9,71 & 15,5 & 1,6 & 24 & 2,4 & 453,3 & 46,6 & 802,3 & 82,6 \\
\hline 1649 & 9,60 & 15,5 & 1,6 & 24 & 2,5 & 443 & 46,1 & 862 & 89,7 \\
\hline 1650 & 9,45 & 15,5 & 1,6 & 24 & 2,5 & 443 & 46,8 & 862 & 91,2 \\
\hline 1651 & 9,21 & 15,5 & 1,6 & 24 & 2,6 & 443 & 48,1 & 868 & 94,2 \\
\hline 1652 & 8,82 & 15,5 & 1,7 & 24 & 2,7 & 447 & 50,6 & 872 & 98,8 \\
\hline 1653 & 8,59 & 15,5 & 1,8 & 24 & 2,7 & 438,2 & 51,0 & 884,2 & 102,9 \\
\hline 1654 & 8,44 & 15,5 & 1,8 & 24 & 2,8 & 438,2 & 51,9 & 914,2 & 108,3 \\
\hline 1655 & 8,28 & 15,5 & 1,8 & 24 & 2,8 & 465,8 & 56,2 & 941,8 & 113,7 \\
\hline 1656 & 8,12 & 15,5 & 1,9 & 24 & 2,9 & 465,8 & 57,3 & 941,8 & 115,9 \\
\hline 1657 & 7,96 & 15,5 & 1,9 & 24 & 3,0 & 465,8 & 58,5 & 938,8 & 117,9 \\
\hline 1658 & 7,82 & 15,5 & 1,9 & 24 & 3,0 & 465,8 & 59,6 & 938,8 & 120,0 \\
\hline 1659 & 7,63 & 15,5 & 2,0 & 24 & 3,1 & 432,7 & 56,7 & 905,7 & 118,7 \\
\hline 1660 & 7,50 & 15,5 & 2,0 & 24 & 3,2 & 432,7 & 57,7 & 905,7 & 120,7 \\
\hline 1661 & 7,35 & 15,5 & 2,1 & 24 & 3,2 & 432,7 & 58,8 & 885,7 & 120,5 \\
\hline 1662 & 7,38 & 15,5 & 2,1 & 24 & 3,2 & 451 & 61,1 & 890 & 120,6 \\
\hline 1663 & 7,34 & 15,5 & 2,1 & 23 & 3,2 & 457 & 62,2 & 896 & 122,0 \\
\hline 1664 & 7,38 & 15,5 & 2,1 & 24 & 3,2 & 457 & 61,9 & 896 & 121,4 \\
\hline 1665 & 7,29 & 15,5 & 2,1 & 24 & 3,2 & 462,5 & 63,4 & 901,5 & 123,6 \\
\hline 1666 & 7,14 & 15,5 & 2,1 & 24 & 3,3 & 462,5 & 64,7 & 912 & 127,7 \\
\hline 1667 & 7,01 & 15,5 & 2,2 & 24 & 3,4 & 441,5 & 62,9 & 891 & 127,1 \\
\hline
\end{tabular}




\begin{tabular}{|c|c|c|c|c|c|c|c|c|c|}
\hline \multirow[b]{2}{*}{ ANO } & \multirow[b]{2}{*}{$\begin{array}{c}\text { Precio } \\
\text { Trigo }\end{array}$} & \multicolumn{2}{|c|}{ CARN. BUR. } & \multicolumn{2}{|c|}{ HTO. BUR. } & \multicolumn{2}{|c|}{ TOTAL BUR. } & \multicolumn{2}{|c|}{ TOTAL ALF-BUR. } \\
\hline & & $\begin{array}{l}\text { Precin } \\
\text { libras }\end{array}$ & $\begin{array}{r}\text { Prodt. } \\
\text { Defi. }\end{array}$ & $\begin{array}{l}\text { Precio } \\
\text { libras }\end{array}$ & $\begin{array}{l}\text { Prodt. } \\
\text { Defl. }\end{array}$ & $\begin{array}{l}\text { Prerio } \\
\text { libras }\end{array}$ & $\begin{array}{l}\text { Prodt. } \\
\text { Defl. }\end{array}$ & $\begin{array}{l}\text { Precin } \\
\text { libras }\end{array}$ & $\begin{array}{l}\text { Prodt } \\
\text { Def! }\end{array}$ \\
\hline 1668 & 7,13 & 15,5 & 2,1 & 24 & 3,3 & 411,5 & 57,7 & 861 & 120,7 \\
\hline 1669 & 7,11 & 115,5 & 2,1 & 24 & 3,3 & 406,5 & 57,1 & 856 & 120,4 \\
\hline 1670 & 7,02 & 15,5 & 2,2 & 24 & 3,4 & 395,5 & 56,3 & 858,1 & 122,2 \\
\hline 1671 & 6,86 & 15,5 & 2,2 & 24 & 3,4 & 395,5 & 57,3 & 872,1 & 127,1 \\
\hline 1672 & 6,76 & 15,5 & 2,3 & 24 & 3,5 & 399,5 & 59,1 & 876,1 & 129,6 \\
\hline 1673 & 6,78 & 15,5 & 2,2 & 24 & 3,5 & 404,5 & 59,6 & 881,1 & 129,9 \\
\hline 1674 & 6,97 & 15 & 2,1 & 24 & 3,4 & 404 & 57,9 & 880,5 & 126,3 \\
\hline 1675 & 7,10 & 15 & 2,1 & 24 & 3,3 & 404 & 56,9 & 860,5 & 121,2 \\
\hline 1676 & 7,31 & 15 & 2,0 & 24 & 3,2 & 404 & 55,2 & 860,5 & 117,7 \\
\hline 1677 & 7,32 & 15,5 & 2,1 & 24 & 3,2 & 404,5 & 55,2 & 851,1 & 116,2 \\
\hline 1678 & 7,26 & 15,5 & 2,1 & 24 & 3,3 & 404,5 & 55,7 & 838,6 & 115,5 \\
\hline 1679 & 7,37 & 15,5 & 2,1 & 24 & 3,2 & 395 & 53,6 & 829,1 & 112,4 \\
\hline 1680 & 7,50 & 15,5 & 2,0 & 24 & 3,2 & 395 & 52,6 & 829,1 & 110,5 \\
\hline 1681 & 7,53 & 15,5 & 2,0 & 24 & 3,1 & 395 & 52,4 & 829,6 & 110,1 \\
\hline 1682 & 7,38 & 15,5 & 2,1 & 24 & 3,2 & 415,5 & 56,3 & 850,1 & 115,1 \\
\hline 1683 & 7,12 & 15,5 & 2,1 & 24 & 3,3 & 415,5 & 58,3 & 850,1 & 119,3 \\
\hline 1684 & 6,86 & 15,5 & 2.2 & 24 & 3,4 & 415,5 & 60,5 & 869,3 & 126,7 \\
\hline 1685 & 6,49 & 15,5 & 2,3 & 24 & 3,6 & 420,5 & 64,7 & 874,3 & 134,7 \\
\hline 1686 & 6,31 & 15,5 & 2,4 & 24 & 3,8 & 435 & 68,9 & 888,8 & 140,8 \\
\hline 1687 & 6,27 & 15,5 & 2,4 & 24 & 3,8 & 435 & 69,3 & 888,8 & 141,7 \\
\hline 1688 & 6,17 & 15,5 & 2,5 & 24 & 3,8 & 435 & 70,5 & 908,8 & 147,3 \\
\hline 1689 & 6,04 & 15,5 & 2,5 & 24 & 3,9 & 435,5 & 71,2 & 895,8 & 148,3 \\
\hline 1690 & 6,02 & 15,5 & 2,5 & 24 & 3,9 & 435,5 & 72,3 & 895,8 & 148,8 \\
\hline 1691 & 5,95 & 10,5 & 2,6 & 24 & 4,0 & 453,5 & 76,2 & 913,8 & 153,5 \\
\hline 1692 & 5,95 & 15,5 & 2,6 & 24 & 4,0 & 453,5 & 76,2 & 894,8 & 150,3 \\
\hline 1695 & 6,09 & 15,5 & 2,5 & 24 & 3,9 & 453,5 & 74,4 & 889,8 & 146, \\
\hline 1694 & $6, \overline{33}$ & 15,5 & 2,4 & 24 & 3,7 & 453,5 & 71,6 & 889,8 & 140,5 \\
\hline 1695 & 6,35 & 15,5 & 2,4 & 24 & 3,7 & 453,5 & 71,4 & 889,8 & 140,1 \\
\hline 1696 & 6,48 & 15,5 & 2,3 & 24 & 3,7 & 453,5 & 69,9 & 872,3 & 134,6 \\
\hline $16 \mathfrak{9} 7$ & 6,64 & 15,5 & 2,3 & 24 & 3,6 & 453,5 & 68,3 & 923,3 & 139,0 \\
\hline 1698 & 6,84 & 15,5 & 2,2 & 24 & 3,5 & 499,5 & 73,0 & 959 & 140,2 \\
\hline 1699 & 6,92 & 15,5 & 2,2 & 24 & 3,4 & 499,5 & 72,1 & 959 & 138,5 \\
\hline 1700 & 6,95 & 15,5 & 2,2 & 24 & 3,4 & 499,5 & 71,8 & 969 & 139,4 \\
\hline
\end{tabular}





\title{
RENTABILIDAD DE UNA PEQUEÑA EXPLOTACION AGRARIA EN VALL DE UXO, 1721.1739
}

\author{
Por Rafael BENITEZ SANCHEZ-BLANCO
}

Universidad de Valencia

INTRODUCCION:

PRESENTACION Y CRITICA DE LAS FUENTES

El interés que para los estudios de historia agraria tienen las cuentas de explotación como via para conocer el funcionamiento de la economia agraria pre-industrial no necesita recalcarse. Tampoco la escasez de tales fuentes. Pero además normalmente, las cuentas conservadas corresponden a grandes explotaciones, existiendo una dificultad muy superior para acceder a los gastos de explotación del pequeño campesino, que no lleva cuentas escritas (1).

Una serie de circunstancias, en parte normales, en parte extraordinarias, nos ha permitido conocer la contabilidad de una pequeña explotación en la llanura costera valenciana, en Vall de Uxó, limite sur de la actual provincia de Castellón. En un proceso típico los arrendatarios de los derechos señoriales del Ducado de Villahermosa no pueden hacer frente a sus pagos y sus tierra son confiscadas; la cosecha está por recoger y se conceden temporalmente en administración a un campesino del lugar(2). Al no surgir postores en las subastas que se realizan, parte de las tierras siguen en manos de este labrador-Geroni Arnau-a quien un buen día se le exigen cuentas de su administración(3). La relación pormenorizada de los gastos que ha realizado en el cultivo de las tierras, y de los ingresos, constituyen la base de este estudio. Sin embargo, la explotación entre 1721 y 1739 según las cuentas presentadas, ha sido deficitaria y Geroni Arnau queda 
acreedor de los administradores del Estado de Villahermosa en cuantia de 285 libras(4).

A partir de aquí se entabla un pleito; básicamente la parte señorial argumenta, no en forma abierta y directa contra las cuentas presentadas, sino contra el haber administrado directamente las tierras en lugar de arrendarlas, como se haria a partir de 1.734(5). Arnau arguye que si a partir de esta fecha se han arrendado ventajosamente ha sido gracias a las mejoras realizadas en los años anteriores y que son resultado de su actuación.

El pleito se centra entonces en el problemático intento de demostrar o negar las mejoras(6). Los testigos presentados por el demandado, se inhiben en su inmensa mayoría, de responder abiertamente a las preguntas sobre la forma en que Arnau ha explotado las tierras, aunque reconocen que es persona honrada y labrador experto. Sólo una minoria se manifiesta abiertamente: pero unos a favor y otros en contra(7). En definitiva, la Audiencia le condenará, sin mayores explicaciones, a satisfacer 40 libras por cada uno de los 19 años que las administró, en total, 760 libras(8).

La fuente no deja de plantear problemas. Ya la propia existencia de un pleito en torno a la gestión-gracias al cual nos ha llegado la contabilidad-deja en suspenso su validez. El pleito, sin embargo, como he señalado, no se dirige directamente contra las cuentas presentadas, aunque en las argumentaciones de los administradores del señorío se apunte la falta de justificantes de gastos e ingresos, y se llegue a hablar de ocultación de frutos(9); pero la acusación apunta más al tipo de gestión-directa-realizada. No llegan a invalidarse las cuentas.

Hecha esta salvedad analicemos, con los pocos datos de que disponemos, la forma en que se han elaborado las cuentas. Estas se presentan al cabo casi de 20 años, lo que necesariamente exige llevar algún registro. Geroni Arnau ha acumulado recibos de los pagos realizados a funcionarios municipales, eclesiásticos y señoriales; recibos que presenta y se incorporan al sumario(10). Pero ¿ha llevado cuentas del resto?. Arnau parece haber rebasado el umbral mínimo del analfabetismo, y así en el folio $19 \mathrm{v}$. aparece su desgarbada firma; es posible también que recurriera a amigos que le anotaran en hojas sueltas los gastos e ingresos que iba haciendo. Como manifiesta su abogado:

"esta escritura se ha formado siguiendo los papeles que van presentados y algunos apuntamientos subministrados por mi parte a quien la impericia no pudo quitarle la buena fe, pero le quitó la formalidad más rigurosa»(11).

Por otra parte, la forma en que se dan las cuentas, pormenorizadamente, implica, o bien llevar anotaciones, o bien una gran capacidad de inventiva, pero con la suficiente coherencia interna como para que puedan ser dadas por buenas. En definitiva, no son tanto los caracteres externos 
del documento, sino su propia coherencia interna la que debe darnos la garantía de su validez. Adelantando las conclusiones, diré que en mi opinión las cuentas presentadas están incompletas por olvido de anotaciones, pero no parecen falsas. Para los jueces no serian, evidentemente, suficientes, pero a nosotros, una vez analizadas a fondo, y seleccionados en su caso algunos años, nos permitirán conocer las técnicas de cultivo, los rendimientos y, por último, hacer algunas especulaciones sobre la rentabilidad. Dada la rareza de este tipo de fuentes, cualquier muestra puede ser interesante.

La explotación se compone de las tierras confiscadas a Joachim Giiii, uno de los arrendatarios fallidos de los derechos señoriales de la casa de Villahermosa(12). Conocemos diversas relaciones de sus propiedades, no todas coincidentes entre si. Eran unas 10 o 12 hanegadas de huerta, según la mayor o menor precisión con que se estimara su superficie, divididas en 4 parcelas. Situadas todas en la huerta de Vall de Uxó, fueron cultivadas por Geroni Arnau y aparecen reflejadas en la contabilidad(13). A las tierras de huerta hay que sumar 2 cahizadas de secano en Nules, y 27,5 cahizadas de algarrobales en Vall de Uxó y Alfondeguilla. Sin embargo, hay constancia de que de estos últimos, el denominado de Aygualid, con 5 cahizadas de extensión, no fue administrado por Arnau, y tal vez algún otro tampoco se refleja en las cuentas ${ }^{(14)}$. En cuanto a las tierras de Nules sólo se incluyen en la contabilidad un año. En definitiva, lo administrado por Geroni Arnau y reflejado en las cuentas era 1 hectárea de huerta y posiblemente aigo menos de 10 hectáreas de algarrobal.

\section{EL CULTIVO DEL TRIGO}

El cultivo del trigo es el fundamental, tanto por las superficies que se le dedican, por su importancia económica, como por su reflejo en la documentación. En efecto, la contabilidad presentada por Arnau nos permite seguir de cerca el cultivo del trigo en la huerta de Vall de Uxó durante una docena de años(15).

\section{A.-LABORES REALIZADAS.}

Veamos en primer lugar las labores realizadas, calculadas por hanegada sembrada ( 1 cahizada $=6$ hanegadas $=0,498$ Has.; de donde 1 hanegada $=0,0831 \mathrm{Ha}$.). (Cuadro 1 ).

\section{I.-Preparación de la tierra}

Requiere dos operaciones; una primera, arar la tierra, conocida como barbechar o guaretar; y la que se denomina sembrar y que realmente es arar o romper la tierra preparándola para sembrar. Operaciones previas a 
la siembra, que se realizan por parejas de caballerias. La primera requiere aproximadamente 0,55 jornales por hanegada, oscilando entre 0,44 y 0,66 , y la segunda, casi uniformemente, 0,33 jornales por hanegada. En conjunto, excluyendo los datos de 1.722-23, irregularmente bajos, 0,83 jornales/hanegada.

A continuación se abona la tierra. Los datos sobre el abonado no constan todos los años. Sólo 8 de un total de 12. La cantidad de estiercol utilizada es variable: oscila entre 4,16 y 10 cargas por barchilla sembrada, o entre 2,5 y 5 cargas por hanegada. La media es de 6,72 cargas por barchilla y 4,08 cargas por hanegada.

Existe una notable correlación entre el número de cargas de estiércol por barchilla sembrada y la Yield ratio, lo que nos habla de la importancia del abonado en los rendimientos.

\section{1.-Siembra}

Conjuntamente con la siembra se realizan una serie de labores: limpiar y preparar las orillas y márgenes-cavar, hacer orillas y márgenes...-, hacer caballones-Caballonar-, y la siembra propiamente dicha. La media de estas labores es de 0,52 jornales por hanegada. Más adelante hablaremos de la cantidad de semilla utilizada.

\section{III. - Cuidados}

El trigo recibe numerosos cuidados: en esencia dos labores de escarda y diversos riegos.

a) La primera de las labores de escarda se denomina cavar o entrecavar; la segunda se conoce como birbar o cavar la segunda vez; la media de las dos es de 3,16 jornales de peón por hanegada, oscilando entre 3 y 3,66 , salvo el año 1729-30 en que sólo se dan 2,11 jornales hanegada, coincidiendo con una yield ratio muy baja: 3,59; en cambio, los años $1.722-23$ y 1.728-29 se emplean más de 3,6 jornales/hanegada, con una yield ratio de 6,34 y 5,71. Parece, pues, existir una cierta correlación entre las labores de escardado y los rendimientos, sin que podamos por el momento precisar el sentido de esta correlación.

b) El trigo, cultivado en huerta, recibe normalmente tres riegos, sal. vo los años 1.726-27, 1.727-28 y 1.730-31 en que se le dan 4 , y 1.732-33 en que, al parecer-puede que se trate de un lapsus de la contabilidad-sólo se da un riego.

Por la tarea de regar se pagaban 4 dineros por hanegada y vez, y además, algunos años, se anotan por hacer brazales para el riego, unos 0,15 jornales por hanegada. 


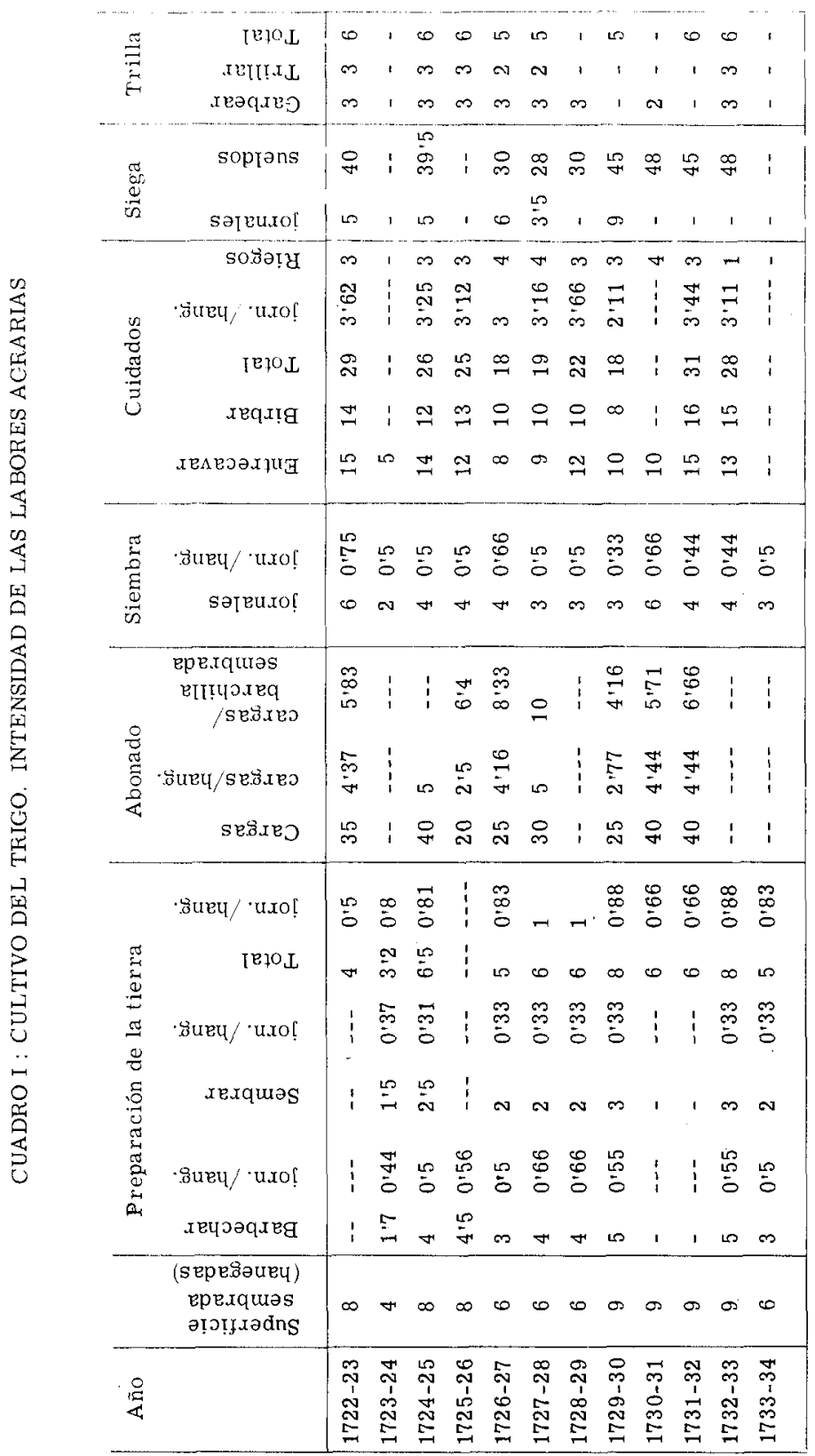


IV.-Recolección y trilla

a) La siega: el gasto medio de la siega es de 5 sueldos por hanegada, con ligeras variaciones.

\begin{tabular}{cccc} 
Año & $\begin{array}{c}\text { Sueldos } \\
\text { gastados }\end{array}$ & $\begin{array}{c}\text { Superficie } \\
\text { sembrada }\end{array}$ & Sueldos/haneg. \\
\hline $1.722-23$ & 40 & 8 & 5 \\
$1.724-25$ & 39,5 & 8 & 4,9 \\
$1.726-27$ & 30 & 6 & 5 \\
$1.727-28$ & 28 & 6 & 4,66 \\
$1.728-29$ & 30 & 6 & 5 \\
$1.729-30$ & 45 & 9 & 5 \\
$1.730-31$ & 48 & 9 & 5,33 \\
$1.731-32$ & 45 & 9 & 5 \\
$1.732-33$ & 48 & 9 & 5,33 \\
\hline
\end{tabular}

Sin embargo este cuadro medio encubre dos formas de realizarse el trabajo de la siega: una contratación normal-jornales pagados a 5 sueldos, y que por lo tanto requieren un jornal por hanegada-; un trabajo que sin llegar a ser, tal vez, "a destajo", es más intensivo: jornales pagados aproximadamente a 8 sueldos, y que requieren 0,6 jornales/haneg. Vuelvo a insistir que sin embargo el coste final es el mismo: unos 5 sueldos por hanegada.

b) Conducción de las gavillas o garbas a la era, y trilla. La documentación especifica dos labores: garbear y trillar la serrada y trillar la paja. Operaciones distintas aunque complementarias, se realizan con una caballería, y requieren 3 jornales para cada una de ambas si se rebasan las 20 barchillas de cosecha neta (unas 28 barchillas de cosecha total), y sólo 5 en caso contrario.

\section{B.-RENDIMIENTOS}

La documentación menciona normalmente la superficie sembrada, la semilla que se compra para sembrar y la cosecha vendida. Con toda probabilidad se puede suponer que el administrador no guarda trigo de un año para otro, sino que vende todo lo que tiene, y adquiere más tarde simiente para sembrar. 
Ahora bien, con toda probabilidad también, como resulta obvio, la parte vendida no es la cosecha total: de ésta hay que descontar el diezmo y la parte de frutos que el señor de Vall de Uxó, el Duque de Segorbe, titulo incorporado en la Casa de Medinaceli, Ileva como censo enfitéutico. La partición era de un octavo(16); el diezmo suponemos que seria de un $10 \%$, aunque tal vez pudiera ser algo superior y ascender también a $1 / 8(12,5 \%)$. En consecuencia, las canticiades vendidas son sólo un $78,75 \%$ del tolai recolectado, extraido un $10 \%$ del diezmo y un 12,5 de censo enfitéutico sobre el remanente. Realizadas estas rectificaciones los resultados puteden onservarse en el cuddro ll.

CUADRO II : CULTIVO DEL TRIGO. RENDIMIENTOS

\begin{tabular}{|c|c|c|c|c|c|c|c|c|}
\hline \multirow[t]{2}{*}{ Año } & \multicolumn{3}{|c|}{ Siembra } & \multicolumn{2}{|c|}{ Cosecha } & \multicolumn{3}{|c|}{ Rendimientos } \\
\hline & 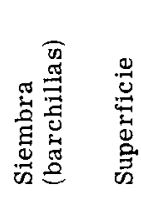 & 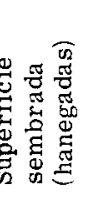 & 焉焉 & 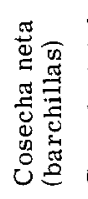 & 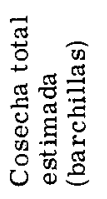 & 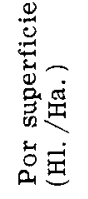 & 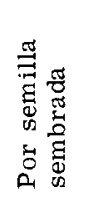 & 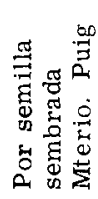 \\
\hline $1722-23$ & 6 & 8 & $1 / 44$ & 30 & 38.09 & $9 \cdot 16$ & $6: 34$ & $9 \cdot 75$ \\
\hline $1723-24$ & 3 & 4 & $1 ' 44$ & 20 & $25 \cdot 39$ & $12 \cdot 21$ & $8 \cdot 46$ & $13 \cdot 55$ \\
\hline $1724-25$ & - & 8 & ---- & 26 & $33^{\prime} 01$ & $7 \cdot 94$ & $\ldots$ & $-\ldots$ \\
\hline $1725-26$ & $3 \cdot 125^{\circ}$ & 8 & 0.75 & 26 & $33^{\prime} 01$ & $7 \cdot 94$ & $10: 56$ & $13 \cdot 45$ \\
\hline $1726-27$ & 3 & 6 & 0.96 & 19 & $24 ' 12$ & $7 \cdot 73$ & 8.04 & $9 \cdot 54$ \\
\hline $1727-28$ & 3 & 6 & 0.96 & $19 \cdot 5$ & $24 \cdot 76$ & $7: 94$ & $8 \cdot 25$ & --- \\
\hline $1728-29$ & 4 & 6 & $1: 27$ & 18 & $22 \cdot 85$ & $7 \cdot 33$ & $5 \cdot 71$ & $-\ldots$ \\
\hline $1729-30$ & 6 & 9 & $1 \cdot 27$ & 17 & $21 \cdot 58$ & $4^{\prime} 61$ & $3: 59$ & $5 \cdot 64$ \\
\hline $1730-31$ & 7 & 9 & $1 ' 49$ & 29.5 & $37 \cdot 46$ & 8.01 & $5 \cdot 35$ & $9 \cdot 78$ \\
\hline $1731-32$ & 6 & 9 & $1 \cdot 27$ & 26 & $33^{\prime} 01$ & $7 \cdot 06$ & 5,50 & $\ldots$ \\
\hline $1732-33$ & 6 & 9 & $1 ' 27$ & 22 & $27 \cdot 93$ & 5.97 & $4^{\prime} 65$ & $\ldots$ \\
\hline $1733-34$ & $3 \cdot 5$ & 6 & $1 ' 12$ & 27 & $34: 28$ & 11 & $9 \cdot 79$ & $9 \cdot 28$ \\
\hline
\end{tabular}


La densidad de siembra es en conjunto semejante a otros datos conocidos de la zona hacia los años 1.740-1.750, estando el valor medio algo por encima de 1,2 $\mathrm{HI} / \mathrm{Ha}$., y siendo en consecuencia muy ligera, alcanzando su cota menor en $1.725-26$, con $0,75 \mathrm{HI} / \mathrm{Ha}$. lo que coincide con la yield ratio más elevada: $10,56(17)$.

Los rendimientos son inferiores a los obtenidos por los frailes del Monasterio del Puig, tanto a la semilla, como por superficie. La media, calculada sobre la cosecha bruta, estimada como se ha señalado arriba, nos da un $8 \mathrm{HI} / \mathrm{Ha}$. y una yield ratio de $6,93 \times 1$. Rendimientos, pues, muy bajos para tierras de regadio(18).

\section{EL CULTIVO DEL PANIZO}

El panizo o adaza, conocido en valenciano como dacsa, y que el documento en otra ocasión denomina maíz, entra en rotación con el trigo. Tanto Cavanilles, para fines del siglo XVIII, como el informe de Sanz Bremón para 1.875 asi 10 manifiestan(19). $Y$ aunque el carácter incompleto de la documentación impide establecer con precisión las rotaciones de cultivos, parece claro que una vez levantado el trigo, parte de la tierra a él destinada se siembra de adaza o panizo - cereal próximo al maíz, pero cuya identificación con el mismo no me atrevo a asegurar.

\section{A.-LABORES AGRARIAS}

El cultivo del panizo tal y como lo realiza Geroni Arnau no incluye la operación de Barbechar, como el trigo, sino que la siembra se lleva a cabo después de una sola reja. Arada la tierra por un par de caballerias se pasa a sembrar y caballonar con peones. Las labores son algo más ligeras que las del trigo, expresadas en jornales por hanegada; prácticamente iguales en la preparación de la tierra: 0,30 jornales/haneg. frente a los 0,33 del trigo, pero sólo 0,37 jornales/haneg. de sembrar y caballonar, frente a los 0,52 dedicados al trigo. Sin embargo, hay que señalar que los salarios abonados por esta última operación son superiores en el caso del cultivo del panizo-media de 5,87-al del trigo-media prácticamente de 4,5 sueldos-, por lo que el coste monetario medio es muy semejante-2,2 sueldos/haneg. para el panizo, frente a 2,3 para el trigo (Cuadro III). 


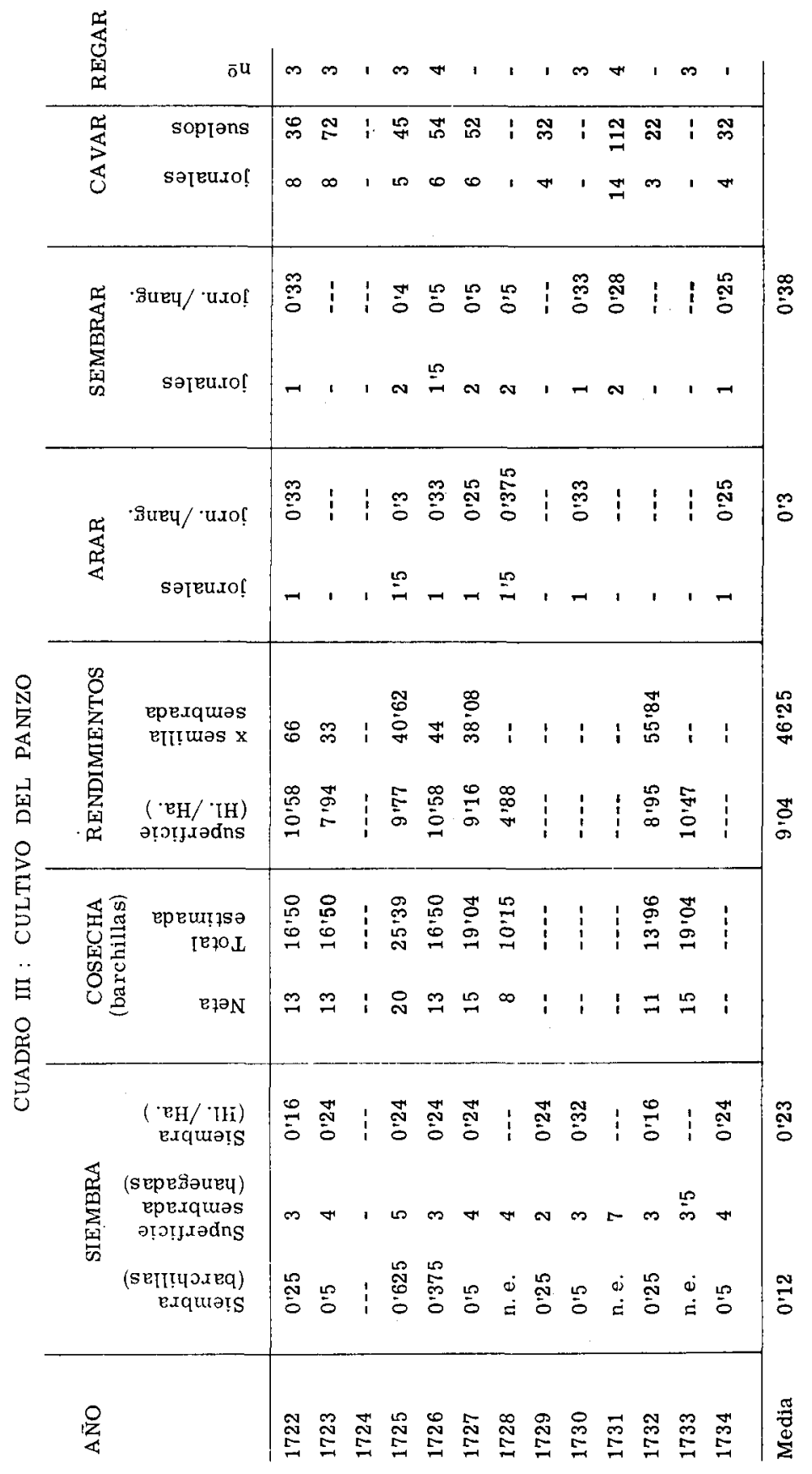


Al igual que el trigo, el panizo recibe por regla general dos labores de escarda. Su intensidad se refleja en el siguiente cuadro(20):

\begin{tabular}{cccc} 
Año & Jornales/hanegada & \multicolumn{2}{c}{ Sueldos/hanegada } \\
\hline 1.722 & 2,66 & 12 & \\
1.723 & 2 & 18 & \\
1.725 & 1 & 9 & (Una sola labor) \\
1.726 & 2 & 18 & \\
1.727 & 1,5 & 13 & \\
1.729 & 2 & 16 & \\
1.731 & 2 & 16 & \\
1.732 & 1 & \multicolumn{2}{c}{7,33 (una sola labor) } \\
1.734 & 1 & \multicolumn{3}{c}{8 (una sola labor) } \\
\end{tabular}

Considerando sólo los años en que constan dos labores, la media es de 2,02 jornales/hanegada, menor que la del trigo que es un poco más de tres. La mayor cuantía de los jornales pagados en el cultivo del panizo hace, sin embargo, que el gasto por hanegada sea incluso mayor que para el trigo; aproximadamente 15,5 frente a 14,12 sueldos/hanegada.

La adaza recibe 3 o 4 riegos: uno para sembrar, y los restantes durante su crecimiento; se pagan, al igual, que los dedicados al trigo a 4 dineros por hanegada y vez. Llevan anejos, aunque la documentación sólo los menciona un par de veces, la preparación de los brazales y ribazos del riego, a lo que se dedican aproximadamente 0,3 jornales. Punto débil de la contabilidad es el relativo a la recolección de este cereal. Sólo se hace referencia a ella en 1.731; coger y conducir el panizo a casa es tarea de un hombre y una caballería, con un importe de 12 sueldos. Dado que este año fue, con 7 hanegadas sembradas, el que más superficie se dedicó a este cereal, puede considerarse como normal la mitad, 0,5 jornales.

\section{B.-RENDIMIENTO}

Las mismas constataciones hechas en los rendimientos del trigo son aplicables a los de panizo. La documentación indica, aunque no de forma tan sistemática como en el caso del trigo, la superficie sembrada, la cantidad adquirida como simiente y la vendida (Cuadro III).

La siembra es muy ligera si tenemos en cuenta que siglo y medio más tarde, Sanz de Bremón señala como normal 0,5 Hl/Ha., mientras que para el trigo sólo $1 \mathrm{HI} / \mathrm{Ha}$., y las cifras que nosotros obtenemos son de 0,23 y 1,2 
$\mathrm{HI} / \mathrm{Ha}$. respectivamente(21). Los rendimientos son en valor medio y tras estimar la cosecha bruta del mismo modo que hemos hecho para el trigo, de unos $9 \mathrm{HI} / \mathrm{Ha}$. y de una yield ratio media para los pocos años que podemos establecerla de $46,25 \times 1$.

OTROS CULTIVOS:

GARBANZOS, CEBADA, ALFALFA

Las huertas son total o parcialmente sembradas de garbanzos, en lugar de hacerlo de trigo, en dos ocasiones dentro del período considerado; en 1.721-22 y en 1.723-24. Las labores que se hacen son las mismas que al trigo y con la misma intensidad, salvo los cavones, ligeramente inferiores-2,44 jornales/hanegada-a lo habitual en el trigo. Arrancar los garbanzos cuesta 2 sueldos por hanegada, más barato por tanto, que el trigo. Conducir los garbanzos a la era y trillarlos requiere dos caballos y un hombre, con un gasto de 36 sueldos para una cosecha neta de 15 barchillas.

Es enormemente aleatorio hablar de rendimientos por tener sólo datos de 2 años. Estos datos son los siguientes:

Año Simiente (barchillas)
Superficie sembrada (hanegadas)
Cosecha neta (barchillas)
$1.721-22$
2,25
9
15
1.723-24
1
3
4,5

No se siembra cebada en la huerta de Vall de Uxó, pero sí en el secano de Nules y Moncofar. Estas tierras sólo parecen una vez en las cuentas y no podemos precisar más sobre su administración. De la heredad de Moncofar no nos ha llegado ningún dato; las tierras de Nules eran 2 cahizadas de secano en la partida de Rachadell. No conocemos la superficie sembrada en 1.726-27, por lo que resulta imposible realizar los cálculos acostumbrados. Las labores dadas a la cebada son las mismas que al trigo, con un mayor peso relativo de la operación de barbechar, que requiere 10 jornales, frente a sólo 2,5 para la reja previa a la siembra. Intensidad requerida posiblemente por ser tierra de secano y necesitar mayor barbecho(22).

En cuanto a los rendimientos, no sabemos sin son o no tierras francas, por lo que es imposible estimar con un mínimo de aproximación la cosecha total. Los datos que poseemos son: 


\begin{tabular}{ccc} 
Año & $\begin{array}{c}\text { Siembra } \\
\text { barchillas }\end{array}$ & $\begin{array}{c}\text { Cosecha_neta } \\
\text { barchillas }\end{array}$ \\
\hline $1721-22$ & 9 & 96 \\
$1726-27$ & 8 & 54 \\
\hline
\end{tabular}

Parte de la tierra de la huerta de Vall de Uxó se dedica al cultivo de la alfalfa; lo habitual no es cultivarla directamente sin arrendarla. A tal efecto, las superficies arrendadas son dos o tres hanegadas. Entre 1.721-22 y 1.724-25 se ceden dos hanegadas a 3 libras cada una; en los años 1.727-28 y 1.728-29 son tres las arrendadas a 5 libras cada una. Por no poder precisar de qué tierras se trata no sabemos cómo se inserta la alfalfa dentro de la rotación de cultivos pero su presencia nos da idea de cómo el campesino valenciano conocía la importancia de esa planta para la mejora de los suelos(23).

En este sentido, creo que debe interpretarse la operación realizada en 1726-27, en que limitando el cultivo del trigo a 6 hanegadas, las otras cinco son sembradas de alfalfa y cebada, recibiendo un abonado muy intenso-80 cargas-de 16 por hanegada, y sin que exista mención de que se recoja dicha yerba.

\section{CULTIVOS ARBOREOS:}

\section{ALGARROBAS, HIGOS, HOJA DE MORERA}

Geroni Arnau se hace también cargo de la administración de varios algarrobales, uno de los cuales incluye algunas higueras. La contabilidad menciona cinco algarrobales-algarroberales-, de los que sólo se han podido identificar tres a partir de las diferentes descripciones de las tierra realizadas con ocasión de tomas de posesión, arrendamientos... Son los denominados Vilambrós, Carmaday y Liavina, que tienen respectiva y aproximadamente 3, 2 y 1,5 jornales o cahizadas de extensión. Al inconveniente de no conocer la extensión de los otros dos algarrobales-Pallarés y la Serrada-hay que añadir la irregularidad con que las labores agrarias aparecen reseñadas, sin que podamos discernir si se trata de olvidos a la hora de confeccionar las cuentas, o del propio ritmo irregular de las labores.

Estas son las siguientes: se ara la tierra con las habituales yuntas de caballerías, con una intensidad que es por regla general de 1, 1,25 y 1,66 jornales/cahizada en Llavina, Carmaday y Vilambrós respectivamente. Posteriormente se realiza la operación denominada desbochar, y que debe designar algún tipo de poda(24). Su intensidad es casi uniformemente de un 
jornal por cahizada en los tres algarrobales mencionados (Ver cuadro IV). Por último, la recogida de las álgarrobas y su conducción por medio de una caballeria al almacén. Labores éstas que están en función de la cantidad recolectada. La primera requiere por término medio 0,13 jornales por arroba neta cogida $(0,10$ jornales por arroba sin descontar la parte de diezmo y del señor suponiendo que sea la misma que en el trigo, $21,25 \%$ ). La segunda exige mayoritariamente un jornal de caballería por cada 45 o 50 arrobas de cosecha neta (57,1 y 63,5 arrobas de cosecha total) (Cuadro V).

Los higos reciben muy pocos cuidados; sólo en dos años se hace referencia a operaciones de cavar y podar-cavar y desbochar higueras-en las que se emplean dos jornales. La recogida exige entre 1 y 2 jornales según sea la cosecha (Cuadro VI).

La hoja de las moreras existentes en las tierra de las huetas era estimada a ojo-alfarrasada-y se vende "por voz de corredor" que llevaba por correr la hoja 3 sueldos cada año. La práctica totalidad de los años la cosecha se calculaba en 6 cargas, siendo su precio bastante variable (Cuadro VII).

CUADRO IV : ALGARROBAS. INTENSIDAD DE LAS LABORES

\begin{tabular}{|c|c|c|c|c|c|c|c|c|c|c|c|c|}
\hline \multirow[t]{3}{*}{ AÑ̃ } & \multicolumn{4}{|c|}{ VILAMBROS } & \multicolumn{4}{|c|}{ CARMADAY } & \multicolumn{4}{|c|}{ LA LIAVINA } \\
\hline & \multicolumn{2}{|c|}{$\operatorname{arar}$} & \multicolumn{2}{|c|}{ desbochar } & \multicolumn{2}{|c|}{$\operatorname{arar}$} & \multicolumn{2}{|c|}{ desbochar } & \multicolumn{2}{|c|}{$\operatorname{arar}$} & \multicolumn{2}{|c|}{ desbochar } \\
\hline & 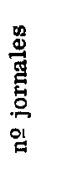 & 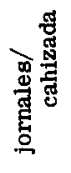 & 量 & 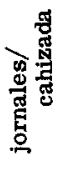 & 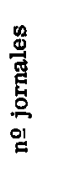 & 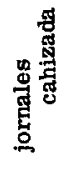 & 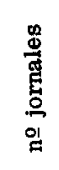 & 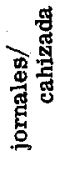 & 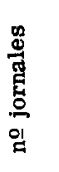 & 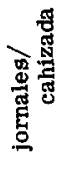 & 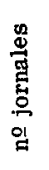 & 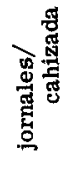 \\
\hline $1721-22$ & 5 & $1 \cdot 66$ & 3 & 1 & $2 \cdot 5$ & 125 & 1 & 0.5 & - & - & - & - \\
\hline $1722-23$ & 5 & $1^{\prime} 66$ & 3 & 1 & $2 \cdot 5$ & $1 \cdot 25$ & 2 & 1 & $1 \cdot 5$ & 1 & - & - \\
\hline $1723-24$ & 3 & 1 & - & - & - & - & - & - & - & - & - & - \\
\hline $1724-25$ & 5 & $1^{\prime} 66$ & 3 & 1 & $2 \cdot 5$ & 125 & - & - & $1 \cdot 5$ & 1 & - & - \\
\hline $1725-26$ & 5 & $1^{\prime} 66$ & 3 & 1 & 25 & $1 \cdot 25$ & 2 & 1 & - & - & - & - \\
\hline $1726-27$ & 5 & $1 ' 66$ & 4 & $1 ' 33$ & $2 \cdot 5$ & $1 ' 25$ & - & - & $1 \cdot 5$ & 1 & - & - \\
\hline $1727-28$ & 6 & 2 & $\mathbf{2}$ & $0^{\prime} 66$ & $2 \cdot 5$ & $1 ' 25$ & 2 & 1 & $1 \cdot 5$ & 1 & $1 ' 5$ & 1 \\
\hline $1728-29$ & 6,5 & $2 \cdot 18$ & - & - & $2 ' 5$ & $1 ' 25$ & - & - & - & - & - & - \\
\hline $1729-30$ & - & - & - & - & - & - & - & - & - & - & - & - \\
\hline $1730-31$ & 6 & $\mathbf{2}$ & - & - & $2 ' 4$ & 12 & - & - & 2 & $1 ' 33$ & - & - \\
\hline $1731-32$ & - & - & - & - & - & - & - & - & - & - & - & - \\
\hline $1732-33$ & - & - & - & - & $2 ' 5$ & 125 & - & - & $1 \div 5$ & 1 & - & - \\
\hline $1733-34$ & - & - & - & - & - & - & - & - & - & - & - & - \\
\hline
\end{tabular}




\begin{tabular}{|c|c|c|c|c|}
\hline 号 & 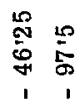 & 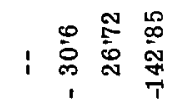 & $\begin{array}{llll}1 & \infty \\
1 & \infty & 1 & 1\end{array}$ & $1 \stackrel{0}{1}$ \\
\hline 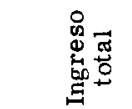 & 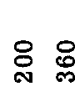 & 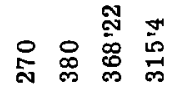 & : & $\begin{array}{lll}\infty & & \\
\infty & \infty & 8 \\
\infty & 0 \\
0 & 5 & 0\end{array}$ \\
\hline
\end{tabular}

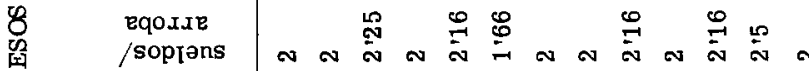

总

seppuән
sвquлte

萦要

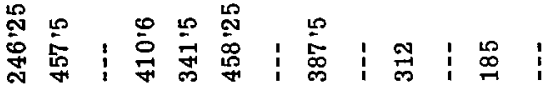

忿

舅

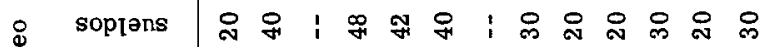

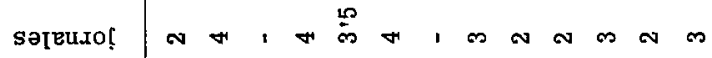

eqox.se

/sopləns

宊占

융 sop[əns

ํํ윰 \&

¿

/soleuxo!

苛苛, $\vec{\Xi}$

sәโеน.jo!

๓

(sop!əns)

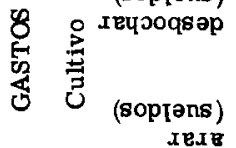

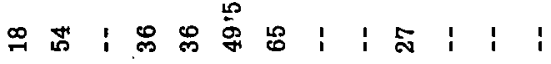

蛋

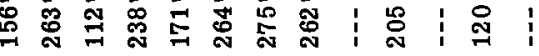

$\stackrel{9}{12}$

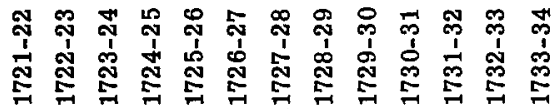


CUADRO VI : HIGOS. BALANCE ECONOMICO DEL CULTIVO

$A \bar{N} O$

GASTO

INGRESO

SALDO

Cultivo Recogida

Total

Venta s./a. Total

sueldos jorn. sueldos

$$
\text { arrobas sueldos }
$$

\begin{tabular}{|c|c|c|c|c|c|c|c|c|}
\hline $1721-22$ & - & 2 & 8 & 8 & 6 & 4 & 24 & 16 \\
\hline $1722-23$ & - & 2 & 9 & 9 & 8 & $4 \cdot 5$ & 36 & 27 \\
\hline $1723-24$ & - & - & - & - & - & - & -- & -- \\
\hline $1724-25$ & - & 2 & 10 & 10 & 7 & 4 & 28 & 18 \\
\hline $1725-26$ & 9 & $1 \cdot 5$ & 9 & 18 & 8 & 4 & 32 & 14 \\
\hline $1726-27$ & 9 & 2 & 9 & 18 & - & - & -- & -- \\
\hline $1727-28$ & - & - & - & - & 4 & 4 & 16 & -- \\
\hline $1728-29$ & - & - & - & -- & 4 & 4 & 16 & -- \\
\hline $1729-30$ & - & 1 & $4 \cdot 5$ & $4 ' 5$ & 4 & 4 & 16 & 115 \\
\hline $1730-31$ & - & - & - & -- & 3 & 4 & 12 & -- \\
\hline $1731-32$ & - & 1 & $4: 5$ & $4 \cdot 5$ & 4 & $4: 5$ & 18 & $13 \cdot 5$ \\
\hline $1732-33$ & - & - & - & - & 5 & 4 & 20 & -- \\
\hline $1733-34$ & - & $1: 5$ & $4^{\prime} 66$ & 7 & 3 & 4 & 12 & 5 \\
\hline
\end{tabular}

CUADRO VII : HOJA DE MORERA. BALANCE ECONOMICO DEL CULTIVO

\begin{tabular}{lccccc} 
AÑO & $\begin{array}{c}\text { cargas } \\
\text { cogidas }\end{array}$ & $\begin{array}{c}\text { sueldos/ } \\
\text { carga }\end{array}$ & $\begin{array}{c}\text { Ingreso } \\
\text { total }\end{array}$ & $\begin{array}{c}\text { Gasto } \\
\text { corretaje }\end{array}$ & SALDO \\
\hline $1721-22$ & 6 & 20 & 120 & 3 & 117 \\
$1722-23$ & 6 & 20 & 120 & 3 & 117 \\
$1723-24$ & 6 & 19 & 114 & 3 & 111 \\
$1724-25$ & 6 & 20 & 120 & 3 & 117 \\
$1725-26$ & 6 & 26 & 156 & 3 & 153 \\
$1726-27$ & 6 & 18 & 108 & 3 & 105 \\
$1727-28$ & 6 & 21 & 126 & 3 & 123 \\
$1728-29$ & 6 & 10 & 60 & 3 & 57 \\
$1729-30$ & 6 & 15 & 90 & 3 & 87 \\
$1730-31$ & 7 & 10 & 70 & 3 & 67 \\
$1731-32$ & 6 & 16 & 96 & 3 & 93 \\
$1732-33$ & 6 & 16 & 96 & 3 & 93 \\
$1733-34$ & $8 \cdot 5$ & 40 & 340 & 3 & 337
\end{tabular}


Concluido el análisis de los distintos cultivos y de sus rendimientos, hagamos un balance económico de la explotación.

\section{BALANCE ECONOMICO}

\section{A.-PRECIOS Y SALARIOS}

Para ello además de considerar la intensidad de las labores agrarias y los rendimientos, es necesario tener presente el montante de los salarios y los precios a que se adquiere la simiente y se vende la cosecha. La contabilidad da noticia de todo ello, y los datos los hemos reflejado en los cuadros VIII y IX.

Los salarios se han agrupado en diferentes categorias buscando una homogeneidad de faenas realizadas y de cuantía pagada. Se indica para cada año el número de jornales de cada categoría y la media de sus importes expresada en sueldos. Se han omitido faenas poco habituales, como las relativas a la cebada, o el arrancar los garbanzos.

El cuadro IX da cuenta de los precios de los diversos productos agrarios considerados. Hemos comparado los precios del trigo aportados por la documentación con las series elaboradas por J. M. Palop de precios del trigo adquirido por el Hospital General de Valencia(25). Se observa una notable concordancia entre la evolución de los precios del hospital valenciano, expresados por años agrícolas de julio a junio, y la del precio de compra de la simiente de trigo por Geroni Arnau; con relación a los precios de venta de la cosecha-con caracteres específicos distintos de los anteriores-esta concordancia existe, pero con un año de decalage, respondiendo los precios de venta del trigo cosechado, no al año agrícola en que normalmente deberia insertarse, sino al anterior. Fenómeno que se puede apreciar en la gráfica, en que estos precios de venta se han retrotraido al año cosecha anterior, sin que podamos aventurar explicación firme sobre él.

PRECIOS DEL TRIGO

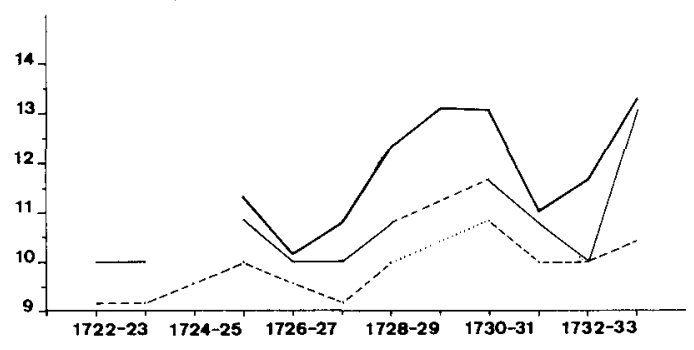




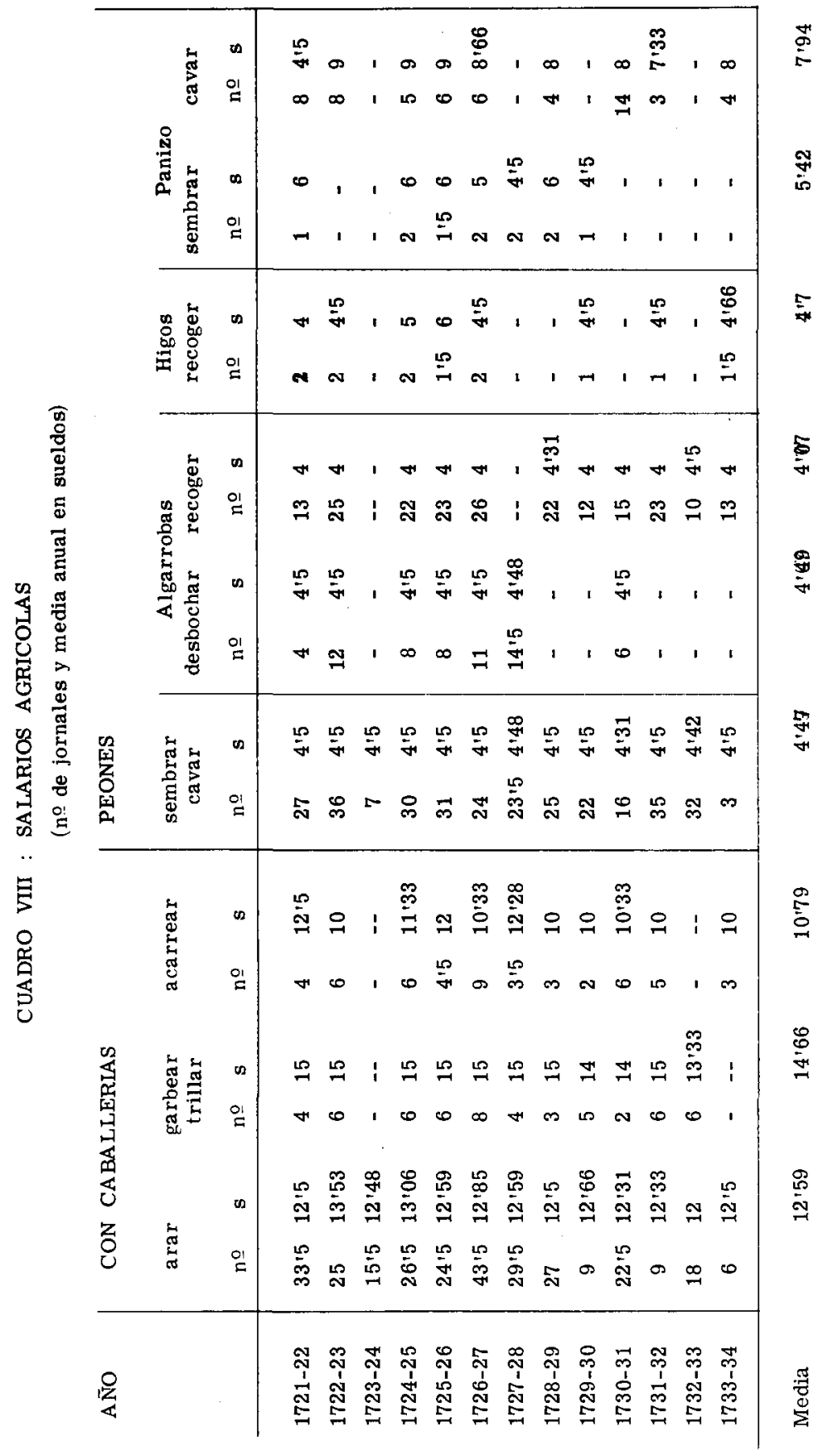


Constatada asi la aparente validez de los precios, al menos por lo que respecta a los de compra, hay que tener presente que nos encontramos posiblemente en el momento de más bajos precios del siglo XVIII valenciano, y esto será importante a la hora de explicar los resultados económicos de la explotación administrada por Geroni Arnau.

En cuanto a los salarios, sus resultados están en cons,onancia con los trabajos en curso que muestran para la misma época.

CUADRO IX : PRECIOS

\begin{tabular}{|c|c|c|c|c|c|c|c|}
\hline \multirow[t]{2}{*}{ Año } & \multicolumn{2}{|c|}{$\begin{array}{l}\text { Trigo } \\
\text { sueldos/ } \\
\text { barchilla }\end{array}$} & \multicolumn{2}{|c|}{$\begin{array}{c}\text { Panizo } \\
\text { sueldos/ } \\
\text { barchilla }\end{array}$} & \multirow{2}{*}{$\begin{array}{c}\text { Algarrobas } \\
\text { sueldos/ } \\
\text { arroba } \\
\\
\stackrel{\pi}{7} \\
\stackrel{0}{0}\end{array}$} & \multirow{2}{*}{$\begin{array}{c}\text { Higos } \\
\text { sueldos/ } \\
\text { arroba } \\
\text { 蒠 } \\
>\end{array}$} & \multirow{2}{*}{ 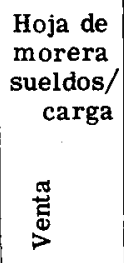 } \\
\hline & 营苛 & 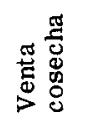 & 营葋 & 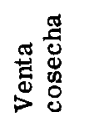 & & & \\
\hline $1721-22$ & - & -- & 10 & 4 & 2 & 4 & 20 \\
\hline $1722-23$ & 10 & $9 \cdot 16$ & 8 & $4 ' 5$ & 2 & $4 \cdot 5$ & 20 \\
\hline $1723-24$ & 10 & $9 \cdot 16$ & -- & $4 \cdot 5$ & $2+25$ & - & 19 \\
\hline $1724-25$ & -- & $9^{\prime} 58$ & $6 ' 4$ & $4 \cdot 33$ & 2 & 4 & 20 \\
\hline $1725-26$ & $10^{\prime} 83$ & 10 & 8 & $\cdot 4$ & $2 ' 16$ & 4 & 26 \\
\hline $1726-27$ & 10 & $9 \cdot 58$ & 8 & 4 & $1 ' 66$ & - & 18 \\
\hline $1727-28$ & 10 & $9 \cdot 16$ & - & 4 & 2 & 4 & 21 \\
\hline $1728-29$ & 1018 & 10 & - & - & 2 & 4 & 10 \\
\hline $1729-30$ & 10 & 10 & 8 & - & $2 \cdot 16$ & 4 & 15 \\
\hline $1730-31$ & $11^{\prime} 66$ & $10 ' 83$ & - & - & 2 & 4 & 10 \\
\hline $1731-32$ & $10^{\prime} 8$ & 10 & - & $4^{\prime} 5$ & $2 ' 16$ & $4^{\prime} 5$ & 16 \\
\hline $1732-33$ & 10 & 10 & - & 5 & $2 \cdot 5$ & 4 & 16 \\
\hline $1733-34$ & $13^{\prime} 09$ & $10^{\prime} 41$ & - & - & 2 & 4 & 40 \\
\hline
\end{tabular}




\section{B.-BALANCE ECONOMICO DE LOS CULTIVOS}

En primer lugar analizaremos, a partir de los datos sobre la intensidad de las labores agrarias, los salarios y los precios, cuál es el resultado económico del cultivo del trigo y del panizo. Para ello construiremos un modelo de explotación de una hanegada de superficie, aplicándole los valores medios obtenidos en el análisis previo. El resultado que nos de la utilización de este modelo lo compararemos con los datos reales de los años en que la documentación es más completa. El modelo de explotación de una hanegada de trigo es el siguiente:

Por hanegada $\begin{array}{cc}\text { Coste } & \text { Coste } \\ \text { unitario } & \text { total }\end{array}$

(Sueidos) (Sueldos)

GASTOS DE CULTIVO

Preparación de la tierra ...

Abonado ...............

Conducción del estiércol . .

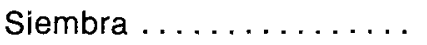

Cuidados de la tierra .....

Riegos ...............

Hacer brazales para el riego

Segar .............

Trillar ..............

SIMIENTE

0‘83 jorn.

4 cargas

$12 ‘ 59$

$10 \times 45$

$0 \times 2$ jorn.

1

4

0‘52 jorn.

$10 ` 8$

2,16

3'16 jorn.

3 riegos

$4 \cdot 47$

2'32

0‘15 jorn.

5 sueldos

$4 \cdot 47$

14,12

0433

1

4447

0.67

1 jornal

5

$14 * 66$

$14^{\prime} 66$

0‘62 barchillas

$10 ' 65$

$6^{4} 6$

GASTO TOTAL ..........

$60 ` 98$

INGRESOS

Cosecha total

4'2 barchillas

$9^{`} 82$

$41 ' 24$

SALDO: Déficit de 19'74 sueldos por hanegada.

El resultado es de un coste medio por hanegada de 61 sueldos, y unos ingresos brutos de algo más de 41 , con un déficit por tanto de casi 20 suel- 
dos. La comparación de este balance obtenido a partir del modelo, con los datos reales de la explotación en algunos años-los más completos - ofrece resultados muy próximos.

\section{$1724-25 \quad 1726-27 \quad 1727-28 \quad 1729-30 \quad 1731-32$}

\begin{tabular}{lllllll}
\hline GASTO POR HANEGADA . . . & $53^{`} 93^{\star}$ & $57^{`} 08$ & $59 ` 66$ & $45^{`} 94$ & $599^{`} 72$
\end{tabular}

\begin{tabular}{|c|c|c|c|c|c|}
\hline rchill./hang.) & $4: 12$ & $3 ‘ 52$ & $4^{\prime} 12$ & $2 ‘ 379$ & \\
\hline Precio de venta (sueldos/bar.) & $9 \cdot 58$ & $9 ‘ 58$ & $9 \cdot 16$ & 10 & \\
\hline INGRESO TOTAL & $399^{\circ} 46$ & 3372 & $33 \times 73$ & $23 \cdot 97$ & 36 \\
\hline
\end{tabular}

SALDO: Déficit......... 14‘46 23‘35 21‘93 $21 ‘ 96 \quad 23^{‘} 12$

* No incluye simiente.

El mismo análisis para el panizo da los siguientes resultados: 30 sueldos de gastos, 20 de ingreso bruto y 10 sueldos de déficit (Cuadro $X$ ). En el caso del panizo los resultados que se derivan del análisis de años concretos difieren de los obtenidos del modelo, ya que no incluyen en ningún caso el coste de hacer brazales para el riego, ni de recogida. Sumando los 7'3 sueldos que ambas operaciones importan, los resultados se aproximan notablemente.

CUADRO X: MODELO DE EXPLOTACION DE UNA HANEGADA DE PANIZO

$\begin{array}{ccc}\text { Por hanegada } & \text { Coste } & \text { Coste } \\ \text { unitario } & \text { total } \\ \text { (Sueldos) } & \text { (Sueldos) }\end{array}$

GASTOS DE CULTIVO

Preparación de la tierra ...

$0 ‘ 3$ jorn.

$12 \cdot 59$

3777

Siembra ...............

0 38 jorn.

$5 ‘ 87$

2 ‘23

Cuidados ..............

2 jorn.

Riego ...............

Hacer brazales para el riego

3 riegos

Coger y conducir cosecha .

0 3 jorn.

$0 \div 33$

0.5 jorn.

4'5

0‘12 barchillas

12

15,5

SIMIENTE

8

1

1335

6

0‘96

GASTO TOTAL

$30 ‘ 81$

INGRESOS

Cosecha total

$4^{\prime} 64$ barchillas

4'31

20

SALDO: Déficit de 10‘81 sueldos. 


\begin{tabular}{lllll} 
& 1722 & 1725 & 1726 & 1727 \\
\hline GASTO POR HANEGADA . & $20 ` 83$ & $177^{\prime} 53^{*}$ & 28 & 22
\end{tabular}

Cosecha total

barchilla/hang......... 5'5

$\begin{array}{llll}5 ’ 5 & 5 ` 07 & 5 ` 5 & 4\end{array}$

Precio de venta

sueldo/barchilla........

$4 \quad 4 \cdot 33$

4

4

INGRESO TOTAL ...... $22 \quad 21 ‘ 98 \quad 22 \quad 19 ‘ 04$

SALDO ... . . . . . . . . . Benf. 1‘17 Benf. 4‘45 Deft. 6 Dft. 2‘96

* Gastos de labrar la tierra bajos.

En el caso de los otros cultivos sólo podemos conocer los resultados de forma global: cosecha vendida descontado el diezmo y la partición de frutos pagados al señor, menos gastos de explotación anotados. Son los siguientes:

Algarrobas ........

Higos ..............

Hoja de morera .......
47 '5 sueldos/año de déficit.

15 sueldos/año de beneficio.

121 '3 sueldos/año de beneficio.

\section{C.-BALANCE GLOBAL}

El balance económico de los cultivos, claramente negativo, exige evidentemente una reflexión. Contrasta además con la realidad del arrendamiento de dichas tierras realizado en 1734 por un importe de 50 libras anuales, siendo, como es, lógico que el arrendatario conociera las tierras y estuviera al tanto de sus posibilidades productivas.

Un balance global aproximado de los ingresos de la explotación-deducido el diezmo y la participación de frutos pagada al señor, pero no otros gravámenes y gastos-arrojaría los siguientes resultados, considerando los rendimientos medios del periodo 1721-22, 1733-34 y suponiendo para el trigo y el panizo una extensión cultivada de 9 y 4 hanegadas respectivamente, cifra evidentemente alta. 
Ingresos totales anuales (pagado el diezmo y partición de frutos)(26)

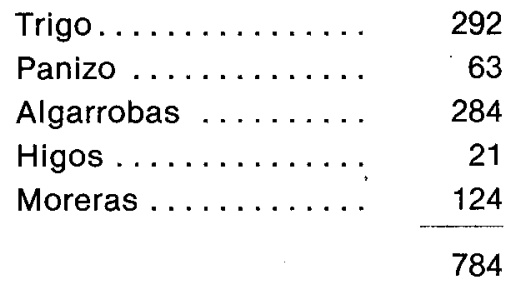

Arrendamiento de tierra para alfalfa:

2 hanegadas a 100 sueldos/hanegada $=200$

Total............ 984

A esto hay que añadir el arrendamiento de una casa en Vall de Uxó y las tierras de secano de Nules. Por la primera se obtenían en los años 1717 a 1720 tres libras (120 sueldos) anuales. La cebada supuso en el año 172627, único para el que tenemos datos de la tierra de Nules, 180 sueldos. En cuanto a los diversos gravámenes, es el arrendador-Geroni Arnau-el que los paga.

Los ingresos totales, pagado el diezmo y la partición, pueden estimarse por tanto en unos 1.300 sueldos anuales. Incluyendo éstos, ascienden aproximadamente a unos 1.600 sueldos, cuyo reparto es, en grandes lineas, el siguiente:

$41,5 \%$ para el arrendador.

$13,5 \%$ correspondiente al diezmo del señor, en especie.

$25 \%$ gravámenes en dinero correspondientes al diezmo, señor y al Estado.

$20 \%$ para el labrador.

De este $20 \%$ aproximado que le queda de la cosecha bruta hay que descontar los gastos de explotación. Sólo una reducción drástica de los gastos salariales, por medio de un recurso a la mano de obra familiar, permitiria un mínimo beneficio.

En efecto, no cabe pensar, vistos los cálculos precedentes, ni en una reducción notable de la intensidad de las labores, que para algunos testigos no eran suficientes, ni en un aumento sustancial de los rendimientos, dado lo que conocemos para las cercanas tierras del Monasterio del Puig. En estas condiciones las alternativas son tres: buscar una sustitución de cultivos, orientando la producción hacia el olivar o la vid-como se obser- 
va en Sagunto y el Puig(27); aprovecharse del tirón alcista de los precios, fenómeno que se produce para el trigo entre 1734 y 1738(28); por último, una explotación realizada sin recurso-o con el mínimo posible-a la mano de obra asalariada.

\section{CONCLUSION}

De la serie de correlaciones establecidas puede deducirse la fiabilidad general de los datos aportados por Geroni Arnau en su presentación de cuentas, a pesar del evidente carácter fragmentario de las mismas. Los resultados obtenidos sobre la intensidad de las labores y su coste salarial creo que son, así como los de los rendimientos, representativos de una pequeña explotación agraria del regadío valenciano; explotación no muy bien trabajada pero que no estará muy alejada de los valores medios.

En cuanto al balance económico, pone de manifiesto varias realidades: en primer lugar la desfavorable coyuntura de principios del siglo XVIII para las grandes explotaciones volcadas al mercado y con necesidad de mano de obra asalariada y para aquellas que, como la muestra estudiada, tratan de imitarlas. Coyuntura que se modificará cuando el alza de los precios corroa el salario real.

En segundo lugar, estamos ante un modelo del absurdo que se produce al valorar al precio de mercado-de un mercado necesariamente reducido-el coste de una mano de obra que en pequeñas explotaciones como la analizada sería normalmente aportada por la propia familia(29).

Por último, la sentencia de la Audiencia no parece ir desencaminada al estimar en 40 libras anuales ( 800 sueldos) el importe, deducidos todos los gastos inclusive el $10 \%$ de beneficio del administrador, que debía abonar Geroni Arnau por los bienes administrados. Cantidad que le hubiera quedado limpia caso de trabajar las tierra en régimen familiar.

Si comparamos estas 40 libras, con el valor en que se tasan las tierras cuando se toma posesión de ellas en 1.720, y que es de 976 libras nos da un rendimiento neto de un $4 \%$. 
(1) Sobre grandes propiedades recordar la sección dedicada al Etude comparée du grand domaine depuis la fin du Moyen Age, en la "Premierè Conference Internationale d'Histoire Economique", Stockholm, 1.960. Aigunas consideraciones tanto sobre rentabilidad de propiedades como sobre aspectos más generales del desarrollo agrario en el área mediterránea pueden verse en: GEORGELIN, J., "Une grande propiété en Vénétie au XVIlle siècle: Angullara", Annales, $E$. S. C., XXIII (1.968), pp. 483-519; AYMARD, M., "Rendements et productivité agricole dans I'Italie moderne", Annales, E. S. C., XXVIII (1.973), pp. 475-498; DAVICO, R., "Baux, exploitations, techniques agricoles en Piemont dans la deuxième moitié du XVIlle sièclen, Etudes Rurales, $\mathrm{n} .^{\circ} 46$ (Abril-Junio 1.972), pp. 76-101; DELILLE, G., "Crises et productivité agricole: l'exemple du Royaume de Napoles" en Typologie des crises dans les pays méditérranéns (XVI-XX siecles), Actes des journees d'etudes. Bendor, 1.976. Nice, 1.977, pp. 115-136. Para áreas más próximas al País Valenciano, las obras fundamentales de Le Roy Ladurie, Les paysans de Languedoc, Paris, 1.966, y de Pierre Vilar, Catalunya dins l'Espanya moderna, vol. III, Les transformacions agráries del segle XVIII català, Barcelona, 1.975. Sobre la propia Cataluña confróntese el $n .{ }^{\circ} 1$ de la revista Estudis d'Història Agrària, con artículos de Eva Serra, E. Canals, etc.

(2) Archivo del Reino de Valencia (A. R. V.), Escribanias de Cámara (E. C.), 1.720-168. La cesión y el compromiso de administrar las propiedades en el fol. 19: "Tomara en deposito y fiel confianza assi las tierra como dichos frutos, los quales a su tiempo y a expensa de ellos los recojera y pondra en limpio, y puestos y pagado el importe de los travajos to remanente que quedará lo tendrá guardado y custodiado en su poder dando de todo buena cuenta y razón a los señores desta Real Audiencian. (Vall de Uxo, 15 de Junio 1.717).

(3) Dio una primera cuenta de la administración en agosto de 1.720 , pero al no estar pormenorizada, ni ajustarse tampoco al esquema de las del período 1.721-1.739, no las he considerado (A.R.V., E.C., 1.720-168, fols. 164-165).

(4) Ibid., fols. 409-451.

(5) "desde este año congedió mi parte-se refiere a Arnau-en arriendo todas las tierras a Joseph Gausi por 50 libras antuales" (lbid. fol. 417).

(6) Curiosamente es un proceso semejante al que Kula señala como tipico de los señores polacos. KULA, W., Teoria económica del sistema feudal, Buenos Aires, 1.974, pp. 35-36.

7.-Los testimonios en fols. 475-560. Algunas muestras significativas: "no comprende el testigo-dice Vicente Romá, labrador-tengan mejoras algunas dichas tierras, antes bien le parece... tienen peoras despues que estan por administración... y esto... proviene del poco cuydado que dicho Arnau ha tenido en el cultivon (fol. 503 v.). Y continúa más adelante: "es labrador muy perito, pero no aplicava el trabajo correspondiente para el aumento de dichas tierrasn. Sin embargo Gerónimo Diago, labrador, afirma lo contrario: "se ha portado con cuydado y vigilancia en el cultivo de dichas tierra" (fol. 552 v.); y Joan Abad, alpargatero, reconoce que hay mejoras (fol. 497).

(8) A. R. V., E. C., 1.720-168, fol. 603-605.

(9) Ibid., fols. 583-584.

(10) Ibid., fols. 334-398.

(11) Ibid., fol. 451. Véase como muestra el capuntamienton contenido en el fol 384.

(12) El arrendamiento se realizó el 25 de Enero de 1.714 por cuatro años (1.714-1.717) y precio de 1.222 libras anuales. Joachim Gili era el arrendatario, en unión de un grupo de fiadores cuyos bienes también son confiscados. El arrendamiento resultó fallido ya desde la primera paga (A. R. V., E. C., 1.720-168, fol. 3-6).

(13) No se hace referencia en ésta a las diferentes parcelas de la huerta, pero al especificarse la superficie dedicada a los diversos cultivos, se observa que el total máximo cultivado era de 10 u 11 hanegadas.

(14) El algarrobal de Aygualid fue vendido a Vicente Ferrer y Joan Forner, vecinos de Segorbe, y por éstos a Agustin Gregori. 
(15) Las cuentas se establecen por años cosecha, de Octubre a Septiembre: «sin embargo de haverse de formar las quentas desde el año 1.721-dice el abogado de Arnau-se formaron en inteligencia de que empezando el año por el mes de Octubre para el efecto de cultivar las tierras, los frutos no se cogen asta el año mil setecientos veinte y dos" (A. R. V., E. C., 1.720-168, fol. 409 v.).

Sobre la tecnologia agraria puede consultarse SIGAUT, F., "La technologie de l'agriculture européenne. Une revue de travaux récents", Etudes Rurales, n. 69 (Enero-Marzo 1.979), pp. 117 126. Del mismo autor, y sobre las labores de barbecho, "La jachére en Ecosse au XVlie siécle: phase ultime de l'expansion d'une technique", Etudes Rurales, n. 57 (Enero-Marzo 1.975) pp. 89105. Un articulo reciente sobre los avances de la técnica agricola en Flandes; Marie-Jeanne TITS-DIEUAIDE, "L'evolution des techniques agricoles en Flandre et en Brabant du XIVe au XVle siècle", Annales, E. S. C., XXXVI (1.981), pp. 362-381.

(16) Escritura de suplemento de títulos de enfiteusis en favor del Duque de Medinaceli y Segorbe, señor de la villa de Vall de Uxo (4 de Julio de 1.736 A. R. V., E. C. 1.720-168, fols. 399-406. Además de la partición de frutos debe pagar de censos en dinero por las tierras y casas 121 sueldos anuales.

(17) BENITEZ, R., "Producción y consumo en la huerta de Valencia en la primera mitad del siglo XVIII. El caso del monasterio de El Puig", Actes du ler. Colloque sur le Pays Valencien a l'epoque moderne, Valencia, 1.980, pp. 257-271. La siembra era de 1 ‘20 $\mathrm{Hl} / \mathrm{Ha}$. en $1.740-41$, y de 1 '28 en 1.753-54.

(18) Creo que son aplicables también en este caso las conclusiones avanzadas entonces: siendo los rendimientos del trigo muy poco espectaulares, máxime tratándose de cultivo de regadio, su finalidad debe ser principalmente asegurar el autoconsumo campesino. (Ibid.).

(19) CAVANILLES, Observaciones sobre la historia natural, geografia, agricultura, población y frutos del Reyno de Valencia, Madrid, 1.795-1.797. Segunda edición, Zaragoza, 1.958, pp. 181 (interesantes reflexiones sobre la técnica agraria a propósito de la baronia de Torres-Torres), 210, y passim. SANZ BREMON, Manuel, Memoria sobre el estado de la agricultura en la provincia de Valencia, y Contestación al interrogatorio publicado por la Dirección General de Agricultura con fecha 20 de Enero de 1.881, publicados en Estudis d'Història Agrària, n. 2 (1.979), pp. 211-253, y 254-288 respectivamente. En particular pp. 235 y 256-57.

(20) Por tratarse de un cultivo de verano sólo se especifica-el año en que realmente se efectua.

(21) SANZ BREMON, pp. 256-257.

(22) Ibid., pp. 234 y 257.

(23) Ibid., pp. 239-240.

(24) Sobre las podas a aplicar a los aigarrobos insiste repetidas veces Cavanilles, en particular en vol. I, p. 73.

(25) PALOP, J. M., Fluctuaciones de precios y abastecimiento en la Valencia del siglo $X$ VIII, Valencia, 1.977.

(26) El cálculo es el siguiente: para la hoja de morera, higos y algarrobas se ha obtenido la media de los ingresos totales (ver cuadros V, VI y VII); para el trigo y el panizo se han utilizado los modelos de explotación construidos, pero en lugar de emplear la cosecha total, se ha utilizado la neta (deducido diezmo y partición) es decir el $78^{\prime} 75 \%$ de aquella que queda para la venta. El dedicar 9 y 4 hanegadas anuales al trigo y panizo respectivamente implicaria reservar dos para la alfalfa y dejar reposar durante el verano y parte del otoño la mitad, aproximadamente, de las tierras dedicadas al trigo. Es, en lineas muy generales, lo que parece deducirse de la distribución de las superficies entre los diversos cultivos.

(27) BENITEZ, Producción y consumo...

(28) PALOP, Fluctuaciones de precios...

(29) Cf. KULA, Teoria económica... pp. 34-35, y en general el primer. capítulo. 



\section{ECONOMIA MONASTICA Y SOCIEDAD RURAL EN VALLADOLID DURANTE EL ANTIGUO REGIMEN: \\ LA REAL CARTUJA DE NUESTRA SEÑORA DE ANIAGO*}

Por José Miguel LOPEZ GARCIA

Universidad Autónoma de Madrid

(*) Este artículo recoge los primeros resultados de una serie de trabajos que, bajo la denominación de «Economia monástica y sociedad rural en la cuenca del Duero", se vienen realizando en el departamento de Historia Moderna bajo la dirección de Pablo Fernández Albaladejo. 
Como es sabido los Monasterios Castellanos no sólo se caracterizaron por ser los conservadores y transmisores de la Cultura en la Edad Media, con la correspondiente importancia que ello tiene para la historia del Arte, sino que también su labor estuvo intimamente ligada a la repoblación emprendida desde los primeros tiempos de la Reconquista y a su posterior actuación dentro de la economía del Antiguo Régimen como unidades de explotación y comercialización. Es sin duda en los territorios de la submeseta norte y en Noroeste de España (Galicia, Principado de Asturias y Corona de León), donde tuvieron lugar los principales asentamientos de las órdenes monásticas desde la Edad Media. En efecto, un vistazo a los informes de Bienes Nacionales y Desamortización, contenidos en la Sección de Hacienda del A. H. N. de Madrid, nos demuestra cómo solamente en estas tres regiones se asentó, al menos, una tercera parte del total de los enclaves monásticos españoles. Las causas de esta situacion nos son perfectamente conocidas. Fue sobre todo en los territorios de la Corona de León, situados en las márgenes del Duero y sus afluentes, donde la labor repobladora monástica adquirió su mayor importancia, siendo buena prueba de ello el elevado número de conventos que tenian algunas de sus provincias en el Antiguo Régimen: sólo en Valladolid 168 monasterios poseian aún tierras a la llegada de la Desamortización(1).

Si bien conocemos bastante bien el papel que jugaron los monasterios durante la Edad Media, puede decirse que no ocurre así en lo referente a la Edad Moderna. En efecto, el estudio de muchos de éstos ha sido bastante bien realizado por los medievalistas, los cuales han formulado algunas premisas básicas sobre las que se puede asentar una metodología válida para la realización de estos trabajos; son ejemplos destacados las obras de José Angel García Cortazar(2) y Salustiano Moreta Velayos(3); sin embargo esta labor no ha sido prácticamente emprendida para el Antiguo Régimen(4).

Nada prueba por el contrario que durante los siglos XVI, XVII y XVIII los monasterios pierdan importancia en relación a la Edad Media. Es más, las campañas de los Ilustrados vienen a probar más bien lo contrario, y sin embargo sabemos muy poco sobre el papel efectivo que los monasterios jugaron a lo largo de ese período. Este trabajo aspira a rellenar una pequeña parte de esa gran parcela por estudiar que constituyen las economías monásticas en la Edad Moderna. La rica documentación que hemos podido manejar dará una idea de las posibilidades que ofrece hacia el futuro este tipo de trabajos.

Es claro que, por otra parte, nuestro trabajo pretende asimismo contribuir a un conocimiento más preciso de la historia rural de Castilla. En este sentido hemos seguido las pautas metodologicas de la historiografía rural francesa(5), y de aquellos otros trabajos que han sentado las líneas genera- 
les de la investigación rural en nuestro país(6). Hasta el momento esta tarea, para Castilla la Vieja, sólo ha sido emprendida por Angel García Sanz $z^{(7)}$, cuyo estudio se nos presenta como uno de los modelos básicos para realizar investigaciones de esta clase. La conjunción de los factores aludidos, junto a la rareza de una contabilidad "empresarial", ha potenciado sin duda el predominio de los estudios macroeconómicos, y de ahí en nuestra opinión la importancia que puede tener la realización de una serie de investigaciones sobre las economías monásticas, ya que ellas nos pueden permitir abarcar y completar, desde una perspectiva complementaria, la todavía poco conocida historia rural de Castilla la Vieja. Es nuestra esperanza alcanzar en un futuro el conocimiento al que alude W. Kula a propósito de "cómo se administraba la reserva (señorial), cuál era su cálculo económico, cómo reaccionaba ante los cambios de situación, a las variables de las cosechas y los precios y qué alternativas elegiaw(8). Ciertamente, la opción microeconómica nos permite abarcar menos en el espacio-sólo es objeto de estudio el área del Dominio de un monasterio-pero más en el tiempo: podemos seguir la evolución de una empresa económica y sus repercusiones en la sociedad rural que la soportaba desde su fundación, ya sea ésta medieval o moderna, hasta su desaparición en el siglo $X I X(9)$.

Asimismo, la mayor precisión en las fuentes nos permite contrastar los datos y las fuentes más frecuentemente utilizados en los estudios macroeconómicos, como los Informes Fiscales de la Corona, de los que es máximo exponente el Catastro de Ensenada. Y esto se ve muy claramente cuando a través de los propios informes de los monjes, de su contabilidad, etc., descubrimos como muchas veces se han tomado, sin ningún tipo de crítica, gran cantidad de datos que se dieron falseados en las encuestas: Tal es el caso del Libro del Mayor Hacendado del Catastro, algunas de cuyas respuestas no coinciden con la realidad de los diferentes lugares. En esta misma situación se encuentran otras respuestas referentes a la productividad de las tierra, explotación de las granjas, productividad de las Aceñas, etc., etc.(10).

Por último, la ventaja más importante de este análisis radica en precisar perfectamente cómo y de qué manera afectó la coyuntura a los diversos elementos, logrando matizar los estudios anteriores: de una parte, ya veremos como el microanálisis nos permite apreciar más adecuadamente la distribución social de la crisis del siglo XVII, que no afectó por igual a la Cartuja de Aniago, a los labradores de la zona, etc., y cómo la ureacción señorial" se vio favorecida por esta crisis, permitiendo al monasterio una fuerte expansión territorial a costa de los pequeños propietarios que, tras arruinarse, tuvieron que vender sus tierras. 
Como es sabido, la economía vallisoletana durante el Antiguo Régimen estuvo muy relacionada con la actuación de las primitivas unidades de explotación agraria, entre las cuales los monasterios jugaron un papel muy importante desde los primeros tiempos de la Reconquista. Si tomamos como punto de partida el "Informe del Mayor Hacendado» del Catastro de Ensenada, nos encontrariamos con que de un total de 4.484.283,7 reales de vellón, en que la administración evaluó el Producto Bruto Provincial de los mayores hacendados, un 25,61 \% correspondia a los Religiosos(11). El conjunto total del informe queda resumido en la tabla número 1:

TABLA N. ${ }^{\circ} 1$

\begin{tabular}{|c|c|c|c|}
\hline MAYOR HACENDADO & $\begin{array}{l}\text { N. }{ }^{\circ} \text { ENTIDADES DE } \\
\text { POBLACION }\end{array}$ & RS. & $\%$ \\
\hline Particulares... & 372 & $1.567 .269,4$ & 34,95 \\
\hline Religiosos . . . . . & 100 & $1.148 .685,2$ & 25,61 \\
\hline Concejos . & 84 & $1.136 .288,6$ & 25,33 \\
\hline Nobles ............ & 51 & $633.041,2$ & 14,11 \\
\hline TOTAL & 607 & $4.485 .283,7$ & 100 \\
\hline
\end{tabular}

De éste resulta que los mayores hacendados de la antigua provincia eran los particulares (Tercer Estado), en 372 entidades de población, que reunían el 34,95\% del P. B. anual. A ellos seguía la Iglesia, los Concejos y, finalmente, los Nobles. Sin embargo, si relacionamos P. B. y $n .{ }^{\circ}$ de entidades de población, nos encontramos con que los Religiosos y los Concejos obtenian los máximos P. B. por entidad (11.486, 85 y 13.527,24 Rs./entidad respectivamente), mientras que los particulares destacaban por la escasa productividad de sus "haciendas» $(4.213,08 \mathrm{Rs}$./entidad).

Por ello no es de extrañar que el mayor hacendado provincial fuera el Concejo de la villa de Mayorga con 96.044 Rs. al año, que procedian de la sembradura de 1901 medidas de tierra, obteniendo de ellas 11.025 fanegas de centeno, 366,16 fas. de trigo, 111 de avena y 85,25 de cebada(12). A este respecto, veamos cuáles eran los 14 mayores hacendados de Valladolid, tomando como baremo la cifra de 40.000 Rs. de P.B. anual: 
Mayorga

Villanueva de los Caballeros

San Martín del Barco

Villafer

Medina de Rioseco

Castromonte

Castropepe

Villalar

Fuensaldaña

Peñaflor

Barcial del Barco

Arroyo

Valladolid

Olmedo
Su Concejo

96.044

Coleg. Jesuíta de Villagarcía

de Campos

75.249

Conde de Benavente

64.505

Su Concejo

61.173

Su Cabildo Eclesiático

$60.118,7$

Su Concejo

$59.118,2$

Su Concejo

56.850

Cartuja de N. ${ }^{a}$ S. ${ }^{a}$ aniago

52.187

Su Concejo

48.087

Su Concejo

44.420

Su Cóncejo

41.830

40.821

40.121

Marquesa de Valverde

$39.930,7$

FUENTE: Libro 662 de la sección de Hacienda (Catastro) del A. G. S.

De las 14 entidades de población, la mitad tenian como mayor hacendado a sus respectivos Concejos, en 5 se daban mayores hacendados Eclesiásticos, en 2 Nobles y en ninguana aparece un Particular que se aproximara a esos 40.000 Rs., coincidiendo estos datos con las evaluaciones por propietarios y entidad de poblacion anteriormente presentadas.

Sin embargo, los Eclesiásticos no sólo obtenian ingresos de sus profesiones rurales, sino que también percibian importantes cantidades por otros conceptos:

1. La Masa Decimal, volumen importante de la producción, que llevaba al Clero a disponer del $33 \%$ del excedente total de la Coronaw(13).

2. El hecho de que la Iglesia tuviese una buena parte de los juros de la provincia.

3. Finalmente, el que en su poder se encontrase el principal mecanismo crediticio de la época, al disfrutar de las $3 / 4$ partes de los intereses de los censos de la Corona de Castilla. 
Dentro de la actual provincia los intereses del Clero, y sobre todo de los monasterios, se encontraban concentrados en las zonas mejor irrigadas $y$, por tanto, de mejor calidad y mayores posibilidades para los cultivos especializados, como los hortofruticolas, etc.: en la red central de afluentes del Duero, como el Pisuerga, el Esgueva, el Cega, el Adaja, etc., se encontraba un importante número de enclaves del Clero Regular. Pero, ¿cuáles eran los monasterios vallisoletanos más importantes?.

Según el informe de "Bienes Nacionales y Desamortizacion", contenido en la sección de Hacienda del A. H. N. de Madrid, habia en esta provincia unos 168 monasterios que tuviesen propiedades en ella, aunque su localización fuera a veces extraprovincial:

-92 establecimientos de Religiosos pertenecientes a 16 Ordenes.

-76 establecimientos de Religiosas perteneciéntes a 10 Ordenes(i4).

Estos monasterior se extendían por dos zonas diferenciadas de la provincia:

A) Los emplazamientos de la Tierra de Campos que se caracterizaban por 3 tipos de explotaciones:

- Los centros de Ordenes Mendicantes, con una importancia económica reducida, casos de la Santa Espina, Matallana, etc., iban unidas a las dos órdenes más antiguas: Bernardos y Benedictinos.

- Los Prioratos, Hijuelas y Granjas dependientes de otros monasterios que tenian una importancia destacable en el Norte de la provincia: Los Prioratos de Melgar y Saelices (dependientes de San Benito de Sahagún), la Granja de Béjar (dependiente del monasterio de Benavides), etc..

B) Los emplazamientos en la cuenca central del Duero, en los que jugó un papel destacable el cultivo de la vid: Aniago, Valbuena, Retuerta, etc..

Sin embargo un factor era común a ambos: los emplazamientos monásticos se dan bien en villas o ciudades, o bien en puntos bastante cercanos a un importante núcleo de población. Asi en Medina del Campo había 16 casas de Religiosos, en Valladolid 39 , etc., mientras que N. ${ }^{a}{ }^{2}{ }^{a}$ de la Mejorada estaba cerca de Olmedo, Aniago de Valladolid, La Santa Espina de Villagarcia de Campos, etc., etc. y esta localización estaba muy ligada a las ventajas que estos núcleos ofrecían para la comercialización de los productos agrícolas.

Estos 168 monasterios poseían 480 fincas urbanas y 2.950 fincas rústicas que ocupaban en su conjunto unas 47.950,35 has.(15). Sin embargo, dentro de éstos, destacaban 10 por su importante patrimonio inmobiliario:

-Orden de San Bernanrdo: La Santa Espina, Valbuena y Matallana.

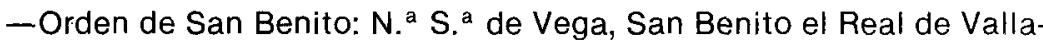
dolid y San Benito de Sahagún. 
-Orden de San Jerónimo: N. ${ }^{a}$ S. ${ }^{a}$ de la Mejorada y N. ${ }^{a}$ S. ${ }^{a}$ del Prado.

-Orden de Santo Domingo: Colegio de San Pablo de Valladolid.

-Orden de la Cartuja: Real Cartuja de N. ${ }^{a}$ S. $^{a}$ de Aniago.

Sólo estos 10 monasterios poseian el $45,22 \%$ del total de las tierras de todo el Clero Regular de Valladolid (unas $21.456,65$ has.), lo que equivale a decir que sólo estos 10 poseían cerca del $3 \%$ de la extensión de la provincia(16).

Si del análisis de la propiedad pasamos al de las rentas, la serie de monasterios privilegiados se reduciría a 7 que aparecen reflejados en la tabla número 3. Estos obtenían el $68,36 \%$ de los ingresos metálicos anuales de todo el Clero Regular; el 47,32 \% del total de las rentas de trigo y el $28,45 \%$ de las correspondientes a cebada. Por tanto, era el análisis de estos siete monasterios el que nos interesaba y, para la elaboración de un primer modelo, elegimos la Cartuja de Aniago por las siguientes razones:

1. ${ }^{\circ}$ Su situación en la confluencia del Duero y el Adaja, en la parte central del Duero a su paso por yalladolid.

2. En el siglo XVIII tenía jurisdicción en tres términos: los despoblados de Aniago y Torrepesquera y el término Redondo de Otea.

3. ${ }^{\circ}$ En este siglo el monasterio era mayor hacendado en 5 lugares: Aniago, Otea, Torrepesquera, Villanueva de Duero y Villalar.

4. ${ }^{\circ}$ Solo el P. B. de su hacienda de Villalar le convertía en el octavo mayor hacendado de la antigua provincia.

5. La Cartuja a la llegada de la desamortización aún poseía unas 2.000 has.

6. Por estas mismas fechas se encontraba entre los 7 monasterios más ricos de la provincía, siendo el máximo perceptor de rentas en trigo de Valladolid (el 5,5\% del total del Clero Regular).

A estos datos se unian dos no menos importantes:

a) Era la única explotación de la orden de la Cartuja en Valladolid.

b) Fue un monasterio de fundación tardia. En efecto, su creación en el siglo XV nos permitía seguir su historia desde su fundación a su desaparición en 1834. 
TABLA N. ${ }^{3} 3$

LOS MONASTERIOS MAS RICOS DE VALLADOLID A LA LLEGADA DE LA DESAMORTIZACION

\begin{tabular}{|c|c|c|c|c|c|}
\hline \multirow{2}{*}{ MONASTERIO } & \multicolumn{2}{|r|}{ R E } & $\mathrm{N}$ & A & \\
\hline & Metálico (Rs.) & Trigo & Morcajo & Centeno & Cebada \\
\hline La Santa Espina . . & 73.767 & 962,25 & - & 一 & 909,75 \\
\hline Matallana ..... & $108.853,76$ & 195,33 & - & - & - \\
\hline Valbuena ...... & 121.596 & 70 & - & - & 70 \\
\hline $\begin{array}{l}\text { Prioratos de San } \\
\text { Benito de Sahagún }\end{array}$ & 1.654 & $1.106,15$ & 一 & - & 36 \\
\hline N. ${ }^{a}$ S. ${ }^{a}$ del Prado.. & $284.318,58$ & 852 & - & - & 422 \\
\hline $\begin{array}{l}N^{a}{ }^{a} .^{a} \text { de la Mejo- } \\
\text { rada (Olmedo) ... }\end{array}$ & 60.059 & 757,93 & - & 55,83 & 36 \\
\hline N. ${ }^{a}$ S. ${ }^{a}$ de Aniago & 14.906 & 1.339 & 4,5 & - & 232,12 \\
\hline TOTAL & $629.154,34$ & $5.282,66$ & 4,5 & 55,83 & $1.705,12$ \\
\hline
\end{tabular}

BAREMO: Rentas superiores a 50.000 Rs. y/u 800 fanegas de Trigo al año.

FUENTE: Madrid A. H. N., Hacienda, Legajo 1.935.

Gracias al Catastro de Ensenada y a la mayor profusión documental del siglo XVIII, podemos presentar una primera visión del estado de la Cartuja de Aniago en su Edad de Oro.

A) El dominio de Aniago.-Situado al SE. de Valladolid y a pocos kilómetros de la ciudad, el despoblado de Aniago se caracterizaba por ser una doble explotación cerealistica y maderera. Su extensión era aproximadamente de unas 376,32 has.(17). La importancia de éste dentro de las haciendas del monasterio aparece reflejada en la tabla número 4 y en el mapa.$^{\circ} 1$. Se componía de una serie de tierras yermas (28 Obradas), 11 Obradas de riberas del Duero y de Adaja y una doble explotación: un gran pinar (llamado el Esparragal) y 70,73 has. de sembradura de primera y segunda calidad. Debido a su localización e irrigación estas tierras eran exepcionalmente productivas: el $80,8 \%$ de éstas eran de primera clase, con una productividad media anual de 1-2,4 en el trigo y de 1-3,2 en la cebada. El 19,2 $\%$ restante eran tierras de mediana calidad (productividad media anual de 1-2 para el trigo-morcajo)(18).

Estas tierras estaban sembradas de trigo, cebada, morcajo, centeno y algarrobas y a ello uniriamos una pequeña huerta, dentro de los muros del 
monasterio, en la cual estaban plantados diversos árboles frutales. La explotación del dominio era realizada directamente por los monjes, quienes contaban para ello no solo con los aperos necesarios y con la asistencia de cuatro mozos de labranza, sino también con 8 pares de mulas y 4 pares de bueyes de labranza(19).

Asimismo, los cartujos poseían una cabaña de importancia: 940 cabezas de ganado lanar ( 800 ovejas de vientre, 90 de "vacio" y 50 carneros) y 120 cabezas de ganado cabrío ( 95 cabras y 25 machos). Esta era completada con ganado caballar, empleado para las diversas faenas agrícolas, transportes, etc.: 18 yeguas, un caballo y 5 pollinos. El producto anual medio del esquilmo de los mismos fue estimado por los realizadores de $\mathrm{Ca}$ tastro en 8.497 Rs. de vellón al año(20).

El monasterio estaba perfectamente dotado en cuanto a instalaciones: poseía una panera que almacenaba el cereal producido en el dominio, una bodega con diversas cubas, cuya capacidad ascendía a 545,28 hectolitros (213 moyos) y diversas dependencias (establos, botica, horno, fragua..., etc.). En la actualidad aún se conserva el edificio de la Cartuja convertido en una granja de explotación ganadera. Rodeado de una muralla con dos entradas, poseia diversas alas de los siglos XV al XVIII, un claustro de estilo gótico tardío, una iglesia principal del mismo estilo y otra, de dimensiones más reducidas, del siglo XVIII.

B) El Factor Humano.-En la Cartuja vivian 60 personas que componían "la familia monásticas(21). Según M. Goldelier esta agrupación, cuya función era de carácter familiar, «funciona como unidad de producción y/o unidad de consumos(22).

La población de Aniago no siempre habia sido la misma. Al fundarse el monasterio éste poseía 24 religiosos y sus sirvientes(23). La hipotesis de Morete Velayos, sobre la correlación funcional entre las posibilidades económicas de cada monasterio y el número de componentes que la familia monástica podia soportar, queda en nuestro caso perfectamente demostrada: en efecto, en el siglo XVII, el número de religiosos había descendido oscilando siempre, a lo largo del mismo, entre 8 y 12(24). Para las fechas de realización del Catastro, el monasterio se encontraba de nuevo en una época de auge: en él vivían 17 monjes profesos, 9 legos profesos y 2 donados. Su estructuración interna se acomodaba a la concepción de la época: los donados y monjes legos trabajaban junto a los criados para que los profesos rezasen. ¿Qué nivel cultural poseían los profesos? Sin duda este era bastante alto para el siglo XVIII; en efecto, los cargos de padre Arquero, Procurador, etc., eran rotativos entre los monjes cada tres años aproximadamente. Ello quiere decir que todos ellos poseian conocimientos sobre contabilidad, explotación de tierras, etc. y no olvidemos que la Cartuja tenia una gran biblioteca(25). 
Las funciones más corrientemente desempeñadas por éstos eran: Boticario, Bibliotecario, padre Arquero (encargado de contabilizar todas las entradas de numerario del monasterio, tarea compleja puesto que existían diversos libros, correspondientes a cada partida-granos, vinos, censos, etc.-, de los que a final de año se sacaba un balance anual), padre Procurador (encargado de contabilizar y cubrir los gastos del monasterio de acuerdo a los presupuestos de Arcas), padre Procurador General (encargado de los asuntos básicamente relacionados con la explotación: asistir a apeos, realizar poderes, encargarse de representar a la comunidad en los pleitos, etc.) y por último el Prior, que no sólo se ocupaba de la dirección de las actividades religiosas, sino también de nombrar a los Arqueros, Procuradores, etc., etc.

Frente a los monasterios medievales, donde se producía una "inflación de las funciones improductivas, con un predominio de individuos parasitarios sobre la gente productoraw(26), la Cartuja de Aniago, en el siglo XVIII, presentaba una situación bien diferente: de los «32 criados que mantiene y paga" la mayoria realizaban funciones productivas. El Catastro regula asimismo el sueldo diario de cada uno:

-Un portero (3 Rs.).

-Un mozo que atendia a la Botica (1.100 Rs. al año). Esta servía para "la curación de sus enfermosn y, además, con sus productos se atendía a las necesidades de algunos pueblos cercanos. Producia una utilidad anual de 1.500 Rs.(27).

-Un sastre (4 Rs. diarios), encargado de confeccionar la ropa de los monjes, etc.

-Un herrero (4 Rs. diarios) que trabajaba en la fragua que la Cartuja poseia para atender a sus necesidades: herramientas, herraduras, ruedas, etc., etc.

- La labranza de las distintas tierras de sembradura se encargaba a un criado labrador (5 Rs. al dia) y 3 mozos de labranza.

- En la Panera trabajaban 2 mozos (4 Rs. cada uno).

- En las cocinas otros 4; 2 mozos de cocina 64 Rs. cada uno) y 2 mozos que asistían a la cocina de los criados (5 Rs.).

- Un barquero que atendia a la barca que los cartujos poseian para atravesar el Duero.

-Un pescador (3,5 Rs.).

-2 mozos espolistas (4 Rs.).

- El pinar era cuidado por un guarda (4 Rs.).

- El ganado era atendido por un guarda del ganado mayor (3,5 Rs.), tres zagales-para el cuidado del ganado lanar-(4 Rs.), tres rabadanes (mayorales de los zagales: 4,5 Rs.) y tres pastores mayorales (5 Rs.). 
- Las caballerizas eran atendidas por un mozo de establo (4 Rs.), "que administra el Puestto que tiene el dho. Monrio. para sus yeguas»(28).

Asi pues, nos encontramos con una unidad de explotación y consumo que tenía en sí misma solucionadas casi todas sus necesidades: no sólo existía una panera, una bodega, etc., sino que incluso la ropa era confeccionada en el propio monasterio. Esta unidad pervivio, aunque experimentando cambios sensibles en cuanto al número de sus componentes, hasta 1.835, fecha en que los liberales realizaron la supresión de la Cartuja y la subasta de sus posesiones.

C) Las Haciendas y su explotación. - Sin embargo la riqueza del monasterio no sólo se basaba en la explotación de una reserva latifundista, sino que además éste poseía haciendas en otras 14 entidades de población, repartidas entre las provincias de Toro, Valladolid y Guadalajara. Esta gran propiedad dominical "constituia la forma especifica de la unidad típica de producción feudal»(29). El mapa número 1 presenta cuál era el dominio de la Cartuja de Aniago en su momento de máxima expansión, que correspondería al cuarto tipo de la clasificación de Slicher van Bath, caracterizado porque sus posesiones se hallaban dispersas por numerosos lugares. En Valladolid sus propiedades se repartían según un esquema radial, a partir del monasterio, estando su crecimiento condicionado hacia el W. debido a la dificultad de adquirir tierras en las zonas vecinas a la ciudad de Valladolid, donde 39 monasterios competían por la adquisición de tierras. Asimismo, hacia el N., las dificultades en el crecimiento estribaban en traspasar las fronteras de las grandes Abadias clistercienses: la Santa Espina y N. ${ }^{a}$ S. ${ }^{a}$ de Matallana.

Este gran dominio disperso tenia como eje de expansión el valle del Duero, estando limitado por los ríos Cega, Adaja y Hornija. Las fincas rústicas aparecen relativamente concentradas en 14 lugares, villas, aldeas y despoblados: Aniago, Otea, Torrepesquera, Pedrosa del Rey, Villalar, Gería, Simancas, Villamarciel, Tordesillas, San Miguel del Pino, Villanueva de Duero, Viana de Cega, Valdestillas y Aldeamayor de San Martín. A ello hemos de añadir las propiedades procedentes de donaciones bastante alejadas de la región y de los intereses de la Cartuja, como un conjunto de pinares y tierras de sembradura en Pastrana. Al mismo tiempo el monasterio contaba con un conjunto de fincas urbanas que no sólo hacian aparición en los municipios mencionados, sino también en Medina del Campo, Valladolid, Madrid, etc. 


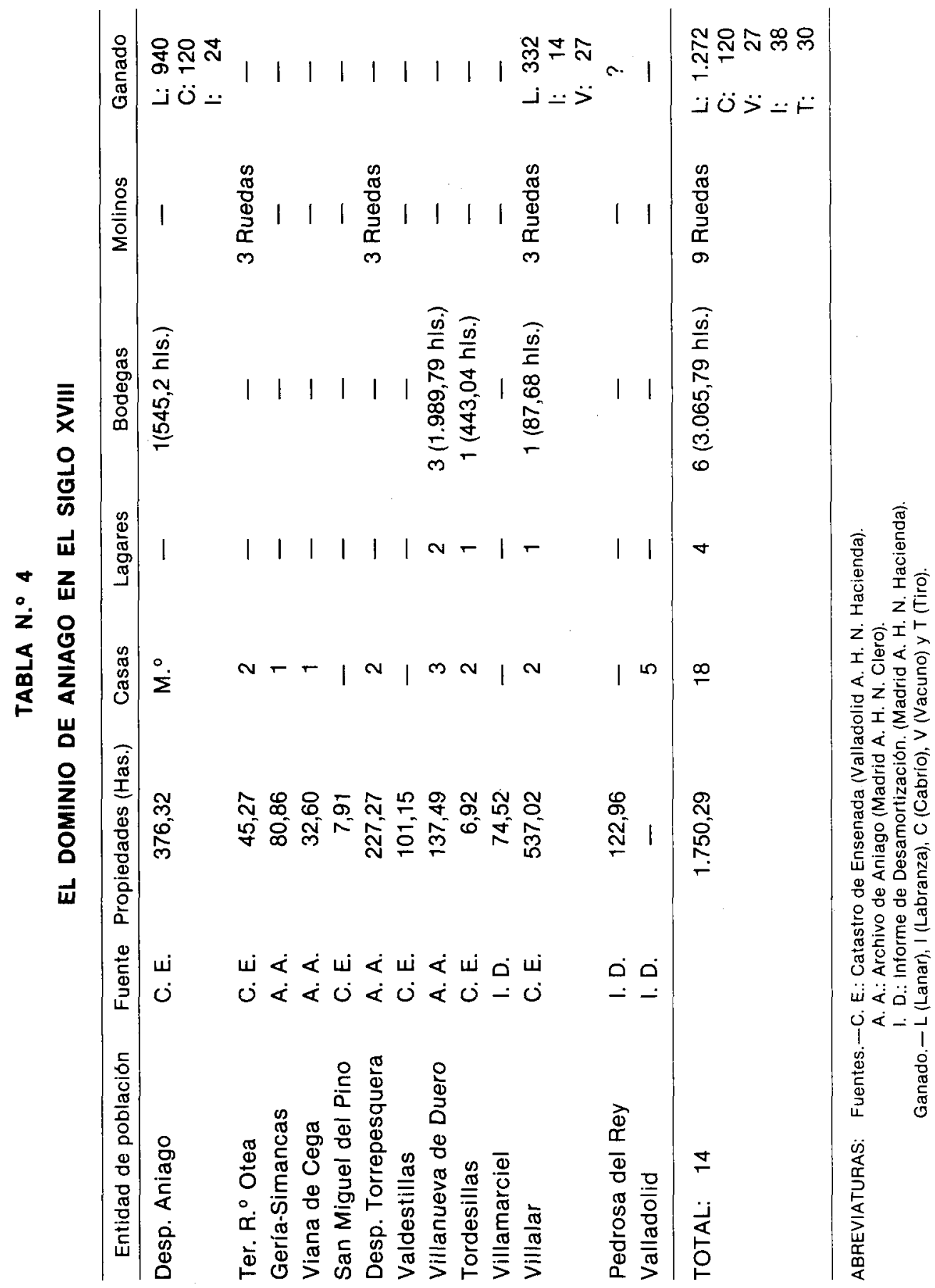




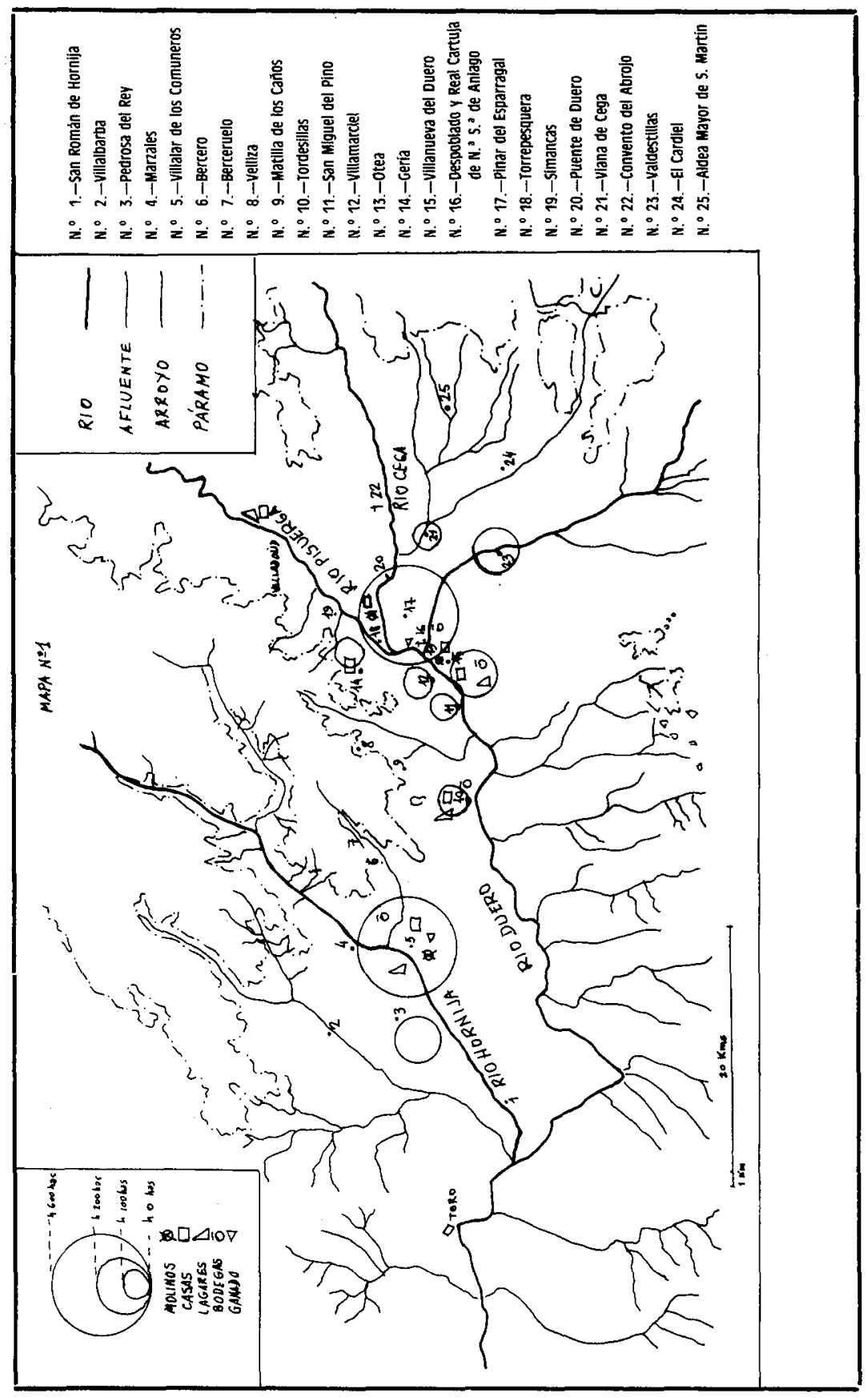


Cerca de la Cartuja existian dos granjas que eran explotadas directamente por los monjes:

a)-Otea.-Era un término redondo de Aniago cuyos orígenes se remontaban a la fundación de éste. Como se aprecia en el mapa, se encontraba situado entre el Adaja y Villanueva de Duero, siendo su extensión de 45,25 has. Dentro de él la Cartuja era el propietario absoluto. El $15 \%$ del término estaba compuesto por tierras de primera calidad (productividad media anual 1-2,4 para el trigo y 1-3,2 en la cebada); el 62,5\% eran de segunda calidad (productividad media anual de 1-2 para el trigo-morcajo) y el $22,5 \%$ restante estaba formado por tierras de tercera clase, en las que se cultivaba centeno (prod. media anual 1-1,6).

Era ésta una explotación cerealista de sembradura de secano por excelencia, cultivándose mediante un sistema de cultivos de año y vez, alternados con el barbecho.

Todas las tierras eran labradas por el monje administrador y sus criados, que vivian en dos casas de campo. Al mismo tiempo, esta granja contaba con 3 ruedas de Aceñas de 404 fanegas (380 de trigo y 24 de morcajo)(30).

b) - Torrepesquera. - En este despoblado el monasterio tenia jurisdicción, como en el caso anterior, aunque no percibiese derechos de ningún tipo. Se encontraba situado frente a Aniago, al otro lado del Duero. En su término se encontraban la granja de San José y la casa de la Huelga, donde residia el alcalde ordinario del término, nombrado por el monasterio, y que solia coincidir con el cargo de administrador de las aceñas.

Asimismo, el alcalde Mayor era nombrado por la Cartuja entre algunos de sus miembros destacados de la Chancilleria; por estas fechas lo era don Antonio Gutiérrez de Matallana, abogado de la misma(31).

El despoblado tenía 894 yugadas, de las que el 55,5\% pertenecía a la Cartuja. En ellas se daban cereales de secano (en cultivo de año y vez), zumacales y viñas (que producían sin intermisión). Aunque en el término habia otros propietarios, pues la Cartuja habia vendido una parte de la hacienda en el siglo XVI, ésta era sin embargo el mayor hacendado al poseer 227,27 has.; de ellas el $67,26 \%$ eran de sembradura, el $16,5 \%$ de vid, el $2,24 \%$ de zumaque y el $14 \%$ restante estaba cedido a censo enfitéutico.

Estas tierras se explotaban de dos formas: el monasterio realizaba la explotación directa de la sembradura, la vid, etc., que representaban el $86 \%$ de la hacienda, para lo que poseía una Granja en la que vivian un religioso lego y "sus mozos de labranza»(32); mientras que el $14 \%$ concedido a censo enfitéutico era explotado por los propietarios del dominio útil, quienes debían pagar una cantidad fija al año en reales(33): 4 Rs. por yugada de tierra, a la vez que Aniago se reservaba los derechos de «tanteo y 
veintenaw(34). En total se pagaban 31 foros perpetuos y el volumen anual de Rs. percibidos por los mismos era de 253,5(35). De otra parte, las aceñas de tres ruedas existentes en el término producian al monasterio 400 fas. anuales (75\% de trigo y $25 \%$ de morcajo).

Asimismo, al pertenecer a la Cartuja la parte del río Duero delimitada entre las riberas de Aniago y Torrepesquera, esta poseía una barca que dedicaba a la pesca. Esta actividad debio ser importante en los primeros tiempos del monasterio: en San José aún existían, por estas fechas, los restos de un gran estanque arruinado que había servido de depósito para la pesca.

Junto a estas dos granjas, la riqueza del monasterio se basaba también en la producción de dos explotaciones semidirectas:

$1 .^{\circ}$ Villanueva de Duero. - Esta villa era, para las fechas de realización del Catastro, un centro vitícola por excelencia en el que el mayor hacendado fue, desde el siglo XVII, el monasterio. En el término la Cartuja poseía 137,49 has. de las que el $70,78 \%$ estaban plantadas de viñedo y el $29,21 \%$ restante de cereales de secano. Los monjes realizaban la explotación directa de las vides, aprovechando para ello el gran número de jornaleros desocupados que había en la villa(36). Los cartujos tenían en Villanueva de Duero 3 casas, 2 lagares y 3 bodegas que reunían 40 cubas, con una capacidad de 1.989,79 hectólitros.

En cuanto a las tierras de sembradura, de las 71 obradas que eran cultivadas en rotación bienal, 18 estaban arrendadas a Manuel Lozano y al presbitero don Diego de Llanos, obteniendo cada uno de ellos una utilidad anual de 144 Rs.(37). El resto eran cultivadas por los propios monjes graneros que residían en la villa, destinándose una de las casas a servir de Panera.

Además la Cartuja poseía el beneficio del curato: ello le suponía pagar anualmente 1.036 Rs. al cura y al beneficiado de la iglesia-518 Rs. a cada uno-y además, anualmente se les entregaban 36 fas. de trigo para su mantenimiento y otras 12 para el sacristán.

La hacienda de Villanueva gozaba de una considerable autonomia, poseyendo su propio depósito de numerario. ¿Cuál era la contrapartida a los gastos anteriormente mencionados?. Evidentemente los diezmos, que estudiaremos en el apartado D.

2. ${ }^{\circ}$ Villalar.-Era un centro de producción cerealística por excelencia. La hacienda del monasterio se remontaba al siglo XV y, como veremos, se habia incrementado sensiblemente en el siglo XVII al absorber diversas haciendas. En esta villa el monasterio era el mayor hacendado al poseer 538 has., siendo ésta su hacienda más grande. La composición de las mismas era variadisima: la Cartuja tenía prados-el único del término 
de primera calidad era suyo-, eras, mimbrerales, zumacales, viñedos y un complejo de tierras de sembradura de secano compuesto por $1.646,25 \mathrm{fa}$ negas( ${ }^{(38)}$. En cuanto a los cereales, el $15,85 \%$ se sembraban en tierras de primera clase (trigo y cebada), el $61,71 \%$ en tierras de segunda calidad (trigo y cebada) y el resto, un $16,09 \%$ lo eran de tercera (en las que se sembraba centeno, avena, algarrobas, etc.).

No es de extrañar que la mayor expansión de Aniago se hubiera realizado allí. En efecto, el índice de productividad de estas tierras denota que eran éstas las mejores de la zona (por ejemplo, las tierras de primera clase tenian una productividad media anlual de 1 a 3 para el trigo y 1 a 3,3 para la cebada)(39).

Hacia 1750 , de esta hacienda se obtenia un P. Bruto de $2.392,75$ fas. de trigo, 1.140,75 de cebada, 216 de centeno, 146,75 de algarrobas, 12,75 de garbanzos, 11,25 de avena y 36 fas. de lentejas(40).

Esta economia se completaba con otras dos fuentes de riqueza: las vides, de las que existían 59,75 aranzadas plantadas (el $90 \%$ de primera clase), que producian anualmente unas $1.723,25$ cántaras de vino y la ganadería, puesto que la Granja poseía una notable cabaña compuesta por 332 cabezas de ganado lanar, 31 cabezas de ganado vacuno, 7 yeguas de cria y 14 animales de tiro (5 mulas y 9 bueyes $)^{41)}$.

Este patrimonio se cultivaba combinando la explotación directa y el arrendamiento. En efecto, del total de tierras que la Cartuja poseía, un $55,05 \%$ estaban cedidas en arrendamiento a diversos labradores:

$-120,75$ fas. estaban arrendadas a 4 vecinos de Bercero que pagaban de renta 30,75 fas. de trigo, regulándoles el Catastro una utilidad de 1.449 Rs. al año.

$-785,75$ fas. estaban arrendadas a 13 vecinos de Villalar que pagaban, en total, una renta de 237,16 fas. de trigo, regulándoles el Catastro una utilidad de 1.449 Rs. al año(42).

El resto de las tierras, un $44,95 \%$ sembrado de cereales, zumaque y vid, eran explotadas por monjes graneros. El monasterio contaba para ello con 2 casas en el pueblo: en una uhavitan los religiosos que se destinan para su administración", era la antigua casa del hidalgo Pedro Felíz, que poseia un pajar y un lagar, y en la otra se hallaba la Casa Panera, donde los renteros de la zona debían depositar las rentas el 15 de agosto. La dotación de esta granja era similar a las anteriores: era administrada por religiosos legos y, a su vez, había diversos mozos de labranza a los que añadiriamos, en ciertas épocas del año, diversos jornaleros contratados para las faenas estacionales. Para su trabajo disponian de 7 pares de animales de tiro.

A la vez se producía un curioso fenómeno: el monasterio actuaba 
como «Arrendador eclesiástico en tierras eclesiásticas». En efecto, la Cartuja labraba 5,5 fas. de tierra de la «testamentaduría de don Josef García de Zaballos" presbtero de Tordesillas, pagando de renta anual una fanega y 35 cuartillos, imputándosele una utilidad anual de 66 Rs.(43).

Para el depósito de vino, la granja contaba con una bodega de 4 cubetas de 87,68 hls. de capacidad. La Cartuja obtenía finalmente ingresos complementarios procedentes de dos fuentes: una renta anual de 200 fas. de trigo $2.400 \mathrm{Rs}$. de las máquilas ide sus tres molinos harineros, movidos por las aguas del Hornija, y 3.955 Rs. de los esquilmos del ganado.

Sin embargo esta hacienda no estaba libre de cargas:

1. La Cartuja pagaba un censo enfitéutico, sobre sus aceñas, de 6 fas. de trigo y 6 Rs. al año al concejo de la villa.

2. Asimismo, pagaba otras 60 fas. de trigo, en calidad de foro, al mayorazgo de Portocarrero.

El resto de las haciendas que Aniago poseía se caracterizaban por ser explotaciones indirectas, es decir que en ellas la Cartuja debía ceder las tierras en arrendamiento (las más) o a censo enfitéutico (las menos). Así nos encontramos con los siguientes casos:

- Geria-Simancas. - La Cartuja siempre agrupo las haciendas que poseía en los dos términos en una sola. En ellas tenía una casa y 80,86 has.: de éstas el $40,3 \%$ estaban dadas a censo o foro perpetuo; mientras que el resto, tierras fundamentalmente de sembradura de secano y zumacales, eran arrendadas cada 8 años.

No es posible evaluar las rentas, etc., que el monasterio percibía en estas dos villas, al haber desaparecido las respuestas Particulares de Eclesiásticos del Catastro de Ensenada de estos lugares(44).

- Viana de Cega. - Esta hacienda tenia su origen en una donación del siglo XVII y se componía de 5 pinares, 6 viñas y una casa, con un corral y un colmenar, ocupando todo el conjunto 32,6 has. Tal parece que la Cartuja no exploto estas tierras hasta bien entrado el siglo XVIII: a partir de 1.765 el monasterio reincorporó estas tierras a la explotación y, cuenta tenida que las cepas de los viñedos estaban deterioradas, Ilas sustituyó plantando majuelos, a la vez que realizaba una obra para reconstruir la casa(45). A partir de entonces se realizará una inversión sostenida en las vides. Si no es posible calcular la importancia de éstas en la economía de la Cartuja, o al menos dentro de sus propiedades vitícolas, si podemos afirmar que era ésta una explotación marginal y secundaria.

- San Miguel del Pino.-De nuevo nos encontramos aquí con una pequeña hacienda de carácter minifundista que debía proceder de una donación. Hacia 1752, el monasterio poseía allí 7,91 has. de sembradura: el 22,1 9 eran de primera calidad (productividad anual media de 1-2,5 en el 
trigo y $1-3,5$ en la cebada), el 5,2 \% era de segunda calidad y el $72 \%$ restante lo eran de tercera(46). Todas ellas estaban arrendadas a tres vecinos de la villa que pagaban una renta anual de 8 fas. de pan mediado y les producían una utilidad anual de 285 Rs. Era esta la hacienda menos importante de la Cartuja de aniago.

- Valdestillas. - La cantidad de tierras que el monasterio poseía en dicho término ascendia a 101,5 fas., todas ellas de sembradura: el 32,86\% eran de primera clase (productividad media anual de 1-2,4 en el trigo), el $44,19 \%$ eran de segunda calidad (productividad media anual 1-1,8 en el trigo y $1-2,8$ para la cebada) y, el resto, un $22,93 \%, 10$ eran de tercera (productividad 1-1,5 para el centeno, etc. $)^{(47)}$.

Todas ellas eran explotadas en régimen de arrendamiento por "Don Bernardos Sánchez Presbítero, Rosa Muñoz Chistobal y Jp. Sánchez vezinos de esta villa y la utilidad que por su industria y trabajo les resulta a los arrendatarios es la de seiszientos Settenta y Dos rs. y veinte y zinco Mrs. de Vellon al año...s(48). Sin embargo el informe no especifica la renta que percibia el monasterio. La única carga que pesaba sobre esta hacienda era de 150 Rs. de aniversarios perpetuos al año, "que se cumplen por la misma comunidad".

- Tordesillas. - Las propiedades que el monasterio tenia en el término eran de carácter netamente minifundista: La Cartuja poseía tan sólo 6,92 has. Las mismas se componían de 2 viñas (6,86 huebras), 2 pinares (12 yugadas) y 5,75 yugadas de sembradura de tercera clase. En esta villa, el centro urbano de mayor importancia del "dominio» después de Valladolid, el monasterio tenía 2 casas: una, en la plaza de San Pedro, se alquilaba por 330 Rs. al año y la otra, llamada "la Alondiga», que estaba a disposición de los monjes. La Cartuja realizará allí una reconversión de las tierras de sembradura en viñedo y, desde la segunda mitad del siglo XVIII, contará en el término de la villa con una pequeña explotación vitícola dotada de modestas instalaciones: un lagar y una mediana bodega, cuyas cubas podían llegar a almacenar 443,04 hls. De hecho en Tordesillas el monasterio comercializaba una parte de su producción en vinos.

Las propiedades descritas tenían una serie de cargas:

—Un censo de 11.000 Rs. de principal y 330 de rédito al año, a favor de la capellanía que disfrutaba Tomás Higueras presbitero de Velilla.

-Dos censos a favor de doña Catalina de los Ríos de 4.000 Rs. cada uno de principal, que, al $3 \%$, reditaban 240 Rs. al año.

- Un censo a favor de la Receptoría Parroquial de San Juan, de 200 ducados de principal y 66 Rs. de rédito(49).

- Villamarciel.-Poco podemos hablar de esta hacienda puesto que no poseemos ningún Apeo de la misma y el libro del Catastro de Ensenada, 
correspondiente a las Respuestas Particulares de Eclesiásticos, ha desaparecido. Por ello, hemos de suponer que la extensión de la misma sería similar a la que tenía en fechas proximas a la Desamortización: 74,52 has. de sembradura de secano que eran explotadas en régimen de arrendamiento, dato que conocemos gracias al Libro de Caja: en 1.735 procedian por este concepto de la misma 70 fas. de trigo, 63,5 de cebada, 3 de centeno, etc.(50).

- En la provincia de Toro nos encontramos con un caso muy similar:

Pedrosa del Rey, muy cercano a Villalar, donde el monasterio poseía una hacienda que ascendía a 122,96 has. en 1835. De ella no conservamos apeos, ni informes, etc., aunque sabemos que algunos se realizaron(51). Si la productividad de sus tierras era inferior a la de Villalar, su economía según las Respuestas Generales dependía fundamentalmente de los cereales, por lo que la estructura de la misma seria similar a la del caso anterior. Por los contratos sabemos que éstas eran arrendadas, en su mayoría, a vecinos de la misma y de Villalar, quienes pagaban una renta anual en trigo, de la que no es posible especificar su cantidad total para un año, debido a que poseemos series fragmentadas de estos contratos.

- En Valladolid el monasterio tenía 5 casas, que servían de almacenes para la comercialización del vino, donde vivían algunos religiosos.

-Finalmente la hacienda más alejada de la Cartuja era, sin duda, la que ésta poseía en Pastrana. Era la hacienda de adquisición más tardía y procedia de una donación y fundación de memorias de don Antonio de Bracamonte, antiguo tesorero y "dignidad que fue de la Santa Iglesia Cathedral de dha Ciudad (de Valladolid)»(52). En 1741 Aniago tomó posesión de la misma: se componía de 76,5 fas. de buena calidad, pues sólo dos eran improductivas y en su mayoría estaban situadas en la Vega de Abajo. Esta explotación fue la que más dificultades creó a la Cartuja que, finalmente, decidió nombrar un apoderado y arrendar las tierras, percibiendo la renta en metálico, siendo ésta la única excepción con respecto a las demás posesiones estudiadas. En 1789 fueron arrendadas por 8 años, a varios vecinos de Pastrana, en 1.200 Rs. al año(53). Es éste el único caso en que la Cartuja se comportó como un mero rentista.

Todas estas haciendas, salvo la última, aparecen reflejadas en el mapa n. ${ }^{\circ}$, que presenta la clasificación de las mismas en función de su tamaño (entre 100,200 y 600 has.) y en la tabla $n .^{\circ} 4$, que presenta u resumen de la situación de éstas en cada término.

D) Derechos Señoriales y Derechos Eclesiásticos.-El monasterio poseía una serie de derechos de caráter señorial que procedían de las compras que, en el siglo XV, había hecho el fundador de Aniago-don Juan de Cepeda, obispo de Segovia y Chanciller Mayor de Castilla-a la villa de Valladolid y al monasterio de Matallana, de los términos de la 
Cartuja, Otea y Torrepesquera. Sin embargo, el hecho de que estos lugares se despoblasen hizo que, prácticamente, estos derechos no se percibieran desde sus orígenes. Así, según la respuesta del monasterio al Apeo de Torrepesquera de 1753: "a mi parte pertenece el señorio vasallaje con Jurisdicción civil y criminal altta, vaja, mero misto imperio de la villa de Aniago la de Ottea y Torrepesquera regalias términos heredades de pan y vino coger aprobechamiento de Pesca y Río que por sus términos transita y así mismo en la villa de Villalar y sus términos le perteneze Casas tierras, molinos y otras heredadesw(54). Como recordaremos, la Cartuja solo nombraba Alcalde Mayor de Señorío y alcalde ordinario de Torrepesquera.

Muy diferente era, sin embargo, la situación de los derechos eclesiásticos y más concretamente de los diezmos y las primicias. El monasterio los percibía en muchos lugares, pudiendo ser éstos de tres clases según los diversos tipos de percepciones:

1.-Lugar en que la Cartuja percibía todo el diezmo.

2.-Lugares en los que el monasterio cobraba dos tercios del globo decimal y otros derechos eclesiásticos.

3.-Lugares en que sólo diezmaba a sus colonos un tercio del globo decimal.

1.-Entre los primeros destaca Torrepesquera. Este era el único de los tres lugares pertenecientes al dominio original donde cultivaban tierras otros propietarios y foreros del monasterio. En él, los diezmos eran la principal base económica que, junto a las explotaciones directas, completaba la falta de rentabilidad de los censos enfitécuticos: en efecto, el forero pagaba 4 Rs. por yugada, pero al ser el dominio eminente del monasterio habia de pagar el diezmo completo.

Según la Respuesta General n. ${ }^{\circ} 15$ del Catastro estos diezmos se componian de:

-10 fanegas de cualquier especie.

- 10 cargas de uva.

-10 arrobas de zumaque.

Sin embargo las primicias eran percibidas de dos maneras diferentes: los foreros las pagaban al monasterio, mientras que los vecinos de otros lugares, con hacienda en Torrepesquera, las pagaban een su lugar de vecindad $2(55)$.

2.-Entre los segundos destaca el caso de Villanueva de Duero. En esta villa Aniago poseía el Beneficio del Curato y de la Fábrica de la Iglesia. En la práctica, ello le suponía percibir dos tercios del globo decimal y apropiarse de todas las primicias del tercio restante. En general, el nombramiento del cura, del sacristán y del mayordomo de fábrica no sólo suponía ventajas, pues, como vimos en el apartado anterior, la Cartuja debía pagar 
a éstos todos los años. También corria por cuenta del monasterio reparar los edificios de la Iglesia y dependencias anexas. Sin embargo, del siglo $X V$ al XIX, la Cartuja tuvo que pleitear con los Obispados que pretendian absorber el beneficio. ¿Por qué?. Si observamos la gráfica número 1, que presenta la cosecha-tipo de Aniago para la primera mitad del siglo XVIII, nos encontramos con un hecho sorprendente: la mitad de la cosecha de vino de la Cartuja procedia de los diezmos y primicias. En efecto, de las 6.101 cántaras recogidas, 2.504 procedian de las tercias de Villanueva, lo que casi equivalia al total de la cosecha de vino que los cartujos recogieron ese año en Torrepesquera, mientras que en concepto de primicias se recogieron 3.597 cántaras, de las cuales casi un $75 \%$ procedia de Villanueva de Duero(56).

No es de extrañar que cuando en 1.806 el obispo de Valladolid separó al.monasterio de este beneficio, éste se lanzase a una serie de pleitos que llegaron incluso a la Cámara Real en 1817(57). Como consecuencia de esta pérdida la vid dejó de ser la primera fuente de riqueza de la Cartuja.

En cuanto a los cereales, en 1735, los diezmos y primicias de Villanueva suponían 200 fs. de trigo, 82 de cebada y 208 de centeno. Compárense estas cantidades con las rentas que, ese mismo año, procedían de dicha villa: 19 fas. de trigo, 14 de cebada y 3 de centeno(58). La Cartuja había logrado tal imbricación con los pequeños propietarios que éstos anualmente le suministraban su principal fuente de ingresos.

3.-Entre los terceros destacan una serie de pueblos: Villamarciel, Gería, Valdestillas, Villalar, etc. En ellos el monasterio sólo podía diezmar de sus colonos y en algunos, como Villalar o Pedrosa del Rey, diversos choques con el obispado de Zamora, le habían obligado incluso a restringir el crecimiento de su hacienda si quería seguir diezmando. En Villalar, por ejemplo, la Cartuja sólo podia diezmar uno de cada treinta, es decir una tercia. En conjunto, la situación para todos los lugares se refleja asimismo en la gráfica $n .^{\circ}$, en su primer apartado: los cereales. Los diezmos y primicias del trigo suponían 228,75 fas. de trigo, frente a las 217,5 procedentes de las rentas(59). Esta proporción disminuye en la cebada (80 fas. de diezmos frente a las 217 procedente de las rentas). Sin embargo, toda la cosecha de avena, algarrobas, garbanzos y guisantes tenía su origen en los derechos eclesiásticos de Aniago: por tanto, en la práctica, gracias a ellos se producia una diversificación de alimentos en el monasterio, puesto que, al basarse la política de rentas de la Cartuja en el trigo, lógicamente los ingresos decimales de este tipo se destinarian al consumo interno de la comunidad y de sus ganados. 


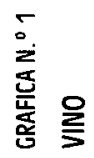
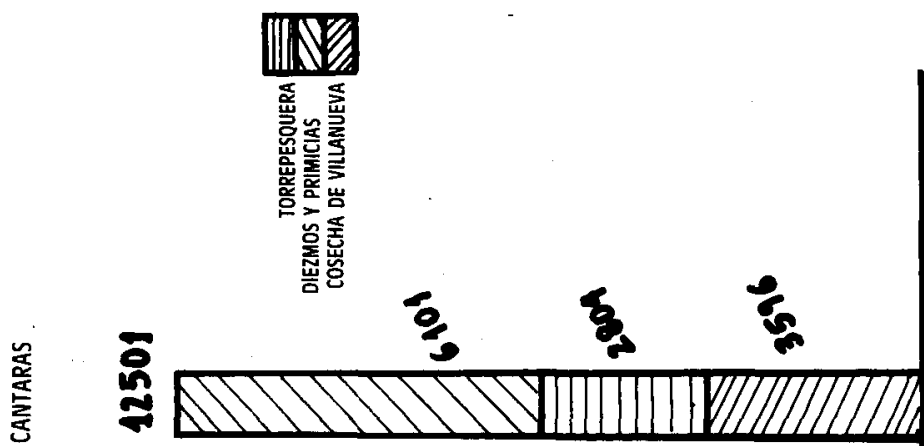

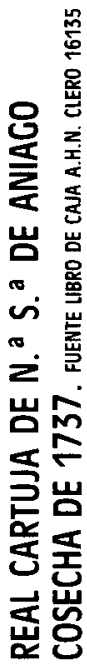

崫
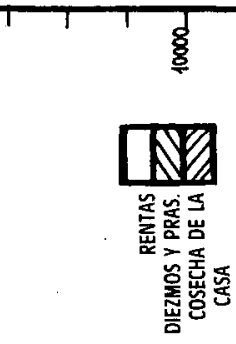

悹 NVA

㟧

突吉芯
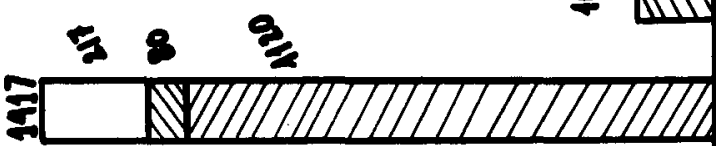

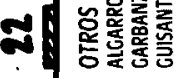
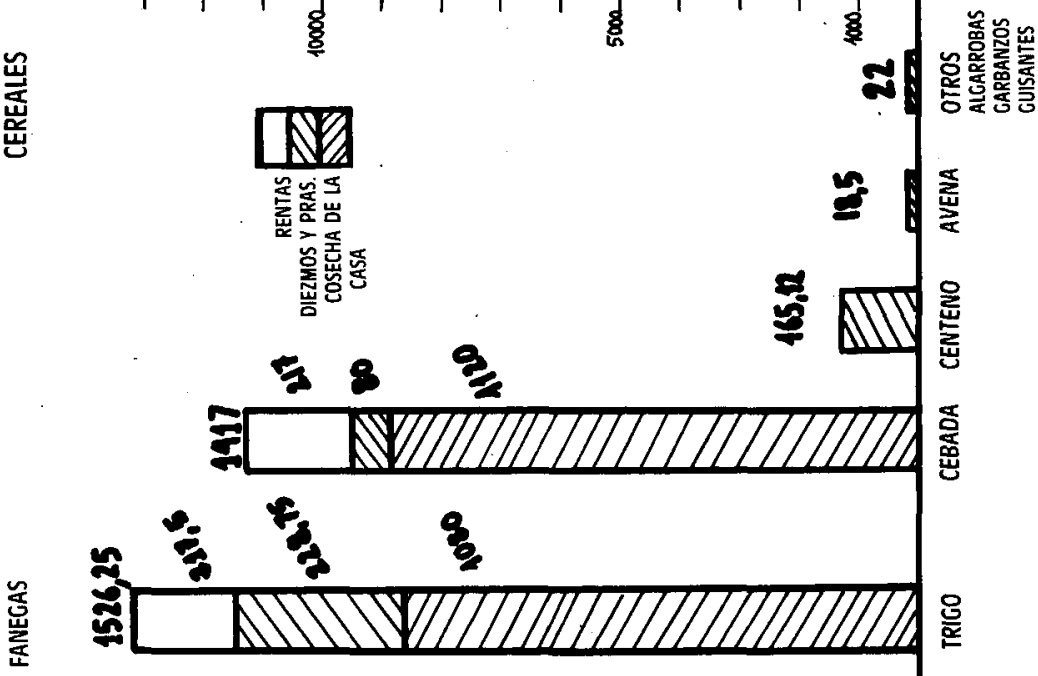
E) Juros y Censos: Además de los conceptos anteriores, la riqueza de Aniago se basaba también, en menor medida, en el disfrute de los réditos de una serie de juros y censos.

En cuanto a los primeros, éstos fueron concedidos por la Corona en el siglo XV, para ayudar a la sustentación de los monjes hasta que éstos pusieran en explotación las haciendas recién adquiridas. Su pago siempre creó problemas a los cartujos a lo largo del siglo XVI y, en el siglo XVII, ante el desplome de las rentas, como consecuencia de las malas cosechas, éstos se vieron obligados a reclamar su pago a la Corona. Por ello en pleno siglo XVIII, una vez superada la crisis, el monasterio aún percibia los siguientes juros:

1.-Un juro de 50 Rs. y 28 maravedis sobre las alcabalas de Valladolid.

2.-Un juro de 882 Rs. y $14 \mathrm{mrs}$. sobre las alcabalas de Madrigal.

3.-Un juro de 434 Rs., sobre las alcabalas y Servicio Ordinario del Campo de Clatrava.

4.-1.664 Rs. y $14 \mathrm{mrs}$. de juro anual, contra los Puertos Secos de Castilla (Salinas de Zamora, etc.)(60).

Si exceptuamos este último caso, destacaba la falta de interés de los mismos dentro de la economia del monasterio. Otro tanto sucede en el caso de los censos: para 1751 la Cartuja tenia movilizado un capital de $52.032,16$ Rs., percibiendo anualmente $1.541,46$ Rs. por sus réditos. Por el contrario, por estas mismas fechas, había pedido prestados 109.200 Rs., pagando unos intereses de 3.067,34 Rs. al año(61). Por ello, estos ingresos tenian una importancia mucho menor que los procedentes de las haciendas o los diezmos y, en su conjunto, nunca llegaron a superar el $10 \%$ de las entradas generales. Solo las crisis de subsistencias lograrán realzar un poco su importancia a finales de siglo.

Conclusiones: Como hemos visto en los apartados anteriores, la riqueza de Aniago procedia fundamentalmente de dos conceptos: el P.B. de sus haciendas (ya fuera éste agrícola o ganadero) y los diezmos. Para los años del Catastro podemos llegar a una aproximación sobre el total de sus propiedades que constituian, en definitiva, su principal fuente de riqueza. Hacia 1751 , la Cartuja poseia $1.750,29$ has. en las provincias de Toro y Valladolid que dedicaban a cinco tipos de aprovechamientos: cereales de secano, viñedo, zumaque, pastos y madera (pinares). Estas propiedades se repartían por 14 lugares, en los cuales el monasterio tenía, además, $18 \mathrm{ca}$ sas, 4 lagares, 6 bodegas-que podian llegar a almacenar 3.065,8 hls. - y 9 ruedas de aceñas, amén de una cuantiosa cabaña: 1.272 cabezas de ganado lanar, 120 de cabrio, 27 de vacuno, 38 de labranza y 30 de tiro. Todo ello convertía a la Cartuja en uno de los mayores hacendados provinciales, sobre todo si se tiene en cuenta la estructura típicamente minifundista de 
Valladolid. Esta privilegiada situación hacia que tuviera una gran influencia sobre las economías campesinas. Pero, ¿cómo se adaptaba el monasterio a las comunidades rurales?.

\section{Monasterio y Sociedad Rural.}

El siglo XVIII nos presenta la culminación de un proceso de adaptación de los monasterios a las economias campesinas. Por estas fechas, la Cartuja confluye én su dominio central, situado al SW. de la ciudad de Valladolid, con otros monasterios como la Santa Espina, N. ${ }^{a}$ S. ${ }^{a}$ del Prado, Santa Clara de Tordesillas, etc. y éstos, unidos a miembros de la nobleza o a entidades como los concejos, ejercerán un papel de primacía.

A. La Población y los recursos: Toda la zona de influencia de la Cartuja de Aniago era eminentemente rural. Según las Respuestas Generales del Catastro de Ensenada vivían en ellas unos 1.500 vecinos que, repartidos en 10 entidades de población, representaban el $2,4 \%$ del vecindario total de la provincia(62). Esta zona era de las más ricas de Valladolid, puesto que soportaba una densidad de población de 150 vecinos por entidad, frente a la densidad media a nivel provincial que era de 96 vecinos por núcleo poblacional(63). De acuerdo a la clasificación de $O$. Quelle, se distinguían dos tipos de emplazamientos:

1.-Las aldeas y villas instaladas en tierras cercanas a los valles: Villanueva de Duero, Villalar, Tordesillas, etc.

2.-Las poblaciones situadas en tierras de transicion entre el valle y el páramo: eran justamente aquellas que tenian peores recursos naturales $y$, por consiguiente, soportaban una menor población: Villamarciel, Gería, etc.

Esta población se encontraba, hacia 1751, en plena recuperación demográfica: Sin embargo, el empuje de las clases privilegiadas en el siglo XVII, habia modificado sensiblemente la distribución de los recursos regionales. Así, ciertas villas entraron en una recesión permanente, mientras que otras se estancaron en su crecimiento debido a que las cargas de la Corona, etc., que ahora pesaban sobre un número menor de vecinos, eran demasiado fuertes, sobre todo si se tiene en cuenta que los "encabezamientos" se habían hecho en una época, para una población y una distribución de los recursos diferentes. Esta situación ha sido constatada por diversos autores; asi Garcia Sanz opina que la causa de la despoblación estribaría en la contradicción entre unas cargas fiscales en constante progresión, a lo largo del siglo XVII, y una población y producción agrarias cada vez más menguadas(64). De otra parte, Domínguez Ortiz ha relacionado la depoblación con la ocupación de tierras por parte de las clases privilegiadas: así, en el caso de Talamanca, en la que la_Cartuja del Paular llegó 
a tener una gran preeminencia, la población disminuyó: en 1621 tenía 214 vecinos y para 1767 sólo 70 . Entre ambas fechas la propiedad monástica había crecido sensiblemente(65).

Ambas situaciones y en general la despoblación, de la que ya no se recuperaría Castilla, pueden ser medidas en el Catastro por dos indicadores:

1.-Las quejas de los pueblos por el excesivo encabezamiento de impuestos que padecian: así en Pedrosa del Rey, el Común pagaba en concepto de servicio ordinario, extraordinario, sisas, etc., 6.799 Rs., "considerando respecto a lo calamitosos de los tiempos hallarse grabado en mas cantidad de la que pueden pagar»(66).

2.-El número de casas inhabitables o arruinadas que se especifican, para cada lugar, en la Respuesta General n. ${ }^{\circ} 22$. Por ejemplo en Pedrosa del Rey eran 24 las casas arruinadas, mientras que en Simancas esta cifra se elevaba a $100(67)$.

Sin embargo, los recursos naturales de la región, junto al auge de las roturaciones, permitian el crecimiento poblacional que se producirá en la segunda mitad del siglo XVIII. En efecto, los 13 términos en los que la Cartuja tenía posesiones poseian una extensión de $27.155,44$ has., con un porcentaje medio de tierras productivas del $80 \%(68)$. En ellas se daban preferentemente la sembradura de secano (trigo, cebada, etc.), el viñedo, los pastos y los recursos madereros y, en menor medida, el zumaque, los árboles frutales, los mimbrerales, etc. Como ya hemos dicho población y recursos naturales estaban íntimamente relacionados: Así Tordesillas y Villalar poseían los términos municipales más grandes de la zona con $8.796,88$ y $4.032,16$ has. respectivamente. Por ello, no es de extrañar que contasen con mayor vecindario que el resto de las poblaciones. Sin embargo, en tordesillas, al estar la propiedad de la tierra más distribuida entre los diversos estamentos, la población era más numerosa que en Villalar (150 vecinos), donde la Cartuja de Aniago poseia una parte considerable del término municipal. Por el contrario Viana de Cega era la villa que menos extensión de tierras productivas tenia, un 67,54\% de 946,97 has., lo cual se reflejaba en su población: era también una de las más bajas de la zona con 17 vecinos $(70)$.

En su conjunto de estas $27.155,44$ has. situadas en la cuenca central del Duero, la Cartuja de Aniago poseía un $6,67 \%$ y este porcentaje era, en la práctica, la base de su hegemonía. ¿Por qué?

B) Atraso tecnológico y Minifundismo. - Es característico de las sociedades rurales en el Antiguo Régimen el que la producción de cada zona se hiciera en función del único mercado existente: el mercado local. Por ello, la producción de cada término se enfocaba de cara a lograr el mayor grado de autoabastecimiento posible dentro de los diversos productos 
agrarios. Sin embargo, existía un atraso tecnológico notable en cuanto a las técnicas de explotación de la tierra. En efecto, mientras que en el siglo XVIII se implantan en Inglaterra los métodos de cultivo intensivo de alternancia de tres y cuatro hojas, como consecuencia de lo que algunos autores han denominado "segunda Revolución Agraria», en España en general, y concretamente en la zona que nos ocupa, la mayoria de los cultivos eran de "año y vez" o rotación bienal: en ellos el barbecho tenía su primacía al ocupar el $50 \%$ de las tierras de sembradura, produciéndose tan sólo dos excepciones:

- Los herrenes o tierras de sementera de cereal para segar en verde; solian ser tierras de primera calidad que daban cosecha todos los años. Su número era muy reducido si se les compara con las tierras de pan llevar.

- Los viñedos que, por sus características, daban una cosecha anual.

De cara a la producción, este atraso tecnológico sólo era compensado por unos tipos de suelo muchas veces notablemente ricos. Las productividades más altas se daban en Villalar-unos 10,8 hls./ha. para el trigo en la sembradura de primera clase-y ello explica el que fuera precisamente allí donde la Cartuja tuviese su hacienda más importante. A la productividad de esta villa seguian las de-Villanueva de Duero, Aniago, etc.(71).

En cuanto a la vid, de nuevo las tierras de mejor calidad se encontraban en las márgenes de algún río importante: el Duero (Torrepesquera y Villanueva de Duero-11,6 hls./ha. en las tierras de primera clase-) o el Hornija (Villalar); en ellas se obtenía el mayor número de cántaras de vino por aranzada(72).

Sin embargo, algunos ejemplos excepcionales nos demuestran ciertas mejoras en las técnicas agrarias regionales, aunque éstas no serăn suficientes para paliar una economía de subsistencia:

1.-En la respuesta $n .{ }^{\circ} 12$ de Villalar se constata una cierta alternancia de cultivos que, indudablemente, beneficiaba a los sueldos: «les constta que para que la mejor Produzión de los fruttos de las tierras de Primera y. Segunda Calidad y que en las desta villa no ai tterzera expezie de siembra, es preciso altternar.en ellas unas bezes ttrigo y ottras zebadas(73).

2.-En otras zonas empezaba a ser común el «sacar los cultivos de ojan: asi en los contratos de arrendamiento de la Santa Espina se especificaba que los campesinos pagarán el diezmo de las lentejas, que éstos solian sembrar en las hojas de barbecho, si las cultivaban fuera de año(74).

El segundo impedimento que incrementaba esta baja productividad era un régimen de propiedad acusadamente minifundista. En efecto, el minifundio ha sido uno de los problemas más importantes que han tenido, y aún tienen, Castilla la Vieja, León y Galicia. En nuestra zona, cada municipio tenía su término completamente fragmentado en un gran número de 
pagos, pertenecientes a un sin fin de propietarios de los diversos estamentos. Como ejemplo introductorio, piénsese que la hacienda de la Cartuja de Aniago en Villalar, de 537,02 has., se componia de unas 231 parcelas de diferentes tamaños, la mayoría de las cuales no superaban las 1,53 has., que eran arrendadas por quiñones o explotadas directamente y que procedian de las compras, "ejecuciones", etc., hechas a un cuantioso número de anteriores propietarios.

Para una primera aproximación, el "Informe del Mayor Hacendado" nos revela hasta qué punto este minifundismo se encontraba desarrollado. En Villamarciel, el mayor hacendado era el colegio de. San Gregorio de Valladolid, que incluso poseia carta de vecindad. Su hacienda, la mayor del lugar, se componia de 98,02 has. que representaban el 7,1\% de las tierras del término(75). En Valdestillas, el presbitero Mateo Muñoz era el mayor hacendado con 156,98 has., que suponían el 5,5\% del término municipal. Estos "grandes hacendados" se van progresivamente reduciendo, en cuanto al porcentaje de sus posesiones con respecto a los totales municipales, en otros términos: Por ejemplo, en Gería don Manuel Velasco Valero era el mayor hacendado con 41 has., es decir el 4,33\% de la extensión del término; mientras que en Tordesillas, siendo el mayor hacendado el Concejo de la Villa, con 249,07 has., èste sólo poseía el $2,83 \%$ del total del término(76). Sin embargo, un hecho era común para todos: todas sus haciendas estaban divididas en un gran número de parcelas que, en la prácitica, dificultaban su explotación y disminuian sus rendimientos.

Si de estos breves datos pasamos al análisis de un término concreto, este minifundismo se nos perfila aún más. Así, en Torrepesquera, cuyo término poseía una extensión de 416,42 has., la Cartuja de aniago era propietaria del $55,5 \%$ de las tierras. Para fechas próximas al Catastro, el monasterio hizo una pequeña encuesta sobre los vecinos que poselan heredades en Torrepesquera, dividiéndolos por vecindades de origen y, dentro de éstas, por su adscripción o no a la condición de foreros. De este informe resulta que un $8,3 \%$ del término estaba repartido entre 62 propietarios directos, al ser sus dueños, o indirectos, al poseer el dominio útil de las parcelas dadas a censo enfitéutico. Si el número resulta sorprendente, aún lo es más el tamaño medio de sus parcelas: $0,5 \%$ has. por propietario 77 ).

Por ello el minifundismo se constituia en uno de los problemas más importantes de la región, generando una serie de problemas básicos que influian en la producción:

1.- «El principal inconveniente de ese parcelamiento excesivo es el tiempo empleado en ir de una parcela a otra para realizar las faenas agrícolas w 78 .

2.-A la vez, se produce un proceso de pérdida de superficies útiles por lindes, que crece a medida que disminuyen las superficies de las parcelas. 
De esta manera, el atraso tecnológico y la excesiva parcelación, condicionaban una agricultura que muchas veces sólo podía cubrir las meras necesidades de subsistencia. Unicamente los grandes propietarios, como la Cartuja, estaban en disposición de poder comercializar los excedentes.

Sin embargo, a lo largo de los siglos, se había producido una adaptación, derivada de la coexistencia, entre estos grandes propietarios y los minifundistas: Por ello en este siglo aistimos a unas relaciones de complementariedad económica entre unos y otros. ¿Cuáles eran sus principales caracteristicas?.

C) La potenciación de la pequeña propiedad y el papel estabilizador del monasterio. - La Cartuja de Aniago se hallaba perfectamente imbricada, a todos los niveles, con la comunidad rural que constituía su soporte. Así, la organización de la unidad monástica respondia a la estructura autárquica de la mayoria de los pueblos castellanos. Su producción se destinaba a cubrir las necesidades de los monjes y, sólo después de realizar esta función, a la comercialización. El monasterio de Aniago, en concreto, poseía dentro de sus muros todos los servicios que, a pequeña escala, habia en Geria: tenia su fragua, una bodega, una botica, una sastreria, un horno-panaderia y, además, toda una serie de criados, etc., que cumplian las funciones de pastores, labradores, molineros, etc.

A la vez, el monasterio era consciente del papel que en su economía jugaban los pequeños labradores: éstos, al poseer extensiones de tierras insuficientes, se veian obligados a trabajar para Aniago. Su crecimiento numérico no podía más que reportar beneficios para los monjes $y$, a este respecto, un ejemplo llama poderosamente nuestra atencion: el caso de Villanueva de Duero. Fundada en tiempos de la Repoblación, esta pequeña aldea basó su economía en los siglos XV y XVI en los cereales, como el resto de los pueblos del partido de Olmedo. En ella, el monasterio tenía fuertes intereses económicos derivados de la posesión del beneficio del curato, que le hacia disfrutar de $2 / 3$ del globo decimal, y de una importante hacienda que fue incrementando a lo largo de los siglos. A partir de 1590 y como consecuencia de la crisis economica generada por las malas cosechas de cereales, Aldenueva inició una sustitución de cultivos. Si no poseemos documentación suficiente para analizar pormenorizadamente el tránsito del cultivo del cereal al del viñedo, para todo el pueblo, sí disponemos de un valioso indicador: la propia evolución de los cultivos de la hacienda de Aniago, que se produjo paralelamente a la anterior y que queda reflejada en la gráfica número 2 . Si en 1590 la vid estaba por debajo del cereal, a partir de entonces se aprecia una progresiva sustitución de éste en beneficio de aquella: hacia 1739 este proceso había concluido(79). ¿Cuáles fueron los resultados más importantes del mismo?. En primer lugar, la población de Aldeanueva no disminuyó sino que, por el contrario, se incrementó en el siglo XVII hasta el extremo que, a finales del mismo, la aldea se había con- 


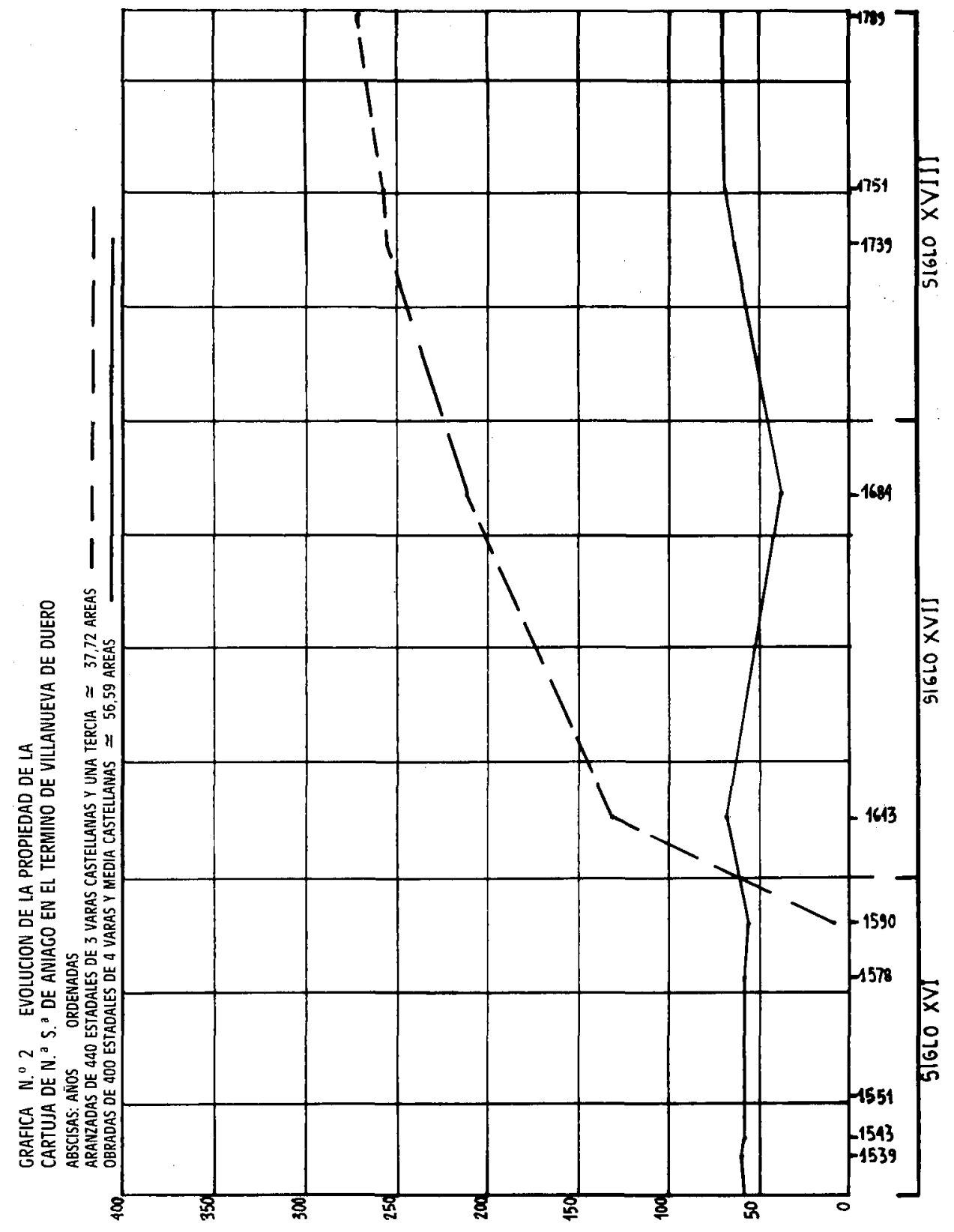


vertido en una villa. En 1751 Villanueva de Duero era uno de los centros viticolas más importantes de la región y, en ella, el viñedo ocupaba más del $30 \%$ de las tierras productivas del término.

Sin embargo, como ha desmostrado Martiniano Peña Sánchez, el viñedo era un cultivo sustentado por la pequeña propiedad y ello explicaría en proceso anterior. Asi, "las reducidas dimensiones (de la pequeña explotación) no son suficientes para emplear toda la capacidad de trabajo de la familia campesina", por ello este cultivo se presenta, en primer lugar, como una forma de ocupación de la mano de obra. Además, permite sacar el máximo partido a las tierras poseídas, puesto que la vid tiene unos rendimientos superiores al cereal y tolera la utilización de las tierras de peor calidad. A estas razones hemos de unir dos no menos importantes: dar una mayor seguridad económica al producir todos los años y dejar un valioso tiempo libre, justamente en la época de la siega, en el que es más fácil trabajar a jornal(80).

Para el monasterio, las ventajas de esta reconversión eran evidentes: de una parte, esta cuantiosa producción vitícola le permitirá obtener unos diezmos y primicias que, como hemos visto, suponia el $\mathbf{4 0} \%$ de la cosecha de vino y de otra, este incremento de los pequeños propietarios, le beneficiará al obtener una mano de obra sobrante que podria emplear anualmente en sus viñedos y explotaciones directas de cereal. Sólo los medianos y grandes labradores podrán aspirar a arrendar aquellos quiñones de tierras que los cartujos no podian explotar.

En esta situación, la Cartuja se comportaba como un estabilizador de estas comunidades: así, en los momentos de crisis o de malas cosechas, son frecuentes los préstamos a labradores por parte del monasterio. Ello le permitirá, como veremos, incrementar notablemente sus posesiones en el siglo XVII. Al mismo tiempo, el monasterio respeta las tradiciones de estas comunidades rurales y potencia aquellas que le son más útiles: tal es el caso del "derecho de trato", que no sólo nos aparece en Castilla, sino también en Picardía y Flandes(81). Por éste, el monasterio daba prioridad en el arrendamiento de un quiñón al anterior arrendatario. A finales del siglo XVIII, la propia competencia entre los labradores hará que éstos ofrezcan una renta más elevada en cada renovación, como consecuencia de la inflación, lográndose asi otro de los objetivos de los monjes: de la profusión de labradores la Cartuja obtendria un incremento de la demanda de tierras arrendables que sólo podría redundar en su propio beneficio. En definitiva, en la debilidad de estos pequeños y medianos propietarios residia su fuerza. Por tanto, esta situación sería típica de «las estructuras sociales precapitalistas en las cuales los campesinos operan preferentemente como pequeños productores, dotados de parte o de la totalidad de los medios productivos, y se encuentran en relaciones diversas de dependencia personal, consuetudinarias o contractuales con relación a la gran propiedad agraria 
socialmente dominante y frecuentemente caracterizada por pretensiones y comportamientos señoriales»(82).

A la vez estos monasterios contaban con otros dos poderosos resortes de poderío económico: el control de la producción y el de la comercialización.

D) El control de la producción y la comercialización.-Junto a los factores anteriormente mencionados, este monasterio basaba su privilegiada situación en la obtención de unos excedentes comercializables, únicos capaces de asegurar una inversión en las tierras explotadas directamente y la compra de otras nuevas que pudiesen incrementar "el dominio". De lo señalado anteriormente se desprende que sólo los grandes monasterios, algunos nobles y labradores ricos, podian comercializar sus excedentes, puesto que la mayoria de los campesinos dedicaban la producción del terrazgo a satisfacer sus propias necesidades. Sin embargo, el Clero Regular contaba con grandes ventajas no sólo a la hora de obtener mayores excedentes-como los procedentes de nuevas tierras donadas por la Corona o algunos particulares -, o por el hecho de no pagar los mismos impuestos que el Tercer Estado, etc., sino que también tenía una situación excepcional a la hora de comercializarlos, lo que hacía que influyese también en los precios.

1.- Todo monasterio, mediante la percepción decimal, conocía anualmente cual había sido la producción de cada término y, por consiguiente, en qué sitios del dominio era más ventajosa la venta de granos. A su vez, para el control de los diezmos contaba con dos poderosas armas: los padres granjeros que supervisaban la siega, la recolección, etc. y sobre todo con el monopolio que, junto a la nobleza, detentaban sobre los principales medios de producción producidos: los molinos. La tabla ${ }^{\circ}{ }^{\circ} 5$ presenta el número de los existentes en la zona y quiénes eran sus propietarios:

-De la misma se desprende que todos estos ingenios harineros eran aceñas, es decir, que aprovechaban la energía del Duero y sus afluentes para su funcionamiento.

- Todos los propietarios eran monasterios o nobles. Estos dos componentes de las clases privilegiadas son, por tanto, los que poseen no sólo el monopolio de la molienda, sino también un control estacional de la oferta general de granos de la zona. En esta situación es fácil entrever una influencia decisiva de la oferta de granos de Aniago en determinados términos como Villalar, etc., y, por tanto, la presión que los monjes podrían ejercer de cara a la obtención de unos precios favorables.

2.-En segundo lugar, las paneras de Aniago, etc., son las únicas de la zona que pueden prestar grano a los campesinos para realizar la siembra. Así, el monasterio aparece como imprescindible dentro de la Comunidad Rural: en efecto, la Cartuja realiza anualmente una importante 
contratación de jornaleros para la siega y la vendimia, cada 8 años renueva los arriendos y, en definitiva, da trabajo a un buen número de campesinos. Sin embargo, esta situación no podía encubrir otra no menos importante: eran estas sociedades de subsistencia, donde muchos campesinos dedicaban el $30 \%$ de la producción a la futura siembra y en las que el peso de las clases privilegiadas habia generado un fuerte desequilibrio social:

\section{TABLA N. ${ }^{\circ} 5$}
L u g a r
N. ${ }^{\circ}$ Molinos Harineros
Propietarios

\begin{tabular}{|c|c|c|}
\hline Otea & Aceñas de 3 ruedas & Cartuja de Aniago \\
\hline Torrepesquera & Aceñas de 3 ruedas & Cartuja de Aniago \\
\hline Villalar & Aceñas de 3 ruedas & Cartuja de Aniago \\
\hline Gería & Aceñas de 2 ruedas & Marquesa de las Sirgadas \\
\hline Valdestillas & Aceñas de 3 ruedas & Monasterio N. ${ }^{a}$ S. ${ }^{a}$ del Prado \\
\hline Simancas & Aceñas de 12 ruedas & Sin especificar \\
\hline Tordesillas & 23 Aceñas & $\begin{array}{l}\text { Conde de la Mora (2) } \\
\text { Marqués de los Gallegos (1) } \\
\text { Marquesado del Inicio (5) } \\
\text { Marqués de Grajal (4) } \\
\text { Granja-Priorato de Eslua-de } \\
\text { la Santa Espina-(4) } \\
\text { M. }^{\circ} \text { de Santa Clara de Torde- } \\
\text { sillas (5) } \\
\text { Sin especificar (2) }\end{array}$ \\
\hline
\end{tabular}

San Miguel del

Pino Aceñas de 4 ruedas $M .^{\circ}$ Sta. Clara de Tordesillas

Fuente: Respuesta General n. ${ }^{\circ} 17$ del Catastro de Ensenada.

A. G. S. Hacienda Libros 646,649 y 661

E) Clases privilegiadas y desequilibrio social. - La doble absorción de gran parte de las tierras y del excedente agrario, por parte del Clero y la Nobleza, había producido un empobrecimiento social a nivel regional. Así, en Simancas de una población de 250 vecinos, 60 eran pobres de solemnidad y 133 jornaleros ${ }^{(83)}$. Pero sin duda, el caso más significativo es el de Villanueva de Duero, donde estos dos grupos constituian cerca del $75 \%$ de la población. Como recordaremos, el sorprendente incremento poblacional de ésta se debía a una reconversión de cultivos. Sin embargo, 
aquélla, había generado más ventajas para la Cartuja que para los propios campesinos, muchos de los cuales, al poseer una parcelas reducidisimas, se habian empobrecido progresivamente. En 1.751 asistimos a la conclusión de este proceso: con una población total de unos 209 vecinos, Villanueva de Duero contaba con 120 pobres de solemnidad y 118 jornalerospequeños propietarios(84), cuya situación era muy similar: "aunque algunos de estos (pobres) tienen casa mui reduzida y jornal si llega el caso de enfermar es necesario pedir por el pueblo para qe en algun modo logren alivion(85).

Si la vida de los pobres de solemnidad dependía de la labor de los Hospitales de Beneficencia y de la caridad de sus vecinos, la de los jornaleros no era más afortunada: trabajarían toda su vida, cada vez por un jornal más bajo. Así, en Villar, Antonio López sólo ganaba un real diario «por lo poco que ttrabaja por su mucha edad»(86). Muchos de ellos morirían a causa de las epidemias, de las que eran fácil presa por su mala alimentación, o llegarian al fin de sus dias gracias a la caridad.

F) Conclusiones. - Frente a la mayoría de la población rural, con un poder adquisitivo muy bajo, la Cartuja de Aniago se alzaba como un importante centro de riqueza:

Mientras que un jornalero trabajando un máximo de 180 días, que es lo que le regulaba el Catastro y que no siempre se cumplia, llegaba a ganar 360 Rs. y con ellos debia alimentar a su familia, etc.; por el contrario, esta cifra en 1750 no suponía más que el $0,9 \%$ de los Gastos Ordinarios del monasterio-36.508 Rs. - y éstos no eran más que una parte de los gastos generales de aquel que, para la misma fecha, se elevaron a 117.488 Rs. de vellón(87). Sin embargo, la contradiccón más importante entre la pequeña propiedad y la gran propiedad monástica no residía sólo en este hecho: en la práctica, el desarrollo armónico de ambas era inviable y, de hecho, la historia ya lo habia demostrado. En efecto, la Cartuja de Aniago habia basado su extraordinario crecimiento patrimonial del siglo XVII en la absorción de muchas de estas pequeñas haciendas. El crecimiento de la una sólo podía llevarse a cabo a costa de las otras.

Ante esta situación se nos plantean dos cuestiones intimamente relacionadas: ¿Cuál era el origen de Jas propiedades de Aniago? y ¿cuál fue su evolución en el Antiguo Régimen?.

\section{Los origenes de un extenso patrimonio.}

Todo monasterio disponía de una propiedad dominical procedente de dos fuentes fundamentales:

A. Unas donaciones en el momento de la fundación (las tierras más próximas a las abadias) que constituian su dominio primigenio. 
B. Otras tierras procedentes de adquisiciones posteriores por donaciones, hipotecas («ejecuciones originadas por el impago de los réditos de un censo) o compras.

A) El origen del dominio: El monasterio de Aniago fue fundado por la Reina de Castilla doña Maria nen 1441. De hecho ésta sólo cumplía un viejo proyecto del Obispo de Segovia, don Juan de Cepeda, quien habia comprado el lugar de Aniago al consejo de Valladolid en 140988). El obispo pens 6 destinar el lugar, desde sus comienzos, a fines religiosos. Según las noticias de los primeros fundadores, hizo allí un Seminario y Hospitai «donde sustentassen ocho sacerdotes y quatro sacristanes mancebos clérigos de ordenes menores con un presidente los cuales sirviesen en el mesmo lugar al culto divino celebrando y rezando con mucha solenidad y devozion el oficio gotico" (este rito es el que hoy en dia conocemos como mozárabe)(89). Para ello comenzó a edificar la Iglesia y compró dos granjas-Otea y Torrepesquera-al monasterio de Matallana, de manera que los productos de éstas asegurasen la alimentación de los religiosos. Tras la muerte del obispo, la Reina donó todo este patrimonio, unas 360 has., a la Cartuja y un año después, en 1442, el Papa Eugenio IV confirmaba la donación a perpetuidad(90). La Corona completaria estas mercedes con otros privilegios de carácter económico y pronto colocó al monasterio bajo Patronato Real.

B) Las nuevas Haciendas: Sin embargo, pronto la Cartuja inició su expansión por las villas próximas. Desde 1479 tenemos noticias de que ésta poseía una hacienda en Villalar, pues en dicho año compro 86,5 fas. de sembradura que, para 1507, se habian elevado a 21991). A esta hacienda siguieron las de Gería y Simancas (primer apeo fechado en 1536) y la de Villanueva de Duero (primer apeo fechado en 1539).

Es precisamente gracias a estos apeos realizados por los cartujos como podemos seguir detalladamente la evolución del 56,94\% del total de sus propiedades. De acuerdo a éstos, se han elaborado la gráfica $n .^{\circ} 3$ y la tabla $n .{ }^{\circ} 6$, que presentan la evolución de las propiedades del monasterios en Villalar, Villanueva de Duero, Gería-Simancas y Torrepesquera. Ambos perfilan un primer modelo o esquema de crecimiento en el que se distinguen tres etapas: 


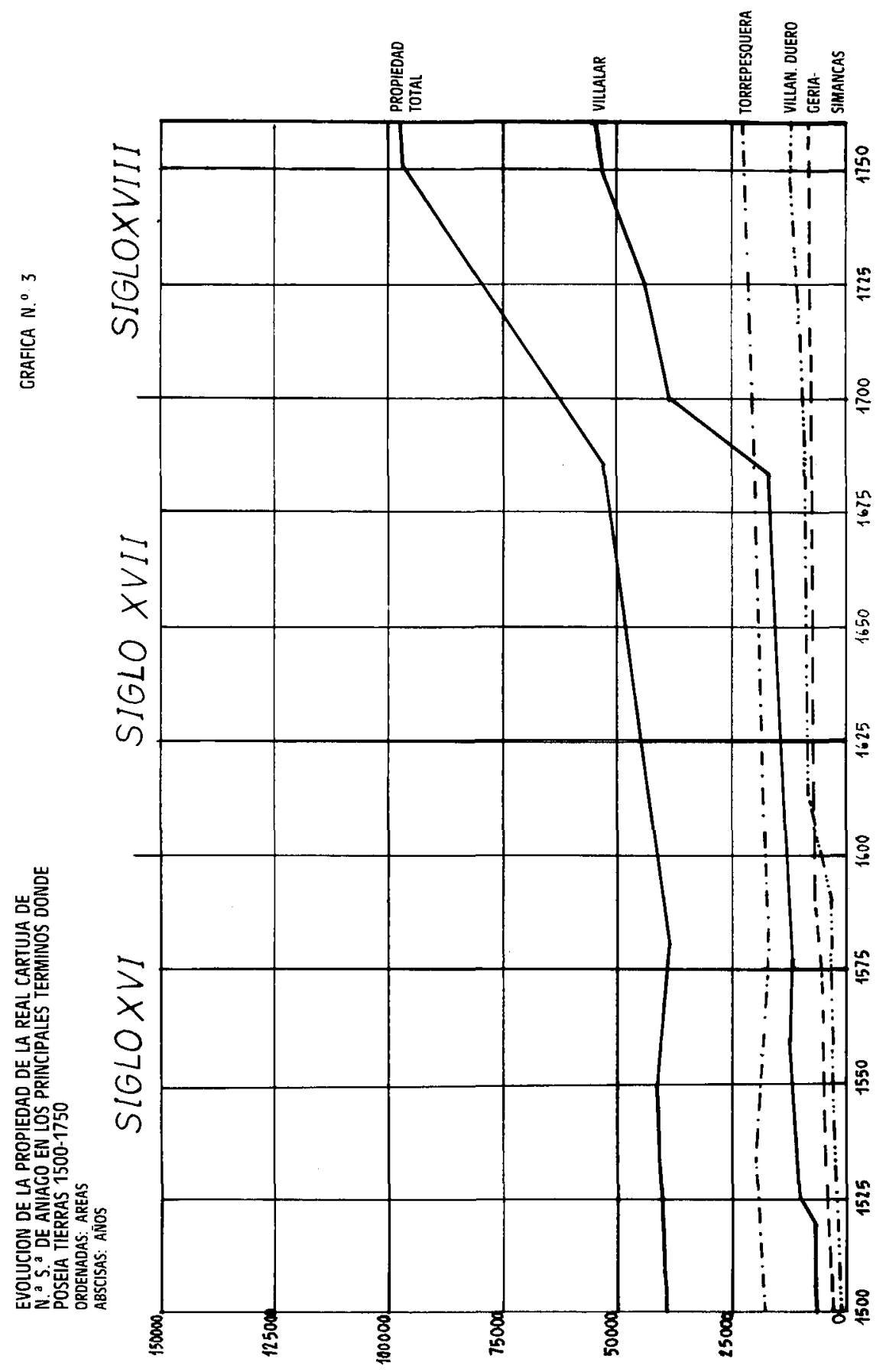


TABLA N ${ }^{\circ}{ }^{6}$

LA EVOLUCION DE LAS PROPIEDADES DE LA CARTUJA DE ANIAGO EN LOS TERMINOS DE VILLALAR, GERIA, SIMANCAS, VILLANUEVA DE DUERO Y TORREPESQUERA

\begin{tabular}{|c|c|c|c|c|}
\hline & rmino & $A \bar{n} o$ & Propiedad (Has.) & Indice \\
\hline Villa & & 1.507 & 67,32 & 100 \\
\hline$n$ & & 1520 & 79,84 & 117,34 \\
\hline$"$ & & 1526 & 100,13 & 148,73 \\
\hline " & & 1528 & 116,81 & 173,51 \\
\hline 》 & & 1535 & 115,88 & 172,13 \\
\hline 》 & & 1560 & 133,56 & 198,39 \\
\hline ") & & 1577 & 128,10 & 190,28 \\
\hline$"$ & & 1683 & 184,50 & 274,06 \\
\hline " & & 1700 & 389,32 & 578,31 \\
\hline n & & 1725 & 452,85 & 672,74 \\
\hline ") & & 1751 & 538,64 & 800,11 \\
\hline Gerí & nancas & 1536 & 55,66 & 100 \\
\hline$n$ & $"$ & 1564 & 56,61 & 101,52 \\
\hline$n$ & $n$ & 1577 & 57,52 & 103,34 \\
\hline$n$ & $"$ & 1590 & 70,91 & 127,39 \\
\hline$n$ & $"$ & 1612 & 72,69 & 130,59 \\
\hline$n$ & $"$ & 1682 & 75,28 & 135,24 \\
\hline$n$ & $"$ & 1738 & 80,86 & 145,27 \\
\hline$n$ & $n$ & 1760 & 93,32 & 167,66 \\
\hline Torre & quera & 1536 & 204,71 & 100 \\
\hline & & 1574 & 169,23 & 82,66 \\
\hline & & 1589 & 171,85 & 83,94 \\
\hline & & 1753 & 227,27 & 111,02 \\
\hline Villa & va de Duero & 1539 & 34,09 & 100 \\
\hline & $"$ & 1543 & 33,52 & 98,32 \\
\hline & $"$ & 1552 & 37,54 & 110,12 \\
\hline & $"$ & 1578 & 33,52 & 98,32 \\
\hline & $"$ & 1590 & 34,90 & 102,37 \\
\hline & $n$ & 1613 & 83,84 & 245,93 \\
\hline & $"$ & 1689 & 94,12 & 276,09 \\
\hline & $n$ & 1739 & 123,89 & 363,42 \\
\hline . & $n$ & 1752 & 137,49 & 403,31 \\
\hline
\end{tabular}

Fuentes: Madrid A. H. N. Clero Libros 16.177, 16.178, 16.181, 16.185, 16.186, 16.187, 16.188, $16.190,16.191,16.192,16.193,16.194,16.195,16.198,16.199,16.200$ y 16.201.

Valladolid A. H.P. o U. Hacienda (Catastro de Ensenada) Libro 380. 
I.-1450-1550: Se observa un crecimiento moderado en todas las haciendas, con dos excepciones: el alza de Villaiar (índice 172,13 en 1535) y la regresion, que se habia iniciado antes de 1536, de la hacienda de Torrepesquera.

II. -1550-1650: Caracterizaría a este período un estancamiento del crecimiento de casi todas las haciendas e incluso una regresión en algunas (Villalar en 1577, Torrepesquera en 1574, etc.); la única excepción sería el espectacular crecimiento de Villanueva de Duero que, alcanzando el indice 245,93 en 1613 , hemos de relacionar con la depresión agraria de la zona y la reestructuración de cultivos ya mencionada.

III.-1650-1750: Etapa de fuerte crecimiento en todas las haciendas, que se produce especialmente en la zona de Villalar en el siglo XVII. Obsérvese como entre 1680 y 1700 se producen espectaculares alzas en todas las curvas.

Sin embargo, el análisis precedente nos planteaba más preguntas que respuestas: nos informa de cómo evolucionó la propiedad de Aniago, pero los apeos contienen poca información sobre las causas de esa evolución. Por ello realizamos un segundo análisis en el que se estudiaron otros documentos: Ios contratos de compra, las donaciones, Papeles Varios del Archivo de Aniago, dos pleitos, etc. A partir de éste se diseñó la gráfica $n .^{\circ}$ 4 que presenta el crecimiento anual de la propiedad, resumiendo los resultados cuantitativos contenidos en más de 300 contratos del A. H. N. de Madrid. El muestreo es suficientemente significativo para matizar la gráfica n. 3 y de acuerdo a éste se perfilan más concretamente 3 etapas de crecimiento:

I.-Crecimiento moderado (1450-1540).

II.-Estancamiento o regresión (1540-1630)

III.-Fuerte crecimiento, con dos etapas:

— La década de los pleitos (1630-1640).

- La expansión del Mercado de tierras (1690-1735).

Con respecto a los resultados anteriores, cabe resaltar la matización de la periodicidad del siglo XVII: Frente al crecimiento lineal presentado por los apeos, nos aparecen en él dos momentos importantes: la década de los pleitos y el periodo final de la crisis castellana, caracterizado por una expansión del mercado de tierras, que el monasterio prolongará en la zona de Villalar al ejercer un monopolio de demanda.

1.--El crecimiento moderado: Entre 1450 y 1540 se producen una serie de compras por parte de la Cartuja, cuya explicación no ofrece grandes prohlernas: Podemos partir de un supuesto teórico según el cual el monasterio acumulaba un excedente que procedia de las rentas, diezmos, etc. y 


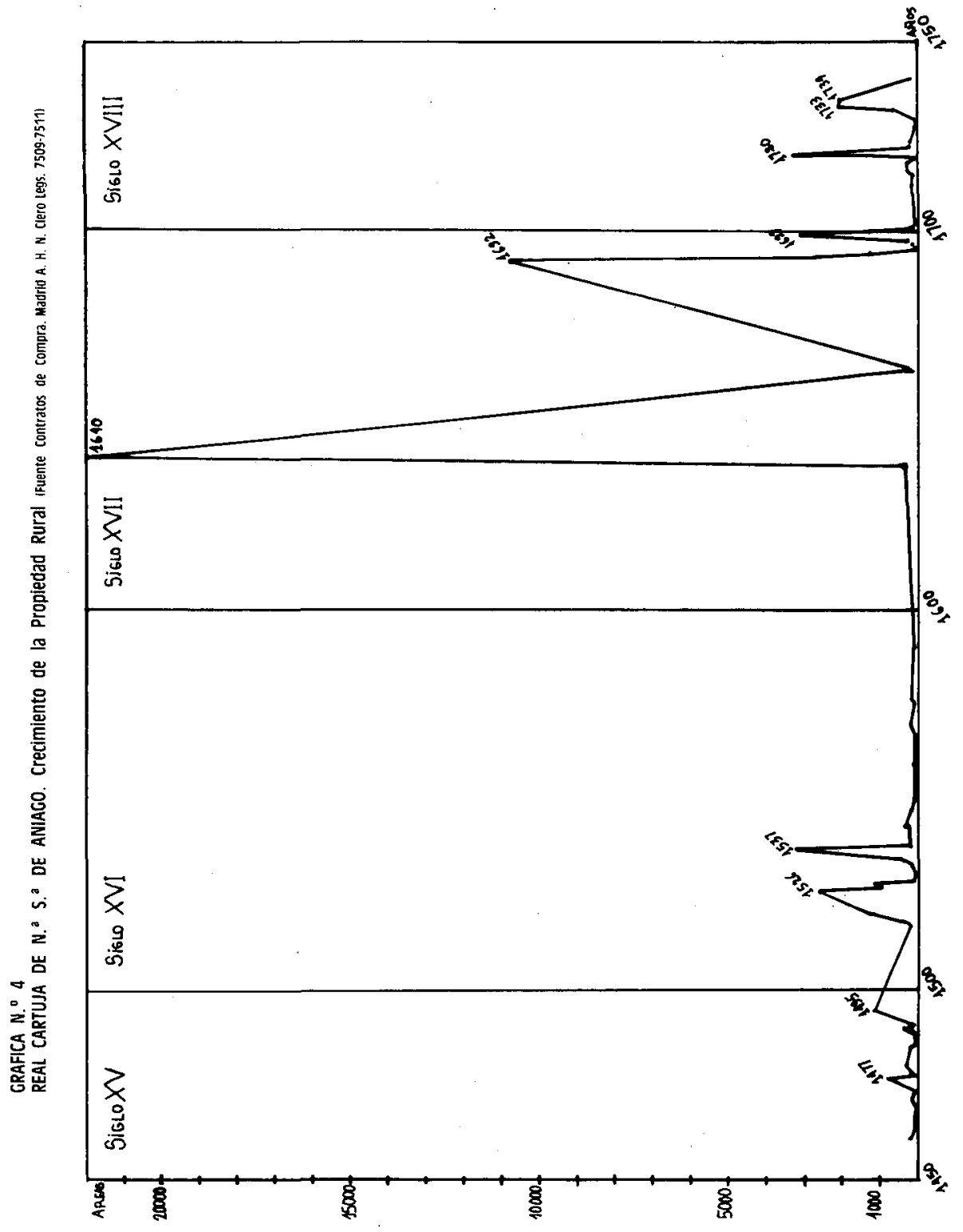


que le permitia mejorar las condiciones de sus cultivos e incrementar las propiedades inmobiliarias. Por ello, los incrementos que se observan en la gráfica de 1477, 1526 y 1537 son perfectamente verosímiles: en efecto, con frecuencia los campesinos a lo largo de la época estudiada, realizaron ventas al monasterio para escapar de apuros económicos. Veamos algunos ejemplos:

-En 1479 Alvaro de Ureña y Beatriz Gutiérrez, vecinos de Tordesillas, vendieron a la Cartuja 86,5 fas. de sembradura que poseian en el término de Villalar(92).

- La situación es muy parecida para los años 1526 y 1537, en los cuales se realizaron las mayores compras de tierras por parte del monasterio. En 1526 la Cartuja compró 26,6 has. a 11 pequeños propietarios, la mayoria de los cuales fueron adquiridas en Villalar en pequeños lotes (10, 7,5 , etc. fas.); mientras que, en 1537, aniago adquirió por 83.000 maravedis, 31,46 has. en el término de Tordesillas y esta vez a un sólo vecino: Bez. Alonso de Moro(93). Sin embargo es evidente que este supuesto no explicaría por si sólo el crecimiento tan desproporcionado que se va a producir en el siglo XVII.

2. La primera gran crisis (1590-1610): Desde finales del siglo XVI, se detecta una primera crisis importante que afectará a las tierras de Valladolid. Sus indicadores más importantes serían:

- un descenso de la población debido a las pestes y epidemias que asolan la Península. Sin duda las más famosas serán las que se produzcan entre 1598 y 1602.

-El hundimiento de las economias campesinas que se detectará por diversos factores, al afectar a los diversos estamentos. En primer lugar, muchos pequeños propietarios de Villanueva de Duero venden sus tierras a la Cartuja (obsérvese el importante incremento de esta hacienda en 1613). A la vez, muchos labradores e incluso algún hidalgo piden créditos al monasterio. Así, entre 1601 y 1609 , varios vecinos de Villalar, y entre ellos el hidalgo Pedro Feliz, piden tres préstamos consecutivos a la Cartuja, en los que moviliza 9.994,11 Rs. a unos tipos de interés altos (entre un

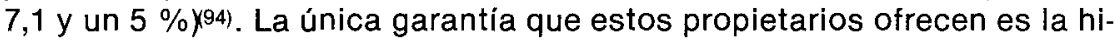
poteca de sus tierras.

-Finalmente, esta crisis afecta al monasterio y ello se acusa en dos hechos importantes: El incremento del papel de las donaciones en la economía del monasterio y la petición de ayuda a la Corona.

Las primeras tendrán una gran relevancia. Por ejemplo, en 1606 Aniago recibe una donación de 700 ducados, procedentes de Ana Flores de Valladolid, en concepto de fundación de misas, etc.

Dos años antes, en 1604, los monjes habian escrito a Felipe III solici- 
tando "alg. ${ }^{a}$ limosna $p .^{a}$ ayuda al reparo de aquella casa y de la necesidad en q se halla por no tener ninguna renta...". La respuesta del monarca es sorprendente por cuanto concede al monasterio el Privilegio de sacar 3.000 botas de vino del reino de Nápoles libres de impuestos(95). Estas permitirán a la Cartuja iniciar su primacia en la Región en cuanto a la producción y comercialización del vino, pues esta importación le permitía forzar el precio del mercado vallisoletano. A partir de entonces, Aniago librará innumerables pleitos con el gremio de vinateros de la ciudad de Valladolid que finalizarán con una concordia en 1709, a la que seguirá una ejecutoria, ganada en la Real Chancillería en 1718, que le permitirá la venta de vinos sin trabas en esta ciudad, para lo cual obtendría una licencia definitiva en 1735(96).

3. Una etapa intermedia (1610-1660). "La década de los pleitos": A la violenta crisis de producción de comienzos de siglo, seguirá un período de transición caracterizado por las secuelas del proceso anterior, que hará cólapsar las economias campesinas de diversos lugares: disminución de la población, descenso de la producción, incremento de los impuestos por la política exterior, etc.... serian algunas de las características. Esta situación favorece al monasterio pues, al poseer un cuantioso número de censos impagados, incrementará notablemente sus posesiones por ejecuciones. Será ahora cuando se produzca la absorción de la principal hacienda de Villalar: la del hidalgo Pedro Feliz.

Como sabemos era muy frecuente, desde comienzos del siglo XVII, el que los labradores, tras una mala cosecha, pidiesen préstamos al monasterio cuya única garantia era la hipoteca de sus tierras: si éstos no pagaban varios años seguidos los réditos, aquellas pasaban al acreedor. Es este el sistema que hoy en día denominamos «ejecución".

Hacia 1590 Pedro Feliz tenia 176,67 has. En ellas se daban cultivos de cereales, viñedos, mimbrerales, zumaque, etc., a lo que añadiriamos varios herrenes, dos huertas, algunos prados de guadaña y un pinar. En 1601 un grupo de propietarios acomodados, entre los que se encontraba aquél, pidieron al monasterio un censo de $112.000 \mathrm{mrs}$. de principal que, a un tipo de interés del $7,1 \%$, reditaban $8.000 \mathrm{mrs}$. al año. A éste, siguieron otros muchos censos que pesaban de tal forma a la muerte de Pedro Feliz, sobre su hacienda, que sus herederos tuvieron que librar un concurso de acreedores. En 1634 se iniciará el pleito en Villalar ante la jurisdicción ordinaria. Desde sús comienzos, los principales aspirantes a estas propiedades serán dos: la Cartuja de Aniago y "Josef de Castro rrosales escrivano de número y ayuntamiento de la villa de medina del Campo patrón de las memorias y obras pias que fundaron y dotaron pedro rrodriguez de contreras y engracia de medina su mujer aba era quién debía cobrar primero, cuestión trascendental ya que la deflación de los productos agricolas y la inflación de los productos artesana- 
les, hacían que la hacienda de Pedro Feliz tuviera ahora un valor çomparativamente más bajo que a finales del siglo XVI. Asi, bastaba con que cobrase primero el deudor de un censo importante para que, en la práctica, los demás no pudiesen cobrar en bienes o tierras. Tras una primera sentencia de subasta dada por el alcalde Ordinario, el pleito quedó paralizado entre el 2 de mayo de 1634 y el 23 de junio de 1635. ¿Por qué?. Las razones de ello llevaron el pleito a la Real Chancilleria y fueron perfectamente explicadas por Juan Castillo, representante de José de Castro; el heredero de la hacienda, Juan Feliz, y el alcalde ordinario, Antonio de Represa, estaban emparentados y por tanto, tenían intereses en paralizar el pleito, vendiendo mientras tanto los bienes más valiosos para su provecho, antes de que el expolio fuera inevitable: "e porque el dicho don antonio de rrepresa siendo alcalde hordinario en la dicha villa y juez del dicho pleito de acrehedores y cuñado del dicho don juan feliz havía comprado mucha cantidad de bienes de la hacienda... y el dicho Antonio derrepresa poderosos en el dicho lugar a que heran alcaldes deel estado de los hijosdalgo de la dicha villa el uno u el otro cada año y los acrehedores no podian alcançar justicia. Porque... como heran poderosos en la dicha villa y justicias en ella ningun acrehedor podía... e aquellos pagavan a quien querian e quando querian en lo que querian... por las quales rraçones su parte ttenía por odiosos y sospechosos a los justicias de la dicha villa de Villalar...p(98).

En la práctica, la sentencia del pleito supondrá el desplome de los hidalgos en Villalar, siendo sustituidos en su hegemonía por la Cartuja de Aniago.

Si el monasterio era un acreedor más a la.hacienda de Pedro Feliz, sin embargo, éste alegará que tenía prioridad en el cobro por ser el único acreedor de su mujer, Ana Guerrero, y ésta "havía de ser preferida y primeramente pagada qe otro ningun acrehedor qe ansi lo pedia porque tambien lo havia deser en tres mill ducados qela susodicha havía llevado por bienes dotales suyos... porque se les havia dado barttolome guerrero padre de la susodicha en biñas y en bienes rraices e muebles....x(99).

La primera sentencia importante, del 19 de enero de 1638, mandaba la separación de los bienes de Ana Guerrero. Sin embargo, ninguno de los acreedorés quedó satisfecho, pues la Cartuja había cobrado una mínima parte y José de Castro podía cobrar su deuda pero no tenia garantía de que este cobro fuese definitivo, al tener el monasterio, por la nueva sentencia, preeminencia sobre los demás acreedores.

ta nueva sentencia dada el 24 de marzo de 1639 en Tordesillas, ordenaba subastar los bienes de Pedro Feliz y pagar primero al monasterio. El dia de la puja en Villalar "se allaron presentes muchas personas", pero "no ubo ni parecio ninguna persona que hiciese postura en ellos". Finalmente el 21 de abril, "pareció Juan Luengo vecino de Tordesillas e hiço postura en los dichos bienes en 5.454 Reales" y otros 246 Rs. para pagar los sala- 
rios y costas de la transaccion. Al no haber ninguna otra postura se adjudicó a éste(100). Śin embago, Juan Luengo actuó como un "hombre de paja" del monasterio, pues al no tener dinero para pagar las tierras, «traspasó las dichas casas lagar... e todos los demás bienes declarados y especificados al primer pregón... en favor del prior monjes y conbento deel monasterio de nuesttra señora de Aniagow(101). El 22 de abril la Cartuja acepto el traspaso y al haber evaluado toda la hacienda en 5.900 Rs., aún podía cobrar hasta un total de 14.939 Rs. Según José de Castro el monasterio habia recibido upor cinco mill rreales bienes que balian a justa y común estimación más de ocho mill ducados»(102). tales:

Este pleito nos permite llegar a una serie de conclusiones fundamen-

1. ${ }^{\circ}$ Supuso la primacía de la Cartuja en Villalar, al duplicar sus posesiones, mediante la anexión de 176,35 has.

2. $\quad$ Esta supremacia fue producto de una crisis general que afecto incluso a los grandes propietarios hidalgos (Pedro Feliz) y a los labradores (como Diego Alonso, cuya ejecución por el impago de los réditos de un censo, de 300 ducados de plata, se produce por estas mismas fechas), que se vieron afectados por las malas cosechas, etc., desde comienzos de siglo.

Asimismo, esta crișis hizo disminuir la población y, sobre todo, la demanda de tierras: no hay gente con dinero o interesada en comprar un bien cada vez más depreciado. Ello aparece perfectamente especificado en el juicio: "la dicha Villa de Villalar es corta e de pocos vecinos e non havía quien comprase 0 arrendase las tierras $\$(103)$. Esto permitiría al monasterio adquirir una importante hacienda a un precio realmente bajo.

$4 .^{\circ} \quad$ Ante el desplome de las haciendas de los burgueses, pequeños propietarios, etc., sólo una institución con excepcionales garantias para la pervivencia, como era la Cartuja, podia hacerse con la primacía regional: el control de Villalar suponía una atención fundamental al mercado de cereales que, en el siglo XVIII, serán una de las bases económicas del monasterio.

5. La hacienda de Pedro Feliz fue el modelo a partir del cual la Cartuja explotó las tierras de Villalar. En la actualidad aún se coriserva en esta villa su casa, con el escudo de armas en la fachada, frente a la iglesia de San Juan.

4. La Crisis de 1670 - 1690: En su configuracion jugaron un papel importante las malas cosechas y. los desastres naturales, cuya culminación se producirá en 1683. En efecto, como ha apuntado Domínguez Ortiz: "las causas hay que buscarlas en una serie de malas cosechas, causadas por adversas condiciones metereologicas, coincidentes con pertinaces 
contagios". Asi, hacia 1677 la primavera fue excesivamente lluviosa y a este año siguieron dos secos, a los que siguieron inundaciones, etc. "La repercusión de estos desastres..., se extendió a toda la mitad sur de España y en menor proporción, también a la Cuenca del Duero; por lo menos consta que la cosecha de 1682-83 fue muy corta, vendiéndose ya en octubre del segundo de los años citados a seis y siete cuartos el pan de dos libras de Medina de Riosecos(104).

A la vez, la fecha de 1680 es resaltada por otros autores. Asi, por este año, "Castilla intentó una última operación contra la inflación de la moneda de vellón: retiró en masa esta moneda de circulación. Fue una verdadera operación quirúrgica que arruinó a muchas gentesw(105). Operaciones hacendísticas de la Corona, malas cosechas, inflacion, etc., arruinaron a muchos pequeños propietarios. La única opcion que les quedaba era vender. A la vez, la crisis afectará a los más fuertes, pero la solución de éstos se verá especialmente favorecida por la coyuntura histórica: será necesario ampliar las haciendas. Por ello, a partir de la segunda mitad del siglo XVII, se producirá una fuerte «reacción señorial» que reforzó el feudalismo como modo de producción(106).

Todos estos sintomas, apuntados por diversos autores, pueden comprobarse en la economia regional de la zona de influencia de la Cartuja de Aniago. Así, en un documento de 1670-71, el monasterio presentó un requerimiento sobre el pago de las rentas y los diezmos a los vecinos de Geria, pues éstos Ilevaban varios años sin pagarlos debido a "la adversidad de los tiempos". Por fin los vecinos se comprometieron a pagar lo que debian: "declaró pedro guzmán estar debiendo hasta el año pasado de setos y setenta tres cargas de trigo = una fanega de garbanzos y una emina de garrobas... que tiene diezmado en la villa de Gerias(107).

A la vez, cuando se realice el apeo de Villalar de 1683, se puede observar un cambio sustancial: todos los grandes renteros que trabajaban para la Cartuja habian desaparecido, dejando su puesto a otros nuevos. El documento hace mención a la ruina de muchos de ellos(108).

La culminación de estos desastres afectó al propio monasterio, que de nuevo se ve obligado a pedir ayuda a la Corona, en 1682, pues "por los accidentes de los tiempos se halla muy pobre y desacomodada y ahora le ha sobrevenido haverle caido y. arruinado la mitad de la Casa y oficinas en que perdió tanbien los frutos que tenía recogidos, quedando derramado el vino, que era lo principal que tenía y destrozadas y enterradas las vasijas....s(109).

Sin embargo, el monasterio se fue recuperando poco a poco y, para mayor fortuna, en 1690 llegó a Aniago una limosna Real de 500 pesos de oro que invertirá en la compra de tierras. 
5. Un periodo de fuerte demanda de tierras (1690-1735): Todos los factores anteriormente mencionados llevaron a una amplicaión sensible del mercado de tierras. No sólo los pequeños propietarios vendian, sino que también lo hicieron los medianos propietarios e incluso los Concejos de las Villas. La gráfica $n .^{\circ} 5$ presenta el comportamiento de la demanda del monasterio y las oscilaciones de los precios de la tierra en Villalar y Pedrosa del Rey..Para su elaboración se han promediado los precios, puesto que los mismos oscilaban en función de la calidad de las tierras: así, en 1692, una fanega de primera clase costaba 75 Rs., una de segunda 68 , y la de tercera $60 \mathrm{Rs}$. El promedio representado, a efectos de no repetir innecesariamente las curvas y complicar la gráfica, es el de 67,66 Rs. Esta misma operación ha sido realizada para los demás años.

En el primer periodo (1690-1700), la Cartuja ya había recuperado sus haciendas y se lanza a la compra de tierras. Así, en 1692 los monjes demandaron más de 300 fas. Esta demanda disminuye en los años siguientes. Obsérvese cómo las fluctuaciones de los precios, se producen en función de la demanda del monasterio y no a la inversa: en efecto, las curvas no representan una situación de competencia perfecta, sino de monopolio restringido de demanda. Asi, en 1695 los precios se elevaron y, sin embargo, la Cartuja, única que puede practicamente demandar tierras, no lo hace; ante esta situación los precios se desploman para el año siguiente. En 1699 , ante el nuevo descenso de los precios, el monasterio vuelve a incrementar su demanda (más de 100 fas.), esto produce una nueva alza de los precios en 1700 y, por ello, una correspondiente disminución de la demanda de Aniago.

El segundo período (1718-1735) nos presenta un comportamiento de la demanda de la Cartuja completamente diferente al caso anterior. En la gráfica, se puede resaltar el incremento de los precios tras la recuperación económica. Obsérvese cómo las fuertes oscilaciones de carácter local no afectan a la demanda del monasterio que se mantiene baja. Sólo la caída fuerte de los precios de 1728-32, produce un incremento de la demanda de tierras; ésta repercute a su vez en la elevación de los precios (1732-33), subsiguiendo como consecuencia de esta elevación una disminución de la demanda, que de nuevo repercute en la caída de los precios.

En su conjunto y gracias a esta excepcional coyuntura, la Cartuja de Aniago incrementó notablemente su patrimonio, a costa de la adquisición de tierras que procedian en su mayoría, frente al caso anterior de 1640 , de los pequeños propietarios.

6: La progresiva paralización del crecimiento (1735-1800): Aunque el crecimiento del patrimonio inmobiliario de Aniago seguirá hasta finales del Antiguo Régimen, en la práctica se produce una progresiva paralización de éste: ¿qué causas la motivaron?. 


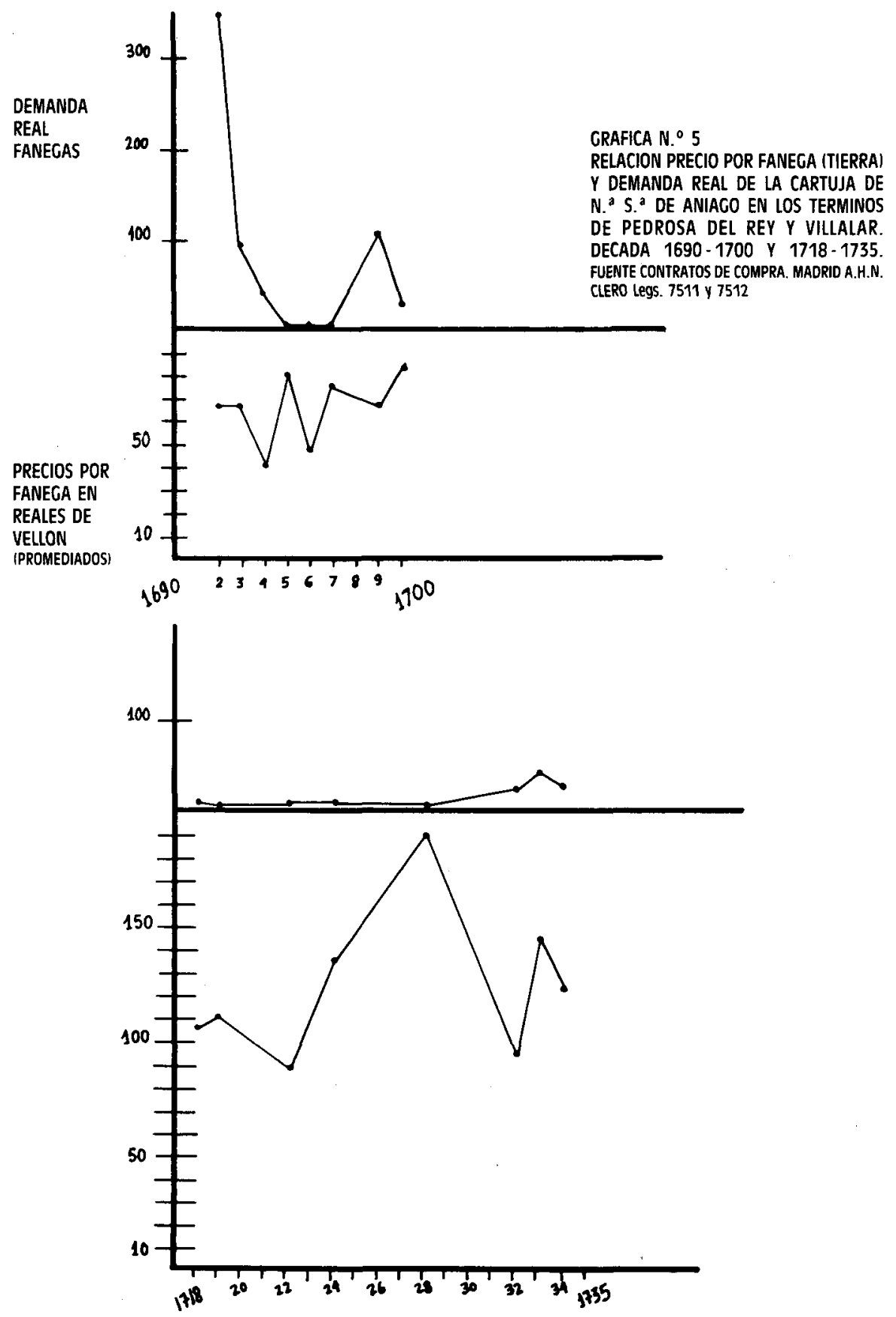


1.-De una parte motivos relacionados con la explotación. Como se aprecia en la gráfica $n .^{\circ} 1$, las explotaciones más rentables y productivas para los Cartujos eran las directas. Es evidente que un crecimiento indefinido hubiera obligado a disminuir e incluso a hacer desaparecer éstas, en beneficio de los arrendamientos generales y de una consecuente pérdida del control de la producción.

II.-A partir de 1712, el crecimiento de la propiedad del monasterio estaba controlado en su mayor área de expansión: Villalar y Pdrosa del Rey. En esta fecha se llegó a una concordia decimal con el obispado de Zamora. Recordemos que en aquellos lugares en los que el monasterio arrendaba tierras, era frecuente que la percepción decimal corriese a cargo de la Cartuja y, como hemos visto, en estos lugares dichas percepciones superaban a los ingresos procedentes de las rentas. Sin embargo, el monasterio no podía cobrar todos los diezmos que quisiera sin chocar con los intereses de las diócesis. A partir de la Concordia, Aniago sólo podría adquirir 160 fas. en estas villas, diezmándolas igual, pero si adquiria más perdería el diezmo e incluso lo pagaria ua la dignidad episcopal y los demás interesadosw(110).

III.-Finalmente, el siglo XVIII conocerá un incremento de la demanda de tierras y de las roturaciones como consecuencia del aumento poblacional. Esta demanda, al ser realizada por otros sectores sociales-nobles, burgueses, etc.-, impedirá un crecimiento monástico tan vertiginoso como el anterior. Además, en este siglo, se producirán dos hechos importantes: la expulsión de los jesuitas y la primera desamortización ilustrada.

\section{Conclusiones.}

1) Como hemos visto, la gran propiedad monástica y el minifundio estuvieron intimamente relacionados a lo largo del Antiguo Régimen. En efecto, no sólo una parte importante de los ingresos de la Cartuja procedía de estos pequeños propietarios, sino que también su propio patrimonio habia crecido a expensas del de los anteriores. Sin embargo, el modelo de crecimiento de Aniago no es generalizable a todos los monasterios: el caso de la Cartuja es el de un monasterio típicamente "moderno" y de fundación tardía. Por el contrario, las ordenes de Cluny y Cister lucharán, a lo largo de la Edad Moderna, por conservar-sus patrimonios y haciendas. En la actualidad es el estudio de este segundo caso el que nos ocupa y, debido a ello, sólo podemos presentar una primera aproximación. Para este estudio, hemos elegido el mayor monasterio de Valladolid: San Pedro de la Santa Espina. Esta sorprendente abadía, cuyo origen se remontaria a 1147, posela un término redondo de más de 3.000 has. e intereses económicos en 50 términos. Sin embargo, su modelo de crecimiento se opone al ante- 
rior: la Espina tuvo a lo largo del Antiguo Régimen, como otros monasterios de origen medieval, un crecimiento negativo. Como explica Fray Hernando de Aedo, que realizó la redacción del Tumbo de la abadia entre 1607 y. 1624, a ésta "pareciole que era mejor, perder algo (aunque fuese mucho) que no perderlo todow(111). Tanto los propios campesinos, al dejar de pagar los cánones de los censos enfitéuticos, como los Concejos, al restringir ciertos privilegios del monasterio en sus términos, realizarán esta ofensiva que alcanzará su apogeo en el siglo XV. Según los propios monges, "todas las haziendas de los monasterios que esta fuera de nros términos y Jurisdicción, y están en la de los concejos poderosos, han corrido riesgo de perderse; y ya que no del todo, a lo menos en parte han desmedrado y disminuyeronsew112). Para la Santa Espina no cabia duda que su peor enemigo había sido el Concejo de Tordesillas y siempre recordaría "lo mucho que ha perdido en cantidad, y calidad, por la codicia, y enbidia de tan poderoso y mal vecino, como ha sido la $V{ }^{a}$ de tordesillas, por la hazienda que tiene en sus terminoss(113).

Sin embargo, a pesar de estas pérdidas, la Santa Espina llegará a la desamortización con más de 5.700 has.(114).

Al mismo tiempo, ambos modelos tienen algo en común: para su comprensión es necesario el análisis de la sociedad rural en su área de influencia. ¿Qué interés tiene el estudio de la sociedad rural en los análisis de economia monástica?. Hemos de partir de la base de que los monasterios estaban perfectamente imbricados en las sociedades rurales, tal es así que la estructura de las haciendas de la Cartuja de Aniago respondia a la estructura generla de cultivo de cada lugar, los monjes utilizaban los mismos métodos de cultivo, etc. Así mismo, el hecho de que los cartujos conservaran divididas las diversas parcelas que adquirían, demuestra hasta qué punto la sociedad rural y el monasterio iban indisolublemente unidos: en casos extremos, cada parcela podía cederse en arrendamiento a un labrador. Es por ello que los estudios de economía monástica aislados merecen una importante crítica. Piénsese, por ejemplo, que cuando asistimos al incremento de las rentas del monasterio, no se puede hablar de éstas en abstracto sin relacionarlas con la realidad rural. Por ello, la hipótesis de ciertos medievalistas acerca de que los monasterios eran explotaciones improductivas o deficitarias, nos parece errónea. No podemos analizar la historia, los rendimientos, etc., de un monasterio por la contabilidad de un.solo año, como ha hecho Moreta Velayos: en épocas de crisis general, como la analizada por este autor o la que observamos en el siglo XVII, al perderse las cosechas, no pagar los campesinos los diezmos, los réditos de los censos o las rentas, cualquier monasterio, como la Cartuja de Aniago, paso por grandes dificultades, pero de nuevo ello se debía a la imbricación :. ésta con las economía campesinas de su área de influencia. 
Por el contrario, como demostraré en otro artículo, en épocas de auge económico los monasterios llegaron a un modelo de explotación y a unos resultados económicos notables para su época. De otra manera, éstos no hubieran pervivido como unidades de explotación durante ocho siglos, ni hubiesen alcanzado estas sorprendentes acumulaciones patrimoniales.

\section{NOTAS:}

(1) Véase totalización general de las rentas anuales de los Monasterios y Conventos suprimidos: Valladolid. Madrid, A. H. N., Hacienda, leg. 1.935.

(2) GARCIA CORTAZAR, José Angel, El Dominio del Monasterio de San Millán de la Cogolla (siglos $X$ al XIII). Introducción a la historia rural de Castilla Altomedieval. Salamanca, Universidad, 1969.

(3) MORETA VELAYOS, Salustiano, Rentas Monásticas en Castilla. Problemas de Método. Salamanca, Universidad, 1974.

Ibidem, El Monasterio de San Pedro de Cerdeña, Historia de un dominio castellano (9021338). Salamanca, Universidad, 1971.

(4) Si exceptuamos algunos estudios, entre los cuales podemos destacar dos: QUINTANS VAZQUEZ, María del Carmen, El dominio de San Martín de Pinario ante la desamortización (rentas de la Abadía). (Prólogo por Antonio Eiras Roel). Santiago de Compostela, Universidad, 1972; y, DOMINGUEZ ORTIZ, Antonio, "Campomanes y los "monjes granjeros". Un aspecto de la política eclesiástica de la llustración». Cuadernos de Investigación Histórica. N. ${ }^{\circ}$, 1977, pp. 99 109.

(5) A este respecto destacan dos obras: LEROY LADURIE, E., Paysans du Languedoc. Paris, 1966; y GOUBERT, Pièrre, Beauvais et le beauvaisis. Parla, 1960.

(6) Vid. ANES, Gonzalo, Las Crisis Agrarias en la España Moderna. Madrid, Taurus, 1970.

(7) Vid. GARCIA SANZ, Angel, Desarrollo y Crisis del Antiguo Régimen en Castilla la vieja. Economia y Sociedad en tierras de Segovia. 1500-1819. Prólogo de Gonzalo anes. Madrid, Akal, 1977.

(8) Vid. KULA, Witold, Teoría económica del Sistema Feudal. (Traducción de Estanislao J. Zembrzuski y revisión de Reyna Pastor de Togneri). Buenos aires, siglo XXl, 1974, p. 48.

(9) Entre lós modelos que hemos tomado como base destacan dos: IRADIEL, Paulino, Progreso Agrario, Desequilibrio Social y Agricultura de transición. La propledad del Colegio de España en Bolonia (siglos XIV y XV). Bolonia, Studia Albornotlana XXXIV, 1978; y el monográfico de la revista QUADERNI STORICI, VV. AA., "Azienda agraria e microstorian. Quaderni Storici. N. ${ }^{\circ}$ 39, 1978, pp. 801-1035.

(10) A este respecto, hemos corregido todos aquellos datos del Catastro de Ensenada que no correspondian con la realidad presentada por los documentos del Monasterio. En un futuro articulo demostraré las discrepanclas de las fuentes de información microeconomicas con las que esta encuesta nos ofrece. N. A.

(11) Vid. el /ib. 662 de la Sección de Hacienda (Catastro de Ensenada) del A. G. S.

(12) Vid. el libro de Mayor Hacendado: Mayorga. A. G. S., Hacienda (Catastro), lib. 662.

(13) Vid. GRUPO '75, La Economia del Antiguo Régimen: la "Renta Nacional" de la Corona de Castilla. Madrid, U. A. M. Depto. Historia Contemporánea, 1977, pp. 200 y ss.

(14) Vid. leg. 1935 de la Sección de Haclenda del A. H. N. de Madrid. 
(15) Vid. leg. 1935 ya citauic.

(16) Elaboración personal, relacionando la actual extensión de la provincia $\left(8.201 \mathrm{Km}^{2}\right)$ con las $21.456,65$ has. que estos 10 monasterios poseian.

(17) La palabra dominio es empleada aqui como sinónimo de reserva territorial vecina al monasterio. Este despoblado será la base de expansión de la Cartuja. Su extensión se ha obtenido promediando los datos suministrados por 3 fuentes fundamentales: según las respuestas Generales del Catastro (A. G. S., Hacienda, $/ i b$. 646), su extensión era de 339,5 has.; según las respuestas Particulares (A. H. U. V. Hacienda, lib. 6), ésta sería de 228,05 has. y según el uinforme de Desamortización” (Madrid, A. H. N., Hacienda, leg. 1935), la misma se aproximaría a las 512,5 has.

(18) Vid. el /ib. 646 de la Sección de Hacienda/Catastro del A. G. S.

(19) Valladolid, A. H. U. V., Hacienda/Catastro, lib. 6 (Aniago).

(20) Valladolid, A. H. U. V., Hacienda/Catastro, lib. 6 (Aniago).

(21) Esta «es una agrupación compleja y numerosa que reúne a los individuos de todas las condiciones deseosos de vivir a la sombra de una abadían. vid.MATTOSSO, J., Le Monaschisme ibérique et Cluny. Les Monestères du diòceses de Porto de L'an mille à 1.200. Lovaina, Universidad, 1968, p. 221.

(22) Vid. GODELIER, M., "Modes des productions, rapports de parenté et structures démographiques». La Pensée, N. ${ }^{\circ} 172,1973$. Cit. por Salustiano Moreta Velayos, Rentas Monásticas... op. cit., p. 27 y ss.

(23) Madrid, A. H. N., Clero, leg. 7511. Cax. $1 .^{\circ}, \mathrm{N} .{ }^{\circ} 31$ (Donación de la reina a la Cartuja).

(24) Vid. el trueque entre el Concejo de Villalar y el Monasterio en 1695. Madrid, A. H. N., leg. 7511 .

(25) Vid. el libro de caja (lib. 16.135 de lá Sección de Clero del A. H. N. de Madrid).

(26) Vid. MORETA VELAYOS, op. cit., p. 33.

(27) Valladolid, A. G. S., Hacienda, lib. 646.

(28) Vid. lib. 646 ya citado.

(29) Vid. MORETA VELAYOS, op. cit., p. 19.

(30) Vid. el lib. 646 ya citado.

(31) Vid. el apeo de Torrepesquera. Madrid, A. H. N., Clero, /ib. 16.177.

(32) A. G. S., Hacienda/Catastro, lib. 646 (Torrepesquera).

(33) Estos foreros eran vecinos de Gería, San Miguel del Pino, Villanueva del duero, Villán, Velliza y Robladillo. N. A.

(34) Vid. el lib. 16.177 de la Sección de Clero del A. H. N. de Madrid.

(35) Valladolid, A. H. U. V., Hacienda/Catastro, lib. 6.

(36) Vid. el Aptdo. E.: Las clases privilegiadas y el Desequilibrio social.

(37) Vid. el lib. 389 (Eclesiásticos) de la Sección de Hacienda del A. H. U. V.

(38) Valladolid, A. G. S., Hacienda, lib. 662.

(39) Valladolid, A. G. S., Hacienda, lib. 649.

(40) Valladolid, A. G. S., Hacienda, lib. 662 (Mayor Hacendado).

(41) Vid. el lib. 358 (Eclesiásticos) de la Sección de Hacienda del A. H. U. V.

(42) Vid. el lib. 358 (Eclesiásticos) de la Sección de Hacienda del A. H. U. V.

(43) Vid. lib. cit. gares.

(44) Asimismo, el archivo de Aniago no conserva contratos de arrendamiento de estos lu-

(45) Vid. el lib. de caja del archivo de Aniago (Madrid, A. H. N., Clero, lib. 16.135). 
(46) Estos datos han sido extraidos de dos fuentes: para la productividad, vid. el /ibro 646 de la Sección de Hacienda del A. G. S., y para la propiedad del monasterio, el /ibro 261 (Eclesiásticos) de la Sección de Hacienda del A. H. U. V.

(47) Valladolid, A. H. U. V., Hacienda, lib. 318 (Eclesiásticos).

(48) Vid. lib. cit., f. 325 V. ${ }^{\circ}$ y 326.

(49) Valladolid, A. H. U. V., Hacienda/Catastro, /ib. 287 (Eclesiásticos).

(50) Madrid, A. H. N., Clero, lib. 16.135.

(51) El monasterio realizo un Apeo de esta tierra en 1735, cuya existencia nos es conocida gracias a dos contratos de arrendamiento: los números 119 y 120 del leg. 7.520 de la Sección de Clero del A. H. N. de Madrid; sin embargo, hoy en día no se conserva.

(52) Madrid, A. H. N., Clero, leg. 7.518.

(53) Vid. leg. 7.520 de la Sección de Clero del A. H. N. de Madrid.

(54) Vid. la primera parte del /ib. 16.177 de la Sección de Clero del A. H. N. de Madrid.

(55) Vid. el lib. 646 de la Sección de Hacienda del A. G. S.

(56) Vid.: “Memoria de granos que han entrado en los troges del convento este año de 1735 de las rentas, diezmos y cosechas de las heredades y demás deudas a favor de esta casan. Madrid, A. H. N., Clero, Lib. 16.135.

(57) Vid. el leg. 7.517 de la Sección de Clero del A. H. N. de Madrid.

(58) Madrid, A. H. N., Clero, lib. 16.135.

(59) Idem., lib. cit.

(60) Vid. el /ib. 6 de la Sección de Hacienda/Catastro del A. H. U. V.

(61) El monasterio tenia prestado capital a 16 particulares, mientras que éste había pedido 7 censos. N. A.

(62) Se ha comparado la cifra de 1.395 vecinos, con la del total provincial que nos afecta el GRUPO ' 75 de acuerdo al Vecindario de Ensenada: 58.178 vecinos, que no incluye el estamento eclesiástico. Vid. La Renta Nacional... op. cit., pp. 52-53.

(63) Recuérdese que estamos hablando de diez entidades de población y la provincia tenia unas 608.

(64) Vid. GARCIA SANZ, Angel, Renta y Sociedad estamental en el Marquesado de Cuéllar. Segovia, Instituto Diego de Colmenares, 1.973. (Separata de Estudios Segovianos, t. XXV. 1973), p. 12. p. 105.

(65) Vid. DOMINGUEZ ORTIZ, Antonio, "Campomanes y los "monjes graneros"'... op. cit.,

(66) Vid. la Respuesta General n. ${ }^{\circ} 27$ del /ib. 632 de la Sección de Hacienda del A. G. S.., f. 11 vuelta.

(67) Vid. Ios libs. 646, 649 y 661 de la Sección de Hacienda del A. G. S.

(68) Datos elaborados a partir de la extensión dada por las Respuestas Generales de cada término. N. A.

(69) Un desequilibrio en la propiedad de la tierra hacia, por consiguiente, de ésta una villa pobre. N. A.

(70) A. G. S., Hacienda, /ib. 646.

(71) Vid. las Respuestas Generales nos. 9 y 12 de estos lugares.

(72) En Torrepesquera una aranzada de primera producia 6 cargas de uva (24 cántaras); en Villanueva del Duero, esta misma aranzada producia 28 cántaras, y en Villalar unas 30 . Vid. las Respuestas Generales nos. 9 y 12 de estos términos.

(73) A. G. S., Hacienda, lib. 649. Respuesta n. ${ }^{\circ} 12$ (Villalar).

(74) Vid. el contrato de roturación de 1796 entre la Santa Espina y 43 vecinos de San Cebrián de Mazote y Ureña. Madrid, A. H. N., Clero, lib. 17.982, ff. 11 V. ${ }^{\circ}$ y 12. 
(75) Datos tomados del lib. 662 de la Sección de Hacienda del A. G. S.

(76) Vid. el lib. 662 cit.

(77) Vid. el documento n. ${ }^{\circ} 3$ del leg. 7.515 de la Sección de Clero del A. H. N. de Madrid.

(78) Vid. TAMAMES, Ramón, Introducción a la Economia Española, 9. ${ }^{2}$ ed. Madrid, Alianza Editorial, 1.974, p. 76.

(79) Vid. el Iibro 16.198 de la Sección de Clero del A. H. N., de Madrid.

(80) Vid. PEÑA SANCHEZ, Martiniano, Crisis rural y transformación recientes en Tierra de Campos. Estudio geográfico del sector Noroeste. Valladolid, Universidad/Depto. de Geografía, 1975, p. 71.

(81) Vid. BLOCH, Marc, La Historia Rural Francesa: Caracteres originales (Suplemento compilado por Robert Dauvergue, según las obras del autor de 1931 a 1944). (Traducción Alejandro Pérez). Barcelona, Crítica/Grijalbo, 1.978, pp. 431-32.

(82) Vid. GIORGETTI, Giorgio, Contadini e propietari nell'Italia Moderna. Rapporti di produzione e contratti agrari del secolo XVI a oggi. Torino, Einaudi, 1974, p. 16.

(83) Vid. las Respuestas Generales nos. 35 y 36 de esta villa. A. G. S., Hacienda, lib. 661.

(84) Vid. las Respuestas Generales nos. 35 y 36 del lib. 648 de la Sección de Hacienda del A. G. S.

(85) Vid. la Respuesta n. ${ }^{3} 35$ de Villanueva de Duero.

(86) Vid. la Respuesta n. ${ }^{\circ} 33$ de Villalar. A. G. S., Hacienda, lib. 649.

(87) Vid. la contabilidad de la Sección de Producción de 1750. Madrid, A. H. N., Clero, libro 16.135

(88) Vid. "Traslados simples de ia Venta de Aniago, que hizo la V. ${ }^{a}$ de Valld. a N. Funfador. Facultad real y Provisión tomada en 1409". Madrid, A. H. N., Glero, leg. 7.511, n. ${ }^{\circ} 11 / 1409$.

(89) Madrid, A. H. N., Clero, leg. 7.511: «Codicilio de Nrô. Fundador de 1437. Trasladado por Josef Sanz del Río en 1.728». 31/1437.

(90) Madrid, A. H. N., clero, leg. 7.511. Cax. $1 .^{\circ}$, envol. 1: confirmación de Eugenịo IV. Florencia 12-1X-1442.

(91) Vid. el Apeo de Villalar de 1507. Madrid, A. H. N., Clero, lib. 16.181.

(92) Madrid, A. H. N., clero, leg. 7.515: Apeos hechos en el término de Villalar en 1479 y copia de $1798 / \mathrm{N}^{\circ}{ }^{\circ}$.

(93) Madrid, A. H. N., clero, leg. 7.510.

(94) Vid. el lib. 16.163 de la Sección de Clero del A. H. N. de Madrid.

(95) Madrid, A. H. N., Clero, leg. 7.511.

(96) Vid. el leg. 7.513 bis de la Sección de Clero del A. H. N. Documento n. ${ }^{\circ} 46 / 12$.

(97) Madrid, A. H. N., Clero, lib. 16.163. Primer pleito, f. 3 V. ${ }^{\circ}$.

(98) Madrid, A. H. N., Clero, lib. 16.163. Primer pleito, ff. 81-84.

(99) Madrid, A. H. N., Clero, lib. 16.163. Primer pleito, f. 170.

(100) Madrid, A. H. N., Clero, lib. 16.163. Segundo pleito, ff. 145 y 145 V. ${ }^{\circ}$.

(101) Madrid, A. H. N., Clero, lib. 16.163. Segundo pleito, ff. 151 y 151 V. ${ }^{\circ}$.

(102) Madrid, A. H. V., Clero, lib. 16.163. Segundo pleito, f. 182 V. ${ }^{\circ}$.

(103) Madrid, A. H. V., Clero, lib. 16.163. Segundo pleito, ya citado.

(104) Vid. DOMINGUEZ ORTIZ, Antonio, Crisis y Decadencia en la España de los Austrias. 3. ${ }^{a}$ Ed. Barcelona, Ariel, 1973: “La crisis en Castilla de 1677-1687», pp. 200 a 202.

(105) Vid. VILAR, Pierre, Oro y Moneda en la Historia (1450-1620). (Traducción de Armando Sáez y Juan Sabater). (Revisión de Jordi Nadal). 3. ${ }^{a}$ Ed. Barcelona, Ariel, 1974, p. 335.

(106) A este respecto destacan las ideas expuestas por Garcia Sanz en su obra Desarro/lo y Crisis... op. cit., pp. 361-371, que contrastan con las de Nöl SALOMON, La vida rural castellana en tiempos de Felipe 1I. (Traducción de Francesc Espinet). (Ed. castellana rev. por el autor y J. Fontana Lázaro). Barcelona, Planeta, 1973. Vid. el capitulo de la "reacción señorial». 
(107) Madrid, A. H. N., Clero, leg. 7.518: requisitoria sobre diezmos.

(108) Vid. el apeo de Villalar de 1683. Madrid, A. H. N., Clero, lib. 16.187.

(109) Madrid, A. H. N., Clero, leg. 7.518.

(110) Vid. el leg. 7.511 de la Sección de Clero del A. H. N. de Madrid.

(111) Vid. el Tumbo del monasterio de la Espina. Valladolid, A. H. U. V., sección Tumbo de la Espina, t. II, f. 140 V. ${ }^{\circ}$.

(112) Vid. el cit. Tumbo, t. II, f. 212.

(113) Vid. el cit. Tumbo, t. I1, f. 134 V..

(114) Vid. el leg. 1935 de la Sección de Hacienda del A. H. N. de Madrid. 


\title{
LA LARGA ESPERA DE LA MUERTE EN UNA CIUDAD VALENCIANA DEL SIGLO XVII. (ORIHUELA ANTE LA PESTE DE 1676-1678)
}

\author{
Por Mario MARTINEZ GOMIS \\ Universidad de Alicante
}

\section{INTRODUCCION}

Hace ya algunos años L. García Ballester y J. M. Mayer Benitez, en un trabajo conjunto(1), estudiaron las incidencias de la peste de 1647-52 en la ciudad de Orihuela, a la sazón capital de gobernación, sede episcopal y centro cultural, Atambién, en una amplia zona que podía recibir el influjo de su flamante Universidad. Desde el citado artículo, y a la espera de que surjan algunos trabajos en curso de elaboración o publicación(2), sólo $\mathrm{H}$. Kamen ha vuelto a ocuparse de los aspectos epidémicos en esta importante área del antiguo Reino de Valencia, y concretamente sobre Orihuela, al dar amplia noticia de la peste de 1676-78 que tuvo su foco propagador en la ciudad portuaria de Cartagena(3). Orihuela, en esta ocasión, junto a Murcia, volvió a quedar, como decía el escribano de su Consejo, "rodeada de un enemigo tan borás y tan mortal como el contagios(4), en el centro de un círculo mortífero cuyos límites se establecieron por el $\mathrm{N}$. hacia la cuenca del Vinalopó, para tener por el E. y S. el mar como barrera, mientras que por el $W$. la epidemia pareció encontrar su freno en esa línea imaginaria que une las poblaciones de Totana, Cieza y Tobarra. Del mismo modo que en en 1648 Orihuela no pudo evitar tan peligroso cerco; es más, acabó convirtiéndose en "cabeza de puente para la transmisión de la peste a las zonas del sur de la penínsulas(5), al cabo de treinta años, en 1678, volvio a sucumbir a sus efectos, aunque en esta ocasión su papel fuera tal vez otro muy distinto: el de contener, en la medida de lo posible, la propagación del mal 
hacia el norte gracias a los medios preventivos puestos en acción conjunta con Alicante.

El objeto del presente artículo no es otro que el de contribuir a rellenar aquellos vanos que la visión obligadamente general de $\mathrm{H}$. Kamen sobre la epidemia de 1676-78 ha dejado abiertos en lo que se refiere al caso específico de Orihuela. La finalidad, lejos de limitarse a la mera aportación erudita, es la de insistir sobre algunos puntos de la prevención sanitaria y de la posterior incidencia del contagio que pudieron alterar, en mayor o menor grado, las constantes económicas o socioculturales sobre las que descansaba esta ciudad valenciana, al tiempo que se pretende insistir, con la mayor objetividad posible, en el clima de tension y terror que las espectativas inevitables de la muerte crearon sobre nuestros antepasados durante la Edad Moderna.

Para la elaboración de este trabajo hemos recurrido principalmente a la documentación existente en los archivos locales: Archivo Municipal y Archivo Histórico de Orihuela. En el primero, hemos de decir que la base de cuanto vamos a exponer se halla contenida en "El libro de la Epidemia de 1678", los "Contestadores" de 1677 y 1680 y el legajo "Varios", siendo obligado hacer una serie de observaciones al respecto: a) que el libro de la "Epidemia" no se ajusta en realidad a documentos de esta fecha, puesto que en su mayor parte contiene copias de la correspondencia de la Ciudad relativas a la casi totalidad del año 1677; siendo tan sólo el "Informe de los médicos de Orihuela" y el "Informe del Comisario valenciano Dr. D. Juan Bautista Orivay" los únicos documentos relativos a 1678, año en que la Ciudad sufrió en realidad los efectos del contagio; b) el recurso a los contestadores de 1677 y 1680 se debe a la ausencia total de otras series informativas que hagan alusión directa al año de la epidemia; c) la consulta del legajo denominado "Varios" responde a ser éste, a pesar de su nomenclatura, un abundante y exclusivo compendio de documentos sobre las diversas plagas y epidemias que sufrió la Ciudad durante los siglos XVIII y XIX. La abundancia de este material no corre pareja, por el contrario, a la originalidad del mismo o a su uniformidad de cara a elaborar un trabajo de tipo demográfico, al menos en lo que respecta al siglo XVIII; d) los datos obtenidos en el Archivo Histórico de Orihuela son auxiliares, y han sido consultados con la intención de obtener noticias sobre las repercusiones de la epidemia en dos de las instituciones más importantes de la Orihuela del Seiscientos: la Universidad y el Colegio de Predicadores de los dominicos.

Hemos de señalar, por último, que las dos incursiones realizadas en el Archivo Histórico Nacional y en la Biblioteca Nacional se deben a informaciones concretas ofrecidas por H. Kamen en su libro citado: el legajo 7.189 de la sección de Consejos y el libro de Juan Bautista Orivay(6) respectivamente. Este libro que el historiador inglés no pudo utilizar ha sido de gran utilidad para nuestro trabajo. 
a) 1676: Los primeros sintomas de alarma ante el contagio de Cartagena.

La peste de 1647-52 se habia ensañado sobre Orihuela reduciendo su población a la mitad de la que poseía a finales del primer tercio del siglo XVII: de unos 12.200 habitantes, 5.000 perecieron entre Mayo y Agosto de $1.648(7)$; la cifra pues de sobremortalidad ciudadana fue de las más altas del reino y a ella se unieron los consiguientes efectos catastróficos de la epidemia: desintegración social, malestar económico, vacio poblacional en los sectores profesionales más cualificados, etc.(8). Toda una serie de hechos que, al cabo de una generación, debían hallarse lógicamente presentes en la mente de los oriolanos que reaccionaron de una manera harto sensible ante las primeras noticias de que el mal podía acecharles de nuevo.

En efecto, el 24 de Junio de 1676, a los pocos días de surgir los sospechosos indicios de plaga pestífera en Cartagena(9), el Consejo de Orihuela enviaba con toda urgencia al catedrático de Prima de Medicina Dr. Jaume Martínez y al cirujano Simón Asencio con la intención de que reconociesen la indole de la enfermedad. El 27 de ese mismo mes la Ciudad recibia un informe preciso, aunque precipitado, de ambos personajes certificando "que les enfermetats que hia en aquella ciutat (Cartagena) son epidemials, contagioses y pestilents y de la matexa especie des que hague en el any mil siscents quaranta huit»(10). Acto seguido el Consejo se apresuraba a poner en marcha alguno de los mecanismos clásicos preventivos tendentes a evitar la repetición de sucesos tan luctuosos como los que habian acaecido unas décadas antes. En primer lugar se constituía la "Junta de Salud Pública" - o "Junta del Morbo"-, y a dictado de la experiencia se proponían las primeras medidas a tomar que serían más tarde perfeccionadas y ampliadas. La índole de las mismas puede muy bien hablarnos de cuanto ocurrió treinta años antes y ahora se trataba de impedir. Al bloqueo comercial con la ciudad portuaria, se unian las ordenes encaminadas a evitar el contagio mediante la quema de mercancías y ropas procedentes de aquel lugar; los primeros intentos de conseguir dinero con el fin de consolidar el aislamiento físico y utapiar y cerrar portes y rampants de la present ciutat per estar aquella ab tants portells com al present constaw(11); las primeras y drásticas coacciones para controlar cualquier tipo de desorden que alterase la vida pública a consecuencia, o al amparo del pánico: "que es fasen les forques necesaries y es porte executor de sentencies" con objeto de que "se observe y guarde tot lo que se ordenarew(12).

La peste que los dos médicos oriolanos no habían dudado en diagnosticar en tan corto espacio de tiempo-por tratarse de ciudad 
ajena-pareció, sin embargo, congelarse al sur con la llegada del invierno de 1676, cuando ya algunos doctores, dada la escasa virulencia de la misma, habian optado por definirla como "tercianas" acompañadas de "algunos tumores detrás de las orexas y en las onglas»(13). La misma Orihuela, tras el sobresalto inicial y alarma de un brote de contagio surgido en Crevillente, paso el verano y el resto de 1676 sin ninguna alteración especial hasta el punto de que la "Junta de Salud" no volvió a reunirse desde mediados de Julio para tratar tema alguno de importancia sobre la enfermedad. $Y$ de este modo el 9 de febrero de 1677, el Cabildo Municipal ordenaba con cierto optimismo una procesión general para dar gracias "de que no haja agut en la present ciutat lo mal contagios que se ha patit en la ciutat de Cartagena y vila de Crevillents(14).

b) El nuevo brote epidémico de 1.677. El aislamiento de Orihuela y las medidas preventivas.

La amenaza de la epidemia, tras el respiro citado, no volvió a cernirse sobre Orihuela hasta la primavera de 1677. A partir de este momento, el estado general de alerta se estableció sin interrupción alguna hasta Mayo del año siguiente en que el cerco fue roto y la ciudad se vió irremisiblemente asaltada por la peste. Entre estas dos fechas se estableció, de modo harto elocuente, la lucha denodada de Orihuela por librarse del contagio a través de todos los medios posibles, la lucha por salvaguardar su pequeño universo amurallado no sólo de la enfermedad, sino también de todo indicio de anormalidad que alterase sus formas de vida.

Es el 21 de Abril de 1677, cuando aprovechando una visita del Consejo Murciano a Cartagena, por tenerse noticias de un nuevo brote epidémico, que Orihuela mandó al Dr. Francisco Moretó y al cirujano Ginés Martínez a recabar informes sobre la epidemia. Estos dos personajes más prudentes que sus predecesores, probablemente a causa del fiasco anterior, certificaron que, en efecto, se trataba de enfermos "de los mesmos que huvo el año pasado aunque no de tanta malignidad"(15). El juicio, lejos de ajustarse a la realidad-pues la ciudad portuaria se encontraba a punto de sufrir un verano más terrible que el de 1676 en cuanto a mortalidad se refiere-no fue compartido con el mismo optimismo por las autoridades oriolanas que comenzaron de nuevo a levantar el tinglado de la prevención. En primer lugar, el 3 de Mayo, tras decidir llevar a cabo el "tapiado" de la ciudad que no se había realizado el año anterior, el Consejo hacía partícipe a todos los lugares de su huerta de la situación de Cartagena para que se tomasen precauciones. Los acontecimientos comenzaron a precipitarse a partir de este momento, cuando el 26 de Mayo la epidemia entraba en Murcia y se extendía hacia sus lugares más proximos(16). El 12 de Junio alarmada la "Junta de Salud" por la llegada de la peste a la vecina villa de Elche, 
se escribía al Virrey dándole cuenta de la gravedad de los hechos: "De Cartagena-decian-no sabemos cosa alguna porque es tal el rigor con que nos portamos en la guarda, que planta alguna de aquella ciudad y sus términos no pisan el nuestro y asi no tenemos noticias fixas»(17); de Murcia se sabía que, a pesar de las muertes habidas, las precauciones tomadas habian impedido que el contagio se extendiese tanto como en 1648; de Elche que pedía socorro y ayuda para abastecerse de trigo por estar sus puertas cerradas al comercio. "Nosotros-exponian los oriolanos-estamos con la maior vigilancia que es posible por si podemos preservarnos de un sitio tan apretado como se ha servido Dios Nuestro Señor ponernos dejándonos en mitad de Cartagena, Murcia y Elchem(18). Y a Dios se encaminaba el primero de los remedios para conjurar el temor-siempre presente-a que se repitiese la gran epidemia del siglo: "la primera diligencia que habemos hecho es acudir a Dios Nuestro Señor que es el remedio más cierto y más eficaz, trayendo a la Santa Iglesia la Virgen de Monserrate que es nuestra Patrona... y al Sr. San Pablo que el año 48 le eligió esta ciudad. y Cabildo por suerte para abogado de la pestew(19). Después, entre las "diligencias humanas", se explicaba al Virrey el estado de alerta permanente de la "Junta de Salud" Ilevando a cabo dos reuniones diarias para tratar cualquier contingencia o imprevisto, el establecimiento de guardas en las puertas de la ciudad, vigiladas por sus fuerzas vivas: la Puerta de Murcia a cargo del Gobernador, caballeros y ciudadanos; la de Elche a cargo del Cabildo eclesiástico; la de Cartagena guardada por los justicia, jurados, racional, síndico y electos del Consejo(20). Otras medidas profilácticas llevadas a cabo se exponían a su excelencia entre las que destacaban la quema de ropa sospechosa y la publicación de pregones ajustándose ua todos los autores que hablan de este punto (la peste) y siguiendo las opiniones más seguras y rigurosas y los dictámenes de los Médicos que consultamos ordinariamente por peritos en esta facultads(21). Pero uno de los motivos principales de la misiva se reservaba para el final, tras hacer referencia a lo que más tarde sería considerado como una de las causas propiciatorias de la epidemia: la falta de medios económicos que afrontaba la ciudad a raíz de las malas cosechas del año anterior, en especial "de la seda que es donde nuestros vecinos se socorren de algún dinero y la del trigo y demás granos»(22). En virtud de ello, para luchar contra la peste, para no cargar todo el peso economico de la misma sobre los vecinos "aniquilados y sumamente pobres»(23) se solicitaba del Virrey que se detuviese por el momento el pago de las deudas contraidas por el Municipio-muchas de las cuales se remontaban aún a las consecuencias de la catástrofe de 1648(24) _, acentuando en este aspecto el tinte dramático de la situación: "...si hoy viniesen executores seía la total y cierta ruina y destrucción de esta ciudad y la más verdadera pestew(25).

Mientras tanto el Consejo habla organizado ya un sistema de recauda- 
ción de fondos con el fin de conseguir 4.000 libras que ayudasen a sufragar los gastos de compra de grano, reparaciones, vigilancia, etc. al tiempo que trataba de arbitrar soluciones para paliar el malestar de los cultivadores de la seda ya afectados por el cierre del comercio con el puerto de Cartagena.

Apelando a un sentimiento de solidaridad urbana que raramente se ponia de manifiesto en las épocas de normalidad, insistiendo reiteradamente en el amor patrio y recurriendo por último, para más seguridad, a la descarada coacción, el Municipio hizo una llamada a los hombres de negocio para que, con arreglo a su fortuna, concediesen una cantidad como préstamo so pena, entre otras, "de desavecindarles perpetuamente, pues el vezino que no ayuda a su patria en una urgencia tan fuerte no deve gozar de los privilegios de serlow(26). Estas razones y la promesa de devolución de lo prestado con el incremento de los correspondientes intereses pareció dar buenos resultados de cara a la consecución de las 4.000 libras a juzgar por las esperanzadas palabras al Virrey: "lo hasen mul gustosos sin haver sido necessario pasar a mayor rigors(27).

En cuanto a lo concerniente al negocio de la seda, al margen de las malas cosechas que hemos mencionado, éste había sido uno de los primeros sectores económicos en padecer las consecuencias del contagio surgido en Cartagena. En efecto, cerrado su puerto a los mercaderes extranjeros donde los oriolanos tenían buen número de clientes, las expectativas hicieron suponer que la ausencia de los mismos podía provocar una caída de los precios al quedar reducida la demanda a la ejercida por los mercaderes locales. Estos, a juicio del Concejo, podrían "comprar la seda a preus molt inferiors confiats en que los vehins la an de vendre a qualsevol preu; perque forsosament an de acudir a posar en cobro sos fruits»(28). Para evitarlo se ordenó fijar los precios tanto de la seda como del capullo, imponiendo severas penas a cuantos, vendedores y compradores, infringieran la ordenanza. Al mismo tiempo se prohibió la acción de los comisionistas locales, intermediarios que vendian a los mercaderes de fuera de la ciudad con gran margen de beneficios.

Mientras esto ocurría, la irrupción del verano de 1677 iba a someter a la aislada ciudad a una serie de duras pruebas, conforme la epidemia iba estrechando el cerco a sus muralles. Alicante, por ejemplo, a mediados de Junio, ante la suposición de la inevitable arribada del contagio a Orihuela, decidió romper sus relaciones comerciales con ella. El pretexto, meramente preventivo todavia, se fundaba en que la ciudad del Segura para comerciar con Alicante tenía forzosamente que atravesar las tierras del Marquesado de Elche, villa ésta que al igual que Crevillente el año anterior padecía ahora la enfermedad. La reacción de Orihuela no se hizo esperar y el 23 de Junio escribía de nuevo al Virrey quejándose de esta medida(29) y exponiendo los graves problemas que la suspensión podia provocar entre 
los oriolanos toda vez que, como era cierto, gozaban estos «todos assi los que habitan dentro de la ciudad como los que viven en las guertas y campos de este termino, una salud lo más felis que habemos conocido de mucho a esta parte, que es más admirable siendo en la estación del verano en que de ordinario ay algunas tercianas y este año aun esta enfermedad regional no se ha experimentado y los médicos están sin tener que haserm(30). El miedo estaba también en razón de que otras ciudades, pueblos y lugares imitasen la decisión de Alicante. No dudaba por ello el Cabildo Municipal en insistir hasta la saciedad en el buen estado de salud de sus habitantes, añadiendo incluso la existencia de un esporádico descenso de la mortalidad normal durante los últimos veinte dias que habían precedido a la drástica decisión de las autoridades alicantinas. En todo este tiempo-decian los oriolanos-sólo en dos ocasiones había salido el Santísimo Sacramento para atender a dos enfermos no contagiosos y ello en la parroquia de la Catedral que era la más numerosa de la ciudad sobrepasando los ochocientos parroquianos(31). El aislamiento con Alicante, por último, podía ser catastrófico, no ya sólo con miras al aprovisionamiento de alimentos, sino porque podía ser causante de facilitar la entrada de la epidemia en Orihuela, como señalaba el escribano de su Consejo. Ello podia producirse debido a la ausencia de nieve en Sierra Espuña, donde la ciudad tenía sus pozos, y a la necesidad de ir a buscarla a la Serella (al NW de Alicante). La ausencia de este elemento era considerada de vital importancia para la salud pública, sobre todo para combatir las "gravisimas enfermedades de tavardillos y calenturas malignas que solo se pueden preservar con la nieve... que es la maior medicina y la mejor preservación de todas las enfermedades, y más en esta tierra por lo cálido de su temperamentom(32).

Durante la primera quincena de Julio, en tanto y cuanto se gestionaba la solución de estos inconvenientes, las medidas de prevención comenzaron a extremarse por el punto más débil que presentaba la defensa de la ciudad: la huerta. Ante reiteradas noticias del libre desplazamiento de los campesinos y el temor a que viajasen hasta Murcia o Elche para suministrar de modo ilegal algún producto con peligro de contraer la enfermedad(33), "la Junta del Morbo" comenzó a mandar a sus delegados por los distintos lugares y partidas del término municipal con misiones concretas de control y vigilancia: imponer "cuarentenas" bajo guardia en aquellos sitios donde se tuviera noticia de que había habido contacto con los focos de infección, introducir agentes "cautelosos" en la comarca con el fin de recabar cualquier tipo de información sobre indicios de la epidemia, nombrar "comisarios" que se encargasen de ejecutar las órdenes emanadas de la "Junta", e incluso, crear patrullas especiales para el acompañamiento de los viajeros que quisieran desplazarse hasta la raya de Castilla. Todo ello con el consiguiente desembolso monetario que comenzaba a desequilibrar la ya de por sí frágil economía municipal. 
Hacia el 10 de Julio un acto conciliatorio entre Orihuela y Alicante en torno a la cuestión del aislamiento comercial, que quedó zanjado a favor de los intereses de Orihuela, vino a desembocar en una de las decisiones más meditadas y costosas de cuantas se relacionaron con la prevención de la epidemia: la creación de un cordón sanitario que salvaguardase del contagio a las dos ciudades(34); una solución que tendia asimismo a aislar a la huerta oriolana del peligro inminente. En efecto, reunidas por esta fecha dos embajadas de ambas localidades en lugar neutral-como se tenía por costumbre en los momentos de crisis epidémica para cualquier tipo de conferencia o transacion-, alicantinos y oriolanos, tras escribir al Virrey recabando ayuda económica, decidieron estudiar los límites geográficos por los que se debía trazar la barrera de aislamiento, así como ajustar el contingente humano que podía hacer efectivo el cordón; un cordón mediante el cual, se pensaba "no sols es preservaran dites ciutats si que es preservara tot lo regnem(35), de aqui el deseo de que Valencia contribuyese a la subvención del proyecto.

Las líneas para cortar "el fuego de la epidemia»(36) debian ser cuatro (véase mapa): las dos primeras en longitud e importancia estarían encaminadas a aislar los focos de Cartagena y Murcia del SW del reino valenciano mediante una línea quebrada a la que se denominó como "el primer y segundo cabo del cordón". Esta debía correr paralela al río Segura, desde su desembocadura hasta los mojones de la ciudad de Murcia-primer "cabo"-para prolongarse desde aquí en dirección S-N hasta Novelda y Monforte pasando por Abanilla - según "cabo"-. Se calculaba a este trazado unas 9 leguas y media de longitud y se distribuian para su control sesenta y seis hombres en veintiun puestos de vigilancia. El tercer "cordón", destinado a aislar Elche y su término de Alicante y Orihuela, era una diagonal en dirección SE-NW que debía de enlazar la desembocadura del Segura con un cabeto situado al N. de Crevillente, cubriendo unas 2 leguas de distancia con diez puestos de vigilancia y veintisiete guardas. Diez cabos y cuarenta y seis hombres a caballo debian recorrer permanentemente los tres cordones citados. Por último, un cuarto "cordón" iría desde el mar - un punto indeterminado al sur de la ciudad de Alicante hasta enlazar con Abanilla. Las 7 leguas de su trazado estarian custodiadas por cincuenta guardas distribuidos en veinticinco puestos de vigilancia, mientras que cuatro cabos y treinta hombres a caballo se encargarían de recorrer la línea. El gasto diario de la operación alcanzaba la no despreciable suma de 951 reales(37). 


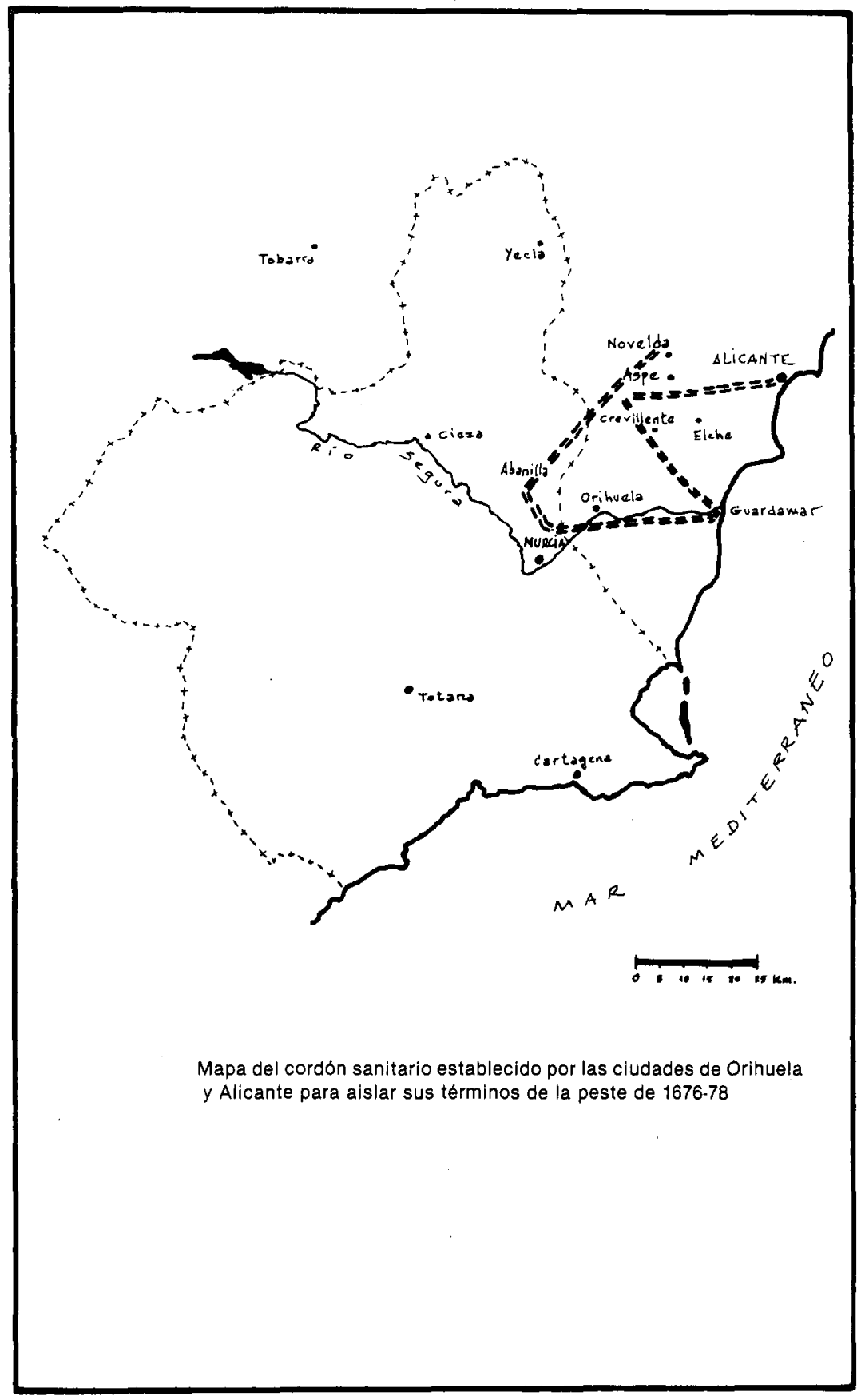


No obstante esta preocupación los motivos de alarma e inquietud continuaron acosando a Orihuela durante el resto de la canícula de 1677. En la segunda mitad de Julio intentos de sacar trigo de contrabando desde Callosa hasta Alicante pudieron ser evitados por las fuerzas de vigilancia del "cordón" sometiéndose a castigo a los infractores(38); a primeros de Agosto, los calores trajeron consigo la necesidad de extremar el aislamiento con el exterior prohibiéndose todo tipo de comercio con uels llochs y viles que esten la Ribera del riu Segura terme de Castellas(39). La noche del 16 de ese mismo mes el tercer "cordón" era roto tal y como denunciaba la Sra. D. ${ }^{a}$ Inés de Rocamora al Concejo por «molt número de gent de acavall y de apeu de la villa de Elig que han entrat en el terme de la present ciutat, en el Ginebrar, y se han llevat una manada de vaques parides y pre-

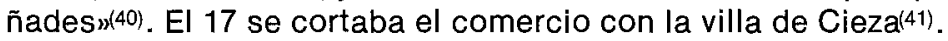

Ni la llegada de Septiembre ni el final del otoño parecieron durante este año traer la tranquilidad a Orihuela. El estado de alerta continuaba. El cordón sanitario, en pleno Noviembre, aunque no se había producido brote alguno de contagio en la ciudad, seguía vigilante mirando hacia el exterior(42) mientras un enemigo interno hacía su aparición: el fantasma del hambre que comenzaba a levantarse sobre las mismas piedras de la capital del Bajo Segura. Un mal anunciado ya en primavera - «la collita del present any ha segut molt tenuew(43) — un mal que las lluvias torrenciales y avenidas de Agosto se encargaron de agravar(44). El Pósito, para colmo de los males, comenzo a menguar y sus fondos de grano dejaron de ser una garantía para soportar el invierno que se avecinaba(45). Si añadimos a esto que el dinero recabado de los mercaderes se iba en reparaciones y vigilancias comprenderemos mejor la progresiva rapidez de las medidas destinadas a conseguir el aprovisionamiento de grano. Primero una orden encaminada a que los deudores de las rentas ordinarias y extraordinarias de la ciudad hiciesen efectivos sus pagos en trigo(46); más tarde, una acentuación de la vigilancia intramuros para evitar la salida de cereal, era seguida por el cierre de las panaderías con el fin de centralizar la venta de harina en el Pósito mismo, por último, con la llegada de' Diciembre, las obligadas y temidas requisas por orden de la "Junta" poniendo al descubierto la desigualdad económica de los oriolanos y los primeros síntomas de insolidaridad social:

"...Aprovem los embargos que se han fet de orde berbal de la Junta en les cases dels vehins de la present ciutat, seglars y eclesiastichs, y les visites de les convents on se a tengut sospita de que y abia forment de alguns particulars seglars, y que esta diligencia es continue, embargant primer lo forment que es trobará en les cases dels mercaders, y demes seglars y lo que es trobará en los combents y será de dits seglars, y en apres lo que es trobará en les cases de les persones eclesiati- 
ques ab president eclesiastich señalant y dixant a cascu lo que porra haver menester pera subvenir sa casa y familia desde hui fins lo dia de Sent Joan primer vinent...(47).

Y como el humo que presagia el fuego, en Diciembre también, el trágico aviso: "en algunes cases de lo camp de la present ciutat se recela a agut alguns vehins del camp de Murcia, es te noticia ay alguns malalts....(48).

c) La ruptura del cerco e irrupción de la muerte en Orihuela durante la primavera-verano de 1678.

Después, tras un paréntesis temporal que el vacío documental nos impide rellenar con minuciosidad, llegamos a las puertas mismas del verano de 1678, el verano del contagio. ¿Qué ocurrió durante el invierno y la primavera?. Sabemos que climatológicamente fueron estaciones extrañas, "que desde el equinoccio vernal, y aun antes, reynaron los ayres occidentales, que llaman vulgarmente Potentes (Sic), con excesivo calor, y sequedad, hasta los primeros de Abril, en el qual tiempo se movieron ayres de Tramontaña, tan frios, que igualavan al inviernow(49); que entre el 1 de Enero y el 10 de Abril enfermaron 120 personas de las cuales perecieron justamente la mitad sin que se huviera visto en ellas sospecha alguna de contagio(50); que la alarma, los primeros indicios de peste, aparecieron entre el 10 de Abril y el 12 de Mayo cuando el número de personas visitadas por los médicos de la ciudad ascendio a 117, falleciendo de ellas $35(51)$ y la capital del Reino, sensibilizada ante el problema, comisionó a uno de los catedráticos de su Universidad, el Dr. D. Juan Bautista Orivay y Monreal, para que informase sobre la situación en Orihuela(52). El resto de la información, en su mayor parte, procede de una de las típicas polémicas protagonizadas por los médicos que se atrevieron a diagnosticar la enfermedad(53).

La llegada del Dr. Orivay a Orihuela el 12 de Mayo de 1678 propició de inmediato una reunión de la "Junta de Salud" en la que el médico valenciano solicitó bajo juramento un detallado informe de los enfermos visitados por los catedráticos de medicina de la Universidad oriolana: Basilio Miravete, Francisco Moretó, Esteve Camurla, Joaquín Genesia y Simón Asencio-este último cirujano(54) - El balance de las visitas realizadas por éstos entre el 10 de Abril y el día de la fecha arrojó una cifra de 117 enfermos, 6 de ellos con "tercianas" que no habían provocado ninguna víctima; 11 calificados de sufrir "tercianas intermitentes" dándose entre ellos 2 fallecimientos; 40 afectados de "fiebres continuas" a consecuencia de las cuales 13 habían perecido; 10 con "tabardillo" muriendo 7 de los mismos, y 50, por último, con "trastornos varios" (cólicos, "incordios gali- 
cos", asma, gota, contusiones, desnutrición, etc.) que habian producido otras 13 muertes.

A pesar de los numerosos casos que presentaban sintomas de peste (vómitos, tumores y bubones en axilas e ingles, fiebre muy alta, etc.)(56) y de que el $42 \cdot 5 \%$ del total de fallecidos presentaban estas señales en sus cuerpos, el Dr. Orivay dictamino con el consenso de sus colegas que el contagio no se debía a peste. De este modo, declaraciones a todas luces sospechosas no fueron puestas en duda y se aceptaron como causa de los síntomas y enfermedades las más extrañas razones. Así, una mujer que presentaba un bubon en la axila y padecía fiebre, tras haber enterrado a su marido y su hija el dia enterior, declaraba que dicha inflamación era debida a un golpe que se había dado èn la mano(56); otra declaraba que su niño había fallecido "por el sofoco de haver oit plorar a sa mare per la mort des altres fills que moriren»(57); el dueño de una esclava indicaba que a pesar de los bubones que ésta presentaba, el fallecimiento de la misma se habia producido a causa de «menjar llet y carchofes»(58); idéntica dieta reconocía el Dr. D. Basilio Miravete como origen de la muerte del criado de un sacristán: «ab una colica viliosa de haver menjat llet y carchofes li feu rapte al cap y li dona frenesi, es Ilança per una finestra y mori rebentat»(59). El Dr. Francisco Moretó describía también sus casos más graves con una especie de resignado laconismo: "...altra dona ab terciana continua, molts vomits, mal alimentada ab un tumor en lingle esquer, ocasionat segons dit to sirugia de unes bastonades, mori el quinse»(60), "...visita a un home ab una tersiana ab molts vomits, tingue un dolor en la regio del ventre corresponen a lingle dret sense elevació notable de la part, mori al quint dia»(61).

¿Era el miedo a las consecuencias del bloqueo comercial lo que cegaba a los médicos?, ¿las presiones del Municipio sobre sus personas?, ¿la duda auténtica en base a los conocimientos de la época, a las interpretaciones silogísticas de los textos de Galeno e Hipócrates, que podian incluso volver del revés sus viejas observaciones?.

Resulta difícil de dilucidar. A tres siglos vista de los acontecimientos, las deliberaciones aparecen ridículas ante lo patético de la situación. Sólo la impotencia de los médicos que parece traslucir de los documentos, justifica en parte las finas disquisiciones argüidas en torno a si la enfermedad de Orihuela era "peste" o "contagio pestilente", "fiebres malignas" o "calenturas" ocasionadas por la "prava victus ratio»(62). Sea como fuere el caso es que el Dr. Orivay, tras estudiar los informes, tras realizar una rutinaria visita a 26 enfermos el mismo día 12 de Mayo trazo el cuadro clínico general de la situación:

«...Observamos variedad de enfermedades, unas benignas, como tercianas, otras intermitentes; otras perniciosas, como calenturas malignas punticulares, uno o dos carbuncos sin calentura, que estavan ya en convalescencia: otros padecian 
bomitos de alimentos indigestos sin calenturas, otros diviesos fuera de los emuntorios, que se llaman Phimata segun Galeno... otros destruidos de fuerças totalmente, sin mas enfermedad que hambre, como lo manifiesto una muger, que delante de todos dixo, no tener mas enfermedad, que no aver tomado alimento de sustancia en quinze dias, de syncope resolutivo murio aquella noche; al otro dia murieron madre y hija y por la misma causa...(63).

La causa de la enfermedad estaba clara para el catedrático valenciano: la escasa alimentación en la gente pobre desde los últimos seis meses. El pronóstico no tanto, pero había que salvaguardar las espaldas: "se puede tener cualquier mala constitución comun y peligrosa»(64). De esta manera Ginés del Portillo, Secretario de la Ciudad, levantó el acta de la visita recogiendo la serie de medidas preventivas que habían de aplicarse con total rapidez, según el propio Dr. Orivay, para paliar el mal: 1) bajar el precio del trigo; 2) Prohibir el consumo de alimentos tales como "carchofes, llet fresca, pa de sivada, de panis, de sigrons, de caravasa y altres semilles....x(65); 3) Proceder a la purificación de las viviendas y ropas de cuantos padecieran fiebres malignas y punticulares; 4) Prohibir a los boticarios de la ciudad la venta de medicinas contra la peste; 5) aumentar el salario de los médicos y cirujanos con el fin de que pudieran asistir gratuitamente a los pobres vergonzantes; 6 ) Prohibir el cultivo de arroz a menos de una legua de la ciudad.

No había más que hacer en Orihuela. El Dr. Orivay la tarde del 14 de Mayo decidió partir hacia Murcia con el fin de recabar informes sobre su situación sanitaria. El 16, sin embargo, recibio un aviso urgente de Orihuela donde, repentinamente, las cosas se habian agravado. El mismo describio el panorama que encontró a su regreso:

"Volví (el 17) con toda celeridad... halle averse declarado el contagio de calenturas malignas, con puntículas, bubones porraceos, sincopales, y muerte inesperada, que el que mas se alargava, no pasava del cuarto dia....s(66).

El número de enfermos.visitados la jonada del mismo 17 ascendio a 40, 26 de ellos presa de graves calenturas, habiéndose producido 14 fallecimientos durante las cuarenta y ocho horas anteriores. No obstante incrementar las precauciones con aceleración-abrir inmediatamente un hospital-el Dr. Orivay siguio en sus trece cuando su colega el Dr. Pablo de Vera, comisionado a su vez por Murcia, se atrevió a afirmar que el mal era upeste declarada, pues todas las señales lo comprobavan»(67). A su respuesta de que resultaba "ser mucha facilidad el dezir era peste, sin más averiguación»(68), siguió una estéril polémica entre ambos que se resolvió en el acuerdo-no sabemos hasta que punto forzado en lo que respecta al médico murciano-por llamar a "la constitución contagio pestilente". 
Pero en forma de "peste» o "contagio pestilente", la muerte, sin comprender tal tipo de sutilezas, se introdujo en la ciudad, y entre el 14 de Mayo y los últimos dias de Junio, roto el cerco que habia durado dos años, comenzo a cobrar sus victimas. Es cierto que, según todos los indicios, la enfermedad no tuvo punto de comparación alguno; en cuanto a morbilidad se refiere, con la peste reconocida de 1648 . El Dr. Orivay que escribió años después un libro en defensa de sus teorias, rebajando tal vez las cifras para mejor respaldarlas, hizo un balance que, aunque trágico, no alcanza las dramáticas cotas de otros contagios: "los enfermos han sido poco más o menos más de mil; los muertos, poco más de quinientos y noventa, y entre ellos 400 niños... y de unos y otros no llegan a treinta las personas de lustre y bien nutridas (69). La información, como puede apreciarse estaba en función de su tesis, aquella que defendía que el mal era debido a "calenturas malignas" que se cebaron discriminadamente sólo sobre los cuerpos mal alimentados. Para el Dr. Orivay la enfermedad duro "mientras ha avido pobres que caer, y destos los más niños y mugeresw(70), afectando sólo a los Arrabales y sin introducirse apenas en el centro de la ciudad donde vivían los acomodados(71). Aquí sólo murieron algunos: aquellos que tuvieron contacto directo con los enfermos "como confessores, médicos, cirujanos y sirvientes y estos en número muy limitado, tanto que es digno de despreciarse»(72). No parece, a pesar de la preocupación señalada, escamotear las cifras de mortalidad el catedrático valenciano. En un decreto del obispo D. Joseph Vergé a los eclesiásticos de la comarca, con fecha 15 de Julio la noticia de fallecimientos hasta ese dia viene a coincidir con su apreciación: "han muerto más de quinientas personas »73). Este dato, en un momento en que la enfermedad comenzaba a remitir, parece acercarse con justeza al número total de víctimas ante el que sólo discrepa una información, a nuestro juicio exagerada, de los dominicos. Estos, a mediados de Septiembre, cuando todo volvía a la normalidad, anotaban en su libro de Consejos: «En el año 1678 fue Dios servido castigar a esta ciudad de Origüela con un lastimoso contagio, del qual (aunque solo duro tres meses) murieron passadas de mil y quinientas personas....s(74). Si tenemos en cuenta que en Murcia, donde la incidencia de la peste fua mayor, el número de muertes fue de 1.098(75), la razón parece inclinarse a favor de los datos ofrecidos por el médico y el prelado.

Sea como fuere el caso es que Orihuela reaccionó ante la epidemia como cabía esperar: con el pánico ancestral que alimentaban los recuerdos. Ricos y nobles huyeron de la ciudad(76); los pobres escaparon también rompiendo el cerco; los médicos abandonaron a sus pacientes(77); hubo incluso hombres y mujeres que fallecieron de miedo(78) y las escenas escabrosas de los antiguos grabados se sucedieron al lado de los fosos de enterramiento donde faltó la cal, y donde se vió a los perros comer cadáveres y correr por los campos portando entre sus fauces miembros humanos(79). El único hospital abierto en el convento de los Capuchinos, 
lejos de contribuir a la curación de los enfermos, les empujó a las zanjas acelerendo el curso de la muerte. En su inadecuado recinto hubo de colocar dos camas en cada celda "y en cada cama dos, y a vezes, tres enfermos; con el desahogo para ventilación de los vapores corruptos, y libertad de muy pequeñas ventanasw(80). El orden, los preparativos, las prevenciones, se vinieron abajo como un castillo de naipes ante lo irremediable del contagio.

Después, al terminar el verano, volvió de nuevo la calma. Como un primer sintoma de la vuelta a la normalidad el Cabildo catedralicio, que había excusado de sus obligaciones a canónigos y prebendados durante la epidemia para que pudieran "huir del peligro», el 29 de Agosto solicitaba ya el regreso de los eclesiásticos a sus funciones(81). El 17 de Septiembre el Concejo, con un solemne "Te Deum" acompañado más tarde de procesión en honor de la Virgen de Monserrate y de San Pablo, celebraba la huida de la enfermedad obligando a la población a portar «luminarias y otras hierbas aromáticas" so pena de sesenta sueldos de multa a quien no cumpliese con este mandato(82). Por último, el 5 de Octubre, los doctores Pablo de Vera y Andrés Fernández, comisionados por la vecina Murcia para visitar Orihuela, certificaban el buen estado general de su salud reconociendo no "haber hallado enfermo alguno del contagio pestilente que se ha padecidos(83), aunque su ciudad aguardase todavia hasta Enero del año siguiente para reanudar las relaciones comerciales(84). La última epidemia importante del siglo XVII pasaba de este modo a la historia sobre la capital del Bajo Segura, mientras su fuerza, esta vez, se detenía ante el río Vinalopo, dejando libre el resto del reino valenciano.

\section{CONSECUENCIAS MAS IMPORTANTES DE LA EPIDEMIA DE 1676-78}

¿Cuáles fueron las consecuencias de esta epidemia en Orihuela?. ¿Hasta qué punto dejó en ella una huella duradera?. Resulta difícil ofrecer, dadas las escasas fuentes que poseemos, una respuesta rigurosa a estas preguntas. Al menos en cuanto hace referencia al punto de vista estríctamente demográfico. Desde esta perspectiva, salvo las escasas apreciaciones cuantitativas ofrecidas en el apartado anterior, la enfermedad no dejo otro tipo de rastro documental que nos permita calibrar con exactitud la incidencia de la muerte en Orihuela. Los registros parroquiales de la época(85), por ejemplo, son en cierta medida insensibles a este respecto como puede apreciarse en los datos que ofrecemos en los Gráficos y Apéndice documental. El hecho de que muchos cadáveres fuesen enterrados en las fosas comunes, escapando así del cómputo eclesiástico, puede ser una de las razones que explique la aparente normalidad de la mortalidad durante los años cruciales de 1677-1678. Pero no podemos olvidar tampoco que otra de las causas de este silencio puede radicar en las 

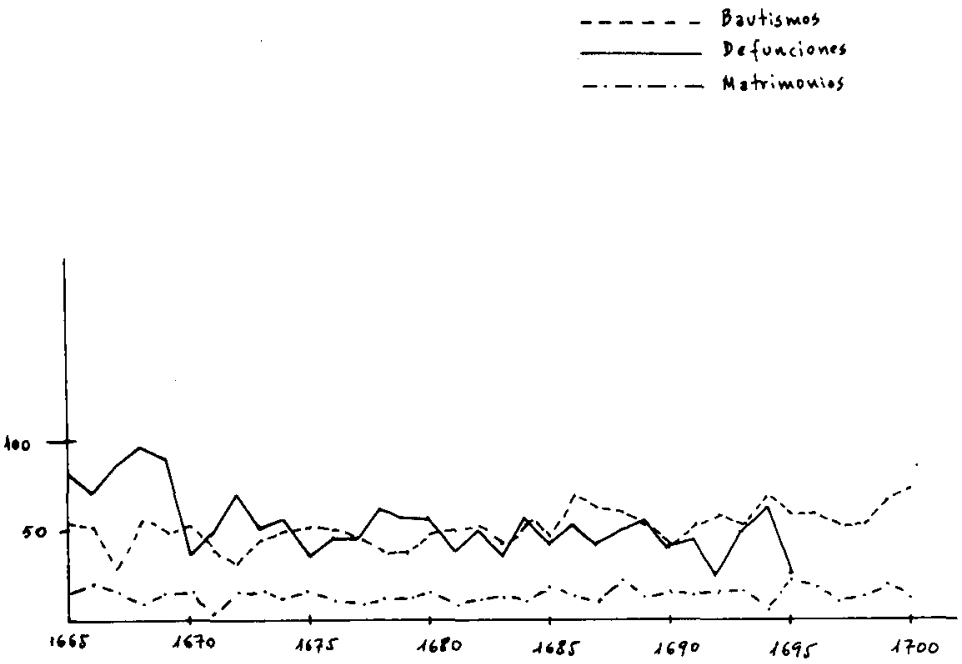

GRAFICO I.-Oscilaciones de los bautismos, matrimonios y defunciones en la parroquia de Sta. Justa y Rufina de Orihuela (1655-1700) 


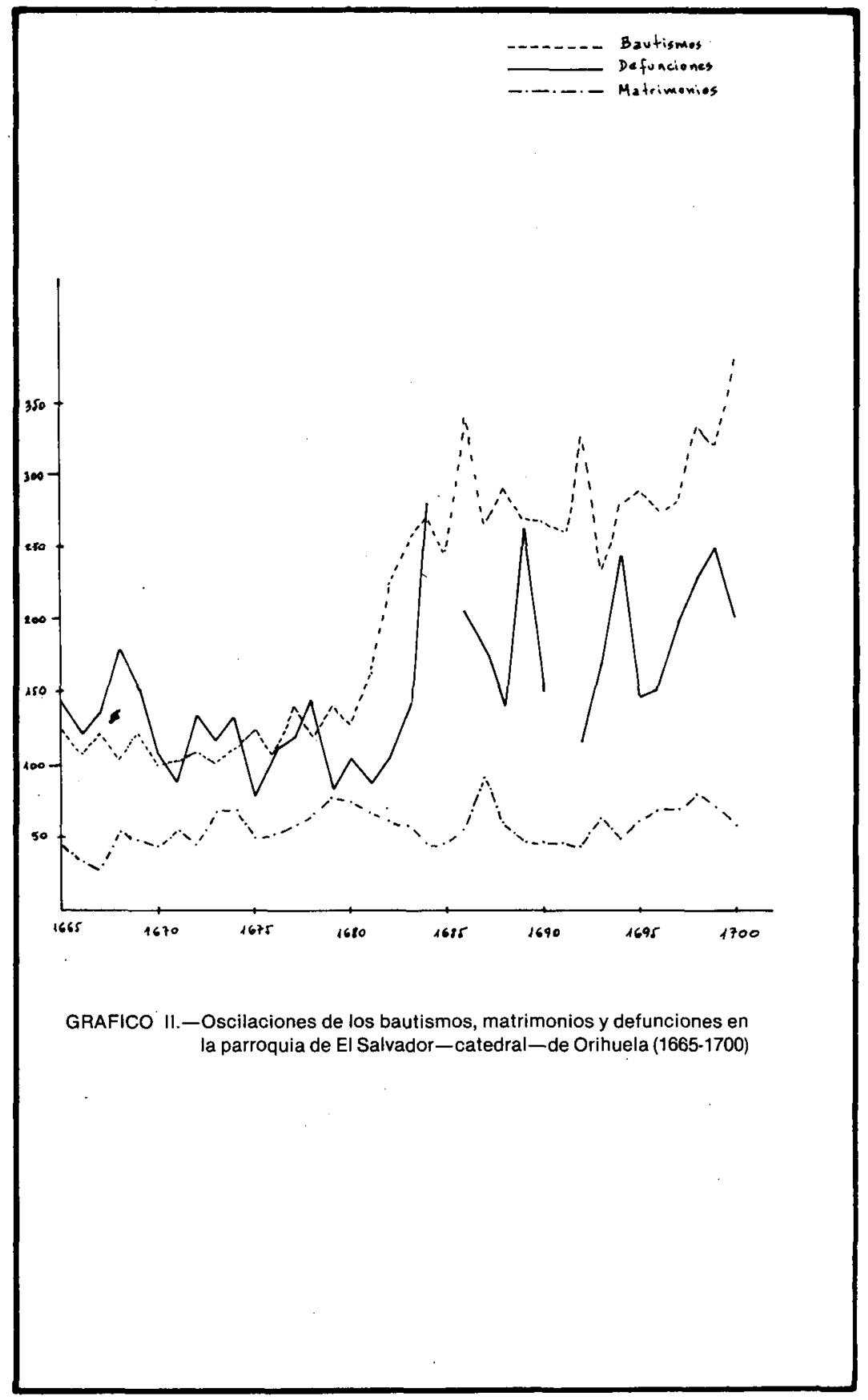


consideraciones vertidas por los contemporáneos: esas escasas quinientas o seicientas defunciones, o el hecho de que la morbilidad afectase menos a los habitantes de los barrios centricos y acomodados de la ciudad que eran, en resumidas cuentas, los feligreses de las parroquias sobre las que ofrecemos las únicas series numéricas de datos existentes.

Las cifras absolutas de mortalidad, por lo tanto, hablan de la escasa virulencia de la epidemia con respecto a otras catástrofes anteriores. La importancia relativa de las mismas resulta en cambio difícil de dilucidar por lo contradictorio de las informaciones que poseemos acerca de la población oriolana durante los años que precedieron y siguieron a la enfermedad y sólo podemos, en base a las mismas, tratar de especular para ofrecer datos aproximativos. Es prácticamente imposible creer, por ejemplo, si las estimaciones de L. J. Ballester y J. M. Mayer Benitez son ciertas, que de unos 5.000 habitantes tras la peste de 1648 , Orihuela(86) pasase en 1675 a unos 11.250 según cifró $R$. Méndez Silva(87) -2.500 vecinos-, máxime si tenemos encuenta que un censo de 1716 estudiado por J. Millán(88) arroja un balance de 6.448 almas y que en 1754-en pleno auge demográfico-la población sólo alcanzaba los 9.423 habitantes(89). La población de Orihuela en visperas de la epidemia que estudiamos según lo que acabamos de exponer, y basándonos en otras estimaciones de los contemporáneos, no debió sobrepasar los cinco millares de seres, tal y como parece desprenderse de un censo de casas realizado en 1660 que presentaba un total de 3.987 habitantes $\left({ }^{(0)}\right.$ y de la opinión del Dr. Joaquín Genesia-protagonista directo durante la enfermedad-quien atribuyo a la ciudad 4.500 habitantes en 1679(91). Esto corroboraría en parte la hipótesis de D. Bernabé Gil acerca del estancamiento demográfico oriolano durante las décadas centrales del siglo XVII, estancamiento producido por la despoblación de su campo y huerta ya iniciado años antes de la epidemia que cerró la década de los cuarenta(92). Las aproximadas seicientas víctimas de 1678 sólo habrian supuesto, por lo tanto, un descenso de la población oscilante entre un 9 y un $11 \%$. Porcentaje lamentable, es cierto, pero fácil de recuperar si tenemos en cuenta que Orihuela-al igual que buena parte de la periferia peninsular-se encontraba a las puertas de abandonar el declive poblacional secular(93) par entrar en una fase de lento pero continuo crecimiento demográfico.

Otra cuestión de tipo diferente es la que hace referencia a los males económicos derivados del contagio. No sabemos hasta qué punto la epidemia pudo paralizar las actividades agricolas, artesanales y mercantiles, ni la duración que este hecho-con los trastornos consiguientes-pudo alcanzar. Los documentos hablan sólo del "malestar general" de un modo vago, haciendo especial hincapié en aquellos desarreglos que afectaron a las arcas municipales. Hemos dicho ya que el Concejo, durante la primavera de 1677 , respondía todavia los intereses de los préstamos contraidos 
durante la enfermedad de 1648. J. B. Vilar ha descrito el estado de total insolvencia en que quedó sumida la ciudad a raíz de este último acontecimiento y la duración de estos efectos(94): cómo se vió obligada a desprenderse de parte de sus propios, cómo hubo de disminuir drásticamente la empleocracia concejil y recortar los emolumentos de los reducidos cuadros de gobierno ciudadano. En 1677, en pleno cerco de la nueva epidemia, una nueva reducción del personal administrativo de la Ciudad tuvo lugar(95) al mismo tiempo que se solicitaba la ayuda económica ya citada de las 4.000 libras a los mercaderes. Las consecuencias pues de una catástrofe, enlazaron al cabo de los treinta años con la otra, y el 27 de Junio de 1678, cuando se comenzaba a vislumbrar la desaparición de esta segunda mortandad del siglo, los aprietos financieros de Orihuela obligaron ya a cargar sobre la esquilmada población una sisa de dos dineros por cada libra de carne vendida en los establecimientos de la urbe que contribuyese a pagar las pensiones del $5 \%$ sobre la cantidad adelantada por los mercaderes; sisa que estaba dispuesto a pagar, también, el estamento eclesiástico por tiempo ilimitado hasta que pudieran ser quitados los censos(96).

Son las fuentes documentales indirectas sin embargo, especialmente aquéllas que hacen referencia a las repercusiones de la epidemia en el ámbito de la Universidad oriolana, las que nos ayudan a trazar un cuadro más completo de la situación del Cabildo municipal en los años siguientes a 1.678 , al tiempo que ponen al descubierto algunas de las consecuencias que derivaron en el orden cultura|(97).

En efecto, el monarca Carlos II hubo de intervenir a finales de 1681 conminando a la Ciudad para que hiciese frente a sus acreedores. Tras ordenar que se congelasen los gastos extraordinarios del Municipio con el fin de que estas cantidades contribuyesen a la amortización de las deudas, la intervención del Vírrey-basada en una libre interpretación de esta orden-fue mucho más lejos y un mandato suyo tendió a lograr una mayor parte en la enajenación de las rentas municipales que afectó de modo muy directo al Estudio General de Orihuela. Aunque la Ciudad pleiteo sin suerte por cambiar esta decisión, al final, un porcentaje también de los gastos ordinarios pasó a engrosar el capitulo de amortizaciones. Entre ellos se contaba parte de la subvención municipal a la Universidad que fue incautada por ser, al decir del Capitán General del reino «...mas principal la obligación de acudir a los pagos de estos creditos, que mantener las catedras de esta Universidad»(98). Hasta últimos de la década de 1.690 en que la Ciudad comenzó a experimentar los primeros síntomas de recuperación económica(99) esta situación se prolongó afectando duramente a la vida universitaria, al tiempo que truncaba muchas de las esperanzas - tal vez ilusorias-que las autoridades oriolanas habian depositado en el Estudio como medio hipotético para sanear la deficitaria economia municipal(100).

La concatenación de los hechos fue la siguiente: a la lógica ausencia 
de estudiantes durante 1677-1678, siguió la incautación y reducción de muchos de los salarios de las cátedras dotadas por la Ciudad-la totalidad de las de Derecho Civil y Canónico, Medicina y algunas de Artes-. Muchas de estas cátedras hubieron de ser ejercidas sin salario, otras fueron otorgadas en encomienda con una gratificación mínima, y otras, quedaron desiertas sin que nadie se ocupase de su enseñanza. Esta situación repercutio en un deterioro de los estudios que lógicamente no contribuyó a la atracción de estudiantes tal y como se esperaba desde 1646 en que se obtuvo el Privilegio Real para la institución: «...el medi major y millor que hia ni es pot buscar pera que la pnt. ciutat es fasa y creixca en numero de gent e se aumenten les sises e imposicions que te, es el posar Universitat de Estudis....x(101). El hecho de que entre 1678-1685 solo se concedieran 102 grados académicos, uno más que en los ocho primeros años del período fundacional de la Universidad, 1610-1617(102), cuando ésta no contaba con ningún tipo de promoción, demuestra a las claras su estancamiento durante el periodo siguiente a la epidemia. Estancamiento que se prolongo mucho más que la crisis económica municipal, ya que Valencia, que nunca habia visto con buenos ojos al Estudio General del Bajo Segura, procuró prolongar hasta 1704 la situación de irregularidad propiciada por la peste poniendo obstáculos a la normalización de la vida académica(103).

Las repercusiones en el orden social han quedado ya esbozadas en el aparato descriptivo de los hechos. No se puso evitar el pánico y sus secuelas. La huida de un sector de la población, la anarquía consiguiente durante los meses críticos de la epidemia tuvo lugar de nuevo, aunque esta vez-a juzgar por las palabras del Dr. Orivay-el vacio de poder creado años antes se vio atenuado por la presencia de algunas autoridades y prohombres que resistieron tal vez ayudados por el convencimiento de que la enfermedad, en esta ocasión, respetaba un poco más a los ricos(104). No obstante el clima de insolidaridad social se puso de manifiesto durante el mes de Julio y un caso elocuente lo tenemos en la actitud de algunos médicos oriolanos, personas con una responsabilidad especial ante la catástrofe. Aunque varios de estos profesionales perecieron en el cumplimiento de su deber(105), otros-paradójicamente aquellos que estando más vinculados a la Universidad habian presidido la "Junta de Salud"-adoptaron posturas poco edificantes. Tal es el caso del Dr. Cristóbal Asencio, catedrático de Vísperas de Medicina, que optó por abandonar la ciudad dejando sin cuidado a sus pacientes ${ }^{(106)} 0$ el del $\mathrm{Dr}$. Joaquín Genesia, catedrático de Curso de Medicina, que se negó por tres veces consecutivas a visitar el hospital de los contagiados por considerar exiguos el salario con que iban a ser retribuidas sus funciones(107). Ambos fueron desterrados de Orihuela y apartados de sus cargos universitarios por unos años, pasados los cuales, tras súplicas y pleitos, volvieron a integrarse en las aulas del Estudio. 
Un caso no tan claro que refleja la desintegración familiar ocasionada por la epidemia y que pone una vez más de relieve las presiones a que estaban sometidos los criterios de los médicos ante las enfermedades de tipo contagioso es el del Dr. Francisco Moreto. Este personaje, catedrático de la Facultad de Medicina oriolana, había estado presente no solo en los prolegómenos de la enfermedad sino también durante toda su incidencia, siendo su dictamen, por último, el que sirvió para la elaboración del bando en que, una vez transcurrida la peste, se dieron las oportunas instrucciones para la purificación de los hogares que habian padecido la infección(108). En 1696, el Dr. Francisco Moretó-sin que sepamos la causa cierta que le motivo a ello-hubo de requerir que se levantase testimonio notarial de su actuación durante el año del contagio avalada por una serie de testigos(109). A través de esta documentación sabemos que en 1678 había desempeñado también el cargo de jurado, que asistió con gran celo a los enfermos y que "per dita assistencia patiren lo contagi la familia de sa casa, de lo qual moriren sa muyer, fills y criats... (que) li cremaren tota la roba y molts alages de sa casa de calitat, que li foch forços pasarse a altra casa despullat....110). Tenemos noticias asimismo de que fue, precisamente él, el primer médico que se atrevió a concluir que uera mal contagios el que patia la present ciutat encara que les altres metges o repugnaven... que per dita raho de haver regonegut y declarat dit contagi, pasi molts treballs y vexacionsw(111).

Resulta curioso ver cómo una postura más bien moderada-declarar tan sólo que el mal era contagioso-pudo acarrear persecución al Dr. Moretó. Máxime si tenemos en cuenta que este médico, tal y como señala el Dr. Orivay en su libro de modo harto explícito, fue el primero también en asentir a su dictamen acerca de que no era peste el mal padecido en Orihuela(112).Sólo una extrema sensibilización de la población, o el hecho de que la palabra tabú "peste» no importase tanto como se ha escrito, ante idénticas prevenciones y resultados para cualquier mal contagioso, explica estas represalias contra un médico cuya labor fue ejemplar. La necesidad psicológica tal vez de buscar una causa material del mal, atribuida en ocasiones a grupos minoritarios-judios, gitanos, etc.-pudo convertir esta vez en chivo expiatorio a un médico; un médico de la localidad que no contaba ni con el respaldo gubernativo que ostentaba el comisario Dr. Orivay ni con la circunstancia de estar de paso en una ciudad contagiada.

\section{CONCLUSIONES}

La reconstrucción de la epidemia de 1676-1678 en Orihuela pone de nuevo sobre el tapete una serie de cuestiones que nos interesa resaltar a modo de conclusión. Por un lado la incuestionable validez de la síntesis metodológica que elaboró en su tiempo B. Bennassar a partir de su 
estudio sobre las pestes castellanas del siglo XVI(113). Su propuesta acerca de esbozar un catálogo que ordenase los temas más relevantes a investigar sobre este tipo de catástrofes(114), ha resultado de enorme utilidad para la elección y descripción ordenada del material que hemos expuesto en este artículo. Es más, como puede observar quien conozca ya su clásico trabajo, resulta difícil, a pesar de la apriorística "originalidad" de nuestra epidemia, o de la diferencia temporal, el añadir algún aspecto novedoso que pueda enriquecer su esquema; un esquema que, fundado en los datos obtenidos entre 1596-1599, se repite en 1676-1678 en casi todos sus aspectos: médicos, sociales, religiosos, económicos, etc. Ello viene a demostrar, en gran medida, lo que podemos considerar como una primera conclusión: la continuidad de las actitudes sociales a lo largo del tiempo ante un fenomeno como la peste que todavía, a últimos del siglo XVII, en vías de desaparición, seguía siendo una amenaza ante la que poco o nada podía hacer el hombre.

Considerando obvio el repetir la coincidencia de estas actitudes ya implícitas a lo largo de nuestro trabajo, optamos por resumir otras conclusiones que, si bien no son excesivamente originales o privativas del caso de Orihuela, se manifiestan en él de una manera clara y comprobable, pudiendo, por lo tanto ser de utilidad para la elaboración de trabajos de orden más general: a) la relación casi directa existente entre el hambre y la muerte en la epidemia oriolana; hambre acentuada por las malas cosechas, pero repartida de modo harto desigual tal y como muestra con claridad el bando mediante el cual, tras las requisas de grano, se aseguró a las clases acomodadas las subsistencias necesarias para afrontar la crisis; hecho que pudo contribuir a la discriminada actuación de la peste sobre los habitantes de los barrios más pobres; b) la mayor incidencia de la muerte sobre la población infantil que supuso-de ser ciertas las apreciaciones del Dr. Orivay-más de un $66 \%$ del total de los fallecimientos; c) el acto reflejo de la inmediata puesta en marcha de las viejas medidas preventivas al margen de las dicusiones de los médicos sobre la índole de la enfermedad; d) los efectos de las hueras argumentaciones escolásticas de los médicos-acordes con las enseñanzas de la época-adaptándose a las conveniencas de la política ciudadana para dictaminar acerca de los casos de contagio y sus causas; e) la imposibilidad que se desprende de los informes médicos para evaluar desde el presente el verdadero carácter de las enfermedades durante el pasado. Esto último no sólo en virtud de su voluntad por tergiversar la causa de los síntomas, sino, también, como señalo $V$. Pérez Moreda(116) por el hecho mismo de que estos síntomas pueden a veces corresponder a afecciones diversas y porque la patología de hoy puede no servir para la descripción de cuadros más o menos análogos correspondientes a tiempos pasados. 


\section{APENDICE DOCUMENTAL}

\section{1}

Datos anuales de los bautismos, matrimonios y defunciones de la parroquia de Santa Justa y Rufina de Orihuela durante el perído 1665-1700

\begin{tabular}{|c|c|c|c|c|c|c|c|}
\hline Años & B. & M. & D. & Años & B. & M. & D. \\
\hline 1665 & 56 & 15 & 83 & 1683 & 43 & 15 & 35 \\
\hline 1666 & 54 & 20 & 73 & 1684 & 58 & 12 & 54 \\
\hline 1667 & 31 & 14 & 88 & 1685 & 48 & 22 & 44 \\
\hline 1668 & 59 & 10 & 97 & 1686 & 72 & 14 & 55 \\
\hline 1669 & 50 & 14 & 90 & 1687 & 67 & 11 & 42 \\
\hline 1670 & 52 & 15 & 36 & 1688 & 63 & 25 & 47 \\
\hline 1671 & 38 & 3 & 48 & 1689 & 54 & 12 & 55 \\
\hline 1672 & 34 & 15 & 73 & 1690 & 40 & 14 & 40 \\
\hline 1673 & 45 & 18 & 52 & 1691 & 53 & 13 & 46 \\
\hline 1674 & 49 & 12 & 56 & 1692 & 61 & 16 & 29 \\
\hline 1675 & 54 & 16 & 34 & 1693 & 55 & 17 & 45 \\
\hline 1676 & 51 & 12 & 46 & 1694 & 71 & 8 & 65 \\
\hline 1677 & 47 & 10 & 42 & 1695 & 62 & 21 & 22 \\
\hline 1678 & 39 & 13 & 62 & 1696 & 62 & 17 & - \\
\hline 1679 & 39 & 14 & 57 & 1697 & 56 & 10 & - \\
\hline 1680 & 48 & 17 & 57 & 1698 & 57 & 12 & - \\
\hline 1681 & 50 & 11 & 39 & 1699 & 71 & 18 & - \\
\hline 1682 & 51 & 12 & 52 & 1700 & 75 & 12 & 45 \\
\hline
\end{tabular}


Datos anuales de los bautismos, matrimonios y defunciones de la parroquia de El Salvador (Catedral) de Orihuela durante el perído 1665-1700

\begin{tabular}{|c|c|c|c|c|c|c|c|}
\hline Años & B. & M. & D. & Años & B. & M. & D. \\
\hline 1665 & 123 & 42 & 144 & 1683 & 257 & 53 & 145 \\
\hline 1666 & 109 & 35 & 119 & 1684 & 270 & 46 & 280 \\
\hline 1667 & 123 & 29 & 136 & 1685 & 247 & 47 & - \\
\hline 1668 & 105 & 52 & 179 & 1686 & 338 & 59 & 206 \\
\hline 1669 & 124 & 49 & 154 & 1687 & 265 & 89 & 178 \\
\hline 1670 & 101 & 44 & 109 & 1688 & 288 & 61 & 141 \\
\hline 1671 & 102 & 55 & 87 & 1689 & 269 & 47 & 265 \\
\hline 1672 & 111 & 46 & 136 & 1690 & 267 & 47 & 152 \\
\hline 1673 & 103 & 67 & 114 & 1691 & 253 & 47 & - \\
\hline 1674 & 115 & 66 & 132 & 1692 & 328 & 43 & 119 \\
\hline 1675 & 127 & 50 & 78 & 1693 & 326 & 62 & 174 \\
\hline 1676 & 107 & 54 & 112 & 1694 & 286 & 52 & 247 \\
\hline 1677 & 138 & 59 & 115 & 1695 & 285 & 61 & 147 \\
\hline 1678 & 123 & 64 & 145 & 1696 & 276 & 68 & 153 \\
\hline 1679 & 139 & 75 & 85 & 1697 & 280 & 70 & 206 \\
\hline 1680 & 129 & 74 & 107 & 1698 & 336 & 79 & 229 \\
\hline 1681 & 166 & 67 & 86 & 1699 & 329 & 74 & 250 \\
\hline 1682 & 225 & 56 & 106 & 1700 & 379 & 60 & 204 \\
\hline
\end{tabular}


Relación de los enfermos visitados por el Dr. Joaquín Genesia, catedrático de Curso de Medicina de la Universidad de Orihuela, entre el 10 de Abril y el 12 de Mayo de 1678. (A. M. O. "Libro de la Epidemia de 1678". Ref. n. ${ }^{\circ}$ 511676, Arm. n. $\left.{ }^{\circ} 16\right)$.

«Relació feta per lo Dr. Joachim Genesia.

Primo lo Dr. Joachim Genesia dix y declara que desde lo dia de deu de Abril ha tingut los malalts seguents $=$

En lo convent de Capuchins un Religios de enfermetat de gota.

Ittem. Ursola Urrach de febres continues y de present esta bona.

Ittem. una neboda de Mossen Rafael Angosto ab una tersiana de que ya esta bona.

Ittem. en casa del Marques de Rafal un llaurador ab una cos de un bou en lo pit y esta bo.

Ittem. la viuda de Montesinos que es una vella, de asma y actualment pateix dit accident.

Ittem. en lo convent de sent Agusti el lector Facundo ab febra continua, el qual esta ya bo.

Ittem. en dit convent el sacrista de tersianes dobles y esta ya bo.

Ittem. en dit convent Fray Pedro Perez ab siatrea y esta millor.

Ittem. el cuiner del mateix convent ab tavardillo del qual es mort haura tres dies.

Ittem. un corista en dit convent ab tersianes continues.

Ittem. altre corista en lo mateix convent ab tersianes dobles intermitents.

Ittem. en lo meso de Miquel del Carpio in chich ab febra continua, ab una inflamacio y floronco en una cama el qual esta millor.

Ittem. una filla de Vicent Agullo de una colica y esta ya bona.

Ittem. en cas de Philip Sanchez, un criat ab dolor en lo pit, sens febra de que ya esta bo.

Ittem. cas de Silvestre el arriero un chich ab pulgo y febra lo qual esta millor.

Ittem. el Pdr. Fray Pedro Pomares en lo convent de la Merse, de febra y uns floroncos segos en lo pit y en los brasos de que ya esta bo.

Ittem. la muyer del mayordom de don Joan Rosell, ab un incordi galich, sens febra. 
Ittem. Baltasar Soto, generos, ab tersianes de que ya esta bo.

Ittem. Sebastia Raya ab febra de un acalorament de que ya esta bo.

Ittem. en lo convent del Carme el pare $m$. fray. Sebastia Vilanova que era molt vell y mori de tersianes continues aura huit o deu dies.

Ittem. el pare prior de dit convent esta ab febra sicona.

Ittem. cas de Benit Pardo una fadrineta de una colica humoral y vapors de utero la qual esta millor.

Ittem. casa de Sebastia Garrigós un malalt ab tersiana continua.

Ittem. cas de Miquel Lozano dos chiquets ab febra continua.

Ittem. en lo hospital un frances ab febra continua de la qual mori.

Ittem. en dit hospital un fadrinet de febra continua ardent ab una papera darrer la orella dreta y mori, lo qual se colig no haguera aplegat a tal extrem si agues estat en terms de curacio, segons la poca malicia que se adverti dels señals de sa enfermetat ser curable, no podentse haver eixecurat remey algu per haver estat en lo camp pasant tota sa enfermetat, fins que el portaren moribundo a lospital, ni del contacte de aquell en la roba del hospital no sia experimentat algu dany de contagi havent deu dies que succehi.

Ittem. altre chove de vint anys en dit ospital que vingue del camp ab febra continua, ab una inflamació darrer les orelles, el qual mori y ab lo consell y cuidat de la Salut publica del dit Dr. Genesia, y mes essent lo puesto comú de malalts com es lo hospital per haverse mort tant promptament apres que entra en son poder, per no haver pogut usar en ell curacio alguna sin rigurosa averiguacio del principi de ses enfermetats, causes y temps de ahon venia, a lo qual li fonch respost que venia de la canyada de D. ${ }^{a}$ Ynes de Rocamora viuda de D. Vicent Ruiz y Rosell que esta en lo camp de sent Gines de la present ciutat, hon estaba segant ab altres tres compañers que foren els que el portaren y que mentres menchaven pa de forment estigue bo, y que en apres havent menchat pa de sivada es senti malalt del bentrell y que es distingue en la dita cañada que esta prop de cinch llegues de la present ciutat sis dies sens haver menjat bosi, y que quant lo portaren aplega a la present ciutat hon estigue cinch dies y haventlo embiat el meche que el curava al hospital en la conformitat que ha referit sens forses ya y moribundo, circunstancies bastants pera que mori de dits accidents.

Ittem. en casa de Frances Gaixi haura quinse dies que mori un fadrinet, lo qual mes de dotse dies abans tenia un dolor en lo bras ombro y pit dret del egersisi de llevantar la prensa de fer fideus (sic) que es fan en la dita casa per no estar acostumat aquell treball, y haventli dit que el sagnara no volgueren sos pares executarlo y apres de alguns deu dies li dona febra $y$ el sangraren una bolta, y aquella nit que el sagnaren es llevanta del Ilit y es vegue un poal de aigua del pou salada y de mala calitat de lo que li dona 
una colica per dalt y per baix de la qual mori dins dos dies.

Ittem. a Maria Gallego la visita del orde dels señors de la Junta de la Salut la qual estava ab febra continua y un tumor inflamatori en la ingle esquerra que li havia pervengut de causa externa per que tenia un colp gran en lo potse de aquell peu, y haventse posat una sabata apretada se li inflama el genoll y de alli es origina el dit tumor, lo que succehi deu o dotse dies abans que li donas la febra y al mateix temps estant ab la evacuacio menstrual tingue un sust del qual se li retira la dita evacuacio, causa bastant per haverli engendrat la febra ab la (tachado) alteracio del peu y el chenoll, causanli un efectesoporos, y crexerli y fomentanli el tumor del ingle sense haver experimentat en tot lo discurs de sa enfermetat señal algu de malaltia sospitosa com se resela per part de dita Junta, y esta bona de present.

Ittem. a Geroni Flaquer visita de orde de dits señors pera efecte de averiguar la enfermetat que tenia y el troba ab un incordi galich ab poca febra del qual estava y apeliorat preguntantli la causa de la enfermetat li rispongue que havia estat tres o quatre dies ab una dona ab qui trata carnalment de lo qual li havia prevengut lo dit incordi y una febreta, y que lo havien sangnat quatre vegades dantli cordials y fentli fer ordens de christia fins aperiorarlo y feu relacio el dit doctor Joachim Genesia a la dita Junta que la enfermetat del dit Geroni no era cosa de cuidado sino uns efectes del mal frances sens perill algu com ab tot efecte de present esta bo y asegura a dits señors que el haverlo fet fer ordens de christia tan aceleradament naixque el haver tingut equivocacio qui li asisti de que podria ser enfermetat pestilent, de lo qual no tenia rastre algu.

Ittem. en lo forn de Miquel del Carpio, visita nit de sent Visent Ferrer de ordre de dits señors, dos dones, la una ab un tumor davall lo bras y una contucio en la ma del mateix bras y sens febra, y preguntantli de ahon li havia originat lo dit tumor li respongue que li havia caigut desde lo alt una pala del forn damunt la má y que li havia pegat un gran colp, y que del dit colp Ii havia sobrevengut lo dit tumor, y que en apres de la afliccio de una filleta que se li havia mort y de veure a son marit malalt havia tingut una febreta pero ya la troba llimpia de dita febra. Y el altra dona estava ya llevantada y combalexent de una febra que dix havia tengut y juntament tenia uns tumors galichs en les parts baixes que son marit li havia pegat y que tenia part dels dits tumors uberts y altres que encara no se havien reventat, pero estaba sens febra alguna. Y en lo mateix forn y havia mort es marit de esta ultima dona, y avent regonegut lo cadaver per medi de Ginez Martinez, sirugia, no se li atrobaba cosa de resel perque havia mort, segons dixeren la muller y la sogra, de haverse azotat lo divendres sant y haver entrat ans de curarse la plaga en un fabar, de lo qual se linflama tota la espala y li dona febra que lleba despues alguns dies sens volerse medicinar, y que begue una begada de aygua de neu y que en apres lo baren sagnar de lo qual mori $a b$ una celeritat empero sens señals ni sospita de mal pestilent. $Y$ aixi ma- 
teix regonegue en lo mateix forn una chiqueta de dos anys poch mes o menys que tambe estaba morta ab totes ses carns, sens haverli fet ninguna evacuació universal, y regonexentla tot lo cos no se li troba tumor, gra, manches ni altre señal sospitos de contagi pestilent, y la mare de dita chiqueta dix que havia mort de febra y poch cuidado que havien tengut de ella per haver estat tots malalts.

Ittem. de orde de dits señors ana al ortet de Cartagena a regonexer una chiqueta de dos anys que havia mort en casa de Don Juan Ruiz de Ballibrera per ser filleta de un ama que els servia, y atroba que el dit angelet era morta de febra y una parotida eo papera y que no havien medicinat ni visitat meche algú, si sols un sirugia que li fee dos sangries, que la segona se la reseta el mateix Doctor Genesia baixant de visitar a Don Juan Ruiz, pero no el tornaren a cridar, ni la beu mes fins que la beu morta, ab que te per cert que mori de no haverla medicinat, perqui no se li atroba señal algu sospitos de contagi pestilent. $Y$ en lo mateix ort va regonexer la mare de dita chiqueta perque havia entengut que tenia un tumor deball lo bras, y la atroba sens febra ni tumor ni altra cosa ni accident algu, perque estaba bona y sana, y aixi feu relacio a la Junta.

Ittem. de orde de la mateixa Junta regonege, juntament ab Simo Asencio, sirugia, un cadaver de una dona que mori en la ultima trabesa del carrer damunt que baixa al carrer del Colegi, per haverse dit que havia mort ab sospita de mal contagios, y atrobaren regonexena ab gran ciudado que no tenia señal, ni tumor, ni mancha alguna que pogues dar cuidado, si que havia mort ab gran pobrea y miserabilitat y de fam segons li digueren les vehins de la dita casa que li asistien.

Ittem. aixi mateix de orde de la mateixa Junta regonegue juntament ab lo Doctor Basilio Miravete, Simó Asencio y Gines Martinez, un aprendis de sirugia de dit Martinez que li dien Jaume, per haver avisat a la Junta lo dit Gines Martinez que havia mort de repent ab un gra damunt una sella, $y$ un bubo davall lo bras esquer, y haventlo regonegut tots los desusdits da. vant dit Gines Martinez y Salvador Oriel sirugia, ab gran cuidado per la importancia de la materia, no li atrobaren gra, ni seca, ni altra mancha, ni cosa alguna sospitosa, y havent procurat inquirir y saber de la mare del dit mort quina causa havia tengut son fill pera la enfermetat de que era mort, $y$ quant temps havia estat malalt, respongue que havia huit dies que estaba malalt quixantse de dolor del ventrell perque havia anat al camp a un favar y havia menchat moltes faves, y el dit Gines Martinez sens ordre de meche algu lo havia sagnat dos vegades, lo qual es demostraba per les sicatrises de dites sangries, causa bastant pera haverse mort y en eixa conformitat faren relacio a dita Junta y aso es la veritat y ferma".

(sigue la firma de Joachim Genesia). 
(1) L. GARCIA BALLESTER y J. M. MAYER BENITEZ, "La peste de orihuela de 1648" y "La crisis demográfica y de subsistencias y las medidas sanitarias de carácter colectivo en la peste de Orihuela de 1648" en Primer Congreso de Historia del Pa/s Valenciano, Valencia 1976, III, pp. 391-399 y $401-409$.

(2) Mientras elaboramos este articulo han surgido una serie de trabajos que hacen referencia directa $O$ indirecta a las epidemias de esta zona. Entre ellos conviene mencionar J. BAUTISTA VILAR, Orihuela una ciudad valenciana en la España Moderna, Murcia, 1981, 3 vols.; D. BERNABE GIL, "Oligarquia municipal e intereses agrarios: Orihuela en la coyuntura subsiguiente a la peste de 1648" en Anales de Historia Moderna de la Universidad de Alicante n. ${ }^{\circ} 1$, Alicante, 1981, pp. 221-250, J. TORRES FONTES, CASAL MARTINEZ, A. J. MULA GOMEZ, J. A. AYALA, P. MARSET CAMPOS, De historia médica murciana. II. Las epidemias, Murcia, 1981.

(3) H. KAMEN, La España de Carlos II, Barcelona, 1981, Ver de modo especial el capitulo "Esquemas de vida y de muerte" pp. 67-106.

(4) Archivo Municipal de Orihuela: Legajo "Varios".

(5) L. GARCIA BALLESTER y J. M. MAYER BENITEZ, Op. cit., p. 392.

(6) J. BAUTISTA ORIVAY Y MONREAL, Teatro de la verdad y claro manifiesto del conocimiento de las enfermedades de la ciudad de Orihuela, del año 1.678, Zaragoza, 1679.

(7) L. GARCIA BALLESTER y J. M. MAYER BENITEZ, Op. cit., pp. 402-403.

(8) Ibidem, p. 398.

(9) Se suponía que el contagio había sido provocado bien por arribada de ropa infectada a través de unos navíos ingleses, bíen por la que habían desembarcado excautivos procedentes de Argel (H. KAMEN, Op. cit. pp. 79-80).

(10) A. M. O., Leg. "Varios».

(11) Ibidem.

(12) Ibidem.

(13) H. KAMEN, Op. cit. p. 80.

(14) A. M. O., Libro de la epidemia de 1678, f. 100 v. 101 r.

(15) A. M. O., Contestador de 1677, f. 336, r.

(16) H. KAMEN, Op. cit. pp. 80-81.

(17) A. M. O., Contestador de 1677, f. 382, r.-384, v.

(18) Ibidem., f. 382, v.

(19) Ibidem.

(20) Ibidem. f. 383, r.

(21) Ibidem.

(22) Ibidem. f. 383, v.

(23) Ibidem.

(24) Ibidem.

(25) Ibidem.

(26) Ibidem.

(27) Ibidem., f. 384, r.

(28) A. M. O., Libro de la epidemia de 1678, f. 103, r.

(29) A. M. O., Contestador de 1677, f. 392, r. y v.

(30) Ibidem., f. 392, r.

(31) Ibidem.

(32) Ibidem. 
(33) A. M. O., Libro de la epidemia de 1678, f. 49v.-50, r.

(34) A. M. O., Contestador de 1677, f. 411, r.413, v. y Libro de la epidemia de 1678, f. 55, r. y v.

(35) A. M. O., Libro de la epidemia de $16^{\top} 8$, f. 55 v.

(36) A. M. O., Contestador de 1677, f. $41^{4}$ r. -413 , v.

(37) A. M. O., Libro de la epidemia de $16.3, \mathrm{f} .79$, r.

(38) Ibidem., 55, r.57, r.

(39) Ibidem., f. 56, r.

(40) Ibidem., f. 64, v.-65, r.

(41) Ibidem,

(42) Ibidem.

(43) Ibidem., f. 51, v.

(44) Ibidem., f. 61, r.

(45) Ibidem., f. $63, v$.

(46) Ibidem., f. 64, r.

(47) Ibidem., f. 88, r.

(48) Ibidem., f. 90, r.

(49) J. BAUTISTA ORIVAY Y MONREAL, Op. cit. p. 181.

(50) A. M. O., Libro de la epidemia de 1.678, f. 2, r.

(51) Ibidem.

(52) Sobre este personaje de la medicina valenciana, discípulo de Matlas Garcla, continuador de la corriente galen/stica más escolástica, ha dado noticia J. M. LOPEZ PIÑERO, "Valencia y la Medicina del renacimiento y del barrocon en III Congreso Nacional de historia de la Medicina. Vol. II. Valencia, 1.971. pp. 95-108.

(53) Polémica que se recoje de modo indirecto en J. BAUTISTA ORIVAY Y MONREAL, Op. cit. Este médico escribió su libro para defender sus teorlas acerca de que no era peste el contagio de Orihuela.

(54) A. M. O. , Libro de la epidemia de 1.678, f. 1, r.-26, r.

(55) Estos datos están extraidos de la relación detallada de todas las visitas que llevaron a cabo los citados médicos, a cuya localización exacta hace referencia la nota anterior. En el Apéndice documental, $n .{ }^{\circ} 3$ ofrecemos a modo de ejemplo-por lo interesante que resultan las declaraclones de médicos y pacientes-el Informe completo de uno de los doctores: el de D. Joaquín Ginesia.

(56) A. M. O., Libro de la epidemia de 1.678 , f. 6, r. y v.

(57) Ibidem., f. 9, $r$.

(58) ibidem., f. 9, v.

(59) Ibidem., f. 10, r.

(60) Ibidem., f. 14, v.-15, r.

(61) Ibidem., f. 14, v.

(62) J. BAUTISTA ORIVAY Y MONREAL, Op. cit., p. 2.

(63) Ibidem.

(64) A. M. O., Libro de la epidemia de 1.678, f. 25, r-26, r.

(65) Ibidem., f. 27, r.

(66) J. BAUTISTA ORIVAY Y MONREAL, Op. cit., pp. 2-3.

(67) Ibidem., p. 3.

(68) Ibidem.

(69) Ibidem., p. 5. 
(70) Ibidem.

(71) Ibidem., p. 116.

(72) Ibidem.

(73) A. M. O., Libro de la epidemia de 1.678, f. 134, r.

(74) Archivo Histórico de Orihuela, Libro de Consejos del Colegio de Predicadores. Desde el 12-2-1.625 al 31-4-1.754, Arm. 159, p. 79.

(75) H. KAMEN, Op. cit., p. 83 y J. BAUTISTA ORIVAY Y MONREAL, Op. cit., p. 186. Este último autor da un total de 1.500 victimas.

(76) J. BAUTISTA ORIVAY Y MONREAL, Op. cit., p. 182.

(77) A. M. O. Libro de la epidemia de 1.678, f. 15, v.

(78) Ibidem.

(79) J. BAUTISTA ORIVAY Y MONREAL, Op. cit., pp. 124-125.

(80) Ibidem., p. 123.

(81) Archivo Historico Nacxional, Sección Consejos, Legajo 7189.

(82) Ibidem.

(83) Ibidem.

(84) H. KAMEN, Op. cit, p. 83.

(85) Agradecemos los datos ofrecidos por G. CANALES MARTINEZ que aparecen en el Apéndice documental, $n .^{\circ} 1$ y 2 . Ellos son fruto de sus investigaciones en torno a su tesis doctoral sobre el tema El Bajo Segura: estudio geográfico-comarcal. En base a ellos hemos elaborado los Gráficos nos. 1 y 2 que presentamos en este artículo.

(86) L. GARCIA BALLESTER y J. M. MAYER BENITEZ, Op. cit., p. 402.

(87) Cfr. J. BAUTISTA VILAR, Op. cit., Vol. I., p. 107.

(88) Cfr. J. A. RAMOS VIDAL, Demografía, economia y sociedad en el Bajo Segura durante el siglo XVIII (Desamortización bajo el reinado de Carlos IV), Orihuela, 1.980, p. 31.

(89) J. A. RAMOS VIDAL, Op. cit. p. 32.

(90) Ibidem., p. 33.

(91) A. H. O., Libro de grados y acuerdos de la Universidad de Orihuela, 1.679-1.685, Arm. 159, f. 60 , v.

(92) D. BERNABE GIL, Op. cit., p. 223.

(93) H. KAMEN, Op. cit., p. 74.

(94) J. BAUTISTA VILAR, Op. cit., Vol. III, pp. 657-658.

(95) Ibidem., p. 658.

(96) A. M. O., Libro de la epidemia de 1.678, f. 143, r.-145, v.

(97) M. MARTINEZ GOMIS, "Aportación al estudio de la financiación y rentas de una Universidad Menor: Orihuela, siglos XVII y XVIIIn, en Simposio Internacional en el Bicentenario de la muerte de Gregorio Mayans, Valencia, 1.982. Vol. II, pp. 429-466.

(98) A. H. O., Libro de grados y acuerdos de la Universidad de Orihuela, 1.679-1.685, Arm. 159, f. 189, r. y v.

(99) M. MARTINEZ GOMIS, Op. cit. p. 447.

(100) Ibidem.

(101) A. H. O. Arm. 159, Lio 05, n. ${ }^{\circ}$. "Concordia de la Ciudad, año 1.643".

(102) M. MARTINEZ GOMIS, Op. cit. p. 446.

(103) Ibidem. p. 447.

(104) J. BAUTISTA ORIVAY Y MONREAL, Op. cit., p. 183.

(105) A. H. O., Libro de grados y acuerdos de la Universidad de Orihuela, 1.679-1.785, Arm. 159 , f. 4 , r. 
(106) Ibidem., f. 180, r.

(107) Ibidem., f. 36, v.-37, r.

(108) H. KAMEN, Op. cit., p. 91.

(109) A. M. O., Legajo "Varios".

(110) Ibidem.

(111) Ibidem.

(113) J. BAUTISTA ORIVAY Y MONREAL, Op. cit., p. 4.

(114) B. BENNASSAR, Recherches sur les grandes epidemies dans le nord de l'Espagne a la fin du XVle. siecle. Problemes de documentation et methode, Parls, 1.969.

(115) Nos referimos aquil al contenido del capítulo II de la obra citada en la nota anterior: "Propositions pour une recherche collective", pp. 35-60; capítulo que ha servido de base para un trabajo más reclente de J. N. BIRABEN, "Les hommes et la peste en France et dans les pays europeens et mediterraneens. Tome II. Les hommes face ala peste., Paris, 1.976.

(116) V, PEREZ MOREDA, La crisis de mortalidad en la España interior (siglos XVI-XIX), Madrid, 1.980, pp. 64-65. 


\title{
LAS TEMPORALIDADES DE LA COMPAÑIA DE JESUS EN ALICANTE. (Siglos XVII-XVIII)
}

\author{
Por Armando ALBEROLA ROMA \\ Enrique GIMENEZ LOPEZ
}

Universidad de Alicante

Han sido escasos los trabajos destinados a valorar el volumen de las temporalidades de la Compañia de Jesús en el momento de su expulsión en 1767. Tan sólo se han acometido aproximaciones parciales al problema, en especial destinadas a documentar el destino de los Colegios y casas de residencia que, en buena parte, fueron convertidos en seminarios diocesanos o destinados a centros de educación seglar.

Sin embargo, el conjunto del patrimonio de la Compañía resulta desconocido, y aún más el proceso de su formación y el volumen de propiedad rústica y urbana que fue sacado al mercado para su venta tras la expulsión.

Este hecho resulta paradbjico, ya que las supuestas riquezas de la Compañía ocupan una parte importante de las consideraciones que Campomanes introdujo en su dictamen fiscal, y recientemente Teofanes Egido ha insistido en esta carencia al indicar que "tampoco se ha medido el alcance economico y social de los bienes raices y muebles, títulos de renta y el tesoro artístico y religioso abandonados por la Compañia(1).

Nuestro propósito es, precisamente, ocuparnos de esta parcela descuidada e importantísima del extrañamiento de los jesuítas en el ámbito de la ciudad de Alicante, localidad que contaba con uno de los 142 colegios y casas de residencia que se repartían por toda España. 

del patrimonio.

La instalación de una comunidad de religiosos jesuítas en la ciudad de Alicante se remonta a las dos primeras décadas del siglo XVII, período en que, de forma paulatina, se fueron creando las condiciones indispensables que aseguraran la estabilidad posterior. El motor de arranque que posibilitó la llegada de la Compañía fue la institución y subsiguiente cesión a la misma; de una administración por parte de Teófilo Berenguer en el año 1613(2); la cual se componía de las siguientes propiedades rústicas: la heredad de La Condomina, el huerto de San Francisco-situado en los secanos de la partida de La Sueca-, y una serie de bienes rústicos y urbanos censidos enfitéuticamente y situados en la ciudad de Alicante; la vecina universidad de San Juan y las partidas huertanas de Benialí, La Verónica-Llopera y Cotella.

Con esta nada desdeñable base económica para iniciar su andadura los religiosos se asentaron rápidamente en la ciudad y, en 1635, cinco de sus miembros alquilaron como residencia un pequeño edificio sito en la calle d'En Llop que lindaba con la ermita de la Esperanza. Con el respaldo del municipio alicantino pudieron construir, en terrenos adyacentes a la casa que habitaban, unos recintos que mejoraran su acomodo, permitieran aumentar la comunidad y pudieran ser destinados como aulas para instruir al pueblo.

Una vez alcanzada la estabilidad residencial, el paso inmediato consistió en asegurar la manutención de los miembros de la Compañía y, a tal efecto, a partir de 1639 el Cabildo de la ciudad elevaba anualmente a la Real Audiencia valenciana resoluciones capitulares en las que se solicitaba la aprobación-que nunca fue negada-de una limosna semanal para sustento de la comunidad jesuítica consistente en una arroba de harina valorada en 10 sueldos. El municipio objetaba que esta ayuda iba

«...dirigida al bé comú de dita ciutat de Alacant per lo fruit $\mathbf{i}$ benefici que causarien los dits religiosos ab la predicació i enseñança de la doctrina cristiana....(3).

La Real Audiencia aprobaba sistemáticamente todas las solicitudes indicando que, a la entrega de la limosna, se firmara siempre la correspondiente apoca o carta de pago por el síndico de la Compañia de Jesús. Igualmente se ordenaba a la persona a cuyo cargo estaba la rendición de cuentas de la Administración de Harinas que admitiera, dentro de las cuentas generales de la ciudad, la legítima data, cargo y descargo de la citada limosna.

Conforme avanzaba el siglo, las rentas de la Compañía fueron aumentando gracias a las donaciones de particulares y al apoyo de los poderes 
públicos. Paralelamente se acrecentaba, de igual modo, su importancia social debido al establecimiento de dos escuelas de Gramática (1640) y cátedras de Arte (1664) y Moral (1670); corriendo el pago de los salarios de los profesores por cuenta del municipio alicantino, que asignó de su presupuesto la cantidad de 270 libras anuales. Otra prueba del prestigio que entre determinados estratos ciudadanos alcanzaban los jesuítas podrian ser dos ejemplos hallados en los protocolos notariales de un escribano de la ciudad. En una de estas escrituras se contiene el testamento de José Paravecino y señala como marmessor o albacea, junto con dos miembros de la familia,

«...al Pare Superior de la casa de Residencia de la Compañía de Jesús que al temps de la mort de qualsevol de nosaltres estará en dita casa de Residenciaw(4).

El otro documento se refiere a la cesión del cobro de las rentas poseídas en la ciudad por Jaume Berenguer, ciudadano, al superior de la Compañía, padre Josep Bonarí. El motivo alegado por el primero es la confianza que deposita en el religioso, el cual tras cobrarle sus rentas se comprometía a enviarle todos los meses 13 libras allá donde se encontrara(5).

Hacia 1670 la comunidad jesuítica inició la construcción de una iglesia, introdujo mejoras en la heredad de La Condomina y acepto el legado de Marco Antonio Pasqual, canónigo de la colegial, consistente en varios edificios y un molino harinero con sus tierras colindantes. El siglo se cerro pleno de realidades puesto que la casa que hasta el momento habitaba la comunidad fue erigida en colegio y se proyecto, tras la obtención de los recursos necesarios, la construcción de un gran edificio que se destinaría a vivienda y colegio. Pero este deseo no pudo ser llevado a la práctica por los avatares de la Guerra de Sucesión, posponiéndose su empresa hasta tiempos mejores.

En las dos primeras décadas del siguiente siglo, tras adquirir los terrenos necesarios y obtener una ayuda de 1.000 libras de Don Pedro Burgunyo, el antiguo proyecto de construcción de un edificio digno fue reavivado. Pero antes, en 1724, la dirección del Colegio estimó conveniente solicitar el patronato de la Corona para la obra antigua. Felipe $V$ aceptó la propuesta de la comunidad y el 9 de agosto del mismo año Don Antonio Rotlá, comisionado real, en solemne ceremonia tomó posesión del patronato, procediéndose a fijar las armas reales en la portada del edificio y en el altar mayor de la iglesia(6).

Al año siguiente dieron comienzo las obras del edificio nuevo destinado a vivienda y colegio, pero tras una inicial celeridad hubo que interrumpir la empresa en 1732 por falta de recursos. No obstante, a los pocos años pudo darse por concluída la misma instalándose en ella los religiosos. 
Estos intentaron la construcción de una iglesia nueva, puesto que la que el colegio posela resultaba excesivamente diminuta para las necesidades del culto, pero el proyecto no pudo llevarse a cabo al producirse la expulsión de la Compañla de Jesús de España en 1766. Actualmente el edificio que fue Colegio de la Compañía de Jesús está ocupado, desde fines del siglo XVIII, por las religiosas Agustinas de la Sangre de Cristo.

Hasta el momento de la expulsión las propiedades, tanto rústicas como urbanas, que los regulares poseian fueron objeto de una cuidadosa administración lo que hizo que las rentas de aquéllas sufrieran incrementos importantes con el paso del tiempo. Estas rentas eran anotadas cuidadosamente en los llamados "Libros de recibo y gasto del Colegio de la Compañian(7), los cuales recogian de forma pormenorizada todas las operaciones economicas realizadas cada mes y que reflejan desde los gastos invertidos en las labores propias del saneamiento de la infraestructura de la residencia-arreglos en griferla, cisterna, carpintería, cerrajeria..., etc. - hasta las cantidades empleadas en la compra de sotanas, ornamentos y objetos para el culto, cera, harina, aceite y vino. Igualmente son recogidos los sueldos pagados a personal eventual que prestaba su servicio en la residencia religiosa-barberos, médicos y músicos-, pero mayor interés tienen los capitulos dedicados al pago de los jornales de quienes intervenian en las faenas del campo. En ellos se aprecia un mayor deseo de precisión con el fin de poder evaluar más fácilmente los beneficios producidos por las tierras que detentaba la Compañía. Están clasificados de forma detallada los jornales percibidos por los recogedores de almendra, vendimiadores, podadores de árboles y cepas, así como los de los encargados de la limpieza y monda de brazales de riego. En época de siega y siembra se llegaba a indicar el número de hombres utilizado en cada jornada, el sueldo pagado y la superficie trabajada en conjunto, siendo destacable el celo empleado al referirse a los cuidados que debian recibir las vides-cava y poda de las cepas, riego en primavera y amorgonamiento de las mismas-pues no en balde representaba el cultivo de mayor rentabilidad para sus propietarios. En las páginas siguientes se lleva a cabo un estudio más detallado de las propiedades rústicas y urbanas de la Compañía, en el que además de su evolución se recoge el destino de todo su patrimonio una vez consumada la expulsión.

\section{Las propiedades de la Compañía de Jesús en Alicante}

La forzosa limitación de las fuentes documentales existentes ha impuesto una necesaria minuciosidad en la elaboración y posterior trabajo de los datos, encaminada a conseguir un triple objetivo: clasificar las diferentes propiedades que la Compañía llegó a disfrutar en la ciudad de Alicante y su entorno, localizarlas geográficamente y evaluar sus superficies y rentas anuales. 
Para ello se ha preferido recurrir a un desglose simple de las mismas atendiendo, básicamente, a sus características diferenciadoras, con 10 que han quedado constituídos tres grupos homogéneos en los que se reseñan las propiedades rústicas, las urbanas y las que, en sentido amplio, hemos preferido denominar como otras rentas, apartado en que figuran los legados, obras pías, limosnas y censales.

\section{a) Propiedades Rústicas}

En este apartado se incluyen todas aquellas parcelas de tierra que los regulares de la Compañía fueron adquiriendo con el paso del tiempo. La forma de explotación de las mismas ha motivado que se produzcan subdivisiones dentro del tratamiento de este primer aspecto, puesto que nos vamos a encontrar desde la pura y simple explotación directa hasta formas un tanto más complejas dentro de los límites de una huerta realenga. En efecto, junto a formas jurídicas de tenencia de la tierra normales en estos casos como puede ser el arriendo a corto plazo, coexisten otras que no déjan de ser un tanto extrañas dadas sus especiales características; nos estamos refiriendo al empleo de la enfiteusis, forma jurídica de tenencia que trae aparejado el disfrute de una propiedad compartida. Según esta fórmula, el propietario de una tierra concede el dominio útil de la misma a un individuo o enfiteuta, reservándose sin embargo el dominio directo de aquélla, así como una serie de derechos inherentes al propio contrato como son la percepción de unos cánones anuales en metálico o en especie; el luismo, o cantidad que percibe el propietario directo en caso de que el enfiteuta venda o permute su propiedad; la fadiga, o derecho de preferencia para adquirir cualquiera de los dominios; y el cabreve, que es la facultad perteneciente al dueño directo para exigir del enfiteuta el reconocimiento de su dominio. En caso de incumplir este último cualquiera de las condiciones establecidas, el censualista podía ejercer el derecho de comiso que comportaba el abandono forzoso de la propiedad por parte del enfiteuta(8).

\section{a.1.) La enfiteusis}

Para el siglo XVII quedan perfectamente delimitadas, tras el análisis del denominado Libro de Enfitéuticos(9), las propiedades que los Jesuítas tenian censidas a diversas personas que habitaban el núcleo urbano alicantíno o cualquiera de las poblaciones próximas. Estas heredades remontaban su origen a "aquellos señoríos de la huerta»(10) que Teófilo Berenguer cedió para la fundación de una comunidad jesuitica en los albores del siglo XVII. La progresiva ampliación de las áreas sometidas a esta forma jurídica de tenencia es claramente constatable. Así, en 1689, fecha en la que aparecen cabrevadas todas las propiedades, la superficie que la Compañía tenía censida enfitéuticamente ascendía a 418 tahullas(11), 
repartidas en 22 heredades o parcelas distribuídas a lo largo y ancho de la huerta alicantina, de las que obtenía una renta fina anual en metálico evaluada en poco más de 41 libras valencianas.

Es interesante destacar, de entre todas las propiedades rústicas que comentamos, la situada en la partida de La Condomina. Esta partida, dotada de un riego seguro de agua del pantano gracias al brazal del Alfadramí, era una de las más ricas de la huerta y, sin duda, la de mayor proyección economica sustentada en un monocultivo viticola del que se obtenian caldos de gran calidad y que generaban una importante demanda exterior.

En esta partida de La Condomina, pues, además de un notable número de tahúllas que el propio Colegio de la Compañía explotaba en régimen de arriendos a corto plazo, existía una superficie de 53 tahúllas que, divididas en tres parcelas, los jesuitas tenlan establecidas enfitéticamente. Pese a haber sometido a examen las escrituras del notario Martí Moliner(12), del cual un comentario hallado en los libros del Colegio men: cionaba que en ocasiones habla recogido los cabreves del mismo, no hemos hallado constancia documental de ningún establecimiento original. Por ello desconocemos la totalidad de las cláusulas por las que se regla la relación entre estabiliente y enfiteuta, aspecto que sería fundamental para determinar si los beneficios anuales que la Compañla de Jesús obtenía de estas tierras censidas se limitan al simple pago de un canon en metálico en el día de San Miguel. Más bien nos inclinamos a pensar que; como en otras zonas proximas a la Huerta y sometidas a idéntica tenencia como es el caso de Busot, las percepciones no debían ser únicamente en metálico puesto que un censo de tipo perpetuo, como es el enfitéutico, está sujeto a las oscilaciones periódicas de la moneda, pudiendo, en consecuencia, llegar a no ser rentable en un momento dado. Por ello, cabe suponer que los enfiteutas deberian ofrecer al censualista algún tipo de compensación en especie junto a los cánones en metálịco anuales, cánones que oscilaban entre las dos y cinco libras valencianas.

Como elemento meramente indicador de la riqueza de la zona y que, a la vez, sirva de índice comparativo con estos cánones anuales tan bajos, valga el dato de que los arrendamientos en el resto de La Condomina, amén de indicar una larga y pormenorizada relación de obligaciones para el arrendatario, no solían descender de las 80 libras al año, limitándose la duración dél contrato a no más de 406 años, en un claro deseo por parte del arrendador de obtener el máximo de rentabilidad a sus tierras. Rentabilidad que podian ver acrecentada tras comprar la cosecha de vid a sus arrendatarios y comercializarla directamente(13).

Si en La Condomina el dominio. del cultivo de la vid es bien notorio-aunque esporádicamente podla ser compartido con algunos almendros y frutales en un claro aprovechamiento del suelo y vuelo-en el 
resto de las partidas huertanas donde existen tierras censidas (La Verónica-Llopera, Beniali, San Juan-Cotella) los huertos y el arbolado, sobre todo almendro y algarrobo, marcan perfectamente las diferencias tanto en rendimientos como en percepciones. (Cuadro 1).

Entre las dos décadas postreras del siglo XVII y la primera mitad del XVIII se produjo una serie de tractos sucesivos en estas tierras censidas, que son palpables en los cabreves conservados del Colegio. Estos cambios de identidad en los propietarios del dominio útil debieron originarse como consecuencia del ejercicio, por parte de los jesuítas en algún momento determinado, de su derecho de comiso motivado por el incumplimiento por parte del enfiteuta de alguna de las cláusulas pactadas. Ello explicaría el posterior nuevo establecimiento y la elevación del canon anual al reciente detentador del dominio útil, con lo que los ingresos anuales del Colegio aumentaron y se produjo, paralelamente, una redistribución de las extensiones cultivadas sometidas a censo enfitéutico.

Pese a que se observa en 1740-50 un descenso de 40 '5 tahúllas en el total de la superficie censida junto con el del número de heredades respecto de 1698, es bien cierto que el incremento de las percepciones en metálico supone, prácticamente, el doble en relación con la misma fecha. En los cultivos no se observa, en general, variaciones fundamentales que afecten a la tipología de la huerta; si acaso es reseñable el hecho de que en La Condomina aparece ya la vid como único cultivo (Cuadro 2).

Es importante hacer, aunque sea breve, una referencia respecto a la sociología de los enfiteutas del Colegio de la Compañía en Alicante. Estos eran, en número significativo, elementos pertenecientes a las capas sociales ciudadanas más pudientes, los cuales tras conseguir el dominio directo de las tierras las arrendaban a corto plazo a los labradores de la zona. De esta forma podian obtener beneficios nada desdeñables una vez que hacian efectivos a la Compañía de Jesús los cánones anuales y la posible compensación en especie, puesto que las producciones de almendra, algarroba y vino eran fácilmente comercializables y permitirían a estos enfiteutas incrementar de forma sensible las rentas que ya obtenian en las tierras de su propiedad.

Estableciendo una comparación individual y nominal entre los cabreves de 1689 y $1740-50$, se pueden observar unas realidades que son sintomáticas y que vienen a corroborar el supuesto anterior. Es interesante constatar que, en 1689, los enfiteutas con tierras en La Condomina fueron personas como Don Ignacio Bojoni, importante propietario en la huerta, o el notario Antonio Cerdá. El primero disfrutaba de una heredad de 20'5 tahúllas, mientras que el segundo poseía el dominio útil de las otras dos parcelas que los jesuítas habian establecido en esta partida.

Los cánones anuales que se pagaban por estas parcelas eran distintos, pues mientras Don Ignacio Bojoni satisfacía 5 libras por su heredad, el 


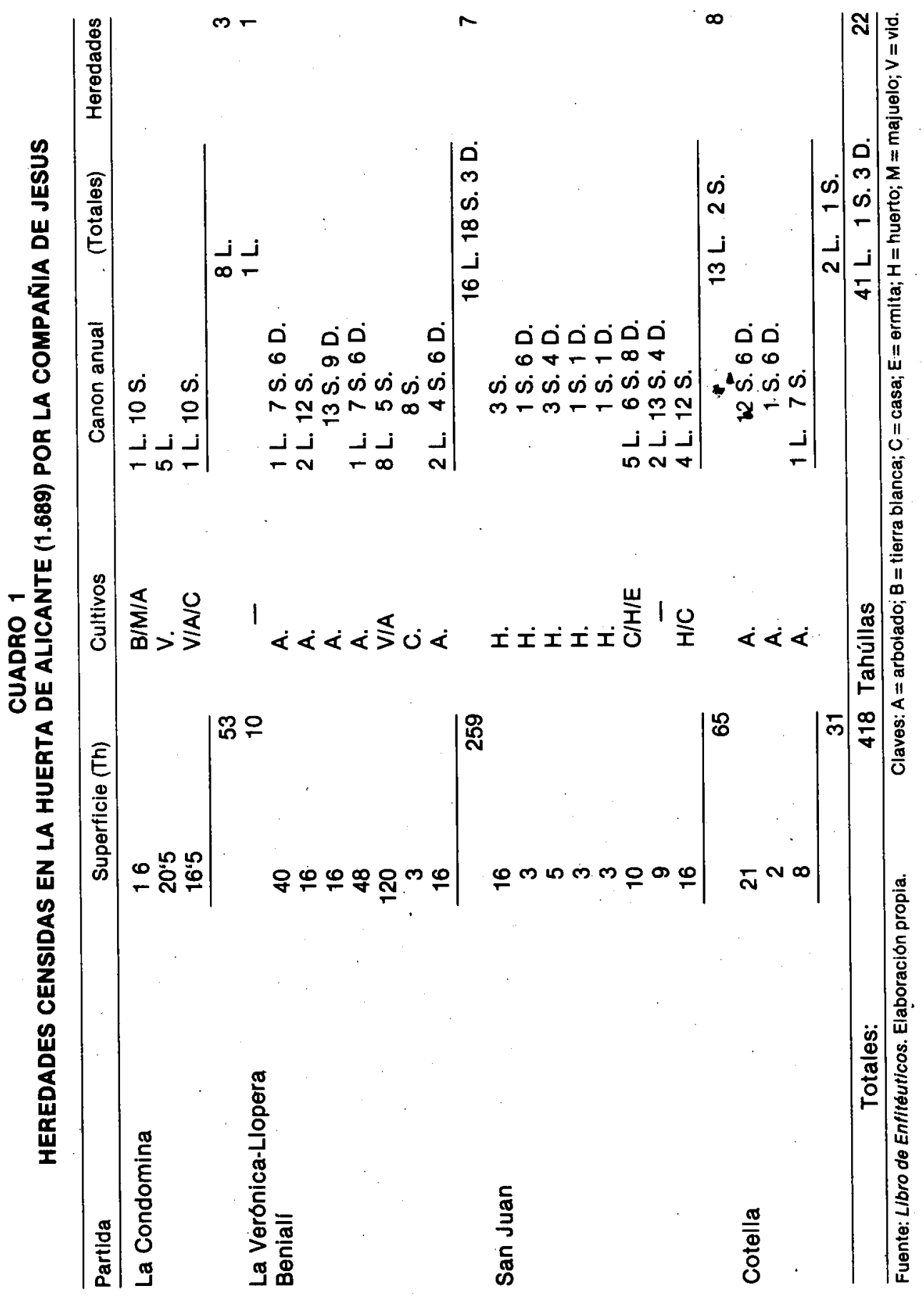




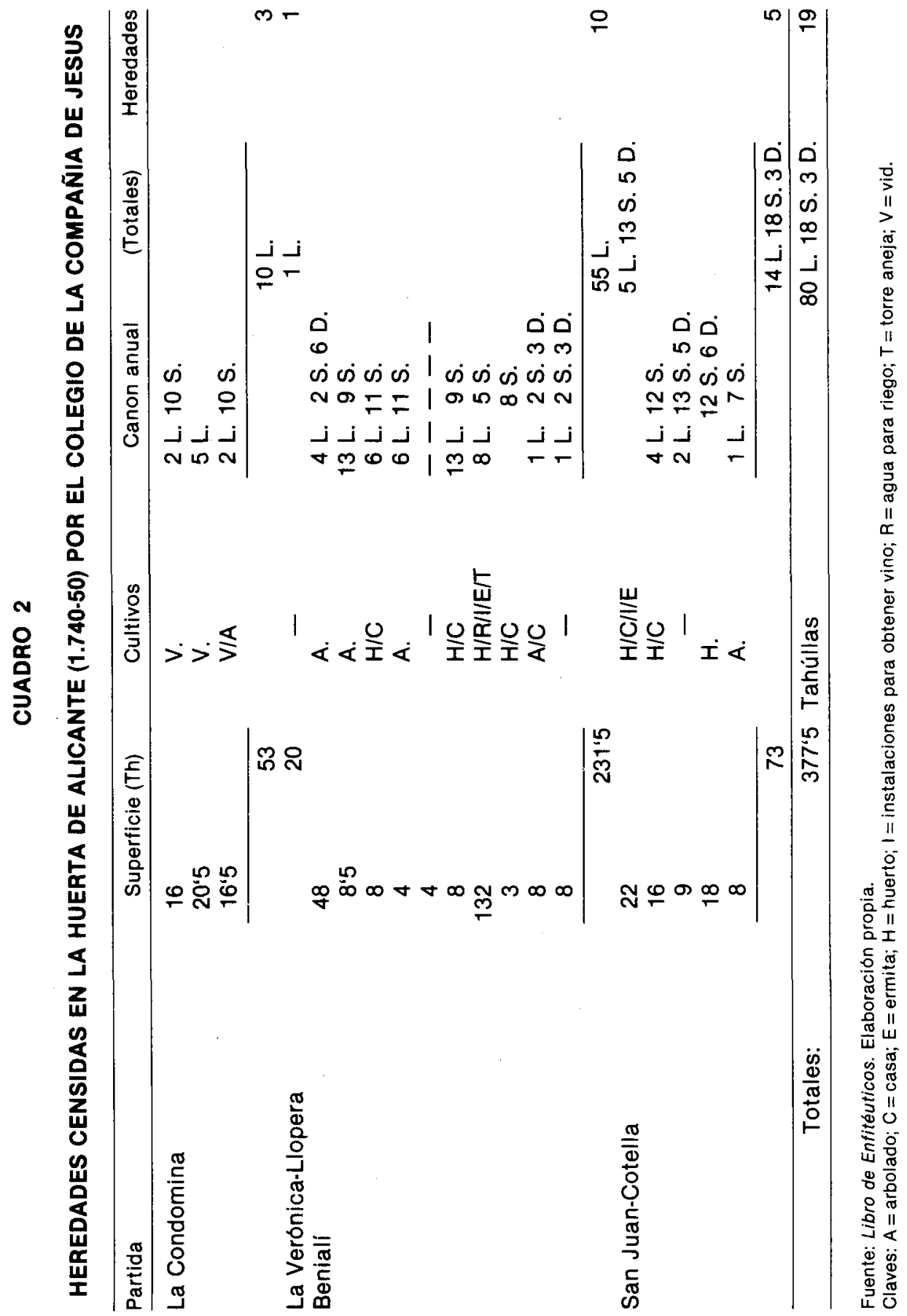


notario Cerdá hacia efectiva idéntica cantidad por las dos que poseía. Estas tres parcelas de La Condomina se mantienen con idénticas extensiones en el cabreve de 1740 , conservando la familia Bojoni sus 20.5 tahúllas de viñedo. Sin embargo, las otras heredades han pasado a pertenecer, de manera sintomática, a dós representantes del estrato social que a lo largo del siglo XVIII desarrollará una importante y rentable función dentro del ámbito ciudadano: el sector de comerciantes y mercaderes; se trata en este caso concreto de los ciudadanos franceses, asentados en Alicante, Pedro Cholí y Pedro Guimbeu. Desde el siglo XVII, la orientación económica de la ciudad hacia actividades mercantiles derivadas del auge de su puerto había facilitado la instalación de una importante colonia de comerciantes franceses, la cual acrecentó su número una vez finalizada la Guerra de Sucesión a raíz de los privilegios y exenciones que Felipe $V$ concedió.

En la partida conocida como de La Verónica o Llopera aparece, en 1.689 , otro individuo con apellido importante: Don Feliciano Pasqual de la Verónica, el cual disfrutaba de 10 tahúllas de tierra censida de las que no se especifica ni su calidad ni los cultivos contenidos, siendo el canon anual de tan sólo una libra. En 1740-50 la familia Pasqual de la Verónica ha aumentado, gracias a diversas compras de dominio útil, hasta 20 las tahúllas que anteriormente tenía concedidas bajo censo efitéútico.

Donde más alteraciones de tipo nominal, respecto de uno y otro cabreve, se aprecian es en la partida de Benialí, en la cual la familia Benedito consiguio antes de 1740 el establecimiento de cinco heredades. Dichas heredades suponian 72 tahúllas de superficie dedicada a un cultivo básico de arbolado, presumiblemente almendros y frutales, junto con dos "casas de habitación" para residir en ellas. Estas parcelas, obtenidas por los Benedito merced a un establecimiento reciente puesto que no figuran en el cabreve de 1689 , muestran un apreciable aumento de las pensiones en metálico que anualmente se satisfacian al Colegio, ascendiendo el pago globalizado de las mismas a la cantidad de 30 libras y 13 sueldos(14).

No obstante lo expuesto hasta ahora, la mayor superficie de tierras que bajo la forma jurídica de censo enfitéutico tenfa concedida la Compañia de Jesús en la huerta alicantina, se localizaba en la partida de Benialí. En ella, doña Isabel Mingot poseía en 1689 el dominio útil de 120 tahúllas plantadas de vid y diversos árboles. Esta heredad figura en 174050 a nombre de Don Luis Juan Torres, sucesor del conde de Peñalva, habiéndose incrementado su superficie hasta 132 tahúllas así como los bienes anejos a las mismas, puesto que en la escritura aparecen consignadas, junto con la propiedad rústica, una casa con torre, la bodega con sus lagares y prensa para obtener vinó, una ermita y cinco hilos de agua para riego exclusivo de estas tierras. El canon, pese a todo, no ha sufrido alteracion y permanece estable en las 8 libras y 5 sueldos reseñadas en el cabreve más antiguo. 
En el resto de las parcelas censidad se observa, en general, un claro auge del sector religioso. Si en 1689 , junto con las capas altas ciudadanas y algunos labradores, aparecian un militar, un notario y dos presbiteros - uno de ellos, mosén Bautista Planelles, detentando dos heredades que sumaban 26 tahúllas, además de una casa y ermita-, en 1740 son ya cinco los religiosos que disfrutaban del dominio útil de otras tantas parcelas situadas en las partidas de Benialí y de Cotella-San Juan. En conjunto suponían 67 tahúllas que reportaban al Colegio unos ingresos anuales de 12 libras 12 sueldos 11 dineros.

Los últimos datos respecto a estas propiedades censidas enfitéuticamente los tenemos documentados en los años próximos a la expulsión de los jesuitas en España. En 1755, una minuciosa puesta al día de los bienes de la Compañia(15) nos indica bien a las claras que se ha producido una reducción, tanto en el número de heredades como en la superficie censida total. Los cánones anuales pagaderos en el día de San Miguel también han sufrido un descenso, aunque no es tan apreciable como podría suponerse puesto que de las 80 libras que se recaudaban en 1740 se ha pasado, en 1755, a 62 libras. En el breve lapso de quince años no se han producido variaciones respecto de los propietarios nominales del dominio directo, manteniéndose en cada heredad los mismos individuos que aparecían en 1740 o sus sucesores. Unicamente no constan en esta relación de bienes censidos los de la familia Benedito, cuya fugaz aparición y subsiguiente ausencia sugiere algún negocio cuyas implicaciones no alcanzamos a evaluar. En efecto, los Benedito que en 1740 llegaban a poseer el dominio útil de cinco parcelas en Benialí han sido sustituídos, apareciendo en su lugar únicamente tres propietarios-Don Nicolás Cañizares, Miguel Castilla y Margarita Sala-que tan sólo disfrutan de 34 '5 tahúllas y pagan un canon global de 19 libras 5 sueldos 9 dineros al año.

\section{a.2) Los arrendamientos}

La forma jurídica de tenencia de la tierra anteriormente descrita se complementaba con la utilización del arriendo en el resto de las propiedades rústicas pertenecientes al Colegio de la Compañia de jesús; propiedades también importantes en número y extensión y que se distribuian tanto en la huerta alicantina como en los secanos del oeste de la ciudad. La carencia de datos relativos al siglo XVII nos obliga a analizar únicamente la realidad de la primera mitad del siglo XVIII; y ésta es posible conocerla gracias a la información extraída del Justiprecio General del Término (1759) y del Manual de Bienes Raizes (1755)16).

Las tierras arrendadas en el regadío se localizaban en dos únicas partidas, el Baver y La Condomina, ascendiendo sus superficies totales 


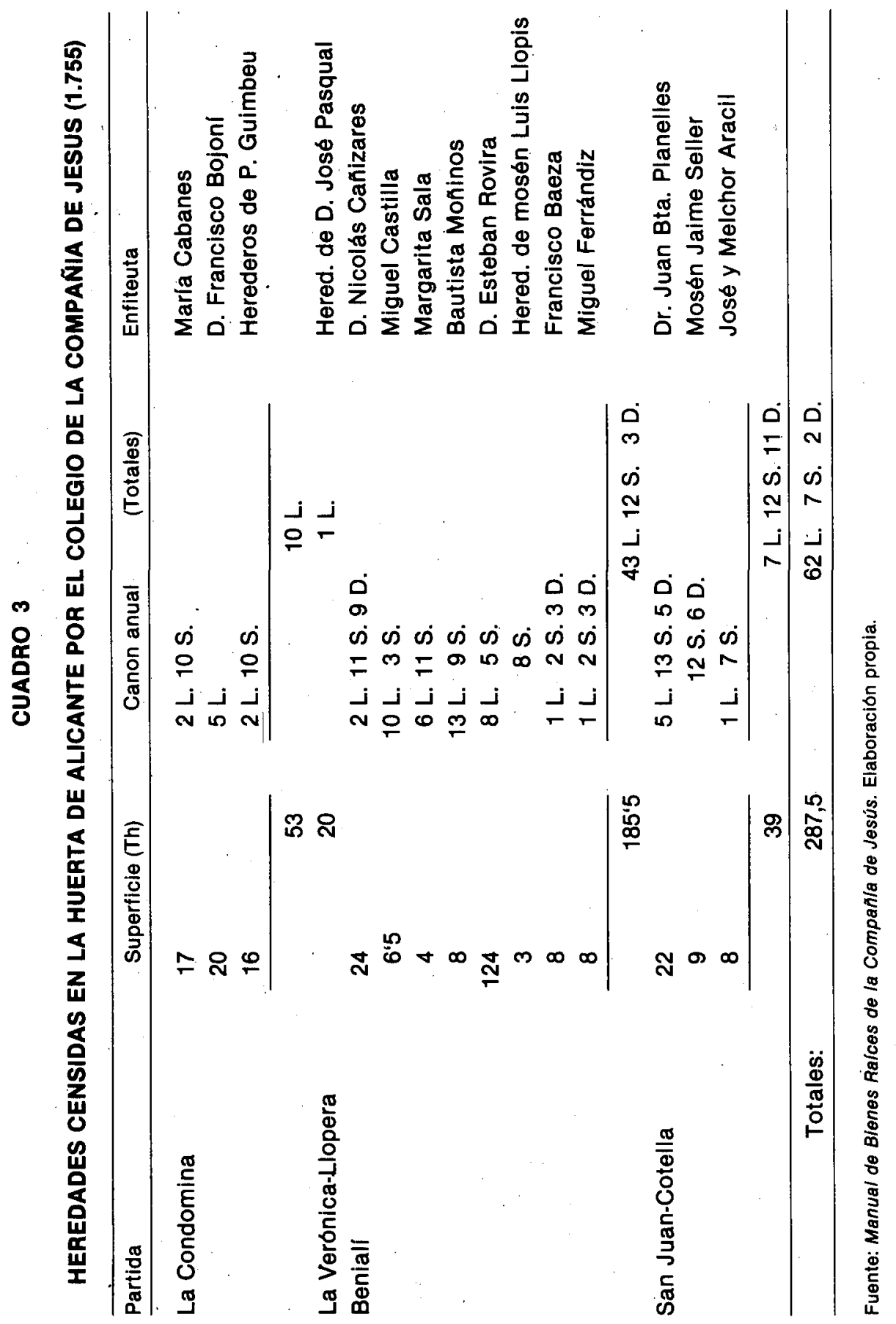


respectivamente a 19 y 73 tahúllas, repartidas en seis heredades. El cultivo fundamental era de vid y majuelo, sobre todo en La Condomina, partida en la que la Compañia ejercía un especial control. La duración de los arrendamientos oscilaba entre los dos y cuatro años, reseñándose normalmente en el contrato que la mitad de los mismos eran de obligado cumplimiento y el resto a elección del arrendatario. Esta fórmula era conocida en siglos anteriores como "temps de ferm $i$ de respit", y para ejercer el derecho de total cumplimiento del contrato el arrendatario debía hacerlo saber al arrendador con la suficiente antelación. Los cánones anuales oscilaban mucho, y estaban en función de la superficie arrendada y la duración del contrato, pero se puede afirmar que eran ciertamente elevados sobre todo si son comparados con los del resto de la huerta. Esto es comprensible si tenemos en cuenta que en La Condomina el valor medio de Ha. cultivada de vid podía estimarse entre las 300 y 500 libras, según los datos del Justiprecio ya citado. Los cánones anuales eran hechos efectivos en dos pagas, normalmente en los días de San Juan y San Miguel.

Los capítulos o condiciones de los arrendamientos eran minuciosamente redactados y contenían todas las labores que el arrendatario debía desarrollar en las tierras que le habían sido cedidas por un limitado período de tiempo. En muchas de las heredades, dentro del arriendo de las mismas, iba incluído el disfrute de determinadas cantidades de hilos de agua para riego, las cuales debian emplearse de modo exclusivo en las tierras a las que estaban adscritas. La limpieza de las acequias corria siempre por cuenta del arrendatario.

Norma general que, a modo de preámbulo, aparece en toda escritura de arrendamiento es la de que quien vaya a trabajar la tierra lo haga «a uso y costumbre de buen labrador". Posteriormente ya se desarrollaba el resto de exigencias, tales como dejar una parte de la propiedad en barbecho o "guaret" y prodigarle cuidados adecuados a las vides. Estas debian ser regadas y podadas según la costumbre huertana y en las épocas del año correspondientes. Si el arrendatario perdia alguna de las cepas por desidia en el riego, debía reponerla a sus expensas y, entre las labores fundamentales que se reseñaban se establecía el labrado de las mismas a dos rejas seguido del entrecavado a legón.

Los jesuítas debian obtener interesantes beneficios de sus tierras arrendadas en La Condomina, puesto que la corta duración de los contratos permitía la continua revisión de los mismos con la consiguiente actualización y revalorización de las percepciones anuales. 
PROPIEDADES EN REGADIO ARRENDADAS POR EL COLEGIO DE LA COMPAÑIA DE JESUS (1759)

\begin{tabular}{|c|c|c|c|c|c|}
\hline PARTIDA & \multicolumn{2}{|c|}{ SUPERFICIE } & CULTIVO & $\begin{array}{c}\text { Valor Total(*) } \\
\text { (Libras) }\end{array}$ & $\begin{array}{c}\text { VALOR } \\
\text { Libras/Ha. }\end{array}$ \\
\hline \multirow[t]{2}{*}{ Baver } & 12 & $1 ‘ 44$ & Regadio & 1.200 & $833 \cdot 33$ \\
\hline & 7 & $0<84$ & Regadío & 700 & $833 \cdot 33$ \\
\hline \multirow[t]{4}{*}{ La Condomina } & 1 & $0: 12$ & Huerto & 70 & $583 \cdot 33$ \\
\hline & 10 & $1 ' 20$ & Majuelo & 350 & $291^{\prime} 66$ \\
\hline & 31 & 372 & Viña & 1.395 & 375 \\
\hline & 31 & 3'72 & Viña & 1.705 & $458 ، 33$ \\
\hline Totales & 92 & 11,04 & & 1.705 & \\
\hline
\end{tabular}

$\left(^{\star}\right)$ El valor hace referencia a lo justipreciado por los peritos tasadores, y no a la renta anual que produce el arriendo.

Fuente: Justiprecio General del Término. Elaboración propia.

Por lo que respecta a las tierras arrendadas en secano cabe decir que suponian 94 jornales(17), distribuídos en 17 heredades de diferentes superficies, localizados en las partidas de La Vallonga, Cruz de Piedra, La Cañada y Antigóns. En estas zonas de secano, los cultivos dominantes eran los denominados de tierra campa y arbolado. Tanto uno como otro término son, evidentemente, confusos e imprecisos pero cabe suponer que el primero se refiere a tierras en las que se cultivaba el cereal y barrilla, y el segundo a superficies ocupadas por el almendro, olivo y algarrobo(18).

Tenemos constancia documental de que, en 1755, el denominado Campo de la Cruz-partida de la Cruz de Piedra-con una superficie de 8 jornales dedicados a tierra campa, lo tenia arrendado Bautista Giner por cuatro años y 13 libras de canon anual pagaderas en un solo plazo el día de Navidad. Igualmente, las dos heredades situadas en Antigóns, que suponían una superficie de 13 jornales, las disfrutaba Vicente Seva según un contrato de arrendamiento realizado ante el notario Juan Galdó en el que constaba una duración de tres años, con canon anual de 42 libras pagaderas el día de San Juan(19). 


\section{CUADRO 5}

PROPIEDADES EN SECANO ARRENDADAS POR EL COLEGIO DE LA COMPAÑIA DE JESUS (1.759)

\begin{tabular}{|c|c|c|c|c|c|}
\hline PARTIDA & $\begin{array}{c}\text { SUPE } \\
\text { Jornales }\end{array}$ & $\begin{array}{l}\text { ICIE } \\
\text { Ha. }\end{array}$ & CULTIVO & $\begin{array}{c}\text { Valor Totall*) } \\
\text { (Libras) }\end{array}$ & $\begin{array}{l}\text { VALOR } \\
\text { Libras/Ha. }\end{array}$ \\
\hline Cruz Piedra & 8 & $3 ‘ 84$ & T. Campa & 80 & $20^{\prime} 83$ \\
\hline \multirow[t]{5}{*}{ La Vallonga } & 3 & $1 \cdot 44$ & Arbolado & 300 & $208^{\prime} 33$ \\
\hline & 5 & $2 ، 40$ & Algarrobos & 350 & $145^{`} 83$ \\
\hline & 4 & $1 ‘ 92$ & Algarrobos & 240 & 125 \\
\hline & 0,5 & 0.24 & Viña & 40 & $166^{‘} 66$ \\
\hline & 15 & $7 \cdot 20$ & T. campa & 150 & $20 \times 83$ \\
\hline \multirow[t]{9}{*}{ Cañada } & 2 & $0 ‘ 96$ & Arbolado & 200 & $208 ، 33$ \\
\hline & 2 & $0 ‘ 96$ & T. campa & 20 & $20^{\prime} 83$ \\
\hline & 15 & $7 \cdot 20$ & Arbolado & 150 & $20^{\prime} 83$ \\
\hline & $7 ‘ 5$ & $3 \times 60$ & T. Campa & 75 & $20 \cdot 83$ \\
\hline & $6: 5$ & $3 \times 12$ & Arbolado & 455 & $145^{\prime} 83$ \\
\hline & 2 & $0 ‘ 96$ & Arbolado & 40 & $41^{\prime} 66$ \\
\hline & 4 & $1 ‘ 92$ & Arbolado & 320 & $166 ` 66$ \\
\hline & 1 & $0 ‘ 48$ & Viña & 90 & $187^{\prime} 50$ \\
\hline & 555 & 2664 & Arbolado & 220 & $83 \cdot 33$ \\
\hline \multirow[t]{2}{*}{ Antigóns } & 8 & $3 ‘ 84$ & Huerto & 320 & $83^{\prime} 33$ \\
\hline & 5 & $2 \times 40$ & T. campa & 100 & $41^{\prime} 66$ \\
\hline Totales & 94 & $45^{\prime} 12$ & & 3.150 & \\
\hline
\end{tabular}

(*) El valor hace referencia a lo justipreciado por los peritos tasadores, y no a la renta anual que produce el arriendo.

Fuente: Justiprecio General del Término. Elaboración propia.

En sintesis, las propiedades rústicas pertenecientes a los jesuitas asentados en Alicante podian evaluarse, en vísperas de su expulsión, en algo más de 280 tahúllas de tierras de regadío censidas enfitéuticamente, junto con otras 92 tahúllas concedidas en arriendo. En secano, por contra, las propiedades arrendadas suponian 94 jornales, representando todas las tierras del Colegio una superficie global de 89 ‘76 hectáreas. 
Las rentas que estas propiedades generaban a la Compañía son difíciles de cuantificar debido a las diferentes formas jurídicas de tenencia a que estaban sometidas; no obstante, por lo que respecta a las censidas enfitéuticamente, queda bien claro que reportaban poco más de 80 libras en metálico a la comunidad cada año. Sin embargo, en las tierras arrendadas es muy difícil conseguir siquiera unas cantidades aproximadas debido a la continua oscilación de los cánones; aunque en base a la nada desdeñable extensión de estas tierras sería lógico concluir que las rentas alcanzarian cotas elevadas visto el exhaustivo control que sobre las propiedades ejercian los administradores del Colegio.

Como propiedad rústica cabe considerar también el llamado Molino de las dos muelas, situado en la partida de Monserrat, y que había sido donado como obra pía al Colegio de los jesuítas por el doctor Marcos Antonio Pasqual, canónigo de la iglesia colegial de Alicante. Este molino, junto con una superficie de 12 tahúllas de tierra huerta y viñas, era arrendado regularmente por el administrador o el rector de la comunidad a los diversos molineros de la huerta, los cuales disponían de una serie de estas instalaciones diseminadas por la zona cuyos propietarios los concedian en arriendos a corto plazo(20).

Conocemos las condiciones en que este Molino de las dos muelas y las tierras inciuídas en la citada obra pía eran arrendados gracias a una escritura signada ante Bautista Alberola, notario de la villa de Muchamiel, entre el rector del Colegio de la Compañía, padre Jaime Sarrio, y el molinero Antonio Sebastiá en 1748 . El contrato en sí es breve y conciso e indica que la duración del mismo se limitaba a cuatro años, de los que los dos primeros eran de obligado cumplimiento quedando los restantes a arbitrio del arrendatario. El canon establecido es de 171 Libras 5 sueldos al año haciéndose efectivo por tercias, respectivamente los últimos días de los meses de enero, mayo y septiembre. No obstante, una cláusula adicional señala que en caso de que al iniciarse el arrendamiento se firmara la paz entre Inglaterra y España la paga anual se elevaría hasta 191 libras 5 sueldos. Otras cláusulas del contrato se refieren a la prohibición de que el arrendatario subarriende el molino sin haber obtenido el correspondiente permiso del administrador del Colegio, así como la obligación ineludible por parte del ocupante de la propiedad de dejarla en las condiciones en que la hubiera encontrado; esto es, con las dos muelas y toda la maquinaria del molino en optimo estado. No obstante, si durante el arriendo se hiciera necesario reponer alguna de las piezas de aquél, los gastos del reparo correrian por cuenta del Colegio siempre que mediara el aviso previo por parte del arrendatario(21). Los últimos capitulos del contrato establecen, además del pago en metálico, la obligación de entregar al Colegio unas compensaciones complementarias en especie. Así, se indicaba que en el dia de Navidad el molinero arrendatario de los jesuítas les llevará a su 
residencia "un serdo grande que esté bueno para matar y dos pares de gallinas", y en la fiesta del patrón San Ignacio dos pares de pollos de buen tamaño. Respecto del tratamiento a dar en las tierras incluídas en ef arriendo, las claúsulas se limitan a indicar que se trabajen «a uso y costumbre de buen labrador".

\section{b) Propiedades Urbanas}

El capítulo de ingresos y gastos que las propiedades urbanas reportaban a la Compañía de Jesús era bastante desigual. Del mismo modo que en las heredades de la huerta, las casas, que tanto en la ciudad de Alicante como en la vecina universidad de San Juan poseian los jesuitas producto de diferentes legados y administraciones instituídas en su favor, estaban sometidas a idénticas formas jurídicas. Así, alquileres y censos enfitéuticos aparecen complementándose y generando una serie de rentas anuales que contribuian al mantenimiento del Colegio.

La fuente manejada para obtener información acerca de las propiedades urbanas censidas ha sido, obviamente, el ya citado Libro de Enfitéuticos. En él, además de un plano esquemático en donde aparece dibujada en planta la ubicación de las casas tanto en la ciudad de Alicante como en la vecina población de San Juan, vienen perfectamente detallados los sucesivos tractos y nuevos establecimientos comprendidos entre 1689 y 1727 53. La amplitud de la fecha final obedece a la ausencia de datos actualizados de muchas de las casas en los últimos cobreves conservados. Pensamos que los cuadros elaborados al efecto son suficientemente explícitos y hacen ocioso un comentario prolijo. No obstante cabe indicar que de 1689 a 1727-53 las casas censidas por la Compañia en la ciudad de Alicante pasaron de 24 a 29 , mientras que en San Juan el aumento de establecimientos fue sensiblemente superior: de 36 a 57 casas entre uno y otro cabreve. Los cánones anuales pagaderos el día de San Miguel resultaban poco gravosos, y dentro de ellos es destacable el hecho de que en algunos casos únicamente se hiciera efectivo el canon simbólico de un vaso de agua. Quizá una explicación de ambos casos estuviera en el hecho de que la vivienda alicantina, claramente influenciada por la escasez de suelo edificable, se configurara como un recinto de dimensiones muy reducidas-en ocasiones las características de estas casas moradas se decriben en palmos, no llegando a superar los 60 palmos de ancho por 50 de profundidad-de una sola planta y, esporádicamente con una o dos estancias superiores.

Entre los enfiteutas que poseian el dominio útil de estas casas propiedad del Colegio de la Compañía en San Juan, se observa un predominio claro de los labradores. Por contra, en Alicante la sociología de los enfiteutas presenta un abanico más amplio que acoge a la práctica totalidad 
de los estratos ciudadanos, puesto que en el cabreve figuran desde nobles y caballeros-D. Ambrosio Pauman, D. ${ }^{a}$ Nicolasa Martínez de Vera, D. ${ }^{a}$ Mariana Salafranca, el Regidor de Alicante, etc. - hasta comunidades religiosas, artesanos e individuos de los que no consta especificación económica-Conventos de San Agustín y del Carmen, un maestro cerero y confitero, un albañil-. Las ventas del dominio útil eran muy frecuentes, precisando para ser llevadas a cabo la licencia del administrador del Colegio, y estarian motivadas por el interés de cambiar de domicilio en un momento del siglo en que se inicia el proceso de ampliación del perímetro urbano.

\section{CUADRO 6}

CASAS CENSIDAS POR EL COLEGIO DE LA COMPAÑIA DE JESUS EN SAN JUAN (1741)

\begin{tabular}{|c|c|c|}
\hline CALLE O PLAZA & N. ${ }^{\circ}$ CASAS & CANON ANUAL (Totales) \\
\hline Cl. 1. ${ }^{a}$ entrando a S. Juan & 2 & $1 \mathrm{~S} .6 \mathrm{D}$. \\
\hline Pla de la Creu & 3 & $2 \mathrm{~S}$. \\
\hline Cl. del Racó & 4 & $6 \mathrm{~S} .8 \mathrm{D}$. \\
\hline $\begin{array}{l}\text { Cl. Horno de Orts o } \\
\text { Camino de Cotella }\end{array}$ & 25 & 22 L. 12 S. 10 D. y un vaso de agua \\
\hline Cl. de la Maimona & 4 & $1 \mathrm{~L}$. $1 \mathrm{~S} .6 \mathrm{D}$ y dos vasos agua \\
\hline Cl. Camino de Alicante & 1 & $3 \mathrm{D}$. \\
\hline Cl. San Antón & 18 & 18 vasos de agua \\
\hline Totales & 57 & 9 D. y 21 vasos de agua \\
\hline
\end{tabular}

Fuente: Libro de Enfitéuticos. Elaboración propia.

\section{CUADRO 7}

CASAS CENSIDAS POR EL COLEGIO DE LA COMPAÑIA DE JESUS EN ALICANTE (1727.53)

\begin{tabular}{lcc}
\hline \multicolumn{1}{r}{ Calle 0 PLAzA } & N. ${ }^{\circ}$ CASAS & CANON ANuAL (Totales) \\
\hline Pza. Fdez. de Mesa & 2 & 4 L. 5 S. 6 D. \\
Partición & 7 & 1 L. 6 S. 3 D. \\
San Roque & 12 & 3 L. 19 S. \\
Pza. San Roque & 8 & 1 S. 6 D. $\left(^{\star}\right)$
\end{tabular}

(*) De las 8 casas censidas, 5 pagan el canon anual simbólico de un vaso de agua en el día de San Miguel.

Fuente: Libro de Enfitéuticos. Elaboración propia. 
Por lo que se refiere a las propiedades urbanas sometidas al régimen de alquiler por parte de los regulares de la Compañia destacan, ante todo los dos Almacenes, denominados Nuevo y Grande, que en 1755 estaban alquilados a Don Tomás Coxen, el cual pagaba anualmente por ambos la cantidad de 70 libras. El resto de inmuebles se componía de siete casas repartidas entre las calles del Muelle, San Ginés, San José y San Francisco Javier, obteniendo de ellas el Colegio una renta global de poco más de 130 libras tal y como se observa en el cuadro siguiente:

\section{CUADRO 8}

CASAS ALQUILADAS POR EL COLEGIO DE LA COMPAÑIA DE JESUS EN ALICANTE (1755)

C A L L E

Del Muelle

De San Ginés

De San José

De San Fco. Javier
INQUILINO

CANON ANUAL (en Libras)
Bautista Haspre

Antonio Salerno

Agustín Martínez

Rita Valero

Cristóbal Ricardo

José Botella

José Alarcón

Leonardo Sánchez
$60 \mathrm{~L}$.

$12 \mathrm{~L}$.

1 L. 10 S. 8 D.

$16 \mathrm{~L}$.

$16 \mathrm{~L}$.

$9 \mathrm{~L}$.

$8 \mathrm{~L}$.

$8 \mathrm{~L}$.

Total 130 L. $10 \mathrm{~S} .8 \mathrm{D}$.

Fuente: Manual de Bienes Raices. Elaboración propia.

c) Otras rentas

En este apartado final relativo a la evaluación de las rentas que el Colegio obtenia en la ciudad de Alicante quedan reflejadas todas aquellas percepciones procedentes de limosnas, obras pías y préstamos hipotecarios facilitados por el Colegio, consignadas todas ellas en el Manual de Bienes datado en 1755.

La ciudad de Alicante tenía asignadas, tradicionalmente, unas ayudas en metálico para las diferentes comunidades religiosas establecidas en ella. Estas ayudas procedían de los caudales públicos y eran incluídas en los presupuestos de gastos, quedando pues institucionalizadas en 
sucesivas Ordenanzas publicadas para el gobierno ciudadano. En el siglo XVII, la Casa Residencia de la Compañia percibia 69 libras anuales en concepto de limosna, de las cuales 30 libras se destinaban a la compra de hábitos para los religiosos correspondiendo el resto a la arroba y media de harina concedida al Colegio al poco de establecerse en la ciudad. Igualmente corría de cuenta del municipio el pago de los salarios de los maestros de la cátedra de Gramática-200 libras al año-, asi como el de los encargados de las de Arte y Teología, aunque el salario de estas últimas cifrado en 140 libras era compartido por los jesuítas y dominicos(22).

En visperas de su expulsión, la comunidad de jesuitas establecida en Alicante percibia de la ciudad 204 libras "por alimentos de los padres maestros" de Gramática y Filosofía, cantidad que se hacía efectiva los últimos meses de abril, agosto y diciembre. Otras percepciones se refieren a las 3 libras de limosna de harina en el mes de mayo y a las 16 libras 10 sueldos con que la ciudad subvencionaba la celebración de la fiesta de San Francisco Javier el 4 de diciembre de cada año(23).

Completando este aporte oficial aparecen consignados diferentes legados de particulares destinados, sobre todo, al mantenimiento de lámparas de aceite en los altares del Santísimo y de San Francisco Javier y que alcanzaban la suma anual de 10 libras además de una porción en especie de 6 arrobas de aceite(24). Finalmente, quedan resumidas en el cuadro 9 las pensiones anuales que, de ciertos censales, obtenia el Colegio y que vienen a cerrar el capítulo de rentas que éste disfrutaba en la ciudad de Alicante.

CUADRO 9

\section{CENSALES CARGADOS A FAVOR DEL COLEGIO DE LA COMPAÑIA VIGENTES EN 1.775}

DEUDOR

Jaime Gómiz

VALOR NOMINAL

PENSION ANUAL

$50 \mathrm{~L}$.

1. L. $10 \mathrm{~S}$.

50 L. 1 L. $10 \mathrm{~S}$.

Tomás Pérez

$44 \mathrm{~L}$.

1 L. $6 \mathrm{~S} .6 \mathrm{D}$.

353 L. 10 L. $12 \mathrm{~S}$.

D. Pascual Lombardón

D. Ignacio Pelegrín
FECHA PAGOS

Fuente: Manual de Bienes Raices. Elaboración propia. 
Lentamente, la expulsión de España de la Compañia de Jesús va encontrando un enfoque interpretativo mesurado, lejos del apasionamiento apologético que el tema tuvo entre partidarios y detractores del extrañamiento. Hoy por hoy, el tópico recogido y aventado por Menéndez y Pelayo de conspiración enciclopedista contra la Iglesia(25) ya no puede sostenerse seriamente, y el enfoque religioso ha sido sustituido por otras implicaciones de carácter político, social y económico(26).

Esta ampliación de la perspectiva ha sido posible gracias a la necesidad de hallar una explicación del suceso en coherencia con la realidad europea del despotismo y con la coyuntura política carlotercerista, encontrando esta actitud terreno favorable en el análisis de nuevos aportes documentales. En esta tarea se han destacado Rafael Olaechea, Corona Baratech y Teofanes Egido, entre otros(27), demostrando los primeros la escasa significación de Aranda en el proceso y el papel decisivo de Campomanes y Roda en la expulsión, así como su responsabilidad en situar en el primer plano del análisis el clima general de antijesuitismo, alentado por los ilustrados reformistas y los jansenistas españoles, los móviles económicos de su actitud-la ocupación de las temporalidades-y los móviles sociales, enmarcados en la lucha por el control de la enseñanza. De Egido, resaltar.su contribución al tema con el hallazgo revelador en el archivo Campomanes de la Pesquisa Secreta y la edición anotada del Dictamen Fiscal de expulsión(28).

Una parte importante del Dictamen denuncia la acumulación de bienes temporales por la Compañia(29):

"De este primer vicio se pasará a demostrar el fiscal el de su ambición de riquezas temporales, que tantas raíces ha hechado en estos dominios y tanta influencia tiene en los momentos actuales»(30).

La cuestión de las temporalidades y su resolución debe inscribirse en los proyectos de desamortizadores inspirados por Campomanes. Es sabido que la desamortización de las tierras de la Iglesia española no llegó a plantearse explicitamente en el siglo XVIII, al contrario de lo sucedido respecto a bienes municipales. Sin embargo, si se planteó el poner límite a la vinculación de las nuevas adquisiciones de bienes inmuebles por la Iglesia. La iniciativa partió del fiscal del Consejo de Hacienda, Don Francisco Carrasco, más tarde Marqués de la Corona(31) y fue secundado por Campomanes, fiscal del Consejo de Castilla con una alegación que seria el fundamento del famoso Tratado de la regalía de amortización, incluído en el Indice de libros prohibidos en 1825. 
El proyecto Carrasco-Campomanes fue derrotado el 18 de julio de 1776 en el Consejo Real por diez votos contra seis. Son muy sugerentes las opiniones que Francisco Tomás y Valiente expresa en su estudio preliminar a la edición facsimilar que en 1975 se realizo del Tratado; según Tomás y Valiente, los votos favorables al proyecto de los fiscales corresponden a los hombres que más tarde constituirían la Sala Extraordinaria encargada de llevar a efecto la Pesquisa Secreta, y al equipo que votaría la expulsión(32). El proceso de enajenación de los bienes de la Compañia, tema de las páginas que siguen en nuestro estudio, cobra así una dimensión mayor: la revancha de Campomanes tras el fracaso de su proyecto de desamortización, y un ensayo limitado de ampliación del mercado de bienes inmuebles mediante la venta en subasta de las temporalidades de la Compañia.

El proceso de expulsión ha quedado como un ejemplo de planificación y ejecución. El Dictamen de Campomanes fue aprobado el 29 de enero de 1767 y firmado por el rey el 20 de febrero, siendo la operación mantenida en un total hermetismo y realizada con gran precisión y por sorpresa. La noche del 31 de marzo fueron ocupados los Colegios de Madrid y el 2 de abril en provincias, a cuyas autoridades el Conde de Aranda habia hecho llegar previamente un pliego cerrado conteniendo la Instrucción y con ordenes expresas de no abrirlo antes del primer día de abril. El mismo día 2 de abril se promulgó la Pragmática Sanción de extrañamiento.

En la ciudad de Alicante, como en toda España, la operación fue llevada a cabo con total secreto y diligencia. El primero de abril se celebró un acto literario en el Colegio de la Compañía, con asistencia del Cabildo Municipal, y el día 2 se presentó en él Antonio Fernando Calderón, Alcalde Mayor en funciones de Corregidor, para efectuar la expulsión, lo que se realizo en la madrugada del día 3 sin incidentes(33), tal y como especificaba la Instruccion remitida por Aranda.

A las veinticuatro horas de la comunicación del extrañamiento, los jesuitas fueron trasladados a distintos lugares de reunión previamente asignados, los denominados Depositos interinos o Cajas Generales. Los catorce Depósitos que señalaba la Instrucción(34) cubrían la totalidad de España, y el correspondiente al Reino de Valencia se situó en Segorbe. Desde Segorbe los expulsados se trasladaron a Tarragona, lugar escogido como Deposito de los jesuitas catalanes, y ciudad a la que también acudieron los jesuitas aragoneses previamente reunidos en el Deposito de Teruel. Finalmente, y como último trayecto en tierra española, los miembros de la Compañia pasarían de Tarragona al puerto próximo de Salou donde serían embarcados. Junto a Salou eran Santander y el Puerto de Santa María los puntos de salida de España.

En toda la operación se pretendía mantener a los miembros de la orden aislados con el exterior, viéndose excluídos de la Instrucción tan sólo 
los procuradores de cada Colegio y los enfermos o persona de edad elevada, los primeros para poder ser sometidos a interrogatorios durante dos meses sobre los caudales y régimen interior de las instituciones y los segundos "hasta tiempo más benigno, o a que su enfermedad se decida)(35), procurándose que unos y otros se encontraran sin contactos exteriores en los lugares de reclusión.

Tras la expulsion, habia que arbitrar el mecanismo regulador de las temporalidades.

\section{Las ventas de los bienes de la Compañia}

Las ventas de los bienes de los jesuitas expulsados se efectuaron siguiendo la reglamentación contenida en la Cédula Real de 27 de marzo de 1769(36). En ella se creaban las Juntas Municipales, pieza básica en las operaciones de tasación, subasta y formalización de las ventas. Estas Juntas estaban formadas por un comisionado del Colegio, un regidor nombrado por el Ayuntamiento, un eclesiástico nombrado por el Obispo y los Diputados y Personeros del Común. Estas Juntas Municipales serían supervisadas y coordinadas por una Junta Provincial, compuesta por el Intendente de la provincia, el Corregidor o Alcalde Mayor de la capital, un regidor nombrado por el Ayuntamiento, un eclesiástico designado por el Metropolitano, el Diputado del Común más antiguo y el Personero del Común.

Las Juntas Municipales de temporalidades debian elegir a los peritos tasadores para la realización de los justiprecios, elección que se efectuaba por votación de los miembros de la Junta. Con las tasaciones, la Junta debia elaborar un estadillo de todas las haciendas de cada Colegio, indicando el valor estimado por los tasadores y el valor líquido vendible, una vez deducidas las cargas, si las hubiere. Dentro de estas tasaciones y estadillos no se incluían los inmuebles dedicados a iglesia o capillas,

"por estar fuera del comercio y por su dedicación a Dios ser invendibles, ni tampoco los ornamentos y vasos sagrados, ni las viviendas que ocupaban los regulares, aulas, ni Casas de Estudios, porque todo esto se debe aplicar al culto, Escuelas y objetos públicos»(37).

Por lo tanto, una parte considerable del patrimonio de la Compañía quedaba excluído del mercado.

Los estadillos confeccionados por las Juntas Municipales se remitían a la Junta Provincial, quien los imprimía y distribuía para darlos a conocer a los potenciales postores.

Esta Real Cédula de marzo de 1769 fue complementada por otra, fechada en San Lorenzo el 8 de noviembre de ese mismo año, en la que se 
garantizaba el carácter seguro y perpetuo de las transacciones de temporalidades de la Compañia:

"....ninguno de mis tribunales, junta o juez de cualquier calidad que sea pueda admitir en tiempo alguno demanda sobre nulidad, rescisión, tanteo, suplemento, restitución ni otra instancia alguna que no sea sobre el cumplimiento de dichos contratos y sus condiciones, o, cuyo efecto aseguro por mi fe $y$ palabra Real esta misma permanencia y perpetuidad «(38).

El empeño por el rey de su palabra para asegurar las transacciones, indica que existía una cierta inseguridad entre los posibles compradores sobre el futuro de las compras, viéndose favorecida la duda por los rumores propalados por los enemigos de la expulsión sobre la ilegalidad de aquellas transacciones, pese a que buena parte del episcopado español se mantenía alerta para abortar las posiciones projesuíticas(39).

Otro peligro que podia empañar la operación subastadora procedía de las irregularidades o corruptelas realizadas o amparadas por miembros de las Juntas Municipales, o por el boicoteo de éstas para impedir las ventas. Por ello, Carlos III instaba a las Juntas Provinciales a extremar su supervisión sobre las Municipales:

"Y prevengo a las referidas Juntas Provinciales que si entendieren $O$ averiguaren que se delatan o perturban las ventas por los Administradores $u$ otros dependientes de las temporalidades por el particular interés de que dure la administración o por otro fin reprobado, los separen y nombren en su lugar personas imparciales, activas y diligentes que faciliten la enajenación, dando cuenta a mi Consejo de las providencias que tomaren en este asuntow $(40)$.

De esta forma el Consejo de Castilla, dirigido por el equipo regalista, asumía el papel de última instancia en el proceso de enajenación. En el estudio de las características de los bienes subastados y en la descripción de las distintas subastas efectuadas en el corregimiento alicantino, se puede apreciar que las tres instancias-Junta Municipal, Junta Provincial y Consejo de Castilla-intervienen en la resolución de los problemas que se fueron planteando.

\section{Las propiedades rústicas subastadas}

La propiedad más valiosa de las subastadas era la situada en La Condomina, en el corazón de Huerta alicantina. De las distintas partidas rurales que constituian el término municipal, esta de La Condomina ofrecía los rendimientos más elevados $y$, en consecuencia, las valoraciones más 
altas. Dedicada preferentemente al cultivo de la vid, sus rendimientos triplicaban al de las tierras de secano circundantes. No es extraño, pues, que se diera en La Condomina la mayor concentración de propiedades de estamentos privilegiados de todo el ámbito jurisdiccional alicantino.

La heredad de la Compañia estaba conformada como un complejo agrario en el que, junto a la explotación del terrazgo, existían dos lagares y una prensa destinados a la elaboración de vino, y una casa bodega con el instrumental necesario para la manipulación de los caldos: toneles, piperío, portaderas, transcoladeras y embudos. La importancia de esta infraestructura era grande, como lo prueba que se justipreciara por una cantidad superior a las 2.000 Libras valencianas(41), lo que venía a suponer casi una tercera parte del valor total.

La explotación tenía una extensión aproximada de 126 tahúlias, de las que la Compañia tenia reservadas para sí, cediéndolas en arriendo, un total de 78 tahúllas, de las que 77 se hallaban cultivadas, las que fueron precisamente expropiadas y puestas a la venta en pública subasta junto a la casa, lagar, tonelería y los derechos de agua para el riego propios de la heredad.

Se puede afirmar que la casi totalidad de la superficie cultivada se hallaba destinada a viña, salvo una pequeña parcela de tierra campa y de 2 tahúllas de huerto. Esta tierra, y los derechos de agua, se justipreciaron en 4.888 libras 11 sueldos, con los que el total de la tasación, al incluir la casa y demás efectos, se elevó a 7.398 Libras 11 sueldos 8 dineros.

La segunda propiedad expropiada se hallaba también en la Huerta, aunque fuera del término alicantino, ya que parte de la partida rural de Cotella, donde se ubicaba la heredad, se encontraba en el municipio huertano de Muchamiel. Esta finca estaba constituida por 39 tahúllas y 2 cuartas, contando con una casa y con derecho de agua de riego del Real Pantano. Parte se encontraba plantada de arbolado y parte se destinaba a sembradura, encontrándose arrendada en las fechas anteriores a la expulsion(42).

La tercera de las propiedades de la Compañia se encontraba en la partida de la Sueca, al oeste de la ciudad y lindante con sus murallas. A excepción de la Huerta, donde era posible un riego intermitente y escaso, esta partida de la Sueca era la única donde era posible un riego de frecuencia suficiente para permitir el cultivo de productos hortícolas. La presencia de la fuente de la Casa Blanca o Fuensanta posibilitaba hasta la existencia de una tabla de regantes(43). La propiedad de la Compañía era de 12 tahúllas y 3 cuartas, y para su riego disponía de una pequeña noria y seis balsas donde se depositaba el agua procedente de la fuente en los dias y semanas que le correspondian. La posibilidad de un riego asegurado que permitía un cultivo horticola intensivo en las mismas puertas de la ciudad, daba a esta pequeña propiedad un valor muy elevado, justipreciándose 
tras la expulsión en 1.220 libras, lo que venía a suponer que la tahúlla alcanzaba un precio superior a las 100 libras, mientras que en las propiedades de Cotella y La Condomina apenas sobrepasaban las 60 libras.

El cuarto lote estaba formado por un molino harinero y su tierra aneja, y por una propiedad dedicada a la sembradura de secano. Lo peculiar de este conjunto es que mientras el molino se encontraba en la partida de Monserrat, en el término de Muchamiel, y por lo tanto en la Huerta, la tierra secana se hallaba a considerable distancia, en la ladera de la Sierra de San Julián, fuera ya de la Huerta.

El molino harinero era el denominado "Molino de las dos muelas", y era uno de los trece que trabajaban en la Gobernación, estando situado en la partida de Monserrat, en Muchamiel, en las proximidades de los conocidos como "Molino de la Carnicería", propiedad del potentado local D. Antonio Pasqual de Riquelme, del "Molino de la Soledad", propiedad de la Condesa de Faura, residente en Valencia, y del "Molino de Monserrate", propiedad del negociante Luis Lombardón.

Estos molinos, y todos los demás, estaban arrendados a molineros y el dominio directo correspondía al Real Patrimonio. En concreto, el "Molino de las dos muelas", propiedad de la Compañía, pagaba una pensión a la Bailia de 15 sueldos anuales, y estaba sujeto a luismo y fadiga. En el momento de la expulsión se hallaba cargado con un censal de 380 libras y una pensión anual de 11 libras 6 sueldos, que al destinarse a la celebración de misas el día de la Asunción, en el cuarto domingo de mayo y en el día de San Francisco Javier, nos hacen suponer que asi lo dispuso el fundador de la Memoria por la que pasó el molino a propiedad de la Compañia.

En cualquier caso, el molino fue justipreciado junto a las 8 tahúllas de huerta que lo circundaban y a los 13 jornales de sembradura de secano en la ladera de la Sierra de San. Julián. El valor de la tasación alcanzo las 1.332 libras 16 sueldos, y ya que disponemos del justiprecio del molino y su tierra efectuado en 1769, estamos en condiciones de afirmar que éste supuso una cantidad de 1.050 libras 16 sueldos, de las que 446 libras y 16 sueldos correspondian a lo tasado de albañileria, cantería, carpintería y cerrajería del molino(44).

La Compañía era también propietaria de cinco hilos de agua, cuyo vaIor fue tasado por D. Carlos Berenguer de Marquina, administrador del RI. Pantano, en 500 libras cada uno. La propiedad del agua que discurria por el cauce del río Montnegre antes de la construcción del Pantano en las postrimerias del siglo XVI, se hallaba distribuida en 336 hilos de hora y media, con turnos de 21 dias ${ }^{(4)}$, y cuando se construyó la pared de la presa se distribuyó el mismo número de hilos a razón de un minuto por tahúlla(46). En 1739 se crearon 16 nuevos hilos para contribuir con su venta a los gastos de reparación de la pared de la presa, dañada desde 1697 por una rotura. 
Pues bien, el precio de salida de cada hilo fue de 500 libras, el mismo que treinta años más tarde fue justipreciado por el administrador(47). La Junta Provincial encargada de las subastas formó con los cinco hilos de la Compañía dos lotes de tres y dos hilos respectivamente.

\section{Las propiedades censidas.}

Las propiedades hasta aquí reseñadas son las que fueron expropiadas y subastadas, pero éstas no suponen la totalidad de las propiedades rústicas de la Compañía antes de su extrañamiento. Esta discordancia tiene su explicación, pues el Colegio poseia tierras que arrendaba y tierras que habia cedido en enfiteusis. Las subastadas son parte de las propiedades arrendadas, mientras que las censidas pasaron al dominio directo de la Real Hacienda, quien pasó a cobrar los derechos enfitéuticos que antes de la expulsión percibía el Colegio.

El ejemplo que se extrae de la venta en 1768 del dominio útil de una propiedad censida que había sido propiedad de los jesuítas, es ilustrativo de lo dicho; se trata de una venta que realiza Margarita Seller, viuda, y su hijo Francisco Pinós, labrador, vecinos de Novelda, a José Seller de Bautista, labrador y vecino de Muchamiel, ante el notario de esa villa Bautista Alberola y Ramón(48). La venta se efectúa contando con licencia previa del "Sr. D. Francisco Alvaro, Alcalde Mayor de la Ciudad de Alicante y Juez de Comisión en las Diligencias de extrañamiento de los regulares de la Compañia de Jesús", quien la otorgó mediante auto. La propiedad traspasada estaba formada por 5 tahúllas 2 cuartas y 11 brazas de tierra de regadio, con almendros y algarrobos, y situada en la partida del Salt o Cotella, en Muchamiel, más el agua que le correspondía para su riego. En la escritura de venta se explicitaba claramente la transmisión del dominio directo:

"...tenido al dominio mayor y directo de los Regulares de la Compañía del nombre de Jesús y ahora, por su extrañamiento, a la Real Hacienda, a censo de 6 sueldos pagaderos cada año en cierto día, con luismo y fadiga y demás derechos emphiteoticales...».

Tras indicar el precio de la venta-332 libras 15 sueldos-y expresar el pago, la escritura señalaba que era la Real Hacienda la receptora del censo y de los derechos de luismo y fadiga inherentes a la propiedad:

«Para de hoy en adelante responder a la dicha Real Hacienda en su debido plazo por el extrañamiento de los Regulares de la Compañía de Jesús los 6 sueldos de pensión en cada año, con luismo y fadiga y demás derechos emphiteuticos...". 


\section{Los inmuebles urbanos.}

Los inmuebles urbanos fueron sometidos a esta misma regla. Los arrendados fueron tasados y puestos a subasta, y los censidos pasaron a propiedad directa de la Real Hacienda.

De los primeros, el de mayor valor e interés era un almacén situado en la calle de San Francisco Javier, en el arrabal de San Francisco. Se trataba de un almacén de dimensiones considerables y con dos puertas, muy apropiado para el depósito de mercancías y próximo al muelle. El justiprecio efectuado le señaló un valor de 3.151 libras 3 sueldos, ligeramente superior al justiprecio efectuado en 1769(49).

El resto de los bienes urbanos lo componían un total de 26 casas, situadas en su mayor parte en el Arrabal de San Francisco, que junto al de San Antón, eran los focos de la expansión urbana. En el Arrabal de San Francisco se habia iniciado la construcción de casas en la segunda mitad del siglo XVII, coincidiendo con el auge de la Compañía en la ciudad, y habia proseguido con tal intensidad en el siglo XVIII entre 1731 y 1756 el número de casas se había visto incrementado en un $21^{\prime} 2 \%$, pasando de 496 casas a 601(50), y estableciéndose por el Ayuntamiento medidas de planificación urbanística para procurar calles de anchura uniforme y esquinas trazadas en ángulo recto(51).

La Junta Municipal dividió las 26 casas en 11 lotes, siendo el mayor el configurado por 12 casas, nueve situadas en el Arrabal de San Francisco, dos en la calle de San Ginés y una en el barrio de San Roque, en la ladera misma del Benacantil. Se trataba de casas pequeñas, deterioradas, y su justiprecio se elevó a 2.269 libras y 19 sueldos.

Un segundo lote, de 3 casas, en el Arrabal de San Francisco, fue tasado en 647 libras 1 sueldo. Y en este mismo Arrabal, en la calle Teatinos, se formaron dos lotes de dos casas cada uno, el primero justipreciado en 1.146 libras 16 sueldos, y el segundo en 984 libras 18 sueldos. Los restantes siete lotes estaban formados por una sola vivienda, oscilando entre las 114 libras y las 896 libras. En las tasaciones intervinieron un maestro albañil, un maestro cantero, dos maestros carpinteros y dos cerrajeros.

En resumen, las propiedades de la Compañia susceptibles de ser vendidas en pública subasta, y el monto de su valor justipreciado, era el siguiente:

\begin{tabular}{lr} 
Tierra y molino harinero $\ldots$ & 12.476 libras 7 sueldos 8 dineros \\
Hilos de agua $\ldots \ldots \ldots \ldots$ & 2.500 libras \\
Inmuebles urbanos $\ldots \ldots$ & 10.763 libras 9 sueldos \\
\hline
\end{tabular}

TOTAL . . . . 25.739 libras 16 sueldos 8 dineros 
La cantidad recaudada fue finalmente superior, en algo menos de mil libras, a los valores de partida. Las tierras y el molino harinero alcanzaron un precio de remate de 14.866 libras, 2.605 libras la venta de los hilos de agua y solo los inmuebles urbanos no alcanzaron lo previsto, con 9.162 libras 4 sueldos. Pero interesa ahora analizar la mecánica de las pujas, los intereses que entraron en juego y los beneficiarios de las temporalidades de la Compañía.

\section{Las subastas de las temporalidades.}

El proceso de las subastas ejemplifica el comportamiento del mercado ante la venta, en un corto periodo de tiempo, de bienes con un monto de capital de cierta consideración.

Donde surgieron las mayores dificultades fue en las subastas de propiedades rústicas, tanto por su valor como por el indudable interés que despertaron.

La subasta, remate y venta real de la heredad situada en Cotella se efectuó sin contratiempos. Francisco Bojoní pujó por el valor del justiprecio, 2.525 libras, y cumplidos los trámites la propiedad fue rematada a su favor, presentando como fiador a José Portes, un negociante español avecindado en la ciudad(52). La relación Bojoní-Portes en la subasta no debe pasar desapercibida, pues forman un tándem en el que Portes actúa como socio capitalista de Bojoni. Este último era caballero, pues la familia Bojoni, de origen genovés, logró el privilegio de nobleza hacia 1641(53), y se hallaba emparentada con las familias más influyentes de la ciudad: los $\mathrm{Pa}$ ravecino, los Scorcia y los Martínez de Vera, entre otros. En 1759, Francisco Bojoní poseía dos importantes propiedades en el término alicantino, una en plena Huerta, en La Condomina, de 104 tahúllas y 1 cuarta-10‘1 Ha.- cultivada fundamentalmente de viña, con una parcela de arbolado y un pequeño huerto; esta propiedad fue justipreciada en 4.650 libras en la fecha indicada. La otra, una propiedad de 20 tahúllas de huerto situada en el Baver, era regada con agua extraída con zúas, y alcanzaba el alto valor de 1.800 libras(54). No era, pues, extraño que Bojoni se interesara por los hilos de agua, ya que éstos podrían asegurar un mejor riego a su propiedad de La Condomina, y por el huerto de la Sueca, cercano a su propiedad del Baver. En el lote formado por los dos hilos de agua, Bojoní hizo postura por el precio de la tasación, ésto es, 1.000 libras. Esta postura se admitió por la Junta Municipal y se remitió a la Provincial el 22 de agosto de 1769. Unos meses después, el 7 de noviembre, el Capitán General del Reino, Conde de Saive, presidente de la Provincial, indicó que se podía proceder al remate, pues habian transcurrido cuarenta dias desde la postura primera. Al efectuarse la subasta pública y nadie ofrecer más, se remataron los dos hilos a Bojoní, quien presentó como fiador, una vez más, al negociante José Portes(55). 
Nuestra sospecha de que José Portes financiaba las operaciones de compra de Francisco Bojoní y de otros interesados en los bienes subastados adquiere visos de probabilidad cuando se estudian los avatares de la subasta del restante lote de tres hilos de agua vieja y de las 12 tahúllas 3 cuartas de huerta en la Sueca. En el primero, la puja inicial fue efectuada por Bojoní sobre la tasación inicial, esto es, 1.500 libras. Admitida su postura y cumplidos los trámites se llevo a efecto la subasta pública el 15 de diciembre de 176956), pero a diferencia con la subasta de los dos hilos de agua, este lote de tres suscitó más interés efectuándose diferentes pujas por personas diversas, siendo la última la de José Portes, alcanzando su postura las 1.605 libras. El remate se fallo, pues, a su favor. Pero poco tiempo después, la Junta Municipal recibio un pedimiento del tal Portes cediendo dos de los tres hilos a Bojoni y el tercer hilo a D. Juan Pastor y Jiménez, vecino de Alicante, operación que fue admitida a fines de 1770 . El papel intermediario de Portes fue exactamente el mismo en la subasta del huerto de la Sueca(57). La primera postura fue la de Bojoní sobre el precio de salida, 1.220 libras, pero encontró en el acto de la subasta como esa cantidad era superada por una propuesta de José Martínez. Hubo de intervenir Portes para ganar la puja por 1.840 libras, un $50 \%$ por encima de lo tasado, y solicitar de la Junta permiso para desprenderse del huerto "para hacer merced y buena obran, cediendo sus derechos a Bojoní.

Pese a nuestra fundada sospecha de la decisiva ayuda que Portes prestaba en la financiación de las compras de Bojoní, hay que considerar que este último disponía de cierto capital procedente de la redención de un censal que la ciudad había contraído con su bisabuelo D. Pedro Bojoní. De ahi su actividad en otras pujas en las que no alcanzo hacerse con el remate: en la heredad de La Condomina y en el almacén del Arrabal de San Francisco.

La adjudicación de la heredad de La Condomina encontró ciertas dificultades y su remate tan sólo alcanzó las 5.201 libras, cuando el valor tasado ascendia a 7.398 libras 11 sueldos 8 dineros. En principio sorprende esta diferencia negativa, la única que encontramos entre los bienes rústicos de la Compañia, pero una serie de circunstancias determinaron que el interés por la propiedad fuera inferior al previsto: de las 126 tahúllas, sólo se subastaban 78, al encontrarse las restantes censidas por los jesuítas $y$, por tanto, exceptuadas de las pujas; era necesaria una cierta inversión, dado que los cultivos se hallaban deteriorados al no cultivarse la propiedad desde la expulsión. La viña era ya muy antigua y su rendimiento no era el óptimo, por lo que el nuevo propietario debía escoger entre una de estas dos costosas alternativas: o arrancar un tercio de las cepas para repoblarla, o dejar la tierra campa y dedicarla a sembradura. Otra dificultad adicional era la escasez de agua aneja a la propiedad, insuficiente para dar los dos riegos anuales a la viña, por lo que se hacía imprescindible 
adquirir agua de los hilos de agua vieja que se arrendaban por San Miguel de septiembre. A todos estos inconvenientes habia que añadir la proximidad de aguas encharcadas, con el peligro de tercianas, endémicas en aquella parte de La Condomina. Estos inconvenientes pesaron en las pujas de manera considerable.

En enero de 1770 se efectuó un total de once pregones anunciando la admision de posturas por la Junta Municipal. La primera fue poco usual: correspondia a D. Bernardo Berardo Jover, vecino de Alicante, propietario de tierras de regadio en el Baver y titular de un mayorazgo al que le pertenecían varios juros. Su propuesta fue pagar lo justipreciado con juros, mejorando el medio diezmo sobre los réditos que se le adeudaban con la condición de que la venta quedara subrogada al mayorazgo. Aunque la postura no agrado, al no tratarse de dinero en efectivo, hubo de admitirse ante el casi nulo interés que la propiedad despertaba. La Junta discutió si una diversificación de la oferta, dividiendo en partes la heredad, estimularía a los compradores, pero esta fórmula fue desestimada cuando algunos sondeos al respecto demostraron que tampoco esa posibilidad encerraba interés alguno:

"...siendo también constante, según informes tomados, que habia menos postores a la referida heredad dividiéndose en trozos, mediante que estando las tahullas cercadas es bastante sólo ese inconveniente para que nadie entre en ellas por partess(58).

La Junta Municipal envió notificación a la Provincial de la postura y condiciones de Berardo, y ésta solicitó instrucciones al Consejo de Castilla. Entre tanto se habían producido nuevas posturas: la de José Satorres, quien estaba dispuesto a pagar 5.000 libras al contado, y la de Sebastián Barceló por 7.600 libras a censo. El 18 de septiembre, José Moñino, fiscal del Consejo, ordenó que se suspendiera de momento el remate hasta que el Consejo considerara la postura de Berardo y se cotejaran los juros que decía poseer con los asientos. Para ello se solicitó de Berardo la presentación de las certificaciones de la Contaduría de la Distribución y Superintendencia de Juros para comprobar la renta líquida que producían aquellos en ese momento, pero Berardo respondio en noviembre de 1770 que sólo poseía los títulos originales, por lo que su postura fue definitivamente desestimada en octubre de 1773, casi tres años después.

Con el tiempo transcurrido la propiedad había seguido deteriorándose y las expectativas de lograr una venta satisfactoria para la Junta disminuian. Cuando se conoció que la propuesta de Berardo había sido rechazada se produjo una doble puja: la de Don Francisco Bojoní, quien ofrecía 4.940 libras, casi 2.500 libras por debajo de la tasacion, y la de Don José Lagier que ofreció 5.000 libras a censo del $3 \%$, estando dispuesto a hipotecar esas tierras. Ambas posturas fueron admitidas, aunque pronto 
se vieron desbancadas por la de José Bernabeu Carratalá, quien se manifestó dispuesto a pagar 5.201 libras al contado, siendo rematada a su favor la heredad de La Condomina. Desconocemos los datos relativos al tal Bernabeu, pero sospechamos se trate de algún testaferro de un comprador que operaba desde la sombra.

La utilización de hombres interpuestos en las subastas es habitual, pero resulta difícil pasar de la sospecha a la certidumbre comprobada documentalmente. Por suerte, en la documentación relativa a la subasta, remate y venta del molino harinero y de las tierras que lo acompañaban, se comprueba nitidamente la utilización de testaferros. La denuncia de esta práctica por algunos de los participantes se conservan en los memoriales que acompañan en el largo expediente de esta subasta(59).

A diferencia de la heredad de la Condomina, el molino harinero despertó un interés considerable. La primera postura, efectuada por Bautista Marhuenda, labrador, inmediatamente después de realizados los pregones, fue de 3.000 libras, estando el lote justipreciado en sólo 1.332 libras y 16 sueldos. La Junta Municipal se vio tan sorprendida por lo elevado de la postura que dejo testimonio de su sorpresa en el expediente al escribir "que siendo tan excesiva al justiprecio de ellos, se hace admisiblew(60). EI propio pastor efectuó un pedimento para que se le permitiera rebajar su postura inicial; justificaba ésta aduciendo desconocer que el molino y tierras estaban gravadas con un censal de 700 libras de capital, por lo que solicitaba que de su puja se descontara el valor del censal, quedando aquella en 2.300 libras. La respuesta a la solicitud la efectuó D. Francisco Rovira, defensor de las temporalidades, quien reconoció la razón que asistia a Marhuenda, aunque expuso dos reparos que la Junta Provincial de Valencia debía considerar: que las cargas refundidas en el molino no eran únicamente de él, sino del conjunto de bienes que fueron gravados por el fundador de la Memoria y que formaban parte de otros lotes, como hilos de agua y el almacén grande del Arrabal de San Francisco; el segundo reparo aconsejaba no admitir rebajas muy cuantiosas sobre las cargas para que no se viera reducida excesivamente el valor de la propiedad:

«...que sólo se descuenten misas y aniversarios que tengan limosna señalada o cuota con arreglo a lo que prescribes(61).

Atendiendo a esta última recomendación de Rovira, la Junta Provincial consideró extinguidas parte de las cargas y sólo reconoció un capital de censo de 380 libras, permitiendo que la postura de Marhuenda quedara rebajada en esa cantidad, esto es, que la postura fuera de 2.620 libras(62). Sin embargo, Marhuenda la retiró definitivamente.

Cuando se celebró el remate las pujas se sucedieron con calor y surgieron los primeros conflictos. Era práctica usual en las subastas públicas que éstas se realizaran en el lapso de tiempo comprendido entre el encen- 
dido de una candela y su extinción; el sentido de esta disposición era evitar el encono entre los postores, pero ocurria con frecuencia que aquellos con mayor interés por ganar el remate esperabana los últimos instantes para gritar la última puja y ganar así la subasta. En este caso concreto, esta situación se produjo en el momento en que la llama de la candela se extinguia: tres postores, José Portes, José Guillem y José Simó efectuaron la misma puja simultáneamente. Cuando ante esta circunstancia, la Junta decidió efectuar un nuevo remate, protesto José Portes aduciendo que Simó no había gritado la puja de 4.151 libras, y que él y Guillem podian llegar a un acuerdo. Lo cierto es que Guillem reconocio «que su voz era la propia de aquél y que cedia su derecho a favor de Portes». La sorprendente declaración de Guillem no impidio encender nueva candela y proseguir el remate ya que Simo insistía en aumentar la cantidad en 100 libras 6 dineros, rematándose finalmente ésta en 4.251 libras 6 sueldos a favor de José Simo, tratante y vecino de Alicante. El conflicto de intereses que se habia desatado durante las pujas demostró que Simó y Guillem eran testaferros de D. Antonio Valcárcel y de Bautista Marhuenda, sin que hayamos podido dilucidar a quién representaba Portes, al que en subastas anteriores hemos encontrado ejerciendo ese papel en favor de D. Francisco Bojoni.

Ante la Junta Municipal se elevaron dos memoriales, uno de Portes y otro de Marhuenda, conteniendo ambos una denuncia grave de corrupción e ilegalidad hacia el miembro de la Junta D. Antonio Valcárcel, Síndico Personero del Común, quien precisamente había tomado la decisión de que prosiguiera el remate encendiendo una nueva candela para que su tes. taferro, José Simo, ganara la puja.

Portes, en su memorial, denunció que Simó pujó fuera de tiempo hábil, pero que no obstante estaba dispuesto a aportar las 100 libras 6 sueldos que aumentó aquél:

"....asunto digno de reparo y que acredita la malicia de Simo cuando presenció éste todos los trámites del remate, y debió pujar las posturas en tiempo hábil, porque de lo contrario se transtorna e invierte todo el método en semejantes actos, y por lo mismo llego esta irregularidad a preocupar y suspender en la atención de los individuos de la Iltre Junta Municipal. Pero a voz del Sindico Personero se admitió dicha postura, encendiéndose vela»(63).

Más explícito en la acusación era Bautista Marhuenda, galerero y labrador y primer individuo que efectuó posturas sobre esta propiedad, como se recordará. Marhuenda reconoció haber enviado a José Guillem para que lo representase "sin otra intervención que la de un testaferro" para la compra del molino, y que la última puja fue ganada por Portes y Guillem. Reconocia, también, que Guillem, al aceptar la propuesta de Portes, había actuado con deslealtad: 
"...se propasó Joseph Guillem impermitidamente al extremo de ceder a Portes el derecho que le asistía, sin atender a que no podía adquirir el menor valimiento tan voluntaria separación, toda vez que concurrió al acto con sólo el nombre acomodado y ceñido a las ordenes y prevencionales conferidas por el exponente".

El centro de la denuncia de Marhuenda era D. Antonio Valcárcel, el que más tarde sería Conde de Lumiares y notable arqueólogo, y por aquel año Síndico Personero del Común. En opinión de Marhuenda, José Simó actuaba siguiendo órdenes de Valcárcel, quien por su condición de Síndico pertenecía a la Junta Municipal y estaba excluido, por consiguiente, de intervenir en las pujas(64):

La Junta Provincial tomó cartas en el asunto, declarando, a últimos de noviembre de 1769, nulo el remate ejecutado por Simó y ordenando que se encendiera de nuevo la candela tomando como precio de salida la postura hecha por Marhuenda de 4.151 libras.

El dictamen de la Junta Provincial fue seguido de un pedimiento del hermano de Antonio Valcárcel, Miguel, en el que declaraba que José Simó actuaba en su nombre y no en el de su hermano, presentando diversos testigos. Aceptada la petición, y tras diversas pujas, el molino y las tierras pasan a propiedad de Miguel Valcárcel por 5.300 libras(65). Al margen de la acción sospechosa de los hermanos Valcárcel, lo cierto es que quedaba demostrada la presencia en las subastas de hombres interpuestos al servicio de intereses que, por la posición social de sus detentadores, no deseaban intervenir directamente en las operaciones.

De las fincas urbanas, la substa y remate de mayor interés es el del almacén del Arrabal de San Francisco, que con 3.151 libras 3 sueldos de salida alcanzó tras las pujas de diversas personas, las 5.003 libras 14 sueldos que pagaron los hermanos Sebastián y Miguel Barcelo, comerciantes. El alto precio logrado estaba en función de su interés comercial, como lo expresaba claramente uno de los compradores:

"...el motivo que me estimulo para la mayoría del precio no fue otro que el querer aprovecharme del enunciado almacén en la estación del Invierno para cuyo tiempo es a propósito y sirve especialmente. por ser el tiempo en que tienen más frecuencia el género que se pueda almacenars(66).

También una casa situada en la calle del Muelle, por su interés para el comercio consiguió mejorar su precio inicial de 896 libras 8 sueldos, ganando el remate un comerciante genovés, Pedro Furco, vecino de Alicante, en 1.083 libras 6 sueldos.

El resto de las casas, a causa de sus pequeñas dimensiones y su deterioro, lograron remates por debajo del justiprecio, salvo una que logró 
rematarse en lo tasado. En su mayoría fueron adquiridas por hombres vinculados al comercio, como negociantes y tratantes, quienes solo pujaban hasta las 2/3 partes de su valor estimado, condición necesaria para que fuera aceptada la puja por las Juntas Municipal y Provincial.

Queda, por último, reseñar la redención de un censal(67). En la Cédula Real de 27 de marzo de 1769 se indicaba explícitamente que en los bienes a vender no debían incluirse por el momento los censales, juros y pensiones perpetuas, a excepción de que fueran redimidos por los deudores(68). En este caso se trataba del quitamiento de un capital de censo de 102 libras 12 sueldos que era de los jesuítas y que rentaba 3 libras 1 sueldo 10 dineros anuales sobre una casa propiedad del negociante Juan Boneón. A su muerte, la casa, gravada con dicho censo, fue adquirida por los administradores de la pía memoria fundada por Luisa Campos, quienes deseando redimir el censal, cuya pensión seguía percibiendo el administrador de los bienes que eran de la Compañía, solicitaron de la Junta Municipal su redención. Consultado el Consejo de Castilla, éste autorizó el quitamiento, efectuándose el depósito el 24 de julio de 1771 y otorgándose la preceptiva carta de pago.

El cuadro resumen de las subastas queda, pues, establecido del siguiente modo: 


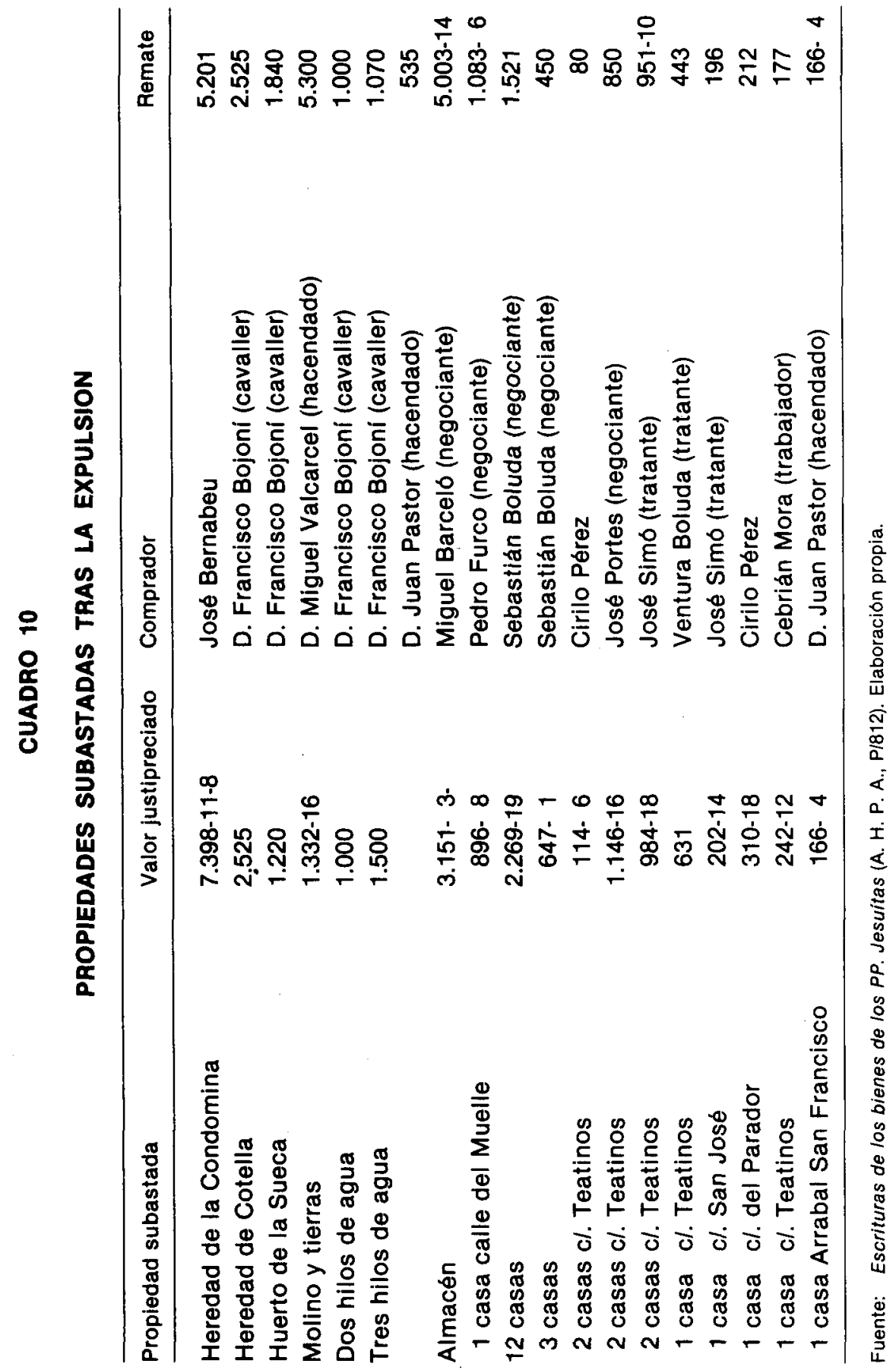


Tal y como queda expresado en el cuadro, las subastas son un fiel refiejo de los comportamientos sociales de los grupos residentes en la ciudad: una nobleza no titulada, la oligarquía local, que se halla volcada hacia intereses agrarios, y un núcleo de comerciantes interesados en inmuebles urbanos, especiaimente en aquellos susceptibles de ser utilizados para fines comerciales o situados en lugares próximos al puerto.

Capitulo aparte merece el tratamiento dado al edificio que servía de residencia y Colegio a los miembros de la Compañia, el cual no podía ser objeto de tasación ni venta tal y como prevenía la Real Cédula relativa a la formación de Juntas Municipales fechada en 176969).

Por ello, la ciudad de Alicante representada por el cabildo procedió a discutir en sucesivas sesiones cuál podría ser el destino que más conviniera al edificio del Colegio. En primera instancia se tuvo como más acertado el establecimiento de un seminario dotado de una escuela de primeras letras y tres cátedras-Gramática, Retórica y Filosofía-, que la ciudad subvencionaría respectivamente con 270,300 y 200 libras $(70)$, elevándose tal resolución al Consejo de Castilla. Este respondió a la misiva de la ciudad (71) solicitando que se reuniera de nuevo el Cabildo alicantino para que, asesorado por el Procurador General de la ciudad, Diputados y Personero del Común, discutiera el empleo más conveniente que se podia dar al edificio de los expulsos teniendo presente para tomar tal decisión lo que indicaba el capítulo $4 .^{\circ}$ de la Carta Circular de 29 de julio de 1767. Dicho capítulo preveía una aplicación de estos bienes de la Compañía no enajenables similar a la de obras pias, y sugeria que fuesen destinados a seminarios, conciliaciones y Casa de Misericordia(72).

En base a esta premisa, el Consejo de Castilla recababa del Ayuntamiento alicantino información acerca de la existencia en la ciudad de Hospicio, Hospital o Casa de Expósitos

"...con el fin de darle este empleo al Colegio o bien como Casa de Pensión para los jóvenes, para que aprendan las primeras letras y latín con maestros seculares....x/73).

Nuevamente volvió a reunirse el cabildo ciudadano(74) y, tras examinar la carta procedente del Consejo de Castilla, se ratificó en su primera decisión de solicitar que el Colegio de los expuisos fuera utilizado en adelante. "como seminario para la educación y enseñanza de la juventud»75). La iglesia aneja al edificio, debido a sus reducidas dimensiones, se consideró oportuno fuera agregada al Seminario con el fin de que pudiera atender las funciones sagradas de los estudiantes(76). Esta resolución fue enviada al Consejo de Castilla y, en un breve lapso de tiempo se expidieron dos cartas más en similares términos(77).

Casi un año estuvo la ciudad sin tener noticias, en uno u otro sentido, de la opinión que se tenía en la corte acerca del parecer por dos veces 
emitido. Finalmente, previo informe elevado por el Fiscal D. José Moñino, el rey resolvía pronunciarse sobre la petición de la ciudad entendiendo que el mejor destino que se podia dar al Colegio de la Compañía en Alicante era el de Casa de Pupilaje para jóvenes, en la que éstos, además de las enseñanzas de Gramática y Retorica previstas, pudieran recibir nociones de Aritmética y Náutica. También indicaba que el pago de los maestros que ocuparan estas cátedra debía proceder de las cantidades que la ciudad tenía dotadas para estudios. Junto con esta decisión, la real carta establecia el cargo de Director Eclesiástico para que rigiera los destinos de la Casa asignándole un salario de 100 libras al año, cantidad que se debia extraer de una Memoria que, en favor de la Compañia, habia fundado D. Francisco Martí.

Del empleo que se habia de dar al resto de los fondos de esta Administración o Memoria el dictamen de la corona era bien explícito: una cantidad estimada en 39 libras debía destinarse al salario de un Portero para la Casa de Pensión, y el sobrante se aplicaría en dotar una plaza de cura o vicario en la isla de Nueva Tabarca. En dicha isla, conocida como de San Pablo, se produjo el asentamiento en 1770 de sesenta y nueve familias italianas que fueron liberadas del dominio del Bey de Túnez, quien los habia esclavizado tras conquistar en 1741 la isla de Tabarca situada frente a las costas africanas. Este contingente humano, tras ser redimido en 1768 por Carlos III, llegó a Alicante y quedó instalado provisionalmente en la Casa que había sido residencia de la Compañía hasta que el Conde de Aranda dispuso su traslado a la vecina isla que cierra la bahía de la ciudad y que tomó el nombre de Nueva Tabarca(78).

El resto de las obras pias que el Colegio poseía antes de la expulsión de sus regulares pasó a pertenecer a la iglesia colegial de la ciudad y a las parroquias más pobres. La parte vieja del edificio residencia de la comunidad jesuítica, incluida la iglesia, se conceia al convento de religiosas Agustinas de la Sangre de Cristo visto el penoso estado en que se encontraba el que ocupaban.

Otras decisiones del Consejo se referian al embargo de la Biblioteca Colegial para su posterior depósito en el Seminario Conciliar de Orihuela, a la supresión de la fiesta de la confirmación de la Compañía de Jesús y a la colocación del escudo real en la puerta del edificio(79).

El ayuntamiento de la ciudad, reunido en sesión plenaria el 16 de diciembre de $1770{ }^{(80)}$, acusó recibo de la Real Cédula y acordó esperar la confirmación oficial para iniciar los trámites precisos para su puesta en práctica. No obstante, sucesivos problemas de tipo presupuestal retardaban en exceso la reforma y adaptación del Colegio a su nueva función. En 1772, la ciudad tomó nuevamente cartas en el asunto solicitando que la dotación de las cátedras de Náutica, Aritmética, Gramática y Retórica se proveyeran con el producto de las temporalidades ocupadas a los expulsos, 
puesto que ella no podía hacer a sus expensas el desembolso que dicha dotación suponía. Como no se vislumbraban soluciones a corto plazo se nombró un grupo de diputados para que se entrevistaran con el obispo de Orihuela, el cual formaba parte de la Comisión que entendía de la distribución de las temporalidades. El obispo Tormo eludió con habilidad el asunto intentando hacer comprender que no existían caudales procedentes de las rentas de los regulares expulsados y que, a lo sumo, únicamente se podía contar con una hacienda en la partida de La Condomina y varios censales; escaso bagaje que no se corresponde con el volumen real de bienes que los jesuítas poseían en la ciudad y que se puede corroborar en las páginas precedentes.

El obispo, apoyándose en este argumento a todas luces incierto, negó cualquier tipo de ayuda en metálico trasladando el problema a las instancias civiles tras sugerir que, para hacer frente a las obras de mejora y acondicionamiento del Colegio asi como para el pago de los maestros de cada cátedra, se concediera el aumento de un dinero por arroba de saladura. Con ello esperaba que la ciudad cubriera, a expensas de sus bienes propios, la financiación de la obra.

Lo confuso del planteamiento, la carencia real de recursos y una clara actitud de "dejar pasar el tiempo" retardaron la puesta en marcha del proyecto. El Consejo de Castilla, en 1775, comunicaba nuevamente a la ciudad

"....no haver lugar a conceder de el fondo de temporalidades dotación alguna para el establecimiento de enseñanzas que propone la ciudad.... (81)

e insistia en que era ella la que debía facilitar los medios. Como el inmueble en sí ofrecía un aspecto poco seguro, tras un largo período de tiempo inhabilitado, el Consejo accedió a que se examinara y se evaluaran las reparaciones que se estimaran precisas para que no fuera declarado en ruína. Igualmente mandó que la contrata para dichas obras se sacara a pública subasta para que se ejecutaran con la mayor rapidez, pagándose su importe de los frutos y rentas de las temporalidades.

Todavia transcurrieron diez años sin que al antiguo Colegio de la Compañia se le diera destino concreto debido a la falta material de medios para ello. Por fin, una Real Orden de 11 de octubre de 1785 decidió liquidar. el asunto indicándose a la Junta Municipal de Alicante que la Casa y Colegio de los jesuítas se concedía a las religiosas Agustinas del Convento de la Sangre. La entrega del inmueble debía efectuarse sin la menor dilación, otorgando la Junta las escrituras correspondientes en las que constara la concesión del mismo a las religiosas bajo cuya responsabilidad quedaba el mantenimiento y conservación general(82).

La entrega formal del antiguo Colegio de la Compañia tuvo lugar el 20 
de octubre de 1785, fecha en que la Junta Municipal con su presidente al frente se constituyó ante el edificio y, de modo solemne, entregó las llaves del mismo al representante de la comunidad de religiosas agustinas(83). Tras la realización de unas obras de acondicionamiento el local fue definitivamente ocupado en 1790, permaneciendo en él las monjas agustinas hasta nuestros días.

\section{NOTAS:}

(1) Teofanes EGIDO: "La expulsión de los jesuitas de Españan, en Ricardo GARClA VILLOSLADA: Historia de la Iglesia en España, vol, IV, Madrid 1979, pp. 745-818.

(2) Un relato más detallado de estos hechos se halla en: Rafael VIRAVENS, Crónica de la ciudad de Alicante, Alicante, 1876. pp. 240 y ss.

(3) A(rchivo M(unicipal) de A(licante). Armario 1, Libro 20, ff. 274-275v.

(4) A(rchivo) de la M(arquesa del B(osch). Protocolos Notariales de Marti Moliner, año 1.650 , ff. 248-256.

(5) A. M. B. Prot. Notariales de Marti Moliner, 1650, ff. 326-328v.

(6) Rafal VIRAVENS: Op. cit., p. 242.

(7) A. M. A. Armario 5, libros 84, 86, 96, 100.

(8) Antonio GIL OLCINA: La propiedad señorial en tierras valencianas. Valencia, 1979, pp. 44-52.

(9) A. M. A. Libro de enfitéuticos de la Compañia de Jesús. Arm. 5, Lib. 10.

(10) Rafael VIRAVENS: Op. cit., $p .240$.

(11) 1 Tahúlla $=0$ 12 Ha. Cifr. en Figueras Pacheco, F. "Provincia de Alicante», en Geografía General del Reino de Valencia dirigida por F. Carreras Candi; Barcelona, s. f., p. 550.

(12) Archivo de la Marquesa del Bosch. Protocolos Notariales de Marti Moliner (1633-1656).

(13) Enrique GIMENEZ LOPEZ: Alicante en el siglo XVIII: Economia de una ciudad portuaria en el Antiguo Régimen. Valencia, 1981, p. 403.

(14) 1 libra $=20$ sueldos. 1 sueldo $=12$ dineros.

(15) A. M. A. Manual de Bienes Raices de la Compañia de Jesús (1755) Arm. 5, lib. 92.

(16) Vid. respectivamente A. M. A. Arm. 5, lib. 113 y lib. 92.

(17) 1 jornal $=0 ‘ 48 \mathrm{Ha}$. Cif. Figueras Pacheco, F. "Provincia de Alicanten, en Geografia General del Reino de Valencia dirigida por F. Carreras Candi; Barcelona, s. f., p. 294.

(18) Enrique GIMENEZ LOPEZ: Op. cit., pp. 88-94.

(19) A. M. A. Manual de Bienes Raizes, Arm. 5, lib. 92. 
(20) En el término huertano existían los siguientes molinos:

-Molino de Juan Senia, en San Juan.

- Molino de la condesa de Peñalva, en la partida de la Maimona.

- Molino de la marquesa del Bosch, en la partida de Canelles.

- Molino de las Ratas, en el término de la ciudad.

- Molino de la Carnicería, propiedad de D. Antonio Pasqual Riquelme y situado en Muchamiel

- Molino de la Soledad, propiedad de la condesa de Faura en Muchamiel.

- Molino de las dos muelas, de los jesuitas.

- Molino de Monserrate, de D. Luis Lombardón situado en Muchamiel.

- Molino de Gosálvez, propiedad de Teresa Riera, en la partida del Conchell.

- Molino de la marquesa del Bosch, en Busot.

- Molino de D. Pedro Martínez de Vera, en partida del Chapitel.

- Molino Nuevo, de D. Juan Ferrández de Mesa, en Muchamiel.

- Molino de Enmedio, propiedad de D. Pedro Domenech.

Vid. A. M. A. Arm. 14, Pedimentos y otros papeles (legajo sin numerar).

(21) $\mathrm{A}$ (rchivo) $\mathrm{H}$ (istórico) $\mathrm{P}$ (rovincial) de A(licante). Protocolos Notariales de Bautista Alberola, Pl. 18-VI-1748.

(22) Estatutos para el Gobierno de la ciudad de Alicante concedidos por la S. C. R. M. del Rey N. S. Don Carlos I (18-XIl-1669).

(23) A. M. A. Manual de Bienes Raizes del Colegio de la Compañia de Jesús en Alicante (1755), Arm. 5, lib. 92.

(24) Estos legados pertenecen siempre a miembros de las capas sociales altas: D. Mariano Domenech, D. ${ }^{*}$ Mariana Llanos, Herederos de D. ${ }^{*}$ Manuela Escorcia.

(25) Marcelino MENENDEZ Y PELAYO: Historia de los heterodoxos españoles, Tomo II, Madrid 1956, pp. 500-511.

(26) Véase el estado de la cuestión en Teófanes EGIDO: «La expulsión de los jesuítas de Españan en Historia de la Iglesia en España, Vol. IV, Madrid 1979, pp. 745-792, especialmente pp. 746-750.

(27) Rafael OLAECHEA: Las relaciones hispano-romanas en la segunda mitad del siglo XVIII, 2 vols., Zaragoza 1965, especialmente vol. I, pp. 308 y ss., Carlos CORONA BARATECH: "Sobre el Conde de Aranda y sobre la expulsión de los jesuítas", en Homenaje al Dr. D. Juan Reglá Campistol, vol. 2, Valencia 1975, pp. 79-106; Teófanes EGIDO: “Motines de España y proceso contra los jesuítas. La "Pesquisa Reservada" de 1766", en Estudio Agustiniano, n. 9 (1976), pp. 219-260.

(28) Pedro R. CAMPOMANES: Dictamen fiscal de expu/sión de los jesuitas de España (1766-67), edición, introducción y notas de Jorge CEJUDO y Teófanes EGIDO, Madrid 1977, 224 pp.

(29) El dictamen dedica 225 puntos a clas riquezas de la Compañía" en Espafia e Indias. Vid. Pedro R. CAMPOMANES: Dictamen fiscal..., Op. cit., pp.95-138.

(30) Ibid. p. 95.

(31) Salvador de MOXO: "Un medievalista en el Consejo de Hacienda: Don Francisco Carrasco, Marqués de la Corona (1715-1791)", en Anuario de Historia del Derecho Español, Vol. XXIX (1959), pp. 609-668).

(32) Francisco TOMAS Y VALIENTE: “Estudio preliminar" a la edición de Pedro R. CAMPOMANES: Tratado de la regalia de amortización (Edición facsimil), Madrid 1975.

(33) Rafael VIRAVENS Y PASTOR: Crónica de la Ciudad de Alicante, Alicante 1876, p. 243.

(34) "Instrucción de los que deberán ejecutar los Comisionados para el extrañamiento (...) en conformidad de lo resuelto por S. M. ", en Colección general de las providencias hasta aqui tomadas por el Gobierno sobre el extrañamiento y ocupación de temporalidades de los regulares de la Compañia..., Madrid 1.767, pp. 6-14.

(35) Ibid., punto XXIV. 
(36) A. M. A. Arm. 1, lib. 45, ff. 93-102.

(37) A. M. A. Ibid.

(38) A. H. P. A. Escrituras de los bienes de los Padres Jesuitas, P/812, ff. 13-14v.

(39) Véase la posición regalista y antijesuitica del Obispo de la Diócesis de Orihuela, José Tormo, en Juan Bautista VILAR: «Dictamen del Dr. José Tormo, Obispo de Orihuela, recomendando la supresión de la Compañia de Jesủs (1769)", en Hispania Sacra, XXXI, (1978-79), n. ${ }^{\circ} 61$ 64, pp. 343-355.

(40) A. H. P. A. Escrituras de los bienes..., P/812, ff. 13-14v.

(41) En 1.769, la finca se justipreció en 2.148 lib., 8 sueldos; Vid. A. M. A. Privilegios y Provisiones Reales, Arm. 1, lib. 45, ff. 248-250v.; y por 2.282 libras, 2 sueldos y 8 dineros en el justiprecio efectuado para las subastas. Vid. A. H. P. A. Escrituras de los bienes..., P/812, f. 255.

(42) A. M. A. Privilegios y provisiones reales, Arm. 1, lib. 45, ff. 248-250v.

(43) A. M. A. Cabildos, 1812, Arm. 9, lib. 107, acta de 18 de julio de 1812.

(44) A. M. A. Privilegios y provisiones reales, Arm. 1, lib. 45, ff. 248-250.

(45) Juan Bautista VERGARA Y PARAVECINO: Manifiesto historico de las especies y adquisión de agua que fluye a la vega de Alicante, Alicante 1.739, pp. 17-18.

(46) Antonio LOPEZ GOMEZ: "Riegos y cultivos en la Huerta de Alicante», en Estudios Geográficos, n. ${ }^{\circ} 92$ (1951) p. 713.

(47) A. M. A. Posturas hechas en los 16 hilos, Leg. 22, $n .^{\circ} 45$.

(48) A. H. P. A. Protocolo de Bautista Alberola, año 1768, P/33, ff. 152-155v.

(49) A. M. A. Privilegios y provisiones reales, Arm. 1, Lib. 45, ff. 248-250.

(50) A. M. A. Interrogatorios, Arm. 5, lib. s. n.

(51) A. M. A. Cabildos 1766, Arm. 9, lib. 56, f. 25.

(52) A. H. P. A. Escrituras de los bienes de los Padres Jesuitas, P/812, ff. 27-38v.

(53) Agustín de ARQUES JOVER: Nobiliario alicantino, (transcripción de Luis Más Gil), Alicante 1966, p. 43.

(54) A. M. A. Justiprecio General del Término, Arm. 5, lib. 113.

(55) Los dos hilos subastados corresponidian a la martava del primer miércoles noche, números 57 y 58 del Libro Giradora.

(56) A. H. P. A. Escrituras de los bienes..., P/812, ff. 53-80v.

(57) A. H. P. A. Ibid., ff. 39-52v.

(58) A. H. P. A. Ibid., ff. 255 y ss.

(59) A. H. P. A. Ibid., ff. 97-124.

(60) A. H. P. A. Ibid., f. $101 \mathrm{v}$.

(61) A. H. P. A. Ibid., f. 106.

(62) A. H. P. A. Ibid., ff. 106-106v.

(63) A. H. P. A. Ibid., ff. 110v- 111.

(64) La Real Orden de 9 de mayo de 1769 prohibia a los componentes de las Juntas adquirir efecto alguno de las temporalidades ni por si ni por persona interpuesta. Vid. A. H. P. A. lbid., ff. 112-113v.

(65) A. H. P. A. Ibid., ff. 116-124.

(66) A. H. P. A. lbid., ff. 67 y ss.

(67) A. H. P. A. Ibid., ff. 251-254.

(68) A. M. A. Privilegios y provisiones reales, Arm. 1, lib. 45, ff. 93-102v.

(69) A. M. A., Arm. 1, lib. 45, ff. 93-120v.

(70) A. M. A., Cartas Escritas y Recibidas, Arm. 12, lib. 21, ff. 264v-265v. 
(71) A. M. A., Arm. 1, Lib. 42, ff. 282-282v.

(72) A. M. A., Arm. 1, lib. 44, ff. 174-175.

(73) A. M. A. Arm. 1, lib. 42, ff. 282-282v.

(74) A. M. A. Cabildos, Arm. 9, lib. 61, ff. 111-113.

(75) A. M. A. Cartas Escritas y Recibidas, Arm. 12, lib. 24, ff. 37-43v.

(76) La solicitud de este destino para el Colegio se fundamentaba en el hecho de que la ciudad ya disponía de Hospital de Pobres, a cargo de los religiosos de San Juan de Dios, Hospital para Militares, administrado por la Real Hacienda, y Casa de Misericordia que daba cobijo a huérfanos, peregrinos, ancianos y pobres. No existia Casa de Expositos pero éstos eran socorridos con caudales procedentes del fondo de Propios de la ciudad.

(77) A. M. A. Ibid., ff. $67-68 \mathrm{v}$ y 112-112v.

(78) Rafael VIRAVENS: Op. cit., pp. 325-331. Vid. igualmente Vicente MARTINEZ MORELLA: Matrícula de Tabarquinos. Alicante, 1970.

(79) A. M. A., Arm. 1, lib. 47, ff. 434-440v.

(80) A. M. A., Cabildos, Arm. 9, lib. 64, ff. 178.

(81) A. M. A., Arm. 1, lib. 54, ff. 146-147.

(82) A. M. A., Arm. 1, lib. 64, ff. 339-342v.

(83) Para más detalles sobre este aspecto vid. Rafael VIRAVENS, op. cit., pp. 243-244. 


\title{
UNA UTOPIA ESPAÑOLA EN BUSCA DE AUTOR: SINAPIA. Historia de una equivocación. Indicios para un acierto.
}

\author{
Por François LOPEZ \\ Universidad de Burdeos
}

En 1975 aparecia entre los fondos del Archivo del Conde de Campomanes, recién ordenados y catalogados por don Jorge Cejudo López ${ }^{(1)}$, dos textos de extraordinario interés, tanto para los estudiosos que se interesan en los orígenes de la llustración como para los eruditos que han ido señalando las influencias y los ecos del pensamiento de Tomás Moro en España. El primero de los textos encontrados es en efecto una utopia perfectamente constituída, rigurosamente conforme con las leyes formales que definen el género creado por una de las más admirables figuras del Renacimiento.

Percatándose del valor excepcional de estos manuscritos, un investigador canadiense, el profesor Stelio Cro, de McMaster University, que había estado investigando sobre el nacimiento de ciertos mitos de la Conquista de América, como el de los tesoros de El Dorado y la Ciudad de los Césares, proporcionó con la mayor brevedad una edición de ambas obras: Sinapia y un complementario Discurso de la educación, con una copiosa introducción y numerosas notas(2).

Al año siguiente se publicaba una importante reseña de este libro en Moreana, debida a Francisco López Estrada(3), y casi al mismo tiempo salía en Madrid otra edición de Sinapia (sin el Discurso de la educación) con prólogo y notas de Miguel Avilés(4). Aparentemente no conocía Miguel Avilés los trabajos de Stelio Cro. En cambio pudo éste ver la edición de Avilés cuando, en 1976, tras efectuar nuevas investigaciones en el Archivo del 
Conde de Campomanes, descubrió y publicó otros dos manuscritos de la misma e inconfundible letra que el original de Sinapia: anotaciones al Journal des Sçavans (años 1682 y 1685), y una lista de "Libros que faltan en la librerías(5).

Las anotaciones al Journal des Sçavans constituian para Stelio Cro un elemento decisivo en lo que se refiere a la datación de la serie de textos por él descubiertos. En efecto, los volúmenes de los que había sacado apuntes el autor de Sinapia eran del año 1682, las anotaciones que procedian de números posteriores del Journal habian sido escritas por otra mano. Estas observaciones minuciosamente consignadas por Cro, y el hecho que no aparecía en Sinapia ni el Discurso ni una sola alusión a cualquier realidad posterior al siglo XVII, le inducian a proponer para todo el corpus de textos considerado una fecha muy temprana: "Therefore we could conclude that the date around which our anonymous author writes is 1682. In fact this date would accomodate all the other manuscripts as wellw(6). Todo esto se oponía radicalmente a lo que Miguel Avilés habia escrito sobre la datación y los posibles autores de Sinapia. Según este erudito, la primera utopía española era una obra de la época de las Luces y su autor podía haber sido el propio Campomanes.

Es de lamentar que los dos libros de Cro hayan tenido por razones puramente editoriales tan escasa difusión en España. Dos recensiones, la ya señalada de Francisco López Estrada y otra de Amancio Labandeira Fernández(7), han subrayado la importancia del descubrimiento de Sinapia, poniendo de realce las relaciones que existen entre el contenido de esta obra y el ideario de la llustración, pero sin hacer resaltar el interés mucho mayor que cobra tal escrito al anticiparse en más de medio siglo a la publicación del Teatro crítico de Feijoo según los argumentos presentados por Cro.

Mientras tanto Sinapia se fue difundiendo ampliamente en la edición de Miguel Avilés, y nadie ha planteado verdaderamente los problemas de datación y atribución que suscita dicha obra. Por eso ha sido más que útil, preciso, que Stelio Cro presentara una síntesis de sus trabajos y repitiera sus conclusiones en una revista española: Cuadernos para Investigación de la Literatura Hispánica (2-3, 1980, p. 27-38).

Hoy día los eruditos españoles que mejor conocen la literatura utópica se inclinan a favor de la tesis de Cro, es decir, esencialmente, a favor de una datación muy temprana de Sinapia. Puede comprobarse este hecho en las más recientes publicaciones de Francisco López Estrada y sobre todo de Pedro Alvarez de Miranda(8).

Al intervenir ahora en este debate, no nos proponemos estudiar los rasgos genéricos ni todo el contenido de Sinapia, sino volver sobre dos problemas: el de la época en que se escribió la obra, y el de la personalidad e identidad de su autor. 
Digamos de entrada que en cuanto a una datación muy temprana, estamos fundamentalmente de acuerdo con Stelio Cro. Su argumentación basada en las referencias históricas que se hallan diseminadas en el texto, la importancia decisiva que cobran las anotaciones al Journal des Sçavans de 1862, bastarian de por si para probar que no son estos escritos los de un llustrado, sino de un "forerunner of the Enlightenment in Spain". Según estos datos, la composición de Sinapia puede situarse, con el más alto grado de verosimilitud, en los dos últimos decenios del reinado de Carlos II, no forzosamente en 1682, a nuestro parecer, (ya que un periódico científico como el Journal des Sçavans podía conservar todo su interés durante varios años), pero sí en un momento que no debe de ser muy posterior. En esa época empieza en España lo que hemos Ilamado, a falta de más exacta formulación, "el tiempo de los novatores". Y salta a la vista cuando leemos Sinapia, el Discurso, las anotaciones al Journal des Sçavans que el autor de estos escritos tiene las mismas curiosidades que los demás novatores españoles y es un partidario de la ciencia moderna, todavia cartesiana, prenewtoniana, experimental en todo caso. En los últimos decenios del XVII hubo, como es bien sabido ahora, activos grupos de novatores en Madrid, Sevilla, Valencia, Zaragoza y Barcelona(9). Es muy plausible que a uno de esos grupos perteneciera el autor de Sinapia.

Pero si no es difícil situarlo en un grupo socio-cultural y en una época, más arduo es encontrar en lo que escribe unos rasgos inconfundibles que permitan descubrir su identidad. Lo que sí es posible, es delinear su personalidad utilizando el conjunto de los textos que nos han sido conservados.

Lo que más nos Ilama la atención en éstos es que el autor aúna con la mayor naturalidad su adhesión a la ciencia moderna (considerada como heterodoxa y abominable por la mayoria del clero español de su tiempo y por todos los claustros) con un humanismo cristiano que resplandece con el acendrado fervor que pudo ser el de un Erasmo, de un Moro, de un Vives. Véase lo que representa la religión en Sinapia:

"La religión, en toda la península, es la cristiana, sin hipocresía, superstición ni vanidad. La disciplina es la que se observaba en el tercer y cuarto siglo. No pueden explicarse los misterios, sino con los términos que los explica la Sagrada Escritura, contentándose con creerlos, sin querer saber el modo. No admiten en estas materias la menor novedad, estando prohibido inventar nuevas devociones sin la aprobación del Sínodo, lo cual aprueba rarísima vez (...).

Ayúdanse, en el ministerio de la palabra de Dios y administración de los sacramentos, de los diáconos, a los cuales ayudan los subdiáconos ( $y$, para la instrucción de las mujeres, las diaconesas) y, para el cuidado de los templos, del canto y 
las lecciones públicas, los acólitos, cantores y lectores. Y este es el orden de todos los eclesiásticos.

No pueden ser acólitos si no son de doce años y saben leer y escribir el sinapiense. No pueden ser cantores si no han ejercido el oficio de acólitos tres años y saben el canto; no pueden ser lectores si no han ejercido el cargo de cantores cuatro años, ni ser ordenados de subdiáconos si no han sido lectores cinco años y saben el hebreo y el griego; ni ser ordenados de diáconos si no han sido subdiáconos seis años y saben muy bien el hebreo y el griego; ni sacerdotes si no han sido diáconos diez años y saben la Santa Escritura e historia eclesiástica (...).

Todos los oficios se hacen en lengua sinapiense y las lecciones públicas de la Santa Escritura (...).

Solos los eclesiásticos pueden enseñar la ciencia divina, pero los seglares pueden muy bien estudiarla y escribir sobre ella, pero no dar a luz los escritos sin la aprobación de la Iglesia(10).

En dos ocasiones apunta Stelio Cro la sugestión de que estas normas de vida religiosa bien pueden ser la de un protestante. Pensamos al contrario que el reivindicar un fundamentalismo biblico era muy propio de una élite católica que no podía ver sin aflición la proliferación de cultos, creencias, supersticiones a la que había dado lugar en España una fe mal entendida. "Another indication of the Protestant inspiration of the author is this reading in the "vulgar" of the Holy Scriptures. National languages were adopted to read the Holy Scriptures during the Protestant Reformation in Germany, England and Hollands(11). Otro argumento que puede utilizarse a favor de una tesis contraria: del Renacimiento a la llustración se mantuvo en España un ideal que llamaremos erasmiano para más comodidad de conocimiento de la Biblia en las lenguas madres, en la Vulgata, en lengua vernácula(12).

Interés apasionado por el conocimiento, por las humanidades y la ciencia moderna, y además fundamentalismo cristiano, deseo de resucitar la más antigua y pura disciplina de la Iglesia: he aquí una configuración intelectual y espiritual que no fue la de todos los novatores españoles, para quienes la ciencia moderna era lo que importaba. En cuanto al humanismo cristiano, su supervivencia o resurgimiento está abundantemente atestado en Valencia cuando Mayáns empieza a publicar sus primeras obras importantes. En otros sitios no parece haber dado frutos esa corriente espiritual.

En 1980, cuando tuvimos la oportunidad de leer los trabajos de Stelio Cro, las observaciones que acabamos de formular nos llevaron a pensar 
que el autor de Sinapia pudo haber sido un novator valenciano. Esta hipotesis cobraba más plausibilidad al considerar algunos detalles del texto que no parecían haber llamado la atención de sus dos editores. Nos referimos a ciertas palabras usadas por el anómimo autor de nuestra utopía para describir el país mítico del que soñaba. Varias veces evoca una geografía ideal con elementos típicamente españoles: p. 76: "acequias", "azudes", "norias"; p. 82: "noria»; p. 84: "huerta»; p. 88 otra vez: "acequias", "norias". Y en la página 99: "en las alturas de toda la costa, sus atalayas, para avisar con fuego o humo la venida de forasteros". Todo esto hace pensar irresistiblemente en el litoral levantino. $Y$ hay otros detalles que confirman que el autor "imagina" a partir de recuerdos, de cosas vistas: p. 104: "A las mujeres se les permiten vestidos de colores varios $y$, cuando van fuera de casa, capucha a la catalana, blanca el verano y negra el invierno"s. Quien esto escribe es catalán o valenciano, e involuntariamente lo manifiesta en este otro trozo: p. 133: "Cuántos de los que trabajan se emplean en ejercicios o inútiles o perjudiciales, como en la multitud de gente que ocupa a los tribunales, la infinidad de soldados que la ambición mantiene en guerras no necesarias, plateros, joyeros, guanteros, parruqueros, cocheros, botilleres, fabricadores de puntas y encajes, banqueros, bordadores, etc., todos inútiles y fomentadores de la superfluidad, madrastra de la abundancian. Es obvio que parruqueres y botilleres son palabras catalanas o valencianas, y en la fotocopia del manuscrito original que tenemos a la vista puede comprobarse que la trascripción de Miguel Avilés es la correcta(13).

Sabiendo cuáles eran las aspiraciones espirituales del autor de Sinapia, qué conocimientos hubiera querido privilegiar (el de la Biblia, en griego, hebreo y lengua vernácula), la afición que manifestaba por un arte depurado, clásico; su interés por el teatro, la arquitectura, su curiosidad abierta a todos los inventos y experiencias de la ciencia moderna; sentando como hipótesis muy plausible que él habia sido un novator valenciano, y teniendo por fin que considerar que Sinapia se compuso en los dos últimos decenios del siglo XVII, tratamos hace dos años con la sola ayuda de los libros de nuestra biblioteca de descubrir quién pudo ser ese personaje.

Nuestras primeras indagaciones nos proporcionaron una serie de indicios que insistentemente apuntaban hacia un autor poco conocido de fines del siglo XVII y principios del XVIII: Manuel Marti, deán de Alicante, a cuya figura y a cuyos escritos acababan de dedicar excelentes trabajos Antonio Mestre y Luis Gil(14).

Nacido en 1663, había llegado Marti a la edad adulta por las fechas que asigna Stelio Cro a la composición de Sinapia (de 1682 en adelante), y sabemos por la Martini Vita, publicada por Mayáns cuando vivía aún el deán (1735), que éste escribió en su juventud numerosas poesias, incluso una silva "a imitación de la primera de Luis de Góngora», pero muy pronto, 
dice Mayáns, "rechazando aquella manera enigmática de escribir, se inclinó de forma maravillosa por la transparencia y claridad del lenguaje. $Y$ de ahí resulto que no parezca que expone las cosas, sino que las presenta como pintadas a la vista, no sólo en la poesia, que es una pintura que habla, sino también en prosaw(15).

De la cultura de Martí nos ofrece un buen panorama su correspondencia con Mayáns. La medicina, la ciencia y la filosofía modernas ("Pedro Gasendo es el Príncipe de la verdadera philosophían), el derecho, la historia antigua, la literatura griega y latina, la numismática, la arqueología, la filosofía apasionaban al deán que parece haber tenido singulares conocimientos en todos esos ramos del saber. Eminente helenista, se habia empeñado durante una primera estancia en Roma (1686-1696) en aprender el hebreo, y lo consiguio(16). Añádase que era Martí gran lector de la Biblia, y habrá que reconocer que el parecido entre el deán de Alicante y el autor de Sinapia es realmente extraordinario.

Volviendo a estudiar la utopía recién descubierta, nos fijamos en unos detalles que antes no nos habían llamado la atención: las ciudades que se describian en Sinapia, algo tenian de villas romanas, con "su patinejo enmedio, con fuente o pozo; puerta a la calle y al jardín, y pórticos con galería" (p. 82). En cuanto a los templos sinapienses, albergaban en su recinto uel cimenterio común. Este es subterráneo, bajándose a él con cinco escalones por cuatro puertas que hay enmedio de las cuatro caras del cuadrado. Compónese de cuatro bóvedas, que le atraviesan en cruz, dejando en el centro (que corresponde debajo del altar) una capilla redonda con su altar. Y por las paredes de las bóvedas están los sepulcros, en nichos como los de las catatumbas" (p. 95). Esta última palabra, catacumba, hoy conocida de cualquier individuo de mediana cultura, era muy poco usada a fines del siglo XVII y principios del XVIII. Desde luego no está en el Diccionario de Autoridades. De lo que eran las catacumbas, sólo podían tener una idea precisa los pocos arqueólogos que las habian visitado en Roma. Un humanista como Mayáns, muy versado en historia antigua y de inmenso saber libresco, necesitó las luces de Manuel Martí para saber qué aspecto tenian esos vestigios de la antigüedad cristiana:

"Es cierto que las catacumbas o cementerios de los mártyres antiguos se extienden muchísimo. Y el famoso Raphael Fabretti, monseñor Ciampini y Joseph de Juliis, me aseguraron que alguno de ellos llegaba hasta el mar que está a 4 leguas de Roma. Y no hay que extrañar se extendieran tanto, siendo el refugio y habitación de los cristianos y Sumos Pontifices, y sepulturas de infinitos mártires que contínuamente padecian martirio. Y Vm. se engaña en creer que allí hay edificios; pues sólo está cavada la tierra y hechas unas como callejuelas, sin que haya cosa de argamasa ni piedras(17). 
Otro hecho incitaba a atribuir a Martí la paternidad de Sinapia y del Discurso de la educación. En dicho Discurso leemos cómo ha de explicarse a los niños lo que es el espíritu («cosa que piensa; pensar es sentir, imaginar, conocer y querer") (p. 111), y qué son las pasiones ("Ay en nuestra alma ciertos pensamientos que llamamos pasiones, las quales son necesaríssimas para nuestra conservación; como su demasía es dañossísima»). Atinadamente observó Stelio Cro que al respecto se inspiró el autor del Traité des passions de Descartes. Pues bien, fue Manuel Martí el único español de su tiempo que escribió un tratado Sobre las pasiones, obra compuesta en los primeros años del siglo XVIII(18).

En cuanto al ideal igualitario que resplandece en Sinapia, no cabe duda que pudo ser compartido por el deán de Alicante, que en sus cartas denuncia la avaricia, "apetito infame de riquezas" (p. 224) y hace el elogio de la vida frugal y sencilla. Por otra parte había sido Martí en Roma miembro de la Academia de los Árcades, cuyo reglamento estableciera Juan Vicente Gravina, y sobre este reglamento hace Luis Gil observaciones por cierto muy notables:

"Constaba el reglamento de doce puntos y estaba escrito en latín arcaico como la ley de las XII Tablas. La primera "ley" atribuia la summa potestas al commune de los Árcades; por la segunda se preveía el nombramiento democrático de un custos rebus gerundis et procurandis con un mandato cuadrienal; la tercera asignaba a un custodis vicarius y a un colegio de 12 miembros la asistencia en las funciones de gobierno al presidente; la cuarta disponia un sistema de votación secreta para la elección de cargos; la quinta señalaba la obligación del presidente de comunicar al pleno de los Árcades las diligencias tomadas por el comité directivo, etc. Este reglamento de carácter estrictamente democrático revela el genio juridico de Gravina, que no en vano renovó la enseñanza del derecho y fue un precursor de Montesquieus(19).

Por fin recordemos las últimas líneas de Sinapia y la profunda amargura que expresan:

"Finalmente, el fin de este gobierno no es dilatar su dominio, enriquecer sus súbditos ni extender su fama, sino hacerlos vivir en este mundo justa, templada y devotamente, para hacerlos felices en el otro. Sólo se estima la verdadera virtud. Sólo se procura la verdadera honra que nace de ella y sólo se apetece el verdadero deleite, que es el que siente una conciencia que nos asegura haber hecho en todo nuestro deber. Todo lo cual solo se puede conseguir en una nación sencilla, que carece de las maliciosas máximas de la política interesada, de la soberbia que engendra la nobleza hereditaria, de la desigual- 
dad de ricos y pobres y que ignora la artificiosa variedad de regalos y comodidades que ha inventado la poltronería y que no está envilecida con la acostumbrada sujeción y está hecha al trabajo y a la necesidad.

Mas, como la corrupción del hombre es tan grande, no han faltado naturales aviesos, que han procurado alterar el gobierno, introduciendo la propiedad, la novedad de usos, la dominación, la moneda, la estimación de las riquezas y el ocio, la vanidad de la sangre, etc., pero se ha remediado con la prontitud del castigo, ayudada de los pocos compañeros que han hallado de su opinión, por lo bien instruídos que están desde niños en las conveniencias que gozan en su gobierno y los inconvenientes y desdichas que experimentan otras naciones en el contrario.

Finalmente se observa que, así en el sitio como en todo lo demás, es esta península perfectísimo antípode de nuestra Hispaña».

Esta vehemencia al señalar las plagas de España, se encuentra casi constantemente en las cartas de Martí a Mayáns. Recojamos algunas de sus palabras: "el desaliño y bestialidad de nuestra nación» (p. 155); "vivir como se vive en España en Materia de letras. A ciegas». (p. 164); "España, en que se malogran los mayores ingenios sumergidos en el cenegal de la barbarie y escolásticos delirios (...) Todo el amor es al lucro, nada a la ciencia» (p. 192); "esta bárbara nación" (p. 198); "Ya que el rigor de mi destino me ha hecho nacer y vivir en esta tierra bárbara" (p. 205); "verá el mundo mi desesperación por haber nacido en esta bárbara region".

Tantas semejanzas con el autor de Sinapia y el deán Martí eran verdaderamente impresionantes, tanto más cuanto que podríase añadir algún que otro punto común a los ya señalados. Una frase que encontramos en una carta de Martí acabó de convencernos de que él era el hombre a quien buscábamos. El 6 de febrero de 1733, respondiendo a Mayáns que por aquel entonces residia en Madrid y disponía de muchas obras del deán del que éste a veces ni siquiera se acordaba, escribía esto a Martí: "No entiendo lo que Ud. me quiere decir con aquellas palabras: de la visión del Etíope no me dice Ud. palabra. En explicándose responderé. Porque yo nunca tuve visión alguna o aparición de Etíope» (p. 272).

En efecto nunca habia tenido Martí visión alguna de Etíope. El sueño del que habla posteriormente a su discípulo y biógrafo no tiene la más mínima relación con Etíope. ¿Como pudo producirse esta confusión? Como el sueño ya aludido ha quedado literalmente plasmado en la Martini Vita, ha tenido Luis Gil que dar alguna aclaración al respecto, y puede notarse cierta perplejidad en su comentario: 
"Reproducción literal de la muy bella ficción literaria de Martí, en la que él familiarizado con la lectura de los clásicos grecolatinos encontrará todos los ingredientes que caracterizan al que he denominado en otras ocasiones «ensueño prostagmáticon. Por cierto que esta ficción se prestó a un curioso mal entendido de Mayáns. En una carta perdida de primeros de febrero de 1733 el deán debía de referirse a ello, provocando la curiosidad de su corresponsal. Martí replicaba el 6 de dicho mes (...). Dias después se aclaraba el equívoco: "La visión que Ud. desea saber, la verá en esa carta que escribí a Verona, al marqués de Maffei, que espero no desagradará a Ud. Solamente le suplico me la restituya bona fide, porque es el original y, si se pierde, se perdió todo»(20).

Pero de hecho, el equívoco, para nosotros, no quedaba bien aclarado. ¿Como pudo Mayáns, tan minucioso siempre, hablar de Etiope cuando en el sueño de Martí, que muy buena letra tenía, se trata de España?. He aqui el texto que literalmente transcribió don Gregorio:

"Cum ex continenti nocturni laboris agitatione fessus somno tandem me tradidissem, primo diłuculo visus mihi sum per quietem matronam intueri augustiore forma, dextra librum tenentem, sinistra expansa cuniculum. Quo ego symbolo facile cognovo eam speciem, quae ante oculos obversabatur, Hispaniam nostram repraesentare".

Este hecho, mínimo por supuesto, avivó nuestro interés porque recordábamos que los manuscritos de Sinapia y las anotaciones al Journal des Sçavans fueron catalogados por un poseedor desconocido bajo el título por cierto sorprendente de Historia Etiópica. La única relación que puede verse entre dicho título y los escritos descubiertos por Cro es que la primera anotación al Journal des Sçavans viene encabezada por esta referencia bibliográfica: Jobi Ludolphi historia Aethiopica. fol. Paris. Todo esto lo comenta Stelio Cro con su sagacidad habitual:

"The title of course would be a very current one in the seventeenth-century, since Heliodorus' homonymous byzantine novel was a major source of inspiration for many important writers, among them Cervantes and his Persiles. More important, the title would also have averted any suspicious eye from MSA (las anotaciones), labelled under such an innocent title. It is also indicative that MSS (Sinapia) and MSA would be listed togetherw21).

Pensamos que lo más plausible es que quien catalogó los manuscritos quiso sustraer a la curiosidad el texto de Sinapia considerando que podia parecer muy subversivo y atraer serios disgustos a su poseedor y a 
su autor. En nuestro edificio argumentativo, este nimio detalle cobraba una importancia fundamental ya que interpretábamos así los hechos: Mayáns, teniendo y ordenando las obras del deán de Alicante en Madrid, se encontró con Sinapia que ya llevaba por escudo el título de Historia Etiópica y quiso consultar a su autor sobre la oportunidad de su publicación, como solía hacerlo con otros escritos de Martí, entre los cuales no faltaban atrevidas sátiras. Así habia hecho don Gregorio con otras obras del deán que, de sus escritos de juventud no tenía a veces ningún recuerdo, sobre todo cuando no eran muestras de su talento de humanista, helenista y latinista.

Esa ha sido, esquemáticamente, la argumentación que presentamos a principios del año pasado en una conferencia que dimos en la Universidad de Alicante. Estábamos entonces totalmente convencidos de que la atribución a Martí de Sinapia y del Discurso de la educación era irrebatible.

Pero luego, teniendo en cuenta un elemento que nunca hubiéramos debido descartar, nos persuadimos que habiamos caído en una equivocación. En efecto todos los indicios que hemos reunido para atribuir Sinapia a Manuel Martí no bastan para salvar un obstáculo al que no prestamos la debida atención. El manuscrito de Sinapia no es una copia. Como lo subrayó Stelio Cro, el texto está escrito y enmendado muchas veces por una misma mano. Es decir que el autor fue el scriptor. Y la letra de los manuscritos no es la de Martí. Suponiendo incluso que su letra pudo cambiar mucho entre los últimos años del siglo XVII y la fecha de 1720 que es la de los más antiguos autógrafos suyos que hoy se conocen, es totalmente imposible que cambiara a este punto.

De un doble examen grafologico al que sometimos una xerocopia de unas páginas de Sinapia por una parte y de una carta de Martí por otra parte, recogimos las conclusiones siguientes: uno de los grafólogos consideraba que el scriptor de Sinapia no puede ser el de la carta. El otro dice que que si hay entre las diferentes muestras de letra un lapso de tiempo de más de veinte años, no puede concluir con certeza, pero que opina más bien que los manuscritos son de dos sujetos distintos, añadiendo que el scriptor de Sinapia fue seguramente un individuo ya entrado en edad o enfermo.

En conclusion, de todas nuestras observaciones sólo tienen plausibilidad las que atienen al origen valenciano (o a un "vivir" valenciano) del autor de Sinapia. La atribución de esa admirable utopía a Manuel Martí es altamente improbable. El hombre cuyo rastro seguimos sólo podrá ser identificado si se realiza un cotejo de autógrafos. Esto supone un paciente trabajo en archivos y bibliotecas donde se conserven manuscritos de los novatores valencianos. 


\section{NOTAS:}

(1) J. Cejudo López, Catálogo del Archivo del Conde de Campomanes (Fondos Carmen Dorado y Rafael Gasset), Madrid, Fundación Universitaria Española, 1975.

(2) Sinapia. A Classical Utopia of Spain, edited by Stelio Cro with and appendix,McMaster University, 1975.

(3) Moreana, 52, 1.976 , p. 53-56.

(4) Sinapia. Una utopia española del Siglo de las Luces, edición de Miguel Avilés, Madrid, Biblioteca de visionarios, heterodoxos y marginados, Editora Nacional, 1976.

(5) Cro, Stelio, A Forerunner of the Enlightenment in Spain, McMaster University, Hamilton, 1976.

(6) Ibid., p. 16.

(7) Revista Canadiense de Estudios Hispánicos, 1, 1976, p. 120-124.

(8) López Estrada, Francisco, Tomás Moro y España, Madrid, Editorial de la Universidad Complutense, 1980, p. 101-107; Alvarez de Miranda, Pedro, "Sobre utopias y viajes imaginarios en el siglo XVIII español", en Homenaje a Gonzalo Torrente Ballester, Salamanca, Biblioteca de la Caja de Ahorros y Monte de Piedad de Salamanca, Salamanca, 1981, p. 351-382.

(9) López Piñero, José María, Ciencia y técnica en la sociedad española de los siglos XVI y XVII, Barcelona, Labor, 1979 (Segunda parte).

(10) Todas las citas se harán según la edición de Miguel Avilés. Véase la p. 93.

(11) A Forerunner..., p. 82.

(12) López, François, Juan Pablo Forner et la crise de la conscience espagnole au XVIIle siècle, Bordeaux, Institut d'Etudes Ibériques et Ibéro-américaines de l'Université de Bordeaux, 1976 , p. 148 y s.

(13) Stelio Cro enmienda aqui el texto: "peruqueros" y abotilleros".

(14) Mayáns y Siscar, Gregorio, Epistolario, III, Mayáns y Marti, Transcripción, notàs y estudio preliminar de Antonio Mestre, Publicaciones del Ayuntamiento de Oliva, 5, Valencia, 1973; Emmanuelis Martini, ecclesiae alonensis decani, vita, scriptore Gregorio Maiansio, generoso valentino, Estudio preliminar, edición bilingüe y comentario de Luis Gil, Publicaciones del Ayuntamiento de Oliva, serie menor III, Valencia, 1977.

(15) Ibid. p. 61.

(16) Ibid. p. 67.

(17) Epistolario Mayáns y Marti, p. 305.

(18) Se publicó como apéndice en el Epistolario latino del deán, t. II, p. 229-254.

(19) Martini vita, ed. y trad. de Luis Gil, p. 324-325.

(20) Ibid., p. 411-412.

(21) Stelio Cro, A Forerunner..., p. 6. 



\title{
UNA VIAJERA RUSA DEL XVIII EN LOS PIRINEOS FRANCESES ${ }^{(1)}$
}

\author{
Por Rafael OLAECHEA ALBISTUR \\ Universidad de Zaragoza
}

En cierta ocasión dijo Mme. de Staël que viajar era "el placer más aburrido". Dejando a un lado el hecho real de que la andariega baronesa aludia con estas palabras a una dura experiencia personal, podemos afirmar, sin ninguna exageración, que su célebre frase tenia plena vigencia en el siglo XVIII, y encerraba una realidad de lo más arriscada y azarosa, si se tiene en cuenta: el pésimo estado de los caminos, la incomodidad y lentitud de los carruajes, o la sordidez de los albergues y posadas, para no hablar de otros incidentes de mayor cuantía ocasionados por las tormentas, las averías de los carricoches, la falta de tiros en los lugares de posta, los latrocinios o el simple bandidaje(2).

Todo esto-dicho en sintesis-significa que viajar en aquella época, aun gozando de buena salud y disponiendo del mejor roulier, era sinónimo de padecer fatigas, de soportar una serie inevitable de contratiempos, y de exponerse en suma a sufrir las penalidades más imprevistas(3).

Los relatos de los viajeros de entonces ofrecen una pintoresca, a la par que inagotable, antología de ejemplos sobre este particular. Yo me ceñiré a presentar aquí algunos casos-no muy conocidos-en abono de lo que acabo de insinuar.

El embajador de España en París, don Carlos Gutiérrez de los Ríos, VI conde de Fernán-Núñez (1735-95), que sería testigo cualificado del estallido de la Revolución Francesa(4), llegó a la ciudad del Sena el 7 de octubre de 1787, después de un viaje no poco accidentado. Desde Bayona, donde tuvo que detenerse varias horas para reparar su carruaje seriamente 
averiado, escribió al conde de Floridablanca (1728-1808), ministro de Estado, las siguientes lineas: "Como los hermosos caminos de Vizcaya no se empedraron con cabezas de vizcainos, cedieron a los balanzos (sic) contínuos de los coches y carros, que los trillaban, y están convertidos en escaleras formales, de modo que no hay carruaje que los resistaw(5).

El comediógrafo madrileño Leandro Fernández de Moratín (1760-1828) nos pinta sus peripecias de viajero con unos colores mucho más abigarrados. El 20 de abril de 1793 salió de Génova, a las 10 de la mañana, en compañía del diplomático español don Diego de La Cuadra, con la intención de digirse a Turín, a donde llegó tronzado el 23 a las seis de la tarde. EI ignoraba por completo que iba a necesitar más de tres días para cubrir una distancia de tan sólo $170 \mathrm{Kms}$. (unas 35 leguas); pero este pequeño «lapsus” de imprevision queda perfectamente aclarado si se recuerda que, para hacer dicho viaje, el autor de El viejo y la niña comenzó por tomar "un coche derrengado, Ileno de agujeros, goteras, parches y apósitos", que avanzaba a paso de buey por un camino que, al principio, era malo, luego peor y después impracticable. "Por último-escribe-, se atasca el coche, se sepultan los dos caballos en el lodo, el vetturino (cochero) reniega, y al cabo de media hora de un contínuo latigueo logra desengastar las dos alimañas; pero no consigue que el coche se enderece ni se mueva de donde está. Pues aqui de la prudencia del vetturino: desata sus caballos, márchase con ellos por el camino adelante, sin decir palabra, y nos deja dentro del coche en manos de la Providencia.

Cuando advertimos su fuga, ya estaba donde no podía oir nuestros alaridos: consulta, confusión de pareceres; pie a tierra. Llegamos a una casuca con el lodo hasta las rodillas, y lloviendo sin cesar; júntanse algunos payos hablando el piamontés, y pidiendo dinero a cada palabra; tráense cuatro robustos bueyes, y a fuerza de cuerdas, de voces y urgonazos sacan el coche del atolladero. Llegamos a un lugarcillo poco distante (...). El vetturino nos recibe con semblante halagüeño, que desarmó nuestra cólera, y como sea ya cosa averiguada y cierta que ningún vetturino es criatura racional, nos pareció más conveniente almorzar-que reñir. Seguimos nuestro viaje; y al pasar por un torrente que venía furioso, para mi tuve que aquel era el cabo y remate de mis peregrinaciones. ¿Para qué (sirve) el mentir?. Mi virtud dominante es el miedo, $y$ al verme alli tuve tantas razones de tenerle, que en mi vida me he visto más cercano de perecern(6).

Pero no acabaron aquí las desventuras de nuestro viajero, porque el 8 de mayo partio de Turín, a las 5 de la mañana, para dirigirse a Milán a bordo de una vettura, que iba «seguida de otros dos o tres carruajes, especie de caravana muy necesaria en aquella ocasión, por cuanto los caminos estaban poco limpios de ladrones. Al llegar al (río) Tesino-anota Moratín-, se pasa un bosque, famoso por los robos y asesinatos que en él se cometen frecuentemente: ya se deja entender el miedo con que yo paséx(7). 
Es un hecho historico comprobado que los salteadores de caminos (highwaymen) pululaban incluso en la civilizada Inglaterra, patria del humanitario bandolero Dick Turpin; no se trataba de asesinos vulgares, ni de ladrones sanguinarios, porque no mataban a los viajeros sino en última instancia-simplemente los desvalijaban-, pero sus asaltos a las diligencias eran tan frecuentes que esta "continuité de vols-escribía el conde de Tilly-fasse naître les réflexions les plus désavantageuses à un gouvernement d'ailleurs si supérieurement conçu»(8).

Pero volvamos al relato de Moratín. "Durante el viaje-dice-nos juntábamos a comer en las posadas (en las cuales posadas comimos muy maly9) todos los viajeros que íbamos en los tres o cuatro coches mencionados. ¡Qué galería de personajes!. Un genovés sórdido, con su mujer y su hija (horrendas las dos), que en vez de hablar ladraba (...). Un fraile muy gordo, sudando siempre, hablando con las mujeres de malos partos, destetes y preñados (...). Una mujerzuela con una chiquilla colgando de una teta (...). Una vieja ridicula, tan poco enseñada a viajar en coche, que en todo el camino no dejo de vomitar; y el fraile se esforzaba en persuadirla que todo aquello era mal de madre; y así que llegábamos a las posadas empezaba a despanzurrar colchones, y a quemar lana para dar humazos a la vieja, de donde resultaba un pebete infernal»(10).

Henos aquí, sin solución de continuidad, ante otra de las desagradables realidades que deparaban a los caminantes los viajes de aquella época: la sordidez de los albergues y posadas.

La archiduquesa austriaca M. ${ }^{a}$ Carolina (1753-1813) llegó a Nápoles en Mayo de 1768 para contraer matrimonio con Fernando IV (1751-1825), soberano de las Dos Sicilias. Al año siguiente recibió la visita de su hermano mayor, el futuro emperador José II (1741-90), que salió de Viena el 3 de marzo de 1769, y llegó a la ciudad de Nápoles el 31 del mismo mes.

En los informes que existen en el Haus- Hof-Staatsarchiv de Viena referentes a este viaje(11), se menciona con reiterado encomio un rasgo de "sencillez" del siempre original José II, es a saber: que tan augusto personaje accedió varias veces, durante el camino, a acostarse vestido y dormir sobre la paja, a falta de un lecho mejor(12). Con ser cierta la noticia, guardémonos, sin embargo, de conceder demasiada importancia a este rasgo "democrático" del príncipe austriaco; era más bien cuestión de higiene.

Todos sabemos que las palabras suelen renovarse como las hojas de los árboles; con el paso del tiempo, las mismas cosas son expresadas por vocablos distintos, y otras veces, una misma palabra sirve para designar realidades diferentes. Tal ocurre, por ejemplo, con la palabra hotel. Nosotros tenemos actualmente una idea muy determinada-quiero decir: 
confortable e higiénica-de lo que es, o puede ser, un establecimiento público de este género; pero en el siglo XVIII las cosas eran muy diferentes, empezando por la simple minucia de que entonces apenas habia categorias hoteleras: se desconocía el significado de las estrellas, y los mesones tampoco usaban el reclamo de los tenedores para indicar el nivel culinario-y crematístico-del menú.

Retrotraigámonos, pues, al XVIII y tendremos la oportunidad de encontrarnos con una intrépida viajera que, procedente de París, se alojó en agosto de 1784 en el flamante "Hotel de Saint Julien", de Nantes, cuya pulcritud dejaba, por lo visto, bastante que desear. "Nuestros lechos-refiere dicha señora-estaban plagados de chinches. Entre mi doncella y yo matamos sesenta; dos dias después desmontaron las camas, y se mataron cuatrocientas. Desde el comienzo de nuestro viaje jamás habiamos visto chinches en tanta cantidad»(13), confesión que tal vez pueda querer indicar, implicitamente, que en otros "hoteles" se habían dedicado a matanzas más discretas.

Todavía a finales del XVIII, encontrar en cualquier parte-o al borde de cualquier camino-un hotel con una habitación particular y su correspondiente cama, era un lujo que no podía permitirse cualquier persona. Por otro lado, si nos asombra un tanto la capacidad de aguante que movilizaban aquellas gentes ante este hecho (para nosotros insólito, pero para ellos habitual), debemos tener en cuenta que tanto la promiscuidad, como el respirar olores mefíticos o la costumbre de escupir en cualquier sitio(14), (para no mencionar-intencionadamente-otras funciones corporales y otros "alivios" somáticos más groseros), eran unos usos sociales tan comunes, que no herian la sensibilidad de las gentes de entonces, porque no traspasaban lo que el historiador $\mathrm{N}$. Elias ha llamado acertadamente uel umbral del pudorw'15).

Como en no pocos albergues y posadas, la sala principal o el zaguán de entrada (que servian de comedor durante el dia), estaban provistos de camas adosadas a las paredes, al llegar la noche se abatían, y aquellos recintos quedaban convertidos en un dormitorio general donde reposaban los viajeros de ambos sexos. Descartando-por supuesto-las posadas modestas o los albergues rústicos, como aquel en que Mme. de Sévigné no encontró más lecho que el heno fresco, «sobre el cual-dice-nos acostamos vestidos ", algo similar ocurría en otros "hoteles" de más viso, donde el número de camas solía ser inferior al de huéspedes, sobre todo si se trataba de un lugar con relevo de postas. De ahi la necesidad inesquivable de dormir a veces en compañia de un desconocido.

La expresión "mal compañero de cama" o "ceder media", que encontramos en nuestra literatura picaresca, o en los informes de los hospitales públicos(16), no se tomaba entonces en sentido figurado, sino a la letra, ya que si alguien, por un sentimiento humanitario, o instado perento- 
riamente por el posadero, ofrecía la mitad de su lecho a un viajero retrasado, nervioso o roncador, se exponía a pasarse en blanco el resto de la noche. De ahí, también, el que muchos viajeros prefirieran ir al pajar; al menos allí se podía dormir con más desahogo, y sobre heno Jimpio, pues no está de sobra señalar de pasada, que las sábanas de las camas del zaguán solian estar cosidas al colchón, y sólo se mudaban cuando empezaban a adquirir tonalidades de color nicotínico.

Dada la indole de estas páginas, parece supérfluo acumular más ejemplos para poner de relieve la variada gama de percances que acechaban entonces a los viajeros que se lanzaban audazmente a transitar ya sea por los caminos de España, ya por los de otras naciones europeas(17), porque, sacadas fuera las excepciones, y hablando en general, puede afirmarse sin ninguna temeridad que, todavia a finales del XVIII, y pese a la "política de los caminos" practicada por los Gobiernos más civilizados, el estado general de las rutas era, en todas partes, igualmente detestable.

Digamos para concluir este apartado, que un hecho destaca meridianamente en este escenario coruscante, y es: que basta seguir los itinerarios-y las peripecias-de los viajeros del XVIII para convencerse de que viajar en aquel tiempo no era, a lo que parece, ningún agradable esparcimiento, y que el hacerlo en semejantes condiciones tampoco ofrecía el menor aliciente para cultivar el turismo, como no sea que exceptuemos a una parte de la gentry británica, que empezó a poner de moda este fenómeno humano Ilamado a adquirir tan gigantescas dimensiones. Hablando en general, el mismo J. J. Rousseau señalaba, a este respecto, que, en su tiempo, eran los nobles ingleses quienes viajaban "turisticamente", mientras que en Francia la aristocracia se quedaba en casa, siendo personas de otros estamentos inferiores las que de ordinario viajaban de esta guisa.

\section{EL VIAJAR COMO FENOMENO SOCIAL}

Una vez aquí, alguien podría preguntar si unas perspectivas tan poco halagüeñas fueron capaces de arredrar a las gentes del XVIII, hasta el punto de quitarles el coraje para salir de sus casas a recorrer los caminos. La respuesta a este interrogante es, desde luego, negativa; más aún, teniendo en cuenta todas las circunstancias adyacentes (eso que nuestros entendidos Ilaman "estructuras coyunturales"), cabe decir-sin establecer ninguna comparación con la movilización del mundo actual-que el número de personas que, por las razones que fuera (incluida la naciente ratio turistica), se ponían entonces en camino, además de ser relativamente muy considerable, fue siempre en aumento con el paso del tiempo, entre otras razones (además de las demográficas y las utilitarias), porque el siglo XVIII no 
sólo descubrio, por así decirlo, sino que impuso la moda de viajar. Y es bien sabido que la moda, a cualquier escala, es "una rabia, una furia»18) que hace verdaderos estragos.

El ya citado conde de Tilly, famoso por sus aventuras galantes, escribia en 1788 como verdadero hijo de su tiempo: «Je me sentais un besoin impérieux de voyager; j'ai eu trop le temps et l'occasion depuis de satisfaire à cette fantasie; mais alors (que sólo tenía 24 años de edad), c'était je ne sais quoi d'inexplicable qui m'agitaitw(19). Pero idénticos impulsos de viajar sentían otros coetáneos suyos.

Este fenómeno histórico incontestable; y de no pequeña envergadura viene corroborado, desde otro ángulo, por el famoso viajero Lorenzo Sterne (1713-68). Si abrimos las páginas de su Viaje sentimental (1768), encontramos que el inquieto clérigo irlandés, no contento con hacer-como Moratín-la descripción de algunos de sus compañeros de camino, establece una curiosa clasificación entre: "Viajeros ociosos; viajeros curiosos: viajeros vanidosos; viajeros melancólicos. A continuación-escribe-vienen los viajeros por necesidad: viajeros felones y delincuentes, viajeros inocentes e infortunados, simples viajeros. $\mathrm{Y}$, finalmente, con vuestro permiso: el viajero sentimental, o sea yo (...), que ha viajado apremiado por el imperio de la Necessity and besoin de voyager (sic) en igual grado que cualquiera de los incluidos en esta categorias(20).

Este modo pintoresco de registrar la variedad de los viajeros no es un simple rasgo de humor inglés, sino una realidad tangible, y por otro lado, tal constatación constituye una forma indirecta de responder a la pregunta inicial, referente a si los peligros inherentes a los caminos frenaban el ánimo viajero de aquellas gentes.

Pero todavia puede darse otra respuesta complementaria para esclarecer esta cuestión, y para ello vamos a establecer una doble distinción. La primera de ellas se refiere a las diferencias existentes entre los viajes interiores y los exteriores; la otra distinción alude a ciertos matices obvios que contraponían el acto o, si se quiere, la empresa de viajar «roussonianamente", al simple hecho de recorrer los caminos. Comencemos por esta segunda.

a.-Es evidente que los hombres han viajado en todos los tiempos y lugares; pero en el siglo XVIII la tarea de viajar se fue convirtiendo, para cierta clase de personas (las que Gaspar Gomez de la Serna ha Ilamado atinadamente "viajeros de la llustraciónn), en una operación importante no sólo desde el punto de vista sociológico, sino en cuanto que tal menester constituyó otra manifestación más del despliegue intelectual del «Siglo de las Luces". No es, pues, extraño que el marqués de Pézai, consciente de este fenomeno, llegara a escribir en 1783, que los auténticos viajeros eran a los Filósofos lo que los boticarios a los médicos, ya que "los Filosofos-decía-apoyan sus sistemas en los relatos de los viajeros»(21). 
No todos los itinerantes, incluso muchos que presumían ser unos consumados viajeros, recorrían los caminos con arreglo a un plan previo, elaborado cuidadosamente; para ellos, el viajar no pasaba de ser un elegante errabundaje. Pero los viajeros que se ajustaban, de alguna manera, al esquema establecido por J. J. Rousseau en el Emile, solían ponerse en marcha no sólo-o no tanto-para ver tierras, paisajes, monumentos y paisanajes, como para conocer pueblos, estudiar costumbres y comparar las formas de gobierno de los distintos países.

Resulta interesante constatar, a este respecto, que fue el propio J. J. Rousseau- "gran errabundo" a su vez-quien encomió este sentido utilitario de los españoles sobre los demás viajeros de su tiempo, ya que adoctrinando a su pupilo le decia, no sin cierta exageracion: "Je ne connais guère que les Espagnols qui voyagent de cette manière (prestando toda su atención a lo que es verdaderamente útil)... Tandis qu'un Français court chez les artistes d'un pays (...), l'Espagnol étudie en silence le goubernement, les moeurs, la police, et il est le seul (entre un francés, un inglés y un alemán) des quatre qui, de retour chez lui, rapporte de ce qu'il a vu quelque remarque util à son pays»(22).

Como se deja entender, este modo de viajar-pragmático o científico-estaba reservado a un exiguo número de personas más o menos cultivadas; el resto de las gentes emprendían los viajes por imperativos políticos (militares o diplomáticos), por asuntos comerciales o administrativos, por razones pedagógicas, familiares y también amorosas, o simplemente por motivos de salud, pero raramente por placer; incluso la mayoría de los miembros del cuerpo diplomático de entonces (que recorrian largas distancias para llegar a sus respectivos destinos, y permanecian en ellos durante varios años) no tenían miras más altas al ponerse en camino, y por lo mismo no se preocupaban de convertir sus traslados en "viajes ilustrados".

No sólo por exigencias de tipo estratégico y económico, o bien para aumentar el aforo del comercio y agilizar la distribución de los productos y mercancías, sino por razones meramente sociales-amén de las politicas-, los Gobiernos de las naciones más civilizadas se hicieron eco de los problemas planteados por la creciente ola de personas que se veian obligadas a trasladarse de un lugar a otro; los afrontaron seriamente, y trataron de darles una solución eficaz, construyendo para ello nuevos caminos, y mejorando la red de comunicaciones.

Para ceñirme únicamente a España que fue con Fernando VI (1746-59), y sobre todo durante el reinado de Carlos III (1759-88), cuando empezó a implantarse en la Península ibérica, de una manera organizada, aunque muy lenta, la llamada "política de los caminos".

El ministro de Estado, don Ricardo Wall (1754-63), que ocupaba al mismo tiempo el cargo de Superintendente de Correos, nombro en 1755 asesor 
jurídico de dicho cuerpo al abogado asturiano don Pedro Rodriguez Campomanes (1723-1802), quien se dedicó con ahinco al conocimiento y fomento ("policia») de este importante ramo de la administración pública, y en 1761 dedicó al ministro Wall un detallado "Itinerario de las carreras de postax(23). En él recogio todo lo que estaba ya legislado sobre este sector, añadiendo importantes mejoras y sugerencias, de suerte que este escrito no sólo sirvió de base a las Ordenanzas de Correos, promulgadas por Carlos III el 23 de julio de 1762(24), sino que constituyó, por un lado, el primer reglamento encaminado a uniformar el trabajo de los empleados en las estafetas y postas de todo el reino (desde los administradores e interventores hasta los oficiales y los postillones), y, por otro, se convirtió en una especie de Guía o Baedecker muy útil para que los viajeros conocieran las vías de comunicación, las distancias que separaban las poblaciones, los precios de las postas y la legislación correspondiente. Actualmente, esta obra de Campomanes sigue teniendo un innegable valor históricogeográfico, como fuente de conocimientos del estado de las comunicaciones de España a mediados del XVIIII. La "política de los caminos» se habia puesto en marcha.

El conde de Floridablanca, ministro de Estado y Superintendente General de Correos desde 1777 hasta 1792, no hizo sino desarrollar este servicio público (poco fomentado por su antecesor el marqués de Grimaldi), con la particularidad de que la llamada "política de los caminos" se fue convirtiendo durante su ministerio en "política de caminos, puentes y posadas»(25), para no hacer mención de los canales, los puertos y los pantanos.

En un Memorial justificativo, que Floridablanca presentó al rey Carlos III el 10 de octubre de 1788, decia el ministro que, gracias a la participación de los mismos municipios, y a la colaboración desinteresada de algunos prelados munificentes, durante los nueve años que llevaba al frente de la Superintendencia de Correos, se habian construido en España más de 200 leguas de caminos nuevos(26), y pasaban de 300 las leguas de caminos arreglados o reconstruidos; se habian erigido, además, 322 puentes nuevos y habilitado otros $\mathbf{4 5}$ más para el tráfico rodado. Cada legua de camino estaba al cuidado de un peón caminero, con un capataz o celador cada ocho leguas, y en todo el reino se habian levantado, para estos mismos camineros, 49 casas nuevas, que eventualmente servian de refugio a los viajeros accidentados. Todo lo gastado en esta empresa de "policía general" rebasaba los noventa millones de reales(27).

Floridablanca aplicó al fondo de rentas del cuerpo de Correos el producto de las Gacetas y la contribución de la sal (sólo ella ascendio a 27 millones de reales en nueve años), amén de otros tributos destinados a la Hacienda; envió técnicos al extranjero al objeto de implantar en España los adelantos y mejoras que observaran en los demás países, tocantes a 
"este ramo de la policía general»; concedió toda clase de ventajas-sin excluir primas y gratificaciones - a cuantos españoles fomentaran las facilidades para viajar con mayor comodidad; aumento considerablemente el número de postas y de estafetas de correos por toda el área de la geografía hispana; uniformó las tarifas de los viajes para evitar exacciones y timos, y hasta llegó a reglamentar, en cada población importante, los lugares y las horas de salida-ya que no las de llegada-de las diligencias públicas y de los servicios regulares, sin perjuicio, naturalmente, de que las personas pudientes, o urgidas por la prisa, pudieran valerse de otros medios de locomoción, o viajar en coches de su propiedad.

Los puntos de salida y de llegada de las diligencias públicas (que equivalían, en cierto modo, a nuestras actuales estaciones de ferrocarril) eran muy concurridos, y solían estar frecuentados por gentes de toda clase y condición; el alboroto de los viajeros y los gritos de los postillones, los abrazos de bienvenida asi como las lágrimas de despedida formaban, con el restallido de los látigos y el ruido ensordecedor de los carruajes, una parte esencial de la escena, que para unos era un espectáculo municipal, y para otros un "divertimento". Los pisaverdes y lechuguinos se plantaban en las cercanias para ver el tobillo de alguna damisela que subía al coche, $y$ en un lugar populoso y trajinero como este es donde el caballero don Grieux conocio a la joven Manon Lescaut (1733).

b.-Hasta aquí nos ha conducido la exposición de algunas diferencias existentes entre el simple hecho de recorrer los caminos (faena que realizaban innumerables personas), y el viajar "roussonianamente" (que era una empresa de minorias); muy de pasada hemos aludido también a la "política de los caminos" del Gobierno español durante la segunda mitad del XVIII.

Pero todavia queda pendiente el abordar la primera distinción que hacíamos más arriba entre los viajes interiores y los exteriores, o dicho con otras palabras: entre los viajeros que no transponian las fronteras de su patria y los que salian al extranjero, bien entendido que en uno y otro caso tomamos la palabra "viaje» en la acepción-más o menos restringida-de "viaje ilustrado", y no como un simple recorrido de leguas y caminos.

Por lo que respecta a los "viajes interiores», el citado G. Gómez de la Serna ha descrito, en un libro delicioso, las características-y las motivaciones-de un puñado de españoles cultos que realizaron unos ejemplares "viajes ilustrados" por el interior de su patria; simultáneamente, ha trazado también una tipología provisional de los itinerarios-geográficos y mentales-seguidos por estos «viajeros de la llustración", y los ha clasificado (sin ningún orden de prelación) en cinco categorías: 1. Viajes económicos, como los de B. Ward y G. Bowles; 2. Viajes cientifico-naturalistas, como el del benedictino P. Sarmiento a 
Galicia en 1745, y el viaje botánico-geográfico del abate A. J. Cavanilles al reino de Valencia; 3 . Viajes artísticos, el más famoso de los cuales fue el de don Antonio Ponz(28), sin olvidar por ello los de A. Vargas Ponce, l. Bosarte y J. Ortiz; 4. Viajes histórico-arqueológicos, cuales fueron los del marqués de Valdeflores, de F. Pérez Bayer, y de Jaime Villanueva, hermano éste último del famoso canónigo J. L. Villanueva; 5. Viajes literariosociológicos, entre los cuales hay que poner el del agustino P. Florez, el del abate J. de Viera y Clavijo, que también viajó por Europa, y el de Tomás de Iriarte a la Alcarria, para no citar otros autores(29). Sin ánimo de ofender, ni de enmendar la plana a nadie, aún se podían añadir a los anteriores los Viajes políticos, como los del comisario Francisco Zamora, confidente del favorito Manuel Godoy, y los Viajes pintorescos, especie de itinerarios histórico-descriptivos, que resultan ser los de Jovellanos, y-aunque francés-los de Alejandro de Laborde.

El gran hispanista francés J. Sarrailh, al que me complazco en citar en esta ocasión, se interesó no poco por los relatos de los viajeros del XVIII(30), y ello-entre otras razones-porque él consideraba este género literario no sólo como una floración típica del setecientos, al mismo tiempo que una plataforma orientada hacia el futuro, sino como una via peculiar de aproximación al conocimiento-en este caso-de la sociedad española de aquella centuria. Nada tiene, pues, de extraño, y si mucho de natural, que Sarrailh dedicara dos capítulos de su copiosa obra sobre «La España llustrada" a estudiar la manera-o una de las maneras-cómo los españoles de la segunda mitad del XVIII podian adquirir un conocimiento adecuado del extranjero, para aplicar luego en su patria las enseñanzas venidas de fuera o aprendidas allende los Pirineos $\left({ }^{(31)}\right.$.

El primero de estos capítulos está consagrado «al extranjero en España", y su contenido rebasa el área de estas páginas, en primer lugar, porque en él se trata de cosas y personas extranjeras-principalmente francesas-llegadas a España, y no de viajeros españoles, tema que, con una excepción(32), centra el contenido de la presente comunicación; y en segundo término, porque los relativamente pocos extranjeros que venian entonces a España eran-a juicio del citado Laborde-unos viajeros ocasionales, que miraban las cosas a través de sus gafas negras, deformaban maliciosamente la realidad, y se burlaban casi siempre del atraso y de las "bizarras originalidades" de nuestro singular pais.

Todos estos puyazos-los chistes irónicos, las mentiras más descaradas, cuando no los errores más crasos, vertidos intencionadamenteproducian la justa indignación de los españoles cultos, y en alguna ocasión provocaron la intervención oficial del Gobierno de Madrid, como ocurrio, por citar un caso, con el infamatorio "Viaje de Fígaro a España", del falso marqués de Langle, nombre con el que se cubria un libelista francés que muy probablemente jamás puso sus pies a este lado de los Piri- 
neos(33). Por otro lado-añade Laborde-, "España se contó durante mucho tiempo en el número de los países olvidados; como no se encuentra en el camino de ningún otro reino (a excepción de Portugal), fue dejado de lado y no entró en los itinerarios de lo que los ingleses llaman uel gran viaje" (the grand tour), que dura (unos) dos años y que, entre ellos, forma parte de la educación de los ricos, con el mismo derecho que la retórica y la filosofían(34), ya que tal viaje venia a ser-y se pretendía que fuera-como el remate de la educación de todo joven aristócrata inglés.

En cambio en el segundo capitulo, Sarrailh habla eruditamente del "español en el extranjero", y con esta aportación trata de completar el tema desde esta otra vertiente.

$Y$ digo que "tratan (sin conseguirlo del todo), pues su exposición se me antoja-y es una opinión puramente personal-un tanto limitada, por falta de casuistica, ya que solamente recoje en su obra los ejemplos de contados españoles, viajeros por el centro de Europa, sin tener en cuenta otros muchos casos análogos, y no menos interesantes que los citados por él, cual es, por ejemplo, el del abate santanderino M. A. de la Gándara (171883), agente general de preces en Roma, y autor de unos interesantísimos "Apuntes sobre el mal y el bien de España", someramente analizados, con voz de alerta, por el gran hispanista G. Desdevises du Dézert, para no referirnos a la pléyade de viajeros españoles que, por distintos motivos, visitaron la península italiana(35).

Este arbitrio selectivo-intencionado o no-, utilizado por Sarrailh en este capítulo, puede producir en el lector poco avisado la impresión de que los españoles del XVIII sólo viajaban a Francia, como si únicamente allí pudieran adquirir conocimientos útiles para su patria. Es cierto que, para los españoles de entonces, Francia solia constituir la meta preferente de sus itinerarios, pero este dato cuantitativo-a la par que objetivo-no invalida el que otro número menor (pero mayor que el aducido por Sarrailh) visitara también otros países europeos que no eran necesariamente "la douce France".

Dos móviles, de importancia desigual, parece que impulsaron a no pocos españoles del XVIII a salir de la Peninsula para conocer el extranjero, y concretamente el reino de Francia. Los más adinerados-que eran a su vez los menos numerosos-cedieron sin duda a la creciente moda de viajar; pero la mayoria se puso en camino impulsada por móviles utilitarios, fueran éstos de tipo pedagógico, diplomático, científico, profesional, económico-comercial, artístico, medicinal o sentimental.

Aparte de algunos hijos de diplomáticos españoles, acreditados en las distintas Cortes europeas, no faltaron en España jóvenes de la aristocracia que, a imitación de los ingleses, hicieron también su "grand tour" por Europa, acompañados de un preceptor idóneo. Tales fueron los casos 
de Carlos Gutiérrez de los Ríos, futuro VI conde de Fernán Núñez; del hijo del marqués de Santa Cruz, que viajó en compañía del citado José de Viera(36); y del guipuzcoano Ramón Muribe, hijo del conde de Peñaflorida, que se desplazo hasta Escandinavia, acompañado por el abate Cluvier, siendo de lamentar que las carraspeantes cartas escritas, en tal ocasión, por el prócer guipuzcoano a su pródigo retoño no tengan el encanto y la fina sabiduría mundana de las que lord Chesterfield dirigio, por aquel entonces, a su hijo mayor, viajero asimismo por el continente europeo.

Lo mismo antes que después de la expulsión de los jesuitas (1767), que habian detentado hasta esa fecha poco menos que el monopolio de la enseñanza media en España, no pocas familias, sobre todo del Pais Vasco, enviaban a sus hijos a Francia para que completaran alli su educación. Así es como el propio conde de Peñaflorida, otro vasco llamado Miguel de Olaso, y José Olazábal de la ciudad de San Sebastián-para ceñirme a tres casos que podrían multiplicarse-pasaron varios años en el colegio de los jesuitas de Tolouse, donde estudiaron ciencias físicas. Así se explica, al menos en principio, el hecho cultural de que el conde de Peñaflorida, miembro integrante de «los aldeanos críticos», entrara en 1758 a polemizar con el autor del Fray Gerundio.

Algunas comunidades religiosas de Pau, preparadas para desempeñar decorosamente cierto tipo de tareas pedagogicas, solían recibir a un gran número de señoritas españolas, que iban alli a aprender la lengua de Molière, y a "formarse en las maneras francesas". El Parlamento del Bearne pidió en 1765 "un buen pensionado para los jóvenes», y años más tarde, las municipalidades de Pau y de Oloron hicieron lo propio, recordando la costumbre que tenian los españoles de acudir alli para instruirse, por to que solicitaban encarecidamente que se fundaran en dichas poblaciones sendos colegios con internado(37).

Después del Tercer Pacto de Familia (1761), el Colegio de Sorèze abrió sus puertas a jóvenes cadetes españoles. El "libro de entradas" de este centro, dirigido por religiosos, registra los nombres de los 86 caballeros españoles que fueron alli, desde 1761 a 1790 , para estudiar ciencias y formarse en el arte militar, además de aprender equitación y esgrima. Los cadetes españoles que acudian a Sorèze desde Madrid, Zaragoza, Barcelona, Málaga, Bilbao, Lugo y otros puntos de la Península ibérica, eran, en general, jóvenes de la pequeña nobleza; entre ellos encontramos a los dos hermanos Angel y Camilo Gutiérrez de los Rios, hijos naturales-legitimados-del mencionado VI conde de Fernán-Núñez, que los llamaba "mis dos pelendengues", por haberlos tenido de sus amores con una bailarina boloñesa, Ilamada Gertruda Marcucci, (a) la Galguilla, que en 1769 fue al Sitio Real de Aranjuez con una farándula de cómicos y cantantes franceses(38). 
A través de estas indicaciones sumarias podemos concluir, sin demasiado error, que las molestias y peligros anejos a los viajes no fueran óbice para impedir que muchas gentes del XVIII se lanzaran a recorrer los caminos, antes muy al contrario; y por lo que atañe a su número, si dejamos aparte a los viajeros de otras naciones europeas, y nos fijamos únicamente en la variada gama de españoles que, de paso o de asiento, iban entonces a las distintas regiones de Francia, y sobre todo a París, nos encontrariamos con una larga lista formada por diplomáticos, cónsules, pensionistas del Gobierno, agentes comerciales, artistas, literatos; profesores, estudiantes, técnicos, curiosos, artesanos y fabricantes bien acomodados, que viajaban por propia iniciativa para perfeccionar las técnicas de su oficio, y finalmente los enfermos aquejados por distintas dolencias.

\section{BARBARA JULIANA VIETINGHOFF DE KRUEDENER}

A esta última categoría pertenecian los acaudalados viajeros españoles y extranjeros-incluidos los americanos-que solían acudir entonces a los distintos balnearios de los Altos Pirineos franceses, ya sea para recuperar fuerzas o para curarse de algún mal específico.

Pero, ¿por qué se dirigían a estos establecimientos termales, tan apartados del mundo, y no a otros centros similares de más fácil acceso?. Sin duda alguna, por dos razones complementarias: la primera y principal, por la virtud curativa de sus aguas, acreditada desde el tiempo de los Romanos; y la segunda, por el exotismo de aquellos lugares y la salubridad de los aires de alta montaña, amén de la buena cocina que caracterizaba-para lo que entonces se estilaba en general-a los albergues emplazados cerca de los manantiales sulfurosos.

La gente de entonces (para no hablar de la de después), depositaba gran fe en la energía curativa de las aguas termales. Además del natural instinto de conservación, ello se debia en parte al poderoso influjo de la moda creciente, no menos que al crédito que ciertos médicos prestigiosos - no me refiero aquí a los médicos empíricos o practicones de las ciudades(39) - concedían entonces a cualquier tipo de hidroterapia, pues la consideraban como un remedio casi infalible para el tratamiento de determinadas enfermedades.

El 11 de junio de 1784, anotaba en su "carnet» de viaje la baronesa d'Oberkirch (1754-1803): "Un hecho muy extraño, pero muy verdadero, es lo mucho que este siglo, el más inmoral que ha existido, el más incrédulo, el más filosóficamente fanfarrón, se vuelve, en sus postrimerías, no a la fe, sino a la credulidad, a la superstición, al amor a lo maravilloso (...). Si miramos a nuestro alrededor, no vemos más que hechiceros, ocultistas, nigromantes y profetas. Cada uno tiene el suyo y se apoya en él,(40). 
La perspicaz dama podía haber colocado en el mismo rango a los cabalistas, a los hipnotizadores, a los magos, a los magnetistas e imposturólogos, y, en cierto modo, bien que "servatis servandis", a algunos médicos afamados-como por ejemplo T. Tronchin (1704-81) 0 , en otro plano. A. Mesmer (1734-1815) - , cuyo influjo sobre sus elegantes e hipocondriacos clientes era tan decisivo, que sus diagnósticos y sus métodos terapéuticos eran tomados como dogmas de fe por aquellas gentes de "cualidad y buen tono", más crédulas que creyentes, aficionadas al maravillosísmo hasta el exceso, y capaces de transformar, con elegante frivolidad, unos remedios curativos en una moda social. Tal ocurrió entonces con el umagnetismon, que se puso de moda, y, como todas las modas bien montadas, fue "una rabia, y una furia" devastadora que produjo estragos(41). Aunque en un grado de intensidad mucho menor, pero extendido a un mayor número de personas, algo parecido sucedio en el XVIII con la hidroterapia y sus aplicaciones balnearias.

Esta era, en general, y muy a grandes rasgos, la dimención terapéutica y social-quiero decir elitista-de las estaciones termales de aquel tiempo, y por tanto no es necesario insistir en que sólo una minoría muy restringida podía beneficiarse de los remedios ofrecidos por tales establecimientos.

Aquí voy a limitarme a analizar el caso de Mme. de Krüdener (17641824), historiada dama rusa, que ejerció un gran influjo sobre don Simón de las Casas, embajador de España en Venecia, como más tarde lo ejercería poderosamente, según veremos, sobre el zar de Rusia Alejandro I (1777-1825).

La infatigable viajera Bárbara Juliana de Vietinghoff, hija del barón Otto Herman y de la condesa Ana de München, nació en Riga (Letonia) el 11 de noviembre de 1764. Nadie hubiera podido pensar entonces en la incoercible propensión hacia la mística proselitista que, años más tarde, manifestaria esta criatura, "romántica antes del Romanticismo" y utopista "iluminada" que, bajo el nombre de Mme. de Krüdener, pasaría no ya a la historia, sino a la gran Historia, pues fue ella quien, además de acuñar la expresión, le dio nombre e inspiró los principios metafísicos de la llamada Santa Alianza, sistema político-religioso de la Restauración cuyo máximo portaestandarte sería el zar Alejandro I de Rusia.

Desde niña, Bárbara dio muestras de tener una mente muy despierta y una gran pasión por los libros. Como correspondía al rango social de la familia a la que pertenecia -el barón Otto Herman era gobernador de Riga, y su abuelo materno era el mariscal de München-, recibió una esmerada educación, dentro de los principios religiosos luteranos, y a los quince años dominaba el alemán, el ruso y el francés, idiomas de los que tanto uso haria en el futuro. En 1776 emprendió, en compañia de sus padres, el primero de los innumerables viajes que trenzarian su asendereada vida. 
En esta ocasión se detuvo en varias ciudades alemanas, y, después de visitar detenidamente Londres, se asentó en Paris, donde permaneció hasta la primavera de 1782 .

La capital francesa era entonces el lugar ideal para poder relacionarse con espíritus brillantes, para estar al tanto de la literatura más vanguardista, y, en fin, para encontrar lo que brumosamente buscaba la temperamental letona. Por eso nos imaginamos que la joven Julia-como ella se hacia llamar-frecuentó los famosos "salones" parisinos, asistió a la ópera para escuchar la música de Gluck y de Piccini, y leyó los libros de moda, aunque sabemos de cierto que aprendió la danza con el maestro de baile Vestris. Pero lo que aqui nos interesa destacar es que Julia se puso en París en relación con dos personajes, cuyas ideas no sólo iban bien con su idiosincrasia mental (tal vez por eso las buscaba), sino que influyeron en la cristalización de sus tendencias "místicas" e incluso con su destino terrenal(42).

El primero de ellos fue el judio portugués Antonio Martínez Pasqualis (1715-79), teósofo y jefe de un grupo de iluminados, que llegó a París en 1778. Habia fundado una secta esotérica que se regía por los ritos cabalisticos; soñaba con la reconciliación del hombre con Dios, y pretendía encontrar todo el saber en la cábala judia. Aunque no adoptó su sistema por entero, el principal discípulo de este lusitano errabundo era entonces Claudio de Saint-Martin (1743-1803), filósofo iluminado y metafísico espiritualista, autor de los Rapports entre Dieu, l'Homme et l'Univers, obra en la que propugnaba el reinado de la armonia entre los hombres y las naciones, y que produjo no pequeña conmoción entre ciertas gentes crédulas, buscadoras de sucedáneos religiosos. Ambos trataban mucho en París con la duquesa de Borbón, hermana del lamentable Felipe Igualdad, duque de Orleans, y las doctrinas de Saint-Martin, que se difundieron por el centro de Europa, serían muy bien recibidas en los círculos de la nobleza de Estrasburgo a los que pertenecia la mencionada baronesa d'Oberkirch.

El otro personaje a que aludiamos fue el célebre-y ya citado-curandero alemán Mesmer, establecido en París en 1778, que pretendia sanar toda clase de enfermedades, sobre todo las nerviosas (recuérdese "La curación por el espíritu", de que nos habla S. Zweig), por medio del magnetismo, y provocaba éxtasis hipnóticos con su milagrosa varita. Su nombre andaba entonces en todas las bocas, y hasta la reina $M{ }^{a}$ Antonieta, arrastrada por la curiosidad y la moda, llegó a consultarle una vez.

Abundan los relatos que describen las multitudes que solian acudir a la consulta del "doctor" Mesmer, sita en la plaza de Vendôme, donde se celebraban las famosas sesiones en las que participaban desde los príncipes y los nobles más encopetados hasta las cortesanas de trapio 
más lujoso, mientras que los criados esperaban en la antesala. El poeta André Chénier, el dudoso bajofondista Restif de la Bretonne, el general La Fayette, y el mismo Saint-Martin se apasionaron por el magnetismo, la hipnosis y el sonambulismo, que entonces hacían furor en las gentes.

Pero aparte de este aspecto sensacionalista, que le producia pingües ganancias, Mesmer-que llegó a hacerse rico de esta guisa-formo una pequeña capilla de adeptos, para pertenecer a la cual habia que pagar de entrada la nada módica suma de cien luises(43). A este grupo esotérico de iniciados pertenecía el abogado lionés Bergasse, que dio al «mesmerismo" un carácter religioso, y fue él quien "evangelizo" con tales principios a la joven Julia, cuya devota gratitud a su iniciador jamás se desmentiría a lo largo de su vida.

La baronesa d'Oberkirch conoció personalmente al impostor Cagliostro, como conoció asimismo al tristemente célebre cardenal Luis de Rohan, enredado con aquél en el clamoroso "affaire du collier»; y también trató con Mesmer y con Saint-Martin, cuyas ideas le influyeron más de lo que ella misma se figuraba. Pues bien, esta dama linajuda que, además de gazmoña, era muy dada al esoterismo, anotaba el año 1778 en sus Mémoires: "Entonces se hablaba mucho en Estrasburgo de una mujer joven, de imaginación brillante y exaltada, que quería crear una secta y reformar las creencias filosóficas, ajustándose a los sueños (rêveries) de Swedemborg (44) y otros utopistas. Esta mujer era la baronesa de Krüdener. Su marido seguía la carrera diplomática y en 1768 fue embajador en Berlín(45). Mme. de Krüdener se limitaba entonces a medir sus fuerzas, y a propalar sus doctrinas en los salones, donde hacía muchos prosélitos con la ayuda de sus dos bellos ojos y de su espiritu fascinador. Yo no puedo menos de ver en ella una especie de Mme. Guyon(46), y se me ha metido en la cabeza la idea de que terminará como ésta: creando una escuela y sufriendo persecución. Es un alma ardiente y honesta, pero seducida por un falso sistema; se ha descarriado del camino y no sabe a dónde va, pero ella sigue siempre adelante y así se figura que asciende. Los espiritus exagerados, cuando no están sostenidos por unos principios seguros, no pueden acabar de otra manera»(47).

Este retrato, tan poco indulgente como falto de precisión, refleja, sin embargo, con gran nitidez los rasgos esenciales que caracterizaban-y caracterizaron más tarde-la fisonomía "mística» de esta mujer ardorosa que, ciertamente, fue cualquier cosa menos un ser vulgar; por lo que se refiere al triste final de Mme. Krüdener, la baronesa d'Oberkirch salió profeta.

Terminada su estancia en París, Julia regresó a su patria, y en septiembre de 1782 se casó, en el castillo de Ramkau (Livonia), con el barón Constantino de Krüdener (1744-1802), veinte años mayor que ella. 
Los nuevos esposos se instalaron en Mittau (Curlandia), donde el barón ejercia el cargo de embajador de Rusia, y en enero de 1784 Julia dio a luz su primer hijo, Pablo(48).

A finales de ese año el barón de Krüdener fue nombrado ministro plenipotenciario de Rusia ante la República de Venecia, a donde se dirigió con su familia. Después de atravesar Polonia y Bohemia, se detuvieron en la imperial Viena, y durante el camino, el nuevo secretario de la embajada rusa en Venecia, Alejandro de Stackhieff, que viajaba juntamente con ellos, se enamoró perdidamente-aunque sin consecuencias-de Mme. de Krüdener.

Parece que el nuevo destino agradó tanto a la joven embajadorá, deseosa de ponerse en contacto con la soleada Italia, y de disfrutar del embrujo de la vida veneciana, como desagradó a su marido, que se sintió un tanto relegado en este puesto; pero este sentimiento despechado da quizá la medida del escaso temple diplomático de la personalidad del barón, ya que el abate Bernis, más tarde cardenal y embajador de Francia en Roma durante casi un cuarto de siglo, refiriéndose precisamente a la embajada de Venecia, a la que fue enviado en 1752, escribia las siguientes lineas: "El ir destinado a la embajada de Venecia se mira bastante comunmente como una comisión poco importante; esto hace que las Cortes europeas no envien, desde hace mucho tiempo, embajadores muy hábiles para ocupar este puesto. Bien es verdad que esto no parece muy necesario, a la vista del poco influjo que la República de Venecia tiene en los asuntos generales de Europa. Esto no obstante, yo no conozco una escuela mejor que la embajada de Venecia para formar embajadores; nada es indiferente en aquel país: cada palabra, cada acción produce su efecto; de ese modo, un embajador atento y reflexivo se acostumbra a razonar todas sus gestiones y a no considerar nada como inútil. Por si fuera poco, en Venecia hay que tratar con un Gobierno invisible, y siempre por escrito, lo cual obliga a usar siempre de una gran circunspección para no enviar al Senado nada que no esté bien digerido y maduramente pensado (49).

La estancia de los Krüdener en Venecia, en la que Julia encontraba, sin embargo, "quelque chose de lugubre", se prolongó hasta diciembre de 1786, fecha en que el barón fue destinado con el mismo empleo a la embajada rusa de Copenhague. En la capital danesa comenzarian las desventuras de Julia, pero durante su tranquila estancia en Venecia es cuando Mme. de Krüdener conoció al embajador de España don Simón de las Casas (1742-98), que acababa de contraer matrimonio con una prima suya.

Este "vizcaino" instruido, y de familia bien acomodada, siempre estuvo protegido por el ministro de Estado, Floridablanca, que lo envió primero de secretario de embajada a Viena, y en 1781 de embajador a Berlín, donde trató de cerca al gran Federico II(50). El aragonés J. N. de Azara, agente de preces en Roma, decía de Casas, al que habia tratado en las covach.uelas 
ministeriales, que «el sol no calentaba mayor camueso que él». Hombre de genio cachazudo y tranquilo, fue destinado a Nápoles en enero de 1785, para sustituir en la embajada española de las Dos Sicilias al achacoso vizconde de la Herreria, cuya corta misión diplomática había constituido un rotundo fracaso. Pero tampoco le fue mejor a Casas, porque su mandato en Parténope apenas duró ocho meses, y después de sufrir los vejámenes más inauditos por parte de la reina M. $^{a}$ Carolina, tuvo que escaparse de Nápoles porque su vida peligraba. Su protector Floridablanca lo destinó entonces a la embajada de España en Venecia, a donde llegó el 14 de mayo de 1786 en compañia de su secretario Clemente Campos, que lo había sido en Nápoles, y que también habia tenido que salir de allí de mala manera después de cerrar la embajada.

El secretario Campos, a quien todo el mundo llamaba Campitos, por su exigua estatura y sus maneras afables, escribiendo a su protector el conde de Aranda, le decía: "Hace seis dias que estamos en este rarísimo país; V. E. que lo conoce confesará que en nada se parece a ningún otro de Europa, bien que no deja de ser muy respetable su constitución y gobierno. Andamos con nuestras capas negras de tafetán, esclavina y capucha de gasa, máscara y sombrero puesto; figúrese $V$. E. qué nuevo se nos hará este traje a los que sólo lo acostumbrábamos a llevar en Carnaval; V. E. sabe que todo el que tiene relación con el cuerpo diplomático acreditado en esta República no puede tratar absolutamente con la nobleza venecianas(51).

Remachando este último punto, referente al aislamiento en que vivían los miembros del cuerpo diplomático extranjero, escribia el propio Casas desde Parma: "Ni los embajadores, ni los secretarios de embajada, ni ningún comensal ni familiar del embajador puede tratar de palabra ni por escrito con ningún indivíduo de la nobleza veneciana de ambos sexos, con ninguno del orden de los Secretarios, ni con sus comensales y criados. Es sabida la vigilancia que hay en esto, los riesgos de la menor infracción, la suma dificultad de ocultarlas, y la severidad con que se castigan „(52).

Es cierto que este uso político tan original puso en frecuente contacto al embajador Casas y a Mme. de Krüdener, que se complacía en evocar en su Journal de Venise su asistencia a las alegres fiestas y saraos organizados por el conde de Rosemberg, embajador de Austria, y por el matrimonio Casas en su "Villa Pisani", casa de campo situada a orillas del Brenta, cerca de Padua(53); pero también es verdad que la separación entre los diplomáticos extranjeros y los nobles venecianos no era tan estricta y rigurosa como se blasonaba. Refiriéndose precisamente a esta extraña costumbre, escribia el experimentado abate Bernis las siguientes líneas: «No se debe creer a la letra que, aunque la nobleza veneciana no puede tener ninguna relación ("commerce») con los embajadores extranjeros (severidad muy sabia, pues si la República renuncia alguna vez a ella, perderá sus costumbres, y muy pronto alterará sus leyes: lo uno sigue a lo otro); no se debe 
creer-repito-que, a pesar de este rigor, los embajadores extranjeros no tengan cierta relación ("liaison") con los magistrados; se habla por terceros; muchas cosas se dicen por signos en la Opera, circunstancia que obliga necesariamente a los embajadores extranjeros a llevar máscara y a frecuentar los espectáculos; y entre ellos y los venecianos se crean incluso amistades vivas y constantes $»(54)$.

A pesar de que el tono externo de su vida era banal y mundano, Mme. de Krüdener no olvidaba sus tendencias religiosas. El 2 de agosto de 1785 anotaba en su Journal: "J'eus le soir une conversation sérieuse avec mon mari au sujet de la Religion. Insensiblement, nous parlâmes du caractère. II me dit que j'avais une forte pente à l'enthousiasme, mais qu'avec tant de douceur que j'en avais, il n'y avait point de fanatisme à craindrew(55).

A Julia le costaba muy poco aceptar el comentario halagador de su marido, y pintar su carácter-o un aspecto de su carácter-con tonos favorecedores, pero ello no invalida el hecho de que el entusiasmo puede ocultar un fanatismo larvado, y aunque así no sea, el entusiasmo suele ser muy a menudo contagioso, y con esta clase de trémolo es como Mme. de Krüdener solía hablar y expresarse en público. Basta leer algunas páginas de su Geraldine, escritas entre diciembre de 1789 y enero de 1790, para ver los transportes «misticos" con que esta mujer iluminada y ardiente describia-ya entonces-no sólo su mesianismo (de hacer el bien a los hombres y unirlos por el amor), sino la seguridad que sentia de creerse especialmente elegida por Dios misericordioso, que se había dignado sembrar en su mente y en su corazón tan sublimes intenciones.

Pero esta llamada mistica de Mme. de Krüdener no ardía solamente con resplandores celestiales; además de lo que tenía de aura sentimental, tambièn despuntaba en sus manifestaciones la veta de una política misteriosa, pero reaccionaria "avant la lettre», entendiendo por tal entelequia una organización internacional regida por unos monarcas "religiosos", nutridos por las esencias más rancias del Antiguo Régimen, que fueran menos soberanos que hermanos de sus súbditos. En una palabra: la sublimación estática de la "res monarchica».

No es fácil saber con exactitud-dessunt acta-hasta dónde pudieron calar, y el influjo que pudieron ejercer sobre Casas las ideas político religiosas vertidas por el "entusiasmo" de Mme. de Krüdener en sus conversaciones-siempre en francés-con el embajador español en Venecia. Lo que sí conocemos muy bien es el comportamiento personal y la actitud política adoptada por Casas, tanto privada como diplomáticamente, a raíz del estallido de la Revolución Francesa. Su reacción ante tamaña convulsión fue a todas luces distinta de la que tuvieron los demás embajadores españoles acreditados entonces en las diferentes Cortes europeas. 
Porque Casas no sólo se pronunció como un antirrevolucionario radical, sino que se hizo realista a ultranza, y no contento con ayudar todo lo que pudo a los emigrados franceses, fugitivos de su patria, suministró abundante información a las potencias enemigas de la República Francesa, para lo cual no tuvo inconveniente en practicar el turbio papel de espía, y colaborar estrechamente con el conde d'Antraigues (1753-1812)(56), personaje de estampa aventurera (el conde d'Avaray, ángel negro de Luis XVIII, lo calificó de "fleur des drôles"), y cabeza de una extensa red de información, que acabaría sus días trágicamente, siendo apuñalado en Londres por un criado suyo que, según se dijo, estaba a sueldo del propio Luis XVIII.

Pase-e incluso es comprensible-que Casas mantuviera con este aventurero tal tipo de relaciones mientras ejercia el cargo político de embajador en Venecia(57), donde permaneció hasta 1795, año en que España dejo de ser enemiga de la República Francesa para hacerse su aliada por el tratado de Basilea (22 julio 1795), y Casas fue destinado a la embajada española de Londres; lo extraño y curioso es que este espionaje antirrevolucionario, del que Casas hizo una cuestion personal (y bien se quejaba de ello J. N. de Azara, embajador de España en Roma hasta 1798), lo siguio practicando privadamente-aunque siempre unido al espía d'Antraigues-cuando, concluida su corta legación en Inglaterra, volvió de nuevo a Venecia como persona particular y sin carácter diplomático alguno.

Pero volvamos de nuevo hacia atrás. Después de haber hecho un largo recorrido por la Península italiana, los Krüdener abandonaron Venecia y emprendieron el viaje hacia Copenhague en diciembre de 1786, pasando por Basilea y Frankfurt; de camino, Mme. de Krüdener-y el dato es altamente significativo-hizo un alto en Neuwied, para visitar alli a una comunidad de Hermanos Moravos(58), secta por la que Julia se sintio siempre muy atraida, como tendremos ocasión de verlo.

Tras dos años de riñas y reconciliaciones con su marido, en marzo de 1789 se consumó la ruptura del matrimonio Krüdener, y Julia, que se encontraba sentimental y físicamente agotada, abandono Copenhague con sus hijos y su hijastra Sofía, que siempre le sería fidelísima.

Después de pasar por París, donde vivió la jornada de la toma de la Bastilla y conoció a Bernardino de Saint-Pierre, celebrado autor de la romántica novela Paul et Virginie, del que quiso-en vano-hacer su confidente sentimental, Mme. de Krüdener (que jamás abandonaría el apellido de su marido) se instaló en Montpellier, y allí conoció a Adrián de LezayMarnesia (1770-1814). Este joven universitario, estudiante de botánica y traductor de Schiller en sus ratos de ocio, era cuñado del popularísimo P. C. de Beaumarchais, y tenia propiedades en la región del Jura. Las agitaciones campesinas le obligarian a emigrar de Francia, pero vuelto más 
tarde a su patria, fue nombrado en 1806 prefecto del Departamento de Mosela, y en 1812 del Bajo Rin. Allí se hizo muy amigo del pastor protestante Oberlin, famoso filántropo de Ban de la Roche, que propagaba las utopías del sueco Swedemborg, conocidas ya por Adrián a través de Mme. de Krüdener. Cuando el prefecto Lezay-Marnesia murió en octubre de 1814, Mme. de Krüdener se desplazó hasta Estrasburgo con el fin exclusivo de consolar a su viuda.

Pero este momento estaba todavía muy lejos. En agosto de 1789 , el joven Adrián se sentía enamoradísimo de Mme. de Krüdener, y parece ser que la baronesa, seis años mayor que él, le correspondía de una forma un tanto singular. Porque ha de saberse que Mme. de Krüdener, aparte de su marido con el que había contraido "un mariage de raison", tuvo a lo largo de su intensa vida varias clases de enamoramientos; unos, como el que sintió en 1791 por "su primer gran amor", Carlos Luis de Frégeville, o sobre todo el que tuvo por Claudio Hipólito Terray, que le hizo un hijo en 1798, fueron realmente tórridos; en cambio otros, como los que sintió por el mencionado Adrián Lezay, y por el diplomático napolitano Luis Laffredo, príncipe de Cardito (1758-1827), al que conoció durante su estancia en Copenhague, fueron más bien platónicos.

Mme. de Krüdener, que derramaba lágrimas religiosas en la iglesia de los Recoletos de Montpellier, y sus plegarias eran-como ella misma escribía el 2 de diciembre de 1789- "des transports de bonheur", encontraba en su piadoso recogimiento que «su pasión por Adrián no le espantaba como si fuera un crimen", antes muy al contrario, y ello era asi porque Julia confiaba siempre-son sus palabras- -en la Bondad Indulgente de Aquel que no castiga el mal no reconocido como tal".

Adrián tuvo que abandonar unos días Montpellier por asuntos familiares, y durante su corta ausencia Mme. de Krüdener le escribió en otoño de 1789 las siguientes palabras: "Mon ami, nous ne pouvons renoncer l'un à l'autre. L'Eternité entière ne peut limer la chaîne qui nous attache. Non, jamais l'amour n'a été conçu ainsi que par nous, jamais!. Ce concours de circonstances, et cette chaleur du bien qui était dans nos âmes, a pu se réunir à lui et lui donner un si énergique ressort».

Pero esta declaración amorosa no pasaba de platónica, y por serlo no era óbice para que unas líneas antes le dijera: "J'ai abjuré à jamais la plus légère coquetterie, la vanité et l'emploi frivole de bien de moments; chaque jour doit être marqué par un pas vers le bien, et j'espère alier toujours en augmentant. Je travaille, et sans relâche; mes enfants, mes entours les plus indigents, tous doivent se ressentir de mes progrès; votre vue même n'otera pas un seul moment à mes devoirs. C'est ainsi que vous me trouverez, attendez-vous de ma part à de la rigueur et à la plus sévère attention à ne jamais enlever un instant a vos occupations. Je vous permets un peu d'épicureisme, mais prenez-y garde, assez pour répandre du charme sur la 
vie, assez pour en désirer toujours, mais qu'il soit semblable à la fleur délicate dont on supporte l'odeur agréable, pas à celle qui enivre et qu'on jette loin de soi quand ses funestes et trop violents parfums ont entêtém(59).

Teniendo en cuenta la idiosincracia-un tanto especial-de Mme. de Krüdener, tampoco debe olvidarse que en aquellos momentos todavía estaba viviendo las secuelas del reciente fracaso de su vida matrimonial. Este ideal, en el cual había cifrado todas sus esperanzas de joven sensible y de esposa apasionada, se había venido abajo dejándole un sabor a ceniza. Pero al mismo tiempo se sentía la "amante ideal», que sin renegar de la esposa ideal, y haciendo un escudo defensivo de este contubernio de ideas y sentimientos, esclavizaba a su joven enamorado Adrián, negándole toda consumación física y prometiéndole tan sólo una hipotética sublimación espiritual a base de continencia y de ascesis. Tales eran los designios de Mme. de Krüdener sobre Adrián; ella lo habia dispuesto así, pero su «misión" cubría mal y disimulaba peor su propio egocentrismo, que se confirmaba ante los deseos que ella misma provocaba en el joven enamorado, todo lo cual no tenía otra salida que el fracaso.

Todavía el 19 de diciembre de 1789, la baronesa escribía a su paciente adorador: "Ne me demandez pas de vous répondre sur la question que vous me faites, ne me demandez pas ce que ferais si un jour j'étais dans le cas de disposer de ma main, ne me le demandez. Je vous en conjure. Non, décider d'une question pareille, c'est penser de sang-froid à un événement affreux, et jamais je n'y penserai de sang-froid. Si je le pouvais, dès cet instant, je renoncerais à vous à jamais, mais je n'y puis penser sans frémir, comme je ne puis penser à vous quitter»(60).

Como puede verse, la postura de Mme de Krüdener no dejaba lugar a dudas; era tan clara, y desvariada, como egoista: nada de casarse con Adrián, como éste había aventurado ingenuamente; sólo el pensarlo le hacia temblar de horror; pero tampoco renunciar a él por completo, para tenerlo de ese modo a su lado como un perrillo faldero, y poder disfrutarlo alimentándolo con golosinas platónicas.

Aconsejada por los médicos, Mme. de Krügener siguió las huellas de Boudon de Saint-Amans, haciendo un "viaje sentimental» a la estación termal de Barèges, en los Altos Pirineos, donde permanecio desde junio hasta septiembre de 1790 en compañía de Adrián, que durante sus paseos por los alrededores pudo ejercitar sus aficiones de herborista, mientras Mme. de Krüdener prefería quedarse en el poblado y seguir trenzando sus ubizarras ideas", que destruyeron por completo su no menos bizarra relación con el joven botánico, cada vez más reacio a convertirse en neófito de una catequesis tan utópica e irreal como insípida(61).

Rotas, pues, definitivamente sus relaciones en Barèges, Mme. de Krüdener volvió con sus hijos a Montpellier, donde se consolo muy pronto de 
este fracaso sentimental, pues antes de la primavera de 1791 se habia encontrado con el apuesto Carlos Luis de Frégeville, su "primer gran amor", cuyos hechizos transformaron como por arte de magia sus elevados deliquios místicos con unos ardores más a ras de tierra. "Qui fait l'ange, fait la bête!" es, como todos saben, una frase del perspicaz Blas Pascal.

A partir de entonces comenzó la vida giróvana de Mme. de Krüdener, a la que encontramos en Bruselas, Hamburgo, Koenigsberg (donde se separó de su amante Frégeville), Riga y San Petersburgo, a donde se dirigió para asistir a la muerte de su padre. En otoño de 1793 conoció en Leipzig al emigrado francés Claudio Hipolito Terray, cuyos padres habian sido guillotinados en Paris, y a las pocas semanas de relación con él estableció una especie de "matrimonio secreto», según comunicó ella misma a su madre. En 1795, Terray se instaló en Lausana; entonces, Mme. de Krüdener pidió el divorcio a su marido, sin impetrarlo, y comenzo a corresponderse epistolarmente con el príncipe de Cardito, diplomático napolitano al que escribía largas cartas sentimentales.

En 1797 se fue a las caldas de Aix-les-Bains, muy visitadas por los ingleses, y allí volvió a reunirse con Terray. Fueran o no prolificas las virtudes de aquellas aguas termales, el caso es que, en febrero de 1798, Mme. de Krüdener dio a luz un niño que fue bautizado con los mismos nombres que su padre Claudio Hipólito, y muy pronto sería llevado a Ginebra para ser confiado a los cuidados de una experta institutriz. Mme. de Krüdener vivió siempre separada de esta criatura a la que apenas prestó atención, pero ello no fue impedimento para que, a imitación del autor de Emile, que mandó a sus cinco hijos a la inclusa, también ella comenzara en 1779 la redacción de un tratado de educación titulado Elisa ou l'éducation d'une jeune fille; ni para que, aprovechando un viaje a Riga por cuestiones de herencia, se detuviera en Gnadenfrei, sede de una comunidad de Hermanos Moravos, cuya vida compartió durante algunas semanas.

El verano de 1800 se reunió en los baños de Teoplitz con su anciano marido, el barón de Krüdener, que había sido nombrado embajador de Rusia en Berlín, pero no espero a su muerte (que ocurriria en junio de 1802) para separarse nuevamente de él-esta vez de una forma definitiva-, y marcharse a París, donde empezó a codearse con Mme. de Staël, Benjamin Constant, Joubert y Chateaubriand, que acababa de publicar el Génie du christianisme(62).

Cuando Mme. de Staël fue expulsada de París por el cónsul Bonaparte, Mme. de Krüdener se fue a vivir a Lyon, desde donde siguió correspondiéndose con el príncipe de Cardito. En 1803 publicó en París Valérie, novela que alcanzó un gran éxito, pero sin tiempo para disfrutar de él, abandonó repentinamente la capital francesa para refugiarse en Koenigsberg, donde permaneció hasta 1807 sin apenas moverse de alli. Durante este largo retiro se adentró en las vias místicas, poniendo un irrevocable punto 
final a sus devaneos sentimentales (la baronesa tampoco era ya una niña, pues frisaba los 43 años de edad), y el invierno de 1807 marchó a Herrnhut, con su hija Julia, para pasar allí una temporada con los Hermanos Moravos.

Durante los años siguientes, Mme. de Krüdener entraría en contacto con miembros de otras sectas, y conocería al filantrópico pastor Oberlin (relacionado, como dijimos, con Adrián de Lezay-Marnesia), que le ayudó a formar una misión-asi llamaba la baronesa a su "capilla"-, cuyos miembros se establecieron en un pueblecito cerca de Stuttgart; pero a los tres meses de permanencia allí el rey Federico I de Wurtemberg les ordenó salir de sus dominios por considerarlos peligrosos y perturbadores de la paz. Mme. de Krüdener se sometio, y a continuación marchó a Baden, donde entró en relación con la reina Hortensia de Beauharnais, esposa de Luis Bonaparte, pero tuvo que marcharse precipitadamente a Riga, para asistir a su madre que murió en enero de 1811, dejando a su hija una herencia nada despreciable. A su regreso se detuvo un tiempo con los Hermanos Moravos de Gottesberg (Silesia), y después de pasar por Dresde, Weimar y Carlsruhe, se reunió en Ban de la Roche con su venerado pastor Oberlin.

Los años 1812 y 1813 fueron para Mme. de Krüdener un tiempo de contínuas idas y venidas para instalar una "colonia cristiana" en las cercanías de Heidelberg(63). En uno de estos viajes entró en contacto con la zarina Isabel, y a través de ella con el zar Alejandro I, trece años más joven que Mme. de Krüdener, la cual tuvo entonces con el monarca ruso varias entrevistas, que a veces duraban horas y horas (llegando a producir celos en la zarina), y en julio de 1815 lo siguió a París, donde el 23 de septiembre el zar Alejandro I presentó a sus "hermanos», el rey de Prusia y el emperador de Austria, el texto de la Santa Alianza, que se firmo el 26 del mismo mes. Esta jornada marco el zénit de Mme. de Krüdener, no menos que el comienzo de su ocaso.

A continuación, Mme. de Krüdener pasó nuevamente a Baden, cuya municipalidad (ya no estaba allí su amiga Hortensia de Beauharnais) le prohibió reunir asambleas y predicar "la buena palabra". A lo largo de 1817 comenzo a sentirse perseguida, y no encontrando refugio seguro en ninguna parte pidio al zar Alejandro I permiso para establecerse en Rusia con sus adeptos, pero al llegar a la frontera la policía rusa la admitió a ella, prohibiendo la entrada a los demás acompañantes. Separada de éstos, Mme. de Krüdener se retiró a Mittau, y desde alli escribió al príncipe Galitzin, ministro ruso de cultos, una larga carta en la que explicaba cuál era el sentido de su "misión", y cómo debía interpretarse el texto de la Santa Alianza. Este paso le deparó una nueva entrevista con el zar, que tuvo lugar en septiembre de 1819, pero la baronesa no obtuvo nada que concerniera favorablemente a su "capilla". Al año siguiente escribio un tratado Sur l'éducation des princes, que dedicó a Alejandro I, al tiempo que le instaba 
a ayudar a los griegos, en lucha contra los turcos para alcanzar la independencia de su país; pero el zar no le prestó oidos, aunque en septiembre de 1821 le concedió una última entrevista, que fue secreta.

En mayo de 1822, Mme. de Krüdener recibió la orden de abandonar San Petersburgo, y en agosto de ese mismo año se promulgó un "úkase» por el que se prohibia en Rusia la existencia de todas las sectas y sociedades secretas, fueran religiosas o no. Mme. de Krüdener hizo todo lo posible para prolongar su estancia en la ciudad del Neva, a fin de ver nuevamente al zar, quien después de muchas vacilaciones no se atrevió a recibirla, porque temía al clero ruso y a la policia, hostiles a las ideas de esta mujer, cuyo ascendiente sobre Alejandro I temian.

En mayo de 1824, Mme. de Krüdener, su hija Julia y el marido de ésta, Francisco de Berckheim, se embarcaron en San Petersburgo con la intención de establecerse en Crimea, para fundar alli una "colonia cristiana". Durante la travesía, que no fue nada fácil, Mme. de Krüdener se sintió desfallecer, de suerte que a poco de llegar a Korasoubazar, su último asilo terrenal, se sintio gravemente enferma, y el 13 de diciembre de 1824 , a los 60 años de edad, y rodeada de un puñado de adeptos, entregó su alma al Dios de la Indulgencia.

\section{NOTAS:}

(1) Estas páginas constituyen la parte final de una comunicación titulada: Viajeros españoles del siglo XVIII en los balnearios del Alto Pirineo francés, que el autor presentó en el "Coloquio de Paun (26-30 de mayo de 1981).

(2) L. FERNANDEZ DE MORATIN, Obras póstumas (2 vols.). Madrid, Rivadeneira (1867-68) t. I, pp. 293-94. «Día 23 de agosto de 1793. Las sillas de posta de Ostende a Suiza son de lo más indecente $e$ incomodo que puede imaginarse, muy semejantes a nuestras calesas: regularmente son de cuatro ruedas; viejas, sucias, desabrigadas, llenas de remiendos y apósitos(...); los postillones, del todo execrables: lerdos, sordos, embusteros, estafadores a no poder más".

(3) Ibidem, t. I. p. 317. «Dia 18 de septiembre de 1793. Pasé de Fiorenzuola(...). Iba leyendo en mi carricoche, bien ajeno de toda desgracia; me ocurre mirar por la ventanilla de la trasera, y me encuentro sin cofre: pié a tierra; desata el postillón uno de los caballos, corre más de media legua, y vuelve con la plausible noticia de que el cofre no aparece, esto es, que he perdido, además de mi ropa, mis apuntaciones diarias de trece años a esta parte, las cuentas de mis intereses en España, las recomendaciones para los Embajadores, las observaciones hechas en mis viajes por Francia, Inglaterra, Flandes, Alemania (...), el trabajo de todo un año, obras manuscri. tas y qué sé yo qué más: si esto es bastante para hacer desesperar a cualquiera, nadie extrañará la desesperación en que me vi».

(4) A. MOUSSET, Un témoin ignoré de la Révolution: le comte Fernán-Núñez, ambassadeur d'Espagne à Paris (1787-1791). París, E. Champion, 1924.

(5) Fernán-Núñez a Floridablanca. Bayona, 14 de septiembre 1787. AHN (Archivo Histórico Nacional, Madrid), Estado, leg. ${ }^{\circ}$ 4.640; B. d'OBERKIRCH, Mémoires. París, Mercure de France (1.979), p. 143. "Le 15 (de mayo de 1782) nous couchåmes à Dormans (...). Depuis Saint-Dizier, il pleuvait sans cesse, et les chemins étaient abominables. J'avais les cótes brisés de cahots, bien que notre voiture fût excellente». 
(6) FERNANDEZ DE MORATIN, o. c. t. I., pp. 521-22.

(7) Ibidem, pp. 538-40.

(8) A. de TILLY, Mémoires. París, Mercure de France (1965) p. 345.

(9) OBERKIRCH, o. c. pp. 230-31. "Cette Basse-Bretagne-escribía la baronesa el 29 de junio de 1782-est un pays affreux (...). On trouve de tout à manger dans ce pays, mais c'est si mal apprêté, tout y est si sale, qu'on mange point $n$; L. S. MERCIER, Le tableau de Paris. Paris, Maspero (1979) pp. 183-85. De lo caro y mal que se comia, de 1781 a 1788, en los restaurantes populares de Paris.

(10) FERNANDEZ DE MORATIN, o. c. t. I, pp. 538-40.

(11) R. OLAECHEA, José $/ /$ y J. N. de Azara. Los dos viajes del emperador austriaco a Roma. En «Miscelánea Comillas», t. 45 (Comillas, 1964) pp. 1-81.

(12) OBERKIRCH, o. c. p. 94. «Je parle ici de l'empereur Joseph II pour la première fois-escribia la baronesa en 1777-, et nous le retrouverons encore plus loin (...). Ses habitudes et sa vie ne se ressemblaient à celles de personne. Il couchait sur une paillasse recouverte d'une peau de cerf".

(13) . A. d'AVENEL, Les moyens de transport depuis sept siècles. En "Revue des Deux Mondes", t. II (Paris, 1913) p. 827.

(14) MERCIER, o. c. pp. 39-40, 263.

(15) N. ElIAS, La civilisation des moeurs. Paris, Calman-Lévy (1972) p. 221; Mme. de KRUEDENER, Lettres de voyage de Lyon à Paris (1803). Apud R. DERRÉ, Ecrits intimes et prophétiques de Mme. de Krüdener (1785-1807). París, CNRS (1975). «Lady B., après s'être placée ce matin comme de coutume à cóté de moi dans la berline, a rejeté sa tête en arrière, car elle aime à se tenir droite et cela lui réussit malgré les cahots de la voiture; puis, elle a tiré son mouchoir, l'a déployé lentement, a pris du tabac (rapé), et ensuite a craché hors de la portière avec le plus grand sang-froid du monde. Or, il faut vous dire que dans ce moment nous passions sur un pont, que sur ce pont passait un passant, et que Milady, comme si elle l'avait fait exprès, lui a craché droit sur le nez".

(16) MERCIER, o. c. pp.80-81, 214. La sensible Mme. de Necker vio que en una sala del hospital parisino de Bicêtre, que apestaba, se amontonaban en un mismo lecho seis miserables enfermos, embadurnados de sus propios excrementos. Ante tal espectáculo, "Mme. Necker puso en juego todo el crédito de que gozaba para hacer construir lechos en los que no se acostaran más de dos personas". Lo mismo ocurría en el hospital "Hótel-Dieu" de París.

(17) R. FOULCHE-DELBOSC, Bibliographie des voyages en Espagne et Portugal. (Paris, 1896); A. FARINELLI, Viajes por España y Portugal (3 vols.). Roma-Florencia, 1942-44; J. GARCIA MERCADAL, Viajes de extranjeros por España y Portugal (3 vols.) Madrid, Aguilar, 1962. El tomo III corresponde al siglo XVIII. En enero de 1745 aparecieron "Chez F. Didot" los dos primeros volúmenes de la Histoire générale des voyages, del abate Prévost, a los que seguirian trece más; el último volumen se publico en 1759.

(18) OBERKIRCH, o. c., p. 333.

(19) TILLY, o. c., p. 329.

(20) L. STERNE, A sentimental journey through France and Italy. Londres, Penguin Books (1967) pp. 34-35.

(21) M. PEZAl, Observations générales sur les voyages (4 vols.). París (1783) t. IV, p. 5.

(22) J. J. ROUSSEAU, Oeuvres Complètes (3 vols.). París, Ed. Seuil (1971) t. III, p. 308; J. CADALSO, Los eruditos a la violeta. Madrid, Aguilar, Crisol, Ed. de J. L. Aguirre (1951), pp. 115 ss. Instrucciones dadas por un padre anciano a su hijo que va a emprender sus viajes. 209.

(23) F. ALVAREZ REQUEJO, El conde de Campomanes. Su obra histórica. Oviedo (1954) p.

(24) Ibidem, p. 25, n. $^{\circ} 47$ y 48.

(25) FLORIDABLANCA, Obras originales. Madrid, BAE (1912) t. 59, pp. 282, 295 y 330; R. OLAECHEA, El reino de Navarra en el siglo XVIII. Pamplona (1980) pp. 15, 16, 68-70. 
(26) Una legua equivalia a unos $5 \mathrm{kms}$.

(27) FLORIDABLANCA, o. c., pp. 297, 300-301.

(28) J. PUENTE, La visión de la realidad española en los viajes de don Antonio Ponz. Madrid, Moneda y Crédito, 1968.

81.

(29) G. GOMEZ DE LA SERNA, Los viajeros de la llustracion. Madrid, Alianza (1974) pp. 72 -

(30) J. SARRAILH, Voyageurs français au XVIII siècle: de l'abbé de Vayrac à l'abbé Delaporte. En "Bull. Hispanique», t. 36, Burdeos, 1934.

(31) J. SARRAILH, La España ilustrada de la segunda mitad del siglo XVIII. México, FCE (1957) pp. 290-338, 339-374.

(32) Véase la nota $n .{ }^{\circ}$, en la que se indica que la comunicación sólo se refiere a uviajeros españoles", con la excepción de la rusa Mme. de Krüdener, por la relación que tuvo esta viajera con el embajador de España en Venecia, don Simón de las Casas.

(33) J. A. FERRER BENIMELI, El conde de Aranda y su defensa de España. Refutación del "Viaje de Fígaro a España". Madrid-Zaragoza, 1972; Mémoires d'une femme de qualité sur le consulat et l'empire. Paris, Mercure de France (1966) pp. 342-43.

(34) A. LABORDE, Itinéraire descriptif de l'Espagne (6 vols.). Paris (1834) t. I, pp. 207 y 169; J. J. ROUSSEAU, o. c., t. III, pp. 281-82, 306-7.

(35) R. OLAECHEA, Las relaciones hispano-romanas en la segunda mitad del siglo XVIII (2 vols.). Zaragoza (1965) t. I, pp. 297-336.

(36) J. VIERA CLAVIJO, Viajes a Francia, Flandes, Italia y Alemania por los años de 1777 a 1781. Santa Cruz de Tenerife, 1849.

(37) SARRAILH, La España... o. c., pp. 353-54.

(38) M. VILLAURRUTIA, Fernán Núñez, el embajador. Madrid (1931) p. 13.

(39) MERCIER, o. c. pp. 278-80.

(40) OBERKIRCH, o. c. p. 334; P. HAZARD, El pensamiento europeo en el siglo XVIII. Madrid, Guadarrama (1958) pp. 137, 320-23, 359.

(41) OBERKIRCH, o. c. p. 495. La baronesa escribia en 1789: "La fin de ce siècle si incrédule est marquée de ce caractère incroyable d'amour du merveilleux, je dirais de superstition, si je n'en étais moi-mẻme imbue, quoique malgré moi, ce qui dénote, assure-t-on, une société en décadence. II est certain que jamais les rose-croix, les adeptes, les prophètes et tout ce qui s'y rapporte, ne furent aussi nombreux, aussi écoutés. La conversation roule presque uniquement sur ces metières; elles occupent toutes les têtes; elles frappent toutes les imaginations, même les plus sérieses...n; MERCIER, o. c., pp. 259, 268-69. Señala que a mediados del siglo toda dama de "cualidad" tenía su "geómetra"; y hablando del culto al maravillosismo que daban los parisinos, añadía: "On ne dipute plus nulle part sur la religion. C'est un vieux procès définitivement jugé".

(42) En 1798, Mme. de Krüdener visitaría en Zurich al fisiognomista e inventor J. G. Lavater $(1741-1801)$.

(43) M. DEFOURNEAUX, Pablo de Olavide ou l'Afrancesado (1725-1803). París, PUF (1959) pp. 408-9; OBERKIRCH, O. c. p. 333.

(44) M. Swedemborg (1688-1772), hijo natural de la reina Ulrica de Suecia, fundó una secta ecumenista, pero sus adeptos formaron la llamada iglesia de Jerusalén; OBERKIRCH, o. c. p. 490 .

(45) El barón de Krüdener no fue embajador en Berlín hasta el año 1800.

(46) En septiembre de 1808, Mme. de Krüdener se relacionaría en Ginebra con los pastores Cellérier y Mouliné, y con algunos miembros de la secta de las "Almas Interiores", que habia sido fundada por el caballero Dutoit-Membrini, discípulo de Mme. Guyon y autor de La philosophie divine, obra de espiritualidad aparecida en 1793. Véase F. MALLET-JORIS, Jeanne Guyon. París, Flammarion, 1978. Fuera de algún mínimo aspecto puramente anecdótico, no hay posibilidad de comparación entre Mme. de Krüdener y Mme. Guyon. 
(47) OBERKIRCH, o. c. p. 490 . Este texto parece haber sido reelaborado por los editores que publicaron estas Memorias muchos años después de muerta la baronesa d'Oberkirch.

(48) F. LEY, Mme. de Krüdener et son temps. Paris, PIon, 1961. En julio de 1787 daria a luz a su hija Julia; el barón tenía a su vez una hija, Sofía, de un matrimonio anterior.

(49) Cardl. de BERNIS, Memoires. Paris, Mercure de France (1980) pp. 116-17.

(50) Kaunitz-Quetemberg a Kaunitz. Madrid, 28 abril 1.780. Apud Berichte der diplomatischen Vertreter des weiner Hofes aus Spanien in der Regierungszeit Karls III. Madrid, C.S.I.C. (1979, t. VIII, p. 33; Kaunitz-Rietberg a Kaunitz. S. Ildefonso, 27 de agosto 1781. Ibidem, t. VIII, p. 303. Se revoca el destino de Simón de las Casas a Toscana, para enviarlo a Berlín, gracias a las influyentes gestiones del general O'Reilly y de don Simón de Aragorri, marqués de Iranda, rico comerciante, tío de Casas.

(51) Campos a Aranda. Venecia, 20 de mayo 1786. AHN, Estado, leg. ${ }^{\circ} 2.847$.

(52) Casas a Floridablanca. Parma, 2 septiembre 1786. AGS (Archivo General de Simancas), Estado, leg. ${ }^{\circ} 5.795$. Esta costumbre hacía que, en general, los miembros del cuerpo diplomático extranjero trataran con frecuencia entre si.

(53) Ch. EYNARD, Vie de Mme. de Krüdener (2 vols.). Paris,. Cherbuliez (1849) t. 1, p. 15.

(54) BERNIS, o. c., pp. 124-25. En su despacho del 21 de agosto de 1754, escribía Bernis desde Venecia: "J'entretiens un commerce sécret avec les principales familles de la noblesse; mais la plus importante de mes liaisons est avec $\mathrm{M}$. le procurateur Emmo, le premier homme de cette République, malgré son grand âge...".

(55) DERRÉ, o. c., p. 63. El subrayado es mío.

(56) L. PINGAUD, Un agent secret sous la Révolution et l'Empire: le comte d'Antraigues. París, Plon, 1894; J. GODECHOT, La contre-révolution, 1789-1804. Paris, PUF (1.961) pp. 186-215; Duc de CASTRIES, La vie quotidienne des émigrés. París, Hachette (1966) pp. 216-21.

(57) J. CHAUMIE, Les rélations diplomatiques entre l'Espagne et la France: de Varennes à la morte de Louis XVI. Burdeos (1957) pp. 34-35; IDEM. La corréspondance de Las Casas et du marquis de Bombelles, ambassadeurs de France et d'Espagne à Venise sous la Révolution. Paris, Pedone, 1952.

(58) Secta protestante husita surgida en Bohemis tras la muerte de Juan Huss (1415). Sus miembros admiten los artículos de la fe, si bien dentro de una total libertad de conciencia por parte del creyente. Esta secta se extendió por el centro de Europa, llegando hasta América del Norte.

(59) DERRÉ, o. c., pp. 112 y 110-11.

(60) Ibidem, p. 126.

(61) BOUDON DE SAINT-AMANS, Fragmen(t)s d'un voyage sentimental et pittoresque dans les Pyrénées. Metz, 1789. Este episodio de uplatonismo sentimental» trae a la memoria (por sus semejanzas) el romance platónico vivido el verano de 1825, en Cauterets, por Jorge Sand (1804-76) con el joven bordelés Aureliano de Sèze. Véase A. MAUROIS, Lélia ou la vie de George Sand. Paris, Marabout-Hachette (1952) pp. 79-87.

(62) F. LEY, Bernardin Saint-Pierre, Mme. de Staël, Chateaubriand, Benjamin Constant et Mme. de Krüdener. Paris, 1967.

(63) Mémoires d'une femme de qualité... o. c., pp. 362 y 382 . Relaciones de Mme. de Krüdener con la reina Luisa de Prusia, y el ministro prusiano Hauwigts, que era un «iluminadon. 


\title{
CONTINUIDAD Y RUPTURA EN LA RENOVACION CIENTIFICA VALENCIANA
}

\author{
Por Emilio BALAGUER PERIGÜELL
}

Universidad de Alicante

La renovación científica no fue, en absoluto, un factor aislado de aquellos otros que determinaron el cambio de la sociedad valenciana en las últimas décadas del siglo XVII. En realidad, fue un factor más de transformación y consecuencia al mismo tiempo, de los avatares de la sociedad en esos momentos:(1).

A partir de 1680 encontramos signos de recuperación económica en la periferia peninsular, y aunque los beneficiosos efectos se manifiesten también en Castilla, donde la deflación del mismo año y los subsiguientes ensayos de colbertismo del ministro Oropesa, actuaron como medida dominadora del caos; sin embargo, la autonomia monetaria de la Corona de Aragón salvó a estos de las fluctuaciones inflacionistas-deflacionistas que sufrieron los otros reinos. Por otra parte, desde la demografia, se observan signos incuestionables de recuperación, y el centripetismo del siglo XVI cedió el paso a una situación cada vez más favorable a la periferia. En la ciudad de Valencia los rasgos característicos de esta recuperación económica vendrán dados fundamentalmente por la introducción de nuevas manufacturas textiles y una coherente politica de impulso comercial(2).

Junto a este proceso de transformación de las estructuras económicas y sociales en el País Valenciano, tendrá lugar un proceso de renovación cultural, renovación llevada a cabo por núcleos de personas de carácter pre-ilustrado procedentes de los distintos estamentos sociales que tenian acceso a la cultura: la nobleza, el clero y la burguesia. 
La nobleza desempeñó un importante papel de mecenazgo en esta renovación, gracias al mejoramiento de su situación económica debido en parte a las fuertes exacciones señoriales. Dicho papel se concretó en el apoyo prestado a la creación de tertulias, en un principio de carácter literario y más tarde científico, aunque en estas últimas se debilitara el papel de la nobleza. $Y$ es en estas tertulias donde se situó el centro de la actividad de los «novatores". La Universidad (como señala García Martínez), "en estat de postració com a resultat final de la trajectoria del barroc", no modificó sensiblemente su carácter tradicionalista y conservador(3). Los catedráticos no abandonarán fácilmente los privilegios que el "saber» enraizado en la tradición escolástica confiere, y los "novatores" tratarán de constituir academias adoptando como modelo las sociedades científicas europeas: "Académie des Sciences" de Paris, "Accademia del Cimento» de Flo. rencia, "Royal Society" de Londres, etc.; por las que los científicos valen. cianos no ocultaban su admiración(4).

A pesar de ello, la Facultad de Medicina recoge en los últimos lustros de la centuria el $77 \%$ del total de las Facultades Mayores, lo que en último caso no sólo es un exponente del mayor interés social por la medicina, sino también del digno nivel mantenido en la enseñanza en comparación a otras universidades españolas.

Pero además, contrastando con la gran resistencia con que se encontraron los introductores de las novedades en el campo de la física o la astronomía, en el terreno ideológico, el tradicionalismo médico y biológico carecía de una coacción social que explícitamente lo defendiera. Aunque en último caso, «impugnar a Galileo en Medicina (afirma Vicente Peset) era impugnar a Aristóteles en Filosofia natural y, por tanto, poner en crisis todo el conglomerado científico-filosófico y aun religioso, en que vivía el paísw(5). Si esta interrelación no fue un sentimiento social generalizado, como en el caso de la astronomía en la que pesaba una prohibición expresa del Santo Oficio (1616 y 1633), no cabe ninguna duda que los galenistas más inteligentes supieron darse cuenta del peligro que suponía para el sistema las nuevas doctrinas. Buen ejemplo de ello fue la evolución del catedrático de anatomía Matías García (+1691), frente a la obra de Harvey (1578-1657). Durante muchos años encontró aceptable la doctrina de la circulación mayor, más tarde, sin embargo, llegó al convencimiento del «inmenso daño" que tal descubrimiento podría significar para los dogmas galenistas, peligro que comparó a un "veneno casi contagioso" que llegaría a "pervertir muchos preceptos médicos verdaderos»(6). En consecuencia, consagró su vida a la impugnación de Harvey y los seguidores de las teorías biológicas modernas. Resulta conmovedor ver a un hombre de tal capacidad (dice López Piñero), que confiesa el trabajo, los malos ratos y hasta el dinero que le costó su empresa, instalado en un camino tan a contracorriente de la evolución de la medicina de su tiempo(7). 
No deja de tener interés que el proceso de renovación de las ciencias médicas y biológicas en el País Valenciano, posean características similares a la forma en que se desarrolló en Italia. Aquí como en Italia, fueron fundamentalmente matemáticos los que se replantean una nueva metodologia para el estudio del movimiento animal. Esto nos hace pensar, en principio, en unas fuentes de información muy típicas del país. Marco Cuellar ya hizo notar la influencia de los jesuitas en la obra del Padre Tos$\mathrm{ca}^{(8)}$, y Navarro Brotons ha podido detectar la misma influencia en la Aritmética del matemático Juan Bautista Corachán(9). Pero no debemos olvidar la pertenencia de Nápoles y Sicilia a la monarquia española y las relaciones históricas de estos territorios con la corona de Aragón. Es muy significativo, que mientras los protagonistas de la renovación médica y biológica en Valencia, están muy bien informados de las novedades italianas, posean un pobre conocimiento de lo llevado a cabo en este mismo terreno en otras partes de Europa. Será necesario llegar a la llustración para que se modifique esta tendencia.

Desde la disolución de la "Accademia del Cimento" (1667) e incluso antes, que un grupo de discipulos de Galileo desarrollaron sus actividades en Nápoles y Messina. Leonardo di Capo y los promotores de la "Accademia degli investiganti" en Nápoles, intentan aplicar nuevos métodos en la investigación biológica. En Messina, un catedrático de matemáticas de origen español, G. A. Borelli (1608-1679), se interesa por estudiar las fiebres malignas con el nuevo "método matemático". Lo significativo de todo esto es que fueran estos nuevos planteamientos de la biologia italiana los que recogieron nuestros autores en el ambiente valenciano de la renovación.

Parece una contradicción que existiendo en España una larga tradición alquimista, las ideas iatroquimicas no hicieran mella en los científicos valencianos(10), pero como recientemente ha estudiado López Piñero, los alquimistas hispanos, incluyendo el grupo de "destiladores de su Majestad" que durante el reinado de Felipe II llevó una gran actividad en el Escorial, nunca llegaron a penetrar en la cultura académica(11). Todos ellos, hasta que Giambattista Giovanini (Juan Bautista Juanini (1636-1691) para los autores españoles) introdujo las doctrinas del holandés Silvio (1614-1716) y de Willis (1622-1675), Mayow (1645-1679) y Vieussens (16411716)(12); pertenecieron a una subcultura científica influidos por el también poco académico Paracelso (1493-1541), cuyos textos, de hecho, no fueron muy depurados por la Inquisición(13). Pero a partir de la publicación de la Carta filosófica, médico-chymica (1687) de Cabriada, las modernas doctrinas iatroquímicas gozan del favor de los «novatores". A pesar de ello, los introductores de la biología iatromecánica(14), fundamentalmente Tosca y Corachán, no prestan gran atención a los aspectos químicos y el hecho de que sea Bayle (1647-1706) uno de sus fundamentos habla en favor de un eclecticismo muy precavido en relación a la química. 
No vamos a desarrollar en este lugar una exposición sistemática de las ideas biológicas de Juan Bautista Corachan (1611-1741) y de Tomás Vicente Tosca (1651-1723). Pero podemos afirmar sin duda su vinculación ideológica con los miembros de la "Accademia del Cimento", fundamentalmente con uno de los máximos representantes de la investigación biológica en aquella institución: Borelli(15). Es muy significativo que éste, como nuestros valencianos, fuera matemático de profesión y que tanto unos como otro más partidarios del mecanismo físico de Boyle y el atomismo de Gassendi, que de la filosofía cartesiana.

Tosca y Corachán, son los responsables de la introducción de la fisiología iatromecánica en nuestro ambiente. El primero en su Compendium Philosophicum (1721), estudia el "movimiento animal» recurriendo a las clásicas exposiciones de Borelli sobre el sistema quinético, hasta tal punto, que algunas de sus proposiciones son una copia literal(16). Corachán, por su parte, sigue en la exégesis IV de su Mathesis Sacra, redactada en 1725 y publicada por Gregorio Mayans en 1757; los mismos estudios de Borelli sobre tema biológico. Sin embargo, no podemos pensar ante los hechos, que la mentalidad moderna de nuestros pre-ilustrados fuera la misma que informo a los científicos europeos. Es curiosa la resistencia de nuestros hombres en la aceptación de un hecho demostrado suficientemente por Borelli y que desmontaba totalmente la doctrina aristotélica de que el corazón poseía un calor innato que transformaba la sangre en un humor adecuado para cumplir sus funciones. Borelli se limitó a medir con el termómetro de Torricelli el calor del corazón demostrando así su uniformidad térmica con el resto del cuerpo. Tosca, que ya hace equilibrios dudosos con las doctrinas copernicanas, acepta la exposición de Harvey sobre la circulación mayor de la sangre, piedra angular de la dialéctica entre "novatores" y galenistas(17); en el mismo lugar recoge en parte los estudios de Borelli sobre el movimiento del corazón, sin embargo, cuando se refiere al calor innato sólo afirma lo siguiente: "la sangre, que circula por las arterias, es el vehículo del calor innatow(18). ¿Es falta de información o miedo a destronar el corazón, núcleo fundamental de la biología aristotélica?.

En el caso de Tosca podríamos pensar que lo que deseaba era evitar nuevos enfrentamientos, sin embargo, la aceptación del mismo hecho por parte de Corachan fue en privado, lo que tiene mayor significacion. En su manuscrito Notationes misce/laneas, fechado en 1685, acepta en la centuria VIII, totalmente, la doctrina del calor innato y la finalidad de ese manuscrito no era su publicación(19). En definitiva, el peso de la inercia en muchos casos o el temor a socavar demasiado un cuerpo filosófico, en otros, es todavía un factor importante en nuestros científicos modernos.

Un aspecto muy interesante y particularmente vinculado con el tema que estamos tratando, fue el interés de estos hombres por introducir las matemáticas en la enseñanza médica. En la Facultad de Medicina de 
Valencia existía ya una Cátedra de Astrología y el mismo Padre Tosca demostró cierto interés cuando presionó para que la ocupara Francisco Lloret $(+1736)$ quien la regentó hasta $1714(20)$. Sin embargo no era la astrologia el tipo de disciplina más adecuado para la idea que tenian los novatores del papel de las matemáticas en medicina. La astrologia era de hecho un fósil del pasado, "adivinar", dice con razón Corachan en sus Apuntamientos para las Constituciones que se han de hacer en la insigne Universidad de Valencia en lo tocante a las Mathemáticas(21). La idea de la necesidad de las matemáticas para comprender las modernas orientaciones médicas, es algo que no dudaba en defender Corachan siempre que tuvo oportunidad. En otra ocasión afirmaba que "la medicina tiene aún más necesidad de la mathemática, no sólo por la philosophia Natural que es su fundamento, sino también por la anatomía y otras cosas médicas que ahora explican los modernos por principios mathemáticoss(22).

Con todo esto, Tosca y Corachán consiguen crear un ambiente propicio para que en la medicina valenciana se desarrollen las doctrinas iatromecánicas. Sin embargo, este fenómeno se dio a niveles personales, en absoluto repercutió en la Universidad hasta 1786, cuando habia pasado casi medio siglo(23). Los continuadores de aquellos matemáticos, siguen insistiendo en la necesidad de la enseñanza de la disciplina en los estudios médicos. Bordazar (1671-1744), afirma, como antes Corcharán, que pocos "progresos podrá hacerse en cualquiera de los sistemas que se propone-en medicina-, sin el conocimiento de la mecánica y de la hidrostática, de la hidráulica y de su combinación para los movimientosw(24). La necesidad de las matemáticas para el médico, acabará trascendiendo los límites de las propuestas y proyectos para transformarse en una polémica pública(25). En realidad, lo que se debatia era la necesidad de renovación y como antes, los cómodamente instalados en sus saberes, se negaron a reconocer las nuevas corrientes.

Ciertamente que las cosas habian cambiado en algún sentido. En plena juventud, publico Andrés Piquer (1711-1772), el que sería uno de los médicos más representativos de la llustración, su Medicina vetus et nova (1735), proclamándose seguidor de las doctrinas mecánicas, "ya que el cuerpo humano está constituido tanto por máquinas sólidas como líquidas»(26). El problema de Piquer como el de cualquier partidario de la iatromecánica, era el hacerse entender en un ambiente en el que la física y las matemáticas no habian experimentado un cambio adecuado. Precisamente por ello, publicó en 1745 La Fisica moderna racional y

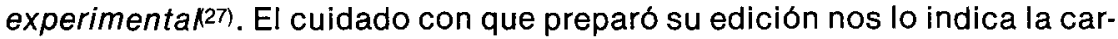
ta que el 23 de enero de 1744 le dirigió a Gregorio Myans: "el haber quedado Vm. algo satisfecho de mi Phisica, es una de las razones que más inclinan a continuar un trabajo que me enflaquece la cabeza...,228).

La receptividad del ambiente valenciano no fue, sin embargo, tan pro- 
picio como cabia esperar después del gran esfuerzo desarrollado por los "novatores". Bordazar ya fracasó en sus intentos de crear una "Academia de Matemáticas" y Mayans no pudo conseguir que la creada por él, a la que estuvo muy vinculado Piquer, perdurara mucho tiempo. La vieja controversia entre antiguos y modernos ya no estaba planteada en los mismos terrenos, pero no hay que olvidar que la controversia ciencia-religión, más concretamente entre ciencia-teologia oficial, no se habia resuelto. Ciertamente que la mentalidad de los modernos perteneciente al estamento eclesiástico como Tosca, era muy distinta a la de los filósofos oficiales, pero en último caso eran estos últimos los que podian presionar en supuesto caso de peligrosidad. Buen ejemplo de lo que venimos diciendo es el tono de las dos aprobaciones que prologan la Física de Piquer. José $\mathrm{Ne}$ bot y Sanz, abogado de los Reales Consejos, acepta totalmente el libro de Piquer porque "descubrimos las causas y el modo de obrar de los seres, lo que no sucede asi en la Física de las Escuelas llamadas Aristotélicas, que no es más que una metafísica como decia (después del célebre crítico valenciano) aquel gran filósofo y matemático honor de nuestra Patria el Padre Dr. Thomas Vicente Tosca, a quien oi muchas veces en el tiempo que fui su discipulo, que le era muy fácil enseñarla a cualquiera en media hora, como se acordase de los nombres qualidades, entidades, cocreto, formas, agentes, atracciones, y otros semejantes para que preguntándole ¿porqué una cosa era blanca? respondiese, porque tiene una cualidad de esta especie»(29).

En contraste con esta actitud, está la aprobación del catedrático de Filosofía José Climent. Desde luego que, Climent, acepta la necesidad de experiencias para conseguir evidencias; incluso defiende que la novedad "sólo por ser novedad, no debe reprobarse, porque hemos de decir que los antiguos no tuvieron la facultad privativa de descubrir las verdades naturales y la autoridad de fijar una época después de la cual se hicieron imposible los descubrimientos»(30). A pesar de estas concesiones, más obligadas por el ambiente que voluntariamente admitidas, Climent, no pudo ocultar su pertenencia a los grupos tradicionalistas. Mientras que Nebot tilda a la filosofía aristotélica de propia "para disputar en los espacios imaginarios pues se fragua en la fantasías(31). Climent, celebra el hecho de que $\mathrm{Pi}$ quer haya «sabido librarse del escollo de los dicterios contra los Antiguos, en que comunmente fracasan los Físicos Modernos. Con qué desprecio tratan a la persona, y escritos de Aristóteles!. Nada más, que imitar a Lutero, fiero enemigo de aquel gran Filosofo y de sus Discípulos; los cuales podrán gloriarse de que lo fuese, como se gloriaron los cristianos por boca de Tertuliano, de que Nerón les hubiese perseguido, diciendo, que no podía dejar de ser bueno lo que un hombre tan malo habia aborrecido»(32). La comparación entre Lutero y antiaristotelismo, hecha además por un hombre que dice aceptar la ciencia moderna, nos indica hasta que punto aristotelismo y religión caminan todavía juntos. Tosca, tenía muy claro 
que una de las batallas que era necesario ganar para introducir la ciencia moderna en las instituciones oficiales, era establecer una clara diferencia entre la verdad religiosa y el conocimiento científico. En este sentido sus palabras son concluyentes: "En lo teológico sigo de buen grado a Tomás de Aquino; en lo filosófico, a Tomás Apóstol»(33). La actitud de Climent es un exponente de cómo se resistía en aceptar esa actitud símbolo de modernidad.

\section{NOTAS:}

(1) Entre los diversos autores que han estudiado ya dicho periodo, puede consultarse: PESET LLORCA, V., "La Universidad de Valencia y la Renovación cientifica española", Asciepio, 16, 214-231 (1964); GARCIA MARTINEZ, S., Els fonaments del Pais Valencià modern, Valencia, 1968; LOPEZ PIÑERO, J. M., "Galileo en la España del siglo XVIll", Revista de Occidente, núm. 40, 99-108 (1966); del mismo autor,La introducción de la ciencia moderna en España, Barcelona, 1969 y Ciencia y técnica en la sociedad española de los siglos XVI y XVII, Barcelona, 1979; NAVARRO BROTONS, V., "La renovación de las ciencias físico-matemáticas en la Valencia preilustrada", Asclepio, 24, 367-378 (1972); BALAGUER PERIGÜELL, E., "La introducción de la iatromecánica en Valencia», Asclepio, 24, 379-389 (1972) y también la sintesis "La ciencia y la técnica en el siglo XVIIIn, en : Historia General de España y América, T. X, I, Cap. VIII, Madrid, RIALP (en prensa).

(2) VICENS VIVES, J., Historia económica de España, Barcelona 1969. Ver también REGLA CAMPISTOL, J., "Edad moderna", en: Introducción a la Historia de España, Barcelona 1967.

(3) GARCIA MARTINEZ, Els fonaments..., p. 149.

(4) PESET, M. y PESET, J. L., La Universidad Española (siglos XVIII-XIX), Madrid, 1974.

(5) PESET LLORCA, V., "La Universidad...", p. 21.

(6) LOPEZ PIÑERO, La introducción..., p. 33.

(7) Ibidem.

(8) MARCO CUELLAR, R., “EL Compendio Mathemático del Padre Tosca y la introducción de la Ciencia Moderna en España", Actas II Congr. Nac. Hist. Med. Vol. I, Salamanca, 1965, p. 325-358.

(9) NAVARRO BROTONS, “La renovación de las ciencias físico-matemáticas...".

(10) La iatroquímica pretendia estudiar todos los fenómenos propios de los seres vivos, reduciéndolo a los procesos químicos que acontecerían en el organismo. En último caso, puede entenderse como una racionalización y cuantificación del panvitalismo de Paracelso.

(11) LOPEZ PIÑERO, J. M., "Paracelsus and his Work in 16 th and 17 th Century Spain". Clio Médica, 8, 113-141 (1973). Del mismo autor: "Química y medicina en la España de los siglos XVI y XVII. La influencia de Paracelson, Cuad. Hist. Med. Esp., I, 17-54 (1972).

(12) LOPEZ PIÑERO, J. M., "La contribución de Juan Bautista Juanini (1636-1691) y la introducción en España de la medicina y la ciencia moderna. Actas // Congr. Nac. Hist. Med., Vol. I, Salamanca, 1965, p. 403-422.

(13) LOPEZ PIÑERO, “Paracelsus...”.

(14) En contraste y en muchas ocasiones en contraposición a la iatroquímica, la iatromecánica pretendia estudiar los mismos fenómenos pero con los métodos de la física moderna. 
(15) Borelli abandonó Messina en 1656 para ocupar la cátedra de matemáticas del Studio di Pisa. A partir de estos momentos y hasta la disolución de la "Accademia del Cimento", fue uno de sus miembros más entusiasta.

(16) Compedium Philosophicum, T. V, Tract. X, Liber III, Caput III, Propos. X, XI, XII.

(17) Idem, caput VI.

(18) Idem, prop. XXXIII.

(19) Todos los manuscritos citados se encuentran en la «Biblioteca Mayáns", (Colegio del Corpus Christi de Valencia). Un inventario de los temas cientificos ha sido elaborado por NAVARRO BROTONS, V., "Inventario de los manuscritos científicos que figuran en la biblioteca mayansiana». Actes I. Congrés d'Historia del País Valencià.

(20) HERNANDEZ MOREJON, A., Historia bibliográfica de la Medicina Española, Vol VIl, Madrid, 1850, p. 9.

(21) Los Apuntamientos junto con dos manuscritos más, Memorial a la Ciudad de Valencia y De la necesidad i utilidad de las Mathemáticas; se encuentran en un volumen de obras de BORDAZAR con el titulo genérico de Miscellanea Mathemática.

(22) Miscellanea..., fol. 429.

(23) PESET REIG, J. L., Reforma de los estudios médicos en la Universidad de Valencia. Valencia, Tesis de Licenciatura, 1969.

(24) BORDAZAR, A., Idea de una Academia de Mathemáticas. Valencia, 1740. p. 27.

(25) Respecto a un informe publicado por PIQUER: Manifestaciones de las razones y fundamentos que tuvo el Dr. Andrés Piquer, médico titular de esta llustre Ciudad de Valencia y catedrático de Anatomia de su Universidad, para juzgar y declara ser hético Vicente Navarro, escrivano de la misma, Valencia, 1746; se entabló una polémica entre PIQUER y los doctores MANUEL MORERA y JOSE CASALLAS. Estos últimos criticaron todos los aspectos defendidos por PIQUER y desde luego, su opinión favorable a las matemáticas.

(26) Medicina Vetus, et nova continens pharmaciam Galenico-Chimica, et febrilogiam Galenico-modernam ad Tyrones. Valenciae, 1735.

(27) Un pormenorizado estudio en torno a la Física de PIQUER y la influencia de Mayans, puede consultarse en PESET LLORCA, V., Gregori Mayáns i la cultura de la ll.lustració. Barcelona, 1975.

(28) Cfr. MAGRANER Y MARINAS, J., «Ensayo biográfico-bibliográfico del Dr. D. Andrés Piquer y Arrufat». En Solemne sesión apologética celebrada en la Facultad de Medicina para honrar la memoria de sus antiguios catedráticos los doctors Plaza, Collado y Piquer. Valencia, 1895.

(29) “Aprobación del Dr. Josef Nebot y Sanz, Abogado de los Reales Consejos y Académico Valencianon. En: PIQUER, Fisica moderna, Valencia, 1745.

(30) "Aprobación de Don Josef Climent, Presbytero, dos veces cathedrático de Filosofía, Doctor Theólogo en la Universidad de Valencia...". En: Física moderna.

(31) "Aprobación del Dr. Josef Nebot...".

(32) "Aprobación de Don Josef Climent...".

(33) Cfr. QUIROZ-MARTINEZ, O., La introducción de la Filosofia moderna en España, México, 1949 . 


\title{
JANSENISMO Y REGALISMO \\ EN EL SEMINARIO DE SAN FULGENCIO DE MURCIA(*)
}

\author{
Por Cayetano MAS GALVAÑ
}

Universidad de Alicante

Als meus pares

En el estudio de la cultura española del siglo XVIII, el colegioseminario conciliar de San Fulgencio de la ciudad de Murcia adquiere personalidad propia como importante foco de difusión del pensamiento janseista y de las ideas ilustradas. La fama que en ese sentido adquirio entre sus contemporáneos perduró a lo largo del siglo XIX; sambenito éste que ha llegado hasta nuestros días(1).

Sin embargo, carecíamos de los necesarios estudios sobre la evolución cultural del colegio durante su etapa más significativa (el último cuarto del siglo XVIII y la primera década del XIX) que ayudasen a centrar el problema desde unas perspectivas distintas a las proporcionadas por el simple tópico(2). Bien es cierto; por otra parte, que este trabajo sólo ha sido posible, desde un enfoque adecuado, cuando la evolución reciente de la historiografia sobre la cultura española del siglo XVIII (y en concreto, sobre nuestro jansenismo), ha permitido articular los estudios más especificos y de menor envergadura sobre líneas cientificas realmente operativas.

(") Este trabajo desarrolla parte de la tesis de licenciatura que, con el mismo titulo, lei en la facultad de Filosofia y Letras de Alicante, bajo la dirección de D. Antonio Mestre Sanchis, el 13 de noviembre de 1981. 
Centrando el tema, pues, en la problemática del jansenismo, se hace necesario, en principio, analizar el sentido y la naturaleza que tal movimiento adoptó en nuestro país.

Desde la perspectiva europea, el nuestro es el más tardío de los jansenismos nacionales. A primera vista, resalta la complejidad de su contenido. Se trata de la "quasi-imposibilidad de dar al término jansenismo un contenido intelectual preciso (...), de definir el jansenismo como un sistema cerrado de ideas que se podrían analizar de una vez por todas «(3). Es decir, que este movimiento entraña, además de unos principios doctrinales sobre la gracia y la predestinación, una serie de actitudes morales rigoristas, y político-temporales, que irán evolucionando hasta ocupar el primer plano de su forma de ser posterior(4).

La aparición de estos últimos componentes-presentes igualmente en España-generó la adopción de una serie de posturas enfrentadas entre sí. Las controversias que siguieron, sobre la naturaleza del jansenismo español, pasaron de los propios "contemporáneos a nuestros historiadores del pasado siglo (Menéndez Pelayo y el P. Miguélez), para manifestarse ante los estudiosos actuales de la llustración en los paises católicos, como problema histórico de primer orden.

Estudiando las conexiones del jansenismo europeo con la llustración, L. Ceyssens ha hecho una de las mejores aportaciones, al distinguir el jansenismo tomado en el sentido teológico (restringido a las cinco proposiciones condenadas en la bula papal "Cum occasione", de 1.653), del jansenismo entendido en un sentido "histórico». Este último, sin aceptar ninguna de las proposiciones condenadas, sí responde a una forma de religiosidad de características definidas. Para precisar en cada momento el significado del término, es preciso partir del hecho de que la existencia de la oposición jansenistas-antijansenistas da origen a dos partidos antitéticos que evolucionan delimitando mutuamente sus conceptos: el jansenismo crea el antijansenismo, siendo el jansenismo histórico; en cada momento concreto, aquello que quieren indicar los antijansenistas.

Appolis, por su parte, ha evidenciado la existencia, entre ambos partidos extremos, de un grupo de moderados ( $(T i e r s$ parti»), que pretendio establecer un equilibrio en el campo doctrinal y moral. Gran parte de los jansenistas españoles puede ser incluida en este, grupo, con lo cual se establece la conexión del jansenismo español dentro de las coordenadas del pensamiento religioso europeo.

Desde sus respectivos prismas nacionales, otros historiadores europeos se han ocupado de estas relaciones. Así, J. Saugnieux ha precisado las corrientes europeas, especialmente francesas, que se dan en el janse- 
nismo español. De importancia capital es, igualmente, la contribución de los estudiosos italianos. Sin descuidar los trabajos de Jemolo y Codignola, habria que insistir especialmente en los realizados por Dammig sobre el jansenismo romano, por cuanto nos permiten explicar la actividad de los españoles (políticos, como Roda o Azara; religiosos, como Francisco X. Vázquez), y el influjo que ejercieron sobre quienes visitaban Roma o ampliaban alli sus estudios(5).

Finalmente, los trabajos de A. Mestre a propósito de la figura de D. Gregorio Mayans arrojan luz sobre las raíces y la cronología del movimiento en España. Paralelamente al desmonte de la interpretación clásica sobre los orígenes del pensamiento ilustrado en España, demostrando la trascendencia y lo temprano del foco intelectual valenciano, los trabajos de Mestre resaltan el carácter fundamentalmente religioso del jansenismo y su inserción dentro de las coordenadas de la religiosidad europea del siglo. Mayans, en contacto permanente con Europa, conoce el pensamiento y los autores jansenistas europeos ya en la década de 1720-1730, al tiempo que las corrientes ilustradas. La influencia del grupo valenciano se proyectará, con personalidad propia, determinando los acontecimientos culturales de toda nuestra llustración. $Y$ es precisamente en este grupo donde tomará carácter un elemento presente en la base de la postura religiosa de nuestros ilustrados: la herencia de la tradición hispánica, del pensamiento español del siglo XVI en general y de los erasmitas en particular, generadora del interés por el conocimiento de la Biblia y por el regalismo(6).

\section{II}

Respecto al objeto de este artículo (el estudio de la evolución seguida por el seminario de San Fulgencio a partir de 1774, año del comienzo de su reforma), es necesario explicar las causas que provocaron su conversión en:

1. Centro de carácter universitario, a efectos prácticos, transgrediendo (aparentemente y por exceso) su estatuto como seminario conciliar. Este va a ser un caso único en su género.

2. Foco avanzado en la difusión del pensamiento jansenista y de las ideas ilustradas, anticipándose (en todos los terrenos) sobre la mayoría de las auténticas universidades. El fenómeno resulta más sorprendente aún' si se tiene en cuenta que el seminario carecia de antecedentes culturales en esa línea.

Una serie de causas complejas y de circunstancias de diverso tipo nos ofrecen las claves para el entendimiento del problema. Lógicamente, 
un primer grupo de factores son los derivados de aquéllos otros que, en el terreno cultural y político, determinaron la evolución general del pais. Exponiéndolos esquemáticamente, serian:

La vinculación entre católicos ilustrados y jansenistas, que aparece como indisoluble en muchas de las personalidades concretas. No obstante, a nivel de corrientes diferenciadas (en proceso de convergencia a lo largo del siglo), algunas cuestiones establecen claramente los nexos: "el odio a la escolástica y a las tradiciones eclesiásticas más recientes, el deseo de una religiosidad interior, una mayor valoración del episcopado y de los concilios nacionales, cierta antipatía por las órdenes religiosas a causa de sus privilegios y exenciones, constituian los puntos fundamentales que, pese a otras divergencias, unian a los ilustrados y jansenistas frente a un ambiente religioso que consideraban decadente $y$ superficial $m(7)$.

La conversión del jansenismo en ideología del poder, a partir del "viraje jansenistan que tiene lugar con la caída del triángulo CarvajalEnsenada-Rávago. Las implicaciones politico-sociales del hecho son trascendentales. Supone, dentro del regalismo, el fin del apoyo en una escuela doctrinal y en una clase social (los probabilistas, es decir la Compañia de Jesús; y la aristocracia, a través de los Colegios Mayores), y su sustitución por otras distintas (los probabilioristas, dominicos y agustinos; los manteistas), que pasarán a ser las dominantes durante todo el reinado de Carlos III.

Resultan obvias, pues, las vinculaciones entre regalismo y jansenismo (este último como aparato ideológico esgrimido en favor del primero a manos de los manteistas y frente a sus enemigos), aunque en España el fenómeno se produjo mucho más tardíamente que en Francia. Pese a ello, ambas corrientes no son idénticas ni por sus principios doctrinales ni por su origen historico, y habian seguido líneas claramente separadas durante la primera mitad del siglo. El círculo se completa cuando establecemos la relación existente entre este jansenismo cargado de matices regalistas y las posturas de los ilustrados, hecho éste también general en Europa.Los ilustrados, que apoyaban el regalismo, tomaron partido por la tendencia rigorista y en favor de la religiosidad interior, del mismo modo que el ejercicio de la crítica los induce al estudio histórico de las fuentes del cristianismo y de la Iglesia Primitiva, censurando la actividad exterior de la Iglesia personalizada en la Curia. En última consecuencia, serán rigoristas en moral y atacarán al laxismo y a los casuistas. Por otra parte, su idea de que la única fuerza capaz de realizar sus proyectos es el rey (eje de la reforma social que pretenden) les hace colaborar-pese a sus profundas diferencias-, con el despotismo ilustrado(8).

En el campo de la Iglesia, con la elevación de la calidad del episcopado respecto de la anterior centuria, durante la primera mitad del siglo XVIII 
se perfila claramente el ideal del cumplimiento de los mandatos Tridentinos, a nivel general entre los obispos. Dentro de estas esferas, a mediados de siglo comienzan a observarse cambios que llevarán a amplios sectores, primero, hacia posiciones antijesuitas, y posteriormente jansenizantes. La influencia del foco valenciano (surgido del círculo Mayans-Mayoral), generará a su vez nuevos focos de difusión jansenista en Salamanca y Barcelona (respectivamente, los obispos Bertrán y Climent).

Presente el jansenismo, pues, tanto en las élites ilustradas del país, como en amplios sectores del episcopado, y convertido en arma ideológica de los manteístas en el poder, la reforma de la sociedad propugnada por los ilustrados y asumida por el Estado se presentó con claros contenidos jansenistas. Dentro de la mentalidad de la época, el medio fundamental para la trasnformación era la reforma de la enseñanza, tanto en el terreno seglar como en el eclesiático. Junto a la nueva pedagogia, el regalismo aparecía como factor decisivo. En conclusión, reforma general, reforma universitaria y reforma eclesiástica se presentaban como aspectos intimamente relacionados.

En el caso concreto de San Fulgencio, otro tipo de circunstancias que determinaron su evolución durante el periodo que estudiamos son las que dimanan de su propia entidad en cuanto centro docente en general y como seminario en particular, con una larga historia que arrancaba desde finales del siglo XVI. No pueden tampoco ser olvidados los factores de orden local, es decir, los condicionamientos que sufrió como institución inserta en el ambiente social concreto de Murcia. En la medida en que la intervención estatal sólo se dará (bien que con carácter casi exclusivo) desde 1768 (Real Cédula de 14 de agosto sobre "Erección de seminarios conciliares»), este último grupo de influencias serán las que regirán la vida del seminario hasta las reformas de la década de 1770-1780.

Desde su fundación en 1592 hasta las reformas de 1774, el seminario de San Fulgencio siguió una trayectoria semejante a la del resto de las instituciones conciliares españolas. Sin perder nunca (tampoco después de la última fecha) su inicial estatuto Tridentino (las reformas carlotercistas son las responsables de que por vez primera los seminarios alcanzasen la plenitud en el cumplimiento del decreto "pro seminariis", de 1563), hubo de adaptarse a la situación general de la sociedad española en cada momento, y a la del sistema educativo en particular.

Los seminarios españoles atravesaron lánguidamente el Barroco. Abandonados por Roma y por el Estado, carentes de recursos económicos y jugando un papel secundario en el sistema educativo (predominio de los colegios de la Compañía de Jesús en la enseñanza que pudiéramos llamar secundaria), la mayoria - también el murciano-pasaron a ser controlados por los cabildos catedralicios, en presencia de obispos indolentes o desinteresados(9). 
Los primeros indicios de cambio se darán en la primera mitad del siglo XVIII. La labor Ilevada a cabo por los prelados murcianos que ocupan ese período-en especial, Belluga-preparo el terreno para las posteriores reformas. Ausente aún la intervención estatal, estos obispos asumirán el papel protagonista, dispuestos a hacer valer su autoridad ante los cabildos, para el exacto cumplimiento de los decretos tridentinos. Belluga, sin rupturas ni enfrentamientos, sienta las bases para la emancipación de las servidumbres que gravaban al seminario en el servicio de la catedral, lo dota de nuevas constituciones y mayores medios económicos, y establece los estudios de filosofia y teología para los seminaristas (hasta entonces inexistentes, limitados como estaban a la gramática latina y la moral), mediante el sistema de asistencia, divididos por escuelas, a las aulas públicas de los conventos de la ciudad(10). Preocupado por la formación sacerdotal, creó un seminario para el perfeccionamiento de los teólogos (el de San Isidoro), confiándolo a la dirección de los "pios operarios evangélicos", del P. Ferrer, uno de los movimientos de reforma sacerdotal en vanguardia(11). Finalmente, en 1741 erigía las dos primeras cátedras superiores en el interior del seminario, una para el derecho civil, y la otra para el canónico(12).

La anómala aparición de la cátedra de derecho civil en el interior de un seminario clerical(13), encuentra su razón en el carácter mixto (eclesiástico-seglar), que tuvieron los seminarios en su historia anterior: su inserción en el sistema educativo español los hizo actuar en respuesta a la demanda social de enseñanza, abriendo sus aulas a los alumnos seglares. Así ocurrió en Murcia con la cátedra de gramática latina durante todo el siglo XVII, y a mediados del siglo XVIII con las de derecho: la mejoria económica y social del nuevo siglo, y la inexistencia de universidad (en una época en que faltaba el aparato docente estatal), hizo canalizar la satisfacción de la necesidad de estudios universitarios hacia la Iglesia y sus instituciones, en concreto hacia la persona de su gran cardenal protector, Belluga, y su seminario de San Fulgencio. Es el primer precedente de la evolución universitaria del seminario.

Los sucesores de Belluga (en especial D. Diego de Roxas Contreras, obispo de Murcia de 1752 a 1772) continuaron el camino emprendido. Como consecuencia, al comenzar el pontificado de D. Manuel Rubin de Celis, esta sana corriente de reforzamiento de la autoridad episcopal habia conseguido que el seminario alcanzase una posición sustancialmente distinta de la que ofrecía al comenzar el siglo: con rentas suficientes y alumnado numeroso, emancipado-como disponía el Concilio-de cualquier instancia ajena a la episcopal, con un programa de estudios completo para sus alumnos, e incluso con cátedras de derecho en su mismo interior.

Este proceso hacia la adquisición de rango universitario no hubiera sido posible sin la presencia de un fenómeno de carácter general, patente a 
finales del siglo XVII: la decadencia de las universidades. Vinculadas a los intereses del grupo que ellas mismas formaron-los profesionales del derecho-, habíanse alejado del conjunto de la sociedad para centrarse en los Colegios Mayores, el estudio de la jurisprudencia y la consecución de los cargos de letrados, desde una perspectiva ideológica francamente inmovilista(14). Con ello, quedaban abiertos nuevos caminos para el resto de las instituciones docentes, en las que necesariamente habia de encauzarse todo el proceso de innovación científica o cultural. Estas son, pues, las coordenadas (generales y locales), de las que el seminario murciano se benefició, facilitando el avance de la reforma mucho más que instituciones de mayores proporciones y de más larga tradición, cuales eran las universidades.

Ya en el poder, el grupo manteista había de asegurarse el control en la difusión ideológica. De ahí que la reforma de la enseñanza pasase por el extrañamiento de sus principales oponentes (los jesuitas), la reforma de las viejas estructuras (Colegios Mayores y universidades) y la propagación del jansenismo.

En materia de seminarios, la citada Real Cédula sobre seminarios conciliares (1768), cargada de matices regalistas e ilustrados, marca el punto de partida para la intervención estatal(15). En ella, el rey se arrogaba el derecho de intervenir forzando el cumplimiento del decreto tridentino "pro seminariis", dando comienzo a una etapa de esplendor en cuanto a reformas y fundaciones de seminarios. Por otra parte, la política seguida en este terreno por el gobierno presenta fuertes parecidos y vinculaciones con la desarrollada en las universidades. A los iniciales ímpetus centralizadores (la real cédula disponía que se redactase un plan de estudios común para todos aquéllos), sucedió la inclinación gubernamental por las soluciones parciales(16). De este modo se introducía un elemento diferenciador en la política estatal, que vino finalmente a posibilitar la evolución hacia la universidad de que venimos hablando para el colegio fulgentino.

En definitiva, desde 1768 la influencia de la corriente regalista sobre los seminarios será dominante y excluyente. Hacia esas alturas del siglo, los dos grandes agentes de la reforma que entonces comenzaba habian alcanzado el punto común de su anterior convergencia. De un lado el rey y su instrumento, el regalismo. De otro, los obispos, con un importante sector filojansenista o, cuando menos, favorable a las regalías. Uno y otros, rey y obispos, eran conscientes, cada cual en su posición, de la necesidad de apoyo mutuo que se debían, en un momento en que los objetivos se mostraban comunes. 
Fue D. Manuel Rubin de Celis, obispo de Cartagena entre 1773 y 1784 , el autor de la reforma del seminario. Tan citado como poco estudiado(17), su personalidad nos coloca ante un prelado que auna en su carácter las vinculaciones existentes entre jansenistas e ilustrados. Su biografía ofrece, en este sentido, algunas notas reveladoras. De origen noble y acaudalado, se formó como jurista y mantuvo, como evidencia de su trayectoria ascendente, buenas relaciones con los gabinetes ilustrados de Carlos III. Pero importa, sobremanera, su estancia en el colegio "De propaganda fides romano, en donde, aparte de conocer personalmente al $\mathrm{P}$. Jacquier, se familiarizaría con la problemática religiosa italiana de mediados de siglo(18). Sin temor al error, podemos afirmar que (como señalaba Dammig para el caso de otros españoles), también el influjo recibido por Rubín durante su estancia en Roma, determinó su inclinación filojansenista y su postura abierta ante las ideas ilustradas.

Los dos planes de estudios otorgados por D. Manuel al seminario de San Fulgencio en 1774 (filosofía y teología) y 1778 (derecho civil y canónico)(19) constituyen la mejor base para el análisis de su pensamiento, a la vez que la base de la reforma de que estamos tratando. Continuando la labor de sus predecesores en la sede murciana, y apoyándose en la Real Cédula sobre seminarios, los planes comportaban innovaciones estructurales que venían a culminar el proceso abierto por Belluga. Con la creación de cátedras de filosofía y teologia en el interior del colegio, Rubín ponía fin a las salidas diarias que el seminarista tenia que hacer fuera de la casa, a la vez que a la división del alumnado por escuelas y al monopolio que sobre la enseñanza de los fulgentinos gozaban los regulares.

Pero la auténtica innovación se registra en el contenido básico de los planes, el cultural y el pedagógico. Y en este terreno, los nuevos textos desempeñan el papel central.

La filosofía se cursaba en tres años, comprendiendo las materias de lógica y primera parte de la metafísica; segunda parte de la metafísica y física general; y física particular y filosofía moral o ética, respectivamente en cada curso. El texto elegido son las "Institutiones philosophicae ad studia theologica potissimum accomodatan, del P. F. Jacquier(20), colocado por Herr en la misma línea de Ilustración-oficialmente aceptada-que sostenían autores como Bacon, Descartes, Newton, Leibniz, Wolf, Locke, Condillac, etc. La obra comenzaba con dos tomos de lógica y ontología de sabor escolástico, pero los restantes trataban libremente de aritmética, álgebra, geometria, física, astronomia, geografía y filosofía moral(21).

Es en los estudios de teología donde claramente aparece el jansenismo del prelado. D. Manuel creó un cátedra de lugares teológicos, tres de teologia escolástica (aunque los años de enseñanza se convirtieron, más 
tarde, en cuatro), y una de teologia moral (con dos años de enseñanza).

Para la primera, el texto era el tratado "De Locis Theologicis" de Gaspar Juenin(22), autor conocido por sus tendencias filojansenistas y por su rigorismo moral. Postura que se confirma en el texto prescrito para la enseñanza de la teología moral, el compendio "Theologia christiana dogmatico-moralisn, del P. Daniel Concina, conocido por su antiprobabilismo acérrimo, oposición a los casuistas y por las polémicas que sostuvo con los jesuítas en Italia(23).

Junto al rigorismo, el agustinismo doctrinal: en las cátedras de teologia doctrinal se estudiaba la obra del P. Lorenzo Berti "De theologicis disciplinis", a través del compendio elaborado por el P. Gerónimo M. Buzi(24).

En relación con el plan, cabe la formulación de algunas consideraciones generales. A primera vista se observa, en los textos, una innovación propia del siglo XVIII y de los planteamientos ilustrados: la preferencia por la elección de compendios, con el fin de proporcionar al estudiante una visión clara y concisa de los conocimientos que se consideran necesarios para su formación. Ahora bien, esta aparición del compendio se encuentra ligada con el esfuerzo ilustrado por desterrar el engorroso método escolástico. Rubín dio el primer paso aboliendo el sistema de las escuelas, completado ahora con la selección de textos completamente nuevos.

Es preciso notar que los planteaminetos de Rubín distan del radicalismo presente en algunos ilustrados (como Olavide o el P. Truxillo), para acercarse a los más moderados formulados por Mayans en su plan general para la enseñanza universitaria, de 1767(25). El valenciano, a la par que deseaba la separación entre dogma y escolástica-demandando un compedio de teología dogmática-, consideraba que la escolástica no debía ser desterrada totalmente, pues formaba parte de la evolución del pensamiento cristiano. Y a pesar de la denominación utilizada por Rubín (teología "escolástica"), en realidad seguía la línea de D. Gregorio al decidirse por adoptar un compendio en donde se resumia y separaba el dogma de la escolástica. Este criterio es el que aplicó también al establecer una cátedra de lugares teológicos separada de las restantes(26).

La cuestión es nítida en lo que atañe al método de enseñanza que elige, básicamente integrado por las clases y los actos académicos (academias, conclusiones y lecciones de puntos). Las primeras se basaban en la explicación del profesor y en las preguntas que éste formulaba a sus alumnos. El método escolástico de las argumentaciones quedaba reducido a un corto espacio en los momentos finales de la clase, y sólo con vistas a que el alumno dominase su funcionamiento de cara a los actos académicos 0 a su posterior vida profesional. Dichos actos conservaron más ampliamente el método escolástico, pero se orientaban hacia ese mismo 
objetivo. Erradicadas las engorrosas disputas, la escolástica era devuelta a su primitivo fin: servir como herramienta de trabajo intelectual, pero nunca como fuente de conocimiento.

La exacta ponderación de la importancia del plan de 1774 exige situarlo en relación con la situación general de la enseñanza universitaria. Destaca aquí el aspecto cronológico. Mientras que la introducción de textos como el de Jacquier sólo puede considerarse masiva en la década de 1780 , el seminario murciano es sin duda uno de los primeros centros que lo adopto(27). Y si la práctica totalidad de los seminarios españoles entraron en franca dependencia, en materia de planes de estudios y textos, respecto de las universidades (habida cuenta de la politica de incorporaciones seguida por el Consejo), con el plan de teología del seminario de San Fulgencio asistimos a la inversión de tales términos.

En efecto, Valencia fue el otro gran centro en donde el agustinismo cobró fuerza(28), especialmente durante el tiempo en que Juan Antonio Mayans fue rector de la universidad (1775-1778). No extraña pues el interés que alli se levantó por el plan de estudios murciano: casi inmediatamente (31 de marzo de 1775), el rector y claustro de la universidad valentina pidieron licencia al Consejo para establecer alli los mismos textos que en el seminario fulgentino. Esta situación de vanguardia cronológica no se hubiese dado a no ser por la concurrencia de una serie de condiciones:

1. La autonomía jurídica del seminario, por su estatuto conciliar, que le colocaba en dependencia directa y exclusiva respecto del obispo.

2. La aparición en la sede murciana de un obispo reformista.

3. El apoyo del Estado regalista.

Sin las trabas que ofrecian las universidades para la introducción de los nuevos planes, propugnada por el Consejo, en Murcia bastó la eficaz alianza entre un obispo reformista y un gobierno que sostenía los mismos criterios para que el seminario se elevase hasta cotas insospechadas que, como indicábamos, eran impropias a su fin y al que en principio había marcado el propio Estado.

No obstante, en los primeros momentos del cambio, el factor más importante de la innovación fue la mentalidad del obispo. Sin soslayar el hecho de que los autores contenidos en el plan fuesen conocidos en Valencia con bastante anterioridad a 1774(29), es en la estancia italiana de Rubín en donde hemos de centrar nuestra atención (implantación de Berti, Concina y Jacquier), y en general, en la suma de experiencias vitales de $D$. Manuel (conocimiento de los círculos ilustrados de la Corte).

Algunas ausencias en el plan de 1774 pudieran ser significativas ( $v$. gr., las referencias concretas a las cátedras de Sagrada Escritura), pero 
hallan fácil explicación si consideramos que la misión fundamental del seminario era la formación de sacerdotes, contando con la limitación temporal que imponian las becas de sus alumnos, y la diversidad de materias en las que éstos debían estar versados, que excedian las puramente teológicas. El hecho ya estaba forzando la elección de los compendios. Ahora bien, la misma lectura de estos textos, así como la de alguno de los impresos de conclusiones realizados por profesores y alumnos $(30)$, pone en claro que la enseñanza de teología impartida en el seminario pretendia abarcar esta materia en su totalidad. Mientras que se tocaban materias puramente escriturísticas, dogmáticas o históricas, la Escritura era colocada como fuente principal del conocimiento teológico y la escolástica se veía reducida a un plano secundario. En correlación, se detecta la preocupación por el conocimiento del hebreo y del griego para el estudio del Antiguo Testamento(31).

El jansenismo no podía dejar de aparecer, ahora en sus matices más propiamente jurisdiccionales, en el plan de estudios de derecho (1778). Una primera aproximación obliga de nuevo a efectuar una diferenciación básica. $\mathrm{A}$ las dos cátedras de Belluga, Rubin añadió otras dos (una para derecho civil y otra para el canónico). Con las cátedras de derecho civil, Rubín no hacía más que seguir satisfaciendo una demanda en aumento-son los momentos más prósperos del siglo-, que ya habia sido canalizada hacia el seminario por Belluga(32).

Las posibles incompatibilidades no rigen en cuanto afecta al derecho canónico(33), concebido ahora como prolongación lógica del estudio teológico (no en vano, Rubín se habia formado como jurista). Es aquí donde surge prontamente la implicación con el regalismo. En las mentes ilustradas, los obispos y los eclesiásticos en general debian aprender en los cánones a reducir los derechos de la Iglesia a los límites espirituales entendidos según el pensamiento regalista. Este estudio exigia un conocimiento histórico rigurosamente crítico y un método científico(34). Así lo entendía Rubín cuando marco como objeto para los estudios canónicos "/a perfecta inteligencia de la Disciplina, y Jurisdicción eclesiástica, y del modo con que en diferentes tiempos se han egercitado una y otraw(35).

Consecuentemente, los cursos se articulan en función del desarrollo histórico, estudiándose primeramente la disciplina antigua y después la nueva (año y medio para cada materia). El texto que utilizarán los estudiantes en la primera asignatura es el de las "Institutionum canonicarum libri tres", de Julio Lorenzo Selvagio, considerado jansenista por su inclinación galicana(36). Para el estudio de las decretales (derecho nuevo), aunque D. Manuel se inclinó por mantener el texto ya impuesto por Belluga(37), justifica la permanencia del autor (Andrés del Vaulx), en razón del buen juicio que de su obra hiciese Van Espen. Este dato viene a confirmar las tendencias regalistas presentes en Rubin(38). No obstante advertía a los profeso- 
res sobre el manejo de la obra, "pues se le notan equivocaciones al autor, ya por falta de crítica, ya también por su modo de resolver en algunos puntos con demasiada indulgencian. Crítica científica y rigorismo moral, derecho canónico y teologia, son aspectos que Rubín de Celis no separa.

El método-en lo tocante al uso de la escolástica-es aún más relajado que en el anterior plan: salvo en los días que estime convenientes, el catedrático ya no dejará tiempo para las argumentaciones en clases y academias.

No obstante estar dirigido al alumnado seglar, la parte del plan de 1778 que se dedica al derecho civil se encuentra en la misma línea que venimos observando. Es aquí, por otra parte, donde mejor apreciamos la coincidencia de criterios entre el obispo y la línea de ilustración oficial: los textos son compendios que el Consejo había aprobado para su implantación en las universidades.

En los dos primeros cursos de esta facultad se estudiaba el derecho romano, utilizando el método comparativo ("Los catedráticos... después de haver explicado a sus Discipulos lo que el Derecho de los Romanos dispone en los puntos, que comprehende la lección del día, les manifestarán con claridad, y método el Derecho de España en aquellos mismos puntos"). Como texto, las "Justiniani Institutiones libri quatuor", con los comentarios de Arnold Vinnen(39).

El tercer año de carrera se dedicaba a la historia de la jurisprudencia (por los compendios de Backio o Brunquelio), y al estudio del derecho natural y de gentes. En la primera disciplina aparece otra novedad pedagógica: junto al manual del alumno, el profesor disponía para su uso particular de los tres tomos del "Originum iuris civilis", escritos por Gian Vicenzo Gravina(40). El influjo de Gravina (que en sus polémicas con los jesuitas tomó postura por los planteamientos filojansenistas) pasó a España-como en otros casos-a través del grupo valenciano, dada su intima amistad con el deán Martí.

Para el derecho natural y de gentes, Rubín impuso los «Elementa juris naturae et gentium", de J. G. Heinecke, reeditados "con correcciones, según la doctrina católica", por D. Joaquín Marín y Mendoza(41). El texto de Marín estaba protegido por el rey para su introducción en las universidades. Destaca Murcia, una vez más, por lo temprano de la fecha en que es adoptado(42).

En el cuarto y último año de enseñanza de jurisprudencia civil se impartía la del derecho común y la legislación de España, por las "Instituciones del Derecho Civil de Castillan, publicadas en 1771 por D. Ignacio Jordán de Asso y D. Miguel de Manuel Rodríguez. Con respecto a esta obra, Herr subraya su carácter profundamente histórico, en un momento en que esta materia sufría su primera gran eclosión(43), incubada desde los 
ya lejanos trabajos de Mayans, Flórez o Burriel durante la primera mitad de siglo.

El regalismo de Rubín, el apoyo que le prestaba el Consejo, y la actitud de este organismo ante la adopción del agustinismo en Murcia, son algunos de los factores que se habían manifestado con anterioridad a este plan de 1778, en el curso de la controversia suscitada por los dominicos murcianos a raíz del plan de estudios de teología y filosofía.

En efecto, una vez producida la expulsión de la Compañía, el frente común que hasta entonces presentaron frente a ella los dominicos y agustinos se escindió. Los dominicos vinieron a inclinarse por un tenaz conservadurismo que les convirtió en herederos del papel de defensores del ultramontanismo(44), aproximándose a la Santa Sede y defendiendo la doctrina de Santo Tomás como la ortodoxa; en este sentido, insistian en el peligro de la proximidad de las tesis agustinianas a los principios jansenistas. Los agustinos por su parte, continuaron defendiendo sus doctrinas sobre la gracia, y en buenas relaciones con la Iglesia de Utrecht y los jansenistas italianos y franceses. Las polémicas, en las que se disputaban el vacío dejado por la Compañía en el monopolio de la enseñanza, son la expresión de una divergencia de mayor amplitud que abarca toda Europa, y de manera especial, al mundo religioso italiano(45).

En Murcia se contaba con un precedente, ya en 1767. Cumplida la expulsión, los alumnos fulgentinos que asistían a las cátedras suaristas se pasaron a las aulas franciscanas. Celosos de perder el papel predominante que hasta entonces tuvieron, los dominicos murcianos levantaron pleito ante el Consejo, pretextando que los discipulos tomistas sufrian la persecución de los rectores de los seminarios de San Fulgencio y de San Isidoro, que pertenecian a la escuela escotista(46). No conocemos la decisión del Supremo Tribunal, si es que la hubo. Simplemente, parece que la cuestión languideció en Madrid, desde donde todavía en 1772 se solicitaba algún informe para el expediente.

Pero es el 24 de septiembre de 1774 (cinco días después de la publicación del plan de Rubín), cuando los dominicos reemprenden sus ataques, ahora enviando una representación al Consejo en la que se delataba el plan(47). Las acusaciones, sintomáticamente, iban dirigidas contra los autores: su conocimiento de las directrices gubernamentales les impedía arremeter contra el plan en su integridad, y menos aún directamente contra el obispo.

De este modo, imputaban a Berti el no admitir la necesidad de la gracia eficaz en todos los estados de la naturaleza criada. Con la cuestión del regalismo como telón de fondo de la polémica, más grave resultaba todavía la acusación de antirregalista que lanzaban contra este autor. Según los dominicos, el agustino italianọ defendía las tesis de la potestad 
civil del papa sobre los príncipes y de la inmunidad de las personas y bienes eclesiásticos, con origen en el derecho divino, "...por lo que es de temer, que este modo libre de opinar sea fomento de inquitudes y facciones perniciosas al Estado, como lo fue el que invento Luis de Molina (...) $y$ el de Cornelio Jansenio, no obstante de asegurar estaba conforme a la mente de San Agustin"..

Basándose en la condena que pesaba sobre sus Institutiones, los regulares también arremetian contra Juenin. De modo semejante a como lo hicieran en 1767 denunciando a sus enemigos por probabilistas y projesuitas, los dominicos creían ahora tocar la fibra sensible del equipo gubernamental presentando al seminario reformado como foco de incubación para las doctrinas opuestas a las regalías. El alegato terminaba solicitando del Consejo que la teología escolástica se enseñase por la "Suma" de Melchor Cano: tras tal petición se escondía su intento por mantener-a través de métodos indirectos-el control sobre la enseñanza del colegio.

Requerido por el Consejo, Rubín enviaba una enérgica respuesta contra la delación, fechada el 21 de febrero de 1.775(48). En opinión del obispo-que recalca haber elaborado el plan ateniéndose a la Real Cédula de 1768-, los regulares habían procedido de mala fé: los hechos estaban tergiversados en razón de sus intereses, pues "callan que sólo he propuesto en mi plan el tratado particular de Lugares teológicos, que escribió Gaspar Juenin, en el qual se halla compendiado con méthodo fácil, y acomodado a la inteligencia de los principiantes lo mejor que escribio el Docto Melchor Cano, sin las preocupaciones que se le notan a éste, y fueron comunes a su tiempon.

Este planteamiento moderado ante la figura del teólogo escolástico, favorable a los compendios y emparejado a su irritación ante unos regulares que pretenden inmiscuirse en cuestiones de estricta incumbencia episcopal, recuerda la postura de Mayans sobre el mismo punto(49). La obra de Cano es contemplada por Rubin desde una perspectiva superadora; no está dispuesto a admitirla, en ningún momento, desde las razones de autoridad que alegaban aquéllos. Lejos de despreciar al obispo de Canarias,cree que el conocimiento debe progresar sin estancarse en la interpretación-siempre parcial y limitada-de un maestro en particular, por importante que éste sea.

Por lo demás, D. Manuel insiste en que el texto de Juenin está aprobado por el Consejo, al igual que la ortodoxia de Berti confirmada por Benedicto XIV. Las acusaciones sobre puntos de gracia han sido hechas sin probarlas en ningún momento. A propósito del primer autor, previó con agudeza el papel de defensores del ultramontanismo, que asumirian los dominicos en los años siguientes: "...quan reparable es, que unos Regulares Dominicos, quieran resucitar en España la persecución, que los Jesuitas movieron en Francia contra dichas Instituciones", y más adelante, 
"...mi veneración, y cordial afecto al Angélico Maestro, me obliga a decir que los Dominicos confunden sus opiniones particulares con las verdaderas, y genuinas del Sto. Doctor; y el sistema que han adoptado después de las famosas Congregaciones de auxiliis con el de Sto. Thomás».

La escolástica, degenerada a causa de los manejos interesados de las Ordenes, es la responsable de la desfiguración de las opiniones de San Agustín y Sto. Tomás. Una cosa es la enseñanza de la verdadera doctrina de los Santos Doctores, y otra bien distinta el aparato escolástico montado sobre ella.

Rubin defiende a Berti también en el tema de las regalías, pues tal autor expuso la cuestión sin tomar partido. En todo caso, la obra utilizada en el seminario es el compendio de Buzi, expurgado por el rey de cualquier opinión sospechosa. Es más, el obispo volverá contra los dominicos la acusación de antirregalismo, adjuntando a su informe un impreso de conclusiones difundidas en el convento murciano en 1765, entre las cuales se establecia la doctrina de la potestad temporal del papa sobre los príncipes(50).

Justificando su postura personal, el prelado hace uso del recurso a la historia. Basa su juicio en los estudios de Noël Alexandre (otro conocido autor galicano tachado de jansenista), para afirmar que el origen de la difusión del ultramontanismo se halla en las falsas decretales. Y sin solución de continuidad, pasa a ocuparse del jansenismo:

"Qué comparación puede caber entre los autores de mi Plan, y Luis de Molina, de quien distan tanto como éste de San Agustín? Con qué fundamento temen los Regulares quejosos el Jansenismo en el P. Berti, cuio sistema de Gracia se aprobó por la Santa Sede, la misma que condenó al de Jansenio? Con más razón podía temerse, que los Regulares quejosos adopten las artes de los extinguidos, para encender en nuestra España el fuego de la discordia, que tantos estragos causó en otros Reynos".

El texto resume cuanto venimos observando. El sentido del equilibrio que manifiesta Rubin de Celis es el mantenido por nuestros hombres ilustrados: la autoridad dogmática de Roma permanece indiscutida, sin perjuicio para las regalías del soberano.

Este informe sentenciaba prácticamente la polémica, aunque los dominicos todavia enviaron otra representación el 25 de febrero de 1775(51). En efecto, previo informe del fiscal, que alaba la reforma del obispo y muestra una total coincidencia con los criterios que éste exponía en su defensa, el 16 de marzo el Consejo resolvia, quedando «...mui enterado y satisfecho de su acreditado celo Pastoral en promover la enseñanza pública (...) no obstante la delación (...) que como infundada ha desestimado el 
Consejo (...) al Prior y religiosos de dicho Convento, expresándoles que ha sido mui del desagrado del Consejo su representación contra el Plan de Estudios para dicho Seminario.... $\times(52)$.

El predominio general del tomismo no habia ahogado el desarrollo del agustinismo. Colocada la cuestión doctrinal al margen, era más importante para el gobierno apoyar a quien sabía su mejor agente reformista (el obispo), y sofocar cualquier brote de oposición-encarnada por los regulares -, máxime cuando ésta adquiria tintes antirregalistas.

La necesidad era recíproca: el obispo sabía que toda su fuerza se basaba en la ayuda que Madrid le prestase. Y con la resolución favorable al obispo y a su plan de estudios en 1775, tomaba cuerpo una alianza que no se quebrantaria hasta el cambio de circunstancias producido en tiempos de Carlos IV. Es este el momento (exactamente entre 1777 y 1783), en el que el seminario, a través de una serie de gracias concedidas por el consejo, alcanza la facultad de conceder títulos de Bachiller, a la sazón los más útiles y versátiles entre los expedidos por las universidades en aquella época(53).

En la concesión de cada una de las gracias, los ministros mostraron un parecer unánimemente favorable, salvo una solitaria excepción(54). La situación en la ciudad de Murcia era sustancialmente distinta. Al contrario que en el Consejo, la práctica mayoría de los componentes del cabildo municipal murciano, aun siendo partidarios de que se erigiese universidad en Murcia, se resistian a que el seminario desempeñase tal papel, pues no era institución creada-ni adecuada-para ese fin. Sin embargo, bajo la aparente logica de estas argumentaciones, la lectura detallada de los expedientes(55) pone en claro la presencia en la politica local murciana de un grupo de oposición al cambio, con implicaciones ideologicas reaccionarias. Este sector, identificado con los regulares y sus intereses, actúan como portavoces en el nunca abandonado intento de estos últimos por ejercer en la ciudad el dominio sobre la enseñanza. El respeto por la autoridad real, que apoyaba firmemente al obispo, les hizo mantenerse en unos niveles moderados, eludiendo plantear ataques directos contra las nuevas realizaciones.

En la base de la postura sostenida por el Consejo podemos apreciar criterios francamente utilitarios. Como ya se dejo apuntado anteriormente, le resultaba más cómodo establecer los estudios universitarios (de acuerdo con sus planteamientos para difundir las "luces») en una institución ya existente y en la que podia mantener sin dificultades el control ideológico, a salvo de los grupos de oposición (ayuntamiento y regulares), que aventurarse creando una universidad de nueva planta. Finalmente, un último factor vino a incidir sobre tales presupuestos. Floridablanca, primer secretario de Estado entre 1776 y 1792, presto su decidido apoyo a los progresos del seminario(56). 
De entre los documentos estudiados, destaca, por su extensión e interés, el que contiene el comentario que $\mathrm{D}$. Manuel Rubín de Celis hiciera a la bula papal de extinción de la Compañía de Jesús (publicado para su difusion en la diócesis murciana en 1773). Aparecen aquí, resumidos y enriquecidos, aquellos aspectos de su personalidad que venimos estudiando(57).

Tras reconocer la autoridad del pontífice en el gobierno de la Iglesia, califica la extinción de la orden como "suceso desgraciado" que encuentra su razón en la degeneración que habia experimentado a lo largo de su trayectoria histórica. El ideal de una Iglesia universal, le hace salvarla por encima de sus religiones:

«...quiera Dios no lleguen a pensar, que sin ellas no se puede mantener la Iglesia. Este error se desvanece solamente con acordarse de los pasados siglos, que precedieron a las Religiones, sin las quales se conservó la Iglesia por trescientos años».

En correspondencia al ideal, el modelo-tipicamente jensenista-ofrecido por la Iglesia primitiva, consecuencia lógica del recurso a la historia. Parejamente, la actitud ante los regulares encuentra su moderación, no en un odio visceral, sino como resultado de la serena mirada al pasado:

"...estamos muy distantes de presumir, que alguna religión, o todas ellas juntas son la Iglesia (...) no son ellas el todo, sino la parte (...) si todas ellas llegasen a faltar (lo que no permita Dios) no por eso había de faltar Iglesia».

El documento prosigue en un tono semejante, alternando el análisis histórico, para ir desgranando los errores en que habian caído los religiosos (en especial, la producción de una escolástica sin calidad y que sólo servía a los intereses particulares de cada Orden), con las alusiones a los SS. PP. (San Pablo, San Agustín y Santo Tomás). Como subrayábamos, esa moderación le hace reconocer la justa utilidad de las Ordenes religiosas y de los métodos escolásticos-parte integrante del patrimonio heredado por la Iglesia-, cuando son bien empleados.

El tema del jansenismo resultaba ineludible en un documento como éste. A tal efecto, realiza una serie de diferenciaciones, centradas en la defensa del antiprobabilismo, importancia de la gracia, y crítica de los criterios laxos, que-como fue común en los jansenistas españoles-cree derivados de las posiciones probabilistas. Sus criterios rigoristas le hacen condenar, por otra parte, el lujo excesivo, el trato familiar con las personas de sexo diferente, y defender la necesidad de la contrición en el sacramento de la penitencia. Todo ello viene matizado por la visión pesimista del mundo caracteristica en los jansenistas-implícita a lo largo de todo el documento. Vale la pena una larga cita: 
"No merecen más respuestas los que con voces, que pasan de temeridad, y suenan mucho a blasfemia, se atreven a decir, que los Jansenistas han conseguido un gran triunfo con la Bula de extinción: ¿adónde está su victoria? (...) No lo saben los que ignoran quánto dista el Jansenismo del Antiprobabilismo: no lo sabrán los que nunca quieran determinarse, y resolverse a conocer lo que pueden favorecidos de la Divina gracia (...) Los que no siguen tan divino exemplo se propasan a decir, que les mandan imposibles quando les proponen el dulce yugo de la Divina Ley: en esto mismo confiesan su tibieza, y falta de amor de Dios, cuya carga es suave para quien le ama, dura para quien no ama, según nos declaro San Agustín (...) gritan que a sus Personas todo es imposible, que es estilo, que es moda, que es inexcusable (...) Es imposible servir a dos Señores: es necesario romper con Dios, o el mundo: los que con opiniones peregrinas pretenden persuadir a sus Alumnos, que es posible complacer a estos dos dueños, podrán sólo divertir, o adormecer el clamor de su conciencia; pero cuando estubieren más embelesados con el sonido del organo, y la cítara, descenderán en un punto a los infiernos".

En la defensa de su postura religiosa, que insiste en separar del jansenismo doctrinal, se centra en el ataque al probabilismo:

"¿Quién de los dos será más Jansenista? El que consiente al hombre en el peligro, le dificulta el precepto; el que le aparta de las ocasiones le facilita más su cumplimiento: luego más lejos está del Jansenismo el que lleba lo seguro, que el que sigue lo probable".

A la vista de lo expuesto, Rubín de Celis puede ser calificado como jansenista en el sentido "histórico" que del término venimos haciendo uso. Por lo demás, su propia concepción, que contempla al jansenismo como una acusación en manos de probabilistas y jesuitas, está próxima a la que sostuvo en las Cortes de Cádiz el diputado liberal Joaquín Lorenzo Villanueva cuando subrayaba que su uso debía ser restringido a los defensores de las cinco proposiciones y que lo demás era un mito, un ufantasman, creado por los jesuitas para denigrar a quienes no aceptaban el probabilismo como sistema moral(58).

Favorecedor de innovación científica, caritativo y limosnero, vinculado a la Sociedad Económica de Amigos del País de Murcia, partidario de la difusión de la enseñanza y de la mejora del clero, Rubín fue auténtico hombre de su tiempo y obispo cilustradow(59).

El aspecto tocante a las relaciones entre el obispo y los indivíduos del seminario con la Sociedad Económica adquiere una relevancia excepcional. Herr señala tres instituciones particularmente importantes apoya- 
das por el gobierno para la introducción de las «luces" en España: periódicos, universidades y Sociedades Económicas de Amigos del País(60). La de Murcia, fundada en 1777, siguió una trayectoria muy similar a la de sus hermanas españolas. Pese a sus sinceros intentos en pro del fomento de las artes, la economia y la llustración, se vió siempre determinada por la cortedad de las rentas de que disponia. Es aquí donde Rubín aparece como protector de la institución: apoyó la academia de dibujo (a cuyo cargo se puso al escultor Salzillo), entregó 300.000 reales para premios en los distintos concursos (1781), e impuso 500.000 reales sobre la renta de tabacos a fin de cubrir las necesidades de las escuelas creadas. Años más tarde, esta política sería seguida por su sucesor en la sede murciana, D, Victoriano López Gonzalo, quien llegó a ser director de la Sociedad(61).

Las vinculaciones entre el clero murciano y la Económica no se circunscriben a los obispos. En este sentido, los datos iniciales con los que contamos confirman la vinculación indicada por Herr en el plano institucional y con carácter general para todo el país. En el caso de Murcia, el análisis del círculo compuesto por el seminario de San Fulgencio (como centro universitario), la R. S. Económica, y el Correo Literario de Murcia, permite comprobar la íntima relación existente entre los indivíduos de estos organismos, que a su vez delimita el círculo ilustrado murciano. La referencia a tres personajes concretos resume cuanto apuntamos: Luis Santiago Vado, Mariano Garcia Zamora, y Francisco Meseguer(62), todos alumnos fulgentinos, relacionados con la Económica, y fundadores y asiduos colaboradores del Correo Literario. La lista, a buen seguro amplia, comprende a hombres como Gregorio Gisbert (socio nato y censor de la R.S.E.A.M.), José López Padilla (fundador de la misma), etc.

Rubín de Celis murió el 9 de agosto de 1784, en el monasterio de los Gerónimos (La Ñora, Murcia). Carlos III lo hacía cuatro años después, y en 1789 estallaba la crisis revolucionaria francesa. El periodo que se extiende, aproximadamente, hasta esa fecha, conoció la máxima pujanza del seminario. Con un desarrollo casi perfecto de los planes de estudios, al tiempo que se duplicaba su número de alumnos (de 254 en el curso 1773-74, hasta 486 en el de 1799-1800, sin contar los cursantes de gramática), y sin problemas económicos, la institución cobró fama nacional. Apoyada por el gobierno, seguía con ello la marcha general del país, dentro de un contexto de llustración sin las fisuras que se presentarian en tiempos de Carlos IV. Simultáneamente, las fuerzas locales de oposición permanecieron acalladas, ante la fuerza abrumadora que protegía al colegio.

Durante este lapso de tiempo, el desarrollo cultural del centro progresó también sin irregularidades ni sacudidas, manteniendo una línea de uniformidad en la trayectoria ideológica y cultural entre las disposiciones del obispo y su cumplimiento. Junto a los textos, un profesorado de calidad era la clave de la sintonía. Al corte con las órdenes religiosas, sucedio el 
nombramiento por Rubín de catedráticos nuevos, más acordes con el espíritu de la reforma que pensaba realizar. A través de éstos se establece nuevamente la relación con Valencia: son los casos de D. Tomás Fuentes, catedrático de humanidades, de D. Joseph Pérez, rector entre 1772 y 1780, $e$ incluso de D. Antonio Cavanilles, catedrático de filosofía, entre otros(63).

Asi pues, la relación con el círculo valenciano (sin considerar la que, con carácter general, ejercio Mayans sobre toda nuestra llustración, que bien se manifiesta en los criterios moderados de Rubín de Celis), se concreta en el interés de los valencianos en el terreno doctrinal (agustinis$\mathrm{mo}$ ), en los textos y en los mismos indivíduos. Por esta vía podemos comprender aún mejor la naturaleza no radical, católica y equilibrada del pensamiento irradiado del seminario murciano.

Las relaciones de los fulgentinos con la Corte también resultan evidentes, como lo testimonia el apoyo del gobierno, la trayectoria anterior de Rubín de Celis o del propio D. Joseph Pérez, o la aparición-ya en estos tiempos-, de algunos de los profesores o alumnos del seminario en las cátedras y canonjías de San Isidro(64).

De ahi que (soslayando el terreno teológico, que hemos tratado anteriormente), fuese el obispo quien marcase en el seminario, con su propia actitud personal, abierta a la llustración, una línea favorable a la innovación científica y filosofica, que tenía su base en el intento de los ilustrados católicos por armonizar razón y fe, luchando contra los extremos que representaban la ignorancia y la superstición, o el racionalismo deísta y ateo. Así lo deducimos de la lectura de algunos impresos de conclusiones leídas en el seminario(65). Destaca en su contenido el conocimiento de las teorias y experiencias científicas modernas, que se aceptan y defienden: Newton, Torricelli, Tycho Brahe, Copérnico... La historia misma es contemplada como una disciplina científica que sólo tiene validez si se apoya en una crítica severa de las fuentes. Alejada la escolástica, había sido posible abrirse a la Ciencia, sin caer en contradicciones con el dogma religioso(66).

La evolución sufrida por España durante el reinado de Carlos IV-con la Revolución Francesa como telón de fondo-, produjo una serie de consecuencias fundamentales, que Mestre ha resumido asi(67):

-Desprestigio del despotismo ilustrado. Se rompe la unión entre monarquía absoluta y reformismo, y el monarca deja de ser el motor de las reformas.

- Los reformistas evolucionan hacia el liberalismo, unos desde los principios ilustrados, otros por influjo revoluciona- 
rio, o a través de muchos vericuetos y partiendo desde el jansenismo.

- La crisis del Antiguo Régimen se ve agravada en su evolución interna por el desastre económico de las guerras provocadas por la Revolución.

-En el campo espiritual, se produce la ruptura entre revolucionarios y reaccionarios, con la Revolución como cuña separadora.

Cambian los personajes políticos y aparece una nueva generación jansenista, más radical que las precedentes: obispos (Tavira, Abad y La Sierra, López Gonzalo...), clérigos intelectuales (canonigos de la colegial de San Isidro y profesores de los Reales Estudios de San Isidro), religiosos (agustinos), y seglares (el grupo en torno a la condesa de Montijo). Asimismo, desaparecen progresivamente los antiguos focos jansenistas para ir centrándose en los ambientes madrileños.

La fuerza que adquiere el jensenismo en estos tiempos halla su explicación tanto en la propia evolución de las corrientes internas (con base en los planes de estudios universitarios implantados desde 1771, correspondiendo con la actitud más abierta de los agustinos), como por el influjo de los acontecimientos europeos, entre los que destacan el Sínodo de Pistoya y la Constitución Civil del Clero (predominio, en cada caso, del episcopalismo y del galicanismo).

La radicalización aparecía también en el campo de la infiltración del pensamiento ilustrado francés. En este contexto, con una antipatía creciente ante el Santo Oficio, se perfilan acusadamente las relaciones entre ilustrados y jansenistas. Superadas las diferencias de los tiempos pasados, ahora las dos corrientes se habian acercado en una línea unificada frente a los conservadores que se les oponían. Jovellanos es aquí el eslabón más importante.

Por su parte, los conservadores, aglutinados bajo la consigna de combatir la llustracion racionalista francesa, identificaban los intereses eclesiásticos y religiosos con los planteamientos temporales de la Iglesia, vinculada a la estructura político-social del Antiguo Régimen. De este modo, los apologetas considerarán necesaria la unión del Altar y del Trono para la defensa del catolicismo (ataques al liberalismo).

La postura política sostenida por el Estado frente a la radicalización general tuvo sus alternativas. Tras las medidas restrictivas tomadas por Floridablanca en el intento de detener la infiltración de propaganda revolucionaria, el ascenso de Godoy vino acompañado por una mayor libertad de prensa. Los años subsiguientes presencian el ascenso del jansenismo, que tuvo su climax en el llamado "cisma de Urquijo". La caída del ministro precedió a la aceptación de la bula "Auctorem fidei" y al comienzo de la 
persecución de los jansenistas, protagonizada por el ultramontanismo y la Inquisición, a la sombra del poder político. Sin embargo, la tácita tolerancia gubernamental (que veía en los jansenistas un punto de apoyo seguro en la defensa de las regalías) posibilitó que el movimiento no desapareciese(68).

El cambio en la situación general tuvo sus efectos sobre el seminario de San Fulgencio. La evolución del colegio durante este periodo se vería presidida por el cada vez más tibio apoyo del gobierno en el terreno cultural, que derivó finalmente en la represión, en coincidencia con la ruptura entre el poder absolutista y los reformistas. Paralelamente, el centro, en su conjunto, se orientó hacia posturas más radicales.

Dos aspectos cabe diferenciar en el análisis del período que se extiende hasta 1808 (reinado de Carlos IV y pontificado de Victoriano López Gonzalo). El primero es el cronológico. Aquí, las informaciones difieren según se trate de los superiores y profesores del seminario, o de los religiosos y oponentes en general(69). En cuanto a los primeros, coinciden en señalar un correcto funcionamiento de los planes de estudios hasta 1790-1795, en que aparecen elementos extremos. Los segundos, sitúan cualquier época de esplendor del colegio con anterioridad a las reformas de Rubín de Celis. Es decir, que sobre un sustancial continuismo en la enseñanza del pensamiento jansenista e ilustrado entre 1774 y 1808, al comenzar la década de 1790 se hace patente la infiltración del pensamiento radical, tanto filosofico como religioso, en relación con los acontecimientos producidos en el extranjero (Revolución Francesa, Sínodo de Pistoya y Constitución Civil del Clero, ya citados).

Sin embargo, conviene resaltar un hecho fundamental: la evolución hacia el jansenismo radical y, después, hacia el liberalismo, tuvo sus primeras raíces en los mismos textos empleados en el seminario desde los tiempos de Rubín de Celis. Su sucesor, D. Victoriano López Gonzalo, mantuvo los mismos textos e introdujo algunas reformas que apuntaban la radicalización de posturas, como veremos a continuación.

El segundo aspecto, íntimamente relacionado con el primero, atañe directamente a la naturaleza de las doctrinas que durante este periodo hallaron cobijo en el interior del seminario. La documentación utilizada(70) confirma la difusión en el colegio de las obras de Tamburini, Sínodo de Pistoya, etc., así como de los filosofos racionalistas franceses: Voltaire, Rousseau, Diderot y D'Alembert son citados en algunas ocasiones. Sin embargo, el conocimiento de otros autores racionalistas hubo de ser anterior a 1790, como se vio en el apartado IV. En este grupo se englobarían las obras de Montesquieu, Puffendorf, Condillac, e incluso las "Instituciones políticas" del barón de Bielefeld, alguno de los cuales era citado en las clases. 
No obstante, si hemos de dar crédito a las acusaciones de los regulares, las doctrinas que circulaban en el seminario eran ciertamente extremas:

-Ridiculización de las ceremonias y, en general, crítica a las procesiones y formas de religiosidad exterior, «llamando Saynetes espirituales a las (procesiones) del Viernes Santon. -Ataques a la Curia y al Papa, a quien llamaban "Obispo de Roma y nada más". A propósito de su infalibilidad, decían los regulares que "cuando hablaban de la precisión de algún reloj, decian que era más infalible que el Papan.

-En tono similar, se describen los ataques contra los regulares y contra el método escolástico, extendido al método silogístico, al latín e incluso al rechazo de Santo Tomás y de Aristóteles. En algunos profesores, se llegaba a no respetar ni seguir el método y autores de los planes oficiales.

Junto a estas doctrinas, puramente jansenistas, se plantea la oposición al absolutismo, de tal manera que la evolución hacia el liberalismo y el constitucionalismo en los indivíduos del seminario es un proceso evidente ya hacia el cambio de siglo.

No faltaron los problemas con el Tribunal de la Fe. Como dicen los regulares y confirma Llorente, en 1800 el obispo López Gonzalo fue delatado y procesado como jansenista, al haber permitido defender en el seminario algunas conclusiones relativas a la aplicación del valor del sacrificio de la misa y sobre los milagros. A través de una enérgica representación, el obispo consiguio detener el proceso abierto contra su persona(71). Anteriormente (1788), también fuerǫn delatadas las conclusiones sostenidas por Ramón Campos, que contenian la negación de la infalibilidad papal(72).

La difusión de las nuevas corrientes en el seminario contó con factores que la propiciaron. Los mismos superiores del seminario creían que éste tenia licencia para retener libros prohibidos. La procedencia de estas obras hubo de ser varia, aunque en una ocasión se indica expresamente su origen en Cádiz ${ }^{73)}$. También debe ser considerado el contacto secularizador entre alumnos internos y externos, a causa de la gran masa de manteístas que acudian a las aulas del seminario, asi como la actitud de los profesores más radicales. Sin embargo, la aceptación de las teorias extremas que hemos descrito sólo se dio precisamente entre el reducido grupo de tales profesores. Caracteres distintos, mucho más moderados, se derivaban de la línea oficialmente sostenida en los planes de estudios, cuyo primer protagonista va a ser el obispo, y que es la seguida por la totalidad de los superiores y la mayoría de los catedráticos. Esto es así hasta el punto de que $\mathrm{D}$. Victoriano no dudó en expulsar a todos aquellos que transgredieron los planes, adentrándose en la senda del deísmo o del 
ateísmo(74). El que la enseñanza de las nuevas ideas introducidas al margen de aquéllos se produjese en reuniones privadas $y$-salvo raros casos-por vía distinta de la académica, confirma cuanto exponemos. No cabe duda de que eran conocidas por todos los fulgentinos (alumnos y profesores), y de que religiosidad y posturas jansenistas, conocimiento de los "filosofos" francéses y evolución hacia el liberalismo se presentarán unidas en los indivíduos en particular y en la institución en general. Pero los liberales salidos de San Fulgencio, en sus casos más significativos, heredaron la postura de los ilustrados católicos: conocer el deismo y el ateismo significaba, casi siempre, refutarlos.

En la dirección del seminario, el prelado continuaba teniendo el papel más relevante. Victoriano López Gonzalo (obispo de Cartagena entre 1789 y 1805), siguió con la política de reformas emprendida por Rubín de Celis. Director de la Sociedad Económica de Murcia, reformará el plan de estudios de cánones, conseguirá del Consejo la gracia de que los seminaristas teólogos pudiesen optar a los exámenes de grado mayor, y redactará las constituciones de 1803, en las que incluia el plan de gramática latina que otorgó en 1801(75). En su obra reformadora, destacan precisamente las nuevas constituciones, por cuanto recogen-en lo cultural-todas las disposiciones anteriores sobre estudios (o introducen nuevos elementos pedagógicos, totalmente abiertos), a la vez que dan al seminario una nueva estructuración, más compleja y acorde con los nuevos tiempos, sin hacerle perder por ello su carácter de auténtica institución conciliar.

Las coincidencias con Rubín de Celis son más extensas, en especial en materia de estudios, terreno éste en el que mantuvo los textos vigentes desde 1774. El jansenismo y la apertura ante la ilustración científica están también presentes en su postura personal: desprecio de la moral laxa y de la escolástica, unido a iguales sentimientós frente a las novedades doctrinales o los entretenimientos profanos. Se advierte, eso sí, un matiz más ra. dical en sus opiniones(76), que nos permite enmarcar la reforma del plan de cánones. Se introduce en él la obra de un autor más claramente jansenista: las Instituciones canónicas, de Domingo Cabalario, en sustitución de los textos de Selvagio y Del Vaulx, que se suprimian por lo inútil de algunas partes del primero y la excesiva indulgencia del segundo. Dos nuevos textos se consagran en las constituciones de 1803: el catecismo del obispo de Soissons, Francisco de Fitz-James (jansenista), y el Compendium elementorum mathesae universae (in usum studiosae Juventutis adornatum), de Christian Wolf (ilustrado)(77).

Pero si la controversia sostenida con los dominicos en 1775 marcó el comienzo del ascenso del seminario, merced al apoyo estatal, la que se levantó a ráiz de la aprobación de las constituciones señalaria el punto final del proceso: Por otra parte, es en su desarrollo donde mejor expuso López Gonzalo sus planteamientos personales. 
La cuestión se enmarca en el cambio de circunstancias políticas que se produjo en 1800 (caída de Urquijo y comienzo de la ofensiva antijansenista). Todavia dos años antes, el Consejo había aprobado sin ningún problema la reforma del plan de cánones. Siguiendo el tramite normal, las nuevas constituciones, una vez remitidas a Madrid por el obispo, fueron informadas favorablemente por los fiscales, y aprobadas por el Consejo, con fecha de $1 .^{\circ}$ de diciembre de 1800.

Días más tarde, Urquijo era destituido de su cargo, y el 27 de diciembre, el rey enviaba el texto de las constituciones a un indivíduo de su confianza. El informe que este censor (anónimo) remitió(78) dirigía sus críticas, básicamente, contra los planes de teología y derecho. Con criterios tradicionalistas cargados de nacionalismo, recurre a los grandes teólogos españoles del siglo XVI, para acusar de galicanismo a Juenin y a Berti de "formar cierta escuela" siguiendo todas las opiniones agustinianas. Las objeciones son aún más graves en cuanto se refiere a Cabalario, a causa de su desprecio por la Inquisición, reducciones a la autoridad papal y ponderación excesiva de los abusos de Roma; asimismo, tras colocar a este autor en posiciones próximas a las de luteranos y calvinistas, no le parecen adecuados los ataques que dirige contra los regulares, ni el énfasis que pone en describir los primeros siglos de la Iglesia.

El 10 de mayo de 1802, contestaba el obispo a los argumentos de su crítico(79). Todo el informe de López Gonzalo se ve presidido por la extrañeza-mezclada con tintes de amargura-que siente ante lo ocurrido: el plan literario que había remitido inserto en las constituciones habia sido aprobado por el Consejo hacía ya más de veinte años. Sobre los cursos de teologia, López define al censor como "enteramente huésped en materias teológicas", y opone al nacionalismo de su contrario, la concepción que él tiene de una lglesia universal, no sujeta a las barreras impuestas por uno u otro Estado:

"Quisiera yo que quando se trata de cosas pertenecientes a la Yglesia que cuenta entre sus caracteres el de Católica o universal a una congregación que es de todos tiempos y Payses, (...) según enseña San Pablo (...) Quisiera yo, digo, que nunca se oyera hablar de Teólogo español, de Juventud española, sino de teólogo cristiano, de Juventud cristiana».

Esta visión exige la separación entre la potestad papal y la real, entre Iglesia y Estado, que explicaría la defensa que hace a continuación de los cuatro artículos de la declaración del clero galicano de 1682.

Por otra parte, la obra de Berti-prosigue-se ajusta exactamente a la doctrina de San Agustín, y además lo hace con una admirable exposición dogmática alejada de escolasticismos estériles. Tanto en esta obra como en la de Juenin, la base fundamental es la Sagrada Escritura, 
seguida de los Santos Padres, concilios y teólogos y comentadores más célebres.

En cuanto a la obra de Cabalario, el obispo insiste en que debe dejarse aparte el juicio personal sobre la vida del autor, y recuerda que la obra ha sido aprobada por el rey y por la Inquisición.

Los párrafos finales del documento, siempre repletos de amargura, contienen las advertencias que hace un hombre ya cansado y desengañado:

"¿Querrá el Consejo que se vuelvan a entronizar las falsas decretales, origen de tantos daños causados al Sacerdocio y al Ymperio? ¿Querrá que a la sombra de estos supuestos y perniciosos documentos se vuelvan a concentrar todas las clases de autoridad en una sola mano? ¿Querrá que a fuerza de exaltar desmedidamente las prerrogativas de la Santa Sede se desconozcan otra vez los derechos del Episcopado y de la Soberanía?... Descartemos norabuena las peligrosas novedades, resistamos a los innovadores que a título de reforma quisieren alterar la unidad de la Yglesia, y a privar a la Silla Apostólica de la primacia y respeto legítimo que le es debido: pero resistamos también a la pérfida astucia de los que so color de precaver este inconveniente quieren cerrar la puerta a toda reforma, a los que sembrando temores vanos en las almas timoratas y débiles tiran a perpetuar los abusos, y a pretexto de establecer la autoridad de la Santa Sede (...) quieren realmente acreditar las máximas favorables a la ambición y codicia de los curiales...".

Estos párrafos (perfecto resumen de la mentalidad de López Gonzalo), no surtieron efecto: las constituciones, publicadas en 1803, fueron totalmente mutiladas en su parte literaria. La Corona había anulado, con efectos que serian definitivos; los textos y la obra que ella misma habia sido la primera en apoyar, veinticinco años antes. El hecho no deja de estar cargado de simbolismo: se había roto la antigua armonia-y López era plenamente consciente-vivida en tiempos de Carlos III.

A partir de ese momento, el seminario comienza su caída, en todos los órdenes. Una sublevación, protagonizada por los mateístas al promulgarse las constituciones (1804), hizo que el propio obispo se pronunciase por la supresión de la cátedra de derecho civil y la restitución del seminario a su estricto carácter conciliar. Entretanto, el Estado retoma sus antiguos ímpetus centralizadores, con la promulgación del Ilamado "plan Caballe- 
ron, (1807), que había de aplicarse también al seminario murciano. Este hecho suponía la abolición de la vigencia oficial de cualquier plan de estudios anterior, incluidos los de 1774 y 1778 . En virtud de la misma ley, cesaba el colegio en la facultad de conferir grados mayores, y en el privilegio que permitia a sus seminaristas teólogos acceder a grado mayor. Aprovechando el momento, el nuevo obispo José Ximénez suprimía todas las cátedras de derecho, civil y canónico. Todas las reformas comenzadas, no ya con Rubin de Celis, sino incluso algunas de las realizadas por Belluga, habian sido borradas en apenas unos meses(80).

Pero el fruto de la época de reformas no habia desaparecido. En la primera década del nuevo siglo, el flujo de antiguos alumnos fulgentinos hacia la Corte se hace más intenso. Allí los vemos en las canonjías de San Isidro o en el círculo de la condesa de Montijo, relacionados con personalidades de la talla de Jovellanos. Algunos de ellos, como Antonio Posadas Rubín de Celis o Diego Clemencín, tuvieron destacado papel en las primeras etapas del liberalismo español. Se cumplia así en el seminario de San Fulgencio la evolución hacia el constitucionalismo desde los planteamientos jansenistas y los criterios de los ilustrados católicos. La mejor prueba que podemos aportar son las "Proposiciones sobre la armonia de la religión católica», leídas en el colegio en 1.821, cuyo fin era "manifestar la perfecta conformidad de nuestra Constitución con la Religión católica y el reciproco auxilio que se prestan»(81).

\section{NOTAS}

(1) Vicente DE LA FUENTE, Historia de las universidades, Colegios y demás establecimientos de Enseñanza en España. Madrid, 1889, tomo IV, pp. 144-146.

(2) El único trabajo que se ha ocupado del seminario ha sido el de F. GIMENEZ DE GREGORIO, "El colegio-seminario conciliar de San Fulgencio», en Anales de la Universidad de Murcia, vol. VIII, años 1949-1950. Es muy valiosa la aportación de fondos documentales para el estudio del seminario.

(3) E. APPOLIS, Les jansenistes espagno/s. Sabodi, Bordeaux, 1.966 p. 5.

(4) A. MESTRE, «Religión y cultura en el siglo XVIII español», en Historia de la Iglesia en España, B.A.C., Madrid, 1979, tomo IV p. 641.

(5) Ibid., pp. 641-646.

(6) Ibid., p. 648. Id. "Los humanistas españoles del XVI en la religiosidad de los ilustrados valencianos", en Hispania Sacra, XXXIII, (1981), pp. 229-273.

(7) Ibid., p. 657.

(8) A. MESTRE, Ilustración y reforma de la Iglesia, Valencia, 1968, pp. 451-454.

(9) F. MARTIN HERNANDEZ, Los seminarios españoles: Historia y pedagogia, 1.563-1700. Ed. Sigueme, Salamanca, 1964, Caps. IV y V. 
(10) Desde principios de siglo, estas escuelas eran la suarista, tomista y escotista. En razón de la pertenencia, los alumnos acudian, respectivamente, a los conventos de la Anunciata (jesuitas), Santo Domingo (dominicos) e Inmaculada Concepción (franciscanos).

(11) Archivo Municipal de Murcia (A. M. M.) «Escritura definitiva de fundaciones. (Roma, 18 de noviembre de 1741). Reimpresa en Murcia en 1777, $76 \mathrm{pp}$. Las Constituciones de Belluga, otorgadas en 1707, en Archivo Histórico Nacional, Madrid, (A. H. N.), Consejos, Leg. 5.496.

(12) Escritura cit., punto 144, p. 46. Floridablanca confirmó personalmente haber sido el primer catedrático del seminario. Archivo General de Simancas (A. G. S.), Leg. 971 antiguo. Expte. El rector y seminario... (1781), nota autógrafa de 29 de octubre de 1781.

(13) V. DE LA FUENTE. loc. cit.

(14) R. KAGAN, Universidad y sociedad en la España Moderna, Tecnos, 1981, p. 230 y ss.

(15) F. y J. MARTIN HERNANDEZ, Los seminarios españoles en la época de la llustración, C. S. I. C. Madrid, 1963. p. 198 y ss. Significativamente, dos dias antes el gobierno habia decretado la extinción de las cátedras y autores de la escuela jesuistica en todas las universidades y estudios del Reino.

(16) Este plan nunca se redactó, pero si se hizo el destinado a las universidades, obra de Mayans en 1767. A. MESTRE, «Religión y cultura...», pp. 671-672.

(17) Algunos datos biográficos en P. TEJERA, Biblioteca del murciano o ensayo de un diccionario biográfico y bibliográfico de la literatura en Murcias, Madrid, Tip. Rev. de Archivos, 1922. Tomo II, p. 164 y ss., asi como en dos sermones fúnebres que le dedico la R. S. E. A. P. de Murcia, en 27 de noviembre de 1784 y $1 .^{\circ}$ de diciembre de 1831, pronunciados, respectivamente, por Fr. Antonino Galvez y por D. Leandro Alvarez (A. M. M.). Rubin de Celis nació en el valle de Cabuérniga (Santander), posiblemente a principios de siglo. Se doctoró en derecho civil y canónico en la universidad de Valladolid. Coadjutor vicario y provisor interino, sucesivamente, en los obispados de Murcia (con el obispo Mateo López, 1742-1752) y Palencia. Juez Inquisidor y, más tarde, obispo de Valladolid, desde donde pasó a ocupar la sede murciana.

(18) Elogio fünebre de Galvez, ya cit., p. XLIV, nota 4. Este viaje hubo de tener lugar en los años anteriores a 1740, año del fin de la estancia de Jacquier en el citado Colegio. Por otra parte, es el momento en que Rubin ya ha terminado sus estudios, pero aún no ha pasado a ocupar su primer destino.

(19) Plan de estudios para filosofia, teología escolástica y teologia moral (16 de septiembre de 1774). Plan de estudios para derecho civil y canónico (16 de septiembre de 1778). Ambos en A. H. N., Cons., leg. 5496 Expte... sobre aprobación de las Constituciones o Estatutos que ha formado para el gobierno del seminario conciliar de San Fulgencio... (Murcia, 1800).

(20) La primera edición es de Roma (1757, 6 tomos). Jacquier era francés, religioso mínimo (1711-1788). Consumado matemático, conocedor de las lenguas antiguas (hebreo y griego), penetró en el terreno del cálculo integral y de la astronomia. Divulgador de Newton (Comentario sobre Newton, 1739), catedrático de Sagrada Escritura y de física experimental en el Colegio Urbano de Roma, y miembro de multitud de academias europeas. (Biografía eclesiástica completa. Madrid-Barcelona, 1856, tomo X, p. 499).

(21) R. HERR, España y la Revolución del siglo XVIII. Madrid, Aguilar, 1964. pp. 141-142 y 144. Oficialmente apoyada por el Consejo para su introducción en las universidades, alcanzo al menos seis ediciones antes de 1805. El Archivo Histórico de Orihuela (A. H. O.) posee varias de ellas, como la de Venecia (Occhi, 1773) y dos de Valencia (1778 y 1782, por B. Monfort).

(22) Teólogo, oratoniano (1650 -1713). Sus Institutiones theologicae ad usum seminariorum levantaron vivas polémicas en Francia, en las que fue acusado de jansenismo. La campaña culminó con la prohibición de la obra "donec corrigatur", efectuada por Clemente XI en 1708 (Dictionaire de Theologie Catholique, Paris, 1925, tomo VIII, 1719). El tratado elegido por Rubin es el De Locis Theologicis liber singularis ex institutionibus ad usum seminariorum, primer tomo de las referidas Institutiones... El A. H. O. posee ejemplares de la edición valenciana de 1771 (Monfort).

(23) DANIEL CONCINA. Teólogo dominico (1686-1757). Gozó de la protección de Benedicto XIV, pero Rávago hizo lo posible por impedir su difusión. 
(24) Librorum XXXVII De theologicis disciplinis accurata synopsis, quam ad usum seminarii auximatis concinnavit... F. Hieronymus Maria Buzius agustinianus... EI A. H. O. conserva un ejemplar del $4 .^{\circ}$ y último tomo, impreso en Roma «sumptibus remondinianis, en 1759. Juan Lorenzo Berti era un teólogo agustino italiano (1696-1766). Su obra De theologicis discip/inis se publicó en Roma entre 1739 y 1745. Denunciada como jansenista, Benedicto XIV aprobó la ortodoxia de la obra (D. T. C., tomo II, p. 795; Cf. B. E. C., tomo II, p. 632).

(25) A. MESTRE, «Religión y cultura...», p. 671.

(26) Por otra parte, la Real Cédula sobre «erección de seminarios conciliares", prohibía la adopción de sistemas particulares, reduciéndose a un justo límite las sutilezas Escolásticas, prohibiendo la enseñanza de interpretaciones distintas a las de San Agustín o Santo Tomás. Años más tarde, el obispo López Gonzalo utilizará claramente la denominación «teología dogmática». (A. H. N., Cons. Leg. 5.496, Expte. sobre las Constituciones,... 1800).

(27) Todavia en 1790, Jovellanos-en el plan de estudios que propuso para el Colegio Imperial de Calatrava-abogaba por la implantación de autores vigentes con un decenio largo de anticipación en Murcia: Heinecke, Berti, Selvagio, Wolf, Jacquier, Gravina, Vinnen, Asso y Manuel, etc. (J. SARRAILH, La España ilustrada de la segunda mitad del siglo XVIII, F. C. E., México-Buenos Aires, 1.957, pp. 156-157).

(28) A. MESTRE, Ilustración y reforma..., p. 446. Aunque las universidades se inclinaron por la tendencia tomista, favorecida por el Consejo, no se obstaculizó el desarrollo del agustinismo.

(29) Ibid., p. 410. La opinión de Mayans respecto a Concina no era muy favorable.

(30) Uno de ellos, de 1778, en A. H. N., Cons., Leg. 5.496.

(31) En 1781, Rubín de Celis puso un pasante para explicar griego a los alumnos más adelantados. (A. H. N., Cons., leg. 5.496, Diligencia de visita... 1815).

(32) Básicamente, el alumnado de esta cátedra era los seglares manteístas. En su esfuerzo por preservar el carácter conciliar del seminario, los prelados murcianos prohibieron repetidamente la concurrencia a estas aulas de los colegiales seminaristas (internos, becas de gracia o porcionistas), que se educaban para la carrera eclesiástica. (A. H. N., Cons., Leg. 5.496, Diligencia de visita...).

(33) Estas incompatibilidades no existieron en la mente de Rubín, que más bien consideraba a los dos planes de estudios como componentes de un todo sin soluciones de continuidad.

(34) A. MESTRE, Ilustración y reforma..., p. 344.

(35) Plan de estudios de derecho (1.778), loc. cit.

(36) J. Lorenzo Selvagio (1728-1772), eclesiástico, catedrático de derecho civil y canónico, arqueólogo.

(37) Vallensi, andrea, (vulgo, del Vaulx). Paratitla sive summaria et methodica explicatio decretalium D. Gregorii papae IX. Antuerpiae, apud Petrum Bellerum, 1660. La edición consultada en A. H. O.

(38) Aunque no se colocase ninguna obra de Van Espen, nótese la correlación existente entre su predominio en el campo de la enseñanza universitaria del derecho canónico y el establecimiento de textos que defienden el rigorismo moral (A. MESTRE, "Religión y cultura...", $p$. 674). En Murcia, al conocimiento de Van Espen se une el uso de Juenin y Concina.

(39) Arnold Vinnen, latinizado Vinnius. Jurisconsulto holandés (1588-1657), profesor de Derecho Romano en la universidad de Leyden. Este texto ya fue elegido por Belluga para esta cátedra del seminario. Mayans leyó y apreció en su juventud los Arnoldi Vinii comentarii Institutionum Imperialum (A. MESTRE, Ilustración y reforma... pp. 41-42). El A. H. O. conserva una edición de Valencia, de 1767, por Monfort, completada con anotaciones de Heinecke.

(40) Gravina, J. V. (1644-1718). Jurisconsulto y literato, profesor de derecho civil y canónico, miembro de la Academia de los Arcades y fundador de la de Quirini (1711). La obra puede consultarse también en el A. H. O. (Originum iuris civilis, libri tres, et de romano imperio, liber singularis. Nápoles, 1778, Ex typographia Haeredum Pittanti, 4 volúmenes en un tomo. Otra edición, también veneciana, en 1758). 
(41) J. G. Heinecke (Heineccius). Jurisconsulto y filósofo alemán (1681-1741). La obra de Marín y Mendoza - a la sazón catedrático de esta disciplina en los Reales Estudios de San Isidro-, son los Joan Gotlieb Heineccii Elementa iuris Naturae et Gentium, castigationibus ex catholicorum doctrina et Juris Historia aucta, ab Joachimo Marin et Mendoza, J. N. et G. in regio matrit. Lyceo Prof. Matriti: ex Officina Emmanuel Martini. Anno 1776 (en 4. ${ }^{2}$ ). Cfr. J. SEMPERE Y GUARINOS, Ensayo de una biblioteca española de los mejores escritores del reinado de Carlos III (Madrid, 1785-1789, volumen IV, pp. 9-11).

(42) La expresión "derecho natural y de gentes", que circulaba por Europa desde hacía más de cien años (en las universidades católicas y protestantes), lejos de tener relación con las teorias rousseaunianas, significaba el concepto que del derecho natural tenían los ilustrados católicos, "como conjunto de leyes dimanadas de Dios y participadas a los hombres por medio de la razón natural». El monarca insistió en que la enseñanza de esta materia debla demostrar "la unión necesaria de la Religión, de la Moral y de la Política". El derecho de gentes consistía en los mismos principios aplicados en las relaciones entre los Estados. El cambio en las circunstancias políticas hizo que esta ensenanza fuese suprimida y prohibida el 31 de julio de 1794. Sin embargo, el interés por ella, sembrado en los años precedentes, no disminuyó ( $R$. HERR, op. cit., p. 145; 310-311).

(43) Ibid., p. 282. Cf. J. SEMPERE Y GUARINOS, op. cit.,vol. l, p. 147-154.

(44) R. HERR, op. cit., p. 141-144.

(45) A. MESTRE, "Religión y cultura...», p. 676.

(46) A. H. N., Cons. leg. 5.495. Representación del Prior de Santo Domingo de la Ciudad de Murcia... 1767.

(47) A. H. N., Cons. Leg. 606-607. Representación del Prior y Religiosos del combento de Santo Domingo de la Ciudad de Murcia... (24 septiembre 1774).

(48) A. H. N., Cons. Leg. 606-607 Informe de Rubin de Celis (21 febrero 1775).

(49) A. MESTRE, Ilustración y reforma de la lglesia, pp. 340-342.

(50) Este impreso en el citado legajo 606-607 del A. H. N.

(51) Ibid.

(52) Ibid. En Valencia, el resultado de la controversia tuvo gran interés para los partidarios del agustinismo. Mayans copió íntegramente la resolución del Consejo. (B. A. H. M., 650, autógrafo de Mayans).

(53) - Real Provisión de 22 de agosto de 1777, por la que se incorporaban los estudios del seminario de San Fulgencio a las universidades de Orihuela o Granada, declarándose válidos los que en aquél se efectuasen (de teología y filosófía) para la obtención de grados en dichas universidades. No se facultaba para la obtención de grados mayores (solo el de Bachiller), ni tampoco se comprendla a los manteístas (y si a los colegiales y porcionistas).

-Real provisión de $1 .^{\circ}$ de diciembre de 1781 , extendiendo la gracia anterior a los cursantes de derecho civil y canónico desde el plan de 1778 , e incluyendo a todo el alumnado.

-Real Cédula de 22 de julio de 1783, por la que se concedia al seminario la prerrogativa de conceder a sus alumnos el grado de Bachiller, sin más requisito que cumplir lo dispuesto legalmente en materia de matrículas y exámenes por el Consejo para todas las universidades.

(54) Durante las discusiones en el Consejo sobre la concesión de la gracia de 1781, el mjnistro Juan Acedo Rico se opuso a ella, mostrando argumentos de marcado matiz conservador.

(55) A. H. N. Cons. Leg. 5.496, varios expedientes entre 1777 y 1783.

(56) A. G. S. Leg. cit. El expediente de 1783 fue promovido por orden de Moñino (A. H. N., Cons., Leg. 5.496).

(57) El documento, impreso, está fechado el 3 de diciembre de 1773 (en A. M. M.).

(58) A. MESTRE, "Religión y cultura...», p. 665.

(59) P. TEJERA, loc., cit., le imputa la realización de dos traducciones: un Tratado de cánamo, de M. Marcandier (Madrid, 1774, por Sancha), y una Historia de los progresos del entendi- 
miento humano en las ciencias exactas y en las artes que dependen de ella, de $\mathrm{M}$. Saverien (Madrid, Sancha, 1775). HERR, op. cit., cita tanto las traducciones como su papel de obispo, pero en ningún momento afirma si se trata del mismo personaje o de dos distintos. Por su parte, SARRAILH, op. cit., lo da como traductor de Saverien, y le atribuye otro opúsculo: Junta que en casa de D. Santos Celis tuvieron ciertos eruditos a la violeta, y parecer que sobre dicho papel ha dado el mismo D. Manuel Noriega... (publicado en Madrid en Los eruditos a la violeta, 1781). Este opúsculo confirma casi con total seguridad la identidad de Rubin de Celis como autor de estas traducciónes, puesto que D. Manuel Noriega no es otro que D. Manuel Rubín de Celis Noriega, rector que fue del seminario en varias ocasiones.

(60) R. HERR, op. cit. p. 129.

(61) Reseña histórica de la R. S. E. de Amigos del País de la Ciudad de Murcia (A. M. M.).

(62) Vado fue conocido como matemático, García Zamora como predicador, y Meseguer como médico y hombre polifacético. Sobre sus biografias, Cf. TEJERA, op. cit.

(63) Cuatro cartas de Tomás Fuentes a Gregorio Mayans revelan la amistad que unia a Fuentes con los hermanos Mayans (Archivo Ayuntamiento de Valencia, fondo Serrano Morales, cajas 19 y 60. Agradecemos a D. Antonio Mestre estas referencias). En cuanto a Pérez, arcediano de Chinchilla, pertenecia al gremio y claustro de Valencia. Anteriormente, aparece en el círculo de valencianos en la Corte, en donde se presentó como candidato al nombramiento de director de los Reales Estudios de San Isidro. Gregorio Mayans, Epistolario VI. Mayans y Pérez Bayer. Estudio preliminar por A. MESTRE, p. LXII-LXIII. Los regulares, en 1815, atribuyeron la iniciativa de las reformas a este personaje. Aunque sin lugar a dudas exageraban, Pérez hubo de ser el más eficaz colaborador de Rubin de Celis en la tarea reformista, y puente directo de la re. lación con los valencianos, tanto en dicha ciudad como en Madrid.

(64) El primer fulgentino que aparece en una canonjia de San Isidro fue Antonio Puyal, en 1777. El flujo sería cada vez más fuerte. (A. H. N., cons., Leg. 5.496, Diligencia de visita...).

(65) Conclusiones..., (A. H. N., Cons., Leg. 5.496).

(66) En el campo de la psicología, el deseo de armonizar razón y dogma les hace caer en la formulación de teorías artificiosas y apriorísticas. Esta tara se deriva del postulado previo que se establece para el estudio psicológico: la defensa ante los impíos de la inmortalidad del alma (identifican mente y alma). En otros terrenos, se cita a Leibniz y Hobbes, pero para su refutación. En lógica se advierte la inclinación hacia las tesis sensualistas (en las que destacaria más tarde un fulgentino, Ramón Campos, claramente influido por Condillac). Se condena el lujo inmoderado, aunque son partidarios del fomento del comercio, en especial si estimula la producción.

(67) A. MESTRE, «Religión y cultura...", pp. 717-743.

(68) Ibid.

(69) A. N. H. Cons., Leg. 5.496, Diligencia de visita... (1815).

(70) Ibid.

(71) J. A. LLORENTE, Historia critica de la Inquisición en España. Tomo IV, p. 105.

(72) A GUY, "Ramón Campos, disciple de Condillac», en Pensee hispanique et philosophie française des /umieres. Universidad de Tolouse-Le Mirail, 1.980.

(73) A. H. N. Cons., Leg. 5.496, Diligencia de visita...

(74) Ibid.

(75) - Real provisión de 3 de septiembre de 1799, por la que se concede la gracia de que con seis matrículas, los colegiales teólogos pudiesen acceder a los grados mayores en cualquier universidad aprobada.

-Plan de estudios para derecho canónico, aprobado en la misma Real provisión.

- Plan de estudios para gramática latina, de 17 de agosto de 1801.

Todas estas disposiciones, así como el plan gubernativo de 23 de octubre de 1790 , se incluyen en las constituciones de 1803 (A. H. N., cons., Leg. 5.496).

$$
\text { D. Victoriano López... a su seminario conciliar..., } 1799 \text { (A. M. M.). }
$$


(77) Varias ediciones de esta obra en A. H. O.

(78) A. H. N. Cons., Leg. 5.496 Expte... sobre aprobación de las Constituciones, 1801.

(79) Ibid. Contestación de López Gonzalo, 10 de mayo de 1802.

(80) A. H. N. Cons., leg. 5.496, Diligencia de visita..., 1815.

(81) Proposiciones del mismo título. Murcia, Imprenta del ciudadano Mario Bellido, año 1821 (A. M. M.). 


\title{
JUAN NICOLAS BÖHL DE FABER Y LA POLEMICA DIECIOCHESCA SOBRE EL TEATRO (*)
}

\author{
Por Guillermo CARNERO
}

Universidad de Alicante

La polémica literaria que, en la España del segundo decenio del siglo XIX, enfrentó a Juan Nicolás Böhl y sus acólitos con José Joaquín de Mora y Antonio Alcalá Galiano, sienta las bases de una de las vetas del pensamiento romántico en nuestro país, por la adhesión de los primeros al ideario schlegeliano y su reivindicación de determinada literatura tradicional hecha bandera de combate contra la preceptiva Neoclásica. Claro

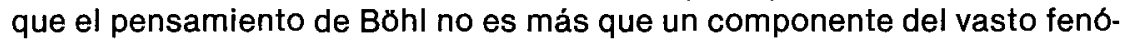
meno cultural que se llama Romanticismo; un fenomeno plural como lo es la respuesta de la intelectualidad europea ante la nueva era que inaugura la Revolución Francesa; un fenómeno que se va sucesivamente definiendo en solidaridad con la aceleración histórica que caracteriza a la primera mitad del XIX europeo. Ello obliga a hacer, entre otras pertinentes, una lectura política del origen, variantes y evolución del movimiento romántico, como he intentado en otro lugar(1) a propósito de Böhl.

El primer Romanticismo teórico, en el que éste se inserta, obedeciendo a su coyuntura histórica, se esfuerza por definir una voluntad y una conciencia nacionales, partiendo de una filosofía en cuyo centro está el equívoco concepto de "pueblo". Las supuestas manifestaciones culturales de ese "pueblo" son indagadas y manipuladas desde un folklorismo ingenuo y acrítico, que considera castizo todo lo que no lleve el sello de la sabiduria cosmopolita dieciochesca, y que no distingue el auténtico folklore del popularismo culto del pasado. Así Böhl y sus cofrades escogerán como cifra del espíritu nacional español el teatro del Barroco, y concreta- 
mente la obra de Calderón. Tal elección es una opción política, y ya expondremos sus dimensiones. Obedece, en última instancia, al deseo de presentar una alternativa a la lectura censoria que de ese teatro habían hecho, pensando también políticamente, las minorías llustradas de la segunda mitad del XVIII.

Pero el debate sobre nuestro teatro tiene una larga prehistoria cuando lo asumen los participantes en la polémica Böhl-Mora; lo que hará Juan Nicolás es retrotraerlo y adaptarlo a cuestiones de candente y peligrosa actualidad en la España de su tiempo: la Guerra de la Independencia, el "afrancesamiento" y el liberalismo. Un terreno en el que sus adversarios, en la España del Sexenio, se ven privados del derecho de réplica, por una autocensura explicable desde el instinto de conservacion. El ataque a $\mathrm{Cal}$ derón, por Mora y Galiano, desde una óptica casi exclusivamente estilística-lo único que pueden hacer sin peligro-interesa poco. Lo que sí tiene interés histórico es la acuñación por Böhl, desde la coetaneidad política, de un fervor calderoniano tan tradicional como su opuesto.

De hecho, el debate sobre el teatro estalla en la Europa culta en el siglo XVII, y se recrudece en el XVIII al compás de los nuevos vientos ideológicos. Para historiarlo en términos generales no hay lugar aquí; para el caso español, sentó las bases Cotarelo(2). Limitándonos a España, si las reservas a lo que los manuales llaman la formula de un «teatro nacional» parten inicialmente de consideraciones estéticas y de moral universal, en el XVIII van a concretarse, sin olvidar esos precedentes, sobre la base de los propósitos de las minorías llustradas, que ven en el teatro, medio privilegiado de comunicación de masas, un agente rector de la conciencia colectiva en los ámbitos del respeto a la universalidad de la Legislación del Estado, de la formación de las clases dominantes y del pueblo bajo, de la difusión de una religiosidad consciente y equilibrada y, en general, de todas las dimensiones del ser moral, ya individual e intimo, ya colectivo y civico.

En la segunda parte de este estudio veremos los argumentos de Böhl y sus adláteres, y los de Mora y Alcalá Galiano. Unos y otros se tiñen de significado tocante a las pugnas ideológicas de la España fernandina. Pero no surgen en ella ab ovo. Investigar su ascendencia puede ayudar a perfilar el problema. 
"Quiero decir que las cuestiones sobre la utilidad o perjuicio del teatro, sobre su licitud o ilicitud, sobre su tolerancia o extinción, tienen a su favor y contra sí, igual número y peso de razones".

J. P. Forner, Respuesta del Cura de Mairenilla

La Taconera a la carta de Juan Perote...(3).

Empecemos por los antecedentes de la censura del teatro barroco en Mora y Galiano. Para encontrarlos no es preciso llegarse a la llustración ni al Neoclasismo. Muchos años antes de Boileau y de Pope, en 1641, un fino erudito, injustamente olvidado a pesar de los toques de atención de Mayans, Menéndez Pelayo y Erasmo Buceta (editor de sus Paradojas racionales), o sea Antonio López de Vega, se expresaba así en el segundo de los Diálogos dedicados a las Letras en su Heráclito y Demócrito de nuestro siglo, al censurar a los poetas dramáticos de su tiempo:

"El Cómico (empecemos por él) se confunde con el Trágico, y no siendo uno, ni otro, no sólo alterna en una misma fábula el Coturno con el Zueco, mas aun al mismo tiempo dando su pie a cada uno, se los calza a entrambos juntos (...) Introduce lo jocoso muchas veces en el paso de suspensión, que moviendo a risa, disminuye, y aun desvanece el afecto que era del intento. Hace sentir, obrar y hablar los Reyes como los ínfimos del pueblo; y los ínfimos del pueblo tal vez como los Reyes. Ríense de los rigores del Arte...".

"Guárdese, así en la invención del caso, como en el estilo, la propiedad conveniente a las personas introducidas".

"En cuanto a lo prudencial, disposición y verosimilitud de cada una (Tragedia y Comedia), ¿qué costumbre moderna puede disculpar los monstruos, inverosimilitudes y desatinos que cada día nos hacen tragar los más de nuestros Cómicos (...) Fingid con novedad y verosimilitud. Disponed con suspensión y claridad (...) Forman otros la maraña de casos y accidentes inverosímiles: pareciéndoles, si se lo notamos, que satisfacen con que al examen de la Naturaleza se hallen posibles; sin acabar de reconocer esta diferencia entre la posibilidad y verosimilitud, ni queriendo persuadirse a que no todo lo posible es verosimil (...) y no es su Comedia otra cosa que una junta de impropiedades, indecencias y pasos mal avenidos; pueril la invención; confusa o vulgarísima la disposición de la maraña; y su nudo, aun sin haberlo apretado, más cortado que suelto, como si fuera el Gordiano.... $x^{(4)}$. 
Lo que reprende López de Vega es, pues, la mezcla de lo trágico y lo cómico, la falta de "decoro" (en el sentido neoclásico de adecuación a su arquetipo) en los personajes, el desconocimiento de la diferencia entre "verdad" y "verosimilitud" y la obligación de atender sólo a la segunda, la falta de transparencia de la trama por proliferación confusa de lances, el argumento múltiple, la arbitrariedad inmotivada del desenlace... En el fondo, que el teatro se encamine a divertir y sorprender, hecha la obra un haz de episodios inconexos, incapaces de asimilación unitaria, donde los personajes - tipo no actúan ni están trazados como corresponde, y donde no caben consecuencias catárticas. Si a esto unimos lo que más adelante se condena en los poetas líricos, el «brío loco" de los culteranos, que llenan sus versos de "vocablos de boato", confunden la palabra común adecuada "con las triviales y plebeyas", "echan mano de la carantoña de la colocación intrincada, ya con el hipérbaton viciosamente repetido, ya con diversas y siempre extrañas alteraciones", "violentan, duplican, frecuentan y arrastran las metáforas de cien leguas", resultando de todo ello "la confusa noche de sus escritos»(5); si unimos a la censura del teatro la de la poesia, nos hallamos frente a un modelo de pensamiento que podría asumir cualquier neoclásico, dotado incluso de un apreciable margen de tolerancia, ya que López de Vega recomienda no andar esclavo de "las antiguas reglas" y "ancianas menudencias", pensando sin duda en las pueriles controversias de los preceptistas neoaristotélicos del siglo XVI sobre cuestiones tan debatidas como la famosa casuística acerca de la Unidad de Tiempo. Que López de Vega no haya recibido ni reciba la atención que merece, él que decia pertenecer al "Gremio de los Desengañados" por efecto de la "Tacañería» de su tiempo, es un síntoma de la del nuestro(6).

La apretada síntesis de López de Vega contiene en esencia los argumentos de Luzán, y con ello saltamos al siglo XVIII, que nos ofrece una rica cantera de diatribas contra el teatro barroco, que llegaron, como es sabido, a tener consecuencias juridicas.

En 1749 aparece la edición de teatro cervantino preparada por Nasarre(7), cuyo primer volumen lleva un «Prólogo del que hace imprimir este libron, 52 páginas sin paginar ni firmar. Prescindiendo del desacierto de suponer que Cervantes, con "método socrático» e «ironía finísima»(8), escribiera un teatro de intención paródica, Nasarre considera a Lope corruptor del teatro, y mucho más a Calderón:

"El artificio y afeite con que hermosea los vicios es capaz sin duda de corromper los corazones de la juventud. A más de que la ingeniosidad de la maraña es casi siempre inverosimil (...), los anacronismos, la falta de Geografía, de Mitología, de Historia, se dejan ver a cada paso (...) Sus personas vagan desde el Oriente al Occidente, y obliga a los oyentes a que vayan con ellas (...) La ufanía, el punto de honor, la pendencia y bravura, la 
etiqueta, los ejércitos, los sitios de Plazas, los desafíos, los discursos de Estado, las Academias Filosóficas, y todo cuanto ni es verosímil ni pertenece a la Comedia, lo pone sobre el teatro (...) (los personajes femeninos actúan) representando al pueblo pasiones violentas y vergonzosas, y enseñando a las honestas e incautas doncellas los caminos de la perdición (...) Hace hablar a sus personas una lengua seduciente, con metáforas ensartadas unas en otras (...) El enredo hace toda la esencia de sus Comedias; el carácter está absolutamente despreciado; rara vez se contenta con una materia simple y única (...) mezcla, no liga, los asuntos, pero de modo tan infeliz que parece se ven representar de una vez dos comedias...".

Son los puntos de vista del Heráclito y Demócrito de nuestro siglo, más la insistencia del XVIII en la inmoralidad del teatro calderoniano, que hace, se dice, que las mujeres pierdan el recato, y los hombres, viendo ensalzado "el punto de honor" y "la pendencia", el respeto y subordinación a las leyes y sus magistrados. Por ellos lucha la llustración, frente a la mentalidad señorial apegada a privilegios y fueros jurídicos, y al hábito de ser médico de su honra. El ejemplo que a este respecto da la comedia barroca es funesto, según Nasarre, porque:

"No supo Calderón que los autores de las Comedias, conociendo la utilidad de ellas, se deben revestir de una autoridad pública, para instruir a sus conciudadanos, persuadiéndose que la Patria les confía tácitamente el oficio de filósofos y de censores de la multitud ignorante...p(9).

A los cinco años se imprimen en Málaga los Orígenes de la poesía castellana de Luis Josef Velázquez ${ }^{10)}$, libro mediocre que cita a López de Vega igualmente(11).

En Nicolás Moratín tenemos una de las voces más autorizadas en el asunto. En la "Dissertación» de 19 páginas que precede a La petimetra(12), recomienda echar a un lado, con licencia de su autor, todas las obras de Lope; se levanta contra el error, dice, de suponer que el vulgo no queda estupefacto ante las excesivas libertades dramáticas, y que le resultan repugnantes las obras compuestas según las Reglas; defiende las Unidades; recuerda los precedentes que amparan su crítica, desde Cervantes; censura la "multiplicidad de lances" amontonados en una sola obra, para confusión del espectador, y lo que llama "desunión de lugar", o sea los atentados contra la Unidad de Lugar, "pues hay alguna (obra) cuyas tres jornadas se representan en las tres partes del mundo, y me admiro que no hayan puesto cuatro actos para que no quede desconsolada la América (...) Yo he visto comedia del giro que hizo en el orbe la nave La Victoria, donde es gusto hallarse, ya en el estrecho de Magallanes, ya en las islas Marianas, ya en las Filipinas, ya en las Molucas y Maldibias, ya en el Cabo de Buena 
Esperanza, ya en las Canarias, hasta llegar a Sanlúcar, donde se empezó la comedia...(13). Los personajes actúan indecorosamente, el lenguaje es excesivamente alambicado, y por ello inverosímil, en boca de los vulgares... Pero acaso sea lo más grave el atentado contra la Unidad de Acción, el laberinto de enredos, del que es Calderón principal responsable; y lo es porque la incomprensibilidad argumental, por encima de toda otra consideración, impide el didactismo(14). No puede haberlo sin asimilación de la catástrofe, y tampoco sin la identificación del espectador que es consecuencia de la ilusión escénica, constantemente suspendida, según don Nicolás, por la reiterada vulneración de las Unidades; y es que toda obra dramática correcta, "aunque sean lances muy antiguos, finge que están sucediendo, y cuanta más propiedad tenga la ficción será mejor la Comedias(15). Que Lope y Calderón ignoraran las Reglas voluntariamente, ya que en su tiempo eran conocidas-ahí está el ejemplo de Cascales-no los excusa, a pesar de la "prodigiosa afluencia, tan natural y abundante, del profundo Calderón» y de la "facilidad natural y la elegancia sonora del fecundísimo Lope»16).

En la misma línea argumentará Moratín padre en el primero de los $D e$ sengaños al Teatro Español..(17), atacando el cambio de lugar escénico, la excesiva duración de la acción dramática, las intervenciones del gracioso, y el lenguaje inadecuado a personajes y situaciones, todo lo cual va en detrimento de «la ilusión, o engaño teatral: de manera que aquella comedia o tragedia tan bien escrita y representada que no deje resquicio al auditorio por donde pueda conocer que aquello es falso, sino que lo imagine sucediendo, aquella es buenas(18). Desde cuyo punto de vista, Lope y Calderón son culpables ante el tribunal de las Reglas, la Naturaleza y la Razón; y también ante el de la Moral y el Orden Público:

"Después del púlpito, que es la cátedra del Espíritu Santo, no hay escuela para enseñarnos más a propósito que el teatro, pero está hoy día desatinadamente corrompido. El es la escuela de la maldad, el espejo de la lascivia, el retrato de desenvoltura, la academia del desuello, el ejemplar de la inobediencia, insultos, travesuras y picardias (...) ¿Quisiera Ud. que su hijo fuese un rompe esquinas, matasiete, perdonavidas, que galantease a una dama a cuchilladas, alborotando la calle y escandalizando al pueblo, forajido de la justicia, sin amistad, sin ley y sin Dios? Pues todo esto lo atribuye Calderón a D. Félix de Toledo como una heroicidad grande. ¿Quisiera nadie que su hija, aunque con fin de matrimonio, no contenta con entrar ocultamente en su casa a un hombre tan revoltoso, vaya a la posada de un mozo solo, como la más infame barbacanera? Pues doña Leonor da ejemplos de ello a las mocitas solterasis(19). 
En los Desengaños segundo y tercero arremete contra los personajes alegóricos, los errores históricos y la liviandad y vaguedad teológica de los Autos calderonianos, y ridiculiza El colmenero divino de Tirso.

En la Sátira Primera, la Musa Castellana se presenta en visión a don Nicolás, y tras excitarlo a cumplir sus deberes censorios en España, "del vicio infiel morada", ocupación propia del poeta responsable, cuyo verso "reduce la república a perfeta", amparado por "la noble protección del magistrado", le pinta el cuadro de depravación al que debe poner remedio:

"¿No adviertes cómo audaz se desenfrena

la juventud de España corrompida de Calderón por la fecunda vena?

¿No ves a la virtud siempre oprimida

por su musa en el cómico teatro, y la maldad premiada y aplaudida...?.

¿No ves el arte cómica ignorada,

y si la acción empieza en Filipinas,

en Lima o en Getafe es acabada?

¿No ves, no ves salir de las cortinas

cosas que ni en el mundo han sucedido

ni pueden, sin con juicio lo examinas?».

Y en la Segunda, síntoma de la decadencia de España es que allí "aplauden la comedia disoluta", donde se dan halagüeños ejemplos de conducta viciosa y "se ven premiadas insufribles/maldades..."; todo es consecuencia de que la escena española no tiene otro maestro que ula imaginación más descompuestan; así en una comedia se muda el lugar de Nicomedia a $\mathrm{Fi}$ lipinas y Barcelona; la fábula es "fanfarrona»; el galán "espadachin, soberbio e inhumano" y amigo de resolverlo todo a cuchilladas, burlándose "del alcalde más severo" y persiguiendo a "doncellas y casadas"; las damas dan ejemplo de «infame y libre vida»; $y$, en cuanto a la técnica dramática, “infinitas verás impropiedades": quebrantamiento de las Unidades, falsificación de historia y costumbres del pasado, incoherencia psicológica de los personajes(20).

La quinta parte de El Pensador, cuyo primer volumen aparece a nombre de Joseph Alvarez y Valladares, saliendo ya desde el segundo con el de Clavijo(21), está ocupada por asuntos relativos al debate sobre el teatro. Aparecen en el Pensamiento tercero, parodia de discurso apologético en el que se afirma burlonamente que, si la función de las Reglas es crear en el espectador "ilusión", o sea engaño, los buenos españoles no quieren engañar a nadie; que el teatro español respeta la Unidad de Lugar, porque las 
comedias se representan de cabo a rabo en un mismo edificio, y la de Tiempo, porque las representaciones no duran más de un día, ni tienen lugar de noche; que la inventiva de los comediógrafos españoles es más elogiable que la que ha producido inventos extranjeros como la imprenta o el telescopio; y mil chuscadas más.

En el Pensamiento noveno, un viajero americano se sorprende del estado del teatro español, en el que son defectos habituales mezclar tragedia y comedia, introducir absurdos personajes sobrenaturales y alegóricos, ver a actores de vida airada haciendo de Cristo, la Virgen o los Santos, usar un lenguaje disparatado, ridiculizar los impulsos nobles en las intervenciones del gracioso y disponer una trama prolija e incoherente. Sucesivas disquisiciones sobre la Tragedia, la Comedia y la Opera tienen en común el reconocimiento de la finalidad didáctica del teatro:

"Un corazón acostumbrado a esta especie de impuisos (los de la catarsis trágica), nacidos de la frecuente magia con que el Teatro lo conmueve, se hace más dulce, más benéfico, más piadoso. Allí desenvuelve todas las virtudes morales, cuya semilla tenía en el corazón (...) Alli se pinta el horror de los delitos y la hermosura de la virtud....222).

"La buena Comedia es tan capaz de reformar un pueblo y de mantenerlo reformado, como la que presenta malos ejemplos es capaz de pervertirlo o mantenerlo corrompido. Por esto todos los grandes hombres han dicho siempre que éste debía ser uno de los principales objetos del Gobierno....(23).

Se nos asegura finalmente que no se puede culpar al gusto popular de la extravagancia del teatro español; el pueblo la sufre con agrado no excesivo, ya que no se puede aprobar plenamente lo ininteligible.

En el tomo II, el Pensamiento XX, tras discurrir sobre el tocador, costumbres, pereza y presunción de las damas, reitera los argumentos vistos en el IX, y lo mismo hacen los Pensamientos XXII, XXIII y XXVI, el último de los cuales cita a López de Vega.

En el tomo III, el Pensamiento XXX incluye un argumento burlesco de comedia disparatada, cuyos personajes son, entre otros no menos peregrinos, Aquiles, Catón, Cromwell, Tamerlán y Gengis Kan. Y el XLII la emprende con los autos Sacramentaleș, negando que su función sea instruir y edificar moral y religiosamente al pueblo, ya que ponen en escena misterios incomprensibles que es contrario a la fe el querer penetrar; $y$, aunque no lo fuera, no ayudaria a ello, dice Clavijo, la oscura alegoria calderoniana. La religiosidad del pueblo inculto corre peligro de quedar más lesionada que robustecida por los Autos, ya que suponen:

"elevar el Teatro hasta una esfera muy distante y muy ajena de su institución, o rebajar el Santuario, queriendo trasladar a un 
lugar inmundo la Cátedra y el Sacerdocio. A la verdad, parece increíble que una nación tan cristiana pueda ver sin horror profanados los misterios de su Religión y los signos, representaciones o figuras de las cosas más sagradas»(24).

Calderón tuvo al componerlos "una devoción fervorosa aunque indiscretas(25). Los Pensamientos XLIII y XLIV, ya en el tomo IV, continúan la crítica de los Autos. No hablaremos, para no incurrir en prolijidad, de los Pensamientos LXVIII a LXXI (tomo V), y LXXVI a LXXVIII (tomo VI).

La "Prefación" de 46 páginas a la Jahel de Sedano(26) considera intolerable el tratamiento español de los temas bíblicos:

"He admirado yo siempre la facilidad, o por mejor decir, la ligereza y falta de miramiento con que muchísimos, o los más de nuestros poetas cómicos, se han arrojado a escribir y a destinar a un teatro profano asuntos tan sacrosantos, y manejados éstos con tan poca exactitud y decoro, faltando por lo comủn a la verdad, al carácter de las personas, a la cronología, a la verosimilitud y a la decencia, con interpretaciones violentas, inteligencias falsas, alegorías insulsas, metáforas extravagantes, y lo que es más lastimoso, contagiados de las mismas máximas erradas, aplicaciones indignas, proposiciones delatables, graciosidades torpes, amoríos indecentes, y moral corrupta, que todas las demás piezas que nos presentan cada días(27).

Oigamos a Tomás de Iriarte en Los literatos en cuaresma(28), cuando le toca a don Silverio ejecutar el plan del tercer domingo, en el que ha de predicar Cervantes. Nos explica que la Unidad de Tiempo diferencia al teatro de la novela; los absurdos que conlleva el no respetar la de Lugar; qué es la de Acción; cómo debe cuidarse la verosimilitud y adecuación del lenguaje y estilo de los actores. Pero, sobre todo, habría que educar al público y conseguir que no exigiera tal caballero de la luneta utempestades, eclipses, batallas, caballos, leones, tigres y toda casta de monstruos, fieras, vestiglos, alimañas y sabandijas descomunales; 0 algunas comparaciones poéticas que abunden en flores, troncos, plantas, cumbres, peñascos, prados, selvas, malezas, astros, signos del Zodiaco, constelaciones, pájaros, peces, arroyuelos, olas, escollos, arenas, nácar, perlas, coral, conchas, caracoles y todo género de mariscon; que tal mozo del patio no estuviera atento sólo a las apariciones del gracioso; que tal cateto no admirara exclusivamente los trucos de máquina y tramoya; que tal señora de la $\mathrm{Ca}$ zuela no se fijara ante todo en el vestuario, o valorase únicamente lo estrambótico y sobrenatural «que acontezca por arte mágico, sea Nigromancia, Quiromancia, Hidromancia, Aeromancia, Piromancia, Geomancia, Cleromancia, Espatulomancia u otra brujería de nueva invención»(29). 
Mucha atención dedico a estas cuestiones Leandro Moratín. La Comedia nueva está destinada a satirizar el teatro de raigambre barroca; veamos, como botón de muestra, la definición de $D$. Pedro en la escena 5 del acto segundo: "un hacinamiento confuso de especies, una acción informe, lances inverosímiles, episodios inconexos, caracteres mal expresados o mal escogidos; en vez de artificio, embrollo: en vez de situaciones cómicas, mamarrachadas de linterna mágica... ¡Y el estilo! Cuando debe ser noble y afectuoso, es oscuro, campanudo y hueco; cuando debe ser sencillo y gracioso, es chabacano y frio. La moral, no la busque usted....(30).

La Lección Poética... halla al teatro español "en errores sepultado»: el público presencia el encomio de las peores pasiones y dislates, "y de juicio y moral se queda a oscuras"; se ve frente al indecoroso comportamiento de las disfrazadas de varón, a la malicia de las comedias de enredo, a la impertinencia dramática del gracioso, a la bravuconería elevada al rango de suprema virtud varonil; al estrafalario desprecio de las Unidades, a la impropiedad de conceptos y lenguaje(31). Pero quizás sea en la carta a Godoy de 20 de diciembre de 1792 donde con más claridad se expresa el pensamiento de Leandro Moratín. La reforma del Teatro, dice, es necesaria por la ignorancia de los cómicos del arte de la declamación, por la impropiedad y rudeza de vestuario, decorados y tramoya, por la incomodidad y suciedad de los coliseos, y, sobre todo, por la despreocupación de los poderes públicos, que no quieren percatarse del "poderoso influjo que tiene el Teatro en las ideas y costumbres del pueblo: éste no tiene otra escuela, ni ejemplos más inmediatos que seguir que los que allí ve, autorizados en cierto modo por la tolerancia de los que le gobiernan. Un mal Teatro es capaz de perder las costumbres públicas, y cuando éstas llegan a corromperse, es muy difícil mantener el imperio legítimo de las leyes (...) En las comedias antiguas que se representan, parece que apuraron nuestros autores la fuerza de su ingenio en pintar del modo más halagüeño todos los vicios, todos los delitos imaginables, no sólo hermoseando su deformidad, sino presentándolos a los ojos del público con el nombre y apariencia de virtudn. Estos vicios y delitos son: la deshonestidad de las mujeres; el equivocado concepto del honor, resumido en el donjuanismo y el machismo pendenciero, y contrario al respeto a las Leyes del Rey, fundamentalmente. "En una palabra-resume Moratín-cuanto puede inspirar relajación de costumbres, ideas falsas de honor, quijotismo, osadía, desenvoltura, inobediencia a los magistrados, desprecio de las leyes y de la suprema autoridad". Por no hablar de las Comedias de Magia, "que mantienen al vulgo en una ignorancia estúpida o que, por mejor decir, le llenan de errores groseros, no menos opuestos a una sana razón que a las verdades augustas de nuestra Religión santísiman. Siendo el teatro escuela de costumbres, concluye Moratín, nadie se extrañe de las inclinaciones y desafueros, tanto de la clase alta como del pueblo, contrarios a «la estabilidad del orden civil, que mantiene los Estados en la dependencia justa de la suprema autoridad $m(32)$. 
Es muy verosímil atribuir a la musa volteriana de Samaniego el discurso XCII de El Censor(33), donde la censura y reforma del teatro es considerada la más urgente de las tareas a emprender, ya que de la escena dependen "todas las virtudes naturales, morales y civiles", ya que "no hay condición, estado, edad ni sexo que no le frecuente, que no reciba en él lecciones, y que no pueda beber en esa fuente o la ponzoña del error o las aguas de la buena y saludable doctrina». Como sugería Moratín a Godoy, "la elección de los dramas que se ofrecen al público debiera ser uno de los primeros cuidados de nuestra policían. Al tipo de héroe que ofrece el teatro "español" hay que atribuir "aquel resabio de majismo que afectan hasta las personas más ilustres de la corten-y no olvidemos que una de las ideas centrales de la llustración es la educación cívica de la nobleza, determinante, por su papel rector desde el poder, del estado de la sociedad. Coincide con el mencionado discurso el severo Jovellanos en su Memoria para el arreglo de la policía de los espectáculos y diversiones públicas...(34), aprobando la supresión de los Autos, escuela, en su opinión, de superstición, necedad e indecencia, en grave detrimento de "la santidad de su objeto"; lamentando que se siga permitiendo representar "unos dramas en que el pudor, la caridad, la buena fe, la decencia, y todas las virtudes, y todos los principios de sana moral, y todas las máximas de noble y buena educación son abiertamente conculcados". Para Jovellanos, los poderes públicos deberian procurar:

«un teatro donde puedan verse continuos y heroicos ejemplos de reverencia al Ser supremo y a la religión de nuestros padres, de amor a la Patria, al Soberano y a la constitución; de respeto a las jerarquias, a las leyes y a los depositarios de la autoridad; de fidelidad conyugal, de amor paterno, de ternura y obediencia filial (...) En una palabra, hombres heroicos y esforzados, amantes del bien público, celosos de su libertad y sus derechos, y protectores de la inocencia y acérrimos perseguidores de la iniquidad (...) Un teatro tal, después de entretener honesta y agradablemente a los espectadores, iría también formando su corazón y cultivando su espíritu; es decir, que iría mejorando la educación de la nobleza y rica juventud, que de ordinario le frecuenta...".

Está bien claro, en el anterior párrafo, el pensamiento conservador y antidemocrático de Jovellanos, que centra la ética teatral en la influencia de las representaciones sobre el espíritu cívico de la nobleza y alta burguesia; más adelante dice: "conviene dificultar indirectamente la entrada (en los coliseos) a la gente pobre, que vive de su trabajo, para la cual el tiempo es dinero, y el teatro más casto y depurado una distracción perniciosa. He dicho que el pueblo no necesita espectáculos; ahora digo que le son dañinos". Para Jovellanos, la misión del pueblo es obedecer y produ- 
cir, y no perder horas de trabajo, o de reposo necesario para mejor trabajar luego, en ocios y distracciones, y mucho menos ante unas representaciones dramáticas que podrían hacerle desear formas de vida propias de las clases privilegiadas.

Desde un punto de vista algo más avanzado, Mariano Luis de Urquijo, en su discurso preliminar a la traducción de La muerte de César de Voltaire(35), considera el teatro escuela de costumbres populares; hace su historia desde Grecia y Roma y sitúa su degeneración en los siglos XVI y XVII, citando a Shakespeare, Ben Johnson, Lope y Calderón; enumera los defectos de la escena española, heredados del Siglo de Oro, en términos similares a los vistos más arriba en otros tratadistas, y pondera, como es habitual, sus perniciosos efectos sociales:

"Padres y demás a quienes está encargada la educación de la juventud, ¿vosotros podréis permitir que vayan a aprender a tan infame y seductora escuela el modo de ser útiles a la patria, y hombres de bien, unos jóvenes tiernos, y a que beban tanta ponzoña en lugar de virtud?s(36).

Termina, como Moratín y Jovellanos, proponiendo medidas concretas de intervención estatal: una Escuela de Arte Dramático, un Tribunal de censura y control de las representaciones, levantar los gravámenes de Obras Pias que afectan a los coliseos, y subvencionarlos si fuera preciso...(37).

A Nipho hemos de colocarlo en el gremio de los indecisos; si bien reconoce defectos en el teatro español, el ver lesionado el honor de la Patria suele conducirlo al bando opuesto, sea por intimas y viscerales convicciones o por el deseo de repicar y a la vez ir en la procesión, y no perder lectores por tacha de partidismo. En el Diario Extraniero de 26 de Abril 1763(38) opina que la Mari Pérez de Cañizares «y otras muchas Comedias históricas son perjudiciales para el pueblo, y contra la educacion de nuestros jóvenes", por lo que la Justicia deberia tomar cartas en el asunto. En el de 10 de Mayo leemos de El diablo predicador de Luis de Belmonte:

"Esta Comedia es de aquellas muchas que mantienen el error de nuestro bajo pueblo, dando crédito a hechos no sólo dudosos, sino opuestos a las verdades puras de una sana creencia. El asunto, lejos de ser oportuno para Comedia, es contrario a las leyes que prescriben los preceptos de una enseñanza pública. Mientras duren estas perjudiciales representaciones, ni se civilizará nuestra Nación, ni se perfeccionarán nuestras costumbressy(39).

De Afectos de odio y amor de Calderón se dice, en el mismo número, que es obra llena de disparates, hechos inverosímiles y extravagancias(40); Progne y Filomena, de Rojas, es urepresentación absolutamente indigna 
de ofrecerse a unos espectadores cristianos", y deberia prohibirse y quemarse en público(41).

En el número de 24 de Mayo le toca el turno a El falso Nuncio de Portugal, de Cañizares, conjunto, se dice, de falsedades, engaños y "cosas opuestas a la justa razón»(42). En el mismo encontramos una preciosa observación acerca de La vida es sueño, representada en el Teatro del Príncipe los días 17 y 18: «¿Quién creerá que una Comedia doctrinal como ésta, y tan bien desempeñada por parte de los representantes, ha tenido casi ninguna asistencia de los espectadores?...»(43). Relaciónese con la clase de espectadores-digo clase pensando en el precio de las localidades-que enumera Iriarte en Los literatos en Cuaresma, en abono de la negación por Andioc(44) del tópico, repetido por los historiadores tradicionalistas, según el cual era el pueblo bajo encarnizado enemigo de las innovaciones, en materia dramática, de llustrados y Neoclásicos.

Pues bien: en su Entusiasmo o Sainete nuevo...(45), impreso el mismo año 1763, Nipho nos presenta un tribunal presidido por La Poesía Dramática a la que asisten La Comedia y La Tragedia, Menandro y Euripides; la presidenta abre la sesión con estas palabras:

"Me consta que hay de mí muchos quejosos

de que anima el teatro a los viciosos, que la virtud en él no es atendida y la malicia en todo preferida; que la decencia sale avegonzada y la desenvoltura bien pagada

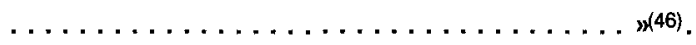

Apelan acto seguido El Valor, un Padre y una Hija, una Madre y un Hijo, la Nobleza, una Casada, una Soltera, una Dama de Corte, un Albañil, un Zapatero y un Francés; en boca de este último se ponen, por burla, argumentos similares a los vistos en el Diario Extranjero, en una torpe parodia de lengua franca que pretende ridiculizar a la francesa:

«........... Les Comedie

de Españe non tien provecho;

pierque están de metaforas

Ilenis todos sus más viersos.

Nen tien primor, nen verdad, todas sun cuentis de viecos, ne enseñen una palabre

que valguia un chavo nen medio.

An Fransia son les Comedie

e le Tragedie un portento (4) $(47)$ 
La Poesía Dramática expulsa entonces al Francés, y comenta que sus compatriotas no ven cosa buena fuera de su propio país; encomia la excelencia y superioridad sobre Francia del ingenio español, y recomienda la composición de obras mesuradas y didácticas, lo cual prometen los personajes que al principio han apelado al Tribunal. Calderilla galófoba para fácil halago de oidos patrioteros.

En el Diario Extranjero de 7 de Junio 1763(48) se ataca a Romea y Tapia; en el de 14 del mismo mes, unas "Noticias de Moda, que aspiran a que se haga moda la Decencias(49), Ilaman la atención sobre la glorificación de la pasión amorosa en el teatro: "¿Qué corrección se puede esperar de una pasión tratada de este modo, particularmente cuando finaliza triunfando...? »(50). En el de 12 de Julio, otras "Noticias de Moda, que van en busca de una belleza difícil de hallar en nuestros días «(51) insisten en el pernicioso ejemplo que es el teatro para la juventud, y en su necesidad de reforma. Ello no impide que, después del Entusiasmo... ya citado, Nipho publique La nación española defendida de los insultos del Pensador...(52), donde afirma que el teatro español es el mejor del mundo, nos espeta, para probarlo, un «Ensayo de lo bellow(53) que contiene, sin venir a cuento, un largo elogio del matrimonio cristiano, y, en general, se arma un lío barloventeando entre el deseo de agradar a los reformadores y el de no escocer a los tradicionalistas. Parecidas pretensiones de eclecticismo conciliador encontramos en el poco interesante Ensayo sobre el teatro español de Tomás Sebastián y Latre(54).

Frente a los detractores del teatro barroco, los argumentos de sus apologistas-con los que Böhl enlaza-son simples, reiterativos y sentimentales. En el Discurso Critico... de Erauso(55) se dice que las obras de Lope y Calderón cifran el "genio" de España(56), y uno de los «sujetos doctos" elegidos por el autor en demanda de aprobación sostiene que defender a los dos comediógrafos es deber de patriotismo. Lo mismo opinan el calificador de la Inquisición y el Examinador Sinodal de Cuenca. En cuando al coriáceo Romea y Tapia(57) el Discurso primero de El escritor sin título pone en remojo al ya citado Diario Extranjero; en el segundo se atribuyen las opiniones opuestas a las del autor, al desprecio a la Patria y a la xenofilia: para ser hombre del día, se dice, basta con "no publicar escrito que no se le pegue cuatro tarascadas a la Madre que nos cria, nos alimenta, nos viste, nos calza, nos enseña una fe pura, sin mezcla de opiniones y sectas descarriadas....258). El Discurso tercero, deformando la verdad histórica, atribuye toda oposición al teatro "español" a la imitación y aclimatación de ideas francesas, y sostiene que, al tener cada nación su carácter y costumbres definitivas, tiene igualmente una peculiar norma estética, que no cabe subordinar a preceptiva universal alguna(59): ideas que habria de recoger y repetir Böhl. La suposición de que se tiene a España por país inculto y necesitado del ejemplo foráneo hace estallar de ira al buen Romea: 
"¿Pues qué, Madrid es alguna hija de puta para que se le enajene del derecho que cada uno tiene a mandar en su casa? $\$(60)$. Los Discursos cuarto a séptimo, dirigidos contra Clavijo y Nicolás Moratín, defienden a Calderón como escritor y teólogo, y la función edificante de los Autos. De poca monta es la apología del ingenio teatral español, y concretamente del calderoniano, en las páginas CXLVII y CXLVIII del "Prólogo del Colector" en el tomo I del Theatro Español de García de la Huerta(61).

Resumamos el legado del siglo XVIII en cuanto al debate sobre el teatro del Barroco. Los argumentos adversos son los más numerosos, y podrían acaso sistematizarse así:

1. ${ }^{\circ}$ La finalidad del Teatro es instruir, no sólo divertir o distraer. Para ello es preciso poner en práctica ciertas Reglas que faciliten la uilusión" (o sea, la identificación) del espectador, que le impidan, diciéndolo con un término actual, "distanciarse".

2. La tradición dramática española es censurable por poseer los siguientes defectos:

a) mezcla de tragedia y comedia

b) argumento enrevesado y múltiple

c) resortes dramáticos inverosímiles y confusión entre verdad (10 meramente posible) y verosimilitud (lo esperable y de antemano aceptable)

d) inconsecuencia caprichosa del desenlace

e) errores de Historia, Geografía, Indumentaria, etc.

f) la figura del gracioso

g) falta de "decoro" (propiedad arquetípica) de los personajes en psicología, conducta y lenguaje

h) carácter masculino fundado en el punto de honor y la valentoneria; carácter femenino fundado en el brujuleo e iniciativa amorosa

i) lenguaje conceptuosos y excesivamente culto

3. Consecuencia de tales defectos es que el espectador:

j) no comprenda con inmediatez y fluidez el texto dramático, y al tener que reflexionar sobre él suspenda la «ilusión»

k) atienda más al ornato de las palabras que a su significado (como el caso de aquel espectador que lanzó un "iViva el Demonio!" tras oirle, en un auto sacramental, un parlamento floreado, con gran zaragata de alguaciles y soplones de la Inquisición)

1) no capte la obra en su conjunto, ya que la reiterada violación de las Reglas evidencia constantemente el carácter ficticio de la representación; y al asimilarla de modo fragmentario, no pueda percibir la Justicia Poética que pueda haber en el desenlace. 
m) asienta a la glorificación escénica de comportamientos reprobables (punto h) y caiga en la tentación de imitarlos.

Toda síntesis es por definición mejorable, y la anterior lo sería si estudiáramos uno a uno el caso de las comedias de enredo, capa y espada, mitológicas, hagiográficas, de Historia profana o sagrada, de magia, de "teatro"... Caso aparte es la crítica de los Autos, que a los defectos genéricos mencionados unen el uso de personajes irreales (sobrenaturales y alegóricos) y el tratamiento indecoroso de las materias de religión.

Los argumentos favorables, por su parte, son, en esencia:

1. ${ }^{\circ}$ El teatro español es consustancial al carácter nacional

2. Respetarlo es cuestión de patriotismo

3. ${ }^{\circ}$ El gusto estético es una peculiaridad nacional distintiva

4. ${ }^{\circ}$ Las Reglas son convenciones de la escena francesa, no universalizables.

Así están las cosas cuando entra en escena Böhl de Faber, a quien dedicamos la parte II de este trabajo.

En un principio, Calderón interesó a Juan Nicolás Bơhl desde un punto de vista erudito animado por un evidente propósito reivindicativo similar al de los hermanos Schlegel: en el artículo "Ueber die Spanische Literatur" que publica en la Nordische Miszellen de Hamburgo de 13 de marzo 1808, exalta la excelencia de la literatura española del Siglo de Oro, especialmente el teatro, y las traducciones calderonianas de Augusto Guillermo Schlegel. Posteriormente, esa predisposición inicial se concretará en una peculiar composición de lugar adecuada a la circunstancia política española de principios del XIX, y en tal cambio hemos de suponer una influencia decisiva de su esposa Francisca Ruiz de Larrea.

En 1805 el matrimonio, y dos de sus hijos, se trasiadan a Alemania, regresando doña Francisca sola a España al año siguiente. La reunión no tiene lugar hasta 1812. En ese lapso de tiempo no existe convergencia ideologica entre los esposos. Böhl conserva la religión protestante, mientras su mujer es católica acérrima, y no se siente vinculado a España, ya que ha adquirido la hacienda de Görslow y conseguido patente de nobleza gracias al apellido Von Faber de su padrastro. De hecho, la voluntad de residir en Alemania y la diferencia religiosa fueron causa de la separación de marido y mujer. $Y$, curiosamente, Juan Nicolás es originariamente bonapartista, como demuestran las cartas a su suegra en diciembre 1805 y enero $1806(62)$. 
La reconciliación del matrimonio, con la consiguiente conversión de Böhl al catolicismo en 1813, y el posterior regreso a España, lo llevan a hacer suyos los problemas de un país que padece desde 1808 una guerra contra Francia y que ha visto surgir la alternativa política liberal, problemas ante los cuales ya tiene doña Francisca una respuesta largamente incubada, en cuyo seno ha cristalizado, desde 1810, una adaptación ideologica muy precisa del significado de la obra calderoniana; en carta a su esposo, de 6 de diciembre de ese año, leemos:

«Me ocupo de Calderón y de nuestros antiguos poetas para procurarme algún consuelo. En los poetas es que se puede percibir el espíritu, los modales y el carácter de las naciones (...) ¡Cómo pinta Calderón esa nobleza, esa generosidad, ese excesivo pundonor que caracterizaba los españoles de su siglo! Pues todavía es lo mismo a pesar de la corteza viciosa que los vecinos desde tanto tiempo han echado sobre esta Nación....(63)

Para doña Francisca, Calderón es compendio de las cualidades distintivas del carácter español, como pensaba Erauso. Ese supuesto carácter consiste en el paradigma de hombría que los adversarios del teatro barroco, tal como se ha visto en la parte I de este estudio, creían modelo de vicios privados y cívicos, $y$, además, en el conservadurismo político y religioso. La esposa de Böhl lo considera aún vigente en el país, ya que la "corteza viciosa" (el pensamiento ilustrado y liberal) que por influjo de "los vecinos" (Francia) afecta a las minorias cultas, no ha podido desarraigar las tradiciones españolas. Y ese carácter ha sido el motor, en su opinión, del alzamiento antifrancés de 1808. Los escritos de doña Francisca, incluso anteriores a $1808(64)$ insisten en similares puntos de vista, asociados a un patriotismo exaltado, chauvinista y galofobo. En enero de 1813 escribe a Augusto Guillermo Schlegel(65), y en esa carta volvemos a topar con el nombre de Calderón asociado al despertar desde 1808, dice, de las virtudes españolas, adormecidas y latentes durante el siglo XVIII, que el país ha atravesado sin asentir a "sistemas y vanas teorías". En la sección de Raros y Manuscritos de la Biblioteca Nacional de Viena se conserva un panfleto de 4 páginas, titulado Fernando en Zaragoza, que doña Francisca publica en Cádiz, 1814, con el seudónimo de "Cymodocea" (tomado de Los mártires de Chateaubriand), en el cual se exalta la Guerra de la Independencia y el patriotismo exclusivista, se insiste en el conservadurismo esencial del pueblo español y en el mantenimiento de la monarquía estilo Antiguo Régimen, y se condena la obra de "una turba que se llama liberal», cuya finalidad es "debilitar el antiguo carácter de la Nación", expresado por Calderón, como ya sabemos(66).

En el año 1814 comienza la polémica Böhl-Mora, con unas «Reflexiones de Schlegel sobre el teatro..." que Juan Nicolás Böhl inserta en el 
Mercurio Gaditano. No es este el lugar de repetif el desarrollo y pormenores de la misma, de los que sólo entresacaré las referencias a Calderón intentando aclarar el espíritu que las preside.

En el citado artículo, Böhl desacredita las Reglas, como hiciera Romea y Tapia, en nombre del relativismo estético propio de los distintos caracteres nacionales, que ha producido en España uun género propio que llamaremos romancesco". La "filosofía moderna" (política) y la "crítica bastarda del siglo filosoficon (neoclásica) no deben apartar a los españoles de sus sendas tradicionales. La respuesta de José Joaquín de Mora, en el mismo Mercurio Gaditano, reproduce las críticas dieciochescas al drama calderoniano, cuyos personajes masculinos están retratados "como asesinos, huyendo unas veces de la Justicia, robando otras las hermanas de sus amigos, y dando de puñaladas a los queridos de sus hermanasi(67).

Tras diversas peripecias, Bohl, en colaboración con José Vargas Ponce, publica en 1814 un folleto titulado Donde las dan, las toman...(68), reimpreso con modificaciones al comienzo de Vindicaciones de Calderón...(69). De dicho folleto no parece haberse conservado más ejemplar que el de la Public Library de Boston, procedente del legado de Ticknor. Consta de cuatro textos, uno de ellos de Vargas, que no nos interesa, y los demás de Juan Nicolás. Estos se titulan: «Contrastes que me ocurrieron al leer la crítica de Mirtilo..." (Mora usó el seudónimo de "Mirtilo Gaditano" al responder a "Reflexiones de Schlegel..."), "Contestación a la crítica de Mirtilo" y "Contestación al artículo comunicado...". En el primero de ellos, Bohl identifica el "espiritu caballeresco" que informa el teatro de Calderón con las motivaciones nacionales de la Guerra de la Independencia, de lo que resulta que quien desprecia lo uno desprecia las otras, y de ahí uel agravio que Mirtilo hace a sus paisanos, los que en la guerra pasada han dado las más grandiosasmuestras de este espíritu", que consiste "en un entusiasmo sin límite por su religión, y su rey, su honra y su dama...". Sólo "la escuela francesa" de Boileau, Luzán, etc. desprecia a Calderón, en contra del afecto que le tiene "el pueblo sano" y aquellos que son "muy religiosos, muy morales y muy amigos del orden social".

En el segundo, los dogmas literarios neoclásicos se definen como "frutos prohibidos" equivalentes a "los principios enciclopédicos», los cuales itratando de una subversión total pretenden introducir el despotismo en la república literaria al mismo tiempo que quieren el republicanismo en el orden social".

En el tercero, se dice que existe contradicción wentre el patriotismo y las reglas eternas e infalibles del guston.

Todo esto significa: $1 .^{\circ}$, que, si como Bohl sostiene, el espiritu nacional español está codificado en la obra calderoniana, quien no la aprecie no puede considerarse patriota; $2 .^{\circ}$, que, si ese espíritu es el responsable 
de la Guerra de la Independencia, los anticalderonianos son afrancesados colaboracionistas; $3 .^{\circ}$, que si ese espíritu se caracteriza por ser conservador en monarquía y religión, los anticalderonianos son heterodoxos y revolucionarios.

De modo que Juan Nicolás Böhl ya ha elaborado en 1814 un peculiar sistema de pensamiento desde el cual está haciendo, so pretexto de reivindicación calderoniana, un alegato político en apoyo del golpe de Estado fernandino de 1814, como al mismo tiempo su esposa con el folleto Fernando en Zaragoza. Con el Sexenio por delante, y en medio de la persecución contra afrancesados y liberales, lleva todas las de ganar. De hecho, sus adversarios enmudecieron prudentemente después de la aparición de Donde las dan, las toman,,,, y quizás la cosa no hubiera tenido continuación de no volver a la carga el mismo Böhl en 1817.

El 1 de abril de 1817 sale el primer número de un periódico fundado por José Joaquín de Mora, la Crónica cientifica y literaria, cuyo proyecto hablaba vagamente de una "ilustración» (en el sentido de mejoramiento de la sociedad) al servicio de la cual se enrolaba la publicación. La palabreja inquieta a Juan Nicolás, que envía un artículo, publicado en el número 3 , en el que se cuestiona "el sentido que debe darse a esta palabra en España». Hay, dice el autor, una "ilustración universal", muy provechosa si se la define como difusión del progreso científico; pero no es en ese sentido, teme, como se la suele entender, sino como pretensión de aplicar en todo lugar los principios de la crítica neoclásica y el liberalismo político revolucionario. Contra esa peligrosa «ilustración» debe definirse la «ilustración nacional», así llamada "por referirse particularmente al carácter e índole de una nación". En el caso de España consiste en "satisfacer la razón con sana doctrinan, no copiar del extranjero más que la «ilustración universal" o científica, y extraer de la tradición autóctona «aquellas heroicas virtudes de fortaleza, templanza, lealtad y fe que hicieron a sus antepasados el pasmo y la envidia del mundo, valiéndose para ello del manantial inagotable de su antigua literaturan. Es decir, que la "ilustración españolan equivale al conservadurismo político, arrullado por nostalgias imperiales, cuya biblia es esa antigua literatura que, como hemos visto, se cifra en la dramaturgia calderoniana 70 ). Dos meses más tarde, en junio de 1817, compone doña Francisca Ruiz de Larrea "Un Sueño", donde, tras desatarse contra la "idolatría de las hechuras transpirenaicas", concluye:

"Vuelvan los españoles a amar y admirar a su patria, nútranse de los recuerdos de sus glorias nacionales, considérense los unos a los otros como dignos descendientes de sus ilustres antepasados (...) y yo aseguro que prosperará de nuevo la España con sólo los sentimientos grandes que inspira el verdadero patriotismos:(71). 
En la Biblioteca del Estado y la Universidad de Hamburgo se conserva la correspondencia entre Juan Nicolás Böhl y su amigo Nicolás Enrique Julius, de 1810 a 1834. En una carta de 15 de julio 1817 escribe Böhl que tiene almacenados veinte ensayos contra la secta anticatolica y antimonárquica, que van "contra la llustración, la filosofía francesa, la economía enciclopédica, y demasiado a favor de la antigua religión, la Inquisición su auxiliar y la monarquía independientew(72). Tales son, con su propio nombre, las ideas políticas del matrimonio en la polémica aparentemente calderoniana, en la que el dramaturgo se ha convertido, por su parte, en un símbolo cuya semántica ya conocemos: exaltación del absolutismo desde el miedo a la revolución. Lo mismo que Francia se ha vuelto cifra de ese miedo, un miedo tan irracional que identifica al Neoclasicismo con la ejecución de Luis XVI: así, en un "Fragmento" de agosto 1817(73), doña Francisca ve en visión al "Genio de la Francia" defendiendo las Reglas con un tomo de Voltaire en la mano, mientras el "Genio de la España» duerme recostado sobre volúmenes de Calderón y Lope.

Böhl colabora en el Diario Mercantil gaditano desde abril 1818 a julio del mismo año. En el número 619, de 12 de abril, inserta una "Carta de un viajero francés residente en España", reimpresa en Vindicaciones de Calderón..., en la que el supuesto viajero observa que, "al mismo tiempo que la soberania legítima se consolidan, es decir, que se afianza el orden de cosas surgido del golpe de Estado de 1814, "los hombres vuelven a las ideas serenas y poéticas». Para Böhl, las ideas poéticas o "caballerescas" incluian, ya lo sabemos, la veneración del Antiguo Régimen, como motivación del pasado esplendor político y literario de la España de los Austrias, proyecto de presente y de futuro para la regeneración de España, e incluso formula que exportar, en forma de cruzada contrarrevolucionaria, a la Europa trastornada por las consecuencias de la Revolución Francesa. Pues bien, reste saludable influjo de los sucesos ha trascendido a la literatura y modificado visiblemente el gusto en la poesía dramátican, modificación que consiste en apartarse el público de las "regularidades" preconizadas por "una crítica bastarda", y volver a estimar a Lope y Calderón, cuyas obras, dice Böhl, "excitan los más vivos aplausos". Muy vivos, en efecto, debían de resonar tales aplausos en el oído de Juan Nicolás, para impedirle percibir el rumor subterráneo que iba al poco a conducir a los acontecimientos de 182074).

Vindicaciones... recoge un «Resumen de las noticias literarias publicadas en el Diario de Cádiz en abril, mayo, junio y julio de 1818,(75). En efecto, en el citado periódico había ido incluyendo, con el título de "Noticias literarias originales", sucesivos artículos donde alaba la moderación de Luzán, censura a Nasarre y Clavijo, y, claro está, alaba a Erauso, Nipho, Romea y Tapia (a quien Ilama "Romero»), Huerta, Estala, citando extensamente a los más significativos para sus propósitos. 
Y en el verano de este año 1818, Böhl y su esposa publican un Pasatiempo crítico en que se ventilan los méritos de Calderón...(76) cuyo primer texto, "¿Por qué odian los Mirtilos a Calderón?", acusa a José Joaquín de Mora de introducir en España "el contrabando filisófico» (las ideas enciclopedistas francesas) cuando pone reparos estéticos a Calderón desde perspectivas neoclásicas; divide a la humanidad en dos clases opuestas, los espiritualistas y los materialistas; entre éstos forman los herejes y los enciclopedistas franceses. Aquéllos, en cambio, son sensibles al espiritu calderoniano, indisolublemente unido a la ortodoxia religiosa. De lo cual se concluye que Mora utrata de seducir a los inocentes con la manzana sobredorada de la ilustración" (a la que Böhl prohija tanto el Neoclasicismo como la revolución), y de ahí que el texto que comentamos termine con la amenaza de que acaso tenga la Justicia que cerrarle la boca(77). En resumen, y como antes vimos, que el Neoclasicismo es elevado al rango de delito político, y así se habla de "funesta inoculación transpirenaica" en el quinto de los textos de este Pasatiempo..., y en el séptimo se dice que censurar a Calderón equivale a "cosas menos fútiles que las opiniones literarias " 78 . Otros párrafos de este mismo folleto podrían citarse, pero palidecen ante los seleccionados.

En otoño de 1818, un estrafalario y oscuro semierudito, Juan-Bautista Cavaleri, colaborador de Böhl en estas lides, hace gemir las prensas gaditanas de Carreño al dar dolorosamente a luz un folleto de 12 páginas titulado Discurso en razón de la tragedia "A secreto agravio secreta venganzan..., que he reproducido en otro lugar(79), y que sirvio para aderezar la velada dramática ofrecida a dos ictiólogos alemanes deseoso de admirar las sublimidades del teatro calderoniano y las peculiaridades de la sepia gaditana, en cuyo folleto, compendio de injurias y rodomontadas, se pondera la "dulzura vigorosa" del verso, y la no menos vigorosa moral del punto de honor calderoniano, que los "hombrecillos" no pueden comprender, como no comprenden que esa dimensión de la hombría hispánica es inseparable, dice Cavaleri, de la energía conquistadora de la España pretérita. Ni recordaba Cavaleri la historia de los últimos Austrias, ni el punto de vista de María de Zayas sobre dos cuestiones que él asocia desde el apriorismo de su furor castizo.

La Segunda Parte del Pasatiempo Crítico... apareció a comienzos del año siguiente, 181980); el primero de sus textos, tras prólogo e índice, no puede ser más taxativo:

"Digolo denodadamente y sin vergüenza: para hacer juicio de cualquier comedia nueva española, solo debiera examinarse: $1 .^{\circ}$, si se acerca a la poesía de Calderón; $2^{\circ}$, si se allega a la nobleza y elevados pensamientos de Calderón; $3^{\circ}$, si tiene la invención de Calderón; $4 .^{\circ}$, si su estilo y dicción se conforman con los de Calderón»(81) 
Poco parece discutible, llegados a este punto; cualquier argumentación razonada no será más que retorica. La de Böhl consiste en traer una vez más a colación el antiguo y no original relativismo de las cuestiones estéticas, de modo que ula primera y tal vez única regla universal del arte es que un poema corresponda a la índole e idioma de su nación „(82); y ya sabemos qué caricatura de la españolidad tiene Böhl en mente, y con qué fines ha sido ingeniada. A esa reiterativa predicación del relativismo del gusto le vemos el rabo cuando, en la misma Segunda parte..., en el capítulo titulado "Al señor D. Juan Gil de Ballecas", leemos que "la verdadera ilustración del dia», o sea lo que antes vimos llamar «ilustración nacional", "requiere una filosofía que, prescindiendo de la aplicación de generalidades abstractas a la sociedad y a la vida (el ecumenismo liberal), sabe apreciar lo peculiar de naciones e indivíduos: sabe combinar y medir las instituciones políticas y literarias con la indole de cada nación»(83).

Una Tercera Parte del Pasatiempo Critico...(84), fines 1819, contiene un capítulo rotulado "De las Unidades de Tiempo y Lugar..." donde se discute el dogma angular de la preceptiva dramática neoclásica, es decir el concepto de «ilusion" o identificación, poniendo de manifiesto su puerilidad: el que es capaz de imaginar, observa Böhl, que se encuentra en el lugar y tiempo escénicos, puede seguir imaginando aunque éstos cambien de un acto a otro. La impresión que es capaz de mover el ánimo del espectador no resulta de creer estar en la piel y circunstancias del personaje, sino en advertir que sus peripecias, por ser humanas, podrían sucederle también a él. Las Unidades, concluye, no son necesarias ni suficientes para que una obra tenga calidad y efecto, pero tampoco los excluyen. Son, sencillamente, irrelevantes. Cuando no le cegaba la pasión política, Böhl era capaz de razonar, y suele hacerlo en este tercer Pasatiempo, porque tiene ya en mente aspirar a la Real Academia, lo que consigue en abril de 1820.

Solo he citado una pequeña parte de los textos que salieron de la pluma de Juan Nicolás Böhl y sus colaboradores, pero parece que podemos dar la razón a Alcalá Galiano cuando escribe:

"Empezo violenta esta lid, y siguió tenaz y enconada. Mezclóse con ella un tanto de política. Böhl y su señora eran acérrimos parciales de la monarquía al uso antiguo. El primero habia dejado la religión protestante, en que se había criado, por la católica; y siendo sincero en su conversión, era hasta devoto. La mujer afectaba la devoción como pasión (...) Ya más ardiente la disputa, entró por parte de nuestros contrarios el acusarnos de jansenismo y de amor a las reformas...

En realidad, desde 1814, con Donde las dan, las toman..., estaba cuajado el sistema de pensamiento de Bohl y señora, que en otro lugar he mostrado concordante con lo más granado de la corriente ultraconservadora propia de los reinados de Carlos III, Carlos IV y Fernando VII, y cuyos 
paladines más significativos y conocidos son "El Filósofo Rancio», Diego José de Cádiz, Antonio de Capmany, Hervás y Panduro, Rafael Tomás Menéndez de Luarca, Rafael de Vélez y Fernando de Zeballos(86).

En cuanto a la respuesta de Mora y Galiano, hemos visto ya un texto significativo y representativo: la "Crítica de las reflexiones de Schlegel...", en el número 127 del Mercurio Gaditano, donde su autor, José Joaquín de Mora, enjuicia negativamente la comedia barroca con palabras que recuerdan la condena dieciochesca del tipo de héroe masculino que aquéllas presentan. En el mismo periódico, en su número 143, insiste Mora, advirtiendo de los peligros a que puede conducir una excesiva confianza en la libre imaginación creadora al margen de toda regla y precepto: "no dar nunca ni por descuido con la verosimilitud y la imitación". Ambos artículos son de 1814 y revelan, en sus conceptos clave, fidelidad absoluta a la crítica del teatro español que se desarrollo en el siglo anterior, y expusimos en la primera parte de este trabajo. A la impropiedad dramática del estilo calderoniano se referirá una colaboración, que hemos de atribuir igualmente a Mora, en la Crónica científica y literaria de 19 de mayo 1818, donde se califica ese estilo de "non plus ultra del más churrigueresco culteranismo»(87). De la misma mano sale un "Artículo remitido" en la Crónica... de 12 de junio, que entre líneas denuncia la politización del problema en los escritos de Böhk88), cuyos adversarios van a defenderse, mientras dure el enfrentamiento, en las dos direcciones señaladas: lamentándose de la violencia que se les hace al no ser posible el diálogo político en la España del Sexenio, y atacando a Calderón en la estela Neoclásico-llustrada. Así dirá Alcalá Galiano en la Crónica... de 4 de agosto 1818, señalando la maliciosa identificación bőhliana entre neoclasicismo y afrancesamiento político:

«En verdad que mueve más a indignación que a risa la malicia del criticastro alemán al recalcar tanto sobre el gusto francés. ¿Querrá, acaso, despertar odios políticos, terminados ya con la causa que los motivó?....»89)

Y en el folleto Los mismos contra los propios..., aparecido en Barcelona a fines de 1818(90), una "Carta de A.(ntonio) A.(Icalá) G.(aliano) a su amigo el editor de la Crónica..." se pregunta:

"¿No fue él (Böhl) quien recalcó la voz francesismo en una época en que esta voz puede dañar a aquél a quien se la aplica?»(91).

En la línea moratiniana está el artículo contra los duelos que inserta la Crónica... de 6 de abril 1819:

"Esperemos que la propagación de las luces verdaderas, que nacen de las ideas religiosas, acabará por desarraigar tan bárbara costumbre; que los escritores trabajarán para destruirla con las armas del raciocinio; que la voz del público se 
alzará contra este abuso del valor; que los poetas dramáticos, en lugar de presentar al público, bajo un aspecto favorable, las fanfarronadas caballeresca y los homicidios en regla, se dedicarán a la pintura de costumbres más suaves....m(92).

La extensión con que desarrollamos los argumentos anticalderonianos de los críticos del XVIII español excusa de citar más textos de Mora - Alcalá Galiano, ya que en el terreno de las ideas literarias no tienen, comparados con los primeros, ninguna originalidad. La de Juan Nicolás Böhl y sus colaboradores, en la adpatación que hacen a la coyuntura política fernandina de los puntos de vista de los apologistas del siglo anterior, la hemos visto en las páginas precedente. Queda con ello expuesto esquemáticamente lo que hay de tradición y de novedad en la famosa "polémica calderoniana".

\section{NOTAS:}

(*) Este estudio se preparó en 1980 pensando en el centenario calderoniano. Una versión abreviada a un tercio fue leída en el Congreso Calderoniano de 1981, y se publica en las Actas correspondientes.

No quiero dejar de recordar otras sintesis sobre la materia que se trata en la Parte l de este trabajo: Menéndez Pelayo, Historia de las Ideas Estéticas, vol. III (Madrid, C. S. I. C.); G. C. Rossi, Estudios sobre las letras en el siglo XVIII, Madrid, Gredos, caps. 1 y 2; R. Andioc, "El teatro en el siglo XVIII", en J. M. Dlez Borque (ed.), Historia de la Literatura Española, Madrid, Taurus, vol. III; M. Hernández, "La polémica de los Autos Sacramentales en el siglo XVIIl», Rev. Lit. juliodiciembre 1980.

(1) Los orlgenes del Romanticismo reaccionario espaffol: el matrimonio Böhl de Faber. Valencia, Universidad, 1978.

(2) Bibliografia de las controversias sobre la licitud del teatro en España (...) por D. Emilio Cotarelo y Mori (...) Mad., Tipografla de la Rev. Archivos, Bibliotecas y Museos, 1904.

(3) En Cotarelo, op. cit. p. 272.

(4) HERACLITO I DEMOCRITO /de nuestro siglo. / Descrivese su legítimo Filósofo. / DIALOGOS MORALES, / Sobre tres materias, La Nobleza, La Riqueza, / i Las Letras. / Dirigidos / A Don Manvel Alvarez Pinto / I Ribera (...) / POR ANTONIO LOPEZ DE VEGA. / (...) (s.l., pero Madrid en el colofón) / Por Diego Diaz de la Carrera. / Año M.DC.XLI. / Acosta de Alfonso Perez Librero de Su Magestad.- Bibl. Nacional, sign. $3 / 72153$. Ver pp. 174-177. Modernizo la ortografla aqul y en los demás textos.

(5) Op. cit. 180-181.

(6) Op. cit. p. 175, y prólogo uA los pocos. Cuerdos y desengañados varones, para vosotros sólo escribo...".

(7) Comedias y Entremeses de Miguel de Cervantes Saavedra (...) con una Dissertación o Prólogo sobre las Comedlas de España. Mad., Impta. Antonio Marín, 1749, 2 vols. Bibl. Nac. sign. Cerv. 82-83, ejemplar que fue de Gayangos.

(8) Op. cit. p. 7.

(9) Op. cit. pp. 25 y 38-42. 
(10) Málaga, Oficina de Fco. Martínez de Aguilar, 1754. Bibl. Nacional sign. 2/26309.

(11) Op. cit. p. 110.

(12) LA PETIMETRA. / COMEDIA NUEVA: / ESCRITA / con todo el rigor del arte, / por Don Nicolás Fernández / de Moratin, Criado de la Reyna Madre / nuestra Señora. / Entre los Arcades de Roma / Flumisbo Thermodonciaco. / Con licencia. / En Madrid, en la Oficina de la Viuda de Juan / Muñoz, calle de la Estrella. Año de 1762. Bibl. Nacional, en el vol. de sign. R - 16269.

(13) Op. cit. p. 12.

(14) Op. cit. pp. 12-13.

(15) Op. cit. p. 7.

(16) Op. cit. p. 19.

(17) . En el mismo vol. de nota 12. El primero, de $16 \mathrm{pp}$.; el segundo, de 23, el tercero de 40, los tres con paginación seguida. El primero en defensa de Clavijo, los otros dos contra los Autos.

(18) Primer Desengaño, pp. 3-4.

(19) Op. cit. pp. 12-13.

(20) Obras de Nicolás y Leandro Fernández de Moratín, B. A. E., pp. 31-33.

(21) En 6 vols., impresos en Madrid por Ibarra, $1 .^{\circ}$ y $2 .^{\circ}$ en $1762,3 .^{\circ}$ y $4 .^{\circ}$ en $1763,5 .^{\circ}$ y $6 .^{\circ}$ en 1767. Bibl. Nacional, sign. $R$ 17459-64.

(22) Op. cit. pp. 10-11, vol. I cuyos Pensamientos llevan paginación independiente.

(23) Op. cit. p. 15, vol. 1.

(24) Op. cit. tomo III p. 406. En este tomo, paginación seguida.

(25) Op. cit. tomo III p. 408.

(26) Madrid, Ibarra, 1763. Bibl. Nacional sign. T-10513.

(27) Op. cit. p. XII.

(28) Colección de obras en verso y prosa de D. Tomás de Yriarte..., tomo VII, Madrid, Imprenta Real, 1805. Bibl. Nacional, sign. 1/23241. Los literatos... en pp. 9-96.

(29) Op. cit. pp. 81-83.

(30) La / COMEDIA NUEVA. / Comedia / en dos actos, en prosa. / Su autor / Inarco Celenio / poeta árcade. / Parma / En la oficina de D. Juan Bautista Bodoni / Impresor de Cámara de S. M. C. I MDCCLXXXXVI. Bibl. Nacional, sign. R-30786. Ejemplar de la biblioteca de José M. a Asensio. Ver p. 92.

(31) L. F. M.-La derrota de los pedantes. Lección poética. Ed. J. Dowling, Labor 1973. Recoge la Lección... según la ed. 1825; v. tercetos 141-160 y 185-186, pp. 117-120.

(32) L. F. M., Epistolario, ed. R. Andioc, Castalia, pp. 141-145.

(33) El Censor (1781-1787). Antología. Ed. E. G. Pandavenes, prólogo J. F. Montesinos, Barcelona, Labor, Ver pp. 168-170.

(34) Obras de Jovellanos, B. A. E., tomo I. Ver pp. 488, 490, 496, 500.

(35) La muerte de César: / tragedia francesa / de Mr. de Voltaire: / traducida en verso castellano, / y acompañada de un discurso / del traductor, / sobre / el estado actual de nuestros teatros, / y necesidad de su reforma. / Por / Don Mariano Luis / de Urquijo. / Madrid: / por Don Blas Román. / M.DCC. XCl. Bibl. Nacional, sign. T-3687.

(36) Op. cit. p. 51.

(37) Op. cit. pp. 71 y ss.

(38) Números 1 a 22, 5 de abril a 30 de agosto 1763, en el vol. Bibl. Nacional sign. 7/11526. La cita del 26 de abril, en p. 61.

(39) Op. cit. p. 87.

(40) Op. cit. p. 87.

(41) Op. cit. p. 90. 
(42) Op. cit. p. 121.

(43) Op. cit. p. 123.

(44) Sur la querelle du theátre au temps de Leandro Fernández de Moratín, Tarbes, Imprimerie St.-Joseph. Ver pp. 15-43.

(45) Entusiasmo, / o / Sainete nuevo: / El Tribunal de la Poesía / Dramática. / Para comenzar la temporada / de invierno de 1763, en la Comedia / Casa con dos puertas, / de Don Pedro Calderón (...) / Dalo a luz / Don Francisco Mariano Nipho. / Con licencia: en Madrid, en la Imprenta de / D. Gabriel Ramírez, calle de Atocha, / año de 1763. Bibl. Nacional sign. T-10583.

(46) Op. cit. pp. 5-6.

(47) Op. cit. pp. 21-22.

(48) Op. cit. p. 148.

(49) Op. cit. pp. 163-171.

(50) Op. cit. p. 168.

(51) Op. cit. pp. 231-234.

(52) En Madrid, G. Ramirez, 1764. Bibl. Nacional, sign. T-12456.

(53) Op. cit. pp. 17-70.

(54) En Zaragoza, Imprenta Real, 1772. Bibl. Nacional, sign. T-13583. Ejemplar que fue de Barbieri.

(55) DISCURSO CRITICO / sobre el origen, / calidad, y estado presente / de las / COMEDIAS / DE ESPAÑA; / CONTRA EL DICTAMEN / que las supone corrompidas, y en favor de sus más / famosos Escritores el Doctor Frey Lope Félix de / Vega Carpio, y Don Pedro Calderón / de la Barca. / (...) / En Madrid: / En la Imprenta de Juan de Zúñiga. Afno MDCCL. (...) Bibl. Nacional sign $3 / 71396$.

(56) Op. cit., Dedicatoria de 12 pp. sin numerar, p. 9.

(57) Romea y Tapia, Juan Cristobal. El Escritor sin título... Madrid, Oficina Manuel Martín, 1763, Bibl. Nacional sign. $2 / 5951$.

(58) Op. cit. p. 36.

(59) Op. cit. p. 77.

(60) Op. cit. p. 78.

(61) Theatro Hespañol. Por Don Vicente Garcia de la Huerta. Parte Primera. Comedias de figurón. Tomo I, Madrid, Imprenta Real, 1785.

(62) Estas cartas se conservan en el Archivo Osborne, en un cartapacio de correspondencia 1.805-1.813. Ver Los origenes... cit. en nota 1, pp. 74-88. Modernizo igualmente los textos citados en esta parte 11 .

(63) En un cuaderno de correspondencia 1806-1810, conservado en el mismo Archivo, y en el ms. 14173 de la Biblioteca Nacional de Viena. Ver Los origenes... p. 157.

(64) Ver Los origenes... pp. 155-158.

(65) Op. cit. pp. 159-161.

(66) Op. cit. pp. 21-25.

(67) Op. cit. pp. 166-169.

(68) DONDE LAS DAN / LAS TOMAN: / En contestación a lo que escribieron Mir - /tilo y EI Imparcial en el Mercurio / Gaditano, contra Schlegel y su traductor / (...) / Cádiz 1814: Imprenta Tormentaria. Ver Los origenes... pp. 170-173.

(69) VINDICACIONES / de / CALDERON / y del / Teatro Antiguo Español / contra los / Afrancesados en Literatura. / Recogidas y coordinadas / por D. Juan Nicolás Bohl de Faber / de la Real Academia Espanola. / Cádiz 1820. / En la Imprenta de Carreño (...) Ver Los origenes... pp. 227-235.

(70) Op. cit. pp. 177-179. 

(71) Op. cit. p. 182.
(72) Op. cit. p. 183.
(73) Op. cit. p. 184
(74) Cito por Vindicaciones..., pp. 26-29 de la primera paginación. Ver Los origenes... p. 228.

(75) Vindicaciones..., pp. 34-59 de la primera paginación. Op. cit. p. 228.

(76) PASATIEMPO CRITICO / en que se ventilan / LOS MERITOS DE CALDERON / y el talento de su detractor / en la Crónica Científica y Literaria de / Madrid / POR EL AUTOR / DE LAS NOTICIAS LITERARIAS DEL / DIARIO DE CADIZ (...) Op. cit. p. 229.

(77) Pasatiempo... pp. 7-14.

(78) Pasatiempo... pp. 39 y 47.

(79) Los origenes... pp. 115-120. Ver también pp. 201-208.

(80) SEGUNDA PARTE / del / PASATIEMPO CRITICO / que trata de lo mismo: / por el propio. $/$ (...) Ver Los origenes... p. 231.

(81) Segunda Parte... p. 19.

(82) Segunda Parte... p. 20.

(83) Segunda Parte... pp. 37-38.

(84) TERCERA PARTE / DEL / PASATIEMPO CRITICO / EN DEFENSA DE CALDERON / Y / DEL TEATRO ANTIGUO ESPAÑOL (...) Ver Los origenes... p. 233.

(85) En Memorias (con Recuerdos de un anciano), ed. J. Campos en Obras escogidas, B. A. E. vol. I, pp. 454-455.

(86) Ver Los orígenes... cap. IV.

(87) Op. cit. pp. 168-170 y 192-193.

(88) Op. cit. pp. 194-195.

(89) Op. cit. pp. 198-199.

(90) LOS MISMOS / CONTRA LOS PROPIOS / O / Respuesta al folleto intitulado / Pasatiempo Crítico (...) Barcelona / Por Don Agustín Roca (...) año de 1818. Ver Los orígenes... p. 315.

(91) Los mismos... p. 25. Publico esa carta en : "Une contribution à l'histoire des idées esthétiques dans l'Espagne du début du XIXe. siècle: un texte inconnu d'Antonio Alcalá Galiano", Mélanges de la Casa de Velázquez, 1.980.

(92) Los origenes... p. 219. 


\title{
QUEVEDO EN LARRA
}

\author{
Por José Luis VARELA \\ Universidad Complutense
}

Corta e intensa-como su vida misma-la carrera literaria de Larra reconoce la presencia constante de Quevedo, desde sus primeras colaboraciones en El Duende (1828) a sus últimos artículos periodisticos; es más, los dias que preceden al suicidio, parece haber acometido con su amigo Roca de Togores la empresa, aboceteada e iniciada en sus primeras escenas, de un drama titulado "Quevedo" (Mesonero publica en sus Memorias el texto de una carta de Molins, en la que éste afirma poseer tales manuscritos)(1).

En el breve espacio de que dispongo, quisiera abocetear ante ustedes una relación de deudas y correlaciones estilísticas entre ambos escritores, a sabiendas de que algunas pertenecen al caudal universal de la literatura satírica, aunque su procedencia en Larra sea fundamentamente quevedesca. Estas caracterizaciones procuraré integrarias en el modesto edificio-aboceteado en otro sitio-(2) que singulariza su estilo personal, con lo que pueden adquirir su verdadera dimensión, original o mostrenca. La ascendencia quevedesca de muchos recursos no fue inadvertida por lectores y criticos, ciertamente; como que el propio Fígaro la señala, mediante cita directa o recuerdo descubierto. A ella hemos hecho referencia más circunstanciada Lomba Pedraja (1934), F. Caravaca (1963), Benítez Claros (1.947), Reyes Cano (1.972) y yo mismo (1.960 y 1.970)(3). Aglutinemos, pues, esas y nuevas deudas en el repertorio formal y conceptual de Larra, o sea, en su estilo.

El protagonista de El café, que no es otro que el propio Larra, agazapa su figura ("que por fortuna no es de las más abuitadas") en el local que le servirá de escenario de observación, se emboza en la capa, baja el ala de 
su sombrero y acecha toda necedad que vaya a pronunciarse, para lo cual "me siento-escribe-a la sombra de un sombrero hecho a manera de tejadon $(1,9)$. O sea, que antes que el repertorio de necedades abra su espita, el observador se ha topado con Don Diego de Noche, quien en el Sueño de la Muerte llevaba "una esclavina por capa y un soportal por sombrero». Pero es más: el bombardeo de necedades y frases comunes, tópicos que la indiscrimación personal hace sentenciar y repetir hasta la más enfadosa de las vulgaridades ("todo el auge de su esplendor, el. sueldo de inválidas que deben gozar las letras... y otras mil chocarrerias y necedades") presagian en este autor la larga cosecha paremiológica de nuestro satírico romántico (en este país, es otra cosa, por ahora, aqui yace, entre qué gentes andamos, etc.) y que tienen su origen en esos «bordoncillos inútiles, pues se puede andar sin ellos y por camino llano en las conversaciones", como dice la Premática de 1600 y que ampliará el Cuento de cuentos (1626), al ofrecer juntas "las vulgaridades rústicas que aún duran en nuestra habla" y que Quevedo quisierra borrar de la conversacion, para lo cual acomete siempre que puede: quien dijera, no pensaba, no miré en ello, no sabia, qué importa (y otras «infernales cláusulas») en la Fortuna con seso, el pensé qué (Sueño del infierno), y, en fin, los personajes y personajillos etnológicos (el rey que rabio, el Rey Perico, Pero Grullo, Mateo Pico, etc.) que viven gracias a la conversación mostrenca(4). Quevedo, pues, denuncia y ridiculiza siempre; Larra los utiliza con fines varios, entre los que cuenta también su revalorización como acuñaciones expresivas de una situación politica o anímica.

Pero la presencia de Quevedo no se acaba aquí, como es obvio. Esta primera muestra del arte literario de Larra entronca con el moralismo tradicional, desde los Saturnalia lucianescos a El mundo por de dentro. Larra va quejándose hasta su casa por todo lo que ha visto y escuchado en el café, $y$ "convencido de que el hombre vive de ilusiones y según las circunstancias", se introduce en la cama, apaga su luz y reconoce, antes de conciliar el sueño, que lo único que no es quimera en este mundo es precisamente el sueño. Ha emprendido el camino satírico, que conduce a desembarazarse de apariencias y a toparse inevitablemente con el desengaño. "¡Qué diferentes son las cosas del mundo de como las vemos!. Desde hoy perderán conmigo todo el crédito mis ojos y nada creeré menos de lo que viere»(5), podria decirse también el Larra de veinte años que inicia su vida literaria.

El amplio uso de imágenes vulgarizantes a que recurre nuestro autor no sólo está en Quevedo ("eché de ver que era caballero de alquiler, como mula; disculpábase conmigo diciendo que le venia de casta, como al rey de Francia curar lamparones", leemos en el Buscón), sino en Isla y en los antecedentes latinos del género, lo mismo que el ilustrar o adobar la narración con alguna fabulilla o chiste que venga a cuento(6). Pero hay un 
ejemplo de Fígaro, provisto, a modo de contera, de un chistecillo verbal y original-precedido por unas oraciones interrogativas, interesadas en sugerir la confusión originada por la sorpresa-que remite al Sueño del Infierno o a la Fortuna con seso. En «El fin de fiesta» (I, 312-313), cuando el ardor belicoso contra la insurrección carlista en el Norte, Larra nos cuenta un sueño: en Bilbao, entre gentes que van y vienen turbadas, "veía gran muchedumbre de facciosos fantasmas, que tal me parecieron, porque queriendo llegar a tocarlos, luego se desvanecían. ¡Cosa más natural en sueños!. "¿Qué hacemos aqui?", gritaban unos. "¿Qué hemos hecho?”, clamaban otros. "¿Qué haremos?”, pensaban los más. “¿Qué nos harán?", añadian algunos. "Estos fantasmas están adelantados-dije yo para mí-; ahora se andan en las conjugaciones: mejor les fuera contentarse con declinar"'s. Pues bien, recuérdese como antecedente de la dilogía citada, el cuartel de los «iOh, quien hubiera!": "...y agora acá se les va todo en decir: ¡Oh quien hubiera oído misa! ¡Oh quien hubiera callado! ¡Oh quien hubiera favorecido al pobre! ¡Oh quien hubiera confesado!». $O$, en fin, los enfurecidos porque la hora les sorprende, y exclaman: "Lobos queremos"; otros: "todos son lobos"; otros: "Todo es uno"; otros: "Todo es malo". Otros muchos contradecían a éstos»(7); con lo que la abigarrada promiscuidad sugerida por la repetición de preguntas 0 afirmaciones-Quevedo gusta, como es sabido, de catervas, chusmas, enjambres, cáfilas, y de sus chismes-confirma la imagen o idea de confusión. No se puede dar crédito al testimonio de los ojos si no queremos padecer mil confusiones: "Tendrás las sierras por azules, y lo grande por pequeño, que la longitud y la proximidad engañan la vistan; la Rueda de la Fortuna mezcla "en nunca vista confusión todas las cosas del mundo"; el hombre va de calle en calle, calles infinitas, y por lo tanto confuso sin saber cuál coger, entre el cansancio y la admiración; "cuando más apurado me había de tener el conocimiento de estas cosas, me hallé todo en poder de la confusión...s(8). Sí, es la lección barroca de la picaresca: el hombre perdido en el caos de su laberinto, donde le engañan los sentidos y pierde el conocimiento de su fin. De aquí procede la configuración larriana del mundo como confusión. En Larra, como he advertido en su lugar, hay formulaciones explicitas e implícitas (entre éstas, la más sobresaliente es quizá La diligencia; entre aquellas, el artículo dedicado al Carnaval en 1833, El mundo todo es máscaras). Pero lo que ahora me interesa es que halla el primer testimonio y formulación en el espectáculo de la sociedad española: el artesano pretende ser artista, el artista quiere parecer empleado y el empleado título del Reino (1832), de tal modo que en 1834 terminará preguntándose si alguien puede ocupar su verdadero puesto. "¿Hay tal confusión de clases y personas?". La pregunta carecerá de sentido poco después, cuando el elitismo artístico-social de Larra entra en conflicto con la ideología radical a que le conduce la gestión de los moderados, la progresista de Mendizábal y el radicalismo perceptible, aunque poco dura- 
dero, desde su estancia en Francia (1835) y los meses de 1836 que precedieron a su aventura política.

También, como es bien conocido, esta descolocación social está en Quevedo, y por supuesto en el moralismo y costumbrismo anterior a Quevedo, aunque éste es progenitor del romántico. "Y es de advertir-se lee en el Sueño de la Muerte-que en todos los oficios, artes y estados se ha introducido el don: en hidalgos, en villanos y en frailes (...) Yo he visto sastres y albañiles con don y ladrones y galeotes en galera. Pues si se mira en las ciencias: clérigos, millares; teólogos, muchos; letrados, todos. Sólo de los médicos ninguno ha habido con don, pudiéndolo tener muchos; $y$ todos tienen don de matar, y quieren más din al despedirse que don al Ilamarlosw(9).

En la estructura coloquial de los Sueños-coloquio precedido generalmente de una breve narración o descripción-se ha señalado el antecedente de algunos famosos artículos como El mundo todo es máscaras o El día de difuntos(10); es justo, si bien cabría acompañarlo de buena parte de la literatura costumbrista anterior y contemporánea. Pero hay más: en el primero de los artículos citados, Larra menciona explícitamente a Quevedo, pretende configurar la idea de confusión (la escalera por la que accede al baile de máscaras es uverdadera imagen de la primera confusión de los elementos" y en el salón se advierte la "confusión de sensaciones encontradas de un baile de máscaras" donde las palabras "se confunden con las voces") y la de desengaño (el protagonista se dirige directamente contra los "observadores de superficies", la cara de algunos personajes es más pérfida que su careta, y, en fin, es el envés o verdad de las cosas lo que interesa). Huelga decir, sin embargo, que Larra ha revalorizado la lección ascética de su maestro: se dirige a la sociedad de 1833, así como luego dirigirá sus dardos a la corrupción de las conductas políticas.

Parece evidente que Larra tiene presente en este artículo al Sueño de la Muerte cuando, fatigado y momentáneamente apartado el protagonista del "enjambre de máscaras", se duerme en un rincón, y tanto el sueño como el ayuno le acercan una "redoma mágica" de la que, en medio de un torrente de luz, aparece Asmodeo, como en el sueño quevedesco, que precede con ardor terrible a la aparición en otra redoma de los jigotes de D. Enrique de Villena. Asmodeo muestra al romántico tipos picarescos que nos son bien conocidos, revelando su verdadero envés: la vejez vergonzante ("un joven de sesenta años disponiéndose a asistir a una suaré»), las viejas y sus afeites engañadores, el médico y el picapleitos, el militar fanfarrón y embustero. Los jigotes que componen a Villena, por el contrario, se resisten a salir de la redoma ante los desafueros que enseñorean el mundo de Mateo Pico (guerra, genoveses, deshonra, deudas, licenciados, médicos, jurisconsultos). Larra toma el sueño quevedesco, y acoge la uensoñación"-quevedesca-de Vélez por medio de Asmodeo (que es, pro- 
piamente, Cleofás en la novela española); como hará poco después ( 9 de agosto de 1835) en uno de los más quevedescos y al par originales artículos salidos de su pluma: la "pesadilla política" que titula Cuasi. Todo el año-mantiene Asmodeo-es carnaval, ya que todo anda siempre encubierto, meramente simulado o del revés. Asmodeo anticipa a Larra su última lección desengañada: que todo Madrid es un cementerio y que el cementerio más próximo será su propio corazón. El trasunto estoico-barroco de la Gran Comedia representada por todos resulta transparente; pero el romanticismo añade un aliño sentimental que consiste en decirnos que la representación no admite jerarquía de papeles ni firmeza, pues se representa precisamente aquello que no es. Muy poco más tarde-marzo del 35, en Un reo de muerte - se representa sin ensayo, de balde y en balde.

Creo que en Cuasi nos hallamos ante el mejor Larra. En este breve artículo se contiene en síntesis preciosa todo lo que ha ido expresando discursiva o narrativamente y, sustituyendo el "argumento" por una visión quevedesca, Larra concentra en una sola palabra, cuasi, todo lo que la existencia tiene de frustración, de apariencia, de imposible plenitud personal, social o política. Después de una breve reflexión sobre la escasez de hombres verdaderos, "sentí sobre mí algo más fuerte que yo"-escribe-y, sin ver, oye, muda de sitio sin andar, y una voz le va señalando desde las alturas la confusión babélica de París y la real estatura-verdaderamente diminuta-de los hombres del siglo, "gusanos producidos por un queso de Roquefort". Bien vistos, no son hombres, sino palabras. Se ha terminado el reino de los hechos y asistimos al de los nombres. Y la palabra que reina sobre todas es cuasi. Otro diablo sin nombre-antes Asmodeo, de Vélez de Guevara; ahora un nuevo "ser fantástico"-le lleva en "sueño"convertido en pesadilla política-sobre un París "donde me encontré volando entre la confusión de palabras vestidas de frac y sombrero, que a pie y en coche recorren las calles de la gran capital».

De nuevo desengaño, confusión y secularización. Más una maestría malabarista para operar con aposiciones substantivas-como cuando hablaba de los dịstintos tipos de calaveras o del hombre globo, pero ahora exhaustivamente-cuya raíz es netamente quevedesca. Asi, "a los maridos calzadores, que los meten para calzarse la mujer con más descanso y sacarlos fuera ellos", los maridos linternas o los maridos jeringas (Sueño de la Muerte), añaden la observación sociopolitica y la fantasia verbal de Figaro los hombres reverberos, las palabras-promesa, palabrasmanifiestos, palabras-calles, palabras-mónstruo, palabras-puercoespin, palabras-pueblo, palabras-arlequín, palabras-percebe, que preceden a la ristra de frustraciones encabezadas por la palabra emperatriz: cuasi rey, cuasi revolución, cuasi nada, cuasi whig, cuasi nación, etc.

El perfecto acabado de este artículo-capaz de reducir a una palabra breve la tesis satírica de su crítica social-es perfectamente abarcable si 
se lo mide con sus bocetos precedentes: Ventajas de las cosas a medio hacer (I, 355), Las palabras $(I, 392)$ y, ya más cerca, Por ahora $(I, 454)$. Pero también advirtiendo que esta nueva uvisión» quevedesca se alía con el antecedente pictórico de los caprichos de Goya, que había citado hacía pocos meses $(I, 26)$ y sugeridores, en mi opinión, de esta breve estampa de la Plaza Mayor madrileña un día de Navidad en que los liberales se baten por Bilbao: "Montones de comestibles acumulados, risa y algazara, compra y venta, sobras por todas partes y alegría. No pudo menos de ocurrírseme la idea de Bilbao: figuróseme ver de pronto que se alzaba por entre las montañas de víveres una frente altísima y extenuada; una mano seca y raida llevaba a una boca cárdena y negra de morder cartuchos, un manojo de laurel sangriento». (II, 314). Nada más. Y nada menos que Saturno devorando a sus hijos. Goya y Quevedo aliados.

Existe un último aspecto que no debe olvidarse y sobre el que formular, si es posible, alguna precision: la de los retratos fisonómicos de ambos escritores. Se ha recordado aquel "rostro acuchillado con varios chirlos y jirones", cubierto con un "ruin sombrero con oficios de quitaguas", y de "mirar bizco, como de quien mira y no mira", que aparece en Empeños y desempeños (I, 88); para compararlo, justamente, con su ascendiente del Buscón, "mulato zurdo y bizco", que "traía la cara de punto, porque a puros chirlos la tenia toda hilvanada" y cubierto por "un sombrero con más falda que monte" (XI, libro I). Los rasgos familiares pueden extenderse, por supuesto, al protagonista de "El hombre menguado» (I, 301). Lo que me interesa, sin embargo, son las divergencias, porque por su rendija podemos vislumbrar la posible originalidad del escritor moderno. $Y$ en este sentido, yo observaría el genialmente desalmado radicalismo manierista con que Quevedo deforma caprichosamente las líneas y acumula, mediante yuxtaposición, comparaciones que proceden-como en la vieja literatura fabulística y satírica-del mundo animal, aunque tengan paralelos pictóricos proximos tan elocuentes como Arcimboldo, que estudio-refiriendo su composición a las caracterizaciones quevedescas - la profesora Levisi. Los rasgos de la famosa Dueña Quintañona, por ejemplo, propician el parangón con el grifo, la lamprea, el mono; de tal modo que su rostro, como los del famoso bibliotecario de Arcimboldo, o las alegorias de las estaciones, componen un conjunto heterogéneo en el que las partes no pierden su individualidad(11). Larra ha pasado por él, y lo aprovecha; pero sin que se precise aludir, como se ha hecho, a una presunta ausencia de genialidad creadora-en contraste con un quevediano contemporáneo, Valle-Inclán-de nuevas fórmulas dentro del mismo estilo; basta, en mi opinión, con aludir a su educación clásica de la mocedad y, con ella, a los inevitables remilgos para aceptar en bloque el legado barroco. Larra suele seguir en consecuencia un hilo de imágenes que no se desvian de la familia estilística original; y prolonga-mediante una perspectiva pseudocientífica, sólo posible en una era para la que el Progreso 
constituia una verdadera religión-las comparaciones de sus tipos humanos o políticos por la escala animal, vegetal o social. Véase, sin llegar a la "perspectiva naturalista", la fidelidad de Larra al modelo arqueológico en la descripción de su cicerone extremeño:

"Mi cicerone es una verdadera ruina, no tan bien conservada como las romanas; sus piernas se plegaban en arco, como si el peso de la cabeza hubiese sido por mucho tiempo oneroso a la base del edificio; sus brazos pendian también como dos arcos laterales cuyo pie hubieran carcomido dos ramales de un río, que hubiesen lamido por muchos años los costados de un hombre. La cara hubiera dado lugar a las más graves investigaciones de una academia; semejante a una moneda largo tiempo enterrada, y tomada a trechos del orín y de la tierra, sus facciones estaban medio borradas, y ora parecian letras en estilo lapidario, ora vistas a otra luz semejaban algo un rostro humano maltratado por la intemperie o la incuria de sus guardianes (...) Su desigual cabello blandamente meneado por el viento, remedaba esa hierbecilla que por entre cornisas y coronamiento de una torre antigua hace nacer la humedad; sus dientes eran almenados, y la posicion del cuerpo todo, fuera al parecer del centro de gravedad, le hacia parecer una pared que comienza a cuartearse, cuyas grietas hubiesen sido la boca y los ojos, y me trajo a la memoria la célebre torre de Pisa".

(II, 90; 30. 5. 35).

El texto es, aunque algo largo, perfecto como ejemplo, quizá no como estilo: todas las imágenes (piernas/arco, brazos/arcos laterales, cara/moneda, cabello/hierbecillas, dientes/almenas, cuerpo/pared cuarteada, boca/grieta) tienden a constituir una glosa de ese villancico inicial ("mi cicerone es una verdadera ruina") y el recuerdo arqueológico de la coda: la célebre torre de Pisa.

Existe también, por vía negativa, otro préstamo quevedesco. En otro lugar he tratado del paulatino abandono del artículo de sátira constumbrista para pasar a la de las costumbres políticas y de ellas a la introspección lírico-dramática, es decir a la sátira desalmada del propio satírico. He pretendido ver en la insurrección carlista y la necesidad de combatirla, amén de otras causas, la determinante del abandono de la estampa costumbrista a partir del otoño de 1833(12). Pero ¿es que Quevedo, en virtud de la virtú manierista o artística, no huye del tema?. ¿No atomiza la escena costumbrista en La hora de todos, reduciéndola a miniatura o boceto, a mero alarde ingenioso?. Larra huye del "cuadro" para entregarse a la "visión" (imaginativa, onírica, lírica). En ese proceso le precede Quevedo, con su inmensa autoridad literaria. Le precede también, con su prestigio artístico y político, D. Francisco de Goya. 


\section{NOTAS:}

(1) En las Memorias de un setentón, Mesonero recuerda que Larra le había hablado udel proyecto de un drama que tenía ya bosquejado, en que quería presentar en la escena al inmortal Quevedo, y hasta me invito a su colaboración, que yo rehusén; a lo que añade en la segunda edición el texto de una carta de Molins por la que sabemos que Larra chabia sacado para ello de la Academia las obras del insigne poeta" y que conservaba todavia "el manuscrito del plan del drama y de las primeras escenas”. (Vid. Sánchez-Estevan, Larra, Madrid, 1.934, 204-205).

(2) Larra ante España, Discurso correspondiente a la solemne apertura del curso académico 1.977-78, Universidad Complutense (Madrid, 1.977), pp. 13 y ss.; la parte primera de este estudio, como se advierte oportunamente, constituye una revisión del artículo «Sobre el estilo de Larra", aparecido en Arbor, dic. de $\mathbf{1 . 9 6 0 .}$

(3) Es de justicia señalar, no obstante, que fuera de las contribuciones de Benitez Claros ( "influencias de Quevedo en Larra» aparecido primero en Cuadernos de Literatura, y recogido luego en Visión de la literatura española, Madrid, 1.963, pp. 227-233) y de Reyes Cano («Los recursos satíricos de Quevedo en la obra constumbrista de Larra", Prohemio, III, 3, dic. 1.972, 495-512), los demás autores señalan simplemente contactos parciales o refieren a Quevedo la esencia satírica de Larra. El estudio de Caravaca ( Notas sobre las fuentes literarias de constumbrismo de Larran, en $R H M, 1.963,1-22)$ se interesa fundamentalmente por los préstamos de Jouy.

(4) Vid. O. C., edic. cit. (Madrid, 1.961), p. 230 (La Fortuna con seso) y p. 156 (Sueños del Infierno), especialmente.

(5) Ibid. p. 168. Esta lección-tan grata al Larra que quiere desentrañar en su literatura constumbrista la verdad entre el caos de apariencias sensibles-está ya en el Luciano que, a propósito de los falsos filósofos, el infierno, o la oración, denuncia la contradicción entre la ilusión y la verdadera motivación de las acciones humanas (Vid. M. Morreale, "Luciano y Quevedo: la humanidad condenadan, en Revista de Literatura, 8 (1.955), pp. 213-27. Otros textos del mismo libro de Quevedo, EI mundo por de dentro, reforzarian esta actitud de Larra; por ejemplo, pp. 165 y 167 , edic. cit.

(6) O. C., edic. cit., pp. 325 y 303. La introducción de facecias que amenicen el relato, o divagaciones, es muy frecuente, y el mero pretexto asociativo de la ocurrencia momentánea ("a este propósito", "me acuerdo den) vale para su introducción, como en ésta de la Fortuna con se. so: "Acuérdome del cuento del que, enfadado de que los ratones le roían papelillos y mendrugos de pan...", etc. (O. C., p. 235). Lo mismo hará Isla después en su novela, las Cartas de Juan de Encina y en el Lía Grande de Navarra.

(7) El Sueño del Infierno, edic. cit., p. 150 y la Fortuna con seso, edic. cit., p. 278.

(8) El mundo por de dentro, edic. cit., p. 172, y prólogo "Al lector»; la Hora de todos, edic. cit., p. 231.

(9) O. C., p. 178. Sigo, sin embargo, la lectura de F. Maldonado en la edición de Castalia-Madrid, 1.972-, p. 196, que acepta la enmienda de Fernández Guerra).

(10) R. Reyes Cano, ob. cit., p. 505.

(11) "Las figuras compuestas en Arcimboldo y Quevedo", Comparative Literature, 1.968, pp. 217-35. Levisi recuerda el carácter eminentemente plástico de la caricatura y de la alegoria, así como la observación de la realidad con ojos disociadores, que caracteriza a ambos artistas. Los ejemplos más convincentes de este paralelismo los encuentra Levisi en la poesía, donde la técnica acumulativa de Quevedo consigue una máxima concentración. Caso superlativo de esta técnica lo constituye el soneto "Erase un hombre a una nariz pegado", donde Quevedo consuma la destrucción del retrato mismo merced al tamaño de los objetos que reemplazan a la nariz del retratado.

(12) Larra ente España, ob. cit. pp. 36-52, especialmente. 


\section{INVENTARIO DE LA BIBLIOTECA DE D. NICOLAS PRO, ILUSTRADO ALICANTINO DEL SIGLO XVIII}

Por Joaquin SAEZ VIDAL I. N. B. «Figueras Pacheco»

El tema de este trabajo está centrado en el análisis del inventario de la biblioteca de un personaje representativo de la correinte ilustrada en nuestra ciudad. Nos referimos a quien fue en los años finales del siglo XVIII secretario del Ayuntamiento de Alicante: D. Nicolás Pró.

El hallazgo de dicho inventario bibliográfico, por otra parte, lo hemos localizado en un legajo existente en el Archivo Municipal alicantino, en el cual se contiene la referencia explícita de los bienes dejados a la muerte de D. Nicolás Pro, en 1787, a sus herederos(1).

El conocimiento de dicho fondo bibliográfico creemos puede resultar de utilidad por cuanto nos permite sumergirnos en las fuentes que estimularian el proceso formativo del pensamiento del lector. Revelaria, así mismo, el bagaje cultural de que dispondría su propietario. Con todo, el inventario de la biblioteca de D. Nicolás Pro, como la de cualquier otra, no supone en modo alguno que la relación de libros que allí aparecen se identifique exclusivamente con el campo de lecturas de dicho señor, ni siquiera con el total de libros que pudiera haber acumulado. Hemos comprobado a este respecto que nuestro autor dispuso igualmente de otros volúmenes, algunos no aparecidos en el inventario, que periódicamente le enviaba desde Madrid D. Simón Gomez Pérez.

Sabemos, merced a la existencia de testimonios documentales aparecidos en el Archivo Municipal, de continuos encargos para la adquisición 
de ejemplares en la capital de la nación. Hubo casos, como más adelante veremos, en que la remisión de obras de determinados autores como Grocio, Montesquieu o Brucker, por él solicitadas, no fue posible por estar incluídos en la lista de autores prohibidos(2).

Asi y todo pensamos que al dar a conocer el conjunto de obras reunidas por el Sr. Pró lo que parece desprenderse claramente es que a través de ellas se patentiza la adecuación de su pensamiento con las tendencias culturales más avanzadas de su época.

Nuestro propósito al detallar la lista de libros consistirá además en destacar el decisivo papel que en el proceso de incorporación al pensamiento moderno por parte de D. Nicolás Pró va a ejercer la figura del erudito de Oliva D. Gregorio Mayáns.

Dicho magisterio adquiere consistencia al examinar el contenido de los libros que forman la biblioteca del alicantino. En relación con esto llama la atención el hecho de que la mayor parte de los títulos se hallan en una coincidente línea ideológica a la manifestada por Mayáns. Hay, pues, un mismo espíritu reformista que puede concretarse en los siguientes rasgos: manifiesta actitud crítica orientada al campo histórico; rechazo de toda opinión basada en los prejuicios o la ignorancia; vuelta al humanismo -herencia del influjo de Marti-; revalorización de los autores clásicos españoles e incluso del propio idioma español; búsqueda de una religiosidad más profunda, inspirada menos en ritos que en una honda reforma interior; familiarización con los tratados más valiosos del derecho y de la jurisprudencia, etc. Elementos todos ellos que en líneas generales constituyen el centro y el eje sobre los que gira la mentalidad renovadora de Mayáns.

Una vez hechas estas precisiones preliminares pasamos a ocuparnos del catálogo del inventario bibliográfico de D. Nicolás Pró. Este se compone de los siguiente títulos, que a continuación trascribimos, con indicación del número de tomos de que se compone cada obra y el valor estimado de las mismas:

....Otrosí recae en dicha herencia los libros siguientes justipreciados por sujeto inteligente

TOSCA: Compendio Matematico, ocho tomos, octavo mayor, por ocho libras.

MARTINEZ: Filosofia Steptica, un tomo en quarto, por ocho sueldos.

BOSSUET: Potestad eclesiastica, seis tomos en quarto, quatro libras.

BOSSUET: Catesismo de la doctrina Christiana, un tomo en quarto pergamino, trece sueldos y quatro.

Ensayos para la historia de Artes y Siensias, un tomo en quarto, diez sueldos. 
ECHART: Diccionario Geografico, tres tomos, quarto, una libra doce sueldos.

ROLLIN: Historia antigua, trece tomos, quarto, siete libras.

ROLLIN: Historia de Artes y Siensias, tres tomos, quarto, dos libras.

ROLLIN: Metodo de estudiar las Bellas Letras, tres libras. y ocho.

ROLLIN: Historia del Cielo, dos tomos, quarto, una libra, seis sueldos

Espectáculo de la Naturaleza, con láminas, diez y seis tomos, doce libras.

Calepino de Salas, un tomo, en quarto, pergamino, una libra, seis sueldos y ocho.

BARBADIÑO: Metodo de estudiar, quatro tomos, quarto, una libra, seis sueldos y ocho.

VERNEl: De re logica, un tomo en quarto por diez y seis sueldos.

VERNEI: De Metafisica, ocho sueldos.

Historia del establecimiento de la Iglesia, seis tomos en quarto, quatro libras.

MARCIAL: Epigramas, cum notu ad usum Delfini, un tomo quarto mayor, una libra, seis sueldos y ocho.

Año Christiano, en frances, a saber los doce meses, quatro tomos de fiestas movibles y uno de la vida de Jesu Cristo y de la Virgen, todo diez y siete tomos en octavo, pasta, doce libras.

Monarquia ebrea por el MARQUES DE SAN FELIPE, dos tomos en quarto, una libra, doce suldos.

Exercicios de RODRIGUEZ, dos tomos en quarto, una libra.

CALATAYUD: Misiones y Sermones y una doctrina práctica, tres tomos en quarto, una libra doce sueldos. quatro.

MAS: su Filosofía, quatro tomos en octavo, una libra seis sueldos y

VIRGILIO, ad usum Delfini, un tomo en quarto, en pasta, dos libras. libras.

CICERON: Epistolas ad usum Delfini, un tomo en quarto, pasta, dos

CICERON: Oraciones ad usum Delfini, tres tomos en quarto, pasta, seis libras.

Diccionario Italiano, Latin y Franses de ANTONINI, dos tomos en quarto, pasta, cinco libras.

VINNIUS: Castigatus, con notas de Sala y el Dro. Español, dos tomos, quarto, pasta, tres libras quatro sueldos.

Diccionario Español y Francés, de SOBRINO, dos tomos en quarto, pasta, quatro libras. 
ORACIO, ad usum Delfini, dos tomos en quarto, pasta, quatro libras. CALATAYUD: Doctrinas Prácticas, un tomo en folio, una libra.

NEBRIJA: Diccionario Latino, en folio, diez sueldos.

NIERAMBELO: Obras, dos tomos en folio, dos libras.

MARIANA: Historia de España, por la Biblioteca de Madrid año ochenta y dos, dos tomos en folio, seis libras.

VAN ESPEN: IUsus Eclesiasticum, tres tomos en folio, seis libras.

COVARRUBIAS: Maximas de recursos de fuerzas, en Madrid, pasta, quatro libras.

Instituciones del Dro. de Castilla, por AZO, un tomo, en pasta, quarto, una libra.

SALUSTIO y algunas Oraciones de CICERON, traducidas, un tomo en quarto, pasta, una libra.

Oficio de Semana Santa, latín y castellano en Amberes, trece sueldos y quatro.

Oficio de la Semana del Corpus, en Amberes, trece sueldos y quatro. Oficio de San Nicolás, trece sueldos y cuatro.

SAN AGUSTIN: Confesiones y meditaciones, dos tomos, octavo, traducidos al castellano por Ribadeneira, diez y seis sueldos".

El inventario establece el 116 el total de tomos de que constaría la biblioteca; aparte de otros de los que no se da referencia explicita del número de volúmenes, lo que sin duda harla aumentar la cifra anterior.

Al ocuparnos ahora del pormenor de los temas tratados en dichas obras, podemos resumirlos globalmente en los siguientes apartados:

\section{1.-Estudios historicos.}

Dentro de la sección de libros de Historia, disciplina que gozó de especial favor entre los ilustrados, cabe destacar títulos como La Monarquía Ebrea, del Marqués de San Felipe (dos tomos) y la Historia de España, del Padre Mariana.

Comenzando por la obra del Marqués de San Felipe, creemos que el ejemplar en cuestión lo podemos identificar no con la primera edición de la obra, publicada en Génova en 1719 y en 4 tomos, sino con algunas de las ediciones madrileñas aparecidas en el siglo XVIII, todas ellas en dos tomos.

A pesar de su título es una obra, como ha señalado el historiador Carlos Seco, moralista y doctrinaria, pero que sin embargo deja traslucir el método del criticismo histórico(3). Llegados a este punto conviene no olvidar las decisivas aportaciones que en la renovación de la metodología 
histórica llevan a cabo personajes de la talla de Nicolás Antonio, Mondéjar $y$, avanzado el siglo, Gregorio Mayáns.

En segundo lugar es preciso aludir al libro del P. Mariana. Su Historia de España, para los ilustrados españoles, se consideró como uno de los textos de más valor para el conocimiento de nuestra historia. Recordemos, a modo de ejemplo, la recomendación hecha por Jovellanos de la obra del P. Mariana al colegio de Calatrava, como recoge Sarrailh(4). Pero aún hay más, Gregorio Mayáns había realizado la introducción de dicho libro en una de las ediciones aparecidas en el siglo XVIII, lo que resulta especialmente significativo(5).

\section{2.-Interés de los llustrados por la pedagogía y la enseñanza.}

La preocupación por la reforma de la enseñanza y de la educación, necesarias para una gradual transformación del país, tan querida por los ilustrados, se concreta aquí en los trabajos de Barbadiño y de Rollin.

El libro de Luis Antonio Verney, más conocido por el "Barbadiñon, titulado Verdadero método de estudiar, se tradujo al español en 1760 . En él se hace una demoledora crítica de los métodos rutinarios de enseñanza en España, particularmente en lo que respecta a los estudios universitarios(6). Esta postura no será compartida por algunos eruditos, como Feijoo, lo que supondrá inevitablemente un enfrentamiento entre ambos. De igual modo, Mayáns y en general el llamado círculo valenciano se opondrán resueltamente a los criterios mantenidos por el benedictino(7). Ello evidencia de manera incuestionable la proximidad ideológica existente entre Barbadiño y Mayáns. Añadiremos a lo dicho que la obra De re Logica, del mismo autor portugués, fue publicada por el valenciano Juan Bautista Muñoz en 1769, el cual, al decir de Mestre, resultaba del agrado de D. Gregorio(8).

Es curioso, por otro lado, que el propio Barbadiño al trazar su plan de estudios escolares y universitarios, en los que sorprendentemente propone una serie de reformas pedagógicas de la más absoluta contemporaneidad, como la recomendación de clases poco numerosas, métodos activos, etc., habla también de la educación de las mujeres recogiendo la opinión de Fenellón y Rollin(9). Cabe, por tanto, pensar que los textos de Rollin citados en el inventario se enmarquen dentro de una misma órbita de pensamiento. De todas formas es posible que una de las obras que el catálogo asigna a Rollin, Historia del Cielo, no corresponda a dicho autor. Acaso quiera referirse a la obra del mismo título del abad de Pluche, así mismo en dos tomos y traducida por el fraile Pedro Rodríguez Morzo.

\section{3.-Desarrollo de las Ciencias.}

Las posiciones críticas y reformistas del siglo XVIII afectarán considerablemente a las disciplinas científicas. En este terreno se advierte un 
sustancial esfuerzo de apertura y acogimiento de la ciencia moderna. Se constata, en efecto, un decidido afán por estar al corriente de las novedades del exterior, para lo cual, en ocasiones, se presentará especial atención por parte de los gobernantes a la formación de nuestros científicos en los centros más prestigiosos del extranjero.

De igual modo los poderes públicos se esforzarán en desarrollar en nuestra patria toda una serie de proyectos científicos, si bien los resultados no fueron todo lo positivo que cabria esperar.

Ciñéndonos al tema que nos ocupa hemos de decir que el interés por los saberes científicos en nuestro autor queda reflejado por los tratados que aparecen en su biblioteca. Así encontramos títulos tan sugestivos como el Compendio Matemático, de Tosca, Ensayos para la historia de artes y siensias (sic), Diccionario Geográfico, de Echart, Espectáculo de la Naturaleza, etc.

Con respecto a la obra de Tosca importa subrayar el hecho de que ésta, al igual que la de Newton-salvando, es lógico, la superior categoría científica del inglés - fueron propuestas en las reformas de la Universidad de Alcalá. Su modernidad, en el caso de la obra del valenciano, viene dada en función del método científico empleado. De todas formas la personalidad de Tosca presenta ciertas lagunas en su proceso formativo, tal como se desprende del desconocimiento que tenía de los estudios llevados a cabo por matemáticos de su misma época, crítica que ya en el siglo XVIII le hizo uno de nuestros más prestigiosos matemáticos: Jorge Juan(10).

Naturalmente no podían faltar obras de divulgación. A título de ejemplo señalemos el Espectáculo de la Naturaleza, del abate Noel Antoine Pluche, sin duda una de las publicaciones que más éxito obtuvieron sobre todo en Francia, su país de origen. La obra, publicada en 1732, resultó ciertamente ambiciosa si nos atenemos al número de volúmenes de que constaba, nada menos que 16 tomos. En España apareció por vez primera en 1753, y hay constancia de que se publicaron tres ediciones más hasta finales del siglo(11). El autor se esforzó, de ahí su principal mérito, en difundir y divulgar los últimos descubrimientos científicos, poniéndolos al alcance de más amplias capas de población.

\section{4.-Difusion del espíritu humanista.}

El término «humanista» en realidad habrá que entenderlo en una doble acepción. De una parte aludirá directamente al estudio de la antigüedad eclesiástica y obviamente de sus más ilustres representantes. En segundo lugar, para los ilustrados españoles de la XVIII centuria significará una revalorización de nuestros grandes humanistas del siglo XVI, como Vives o Nebrija.

Ahora bien, en este proceso evocador del pensamiento humanista lo 
que se buscaba, como argumenta Edith Helman, era sobre todo establecer un medio de reformar al hombre, de formar de una manera totalmente nueva su espíritu, dándole visión crítica e independencia(12). En suma, cambiar la sociedad mediante las "luces" de la razón.

Por otra parte tengamos en cuenta, y en ello ha insistido Mestre, que frente al influjo de la cultura francesa observable en algunos reformistas españoles, como Feijoo, otros, por el contrario-es el caso de los valencianos-, muestran un mayor espíritu de exaltación de las glorias nacionales(13).

Como es natural en el catálogo que comentamos hallamos títulos que entran de lleno en este apartado.

Que Nicolás Pró estuvo compenetrado con la cultura clásica es algo evidente si se considera la lista de autores citados en el inventario: Marcial, Virgilio, Cicerón, Horacio y Salustio. Debe hacerse notar que en este punto el Sr. Pró enlaza con la línea de investigación implantada por el deán Martí al propugnar el estudio y conocimiento de las grandes figuras del mundo clásico.

Idéntica exigencia en la valoración del mundo greco-latino mostrará Mayáns, cuya admiración por el deán es de sobra conocida.

Para cubrir estos objetivos-dar a conocer los textos clásicos-se requería necesariamente emprender la urgente tarea de traducirlos a la lengua española, debido a la escasez de ediciones en nuestra lengua.

Este mismo entusiasmo mostrarán los eruditos españoles del siglo XVIII por la recuperación de nuestros más destacados intelectuales del Renacimiento. A pesar de que en el inventario no aparecen los nombres de Juan Luis Vives, Fray Luis de León o Cervantes, sí se citan, sin embargo, los de Covarrubias y Nebrija. Precisamente de este último autor habia editado Gregorio Mayáns algunas de sus publicaciones.

\section{5.-Desarrollo de los estudios de Derecho y Jurisprudencia.}

En el proceso de transformación cultural español los estudios de las disciplinas jurídicas ocuparán un lugar destacado. En consecuencia los ilustrados no dudarán en aconsejar los textos de mayor categoría científica para el conocimiento de dichas materias. Pero tan buenos propósitos se enfrentaban a una dura realidad, y es que lamentablemente España no contaba apenas con tratados de contenido jurídico. De ahí que quienes se interesaran por estos temas tuvieran que acudir de manera obligada a los grandes textos escritos por extranjeros, como Grocio, Puffendorf, etc. Semejantes declaraciones no impiden afirmar la existencia de obras escritas por españoles. En este sentido es preciso hacer mención forzosa de las Instituciones de Derecho de Castilla, que el catálogo atribuye a Azo. 
La obra en cuestión se publicó en 1770 por dos jurisconsultos: Ignacio Jordán de Asso y del Rio, y Miguel de Manuel y Rodríguez.

En ella se daba a conocer los origenes de la legislación española, aludiendo especialmente al destacado papel otorgado a las Cortes, una de cuyas funciones consistía en limitar el poder reak(14). Otro título, igualmente, afecta a este apartado dedicado a temas jurídicos; nos referimos al que el catálogo cita como Vinnius Castigatus, con notas de Sala y el Derecho español. Se trata del jurisconsulto holandés Arnold Vinnen (1588-1657), a quien Sempere Guarinos consideraba como un hereje legista, pero que, no obstante, las Facultades españolas no tuvieron reparo en admitir sus obras(15).

Tanto el Vinnius como el Derecho Español se enmarcan dentro de la especialidad de Mayáns.

Conviene así mismo recordar que los títulos anteriormente reseñados no agotan el caudal de conocimientos de D. Nicolás Pró en los temas jurídicos. Sin extendernos en más consideraciones sólo queremos añadir un dato que resulta revelador de lo que venimos afirmando. Consiste en un testimonio epistolar inédito fechado en 4 de junio de 1779, por el cual D. Simón Gómez Pérez, agente de la ciudad de Alicante en la capital de España, contestaba desde Madrid al Sr. Pró en estos términos:

«Muy Sr. mío: Los libros Hugo Grocio, Derecho de la Guerra y de la Paz está prohibido. También lo está Montesquieu sus obras, y el Espíritu de las Leyes. Se me dice que está prohibido Bruckero, Historia Crítica de la Filosofía, aunque con alguna duda y que me lo dirán en breve con toda certeza para dar a V. M. aviso ciertow(16).

El interés del documento estriba en que curiosamente los autores solicitados por el secretario municipal alicantino son los mismos que los aconsejados en numerosas ocasiones por Mayáns.

\section{6.-Religiosidad de los ilustrados españoles.}

De este último epígrafe forma parte el conjunto más numeroso de libros que componen el inventario del Sr. Pró. Ello patentiza bien a las claras su profunda religiosidad, aunque entendida ésta de un modo más hondo y vivencial que ritualista. Actitud que en nada difiere a la mostrada por Mayáns.

En la nómina de libros de tema religioso acumulados por el alicantino aparecen autores tales como Bossuet, San Agustín, etc. También obras de idéntico contenido: Historia del establecimiento de la lglesia, Oficio de Semana Santa, Oficio del Corpus, etc. Pero veamos el especial significado de algunos de estos textos, así como la actitud manifestada en orden a una saludable y, por otra parte, necesaria renovación eclesiástica. 
Es un hecho de sobra conocido que los hombres de la llustración española, al contrario que en Francia, por ejemplo, supieron conciliar armónicamente su fe profunda con la exigencia propia del siglo: la crítica y el racionalismo. Esto les llevará en ocasiones a enfrentamientos con la Iglesia, al criticar posturas y actitudes eclesiásticas no acordes con la mentalidad reformadora de los ilustrados, aunque, eso sí, dentro de la más estricta ortodoxia.

Una de dichas cuestiones, y no desdeñable precisamente, consistía en deslindar la esfera de actuación del poder eclesiástico con respecto del poder civil, excesivamente identificados. En este caso uno de los autores que más decididamente se inclinaban por separar las competencias de ambos poderes era Bossuet. Su galicanismo, como establece Mestre al analizar el interés despertado en Mayáns por la obra del célebre orador y escritor francés, se centra en dos puntos cruciales: la independencia de la autoridad temporal frente a la potestad espiritual y, de otra parte, su concepto acerca de los principios que limitaban el ejercicio de la autoridad del Papa(17). Tales cuestiones aparecen y se desarrollan en los seis tomos de su Potestad Eclesiástica.

Sin entrar a discutir su posible adscripción a la corriente jansenista, ni siquiera plantearnos la propia consideración del término, lo que sí parece estar fuera de duda es que Bossuet es uno de los que manifiestan una decidida hostilidad antijesuítica.

De quien bien puede afirmarse su condición jansenista es de Van Espen, autor que, al igual que Bossuet, intereso e influyo grandemente en Mayáns. Sabemos, según declara Mestre, que el valenciano se convertirá en uno de los más fervientes propagadores de la obra del belga. Además, y esto nos interesa, procurará que sus amigos lo lean(18).

Todo parece indicar, y con esto concluímos, que D. Nicolás Pro, una vez analizada brevemente su biblioteca, estaba familiarizado con las tendencias culturales más avanzadas del siglo. Uno de los factores determinantes que le moverán a ello será, justo es decirlo, el influjo de uno de los más prestigiosos ilustrados: D. Gregorio Mayáns. 


\section{NOTAS:}

(1) Archivo Municipal de Alicante. Legajo 39. Arm. 3. Diversorum n. ${ }^{\circ} 81$. Año 1787: «inventario de los Bienes que han quedado por muerte de D. Nicolás Pró, antes Bayona, escrivano primero que fue del IIte. Ayuntamiento de esa ciudad".

(2) Un interesante estudio sobre este tema, en M. Deforneaux: Inquisición y censura de libros en la España del siglo XVIII, Madrid, 1973.

(3) Cf. San Felipe, Marqués de: Comentarios de la Guerra de España e historia de su rey Felipe V el Animos. Estudio preliminar de D. Carlos Seco Serrano, Biblioteca de Autores Españoles, tomo 99, Madrid, 1957., pp. LXV-LXVIII.

(4) Cf. Serrailh, Jean: La España llustrada de la segunda mitad del siglo XVIII, Fondo de Cultura Económica, Madrid, 1974, p. 399.

(5) Vid. Gregorio Mayáns y Siscar: Epistolario; transcripción y notas de Antonio Mestre. Publicaciones del Ayuntamiento de Oliva, Valencia 1972-1973. Tomo III., p. XVIII.

(6) Ci. Sarrailh, J.: Op. cit., p. 199.

(7) Cf. Mestre, A.: Historia, fueros y actitudes politicas. Mayáns y la historiografia del XVIII. Publicaciones del Ayuntamiento de Oliva, Valencia, 1970, p. 82.

(8) Ibid., p. 329.

(9) Cf. Sarrailh, J.: Op. cit., p. 201.

(10) Vid. Gregorio Mayáns y Siscar: Epistolario... Tomo II, p. XVI.

(11) Cf. Herr, Richard: España y la revolución del siglo XVIII, Madrid, 1975, p. 35; también en Sarrailh, J.: Op. cit., p. 201.

(12) Cf. Hellman, Edith: Jovellanos y Goya, Madrid, Taurus, 1970, pp. 15-30.

(13) Este aspecto ha sido ampliamente abordado por Antonio Mestre. Véase de este autor: "Los origenes de la llustración", extra de Historia 16, diciembre, 1978, pp. 62-68; Id.: Historia, fueros..., p. 34; Id.: Despotismo e llustración en España, Barcelona, 1976, pp. 36-40.

(14) Cf. Herr, R.: Op. cit., p. 282, y Sarrailh, J.: Op. cit., pp. 164 y 578.

(15) Cf. Guarinos, Juan Sempere: Ensayo de una biblioteca española de los mejores escritores del reinado de Carlos III, Madrid, 1785-1789, tomo II, p. 3.

(16) Archivo Municipal de Alicante. Cartas recibidas del año 1779. Libro 35. Arm. 12, fol. 58.

(17) Cf. Mestre, A.: Ilustración y Reforma de la Iglesia. Pensamiento politico-religiosos de D. Gregorio Mayáns y Siscar (1699-1781). Publicaciones del Ayuntamiento de Oliva, Valencia, 1968, p. 367.

(18) Cf. Mestre, A.: Despotismo e llustración..., p. 191. 


\title{
MANIFIESTO DE LOS MORISCOS QUE QUEDARON EN GANDIA EN EL AÑO 1611
}

\author{
Por José SANCHIS COSTA
}

Licenciado en Historia

Dentro del interés permanente que entre nuestros historiadores suscita el tema de los moriscos, han proliferado últimamente los estudios sobre los niños que quedaron en España después de la expulsión de 1609. Ya en 1923 Vicente Castañeda publicó la Manifestación de los niños moriscos de Onteniente. En 1971 Barceló presentó una comunicación sobre el tema en Valencia en el Primer Congreso de Historia del País Valenciano. Y más recientemente, Rafael Benítez ha estudiado el caso de los niños moriscos en Málaga con motivo de la guerra de Las Alpujarras y Mario Martínez ha dedicado un extenso trabajo al caso de Alicante. El documento que publicamos hay que incluirio en la línea del que dio a conocer Castañeda y sólo pretende contribuir a la confirmación de ciertos datos históricos que debieron ser generalizados(1).

(1) V. CASTAÑEDA, "Manifestación de los hijos de moriscos que quedaron en la villa de Onteniente al verificarse la expulsión de éstos del Reino de Valencia, 1611", BRAH, LXXXII (1923), 421-427. M. BARCELO, "Els nins moriscos". Primer Congreso de Historia del País Valenciano, Valencia 1976, III, 327-331. R. BENITEZ SANCHEZ-BLANCO, «Guerra y Sociedad: Málaga y Ios niños moriscos cautivos, 1.569», Estudis-3, 1974, 31-54; M. MARTINEZ GOMIS, "El control de los niños moriscos en Alicante tras el decreto de expulsión de 1609", Anales de la Universidad de Alicante. Historia Moderna, 1, 1981, 251-280. 
El cuadernillo, que insertamos, encontrado en el Archivo de Gandía, trata del conjunto de niños registrados en la ciudad bajo la presencia del Comisario Francisco Vargas y que fueron a engrosar las filas de siervos de la clase pudiente en esos momentos.

A la pregunta, ¿de dónde vienen estos niños?, cabría contestar que, de los ochenta y nueve niños computados, solamente en cincuenta y seis de ellos nos especifican el lugar de origen, siendo en su conjunto de treinta y un pueblo diferentes.

Si hacemos un recuento de cuáles son los pueblos que mayor proporcionalidad numérica aportan, veremos en primer lugar, y con enorme diferencia, se encuentra Laguar con nueve niños. Le sigue Orba con cuatro niños y luego Forna, Alcalá y Finestrat en tercer lugar con tres niños cada una de ellas.

Esta proporción numérica que hemos señalado puede tener bastante sentido, aunque no goza de toda confianza, ya que de los ochenta y nueve niños que componen el cuadernillo, solamente cincuenta y seis, como ya decíamos, aparecen computados con la indicación del pueblo de donde proceden.

\section{¿Quiénes compran estos niños?.}

Como cabria pensar, estos niños son recogidos por las diferentes clases sociales aristocráticas o pudientes que entonces imperaban en Gandia; encontrándonos tras un pequeño estudio de los oficios de los compradores, con que el número de comprantes es de treinta y uno, y que todos pertenecen a un estamento social alto.

La relación de cargos por su mayor aparición en el cuadernillo, es la siguiente:

Trece Sacerdotes (6 Canónigos, 2 Prebíteros, 2 Beneficiados de la Seo de Gandía, 2 Doctores, I Rector).

Seis Viudas.

Dos Caballeros.

Un Justicia, Batlle, Mostafsa, Notario, Señor de Ademuz (Daimus), Síndico, Doncella, Labrador, Mesonero, Lencero.

Un dato tal vez digno de mención es, que en el cuadernillo no se especifica si estos niños-as fueron comprados, raptados, o en el mejor de los casos adoptados por compasión o egoismo por las clases sociales que como hemos visto los poseen. Tal vez la balanza se incline hacia ese último punto (adopción), ya que suponemos al pensar en este punto, que lo harían con una intención provechosa a corto y largo tiempo; pues ahora estos niños les sirvirian como recaderos, sirvientes, mozos de cuadra, etc., y 
pensando a largo plazo, cabría la posibilidad de que estos niños les fuesen útiles en su vejez como criados o compañeros.

Tal vez, el basarnos en este punto (adopción), haya sido el comprobar como en un caso el niño toma el apellido del tenente, como tal es el caso de Juan Jusepe Almenara, tomado por Bartholomé Almenara.

Relación de edades de los niños.

Llamándonos la curiosidad la relación que pudiese existir entre las diferentes edades de estos niños, hemos llegado a una relación en la que nos da un baremos de éstas; así pues, hemos comprobado, que de los cuarenta y siete niños que aparecen inscritos, cuarenta y dos nos especifican su edad, mientras que en dos casos solamente no la pone.

De los cuarenta y cinco que nos especifican la edad, vemos, que siete de ellos aparecen en edades comprendidas entre dos y cinco años; veinte y seis entre las comprendidas entre cinco y diez años; y que doce, aparecen entre las comprendidas entre diez y catorce años.

Haciendo un estudio más detallado de la edad de estos niños, podemos comprobar, que la mayor cantidad de niños, nos aparecen en la edad comprendida entre siete y diez años, que nos arroja una cifra de veinte niños.

Por cuanto respecta a la edad más concurrida, hay que decir que es la de siete años, que nos da un total de seis niños.

Por cuanto a las niñas respecta, decir que se han computado un total de cuarenta y una, de las que cinco, aparecen en edades comprendidas entre dos y cinco años; veinte y seis en las comprendidas entre cinco y diez; y diez en las comprendidas entre diez y catorce años.

La mayor cantidad de niñas, nos aparece al igual que en los niños, en edades comprendidas entre siete y diez años, arrojándonos la cifra de veinte y una niña. Por cuanto a la edad más concurrida en estas niñas, decir que es la de siete años, con un total de cinco.

Para terminar esta comparación de edades, podemos decir, que de los ochenta y nueve niños-as, cuarenta y siete son niños, y que de estos, cuarenta y cinco conocemos sus edades; por cuanto a las niñas, decir que son cuarenta y dos, y que de estas, cuarenta y una conocemos sus edades.

\section{Apellidos de estos niños.}

Un dato a destacar, es que de los cuarenta y siete niños tratados, solamente en once nos especifican el apellido, siendo estos: Vicente Gregori; Francisco Faraig; Gaspar Andreu; Luis Mayoral; Juan Fortunado; Pedro Cuevas; Gaspar Dionis; Juan Jusepe Almenara; Luis Jucar; Luis Martí; Juan Martí. 
Por cuanto respecta a las niñas, hay que destacar que ninguna de ellas posee apellido.

Defectos más comunes en estos niños-as.

De los ochenta y nueve niños-as tratados, solamente en quince casos, no nos aparece ningún tipo de malformación o defecto físico; solo decir, que como máximo, en estos quince casos nos especifican si son rubio (dos casos).

La proporcionalidad de defectos de estos niños-as, es como sigue:

Veinte y uno con algún tipo de señal.

Veinte con señales de herida.

Trece con lunares.

Seis con viruela.

Seis con quemaduras.

Dos con tiña.

Dos con berrugas.

Uno con una perla en el ojo izquierdo.

Uno sin muelas.

Uno con las muñecas lisiadas.

Uno con seis dedos.

Para terminar este pequeño trabajo de estos niños moriscos que van a parar a Gandía, podríamos hacerlo preguntándonos: ¿Cual fué el motivo por el cual se quedan estos niños-as en los respectivos pueblos que hemos visto? y ¿Como es que no embarcan con sus respectivas familias rumbo a Orán?.

Se podrían dar varias soluciones a estas preguntas, tales como el que sus familiares hubiesen muerto; o que debido al trajín de venta de enseres y cambio de domicilio, se hubieran perdido estos niños. No obstante, estas no nos parecen soluciones arduas de confianza; por el contrario, después de haber visto que casi todos los niños tienen algún defecto, nos induce a pensar, que tal vez éstos fuesen dejados por sus padres a conciencia, suponiendo que el viaje que les esperaba era duro, y que probablemente las condiciones de vida que encontrasen después de él, fuesen todavía más penosas; así pues, ésto, junto con la gran cantidad de taras físicas y tal vez síquicas que poseían estos niños, nos induce a la creencia de que fueron abandonados por sus padres. 
En la villa de Gandía a nueve dias del mes de setiembre año de mil y seysçientos y onçe, por ante mi Pedro de Peralta scriuano del Rey nuestro señor en todos sus reynos y señorios, y de la comision del Comissario Francisco de Vargas en su presencia se manifestaron y registraron los hijos de moriscos siguientes:

I Domingo Segura manifesto un muchacho que se llama Juan Fortunado de hedad de siete años con señal de herida en la frente, y un piquete sobre la çeja yzquierda ojos garzos con una quemadura en el todillo del pie yzquierdo.

I Jusepe Valero un muchacho que se llama Miguel, natural de la varonia de Planes de hedad de 11 a 12 años con un señal de piquete en la frente oyosso de biruelas.

I Francisco Perez Ximeno un muchacho Juan Francisco Buena ventura natural de Laguar de hedad de quatro años ojos grandes con un piquete sobre la çeja derecha.

I La biuda Nicola Collá del contador Guillem Lerma una muchacha Jusepa María de hedad de quatro a çinco años morena de rostro, ojos negros çejas grandes.

I Baltassar Oriola un muchacho Diego Tomas natural de Orba, de hedad de seysa siete años con un piquete al pulsso derecho y otro sobre la çeja yzquierda y un señal de herida en la barba junto al labio de abajo.

2 Ginés Moltó dos muchachas que la una se llama angela, natural de Laguar de hedad de 10 años poco mas o menos con un señal de berruga en medio la frente, junto al cuello y al cornero yzquierdo otra herida y otro señal al lado derecho junto a la çeja. Y la otra Melchora de hedad de nueve años poco mas o menos, carilarga, dientes claros, roma.

I El doctor Mossen Juan Rodriguez un muchacho Pedro Cuevas natural de Guadalest de hedad de nueve a diez años con dos piquetes al cornero yzquierdo y otro en la frente, y otro junto a la oreja derecha, blanco de rrostro.

I Gonzalo Ruiz de Medina justicia ordinaria de dicha villa una muchacha Maria natural de Orba de hedad de cinco años carirredonda, ojos grandes buen rostro con un señal en la garganta al lado derecho.

2 Luis Perez de Roa cauallero, dos muchachos uno se llama Geronimo Juan natural de Guadalest de hedad de siete años buen rostro ojos grandes con un piquete en la barba, debajo el labio a la parte derecha. Y otro Gaspar Dionis Natural del Arraual de Gandia, de hedad de cinco a seys años moreno de rostro con un piquete entre las dos çejas y otro debajo el ojo derecho. 
I Juan Lozano mostafsa desta villa una muchacha Angela, de hedad de cinco a seys años morena de rostro con un señal al lado del ojo yzquierdo y un piquete en medio la frente, roma.

I Françes Verdull un niño Francisco natural de Laguar de hedad de dos a tres años con señal de herida en la cabeza, al cocote, y una quemadura en la mano derecha, moreno de rostro, roma.

2 Pedro Navarro un niño Gaspar natural de Forna de hedad de 10 años poco mas o menos, oyosso de biruelas, con unpiquete en el cornero yzquierdo y una niña Ana Maria de hedad de siete años buen rostro, ojos y çejas grandes.

I Mossen Luis Antequera, prebitero, un muchacho Miguel de hedad de 10 a 11 años natural de Pedreguer con dos señales de herida, en la nariz y carrillo yzquierdo moreno de rostro.

I Antonio Castillo vayle de Velrreguart un muchacho Antonio natural de Pego de çinco años moreno de rostro romo frente salida.

I Jayme Calderon un muchacho Juan Ausias natural de Benidoles de hedad de çinco años cariredondo, ojos undidos con un piquete en el cornero yzquierdo y otro piquete sobre la çeja derecha.

2 Bartholome Ros notario dos hijos de moriscos que el uno se llama Luis natural de Matosses de hedad de treçe a catroçe años con un señal de herida en el cornero derecho sobre la çeja moreno de rostro, y yna niña que se llama Ana Maria de hedad de çinco años ojos grandes con señal en la çeja derecha.

I Ana Costa y de Monje, biuda, una niña que se llama Esperança Madalena de hedad de ocho años morena de rostro con un señal de herida en el cornero yzquierdo, ojos grandes roma.

2 Francisco Perez de Roa, cauallero, dos hijos de moriscos uno se llama Vicente natural de Orba, de hedad de 12 a 13 años, moreno de rostro ojos hundidos frente grande. Y una niña que se llama Rafaela Eugenia de hedad de ocho a nueve años con un señal de herida en medio la frente ojos undidos.

"Por tener tres se le quito la una Rafaela y se le dio a Francica Perez".

2 Hernando de Avila, dos hijos de moriscos que se Ilama la una Geronima de hedad de 13 a 14 años buen rostro, con un lunar en la frente, y otro en la barba, ojos undidos çeja grande; y otra niña Ana Maria de hedad de nueve años con un señal al cauo de la çeja yzquierda y otra en el corneo derecho.

I El canonigo Jayme Rojer una niña Tomassa, natural de Forna de hedad de nueve a 10 años ojos negros çeja grande con una señal en el carrillo derecho junto al ojo. 
2 El canonigo Onofre Perez de Culla, dos niños que el uno se llama Jayme de hedad de siete a ocho años natural de Castello ojos undidos chica frente; y otro, Gaspar natural de Xalo de hedad de siete años ojos garzos, con un señal en el cornero derecho.

I Bautista Pallol un niño Juan Bautista, natural de Alcala, de siete años con un señal en medio la frente, ojos pequeños romo.

I El doctor Juan Cots, un niño que se Ilama Luis Jucar natural de Castell de Castells de hedad de ocho a nueve años blanco de rostro con un señal en el labio de arriba, al lado yzquierdo, ojos grandes y otro señal debajo la çeja derecha.

I Juan Bauista Caragosa presbytero rector del Real, un niño que se llama, Juan Buenaventura, con un señal de herida en el cornero yzquierdo sobre el pulso junto al cuello moreno de rostro de hedad de siete años.

2 Bartholome de Auila dos muchachas que la una se llama, Vicenta, de hedad de ocho a nueve años moreno de rostro con señales de quemadura en el cuello al lado yzquierdo; y otro Caterina de hedad de 7 a ocho años ojos grandes buen rostro con señales en el carrillo yzqyuierdo.

I Miguel Belssa, una muchacha que se llama Ysabel de hedad de siete años frente salida, buen rostro roma, con señal de lunar en el pulso yzquierdo junto a la oreja.

I Juan Bautista Pujades, un muchacho Miguel natural Benidra de Vall de Guadalest, de hdad de 12 años poco mas o menos carilargo, ojos grandes con un piquete en medio la frente.

2 Don Vicente Ferrer Señor de Ademuz dos muchachas que la una se Ilama Tomassa, natural de Ademuz de hedad de 12 años morena de rostro, ojos grandes, çejas arqueadas con un lunar en el carrillo yzquierdo debajo el ojo; y otra Angel, de hedad de ocho años morena de rostro ojos negros con un piquete en la frente al cornero derecho.

2 El canonigo Geronimo Perez de Roa, cauallero, un muchacho Geronimo natural de la Vall de Ayora, de hedad de 12 años poco mas o menos ojos grandes con un lunar en el cuello al lado yzquierdo, y una señal de herida en el cornero derecho; y una moza Angela natural de Xereza de hedad de 13 a 14 años con señal de quemadura en la frente, y otra debajo el ojo yzquierdo.

I Françes Lopez, una muchacha Angela, de edad de ocho años ojos grandes, con señal de quemadura en el carrillo derecho junto a la nariz buen rostro frente grande.

2 Ysabel Juan Giner biuda del contador Dionissio Cañada un muchacho Luis Marti natural de Laguar de hedad de nueve a diez años con un señal de herida, en el cornero yzquierdo junto al cuello, moreno ojos 
undidos; y otro Juan Marti de hedad de 4 a 5 años con una perla en el ojo yzquierdo.

1 Juan Simon una niña que se llama Jusepa Mariana natural de Alcala, de hedad de tres a quatro años con un señal en medio la frente, ojos grandes buen rostro.

I Cristoual Ortiz na muchacha Maria, natural de Coçentayna de hedad de 12 a 13 años morena de cara, con una berruga en la nariz debajo la çeja yzquierda y un golpe de herida en medio la frente al lado yzquierdo.

I Jayme Serbas manifesto un niño Miguel Juan natural de Gata de hedad de quatro a cinco años moreno de rostro manchada la caueza de tiña, ojos grandes.

I Juan Calderon una muchacha, Tomassa, de hedad de 10 años con un lunar en la barba al lado yzquierdo ojos alegres.

1 Pedro Monje, un muchachi Pedro Juan Bautista, de hedad de 12 años moreno de cara, pecosso de biruelas con un señal debajo la çeja yzquierda.

I Martin Genis una muchacha que se llama Luissa, de hedad de siete años ojos negros menuda de rostro roma.

2 Lurcio Longo, una moza que se Ilama Angela Maria natural de Confrides, Vall de Guadalest, de hedad de 14 años poco mas o menos con un señal en el cornero yzquierdo morena la cara con señal de biruelas en la nariz; y un muchacho Juan Geronimo natural de la Vall de Guadalest moreno de rostro, con un señal de herida en la frente, entre las doc çejas y otra en el carrillo yzquierdo.

I Don Francisco Viñols, un muchacho Vicente Gregorio de hedad de tres años ojos grandes romo, con un señal de lunar en el carrillo yzquierdo.

Matheo de Roda, una niña Angela natural de Benibray señorio de Xalo, de hedad de 12 a 13 años çecijunta las narizes oyossas de viruelas con un señal en la barba.

I Francisco Nauarro, syndico un muchacho que se llama Alonsso de hedad de nueve a 10 años con un señal sobre la çeja derecha, castaño el pelo, con un lunar en el carrillo yzquierdo.

2 La biuda Villaraguda, dos hijos moriscos uno Antonio natural de Fenestrat, de hedad de 14 años, pecosso de rostro, frente pequeña; y otra, Angela de hedad de 11 a 12 años con un piquete en medio la frente, ojos undidos.

I Mossen Vicente Ferrer, rector de Benieto, una niña Tomassa de hedad de 12 años poco mas o menos lissiada de las muñecas con dos lunares en el carrillo yzquierdo. 
I Don Felipe de Çuniga un muchacho Pedro Simon natural de Ebo de hedad de seys años buen rostro ojos grandes con señal de herida en la caueza.

1 Doña Isabel Teyxeda, biuda, una niña Angela, natural de Ebo de 7 años morena de rrostro ojos grandes çejas pobladas con un señal en medio la frente.

I Matheo Talabera un niño Juan natural de Laguar de hedad de 7 años carirredondo romo.

I Geronimo Gomez un muchacho Miguel, de Finestrat de 10 años con un piquete sobre la çeja yzquierda, ojos hundidos çejas pobladas.

I Françes Lozano una niña Ana Maria de 7 años morena de rostro con tres señales en la frente.

I Geronima Altamira, doncella, una niña Madalena Ygnaçia de hedad de dos años salida de frente roma.

I Jusepe Ramos una niña Jusepa de 7 años poco mas o menos morena buen rostro, ojos grandes con un lunar debajo la barba a la parte derecha.

2 Simon Valero una moxa Geronima Vicenta natural de Parçent de 12 a 13 años carirredonda, ojos pequeños con un piquete en la frente; y un hijo Francisco Viçente de 8 años con señal de herida sobre la çeja yzquierda morena de rostro.

I El canonigo Pedro Çifre un niño Juan natural de Laguar de hedad de nueve años con señal de herida en la nariz a la parte yzquierda y un lunar en el carrillo derecho.

I El canonigo y capiscol Vicente Castello un muchacho Juan de la Laguar de hedad de 4 a 5 años moreno de rostro ojos negros romo.

1 Esperança Castello una niña Agustina de 4 años poco mas o menos morena de cara ojos grandes undidos con un lunar en el carrillo derecho.

I Mossen Antonio Marnat beneficiado de la Seo de Gandia una niña Angela Petronila de 9 a 10 años morena de rostro ojos grandes con un lunar en la nariz a la parte izquierda, y un piquete en la çeja derecha.

l Bartholome Melado labrador una niña Jusepa Geronima de 9 a 10 años morena de rrostro con un piquete en la frente pecossa de rostro y un señal en el labio de arriba.

2 Violant Bienes viuda, un muchacho Geronimo de la Vall de Guadalest de 12 años con señal en el carrillo derecho y otra en el yzquierdo moreno, romo; y una moza que se llama Marina natural de Alcoleja de mayor hedad pecosa de rostro con un piquete en medio la frente.

2 Mossen Jayme Bort beneficiado en la Seo de Gandia dos muchachos uno se Ilama Francisco Faraig natural de Arrabal de Gandia de 10 a 11 
años poco mas o menos con señal en el ojo derecho debajo la çeja y otra en la frente, moreno de rostro; y otro se llama Geronimo natural de la huerta de Gandia con señal de quemadura en la nariz a la parte derecha ojos grandes undidos.

I Joachin Plo un niño Juan, frente salida ojos undidos con señal de herida en la frente junto al cuello de 5 a 6 años.

I Pedro Alonso un muchacho Gaspar de 9 años moreno de rrostro con señal de herida sobre la çeja derecha.

2 Bernardo Ybañez dos muchachos que uno se llama Francisco de hedad de dos años tollido de pies y manos con señales de tiña en la caueza; y otra Geronima, de 5 a 6 años, carirredonda ojos grandes roma.

I Miguel Garcia una niña Ana Maria de 8 años carisclara dientes claros con un señal en la frente junto al cuello.

I Françes Franco un muchacho que se llama Luis Mayoral natural de Alcala, de 12 años poco mas o menos, moreno de rrostro, oyosso de biruelas, ojos negros çejas pobladas.

I El canonigo Villalon un niño Francisco natural de Castellon de Rugat de 8 años poco mas o menos moreno de rrostro con un señal de herida en la cauesa sobre la frente y ottra en medio della.

2 Francisca Perez de Roda dos muchachas una que se llama Rafaela Eugenia de ocho a nueve años con señal sw herida, en medio la frente ojos undidos; y otra Juliana natural de Ondara de 12 años poco mas o menos, morena de rostro, ojos negros çeja arqueada.

2 Vicenta Cots, dos, Francisco, natural de Ayalt de 13 años con señales en medio la frente, junto al cuella, sin muelas; y otra Nicolasa de 5 a 6 años morena de rrostro, ojos undidos, çejas pobladas, roma.

I Bartolome Almenara mesonero un muchacho Juan Jusepe Almenara de 10 años poco mas o menos ojos grandes con un señal en el cornero derecho y un lunar junto al ojo derecho y otro en la garganta al lado yzquierdo.

I Juan Ros un muchacho Jayme Gaspar de hedad de 8 a 9 años dientes claros rubio labrios gruessos orejas grandes.

I Domingo Belilla lenzero un niño que se llama Gaspar Andre de hedad de 9 a 10 años pecosso de rrostro, con dos heridas en la cabeza, y en la mano derecha seys dedos.

Todos los quales hijos de moriscos segun y de la manera que van referidos y reseñados fueron entregados a sus dueños, y dicho registro sacado del original que queda en mi poder y entregado a Gonzalo Ruiz de Medina Justicia ordinaria de dicha villa, Gines Molto Jurado en caueza, Ausias 
Vilarnau, Tomas Decho y Jusepe Alfonso, Jurados, y Francisco Juan Nauarro Syndico de dicha villa para que en cumplimiento de lo contenido en el vando publicado por orden de su Magestad en dicha villa, en nueve del presente mes de setiembre, mil y seysçientos y onçe años obseruen y guarden lo en el declarado no permitiendo aya en dicha villa mas de los hijos de moriscos declarados, y si pos tiempo alguno hubiere se de la qual a su excelencia dello en Valençia, y se ponga dicho registro en el libro de la sala de dicha villa para que aya memoria por lo benidero y sepan los Justicia y Jurados que sucedieren lo que deuri obseruar. $Y$ el dicho comissario lo firmo de su nombre:

ante $\mathrm{mi}$

Francisco de Vargas

Pedro de Peralta 



\title{
GIMENEZ LOPEZ, E., Alicante en el siglo XVIII. Economía de una ciudad portuaria en el antiguo régimen, Valencia, Institució “Alfons El Magnànim». Diputació Provincial, 1981, 449 pp.
}

\author{
Por Emilio LA PARRA LOPEZ
}

Hasta hace poco más de una década el siglo XVIII español era prácticamente desconocido. Los historiadores no se interesaron por él, en parte porque las autoridades políticas habian sido poco favorables al movimiento ilustrado, en parte porque la atención, en Historia Moderna, se dirigió hacia la época de los Habsburgo, identificada como la del máximo esplendor del imperio, o a los aspectos políticos del siglo XIX, tema muy apreciado por la historiografía positivista y apto para plasmar en él las más diversas instancias ideológicas. La renovación de nuestra historiografía, protagonizada por investigadores relacionados de alguna forma con la escuela de los Anales y con la metodología marxista, ha posibilitado, por el contrario, un acercamiento, ya muy fecundo, a la centuria setecentista, de forma que hoy es un momento bien conocido y, en gran medida, las obras actuales a él dedicadas superan a las que versan sobre otras épocas.

La transformación de nuestro conocimiento del siglo XVIII se ha operado, de modo especial, desde la historia regional y ha sido posible gracias a los estudios dedicados a dos grandes aspectos: la llustración y las estructuras económico-sociales. No es escaso el papel desempeñado en este cometido por un nutrido grupo de hispanistas franceses. En los dos temas señalados existen sendas obras pioneras, a las que se les reconoce una gran influencia, escritas por historiadores galos: la de Sarrailh sobre los ilustrados y la de Pierre Vilar acerca de Cataluña(1). Las pautas sugeridas por estos autores hallaron especial eco en el País Valenciano, donde diversos historiadores, abiertos a las perspectivas de la moderna 
historiografía europea, han abordado el estudio del siglo XVIII de un modo ejemplar y han logrado cotas difícilmente igualables en otros puntos de España.

Cronológicamente, los estudios sobre la llustración valenciana y sobre el gran momento innovador que la precedió, la obra de los «novatores", ha antecedido a los de historia económico-social. No es éste el lugar para abordar tan interesante aspecto de nuestra historiografía, por lo que nos limitamos a consignar algunos datos reveladores. Al comienzo de la década de los sesenta se publicaron diversos artículos de V. Peset y de Lopez Piñero sobre los "novatores" que replantearon por completo el tema. En 1968, García Martínez ofrecía una síntesis del ambiente preilustrado valenciano recogiendo las aportaciones de los autores anteriores y un año después López Piñero sistematizaba los resultados de estas investigaciones en un breve volumen de amplia repercusión posterior(2). Al mismo tiempo, Mestre publicaba un completo estudio sobre Mayáns, al que han seguido varios volúmenes con la correspondencia cruzada entre Mayáns y diversos ilustrados y otros trabajos, la mayor parte debida al propio Mestre y a los hermanos Peset, sobre la llustración valenciana(3). Gracias a esta labor ha quedado perfilada una visión totalmente renovada de la cultura valenciana del setecientos que obliga por necesidad a replantearse el sentido y carácter de la llustración española en general, como se va reconociendo paulatinamente(4).

Algo similar a lo ocurrido en los estudios sobre la historia de las ideas está sucediendo en el campo económico-social. En este caso ha resultado decisivo el influjo de dos catedráticos de la Universidad de Valencia, J. Reglá y E. Giralt, ambos discípulos de J. Vicens Vives y muy relacionados con la escuela de los Anales. Ellos impulsaron un buen número de trabajos de historia regional que, siguiendo la metodología de la historia serial planteada por Chaunu, fueron clarificando las características históricas valencianas. Como ocurre con la llustración, en este otro campo de estudio se han perfilado unos centros de interés cuyo esclarecimiento está conformando la auténtica fisonomía del pasado socio-histórico valenciano. Con ello, al tiempo que se confrontan con rigor las hipotesis globales formuladas acerca de la historia económica española, se profundiza en la especifidad del caso valenciano, de manera que en la actualidad resulta perentorio el replanteamiento de muchos problemas o la indagación en terrenos hasta ahora desconocidos o tratados con escasa atención.

Aunque es demasiado pronto para aventurarse en cualquier intento de sistematizar las líneas de investigación aludidas, cabe resaltar dos de ellas. Una bascula en torno a la estructura agraria valenciana y a los caracteres del régimen señorial. Ardit desentrañó varios.de sus rasgos generales, completados, centrándose estrictamente en la propiedad señorial, por Gil Olcina(5). A partir de estos estudios se ha acentuado la necesidad de 
profundizar, mediante trabajos monográficos, en el análisis local de los señoríos, labor que cuenta ya con un complejo estudio sobre el de Elche(6) y con varias monografias, impulsadas ahora de forma especial por la Universidad de Alicante, donde ejerce la docencia el doctor Gil Olcina. En intima relación con la temática señorial se sitúa otro asunto, relevante para los estudiosos tras los apuntes de Giralt publicados en 1968(7). Se trata de fijar el carácter de la burguesía valenciana y de averiguar las razones del retraso industrializador en el siglo XIX. Diversos estudiosos han insistido en los efectos derivados del régimen feudal|8), más aunque se han intentado sugestivas hipotesis(9) quedan muchos elementos por desentrañar. Ciertamente el papel protagonista corresponde en este punto a las investigaciones sobre el siglo XIX, mas, como muestran las escasas ya efectuadas (el ejemplo más claro es el libro de Aracil y Garcia Bonafé sobre la industrialización de Alcoy)(10), deben buscarse muchas explicaciones en el siglo XVIII. De ahi la importancia de los estudios dedicados al análisis de los núcleos urbanos significativos en esta centuria.

En 1977 el profesor J. M. Palop daba a conocer, en dos volúmenes(11), la evolución durante el siglo XVIII de los precios y salarios en Valencia, analizando las crisis de subsistencias producidas y las conmociones sociales, de carácter antifeudal, subsiguientes. En su obra aplicaba Palop la metodología de Labrousse, empleada poco antes para el marco nacional español por G. Anes(12). En este último aspecto el estudio del profesor valenciano constituyó un hito, mas su relevancia abarca también al propio tema de investigación: el comportamiento del mercado urbano en el marco de una economía propia del Antiguo régimen. Con ello, al tiempo que afrontaba la etiología de las contradicciones del sistema económico, daba la pauta para entender comportamientos y realizaciones posteriores. EI análisis cuantitativo y el estudio de los dos elementos básicos del mercado urbano del Antiguo régimen, precios y abastecimiento de mercancías, se manifestaron en la obra de Palop como una vía fecunda para adentrarse en el pasado económico y social. El libro de E. Giménez, motivo de estas reflexiones ajenas por completo, insisto, a cualquier intento de sistematización, es un logro manifiesto en este sentido.

Giménez parte de la hipótesis, plenamente confirmada a lo largo de su trabajo, de que el puerto es el centro económico de la ciudad de Alicante. A él afluyen para su exportación las producciones locales más remuneradoras y a él llegan los productos alimenticios y manufacturados necesarios para el abastecimiento y el incremento de bienes de la población. El centro del libro lo constituyen, por consiguiente, el análisis del comercio y de la organización mercantil que lo posibilita, mas buscando una explicación a los diversos elementos ahí contemplados e intentando integrarlos en un conjunto comprensivo más amplio, esto es, en la estructura económica y social de la ciudad, Giménez extiende su estudio a las diversas variables 
susceptibles de aportar elementos de juicio. De esta forma aborda las características del volumen y crecimiento de la población, las estructuras agrarias, las actividades artesanales y la articulación social según el nivel de rentas y las profesiones. En suma, traza la «realidad económica" de la ciudad y su ámbito agrario, todo ello en el marco cronológico comprendido entre la Guerra de Sucesión y 1804, fecha ésta que marca el fin de la expansión secular.

Cabe resaltar de este trabajo diversos elementos. Por una parte, el método empleado; en segundo lugar, las aportaciones realmente novedosas que contiene $y$, por último, pero sin pretensiones de exhaustividad por nuestra parte, su significado global en la producción histórica atual sobre Alicante.

Las distintas variables de la economia alicantina son analizadas por Giménez cuantitativamente, pretendiendo en todos los casos establecer su evolución secular. El autor aplica en este punto la metodología apuntada por Labrousse en sus estudios ya clásicos sobre el Antiguo régimen francés, recogiendo, además, las pautas que sobre dicho método han ido marcando estudios similares realizados en Francia y, como es el caso de Anes, Palop y otros, en España. El intento de dar series largas, ha resultado, en algunos aspectos, realmente difícil por el carácter de las fuentes. Por ejemplo, Giménez constata la ausencia de mercuriales en Alicante (sólo existe uno, para 1770-76), por lo que para la reconstrucción de los precios ha debido recurrir a los asientos del pósito local y a los libros de fábrica de las parroquias. Este caso, repetido en otras variables analizadas, manifiesta el enorme y arduo trabajo sobre fuentes que ha debido realizar para ofrecer series coherentes y fiables.

Es sabido que sobre todo en la época preindustrial tanto las estructuras económicas de cada área geográfica como la documentación existente sobre ellas dificilmente se prestan a generalizaciones. Ello condiciona mucho la investigación, pues no siempre pueden aplicarse modelos extraídos de un lugar a otro. La función del historiador estriba, en gran medida, en calibrar la especificidad del objeto de su estudio y, aunque aplica a él procedimientos ensayados con resultado positivo en otros casos, siempre ha de hallar los más adecuados para ese lugar. En este sentido resulta necesaria, como medida preventiva y aclaratoria, la reflexión constante sobre el método empleado y sobre las limitaciones de las fuentes. Este cometido lo desempeña Giménez con notable maestría, hasta el punto de que sus anotaciones al respecto constituyen importantes guías para el investigador.

Las series de precios, producciones de los diversos sectores, volumen del comercio e ingresos de los grupos sociales sirven a Giménez para explicar el problema esencial de la economía alicantina, cifrado en el ritmo del avituallamiento urbano y el tráfico marítimo. Así, traza la coyuntura 
secular, marcando los ciclos económicos y resaltando los elementos explicativos. Esta labor, fundamental de por sí, le da pie para reconstruir el marco completo en que se desenvuelve la actividad económica. Es decir, de la historia serial pasa a la historia total, reconstruyendo el marco institucional, las relaciones de producción y las bases específicas de la economia de Alicante.

La depurada metodología y la exhaustiva indagación en los fondos documentales del Archivo Municipal de Alicante, hasta ahora nunca explotados con tal intensidad, dan como resultado numerosas aportaciones completamente nuevas sobre el Alicante setecentista. Casi podría decirse que a excepción de lo referente a la evolución demográfica y a ciertos extremos relacionados con los grupos sociales, el conjunto del libro versa sobre aspectos nada conocidos. En todo caso cabría atisbar, desde otros estudios, mas sin sobrepasar el nivel de la hipótesis, determinadas caracteristicas, como por ejemplo la incidencia del comercio de los salazones del pescado en el enriquecimiento de la clase mercantil. El estudio integrado de Giménez, basado en la segura fijación de los hechos, convierte estos y otros aspectos en objetos seguros de conocimiento. Tal vez estribe aqui el valor más sobresaliente de esta obra.

El panorama económico-social de Alicante, delineado de la forma indicada, queda definido por una serie de elementos básicos: las contradicciones de una agricultura incapaz de abastecer a la población urbana de los alimentos básicos pero muy rentable para los propietarios de las tierras dedicadas a cultivos de exportación (vino, barrilla, almendra); la debilidad del sector artesanal, incapaz de satisfacer las exigencias del mercado urbano local, y la magnitud de la red comercial montada sobre las posibilidades del puerto. Este se convirtió en el centro de la distribución de una amplia gama de productos, desde los coloniales (traídos desde Cádiz en embarcaciones de cabotaje) a los propios del campo alicantino, controlada por las casas comerciales en su mayoría filiales o propiedad directa de los negociantes extranjeros. Junto a la vitalidad del sector mercantil se alinea el grupo de los propietarios de las mejores tierras agrícolas, quienes a su vez detentan el gobierno municipal, condicionando una correlación de fuerzas sociales encontradas, fuente de una vacilante política de abastecimientos y de conflictos en el seno de las instituciones que, como el Consulado marltimo, tienen competencias directas en el ordenamiento económico. Queda demostrado además, cómo la economía alicantina estuvo a merced de las fluctuaciones del comercio mediterráneo (Alicante se desentendio, por las características de su flota y de sus compañlas comerciales, del tráfico americano) y cómo la acumulación de capital procedente del mismo fue a parar a manos de extranjeros, sin que se constituyera una infraestructura local potente, antes al contrario, la excesiva supeditación de las actividades económicas respecto a la exportación de los productos 
más rentables, hundió la artesanía local y afectó gravemente, en los momentos de crisis, al nivel adquisitivo de la masa de población urbana.

Tales son las caracteristicas esenciales de lo que Giménez califica como "una ciudad portuaria en el antiguo régimen». Ellas dan una imagen nueva del Alicante de la época, al que se han dedicado pocas monografias hasta ahora. Por eso el libro comentado marca un hito importante en los estudios alicantinos. Hasta ahora se habia abordado, con una metodología dudosa o en el mejor de los casos, como ocurre con los trabajos de Figueras Pacheco, con la mejor carga positivista, la historia de Alicante. A partir de este momento no es posible mantener esta forma de historiar. Será preciso afrontar otras épocas con métodos similares, pues las posibilidades quedan abiertas. Mas no es sólo en este aspecto donde debe cifrarse la incidencia de la obra de Giménez en los estudios sobre Alicante. Hay en ella una serie de sugerencias, como la delimitación social y el comportamiento fiscal del grupo de comerciantes, así como las relaciones de éstos con los terratenientes privilegiados, que por fuerza son puntos de partida para estudios sobre fenómenos esenciales del pasado inmediato alicantino. Pensemos, por ejemplo, en la nula industrialización durante el siglo XIX y, sin embargo, en la pervivencia durante esa centuria de actividades politicas y mentales decididamente liberales.

Con lo dicho no pretendemos más que reflejar, en breves apuntes, el significado del libro de Giménez. Somos conscientes de que tal vez, sea difícil trazar un panorama similar para los siglos anteriores al XVIII, de ahí que incidamos, movidos también por nuestras propias aficiones, en las posibles repercusiones en estudios sobre épocas posteriores. En todo caso, queda demostrada la posibilidad de reconstruir series coherentes economicas y de formar, a partir de ellas, una imagen global del comportamiento económico de la ciudad. Ello justifica por entero la labor de Giménez.

\section{NOTAS:}

(1) SARRAILH, J., La España ilustrada de la segunda mitad del siglo XVIII, México 1957 (La primera edición en francés salió en 1954) y VILAR, P., Catalunya dins l'Espanya moderna, 4 vols., Barcelona, 1964-68.

(2) PESET, V., Gregori Mayans i la cultura de la II.lustració, Barcelona-València, 1975; GARCIA MARTINEZ, S., Els fonaments del Pais Valencià modern, València, 1966; LOPEZ PIÑE. RO, J. M. ${ }^{2}$, La introducción de la ciencia moderna en España, Barcelona, 1969.

(3) MESTRE SANCHIS, A., Ilustración y reforma de la Iglesia. Pensamiento político. religiosos de don Gregorio Mayáns y Siscar(1699-1781), Valencia, 1966. La obra de Mestre sobre el tema es muy extensa, pues además de varios estudios, a él se deben las ediciones y extensos estudios preliminares de varios volúmenes del espistolario mayansiano. Vid. también PESET REIG, M. y J. L., Gregorio Mayáns y la reforma universitaria, Valencia, 1975. 
(4) Una confirmación reciente se puede hallar en las Actas del Simposio Internacional en el Bicentenario de la muerte de Gregorio Mayáns, publicadas bajo el título Mayáns y la l/ustración, Valencia 1981, 2 tomos.

(5) ARDIT LUCAS, M., Revolución liberal y revuelta campesina, Barcelona, 1.977; GIL OLCINA, A., La propiedad señorial en tierras valencianas, Valencia, 1979.

(6) RUIZ TORRES, P., Señores y propietarios. Cambio social en el sur del Pals Valenciano. 1650-1850, Valencia, 1981.

(7) GIRALT RAVENTOS, E., "Problemas históricos de la industrialización valenciana” en Estudios Geográficos, núm. 112-113 (agosto-nov. 1968), pp. 369-395.

(8) Vid. ARACIL, R. et al., La industrialización valenciana: historia y problemas, Valencia, 1978. También el estado de la cuestión planteado por PEREZ GARZON, J. S., "La revolución burguesa en Espafia: los inicios de un debate clentifico, 1966-1979", en TUÑON DE LARA et. al.,Historiografia española contemporánea, Madrid, 1980, pp. 125-132.

(9) LLUCH, E., La via valenciana, València, 1976.

(10) ARACIL, R., y GARCIA BONAFE, M., Industrialització al Pals Valencià (El cas d'Alcoi), València, 1974.

(11) PALOP RAMOS, J. M., Fluctuaciones de precios y abastecimiento en la Valencia del siglo XVIII, Valencia 1977 y Hambre y lucha antifeudal. La crisis de subsistencia en Valencia (Siglo XVIII), Madrid, 1977.

(12) ANES, G., Las crisis agrarias en la España moderna, Madrid, 1970. 
$-$ 


\title{
BERNABE GIL, DAVID, Tierra y sociedad en el Bajo Segura (1700-1750), Alicante, Colección Universidad, 1982, 235 pp.
}

\author{
Por Armando ALBEROLA ROMÁ
}

El Secretariado de Publicaciones de la Universidad alicantina inicia con este libro de David Bernabé Gil la que deseamos sea una larga y fructífera andadura en la que, periódicamente, se dé a conocer el estado de las investigaciones llevadas a cabo por los integrantes de este casi recién creado campus.

Tierra y sociedad en el Bajo Segura constituye la Memoria de Licenciatura del autor y, a lo largo de 230 páginas, desarrolla un interesante y documentado estudio de historia rural cuya localización, tanto geográfica como cronológica, ya es de por si sugerente.

La comarca del Bajo Segura, con el importante enclave urbano de Orihuela, se presentaba en la actualidad como una zona casi huérfana de estudios rigurosos $\left({ }^{*}\right)$, de la cual se ignoraba el desarrollo de la problemática agrosocial así como la caracterización de sus estructuras agrarias y la evolución del régimen señorial. El marco cronológico en que se centra el estudio, elegido por el autor por razones metodológicas, presenta los rasgos de una etapa de gran expansión demográfica y económica- -la primera expansión del XVIII", en frase de Bernabé Gil-tras el estancamiento y retroceso vividos en la anterior centuria.

(*) No hay que olvidar los estudios realizados por Jesús Millán, Juan Bta. Vilar y J. A. Ramos Vidal, pioneros en la empresa de intentar la aproximación al conocimiento histórico de la comarca. 
La obra parte de un presupuesto básico como es el análisis de la estructura social y la distribución de la riqueza dentro de una ciudad realenga, Orihuela, en los albores del siglo XVIII. Este análisis, desarrollado a lo largo del primer capitulo a partir del Padrón de 1717, presenta a Orihuela como el único núcleo urbano importante del Bajo Segura, foco de atracción y asentamiento de numerosa población en virtud de su condición de sede política, religiosa y cultural.

La vida económica está presidida por un marcado carácter rural debido a que la mayor parte de las rentas y actividades de los habitantes están directamente relacionadas con la explotación de la tierra. La cúpula de la pirámide social está claramente dominada por una oligarquia urbana compuesta por nobles, caballeros y eclesiásticos residentes, en su práctica totalidad, dentro del recinto ciudadano. Este estamento de privilegiados acaparó, desde el siglo XVII, todos los cargos municipales merced al sistema insaculatorio y, tras la Guerra de Sucesión y la instauración de la Nueva Planta borbónica, siguió disfrutando de sus prerrogativas sin cambios ostensibles. La principal fuente de ingresos provenía del disfrute de la propiedad agraria y de las rentas generadas por su explotación; propiedades que no se limitaban al perímetro de la ciudad sino que debían ampliarse a los términos realengos circundantes. David Bernabé constata que entre los mayores detentadores de tierras se encontraban no pocas mujeres lo que induce a pensar, habida cuenta de la endogamia existente entre las grandes familias propietarias de la zona, en la paulatina acumulación y formación de notables patrimonios.

No obstante, dentro del estamento privilegiado, se detectan casos de empobrecimiento progresivo en elementos pertenecientes al grupo de hidalgos locales que no podían soportar los excesivos gastos que el mantenimiento de su status comportaba. Por otro lado, también es de resaltar que, en términos generales, las rentas agricolas de los privilegiados se veían mermadas, en multitud de ocasiones, debido a las pensiones generadas por censales cargados en fechas pasadas y que debían satisfacer anualmente, asi como por las hipotecas a las que estaban sometidas sus propiedades.

El sector de comerciantes juega un papel poco significativo dentro de la actividad económica ciudadana debido al limitado número de comerciantes mayoristas. La élite de estos comerciantes la constituian ciudadanos franceses asentados en Orihuela el siglo anterior, y se ocupaban en la venta al por menor de ropas importadas de Francia, la comercialización de la seda y en la exportación a ámbitos próximos de ciertos productos agrícolas adquiridos a los grandes cosecheros. Extraña la no vinculación de estos elementos a la propiedad agraria para integrarse en el grupo de privilegiados rústicos, como sucedia por ejemplo en la huerta alicantina, no pareciendo muy aceptable la hipótesis de que cultivaran tierras mediante contratos de arrendamiento. 
Los artesanos, de los cuales es difícil precisar su número, no se muestran como un grupo social potente debido, fundamentalmente, al carácter restringido del mercado con el que contaban. El sector que mayor nivel de contribución reseña el Padrón es el alimenticio-panaderos, confiteros, cereros...-, aunque el que mayor número de individuos agrupa es el textil pese a que las bases imponibles de sus miembros son más limitadas. El resto de los componentes del sector artesano tienen una menor incidencia económica en la vida ciudadana, siendo frecuente que recurrieran al empleo como jornaleros para obtener el mínimo de ingresos necesario para vivir.

La problemática del campesinado queda esbozada en este primer apartado, indicando el autor un desarrollo más profundo en el resto de los capítulos, labor que realiza con gran acierto y espíritu crítico una vez puestas de manifiesto las condiciones en las que se desenvuelve la agricultura en la primera mitad del siglo XVIII. En este período, brillantemente descrito en el capítulo $2 .^{\circ}$, se pone de manifiesto el avance de la productividad agrícola gracias a los rompimientos o roturaciones de tierras, que permitieron la puesta en cultivo de nuevas superficies. La no transformación de las técnicas de cultivo motivó un descenso de los rendimientos a largo plazo así como serias dificultades para el campesinado, a quien la roturación de gran número de tierras comunales había privado de una serie de ingresos complementarios. Entre ellos, el derivado de la utilización, por parte de una reducida cabaña lanar, de las dehesas concejiles convertidas, por mor de las roturaciones, en tierras aptas para el cultivo. Fenómeno similar es observable en la Bailía de Alicante hacia fines del XVIII, debiendo el Ayuntamiento poner coto a los abusos de los particulares y denengando de forma sistemática gran número de solicitudes para llevar a cabo roturaciones de tierra.

La ausencia de padrones locales, que permitirian evaluar la superficie cultivada asi como la distribución de los cultivos, supone un obstáculo para el autor de Tierra y sociedad en el Bajo Segura puesto que restan un cúmulo de datos sin desvelar. No obstante, utilizando información diezmal, nos ofrece noticias sobre las huertas de Catral y Redován. Esta última, sujeta al dominio directo del Colegio de Predicadores, presenta un predominio del cereal, olivares y moreras. Catral presenta las mismas características de agricultura de subsistencia poco diversificada y basada, esencialmente, en el cultivo del cereal y el cáñamo.

En la primera mitad del siglo XVIII se produjo una expansión de las producciones no cerealísticas-lino, cebada, barrilla, morera-que revelaría una cierta atracción de los mercados vecinos, aunque resulta extraño el hecho de que no llegara a existir un artesanado local capaz de absorber y elaborar las materias primas. 
Pero el núcleo del trabajo se ocupa de desvelar el poderío económico de la iglesia y la situación del campesiado en las zonas de dominio realengo y señorial. En el Bajo Segura, el estamento eclesiástico se configura como el gran acaparador del excedente producido en la comarca e incluso fuera de los límites de la misma. Por lo que respecta a cantidades en metálico, el clero ingresaba en sus arcas dinero por diferentes conceptos. Uno de ellos era el relativo a las pensiones de censales pues, desde siempre, el desempeñar funciones de prestamista había supuesto uno de los capitulos fundamentales dentro de la economía clerical y le permitia obtener una serie de ingresos fijos anuales. Otras percepciones en metálico se refieren a los cánones de las tierras arrendadas o cedidas en enfiteusis, asi como a las rentas derivadas de la propiedad rústica o urbana.

En especie también recibía el clero imortantes aportaciones provenientes del diezmo de la producción agrícola del obispado, de las participaciones de frutos de sus enfiteutas y de lo estipulado en la explotación directa de sus tierras.

De este modo, la Iglesia actuaba como un gran almacenista de productos agrícolas comercializables por lo que, en ningún momento se veía afectada por malas cosechas o coyunturas económicas depresivas. Desde el XVIII el clero desarrollará una gran labor inversora en la compra de tierras y participará activamente en los nuevos establecimientos y roturaciones, convirtiéndose en el principal beneficiario de la expansión agrícola. A ello hay que añadir las respetables superficies de tierra que recibia en concepto de donaciones o herencias de fieles.

La Iglesia derivó, con el devenir del 'siglo, hacia posiciones claramente rentistas, impidiendo que la economia agraria pudiera avanzar hacia formas capitalistas debido a la dilapidación de sus fortunas en gastos suntuarios, alimento de pobres, caridad y beneficencia.

La participación del estamento eclesiástico en el total de la superficie cultivada del realengo oriolano era muy notoria, puesto que disfrutaba de la mayor parte del terrazgo en compañía de la oligarquía local y la nobleza foránea. Esta élite terrateniente acumulaba más de la mitad de la superficie útil realenga pese a que, numéricamente, suponia tan sólo el $13 \%$ del total de propietarios - que componia la fuerza más dinámica del sector-y los pequeños propietarios-casi el $50 \%$-que disfrutaban de parcelas con superficies exiguas, aspecto éste mucho más acusado en el regadio que en el secano.

La forma juridica de tenencia de la tierra imperante en el realengo era el arrendamiento. Es al tratar este aspecto donde aparecen los únicos puntos oscuros de todo el estudio. Cuando el autor se refiere a la escasa participación de la oligarquía local como arrendatarios, reseñándola como aspecto destacable, y la contrapone a los innumerables casos de propieda- 
des cedidas en arriendo por eclesiásticos y caballeros se intuye una confusión entre los términos arrendador y arrendatario; confusión que, por otro lado, queda despejada al encontrar en el texto, más adelante, una clara referencia a la frecuente figura del rentista intervencionista-que lo serian la mayor parte de los oligarcas locales-que impone duros capitulos a sus arrendatarios en el momento de signar el contrato de arriendo.

Las condiciones de los arrendamientos son exhaustivamente descritas por David Bernabé gracias al muestreo realizado sobre protocolos notariales y al hallazgo de un documento que pormenoriza cuáles son las caracteristicas del cultivo de las tierras «a uso y costumbre de buen labradorn, permanente citado en todos los arriendos. En este capítulo se encuentra una gran aportación al conocimiento de la situación en que se hallaba la gran masa campesina, la cual en términos reales era crítica y en el límite de la subsistencia por no poder acceder ni siquiera a la labranza de pequeñas superficies agrarias. Los motivos de esta situación los ha captado perfectamente el autor: por un lado, la creciente privatización de tierras comunales y, por otro, la carencia de un capital mínimo que permitiera iniciar la explotación de las propiedades que, en grandes y medianos lotes, arrendaban los rentistas. El carácter marcadamente intervencionista de éstos últimos respecto a los culltivos a desarrollar por sus arrendatarios supuso una transformación importante en el paisaje agrario.

Pese a las condiciones favorables para el desarrollo de un capitalismo agrario en el realengo, los obstáculos fueron múltiples y, sobre todo, no llegó a consolidarse la alianza objetiva entre clase rentista y arrendatarios. Si acaso se echa en falta en este capítulo una referencia a la incidencia de la enfiteusis, sobre todo porque seía un interesante punto de referencia y comparación respecto a la existente en el vecino realengo alicantino en el que la corona tenía establecidos una serie de tierras, casas, hornos y molinos a vecinos de la ciudad y lugares circundantes, de los que anualmente percibia un canon en metálico.

Tierra y sociedad en el Bajo Segura se cierra con dos interesantes y clarificadores capítulos relativos al importante papel jugado por el señorio alfonsino en la zona en una etapa en que el crecimiento demográfico y económico abria amplias expectativas en lo que a puesta en explotación de grandes superficies agrarias se refiere.

En un contexto en el que la estructura social muestra una amplia capa de campesinos sin tierra y una élite rentista que únicamente transige cediendo sus propiedades en arriendos nada ventajosos, la posibilidad de utilizar el contrato enfitéutico ofrecía mayores atractivos, sobre todo a los campesinos que, de este modo, disponian de un cierto margen para obtener rendimientos agrícolas aceptables sin necesidad de hacer un desembolso previo de capital. 
Por otro lado, los propietarios, acogiéndose al Privilegio 78 de la rúbrica foral "De iurisdictione omnium iudicum" concedido en 1239 por Alfonso II, accedian, tras disfrutar de la propiedad de la tierra y cederla en enfiteusis al menos a 15 pobladores, al disfrute de la jurisdicción señorial. La proliferación de estos señorios en el Bajo Segura vendría dada por ese deseo de ampliar la superficie explotada, por la necesidad de garantizar la puesta en cultivo sin gastos de acondicionamiento y, por qué no, por el interés en disfrutar ciertos derechos económicos y juridicos complementarios. David Bernabé documenta el establecimiento del señorío de Molins de Rocamora, y la repoblación, por el Colegio de Predicadores del de Redován y Hondones.

Respecto al primero, creado en 1697 tras establecer D. Alonso Rocamora y Molins en la Partida de Correntía-Huerta de Orihuelalos 15 pobladores que el privilegio Alfonsino determinaba, los capítulos de su Carta Poblacional presentan un relativo recrudecimiento de la presión señorial. El Señorío de Redován, adquirido por los Dominicos del Colegio de Predicadores en 1615 , presenta rasgos más interesantes. La característica del Colegio a lo largo de su existencia había sido la vinculación a cualquier actividad que constituyera un soporte económico, estando pues siempre interesado en ampliar su patrimonio aprovechando la coyuntura de cada momento para invertir en bienes rústicos o urbanos. Desde esta óptica, la actuación de los Dominicos a lo largo del siglo XVII consistió en adquirir tierras incultas y abandonadas por la regresión demográfica pero de las que, con el tiempo y una buena organizacion, esperaban extraer rentabilidad. Esta actitud fue motivo de múltiples choques con el Cabildo Catedralicio Oriolano que veía menguar sus ingresos, pues las tierras adquiridas por el Colegio al dejar de ser consideradas como seglares, cesaban en el pago de los diezmos y el subsidio.

Dentro de este contexto inversionista encaja la compra del señorio de Redován y las posteriores actuaciones del Colegio de Predicadores. Este, en principio, estableció colonos en sus tierras mediante contratos enfitéuticos pero a medida que avanzaba el siglo XVIII, y a la vista del estancamiento de las rentas en metálico, comenzó a asimilar y comprar el dominio útil de muchas parcelas, reduciendo de este modo las posesiones de sus enfiteutas. Acto seguido inició la explotación directa de las mismas mediante arriendos a corto plazo incrementando además sus ingresos gracias al arriendo de las regalías del señorio.

En síntesis, David Bernabé clarifica la actuación del Colegio de esta manera:

-Donde existían superficies incultas abundantes atrajo pobladores para que las pusieran en cultivo, obteniendo de este modo los beneficios de la partición de frutos. 
-Si las tierra escaseaban se imponian condiciones onerosas a los nuevos enfiteutas.

-En último caso, el Colegio consolidaba el dominio útil y el directo cediendo estas tierras en arriendo.

La exposición queda cerrada con la presentación de una muy sugerente hipótesis: el Colegio de Predicadores devino, a lo largo del XVIII, en un empresario agrícola puesto que comercializaba sus propias producciones. Si a esto se la suma la utilización constatada de trabajadores asalariados nos encontraríamos con los rasgos evidentes de un incipiente capitalismo, que vendría a confirmar ese claro dominio económico de los sectores eclesiales en la comarca estudiada.

Tierra y sociedad en el Bajo Segura (1700-1750) es, en suma, un libro que destila abundante espíritu crítico a lo largo de sus páginas y que, mediante una exposición escueta y clara pero ampliamente documentada, nos aproxima al conocimiento de los aspectos fundamentales de la historia agraria de esta comarca que tan señero papel ha desempeñado desde. el punto de vista económico, cultural y religioso. 



\section{BERCHEX, Joaquín y CORELL, Vicente, Catálogo de diseños de arquitectura de la Real Academia de Bellas Artes de San Carlos de Valencia. 1768-1846. 430 p. il. b. y n., 32 '5 cm.}

Por R. N. M.

La idea de presentar un catálogo de diseños arquitectónicos de la Real Academia de San Carlos (1768-1846), realizados en el período en que ésta no sólo expedia los títulos de arquitecto, sino también ejercia el control de la arquitectura pública; supone la posibilidad de relacionarlos, tanto con el movimiento ilustrado, como con su antecedente barroco, e incluso que el propio aporte icónico, al seleccionarse, pueda adquirir por sí solo rasgos de discurso.

Efectivamente, las seicientas cuarenta y tres ilustraciones no sólo permiten detectar la evolución arquitectónica del neoclasicismo valenciano, sino, sobre todo, insinuar el modo en que se orienta en Valencia "la restauración de las artes", tanto en el sentido humanista de Jovellanos, como en el arqueológico de Mengs.

Así, la labor de Berchez y Corell, al recrear mediante la ordenación de los diseños, el desarrollo de la institución: premios, concursos, títulos, grados, etc., permite que, a través de ellos, nos acerquemos a la realidad intelectual y social de la Academia (se ofrecen también ciento catorce someras biografias de los arquitectos representados), y, por consiguiente, que observemos la doble direccionalidad del movimiento: concepción de la belleza y visión del Renacimiento, de tal modo que la arquitectura se nos aparece como lo que fue para los ilustrados, un hecho de cultura.

Por último, una cuidada selección de índices y bibliografía básica, contribuyen a completar un trabajo que habrá de servir de revulsivo a los estudios sobre el tema en la generalidad del territorio.

En definitiva, una obra de indispensable consulta en el conjunto del movimiento ilustrado valenciano. 

